\title{
MERCURY CONTROL WITH ADVANCED HYBRID PARTICULATE COLLECTOR
}

Final Technical Report

Prepared for:

AAD Document Control

U.S. Department of Energy

National Energy Technology Laboratory

626 Cochrans Mill Road

PO Box 10940, MS 921-107

Pittsburgh, PA 15236-0940

Cooperative Agreement No. DE-FC26-01NT41184

Performance Monitor: William Aljoe
Prepared by:

Ye Zhuang

Stanley J. Miller

Energy \& Environmental Research Center University of North Dakota

Box 9018

Grand Forks, ND 58201-9018 


\section{EERC DISCLAIMER}

LEGAL NOTICE. This research report was prepared by the Energy \& Environmental Research Center (EERC), an agency of the University of North Dakota, as an account of work sponsored by the U.S. Department of Energy (DOE) National Energy Technology Laboratory. Because of the research nature of the work performed, neither the EERC nor any of its employees makes any warranty, express or implied, or assumes any legal liability or responsibility for the accuracy, completeness, or usefulness of any information, apparatus, product, or process disclosed, or represents that its use would not infringe privately owned rights. Reference herein to any specific commercial product, process, or service by trade name, trademark, manufacturer, or otherwise does not necessarily constitute or imply its endorsement or recommendation by the EERC.

\section{DISCLAIMER}

This report was prepared as an account of work sponsored by an agency of the United States Government. Neither the United States Government, nor any agency thereof, nor any of their employees makes any warranty, express or implied, or assumes any legal liability or responsibility for the accuracy, completeness, or usefulness of any information, apparatus, product, or process disclosed or represents that its use would not infringe privately owned rights. Reference herein to any specific commercial product, process, or service by trade name, trademark, manufacturer, or otherwise does not necessarily constitute or imply its endorsement, recommendation, or favoring by the United States Government or any agency thereof. The views and opinions of authors expressed herein do not necessarily state or reflect those of the United States Government or any agency thereof.

This report is available to the public from the National Technical Information Service, U.S. Department of Commerce, 5285 Port Royal Road, Springfield, VA 22161; phone orders accepted at (703) 487-4650.

\section{ACKNOWLEDGMENT}

This report was prepared with the support of the DOE National Energy Technology Laboratory Cooperative Agreement No. DE-FC26-01NT41184. However, any opinions, findings, conclusions, or recommendations expressed herein are those of the author(s) and do not necessarily reflect the views of DOE. 


\title{
MERCURY CONTROL WITH THE ADVANCED HYBRID PARTICULATE COLLECTOR
}

\begin{abstract}
This project was awarded under U.S. Department of Energy (DOE) National Energy Technology Laboratory (NETL) Program Solicitation DE-PS26-00NT40769 and specifically addressed Technical Topical Area 4 - Testing Novel and Less Mature Control Technologies on Actual Flue Gas at the Pilot Scale. The project team included the Energy \& Environmental Research Center (EERC) as the main contractor; W.L. Gore \& Associates, Inc., as a technical and financial partner; and the Big Stone Power Plant operated by Otter Tail Power Company, host for the field-testing portion of the research.
\end{abstract}

Since 1995, DOE has supported development of a new concept in particulate control called the advanced hybrid particulate collector (AHPC). The AHPC has been licensed to W.L. Gore \& Associates, Inc., and has been marketed as the Advanced Hybrid ${ }^{\mathrm{TM}}$ filter by Gore. The Advanced Hybrid $^{\mathrm{TM}}$ filter combines the best features of electrostatic precipitators (ESPs) and baghouses in a unique configuration, providing major synergism between the two collection methods, both in the particulate collection step and in the transfer of dust to the hopper. The Advanced Hybrid ${ }^{\mathrm{TM}}$ filter provides ultrahigh collection efficiency, overcoming the problem of excessive fine-particle emissions with conventional ESPs, and it solves the problem of reentrainment and re-collection of dust in conventional baghouses. The Advanced Hybrid ${ }^{\mathrm{TM}}$ filter also appears to have unique advantages for mercury control over baghouses or ESPs as an excellent gas-solid contactor.

The objective of the project was to demonstrate $90 \%$ total mercury control in the Advanced Hybrid $^{\mathrm{TM}}$ filter at a lower cost than current mercury control estimates. The approach included bench-scale batch tests, larger-scale pilot testing with real flue gas on a coal-fired combustion system, and field demonstration at the 2.5-MW (9000-acfm) scale at a utility power plant to prove scale-up and demonstrate longer-term mercury control.

An additional task was included in this project to evaluate mercury oxidation upstream of a dry scrubber by using mercury oxidants.

This project demonstrated at the pilot-scale level a technology that provides a costeffective technique to control mercury and, at the same time, greatly enhances fine particulate collection efficiency. The technology can be used to retrofit systems currently employing 
inefficient ESP technology as well as for new construction, thereby providing a solution for improved fine particulate control combined with effective mercury control for a large segment of the U.S. utility industry as well as other industries. 


\section{TABLE OF CONTENTS}

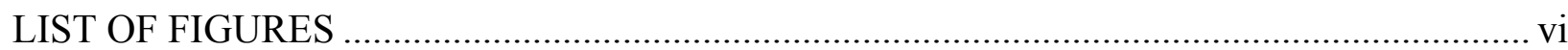

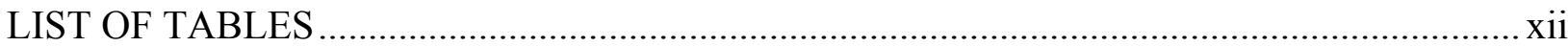

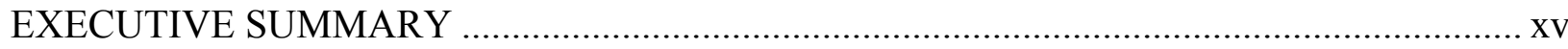

1.0 INTRODUCTION AND BACKGROUND ............................................................. 1-1

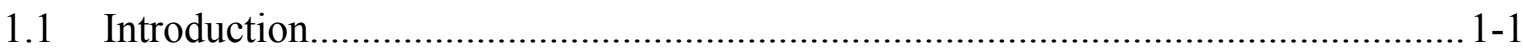

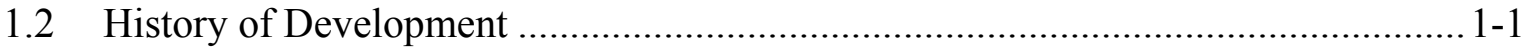

1.3 Concept of the Advanced Hybrid ${ }^{\mathrm{TM}}$ Filter for Particulate Control ........................... 1-2

1.4 Pressure Drop Theory and Performance Evaluation Criteria .................................. 1-5

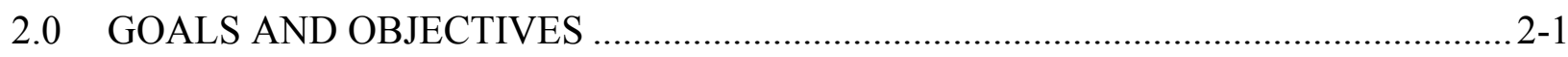

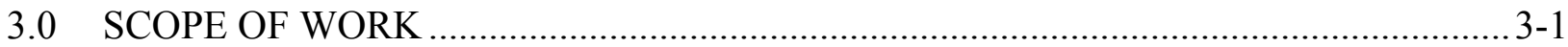

3.1 Task 1 - Project Management, Reporting, and Technology Transfer ...................... 3-1

3.2 Task 2 - Bench-Scale Experiments at the EERC ............................................... 3-1

3.3 Task 3 - Pilot-Scale Tests on the 55-kW (200-acfm) Unit at the EERC ................3-2

3.4 Task 4 - Field Demonstration on the 2.5-MW (9000-acfm) Unit at the Big Stone

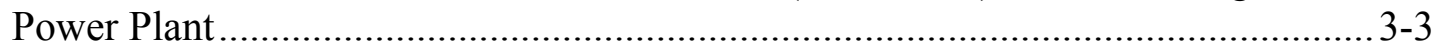

3.5 Task 5 - Facility Removal and Disposition...................................................... 3-4

3.6 Task 6 - Mercury Control Enhancement with Oxidation Additives ....................... 3-4

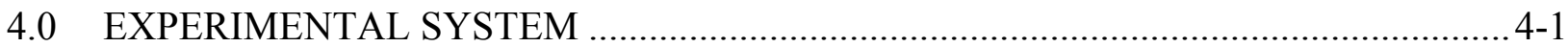

4.1 Bench-Scale System ....................................................................................... 4-1

$4.255-\mathrm{kW}$ (200-acfm) Pilot-Scale Advanced Hybrid ${ }^{\mathrm{TM}}$ Filter Unit at the EERC ......... 4-5

4.3 2.5-MW (9000-acfm) Field Demonstration of the Advanced Hybrid ${ }^{\mathrm{TM}}$ Filter Unit at the Big Stone Power Plant .................................................................................... 4-7

4.4 Experimental Setup of Mercury Stability Tests.................................................. 4-7

4.4.1 Synthetic Groundwater Leaching Procedure and

Long-Term Leaching........................................................................ 4-7

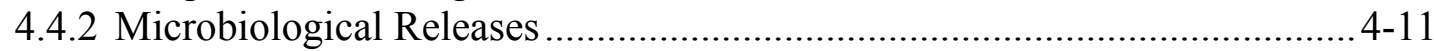

4.4.3 Long-Term Ambient Temperature Release ............................................ 4-13

4.4.4 Thermal Desorption at Elevated Temperatures......................................... 4-14

$4.555-\mathrm{kW}(200-\mathrm{acfm})$ Pilot-Scale SDA/PJBH at the EERC .................................... 4-15

$5.0 \quad$ MERCURY MEASUREMENT ............................................................................. 5-1

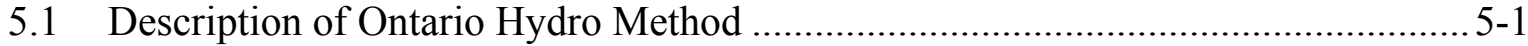

5.2 Description of Continuous Mercury Monitor .................................................... 5-3

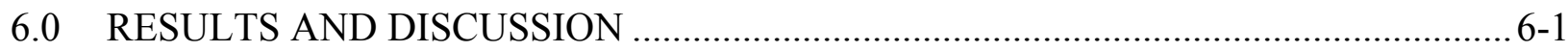

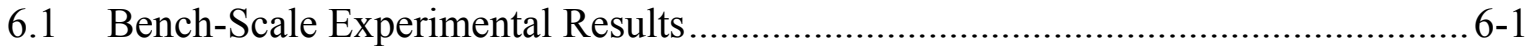

6.1.1 Series 1 Bench-Scale Tests ................................................................... 6-1

Continued ... 


\section{TABLE OF CONTENTS (continued)}

6.1.2 Series 2 Bench-Scale Tests ......................................................................... 6-6

6.2 Experimental Results of the Pilot-Scale 55-kW (200-acfm) Advanced Hybrid ${ }^{\mathrm{TM}}$ Filter Unit at the EERC................................................................................. 6-8

6.2.1 Summary of the Pilot-Scale Testing with the 55-kW (200-acfm) Advanced Hybrid ${ }^{\mathrm{TM}}$ Filter Unit ................................................................ 6-8

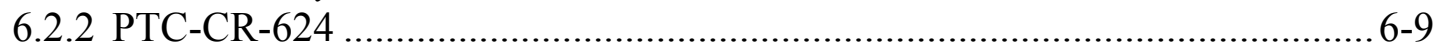

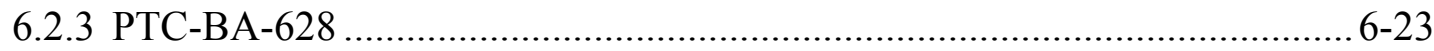

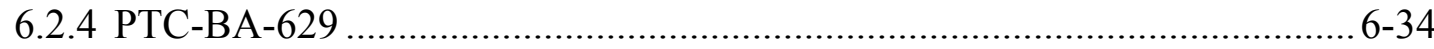

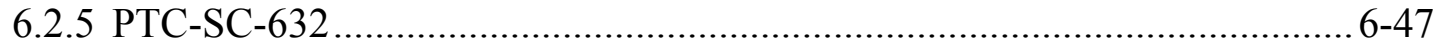

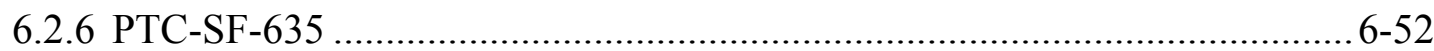

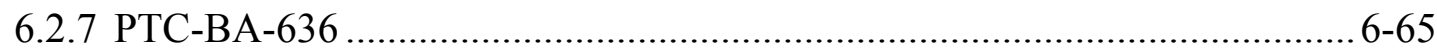

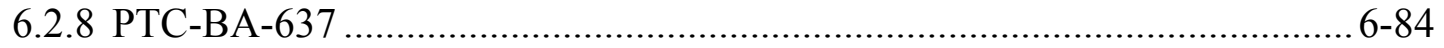

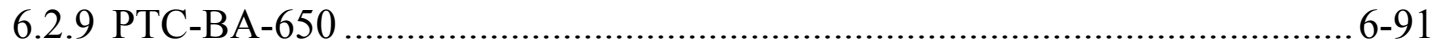

6.3 Field Demonstration at the 2.5-MW (9000-acfm) AHPC Unit at the Big

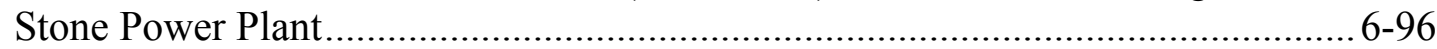

6.3.1 Short-Term Field Test During November 5-10, 2001 ................................ 6-96

6.3.2 Long-Term Field Test June 28-September 6, 2002 …...............................6-113

6.3.3 Short-Term Field Test During November 19-22, 2002 ............................. 6-134

6.3.4 Long-Term Field Test During May 6-June 3, 2003 ................................. 6-145

6.4 Pilot-Scale Testing of Mercury Oxidation Upstream of Dry Scrubber ................. 6-163

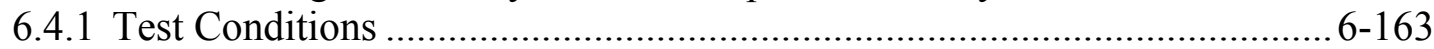

6.4.2 Coal and Flue Gas Analyses .............................................................. 6-164

6.4.3 Discussion of Mercury Results ……………….......................................6-165

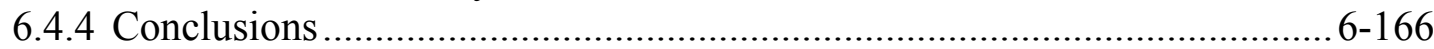

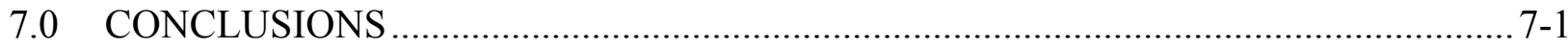

7.1 Bench-Scale Tests at the EERC ....................................................................

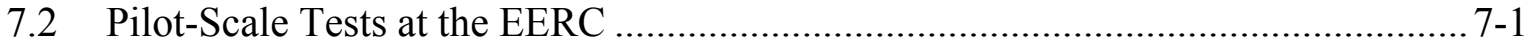

7.3 Field Demonstration at the Big Stone Power Plant ............................................... 7-3

7.4 Pilot-Scale Testing of Mercury Oxidation Upstream of the Dry Scrubber............... 7-4

7.5 Significance of Conclusions .................................................................................

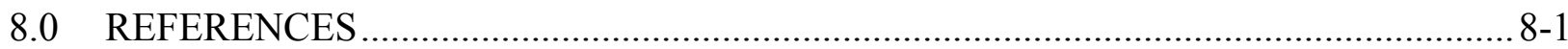




\section{LIST OF FIGURES}

1.3.1 Top view of the perforated plate configuration for the 2.5-MW (9000-acfm) Advanced Hybrid ${ }^{\mathrm{TM}}$ filter................................................................1-4

4.1.1 Schematic diagram of the mercury bench-scale system ......................................... 4-1

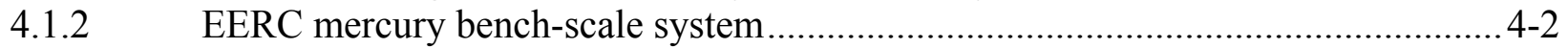

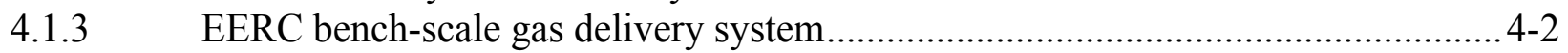

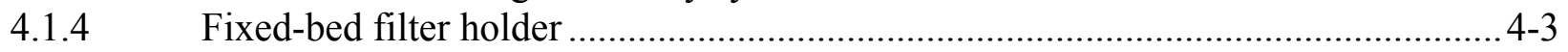

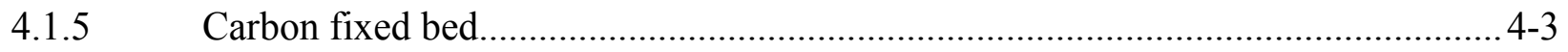

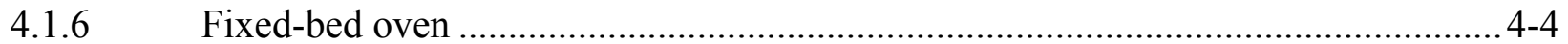

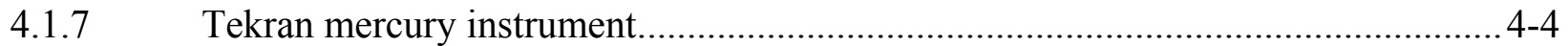

4.2.1 Schematic drawing of the pilot-scale system...................................................... 4-5

4.2.2 Front view of the 55-kW (200-acfm) Advanced Hybrid ${ }^{\mathrm{TM}}$ filter at the EERC.........4-6

4.3.1 Demonstration-scale Advanced Hybrid ${ }^{\mathrm{TM}}$ filter at the Big Stone Power Plant ........ 4-8

4.3.2 Top-view schematic diagram of the perforated plate 2.5-MW (9000-acfm) Advanced Hybrid ${ }^{\mathrm{TM}}$ filter................................................................................. 4-9

4.3.3 Top view of the 2.5-MW (9000-acfm) Advanced Hybrid ${ }^{\mathrm{TM}}$ filter at the Big Stone Power Plant during installation...................................................................... 4-9

4.3.4 Overview of the carbon injection system ..................................................... 4-10

4.3.5 Air-Vac eductor of the carbon injection system ................................................. 4-10

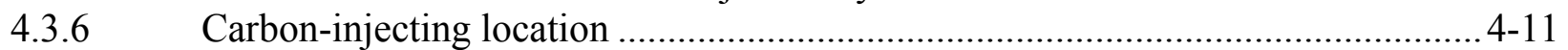

4.4.1 Microbiologically mediated mercury vapor-phase collection apparatus................ 4-12

4.4.2 Mercury vapor release collection apparatus ........................................................ 4-14

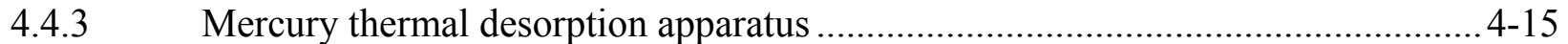

4.5.1 Schematic diagram of pilot-scale SDA/PJBH configuration................................... 4-16

4.5.2 The SDA, Model I provided by Niro Inc.......................................................... 4-16

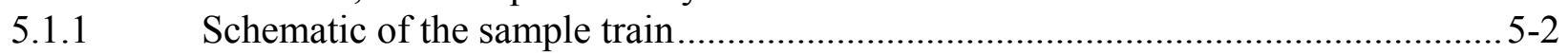

5.1.2 Sample recovery scheme for the mercury speciation sampling train .......................5-3

6.1.1.1 Mercury breakthrough curves at $200 \mathrm{ppm} \mathrm{SO}_{2}$ with varied $\mathrm{NO}_{2}: 5$,

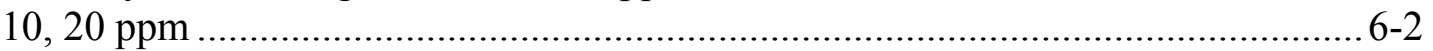

6.1.1.2 Mercury breakthrough curves at $500 \mathrm{ppm} \mathrm{SO}_{2}$ with varied $\mathrm{NO}_{2}$ :

5, 10, $20 \mathrm{ppm}$............................................................................................... 6-3

6.1.1.3 Mercury breakthrough curves at $1600 \mathrm{ppm} \mathrm{SO}_{2}$ with varied $\mathrm{NO}_{2}$ :

6.1.1.4 Mercury breakthrough curves at $5 \mathrm{ppm} \mathrm{NO} \mathrm{N}_{2}$ with varied $\mathrm{SO}_{2}$ :

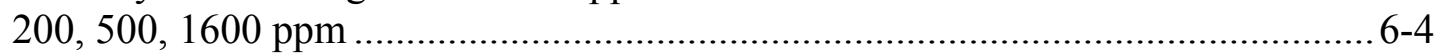

6.1.1.5 Mercury breakthrough curves at $10 \mathrm{ppm} \mathrm{NO}_{2}$ with varied $\mathrm{SO}_{2}$ :

6.1.1.6 Mercury breakthrough curves at $20 \mathrm{ppm} \mathrm{NO}_{2}$ with varied $\mathrm{SO}_{2}: 200,500$,

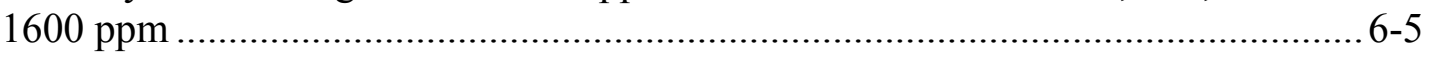

6.1.1.7 Summary of $\mathrm{Hg}$ breakthrough curves at varied $\mathrm{NO}_{2}$ and $\mathrm{SO}_{2} \ldots \ldots \ldots \ldots \ldots \ldots \ldots \ldots \ldots \ldots . . .6-5$

6.1.2.1 Real flue gas testing results ............................................................................. 6-8

6.2.2.1 Speciated mercury concentrations in flue gas at the Advanced Hybrid ${ }^{\mathrm{TM}}$

filter inlet and outlet.................................................................................... 6-13

Continued ... 


\section{LIST OF FIGURES (continued)}

6.2.2.2 Normalized mercury species at the Advanced Hybrid ${ }^{\mathrm{TM}}$ filter inlet

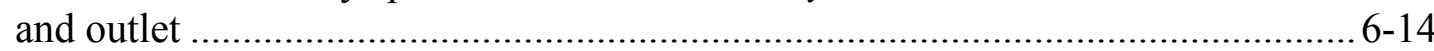

6.2.2.3 Speciated mercury concentration at the Advanced Hybrid ${ }^{\mathrm{TM}}$ filter inlet and outlet in longer residence time test ...................................................... 6-15

6.2.2.4 Normalized mercury species distributions across the Advanced Hybrid ${ }^{\mathrm{TM}}$ filter unit in longer residence time test .........................................................6-16

6.2.2.5 Speciated mercury concentrations at the PJBH inlet and outlet......................... 6-17

6.2.2.6 Normalized mercury species distribution across the PJBH .............................. 6-18

6.2.2.7 Averaged mercury speciation in Advanced Hybrid ${ }^{\mathrm{TM}}$ filter inlet flue gas measured in Big Stone field test (completed in November 2001) and pilot-scale test

6.2.2.8 Normalized $\mathrm{Hg}$ species distribution in flue gas of Big Stone field test and pilot-scale test

6.2.3.1 Mercury species concentrations in the Belle Ayr flue gas across the Advanced Hybrid ${ }^{\mathrm{TM}}$ filter in baseline test....................................................................... 6-26

6.2.3.2 Normalized mercury species distributions across the Advanced Hybrid ${ }^{\mathrm{TM}}$ filter in Belle Ayr coal baseline test ................................................................. 6-27

6.2.3.3 Effect of $19 \mathrm{mg} / \mathrm{m}^{3}$ (1.2-lb/Macf) NORIT FGD carbon injection on mercury emission in the Advanced Hybrid ${ }^{\mathrm{TM}}$ filter ......................................................... 6-28

6.2.3.4 Effect of $19 \mathrm{mg} / \mathrm{m}^{3}$ (1.2-lb/Macf) NORIT FGD injection on mercury emission

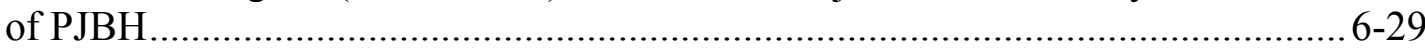

6.2.3.5 Effect of $19 \mathrm{mg} / \mathrm{m}^{3}$ (1.2-lb/Macf) NORIT FGD injection on $\mathrm{Hg}$ emission of the Advanced Hybrid ${ }^{\mathrm{TM}}$ filter at reduced current....................................................... 6-30

6.2.3.6 Effect of $38 \mathrm{mg} / \mathrm{m}^{3}$ (2.4-lb/Macf) FGD injection on $\mathrm{Hg}$ emission of the Advanced Hybrid ${ }^{\mathrm{TM}}$ filter.. 6-31

6.2.3.7 Summary of Advanced Hybrid ${ }^{\mathrm{TM}}$ filter mercury collection efficiency with carbon injection under the different operating conditions 6-32

6.2.4.1 Mercury species across the Advanced Hybrid ${ }^{\mathrm{TM}}$ filter for the baseline test ........... 6-36

6.2.4.2 Temporal variation of mercury species across the system based on the CMM measurements during the baseline test..... $6-36$

6.2.4.3 Summary of mercury species in Belle Ayr flue gas for PTC-BA-629 tests .......... 6-37

6.2.4.4 Mercury species across the Advanced Hybrid ${ }^{\mathrm{TM}}$ filter $(0.5 \mathrm{~mA})$ under $38 \mathrm{mg} / \mathrm{m}^{3}$ (2.4-lb/Macf) continuous FGD injection - Ontario Hydro results ......... 6-38

6.2.4.5 Mercury species across the Advanced Hybrid ${ }^{\mathrm{TM}}$ filter $(0.5 \mathrm{~mA})$ under $38 \mathrm{mg} / \mathrm{m}^{3}$ (2.4-lb/Macf) continuous FGD injection - CMM data............... 6-38

6.2.4.6 Mercury species across the Advanced Hybrid ${ }^{\mathrm{TM}}$ filter $(3 \mathrm{~mA})$ under $38 \mathrm{mg} / \mathrm{m}^{3}$ (2.4-lb/Macf) FGD continuous injection - Ontario Hydro results......... 6-39

6.2.4.7 Mercury species across the Advanced Hybrid ${ }^{\mathrm{TM}}$ filter (3 mA) under $38 \mathrm{mg} / \mathrm{m}^{3}$ (2.4-lb/Macf) FGD continuous injection - CMM data. $6-40$

Continued ... 


\section{LIST OF FIGURES (continued)}

6.2.4.8 Temporal variation of mercury emission of mercury species across the Advanced Hybrid ${ }^{\mathrm{TM}}$ filter $(3 \mathrm{~mA})$ under $38 \mathrm{mg} / \mathrm{m}^{3}$ (2.4-lb/Macf) FGD continuous injection - Ontario Hydro results during the $19 \mathrm{mg} / \mathrm{m}^{3}(1.2-\mathrm{lb} / \mathrm{Macf})$ FGD power-off batch injection test 6-41

6.2.4.9 Mercury species across the Advanced Hybrid ${ }^{\mathrm{TM}}$ filter with $19 \mathrm{mg} / \mathrm{m}^{3}$ (1.2-lb/Macf) FGD power-off batch injection $6-42$

6.2.4.10 Mercury species across the Advanced Hybrid ${ }^{\mathrm{TM}}$ filter under $38 \mathrm{mg} / \mathrm{m}^{3}$ (2.4-lb/Macf) FGD power-off batch injection $6-42$

6.2.4.11 Temporal variations of mercury emission of the Advanced Hybrid ${ }^{\mathrm{TM}}$ filter under $38 \mathrm{mg} / \mathrm{m}^{3}$ (2.4-lb/Macf) FGD power-off batch injection test.

6.2.4.12 Mercury species across the Advanced Hybrid ${ }^{\mathrm{TM}}$ filter under $38 \mathrm{mg} / \mathrm{m}^{3}$ (2.4-lb/Macf) FGD power-on batch injection.

Temporal variations of mercury emission of the Advanced Hybrid ${ }^{\mathrm{TM}}$

6.2.4.13 Temporal variations of mercury emission of the Advanced Hybrid ${ }^{\mathrm{TM}}$
filter under $38 \mathrm{mg} / \mathrm{m}^{3}$ (2.4-lb/Macf) FGD power-on batch injection

6.2.4.14 Mercury species across the Advanced Hybrid ${ }^{\mathrm{TM}}$ filter under $19 \mathrm{mg} / \mathrm{m}^{3}$ (1.2-lb/Macf) FGD continuous injection $6-44$

6.2.4.15 Temporal variations of mercury emission of the Advanced Hybrid
filter under $19 \mathrm{mg} / \mathrm{m}^{3}$ (1.2-lb/Macf) FGD continuous injection.................... $6-45$

6.2.4.16 Comparisons of mercury removal with Advanced Hybrid ${ }^{\mathrm{TM}}$ filter under both continuous and batch carbon injection ............................................................... 6-46

6.2.5.1 Mercury species across the Advanced Hybrid ${ }^{\mathrm{TM}}$ filter in Shade Creek flue gas - 30-min residence time.

6.2.5.2 Mercury species across the Advanced Hybrid ${ }^{\mathrm{TM}}$ filter in Shade Creek flue gas - 24-hr residence time.

6.2.5.3 Mercury species across the PJBH in Shade Creek flue gas - 30-min residence time

6.2.6.1 Ontario Hydro results of mercury species across the Advanced Hybrid ${ }^{\mathrm{TM}}$ filter unit during Tests 1 and 2 ......

6.2.6.2 Temporal variations of gaseous mercury across the Advanced Hybrid ${ }^{\mathrm{TM}}$ filter in Springfield coal baseline test........................................................................... 6-57

6.2.6.3 Four Ontario Hydro inlet mercury samples completed during the PTC-SF-635 testing period $6-58$

6.2.6.4 Temporal variations of gaseous mercury in the Advanced Hybrid ${ }^{\mathrm{TM}}$ filter inlet and outlet flue gas with FGD injection at $135^{\circ} \mathrm{C}\left(275^{\circ} \mathrm{F}\right)$.............................6-59

6.2.6.5 Inlet and outlet Ontario Hydro results with FGD injection at $135^{\circ} \mathrm{C}\left(275^{\circ} \mathrm{F}\right)$....... 6-60

6.2.6.6 Temporal variations of gaseous mercury in Advanced Hybrid ${ }^{\mathrm{TM}}$ filter inlet and outlet flue gases with FGD injection at $135^{\circ} \mathrm{C}\left(275^{\circ} \mathrm{F}\right)$ 6-61

6.2.6.7 Test 7 - Detailed information of mercury emission of the Advanced Hybrid ${ }^{\mathrm{TM}}$ filter under this batch injection test..... 6-61

6.2.6.8 Tests 8 and 9 - Temporal variations of gaseous mercury in the Advanced Hybrid ${ }^{\mathrm{TM}}$ filter inlet and outlet flue gas with FGD injection at $160^{\circ} \mathrm{C}\left(320^{\circ} \mathrm{F}\right) \ldots . .6-62$ 


\section{LIST OF FIGURES (continued)}

6.2.6.9 Advanced Hybrid ${ }^{\mathrm{TM}}$ filter inlet and outlet Ontario Hydro results with FGD

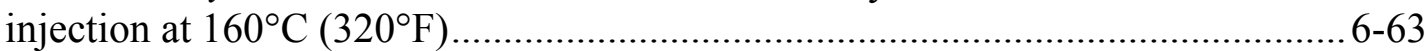

6.2.6.10 Tests 10-15 - Temporal variations of gaseous mercury in the Advanced Hybrid ${ }^{\mathrm{TM}}$ filter inlet and outlet flue gas with FGD injection at $160^{\circ} \mathrm{C}\left(320^{\circ} \mathrm{F}\right) \ldots . .6-64$

6.2.7.1 Mercury species across the Advanced Hybrid ${ }^{\mathrm{TM}}$ filter in the Belle Ayr

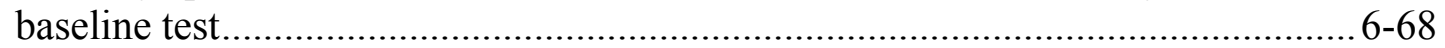

6.2.7.2 Comparison of normalized mercury species distributions in Belle Ayr coal flue gas obtained in the current and previous tests .................................................6-68

6.2.7.3 Temporal variations of gaseous mercury across the Advanced Hybrid ${ }^{\mathrm{TM}}$ filter in the Belle Ayr baseline test

6.2.7.4 Test 2 - Ontario Hydro results in the Advanced Hybrid ${ }^{\mathrm{TM}}$ filter inlet and outlet flue gas with $1.4 \mathrm{~kg} / \mathrm{hr}$ (3-lb/hr) TDF cofiring ............................................ 6-70

6.2.7.5 Flue gas concentrations for PTC-BA-636 ....................................................... 6-72

6.2.7.6 Temporal variations of gaseous mercury across the Advanced Hybrid ${ }^{\mathrm{TM}}$ filter in Day 2 test 6-73

6.2.7.7 Temporal variations of gaseous mercury across the Advanced Hybrid ${ }^{\mathrm{TM}}$ filter in Day 3 test

6.2.7.8 Ontario Hydro results in the Advanced Hybrid ${ }^{\mathrm{TM}}$ filter inlet and outlet flue gas under 3-lb/hr TDF cofiring combined with 1.5-lb/Macf FGD injection 6-74

6.2.7.9 Ontario Hydro sample collected at the Advanced Hybrid ${ }^{\mathrm{TM}}$ filter inlet and outlet with $24-\mathrm{mg} / \mathrm{m}^{3}$ (1.5-lb/Macf) FGD injection

6.2.7.10 Temporal variations of gaseous mercury across the Advanced Hybrid ${ }^{\mathrm{TM}}$ filter in Day 4 tests. $6-76$

6.2.7.11 Ontario Hydro results in the Advanced Hybrid ${ }^{\mathrm{TM}}$ filter inlet and outlet flue gases under $2.7 \mathrm{~kg} / \mathrm{hr}(6-\mathrm{lb} / \mathrm{hr}) \mathrm{TDF}$ cofiring 6-78

6.2.7.12 Ontario Hydro result from the Advanced Hybrid ${ }^{\mathrm{TM}}$ filter inlet and outlet flue gases with $2.7 \mathrm{~kg} / \mathrm{hr}(6-\mathrm{lb} / \mathrm{hr})$ TDF cofiring and $24-\mathrm{mg} / \mathrm{m}^{3}$ (1.5-lb/Macf) FGD injection 6-78

6.2.7.13 Temporal variations of gaseous mercury across the Advanced Hybrid ${ }^{\mathrm{TM}}$ filter in Day 5 tests.

6.2.7.14 Ontario Hydro results in the Advanced Hybrid ${ }^{\mathrm{TM}}$ filter inlet and outlet flue gases under $42 \mathrm{mg} / \mathrm{m}^{3}$ (2.6-lb/Macf) IAC injection 6-80

6.2.7.15 Summary of mercury capture with the Advanced Hybrid ${ }^{\mathrm{TM}}$ filter in Belle Ayr coal flue gas under TDF cofiring combined with carbon injection. 6-81

6.2.7.16 Effect of TDF cofiring on mercury species distributions in the Advanced Hybrid ${ }^{\mathrm{TM}}$ filter inlet flue gases for the baseline and TDF cofiring tests. 6-83

6.2.7.17 Effects of TDF cofiring combined with carbon injects on mercury oxidation in the Advanced Hybrid ${ }^{\mathrm{TM}}$ filter outlet flue gas..... $6-83$

6.2.8.1 Gaseous mercury across PJBH equipped with Cartridge A filters $-149^{\circ} \mathrm{C}$ $\left(300^{\circ} \mathrm{F}\right)$ test 6-86

6.2.8.2 Gaseous mercury across the PJBH equipped with Cartridge A filters $-149^{\circ} \mathrm{C}$ $\left(300^{\circ} \mathrm{F}\right)$ and $124^{\circ} \mathrm{C}\left(255^{\circ} \mathrm{F}\right)$ tests 6-86 Continued ... 


\section{LIST OF FIGURES (continued)}

6.2.8.3 Ontario Hydro results in the inlet and outlet flue gas during PTC-BA-637 .......... 6-88

6.2.8.4 Gaseous mercury across the PJBH equipped with Cartridge B filter $149^{\circ} \mathrm{C}\left(300^{\circ} \mathrm{F}\right)$ test .............................................................................. 6-8

6.2.8.5 Gaseous mercury across the PJBH equipped with Cartridge B filter $149^{\circ} \mathrm{C}\left(300^{\circ} \mathrm{F}\right)$ and $193^{\circ} \mathrm{C}\left(380^{\circ} \mathrm{F}\right)$ tests ...... 6-89

6.2.9.1 Top-view schematic of the Advanced Hybrid ${ }^{\mathrm{TM}}$ filter........................................ 6-92

6.2.9.2 Front view of the Advanced Hybrid ${ }^{\mathrm{TM}}$ filter (perforated plate only) with inlet cover removed $6-92$

6.2.9.3 Mercury emissions from the perforated plate-only Advanced Hybrid ${ }^{\mathrm{TM}}$ filter unit under carbon injection .....

6.2.9.4 Average gaseous mercury removals for baseline and carbon injection tests......... 6-94

6.2.9.5 Particle emissions from the Advanced Hybrid ${ }^{\mathrm{TM}}$ filter - perforated plate only...... 6-95

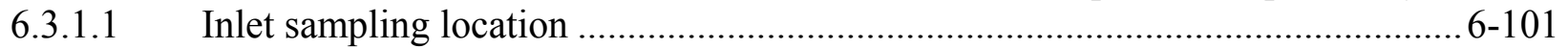

6.3.1.2 Outlet sampling location just before flue gas entered the fan .......................... 6-102

6.3.1.3 Baseline mercury species in the Advanced Hybrid ${ }^{\mathrm{TM}}$ filter inlet

and outlet flue gas ................................................................................ 6-102

6.3.1.4 Normalized baseline mercury species distributions in the inlet and outlet flue gases ......................................................................................... 6-103

6.3.1.5 Ontario Hydro results in the Advanced Hybrid ${ }^{\mathrm{TM}}$ filter inlet and outlet flue gas at $24-\mathrm{mg} / \mathrm{m}^{3}$ (1.5-lb/Macf) FGD injection ....................................... 6-104

6.3.1.6 Ontario Hydro results in the PJBH inlet and outlet flue gas under $24-\mathrm{mg} / \mathrm{m}^{3}$

(1.5-lb/Macf) FGD injection......................................................................6-105

6.3.1.7 Temporal variation of mercury species in flue gas across the PJBH with $24 \mathrm{mg} / \mathrm{m}^{3}$ (1.5-lb/Macf) FGD injection.........................................................6-106

6.3.1.8 Ontario Hydro results in the Advanced Hybrid ${ }^{\mathrm{TM}}$ filter inlet and outlet flue gases with 24-mg/m³ (1.5-lb/Macf) FGD injection for Day 4.

6.3.1.9 Temporal variations of gaseous mercury across the Advanced Hybrid ${ }^{\mathrm{TM}}$ filter with $24-\mathrm{mg} / \mathrm{m}^{3}$ (1.5-lb/Macf) FGD injection for Day 4. 6-107

6.3.1.10 Comparison of mercury species concentration in both the Advanced Hybrid $^{\mathrm{TM}}$ filter and PJBH inlet and outlet flue gas with $24-\mathrm{mg} / \mathrm{m}^{3}$

(1.5-lb/Macf) FGD injection for Day 5 6-108

6.3.1.11 Temporal variations of gaseous mercury across the Advanced Hybrid ${ }^{\mathrm{TM}}$ filter or PJBH with 24-mg/m $3 \mathrm{~m}^{3}$ (1.5-lb/Macf) FGD injection for Day 5 6-109

6.3.2.1 Mercury species in the Big Stone Power Plant flue gas based on Ontario Hydro samples collected August 5-9, 2002 $6-116$

6.3.2.2 Mercury species in the Big Stone Power Plant flue gas based on Ontario Hydro samples collected in August 26-27, 2002

6.3.2.3 Comparison of Ontario Hydro results with CMM data ................................... 6-117

6.3.2.4 Daily average of gaseous mercury (CMM data) in the flue gas over the 1 -month testing period ........................................................................ 6-118

6.3.2.5 Comparisons of mercury species distribution in the Advanced Hybrid ${ }^{\mathrm{TM}}$ filter Big Stone field tests and EERC pilot-scale tests 


\section{LIST OF FIGURES (continued)}

6.3.2.6 Inlet and outlet Ontario Hydro mercury speciation for the Advanced Hybrid $^{\mathrm{TM}}$ filter baseline test at Big Stone, August 5-6, 2002

6.3.2.7 Mercury species concentration in flue gas at the Advanced Hybrid ${ }^{\mathrm{TM}}$ filter inlet and outlet under two FGD injection rates.

6.3.2.8 Advanced Hybrid ${ }^{\mathrm{TM}}$ filter inlet and outlet mercury species at $24-\mathrm{mg} / \mathrm{m}^{3}$ (1.5-lb/Macf) FGD injection. $6-124$

6.3.2.9 Mercury collection efficiencies with the Advanced Hybrid ${ }^{\mathrm{TM}}$ filter at $24-\mathrm{mg} / \mathrm{m}^{3}$ (1.5- $\left.\mathrm{lb} / \mathrm{Macf}\right)$ carbon injection

6.3.2.10 Inlet and outlet mercury speciation results of the batch injection tests 6-125

6.3.2.11

6.3.2.12 Mercury removal efficiencies for continuous and batch FGD injection tests 6-126 Gaseous mercury capture efficiency at Big Stone field unit during AugustSeptember 2002

6.3.2.13 Effect of change in current on mercury emission from the Advanced Hybrid ${ }^{\mathrm{TM}}$ filter field unit.... $6-128$

6.3.2.14 Individual bag flows for one row of the bags over several bag-cleaning cycles.

6.3.2.15 Ontario Hydro results at the Big Stone stack................................................... 6-130

6.3.2.16 Average daily pressure drop for June 28-September 3, 2002 ........................... 6-132

6.3.2.17 Daily average BCI for June 28-September 3, $2002 \ldots \ldots \ldots \ldots \ldots \ldots \ldots \ldots \ldots \ldots \ldots \ldots \ldots \ldots . . . .6-132$

6.3.2.18 $\quad \mathrm{K}_{2} \mathrm{C}_{\mathrm{i}}$ for June 28-September 3, 2002 ........................................................ 6-133

6.3.2.19 Residual drag for June 28-September 3, 2002 .............................................. 6-133

6.3.3.1 Mercury species concentration at the full-scale Advanced Hybrid ${ }^{\mathrm{TM}}$ filter inlet and stack

6.3.3.2 Test 1 Baseline inlet and outlet mercury CMM data for the 2.5-MW (9000-acfm) Advanced Hybrid ${ }^{\mathrm{TM}}$ filter.

6.3.3.3 Tests 2-5 - outlet mercury emission for the 2.5-MW (9000-acfm)

Advanced Hybrid ${ }^{\mathrm{TM}}$ filter.

6.3.3.4 Tests 5-9 - Outlet mercury emission for the 2.5-MW (9000-acfm)

Advanced Hybrid ${ }^{\mathrm{TM}}$ filter.

6.3.3.5 Big Stone Power Plant load during field sampling at the 2.5-MW (9000-acfm) Advanced Hybrid ${ }^{\mathrm{TM}}$ filter.

6.3.3.6 The Advanced Hybrid ${ }^{\mathrm{TM}}$ filter inlet and outlet temperatures.....

6.3.3.7 Tests 9-11 - outlet mercury emission for the 2.5-MW (9000-acfm) Advanced Hybrid ${ }^{\mathrm{TM}}$ filter. 6-143

6.3.4.1 Daily average mercury vapor concentrations, both total and elemental, in the inlet flue gas for the 2.5-MW (9000-acfm) Advanced Hybrid ${ }^{\mathrm{TM}}$ filter.

6.3.4.2 Ratios of $\mathrm{Hg}^{0}$-to- $\mathrm{Hg}_{\text {gas }}$ in the inlet flue gas for the 2.5-MW (9000-acfm) Advanced Hybrid ${ }^{\mathrm{TM}}$ filter.

6.3.4.3 Summary of the inherent mercury captures with the Advanced Hybrid ${ }^{\mathrm{TM}}$ filter during several different baseline testing periods $6-150$

6.3.4.4 Mercury collection efficiencies under different filtration velocities (May 14, 2003) 


\section{LIST OF FIGURES (continued)}

6.3.4.5 Mercury collection efficiencies under different filtration velocities

(May 15, 2003)

6.3.4.6 Mercury collection efficiencies under different filtration velocities (May 20, 2003) $6-153$

6.3.4.7 Measured mercury overall collection efficiencies under the two different sorbent in-flight times (June 2-3, 2003) ......................................................... 6-154

6.3.4.8 The effect of sorbent injection rate on mercury removal (May 12, 2003) ........... 6-155

6.3.4.9 Summary of mercury removal efficiencies with the ESP power on and off ........ 6-156

6.3.4.10 Mercury removals with the 2.5-MW (9000-acfm) Advanced Hybrid ${ }^{\mathrm{TM}}$ filter under $17.6 \mathrm{mg} / \mathrm{m}^{3}$ (1.1-lb/Macf) IAC injection ......................................... 6-157

6.3.4.11 Average total long-term ambient-temperature mercury release or sorption

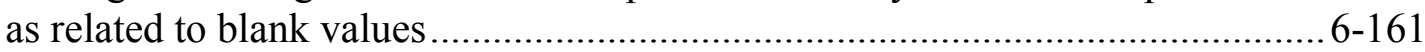

6.3.4.12 Thermal desorption curve for Sample 03-060 ……........................................ 6-161

6.3.4.13 Thermal desorption curve for Sample 03-061 …............................................... 6-162

6.4.1 SDA inlet and PJBH outlet mercury results in the SDA and PJBH

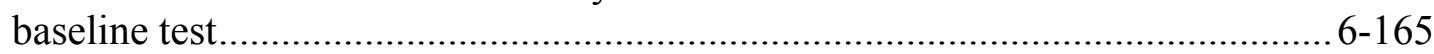

6.4.2 Comparisons of mercury removals in SDA-PJBH with additive alone and in combination with FGD injection .................................................................. 6-167

\section{LIST OF TABLES}

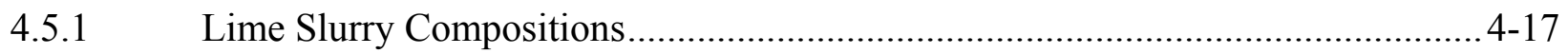

5.1.1 Sample Train Components-EPA Method 17 Configuration ..................................... 5-2

6.1.1.1 Bench-Scale Series $1-\mathrm{SO}_{2}$ and $\mathrm{NO}_{2}$ Concentration .......................................... 6-1

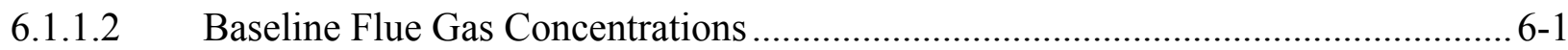

6.1.2.1 Bench-Scale Series 2 - Real Flue Gas Comparison ............................................. 6-7

6.1.2.2 Flue Gas Concentrations for Bench-Scale Breakthrough Tests ............................... 6-8

6.2.1 Pilot-Scale Testing ................................................................................... 6-10

6.2.2.1 Summary of Mercury, Gas, and Solids Samples Taken ..................................... 6-11

6.2.2.2 Coal Analysis for the PTC-CR-624 Test ........................................................ 6-12

6.2.2.3 Summary of Flue Gas Compositions During PTC-CR-624 Sampling .................... 6-12

6.2.2.4 Mercury Concentration in Fly Ash ................................................................ 6-14

6.2.2.5 Summary of Ontario Hydro Mercury Results ....................................................... 6-19

6.2.2.6 Summary of Method 101A Results .............................................................. 6-19

6.2.2.7 Dust Loading at the Advanced Hybrid ${ }^{\mathrm{TM}}$ Filter Inlet and Outlet and the Calculated Collection Efficiency ................................................................. 6-20

6.2.3.1 Pilot-Scale Testing Plan for Run PTC-BA-628 ……........................................ 6-23

6.2.3.2 Coal Analysis for Run PTC-BA-628 ………....................................................... 6-24

6.2.3.3 Summary of the Flue Gas Compositions During Run PTC-BA-628 ..................... 6-25

Continued ... 


\section{LIST OF TABLES (continued)}

6.2.3.4 PTC-BA-628 - Dust Loading at the Advanced Hybrid ${ }^{\mathrm{TM}}$ Filter Inlet and

Outlet and the Calculated Collection Efficiency .....................................................6-33

6.2.4.1 PTC-BA-629 - Summary of the Test Scenarios.................................................... 6-35

6.2.4.2 PTC-BA-629 - Summary of the Flue Gas Compositions During the

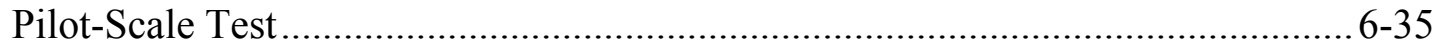

6.2.5.1 PTC-SC-632 - Test Parameters.................................................................... 6-48

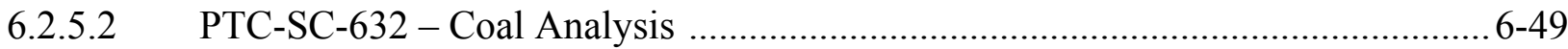

6.2.5.3 PTC-SC-632 - Mercury Concentration in Fly Ash ..............................................6-52

6.2.6.1 Summary of the Test Scenarios for PTC-SF-635 ............................................. 6-54

6.2.6.2 Coal Analysis for the PTC-SF-635 Test....................................................... 6-55

6.2.6.3 Characteristics of Flue Gas for the PTC-SF-635 Test ......................................... 6-55

6.2.7.1 Summary of the Test Conditions for PTC-BA ……….......................................6-66

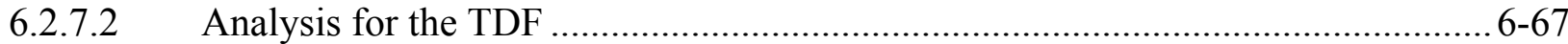

6.2.7.3 Chloride Concentrations in Flue Gas............................................................... 6-71

6.2.7.4 LOI in the Advanced Hybrid ${ }^{\mathrm{TM}}$ Filter Hopper Ash ............................................. 6-72

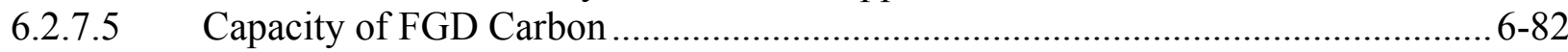

6.3.1.1 Summary of Mercury, Gas, and Solids Samples Taken .......................................6-98

6.3.1.2 Big Stone Fuel Record November 5-10, 2001 ................................................ 6-99

6.3.1.3 Coal Analysis for the Big Stone Power Plant..................................................... 6-99

6.3.1.4 Summary of the Flue Gas Compositions During the 5-day Sampling ................. 6-100

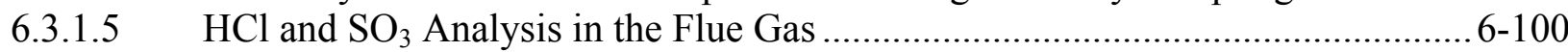

6.3.1.6 Summary of Ontario Hydro Mercury Results .................................................... 6-110

6.3.1.7 Mercury Concentration and LOI in Fly Ash..................................................... 6-111

6.3.1.8 Dust Loadings at the Advanced Hybrid ${ }^{\mathrm{TM}}$ Filter Inlet and Outlet and the

Calculated Collection Efficiency ................................................................... 6-113

6.3.2.1 Big Stone Fuel Record................................................................................. 6-115

6.3.2.2 Chlorine Concentration in Flue Gas at Big Stone Power Plant ........................... 6-120

6.3.2.3 Standard Operating Conditions During August 5-September 6, 2002................ 6-123

6.3.2.4 Big Stone Power Plant Stack Emissions............................................................. 6-131

6.3.3.1 Summary of Test Matrix for the November 2002 Big Stone Power Plant

Field Sampling ......................................................................................... 6-135

6.3.3.2 Big Stone Fuel Record for November 2002 …............................................. 6-137

6.3.4.1 Testing Parameters During May-June 2003 Test................................................ 6-146

6.3.4.2 Fuel Burn Record for the Big Stone Power Plant for May 2003 .......................... 6-146

6.3.4.3 Mercury Content in the Coals and Hopper Ash................................................... 6-148

6.3.4.4 Total Mercury Content of Advanced Hybrid ${ }^{\mathrm{TM}}$ Filter Samples ............................. 6-158

6.3.4.5 Bulk Oxide Data for Advanced Hybrid ${ }^{\mathrm{TM}}$ Filter Samples .................................. 6-158

6.3.4.6 Leaching Data on Advanced Hybrid ${ }^{\mathrm{TM}}$ Filter Samples....................................... 6-158

6.3.4.7 Microbiologically Mediated Release of Vapor-Phase Mercury and

Total Bacterial Count Data for Sample 03-060 ……………............................... 6-160

6.4.1 Mercury Control Test Matrix............................................................................ 6-163

6.4.2 Center Lignite Coal Proximate Analysis Results ................................................. 6-164 


\section{LIST OF TABLES (continued)}

6.4.3 Center Lignite Coal Ultimate Analysis Results............................................. 6-164

6.4.4 Major Flue Gas Compositions of Center Lignite Flue Gas ................................ 6-164

6.4.5 SDA-PJBH Hg(g) Removal Efficiencies (\%) with NORIT FGD Injection ........ 6-166

6.4.6 Average ( $\pm 95 \%$ confidence limit) SDA-FF $\mathrm{Hg}(\mathrm{g})$ Removal Efficiencies

for Sorbents and Additives ..............................................................................6-167 


\section{MERCURY CONTROL WITH THE ADVANCED HYBRID PARTICULATE COLLECTOR}

\section{EXECUTIVE SUMMARY}

Since 1995, the U.S. Department of Energy (DOE) National Energy Technology Laboratory (NETL) has supported development of a new concept in particulate control called the advanced hybrid particulate collector (AHPC). The AHPC, licensed to W.L. Gore \& Associates, Inc., has been marketed as the Advanced Hybrid ${ }^{\mathrm{TM}}$ filter by Gore. The Advanced Hybrid ${ }^{\mathrm{TM}}$ filter combines the best features of electrostatic precipitators (ESPs) and baghouses in a unique configuration, providing major synergism between the two collection methods, both in the particulate collection step and in the transfer of dust to the hopper.

The Energy \& Environmental Research Center's (EERC's) objective for this project was to demonstrate $90 \%$ total mercury control with commercially available sorbents in the Advanced Hybrid $^{\mathrm{TM}}$ filter at a lower cost than current mercury control estimates. The approach included three levels of testing: 1) bench-scale batch testing that tied the new work to previous results and linked results with larger-scale pilot testing with real flue gas on a coal-fired combustion system, 2) pilot-scale testing on a previously proven combustion system, and 3) field demonstration testing at the 2.5-MW (9000-acfm) scale at a utility power plant to prove scale-up and demonstrate longer-term mercury control.

Initial bench-scale results were in good agreement with previous data. Results showed that the $\mathrm{SO}_{2}$ and $\mathrm{NO}_{2}$ concentration effects are additive and have a significant effect on sorbent performance. This finding should facilitate predicting sorbent performance in real systems when the $\mathrm{SO}_{2}$ and $\mathrm{NO}_{2}$ concentrations are known. Further finding from the bench-scale tests was that the fixed-bed sorbent-screening tests using simulated flue gas were in good agreement with similar tests sampling real flue gas. This suggests that as long as the main flue gas components are duplicated, the bench-scale fixed-bed tests can be utilized to indicate sorbent performance in larger-scale systems.

An initial field test of the 2.5-MW (9000-acfm) Advanced Hybrid ${ }^{\mathrm{TM}}$ filter at the Big Stone Power Plant was completed the first week of November 2001. Results showed that the average inlet mercury speciation for seven samples was $55.4 \%$ particulate bound, $38.1 \%$ oxidized, and 
$6.4 \%$ elemental. A carbon injection rate of $24 \mathrm{mg} / \mathrm{m}^{3}$ (1.5 lb/Macf) resulted in $91 \%$ total mercury collection efficiency, compared to $49 \%$ removal for the baseline case.

Following the initial field test, the first planned pilot-scale tests were completed. In the pilot-scale tests, a baseline comparison was made between the Advanced Hybrid ${ }^{\mathrm{TM}}$ filter and a pulse-jet baghouse (PJBH) in terms of the mercury speciation change across the device and the amount of mercury retained by the fly ash. Results showed that for both devices there was very little capture of mercury by the fly ash. There was some increase in oxidized mercury, but no significant differences were noted between the Advanced Hybrid ${ }^{\mathrm{TM}}$ filter and pulse-jet modes of operation.

Even though the same coal was used in the pilot-scale and initial field tests, there was a significant difference in inlet mercury speciation. For the pilot-scale tests, results were more similar to what is typically expected for Powder River Basin (PRB) coals in that most of the mercury was elemental, with little mercury capture by the fly ash. In contrast, for the November 2001 field test, there was much more oxidized than elemental mercury and significant mercury capture by the fly ash. Possible reasons for the difference include higher carbon in the field ash, somewhat higher $\mathrm{HCl}$ in the field flue gas due to the cofiring of tire-derived fuel (TDF), possible variation in the coal, cyclone firing for the field compared to pulverized coal firing for the pilot tests, longer residence time for the field tests, and a finer particle size for the field test.

During April-June 2002, a number of baseline and carbon injection pilot-scale tests were completed with Belle Ayr PRB subbituminous coal, one of the coals burned at Big Stone. For the baseline case, approximately $70 \%$ of the inlet mercury was elemental, approximately $23 \%$ oxidized, and $2 \%$ or less was associated with particulate matter. Very little natural mercury was captured across the Advanced Hybrid ${ }^{\mathrm{TM}}$ filter for the baseline tests, and the level of oxidized mercury increased only slightly across the Advanced Hybrid ${ }^{\mathrm{TM}}$ filter during baseline operation.

With carbon injection, a comparison of short and long residence time in the Advanced Hybrid ${ }^{\mathrm{TM}}$ filter showed that somewhat better mercury removal was achieved with longer residence time. No evidence of desorption of mercury from the carbon was seen upon continued exposure to flue gases up to $24 \mathrm{hr}$. This suggests that desorption of captured mercury from the carbon sorbent is not a significant problem under these flue gas conditions with the low-sulfur subbituminous coal. 
At a carbon-to-mercury ratio of $3000: 1$, from $50 \%$ to $71 \%$ total mercury removal was achieved. When the ratio was increased to $6000: 1$, the removal range increased to $65 \%-87 \%$, even for the difficult case with predominantly elemental mercury and very little natural capture of mercury by the fly ash.

A longer-term field test was completed with the 2.5-MW (9000-acfm) field Advanced Hybrid $^{\mathrm{TM}}$ filter August 6 through September 6, 2002. Carbon injection and CMM (continuous mercury monitor) measurements were continuous ( $24 \mathrm{hr}$ a day) for the entire month, except for an unplanned plant outage from August 29 to September 2. The primary goal of the work was to demonstrate longer-term mercury control with the Advanced Hybrid ${ }^{\mathrm{TM}}$ filter and evaluate the effect of carbon injection on Advanced Hybrid ${ }^{\mathrm{TM}}$ filter operational performance. Another goal of the test was to evaluate the effect of supplemental TDF burning on the level of mercury capture for comparison with results from the previous test completed in November 2001.

The inlet mercury speciation during the August 2002 tests averaged 17\% particulate bound, $32 \%$ oxidized, and $51 \%$ elemental. The significant difference in mercury speciation between the August and November 2001 field data is likely the effect of a higher rate of cofiring of TDF with the coal during the November test.

In the November 2001 tests, 49\% mercury capture was seen for the baseline conditions without carbon injection. The August tests indicated only $0 \%-10 \%$ mercury capture with no carbon injection. Again, the most likely explanation is the much higher TDF cofiring rate and higher $\mathrm{HCl}$ in the flue gas for the November test.

Addition of activated carbon at a rate of $24 \mathrm{mg} / \mathrm{m}^{3}(1.5 \mathrm{lb} / \mathrm{Macf})$ resulted in an average of 63\% mercury removal in the August tests without any TDF cofiring. A small TDF cofiring rate of about 23 tons a day resulted in an increase in mercury collection to $68 \%$. At the highest TDF rate seen in the August tests of 150-177 tons a day, mercury removal of up to $88 \%$ was achieved. This compares with $91 \%$ removal seen during the November tests when the TDF feed rate was in the range from 90 to 250 tons a day. These results indicate that TDF cofiring has the effect of increasing the level of mercury control that can be achieved with a low carbon addition rate.

One of the main objectives of the August tests was to assess the effect of carbon injection on longer-term Advanced Hybrid ${ }^{\mathrm{TM}}$ filter performance. When the carbon was started on August 7 , there was no perceptible change in pressure drop or bag-cleaning interval. Similarly, there was no change in the $\mathrm{K}_{2} \mathrm{C}_{\mathrm{i}}$ value that relates to how well the ESP portion of the Advanced Hybrid ${ }^{\mathrm{TM}}$ 
filter is working. These results indicate that low addition rates of carbon will have no perceptible effect on the operational performance of the Advanced Hybrid ${ }^{\mathrm{TM}}$ filter.

Another short field test was completed with the 2.5-MW (9000-acfm) Advanced Hybrid ${ }^{\mathrm{TM}}$ filter at the Big Stone Plant November 19-22, 2002, to coincide with the first test conducted at the inlet and stack of the full-scale Advanced Hybrid ${ }^{\mathrm{TM}}$ filter after it came online October 26, 2002. The primary purpose of the test was to evaluate the effect of injecting a small amount of $\mathrm{HCl}$ into the flue gas along with the activated carbon. Results showed that without supplemental $\mathrm{HCl}$ injection and a low carbon injection rate of $24 \mathrm{~kg}$ of carbon sorbent/million $\mathrm{m}^{3}$ of flue gas (1.5 lb of carbon sorbent/million acf), from $65 \%$ to over $90 \%$ total mercury removal was achieved. This is somewhat better than the results seen in the monthlong continuous test in August 2002. Part of the reason could be the higher temperatures in the Advanced Hybrid ${ }^{\mathrm{TM}}$ filter during August, which typically were in the range of $132^{\circ}-143^{\circ} \mathrm{C}\left(270^{\circ}-290^{\circ} \mathrm{F}\right)$ compared to $121^{\circ} \mathrm{C}\left(250^{\circ} \mathrm{F}\right)$ for the November 2002 tests.

Little or no effect was seen with the supplemental $\mathrm{HCl}$ injection. This is somewhat surprising because an extensive amount of bench-scale sorbent work has demonstrated the benefit of $\mathrm{HCl}$ for capturing elemental mercury in a simulated flue gas over the temperature range of $107^{\circ}-188^{\circ} \mathrm{C}\left(225^{\circ}-370^{\circ} \mathrm{F}\right)$. However, the benefit of additional $\mathrm{HCl}$ may be marginal in cases where there is already a sufficient amount of $\mathrm{HCl}$ present to achieve good mercury control.

During October-December 2002, a $5.7-\mathrm{m}^{3} / \mathrm{min}$ (200-acfm) pilot-scale test was also completed with Springfield bituminous coal. The purpose of this test was to evaluate mercury control with the Advanced Hybrid ${ }^{\mathrm{TM}}$ filter with a high-sulfur bituminous coal. The Springfield bituminous coal produced a flue gas that was high in all of the acid gases including $\mathrm{SO}_{3}$, and most of the inlet mercury was in an oxidized form. A number of short- and longer-term tests with the NORIT Americas DARCO ${ }^{\circledR} \mathrm{FGD}$ carbon at temperatures ranging from $135^{\circ}$ to $160^{\circ} \mathrm{C}\left(275^{\circ}\right.$ to $320^{\circ} \mathrm{F}$ ) showed that this sorbent is completely ineffective at mercury control under these conditions. This is in contrast to the extensive testing conducted previously with the Advanced Hybrid ${ }^{\mathrm{TM}}$ filter and subbituminous coal, where up to $90 \%$ mercury capture was seen at a low carbon addition rate. The data are consistent with previous bench-scale testing that has shown that flue gas conditions are critical to the mercury capture ability of an activated carbon. 
The previous field studies performed in November 2001 and August 2002 showed there was a correlation between $\mathrm{Hg}^{2+}$ concentration in the flue gas and the amount of TDF fed into the boiler. However, because of the variability of the TDF feed rate, it was difficult to quantify the TDF effect on mercury removal. A 1-week pilot-scale test was conducted on the 55-kW (200-acfm) EERC Advanced Hybrid ${ }^{\mathrm{TM}}$ filter where the coal feed rate and the TDF feed rate were precisely controlled.

Cofiring of TDF with the subbituminous coal had a significant effect on mercury speciation at the inlet to the Advanced Hybrid ${ }^{\mathrm{TM}}$ filter. Firing 100\% coal resulted in only 19\% oxidized mercury at the inlet compared to $47 \%$ cofiring $5 \%$ TDF (mass basis) and $85 \%$ cofiring $10 \%$ TDF. The significant increase in oxidized mercury may be partly the result of increased $\mathrm{HCl}$ in the flue gas with the TDF. However, since the actual increase of measured $\mathrm{HCl}$ was only a few parts per million, other changes in combustion conditions or flue gas components may also be responsible for the increase in oxidized mercury.

The TDF not only enhances mercury oxidation in flue gas but also improves mercury capture when combined with FGD carbon injection. With 100\% coal, test results have shown from $48 \%$ to $78 \%$ mercury removal at a relatively low FGD carbon addition rate of $24 \mathrm{~kg}$ of carbon/million $\mathrm{m}^{3}$ ( $1.5 \mathrm{lb}$ of carbon/million acf). Results showed from $88 \%$ to $95 \%$ total mercury removal with the same carbon addition rate while 5\%-10\% TDF was cofired. These results are consistent with previously reported results from the $2.5-\mathrm{MW}$ (9000-acfm) pilot-scale Advanced Hybrid ${ }^{\mathrm{TM}}$ filter.

W.L. Gore \& Associates, Inc., initiated an innovative concept for control of mercury emissions in flue gas streams. Specifically, the configuration involves a mercury control filter placed inside the existing particulate control filter bag, essentially a bag-within-a-bag. This concept is attractive for use the Advanced Hybrid ${ }^{\mathrm{TM}}$ filter, because of the much fewer number of bags required compared to conventional baghouses.

A week of testing was completed with two different cartridge filters on the $55-\mathrm{kW}$ (200-acfm) pilot-scale Advanced Hybrid ${ }^{\mathrm{TM}}$ filter in March 2003. The filters were installed inside of the four cylindrical all-polytetrafluoroethylene (PTFE) bags in the Advanced Hybrid ${ }^{\mathrm{TM}}$ filter unit. Operationally, the mercury filter elements did not appear to impair the pulse cleaning of the bags. Initial tests with these cartridges showed that nearly $100 \%$ mercury capture could be achieved, but early breakthrough results were observed. 
Another 1-month field test was completed during May-June 2003 with the 2.5-MW (9000-acfm) Advanced Hybrid ${ }^{\mathrm{TM}}$ filter unit at the Big Stone Plant to demonstrate long-term mercury control with the Advanced Hybrid ${ }^{\mathrm{TM}}$ filter and evaluate the impacts of various operating parameters such as filtration velocity, carbon feed rate, and carbon in-flight time on mercury control.

The inlet mercury vapor concentration in the flue gas during the May 2003 test ranged from 4.98 to $10.6 \mu \mathrm{g} / \mathrm{m}^{3}$ with $20 \%-70 \% \mathrm{Hg}^{0}$. The variation in mercury speciation was likely caused by varying coal as well as the intermittent cofiring of TDF and waste seeds. The May 2003 test indicated $0 \%-30 \%$ mercury inherent capture with no carbon addition, typical for western subbituminous coal. At low carbon feed concentrations ranging from 1 to $3 \mathrm{lb} / \mathrm{Macf}$, the Advanced Hybrid ${ }^{\mathrm{TM}}$ filter demonstrated high overall mercury collection efficiencies from $65 \%$ to 95\%. When compared with other research results, the Advanced Hybrid ${ }^{\mathrm{TM}}$ filter clearly demonstrated higher mercury removal efficiency than an ESP under the same carbon feed rate. The overall Hg removal with the Advanced Hybrid ${ }^{\mathrm{TM}}$ filter was similar to a baghouse or COHPAC (compact hybrid particulate collector).

An additional sixth task was added to the project, initiated in April 2003. The planned objectives for this task were to evaluate mercury capture enhancement by using elemental mercury oxidation additives with a spray dryer absorber and test the novel Gore baghouse inserts downstream of the Advanced Hybrid ${ }^{\mathrm{TM}}$ filter or a fabric filter. The planned additional tests included 1) $\mathrm{Hg}$ oxidation upstream of a lime-based spray dryer fabric filter or Advanced Hybrid $^{\mathrm{TM}}$ filter combination in order to control mercury emissions using dry scrubbers and 2) field testing of mercury sorbent technology at a North Dakota power plant using a slipstream baghouse. However, planned field testing of the Gore mercury inserts was not completed because Gore discontinued their development.

A pilot-scale Niro spray dryer system was installed on the EERC particulate test combustor (PTC) upstream of a PJFF (pulse-jet fabric filter) or Advanced Hybrid ${ }^{\mathrm{TM}}$ filter. Several additives and sorbent combinations were tested for mercury control while a Center, North Dakota, lignite was fired. Results showed that $95 \%$ mercury removal was seen with NORIT FGD activated carbon when a sorbent enhancement additive was injected into the furnace, compared to only $37 \%$ control with the FGD sorbent alone or 54\% removal with the additive alone. 
The last planned experimental work for the project was a test completed during JulySeptember 2004 to measure the amount of mercury collected by the perforated plates in the Advanced Hybrid ${ }^{\mathrm{TM}}$ filter apart from any mercury control on the filter bags. To address this question, the 55-kW (200-acfm) pilot-scale Advanced Hybrid ${ }^{\mathrm{TM}}$ filter was modified so that it included perforated plates totally surrounding the normal bag area, but with the filter bags removed. Mercury removal with this configuration using the NORIT FGD carbon injected at $36 \mathrm{~kg}$ of carbon sorbent/million $\mathrm{m}^{3}$ of flue gas ( $2 \mathrm{lb}$ of carbon sorbent/million acf) was $66 \%$, which was similar to previous results with the Advanced Hybrid ${ }^{\mathrm{TM}}$ filter. However, using an EERC proprietary sorbent at the same carbon addition rate improved the mercury collection efficiency to $90 \%$. For both tests, the particulate collection efficiency of the perforated plates alone was $98 \%$. These are important results, because they prove that good gas-solid contact leading to excellent mercury removal can be achieved by collection of the activated carbon on the perforated plates alone, without a significant fraction of the carbon reaching the bags. 


\section{MERCURY CONTROL WITH THE ADVANCED HYBRID PARTICULATE COLLECTOR}

\subsection{INTRODUCTION AND BACKGROUND}

\subsection{Introduction}

This project was awarded under U.S. Department of Energy (DOE) National Energy Technology Laboratory (NETL) Program Solicitation DE-PS26-00NT40769 and specifically addressed Technical Topic Area 4 - Testing Novel and Less Mature Control Technologies on Actual Flue Gas at the Pilot Scale. The project team included the Energy \& Environmental Research Center (EERC) as the main contractor; W.L. Gore \& Associates, Inc., as a technical and financial partner; and the Big Stone Power Plant operated by Otter Tail Power Company, which hosted the field-testing portion of the research.

Since 1995, DOE has supported development of a new concept in particulate control called the advanced hybrid particulate collector (AHPC). The AHPC has been licensed to W.L. Gore \& Associates, Inc., and has been marketed as the Advanced Hybrid ${ }^{\mathrm{TM}}$ filter by Gore. The Advanced Hybrid $^{\mathrm{TM}}$ filter combines the best features of electrostatic precipitators (ESPs) and baghouses in a unique configuration, providing major synergism between the two collection methods, both in the particulate collection step and in the transfer of dust to the hopper. The Advanced Hybrid ${ }^{\mathrm{TM}}$ filter provides ultrahigh collection efficiency, overcoming the problem of excessive fine-particle emissions with conventional ESPs, and it solves the problem of reentrainment and re-collection of dust in conventional baghouses. The Advanced Hybrid ${ }^{\mathrm{TM}}$ filter also appears to have unique advantages for mercury control over baghouses or ESPs as an excellent gas-solid contactor. Mercury control with the Advanced Hybrid ${ }^{\mathrm{TM}}$ filter was the focus of this project.

\subsection{History of Development}

The Advanced Hybrid ${ }^{\mathrm{TM}}$ filter concept was first proposed to DOE in September 1994 in response to a major solicitation addressing air toxics. DOE has been the primary funder of the Advanced Hybrid ${ }^{\mathrm{TM}}$ filter development since that time, along with significant cost sharing from industrial cosponsors. Details of all of the results have been reported in DOE quarterly technical reports, final technical reports for completed phases, and numerous conference papers (1-7). A chronology of the significant development steps for the Advanced Hybrid ${ }^{\mathrm{TM}}$ filter is shown below. 
- September 1994 - Advanced Hybrid ${ }^{\mathrm{TM}}$ filter concept proposed to DOE

- October 1995-September 1997 - Phase I - Advanced Hybrid ${ }^{\mathrm{TM}}$ filter successfully demonstrated at 55-kW (200-acfm) scale

- March 1998-February 2000 - Phase II - Advanced Hybrid ${ }^{\mathrm{TM}}$ filter successfully demonstrated at 2.5-MW (9000-acfm) scale at Big Stone Power Plant

- September 1999-August 2001 - Phase III - Advanced Hybrid ${ }^{\mathrm{TM}}$ filter commercial components tested and proven at 2.5-MW (9000-acfm) scale at Big Stone Power Plant

- Summer 2000 - Minor electrical damage to the bags observed

- January-June 2001 - To prevent electrical damage, the Advanced Hybrid ${ }^{\mathrm{TM}}$ filter perforated plate configuration was developed, tested, and proven to be superior to the original design.

- July 2001-March 2005 - Project to evaluate Mercury Control with the Advanced Hybrid $^{\mathrm{TM}}$ filter - Results are the focus of this final technical report.

- Fall 2002-March 2005 - Full-scale commercial Advanced Hybrid ${ }^{\mathrm{TM}}$ filter demonstration at the 470-MW Big Stone Power Station

\subsection{Concept of the Advanced Hybrid ${ }^{\mathrm{TM}}$ Filter for Particulate Control}

The goals for the Advanced Hybrid ${ }^{\mathrm{TM}}$ filter are as follows: > 99.99\% particulate collection efficiency for particle sizes ranging from 0.01 to $50 \mu \mathrm{m}$, applicable for use with all U.S. coals, and cost savings compared to existing technologies.

The Advanced Hybrid ${ }^{\mathrm{TM}}$ filter combines the best features of ESPs and baghouses in a unique approach to develop a compact but highly efficient system. Filtration and electrostatics are employed in the same housing, providing major synergism between the two collection methods, both in the particulate collection step and in the transfer of dust to the hopper. The Advanced Hybrid ${ }^{\mathrm{TM}}$ filter provides ultrahigh collection efficiency, overcoming the problem of excessive fine-particle emissions with conventional ESPs, and solves the problem of reentrainment and re-collection of dust in conventional baghouses.

The electrostatic and filtration zones are oriented to maximize fine-particle collection and minimize pressure drop. Ultrahigh fine-particle collection is achieved by removing over $90 \%$ of the dust before it reaches the fabric and using membrane fabric to collect the particles that reach the filtration surface. Charge on the particles also enhances collection and minimizes pressure drop, since charged particles tend to form a more porous dust cake. The goal is to employ only 
enough ESP plate area to precollect approximately $90 \%$ of the dust. ESP models predict that $90 \%-95 \%$ collection efficiency can be achieved with full-scale precipitators with a specific collection area (SCA) of less than $20 \mathrm{~m}^{2}$ collection area $/ \mathrm{m}^{3} / \mathrm{s}\left(100 \mathrm{ft}^{2}\right.$ of collection area/1000 acfm) (8). Fabric filter (FF) models predict that face velocities greater than $3.7 \mathrm{~m} / \mathrm{min}$ (12 ft/min) are possible if some of the dust is precollected and the bags can be adequately cleaned. The challenge is to operate at high air-to-cloth (A/C) ratios $2.4-4.3 \mathrm{~m} / \mathrm{min}(8-14 \mathrm{ft} / \mathrm{min})$ for economic benefits while achieving ultrahigh collection efficiency and controlling pressure drop. The combination of GORE-TEX ${ }^{\circledR}$ membrane filter media (or similar membrane filters from other manufacturers), small $\mathrm{SCA}$, high $\mathrm{A} / \mathrm{C}$ ratio, and unique geometry meets this challenge.

Studies have shown that FF collection efficiency is likely to deteriorate significantly when the face velocity is increased $(9,10)$. For high collection efficiency, the pores in the filter media must be effectively bridged (assuming they are larger than the average particle size). With conventional fabrics at low $\mathrm{A} / \mathrm{C}$ ratios, the residual dust cake serves as part of the collection media, but at high $\mathrm{A} / \mathrm{C}$ ratios, only a very light residual dust cake is acceptable, so the cake cannot be relied on to achieve high collection efficiency. The solution is to employ a sophisticated fabric that can ensure ultrahigh collection efficiency and endure frequent highenergy cleaning. In addition, the fabric should be reliable under the most severe chemical environment likely to be encountered (such as high $\mathrm{SO}_{3}$ ).

Assuming that low particulate emissions can be maintained through the use of advanced filter materials and that $90 \%$ of the dust is precollected, operation at face velocities in the range of $2.4-4.3 \mathrm{~m} / \mathrm{min}(8-14 \mathrm{ft} / \mathrm{min})$ should be possible, as long as the dust can be effectively removed from the bags and transferred to the hopper without significant redispersion and recollection. With pulse-jet cleaning, heavy residual dust cakes are not typically a problem because of the fairly high cleaning energy that can be employed. However, the high cleaning energy can lead to significant redispersion of the dust and subsequent re-collection on the bags. The combination of a very high-energy pulse and a very light dust cake tends to make the problem of redispersion much worse. The barrier that limits operation at high $\mathrm{A} / \mathrm{C}$ ratios is not so much the dislodging of dust from the bags as it is the transferring of the dislodged dust to the hopper. The Advanced Hybrid ${ }^{\mathrm{TM}}$ filter achieves enhanced bag cleaning by employing electrostatic effects to 
precollect a significant portion of the dust and by trapping the redispersed dust that comes off the bags following pulsing in the electrostatic zone.

An Advanced Hybrid ${ }^{\mathrm{TM}}$ filter incorporating the perforated plate configuration was designed and installed on the 2.5-MW (9000-acfm) slipstream pilot unit at the Big Stone Power Plant. Figure 1.3.1 is a simplified top view of the 2.5-MW (9000-acfm) Advanced Hybrid ${ }^{\mathrm{TM}}$ filter configuration. The perforated plates serve two very important functions: as the primary collection surface and as a protective grid for the bags. With approximately $45 \%$ open area, there is adequate collection area on the plates to collect the precipitated dust while not restricting the flow of flue gas toward the bags during normal filtration. During pulse cleaning of the bags, most of the reentrained dust from the bags is forced back through the perforated plates into the ESP zone where it is collected on the plates. Excellent ESP collection efficiency is the result of forcing all of the flue gas through the perforated plate holes before it reaches the bags. This ensures that all of the charged dust particles pass within a maximum of one-half of the hole diameter distance of a grounded surface. In the presence of the electric field, the particles then have a high likelihood of being collected on the plates. Test results with and without the electric

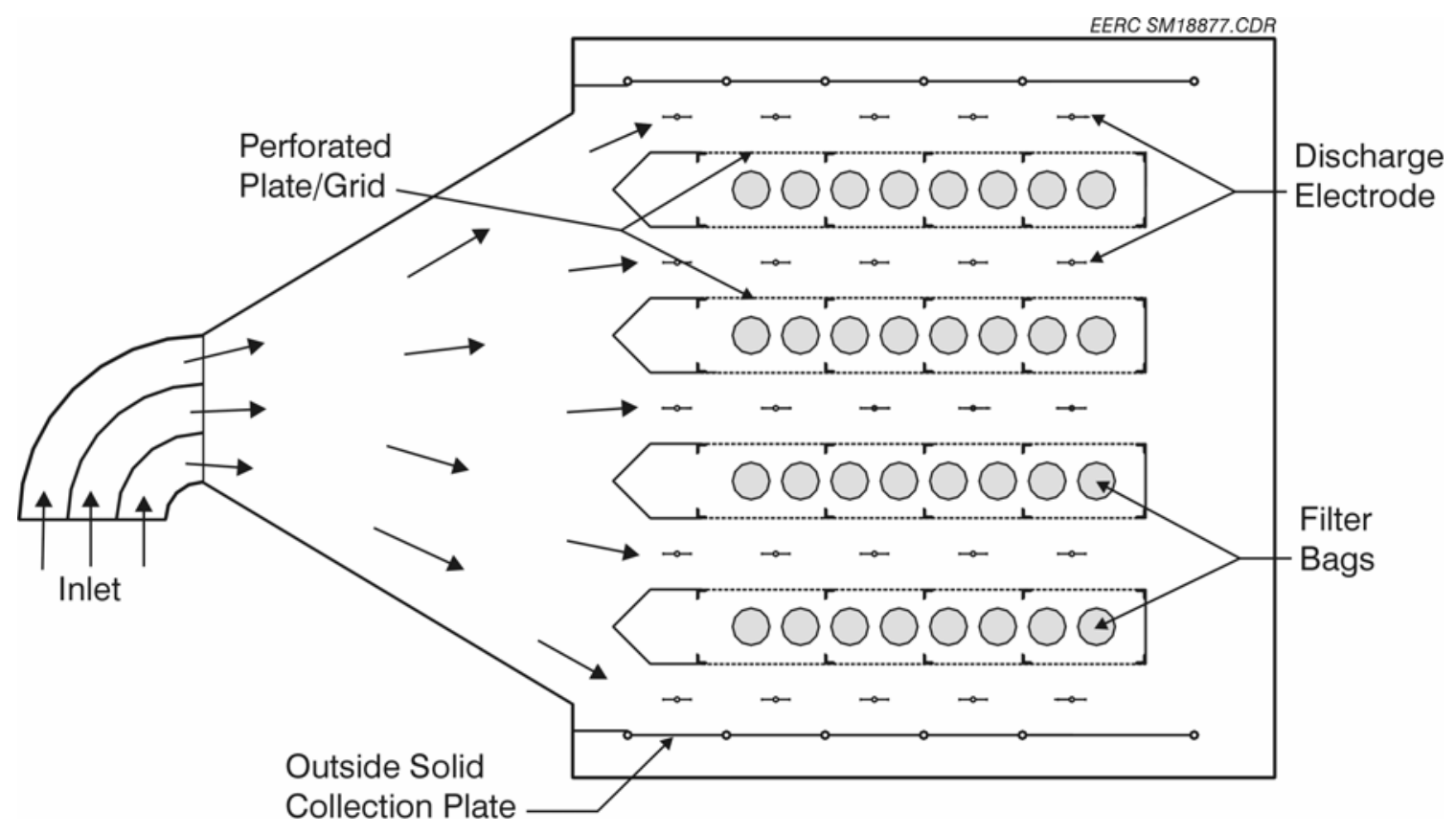

Figure 1.3.1. Top view of the perforated plate configuration for the 2.5-MW (9000-acfm) Advanced Hybrid ${ }^{\mathrm{TM}}$ filter. 
field energized have shown that about $95 \%$ of the dust is collected before the flue gas reaches the bags.

\subsection{Pressure Drop Theory and Performance Evaluation Criteria}

Pressure drop across the bags is one of the main operational parameters that defines overall performance. It must be within capacity limits of the boiler fans at the maximum system flow rate. Since acceptable pressure drop is so critical to successful operation, a detailed discussion of the theory and factors that control pressure drop follows.

For viscous flow, pressure drop across a FF is dependent on three components:

$$
\mathrm{dP}=\mathrm{K}_{\mathrm{f}} \mathrm{V}+\mathrm{K}_{2} \mathrm{~W}_{\mathrm{R}} \mathrm{V}+\frac{\mathrm{K}_{2} \mathrm{C}_{\mathrm{i}} \mathrm{V}^{2} \mathrm{t}}{7000}
$$

where:

$\mathrm{dP}=$ differential pressure across baghouse tube sheet $\mathrm{kPa}$ (in. W.C.)

$\mathrm{K}_{\mathrm{f}}=$ fabric resistance coefficient $\mathrm{kPa}-\mathrm{min} / \mathrm{m}$ (in. W.C.-min/ft)

$\mathrm{V}=$ face velocity or $\mathrm{A} / \mathrm{C}$ ratio $\mathrm{m} / \mathrm{min}(\mathrm{ft} / \mathrm{min})$

$\mathrm{K}_{2}=$ specific dust cake resistance coefficient $\mathrm{kPa}-\mathrm{m}-\mathrm{min} / \mathrm{kg}$ (in. W.C.-ft-min/lb)

$\mathrm{W}_{\mathrm{R}}=$ residual dust cake weight $\mathrm{kg} / \mathrm{m}^{2}\left(\mathrm{lb} / \mathrm{ft}^{2}\right)$

$\mathrm{C}_{\mathrm{i}}=$ inlet dust loading $\mathrm{g} / \mathrm{m}^{3}$ (grains/acf)

$\mathrm{t}=$ filtration time between bag cleaning $(\mathrm{min})$

The first term in Eq. 1 accounts for the pressure drop across the fabric. For conventional fabrics, the pore size is quite large, and the corresponding fabric permeability is high, so the pressure drop across the fabric alone is negligible. To achieve better collection efficiency, the pore size can be significantly reduced, without making fabric resistance a significant contributor to pressure drop. The GORE-TEX ${ }^{\circledR}$ membrane filter media allows for this optimization by providing a microfine pore structure while maintaining sufficient fabric permeability to permit operation at high $\mathrm{A} / \mathrm{C}$ ratios. A measure of the new fabric permeability is the Frazier number which is the volume of gas that will pass through a square foot of fabric sample at a pressure drop of $0.12 \mathrm{kPa}\left(0.5 \mathrm{in}\right.$. W.C.). The Frazier number for new GORE-TEX ${ }^{\circledR}$ bags is in the range from 1.2 to $2.4 \mathrm{~m} / \mathrm{min}$ ( 4 to $8 \mathrm{ft} / \mathrm{min}$ ). Through the filter, viscous (laminar) flow conditions exist, so the pressure drop varies directly with flow velocity. Assuming a new fabric Frazier number of 
$1.8 \mathrm{~m} / \mathrm{min}(6 \mathrm{ft} / \mathrm{min})$, the pressure drop across the fabric alone would be $0.25 \mathrm{kPa}$ (1.0 in. W.C.) at an $\mathrm{A} / \mathrm{C}$ ratio (filtration velocity) of $3.7 \mathrm{~m} / \mathrm{min}(12 \mathrm{ft} / \mathrm{min})$.

The second term in Eq. 1 accounts for the pressure drop contribution from the permanent residual dust cake that exists on the surface of the fabric. For operation at high $\mathrm{A} / \mathrm{C}$ ratios, the bag cleaning must be sufficient to maintain a very light residual dust cake and ensure that the pressure drop contribution from this term is reasonable. The contribution to pressure drop from this term is one of the most important indicators of longer-term bag cleanability.

The third term in Eq. 1 accounts for the pressure drop contribution from the dust accumulated on the bags since the last bag cleaning. $\mathrm{K}_{2}$ is determined primarily by the fly ash particle-size distribution and the porosity of the dust cake. Typical $\mathrm{K}_{2}$ values for a full dust loading of pulverized coal (pc)-fired fly ash range from about 0.5 to $2.5 \mathrm{kPa}-\mathrm{m}-\mathrm{min} / \mathrm{kg}$ (4 to 20 in. W.C.-ft-min/lb) but may, in extreme cases, cover a wider range. Within this term, the bagcleaning interval, $t$, is the key performance indicator. The goal is to operate with as long of a bag-cleaning interval as possible, since more frequent bag pulsing can lead to premature bag failure and require more energy consumption from compressed air usage. An earlier goal for the pilot-scale tests was to operate with a pulse interval of at least 10 min while operating at an $\mathrm{A} / \mathrm{C}$ ratio of $3.7 \mathrm{~m} / \mathrm{min}(12 \mathrm{ft} / \mathrm{min})$. While this goal was exceeded in the pilot-scale tests, a pulse interval of only $10 \mathrm{~min}$ is now considered too short to demonstrate good Advanced Hybrid ${ }^{\mathrm{TM}}$ filter performance over a longer period. With a shorter pulse interval, the Advanced Hybrid ${ }^{\mathrm{TM}}$ filter does not appear to make the best use of the electric field, because of the reentrainment that occurs just after pulsing. Current thought is that a pulse interval of at least $60 \mathrm{~min}$ is needed to demonstrate the best long-term performance.

Total tube sheet pressure drop is another key indicator of overall performance of the Advanced Hybrid ${ }^{\mathrm{TM}}$ filter. Here, the goal was to operate with a tube sheet pressure drop of $2.0 \mathrm{kPa}(8 \mathrm{in}$. W.C.) at an $\mathrm{A} / \mathrm{C}$ ratio of $3.7 \mathrm{~m} / \mathrm{min}(12 \mathrm{ft} / \mathrm{min})$. Note that the average pressure drop is not the same as the pulse-cleaning trigger point. For many of the previous and current tests, the pulse trigger point was set at $2.0 \mathrm{kPa}$ (8 in. W.C.), but the average pressure drop was significantly lower.

To help analyze filter performance, the terms in Eq. 1 can be normalized to the more general case by dividing by velocity. The $\mathrm{dP} / \mathrm{V}$ term is commonly referred to as drag or total tube sheet drag, $\mathrm{D}_{\mathrm{T}}$ : 


$$
\frac{\mathrm{dP}}{\mathrm{V}}=\mathrm{D}_{\mathrm{T}}=\mathrm{K}_{\mathrm{f}}+\mathrm{K}_{2} \mathrm{~W}_{\mathrm{R}}+\frac{\mathrm{K}_{2} \mathrm{C}_{\mathrm{i}} \mathrm{Vt}}{7000}
$$

The new fabric drag and the residual dust cake drag are typically combined into a single term called residual drag, $\mathrm{D}_{\mathrm{R}}$ :

$$
\mathrm{D}_{\mathrm{T}}=\mathrm{D}_{\mathrm{R}}+\frac{\mathrm{K}_{2} \mathrm{C}_{\mathrm{i}} \mathrm{Vt}}{7000}
$$

The residual drag term then is the key indicator of how well the bags are cleaning over a range of $\mathrm{A} / \mathrm{C}$ ratios, but may still be somewhat dependent on $\mathrm{A} / \mathrm{C}$ ratio. For example, it may be more difficult to overcome a $\mathrm{dP}$ of $2.5 \mathrm{kPa}(10 \mathrm{in}$. W.C.) to clean the bags than cleaning at a $\mathrm{dP}$ of $1.3 \mathrm{kPa}$ (5 in. W.C.) For most baghouses, the residual drag typically climbs somewhat over time and must be monitored carefully to evaluate the longer-term performance. Current thought is that excellent Advanced Hybrid ${ }^{\mathrm{TM}}$ filter performance can be demonstrated with a residual drag value of 0.6 or lower.

Between bag cleanings, from the second term in Eq. 3, the drag increases linearly with $\mathrm{K}_{2}$ (dust cake resistance coefficient), $\mathrm{C}_{\mathrm{i}}$ (inlet dust concentration), $\mathrm{V}$ (filtration velocity), and $\mathrm{t}$ (filtration time). For conventional baghouses, the $C_{i}$ term is easily determined from an inlet dust loading measurement, and approximate $\mathrm{K}_{2}$ values can be determined from the literature or by direct measurement. However, for the Advanced Hybrid ${ }^{\mathrm{TM}}$ filter, the concentration of the dust that reaches the bags is generally not known and would be very difficult to measure experimentally. Early in the development of the Advanced Hybrid ${ }^{\mathrm{TM}}$ filter, results indicated approximately $90 \%$ of the dust was precollected and did not reach the fabric. However, subsequent development work showed that the amount of precollected dust is likely to fluctuate significantly with changes to the electrical field and the dust resistivity. Since $\mathrm{C}_{\mathrm{i}}$ is not known, for evaluation of Advanced Hybrid ${ }^{\mathrm{TM}}$ filter performance, the $\mathrm{K}_{2}$ and $\mathrm{C}_{\mathrm{i}}$ can be considered together:

$$
\mathrm{K}_{2} \mathrm{C}_{\mathrm{i}}=\frac{\left(\mathrm{D}_{\mathrm{T}}-\mathrm{D}_{\mathrm{R}}\right) 7000}{\mathrm{Vt}}
$$

Evaluation of $\mathrm{K}_{2} \mathrm{C}_{\mathrm{i}}$ can help in assessing how well the ESP portion of the Advanced Hybrid $^{\mathrm{TM}}$ filter is functioning, especially by comparing with the $\mathrm{K}_{2} \mathrm{C}_{\mathrm{i}}$ during short test periods in which the ESP power was shut off. For the Big Stone ash, the $\mathrm{K}_{2} \mathrm{C}_{\mathrm{i}}$ value has typically been about 20 without the ESP field. For the 2.5-MW (9000-acfm) pilot Advanced Hybrid ${ }^{\mathrm{TM}}$ filter, longer-term $\mathrm{K}_{2} \mathrm{C}_{\mathrm{i}}$ values of 1.0 have been demonstrated with the ESP field on, which is 
equivalent to $95 \%$ precollection of the dust by the ESP. Again, the goal is to achieve as low of a $\mathrm{K}_{2} \mathrm{C}_{\mathrm{i}}$ value as possible; however, good Advanced Hybrid ${ }^{\mathrm{TM}}$ filter performance can be demonstrated with $\mathrm{K}_{2} \mathrm{C}_{\mathrm{i}}$ values up to 4 , but this is interdependent on the residual drag and filtration velocity.

Eq. 4 can be solved for the bag-cleaning interval, t, as shown in Eq. 5. The bag-cleaning interval is inversely proportional to the face velocity, $\mathrm{V}$, and the $\mathrm{K}_{2} \mathrm{C}_{\mathrm{i}}$ term and directly proportional to the change in drag before and after cleaning (delta drag). The delta drag term is dependent on the cleaning set point or maximum pressure drop as well as the residual drag. The face velocity, delta drag, and $\mathrm{K}_{2} \mathrm{C}_{\mathrm{i}}$ terms are relatively independent of each other and should all be considered when the bag-cleaning interval is evaluated. However, as mentioned above, the drag may be somewhat dependent on velocity if the dust does not clean off the bags as well at high velocity as at low velocity. Similarly, the $\mathrm{K}_{2} \mathrm{C}_{\mathrm{i}}$ is somewhat dependent on velocity for a constant plate collection area. At the greater flow rates, the SCA of the precipitator is reduced, which will result in a greater dust concentration, $\mathrm{C}_{\mathrm{i}}$, reaching the bags.

$$
\mathrm{t}=\frac{\left(\mathrm{D}_{\mathrm{T}}-\mathrm{D}_{\mathrm{R}}\right) 7000}{\mathrm{VK}_{2} \mathrm{C}_{\mathrm{i}}}
$$

By evaluating these performance indicators, the range in possible $\mathrm{A} / \mathrm{C}$ ratios can be calculated by using Eq. 1. For example, using the acceptable performance values of a 60-min pulse interval and a residual drag of 0.6 , Eq. 1 predicts that a $\mathrm{K}_{2} \mathrm{C}_{\mathrm{i}}$ value of 2.33 would be needed when operating at an $\mathrm{A} / \mathrm{C}$ ratio of $3.0 \mathrm{~m} / \mathrm{min}(10 \mathrm{ft} / \mathrm{min})$ and a pulse trigger of $2.0 \mathrm{kPa}$ (8 in. W.C.). Obviously, deterioration in the performance of one indicator can be offset by improvement in another. Results to date show that performance is highly sensitive to the $\mathrm{A} / \mathrm{C}$ ratio and that excellent Advanced Hybrid ${ }^{\mathrm{TM}}$ filter performance can be achieved as long as a critical $\mathrm{A} / \mathrm{C}$ ratio is not exceeded. If the $\mathrm{A} / \mathrm{C}$ ratio is pushed too high, system response is to pulse the bags more rapidly. However, too rapid pulsing tends to make the residual drag increase faster and causes the $\mathrm{K}_{2} \mathrm{C}_{\mathrm{i}}$ to also increase, both of which lead to poorer performance. The design challenge is to operate the Advanced Hybrid ${ }^{\mathrm{TM}}$ filter at the appropriate $\mathrm{A} / \mathrm{C}$ ratio for a given set of conditions. 


\subsection{GOALS AND OBJECTIVES}

The overall project objective was to demonstrate $90 \%$ total mercury control with commercially available sorbents in the Advanced Hybrid ${ }^{\mathrm{TM}}$ filter at a lower cost than mercury control estimates for conventional technologies.

Test goals included the following:

- Determine if the bench-scale mercury breakthrough results can be duplicated when real flue gas is sampled.

- Compare the level of mercury control between the Advanced Hybrid ${ }^{\mathrm{TM}}$ filter and a pulse-jet baghouse (PJBH) with sorbents under similar conditions at the 55-kW (200acfm) pilot scale.

- Demonstrate $90 \%$ mercury capture for both a western subbituminous (WSB) and an eastern bituminous (EB) coal.

- Demonstrate mercury capture with the 2.5-MW (9000-acfm) Advanced Hybrid ${ }^{\mathrm{TM}}$ filter at Big Stone.

- Demonstrate $90 \%$ mercury capture over a longer time (3 months) with the $2.5-\mathrm{MW}$ (9000-acfm) Advanced Hybrid ${ }^{\mathrm{TM}}$ filter at Big Stone.

- Evaluate the mercury capture effectiveness of the Advanced Hybrid ${ }^{\mathrm{TM}}$ filter when used with elemental mercury oxidation additives and a spray dryer absorber (SDA).

To meet the objectives, the work was organized into six tasks. The first five tasks were included in the original plan, and Task 6 was added midway through the project:

- Task 1: Project Management, Reporting, and Technology Transfer

- Task 2: Bench-Scale Experiments at the EERC

- Task 3: Pilot-Scale Tests on the 55-kW (200-acfm) Unit at the EERC

- Task 4: Field Demonstration on the 2.5-MW (9000-acfm) Unit at the Big Stone Power Plant

- Task 5: Facility Removal and Disposition

- Task 6: Mercury Control Enhancement with Oxidation Additives

Details of the work completed for each task are given in following sections of this report. 


\subsection{SCOPE OF WORK}

\subsection{Task 1 - Project Management, Reporting, and Technology Transfer}

Task 1 included all of the project management requirements, planning, coordination among team members, supervision of tests, review of results, meeting attendance, and all aspects of reporting.

\subsection{Task 2 - Bench-Scale Experiments at the EERC}

The bench-scale tests were for the purposes of verifying previous results, expanding on the $\mathrm{SO}_{2}$ and $\mathrm{NO}_{2}$ concentration effect, linking the synthetic gas results to the results with real flue gas, and screening sorbents.

The bench-scale tests were divided into three series that follow a logical progression. The purpose of the first series of tests was to ensure that previous results obtained by the EERC and others could be duplicated and, second, to include $\mathrm{SO}_{2}$ and $\mathrm{NO}_{2}$ as variables. Series 1 tests were intended to verify the previous bench-scale work and expand on the $\mathrm{SO}_{2}$ and $\mathrm{NO}_{2}$ concentration effect. In previous work, no tests were completed in which both the $\mathrm{SO}_{2}$ and $\mathrm{NO}_{2}$ were varied at the same time. In all of these tests, the inlet $\mathrm{Hg}^{0}$ concentration was typically $15 \mu \mathrm{g} / \mathrm{m}^{3}$, and each test was run for approximately $4 \mathrm{hr}$ The $150 \mathrm{mg}$ of NORIT FGD activated carbon sorbent is equivalent to a sorbent-to-mercury ratio of 3700 after $3 \mathrm{hr}$ of exposure. This concentration has been shown to provide consistent results in previous testing and is sufficient to accurately measure the amount of mercury in the spent sorbent for mass balance closure.

The second series of bench-scale tests was for the purpose of comparing the bench-scale fixed-bed results sampling real flue gas to those obtained with simulated flue gas for both a WSB and an EB coal. The simulated flue gas concentrations were based on the actual concentrations measured in the combustion tests. The real flue gas tests were part of the pilot-scale tests in Task 3, using a slipstream bench-scale system sampling flue gas from the particulate test combustor (PTC).

Series 2 tests were completed to compare NORIT FGD performance on mercury capture in real and simulated WSB coal flue gases. Similar tests with a bituminous coal were planned but not completed because the pilot-scale tests with the bituminous coal showed that the FGD carbon was ineffective at mercury control for the flue gas conditions produced from combustion of this specific bituminous coal. 
A third series of bench-scale tests was planned for the purpose of screening alternative sorbents, such as an iodine-impregnated activated carbon (IAC). However, since IAC is more costly than FGD, it must be effective at lower concentrations than FGD. The plan was to evaluate the IAC for both a subbituminous and a bituminous coal at two concentration levels and two temperatures. However, since available pilot-scale results indicated no improvement in mercury removal over the FGD carbon, there was no basis for running bench-scale IAC tests.

The plan was to conduct additional screening tests on other promising alternative sorbents to be selected based on new information and availability and then, depending on initial results, further evaluate them in pilot-scale testing in Task 3. Several versions of a non-carbon-based sorbents developed outside the EERC were tested, but results showed poor mercury removal, so there was no advantage over the FGD carbon. Late in the project, an EERC-developed sorbent was testing in the pilot-scale tests. However, this was based on promising results from other research, so no specific bench-scale tests on this sorbent were completed under Task 2.

\subsection{Task 3 - Pilot-Scale Tests on the 55-kW (200-acfm) Unit at the EERC}

A total of 8 weeks of testing on the EERC 55-kW (200-acfm) particulate test combustor (PTC) was completed under Task 3. A week of testing includes an 8-hr heatup period on gas and then 50-100 hr of steady-state operation firing coal. This allows multiple longer-term test periods where the PTC is operated around the clock.

The first 2 weeks were for the purpose of generating baseline data without carbon injection for a bituminous and a subbituminous coal in both the PJBH and the Advanced Hybrid ${ }^{\mathrm{TM}}$ filter models. These tests were for the purpose of establishing the amount of mercury capture by fly ash and determining whether the amount of mercury capture is different between the PJBH and the Advanced Hybrid ${ }^{\mathrm{TM}}$ filter. Another purpose was to establish the inlet and outlet speciated mercury concentrations and whether there was a change in mercury speciation across both devices. A third purpose for these baseline tests was to provide flue gas to support the benchscale testing with real flue gas under Task 2.

Weeks 3 and 4 were conducted to prove the ability of the technology to control mercury at the $90 \%$ level with a WSB coal using NORIT FGD carbon. Both continuous and batch injections were tested at different injection rates to evaluate their effects on mercury emission.

Week 5 was for testing mercury control with NORIT FGD in the Advanced Hybrid ${ }^{\mathrm{TM}}$ filter with an EB coal. 
Week 6 was initially planned for testing alternative sorbents in the Advanced Hybrid ${ }^{\mathrm{TM}}$ filter. Because no alternative sorbent was identified at that point in the project, Week 6 of testing was completed with the FGD carbon combined with cofiring tire-derived fuel (TDF) to evaluate the beneficial effect of cofiring TDF on mercury removal in Advanced Hybrid ${ }^{\mathrm{TM}}$ filter.

Week 7 testing consisted of evaluations of a unique mercury sorbent cartridge developed by W.L. Gore.

Week 8 testing was completed near the end of the project to determine the amount of mercury collected on the perforated plates in the Advanced Hybrid ${ }^{\mathrm{TM}}$ filter compared to the total mercury removal across the Advanced Hybrid ${ }^{\mathrm{TM}}$ filter. Testing of newly developed EERC sorbent was also conducted in Week 8.

\subsection{Task 4 - Field Demonstration on the 2.5-MW (9000-acfm) Unit at the Big Stone Power Plant}

The purpose of Task 4 was to demonstrate mercury control with the Advanced Hybrid ${ }^{\mathrm{TM}}$ filter at a much larger scale by utilizing the 2.5-MW (9000-acfm) Advanced Hybrid ${ }^{\mathrm{TM}}$ filter, which was previously installed on a slipstream at the Big Stone Power Plant. Over the time from November 2001 through June 2003, four separate periods of testing were completed with the 2.5-MW (9000-acfm) Advanced Hybrid ${ }^{\mathrm{TM}}$ filter, ranging from 1 week to 2 months in duration.

The first field test at Big Stone was completed the week of November 5-10, 2001, with baseline testing on the first day, followed by carbon injection in both the Advanced Hybrid ${ }^{\mathrm{TM}}$ filter and pulse-jet operational modes for the remainder of the week.

The second field test consisted of a month of baseline operation followed by a month of carbon injection for mercury control. These tests were completed from June 28-September 6, 2002. Carbon injection along with continuous mercury monitor (CMM) measurements were completed during the entire month from August 6 to September 6, except during an unplanned plant outage during the period from August 29 to September 2. The primary goal of the work was to demonstrate longer-term mercury control with the Advanced Hybrid ${ }^{\mathrm{TM}}$ filter and evaluate the effect of carbon injection on the Advanced Hybrid ${ }^{\mathrm{TM}}$ filter operational performance. Another goal of the test was to evaluate the effect of supplemental tire burning on mercury capture.

During November 19-22, 2002, another short-term test was completed with the 2.5-MW (9000-acfm) Advanced Hybrid ${ }^{\mathrm{TM}}$ filter to coincide with stack mercury testing for the full-scale Advanced Hybrid ${ }^{\mathrm{TM}}$ filter at the Big Stone Power Plant. The primary purpose of the test was to 
evaluate the effect of $\mathrm{HCl}$ injection into flue gas along with the activated carbon on mercury control.

The fourth field test was a 1-month field completed from May 6 to June 3, 2003, to further demonstrate long-term mercury control with the Advanced Hybrid ${ }^{\mathrm{TM}}$ filter unit by carbon injection. Another goal was to evaluate the impacts of various operating parameters such as filtration face velocity, carbon injection rate, and injection location on mercury control with the Advanced Hybrid ${ }^{\mathrm{TM}}$ filter technology.

Two Advanced Hybrid ${ }^{\mathrm{TM}}$ filter hopper ashes collected on May 10 and 21, 2003, were evaluated at the EERC for mercury stability as part of another project. The two ash samples were analyzed for their mercury contents, loss on ignition (LOI), and major chemical compositions. A series of tests including 1) synthetic groundwater leaching procedure (SGLP), 2) long-term leaching (LTL), 3) microbiological release, 4) long-term ambient temperature release, and 5) thermal desportion at elevated temperatures were completed to evaluate the stability of mercury on the Advanced Hybrid ${ }^{\mathrm{TM}}$ filter ashes under different conditions.

\subsection{Task 5 - Facility Removal and Disposition}

The plan was to dismantle and remove the 2.5-MW (9000-acfm) Advanced Hybrid ${ }^{\mathrm{TM}}$ filter at the end of this project if no further testing was anticipated in support of subsequent work at the Big Stone Power Plant. However, the 2.5-MW (9000-acfm) Advanced Hybrid ${ }^{\mathrm{TM}}$ filter has already been used in support of the full-scale Advanced Hybrid ${ }^{\mathrm{TM}}$ filter at Big Stone, so the decision was made to leave the 2.5-MW (9000-acfm) Advanced Hybrid ${ }^{\mathrm{TM}}$ filter in place at Big Stone until no further use of it is anticipated.

\subsection{Task 6 - Mercury Control Enhancement with Oxidation Additives}

Task 6 was added to the project to address the use of mercury oxidation additives to the coal to enhance mercury capture in a North Dakota lignite flue gas. A pilot-scale SDA followed by a PJBH was installed at the EERC 55-kW (200-acfm) combustion facility. Pilot-scale tests were completed to evaluate the effectiveness of NORIT FGD carbon combined with three individual $\mathrm{Hg}^{0}$ oxidation and sorbent enhancement additives $\left(\mathrm{NaCl}, \mathrm{CaCl}_{2}\right.$, and $\left.\mathrm{SEA} 2\right)$ to enhance the $\mathrm{Hg}$ removal efficiency with an SDA-PJBH pollution control system. The sorbents and additives were selected based on previous pilot-scale testing of ESP $\mathrm{Hg}$ removal effectiveness. A Center lignite coal was combusted in the unit while $\mathrm{Hg}$ concentrations were almost continuously monitored at the SDA inlet and $\mathrm{PJBH}$ outlet to evaluate $\mathrm{Hg}$ removal 
performance. The $\mathrm{Hg}$ sorbents and $\mathrm{Hg}^{0}$ oxidation and sorbent enhancement additives were evaluated separately and in combination. The testing occurred during a 4-day period, December $8-11,2003$. 


\subsection{EXPERIMENTAL SYSTEM}

\subsection{Bench-Scale System}

In previous research, the EERC developed a bench-scale fixed-bed system to screen and evaluate sorbent performance on mercury capture in a simulated flue gas environment. A schematic of the system is shown in Figure 4.1.1, and Figure 4.1.2 shows the system in the EERC mercury testing laboratory. The gas-mixing system is shown in Figure 4.1.3.

The fixed-bed reactor consists of a Teflon-coated, 6.35-cm (2.5 in.)-diameter dust-loading filter holder (Figure 4.1.4). A quartz filter loaded with sorbent makes up the actual fixed bed (Figure 4.1.5). The filters are uniformly coated with the sorbents by pulling a vacuum on the outlet side of the filter holder and feeding the sorbent at the inlet side. Typically, $150 \mathrm{mg}$ (3.3 $\times 10^{-4} \mathrm{lb}$ ) of sorbent is used for screening tests, but the process is very repeatable for mass loadings down to $10 \mathrm{mg}\left(2.2 \times 10^{-5} \mathrm{lb}\right)$. The fixed-bed assembly is maintained at the desired temperature inside an oven (Figure 4.1.6) which can be controlled to $\pm 1^{\circ} \mathrm{C}\left( \pm 1.8^{\circ} \mathrm{F}\right)$. A Tekran mercury analyzer continuously measures the elemental mercury concentration (Figure 4.1.7). In order to monitor oxidized forms of mercury, a $\mathrm{SnCl}_{2}$ reduction cell is used prior to the analyzer

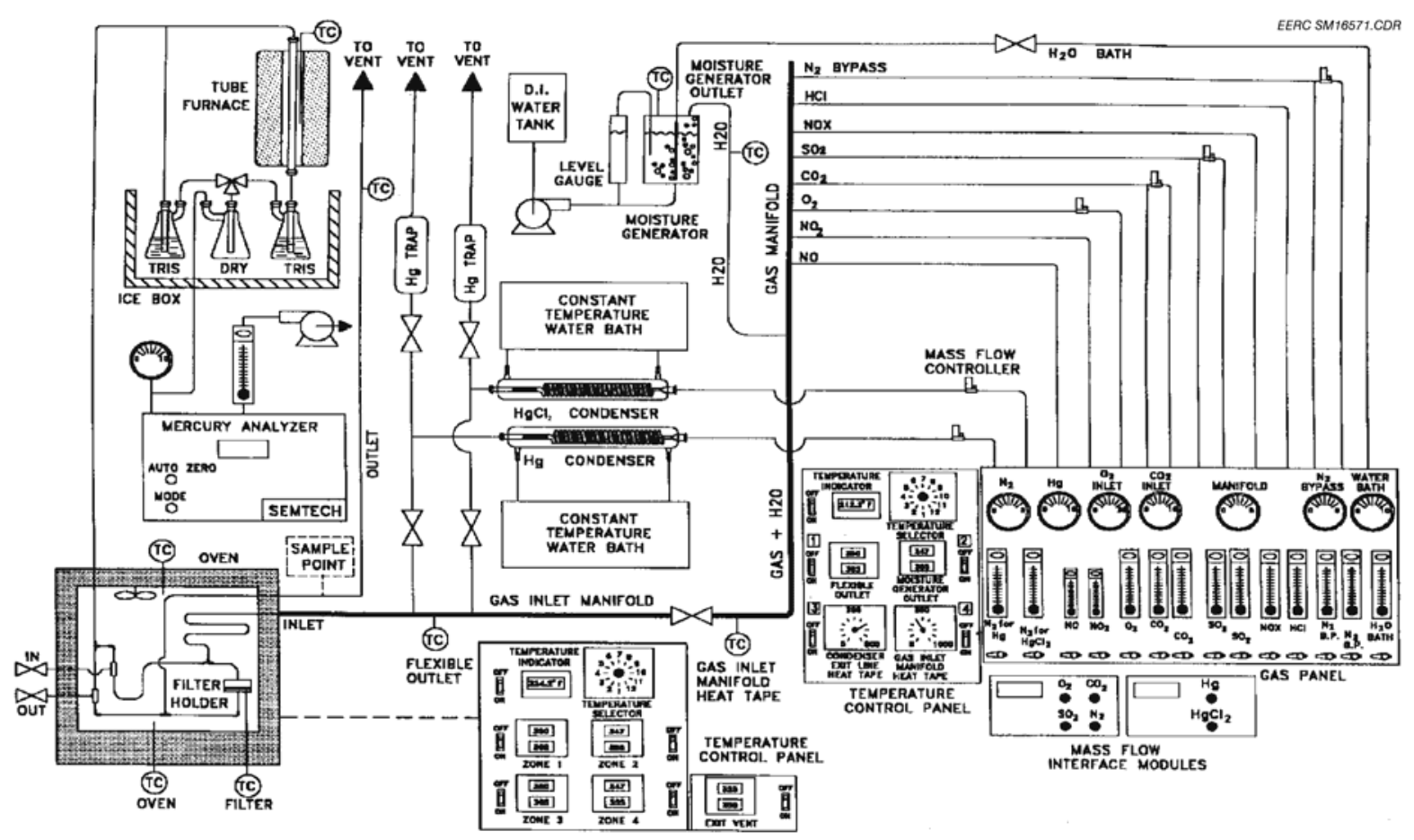

Figure 4.1.1. Schematic diagram of the mercury bench-scale system. 


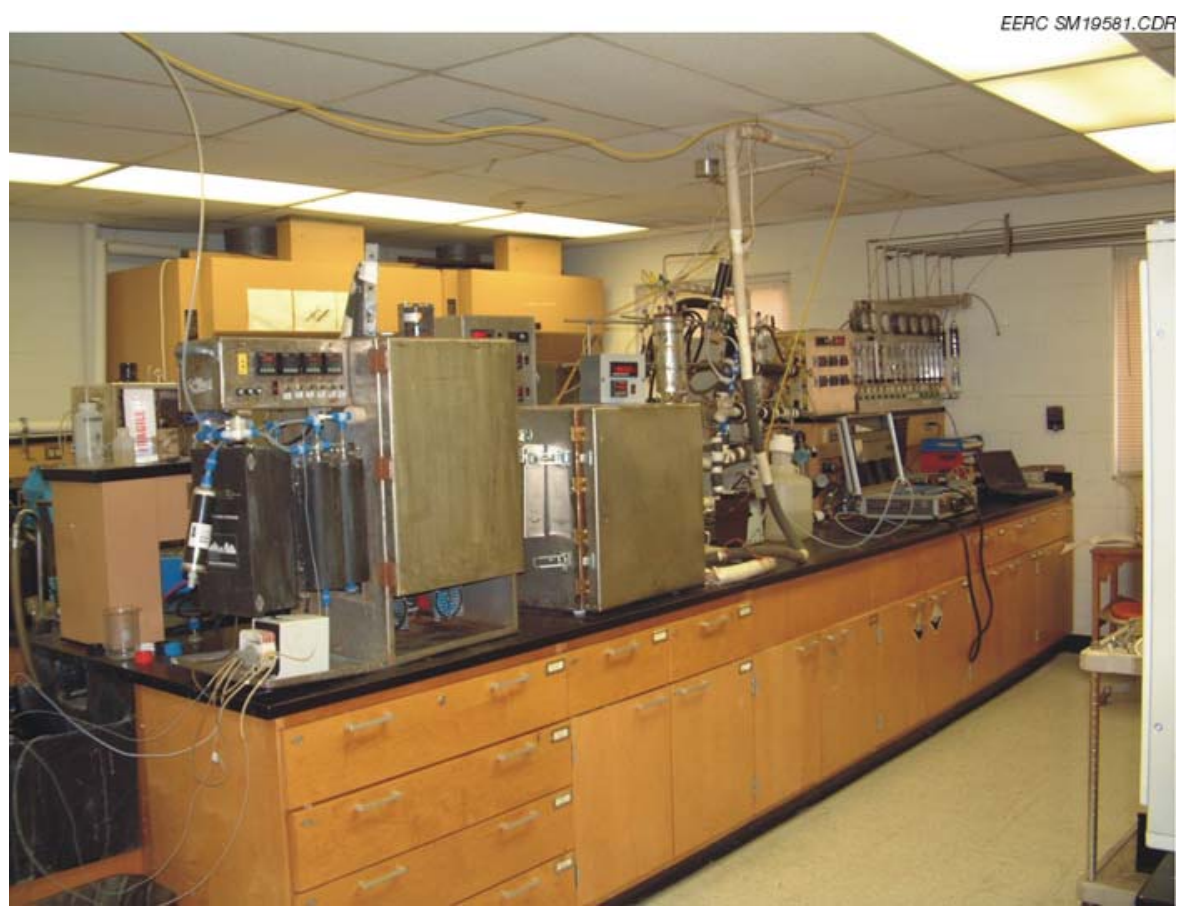

Figure 4.1.2. EERC mercury bench-scale system.

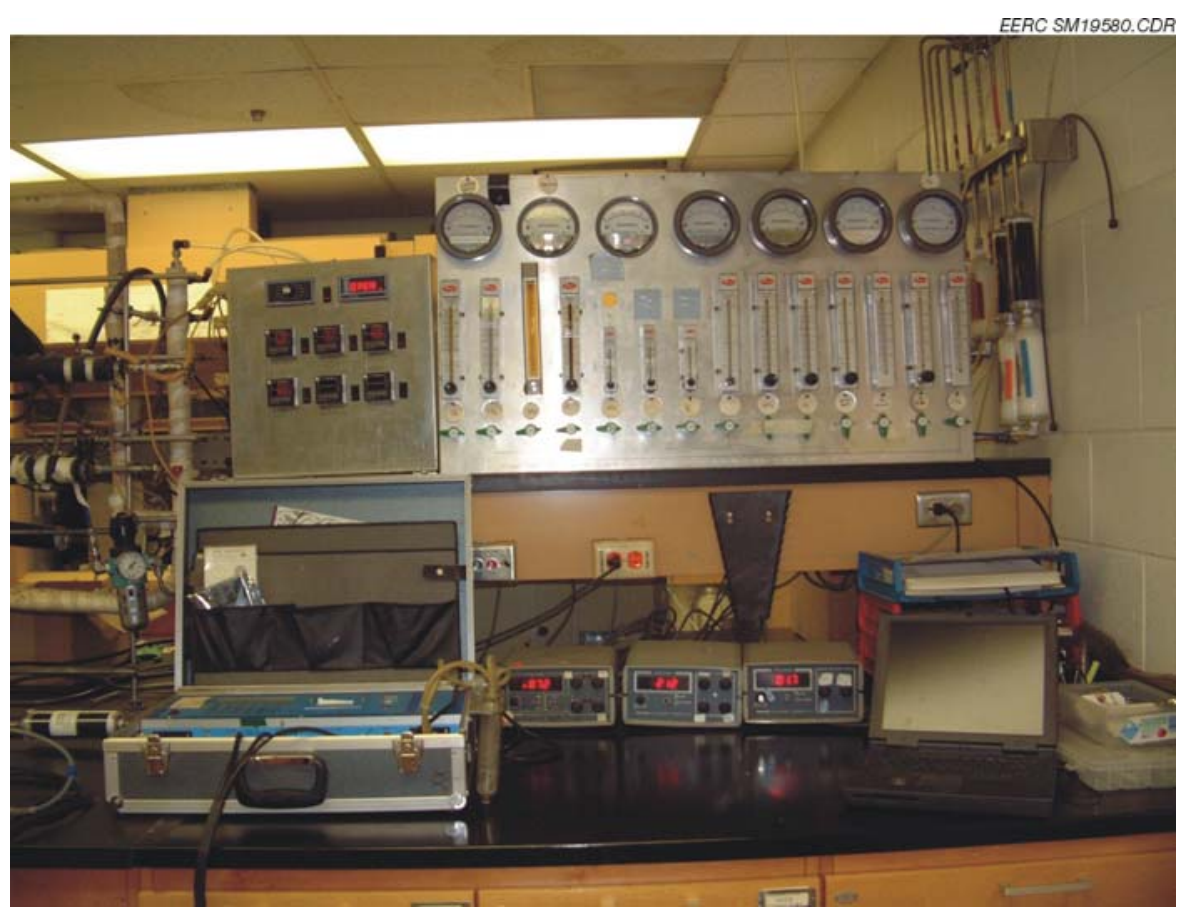

Figure 4.1.3. EERC bench-scale gas delivery system. 


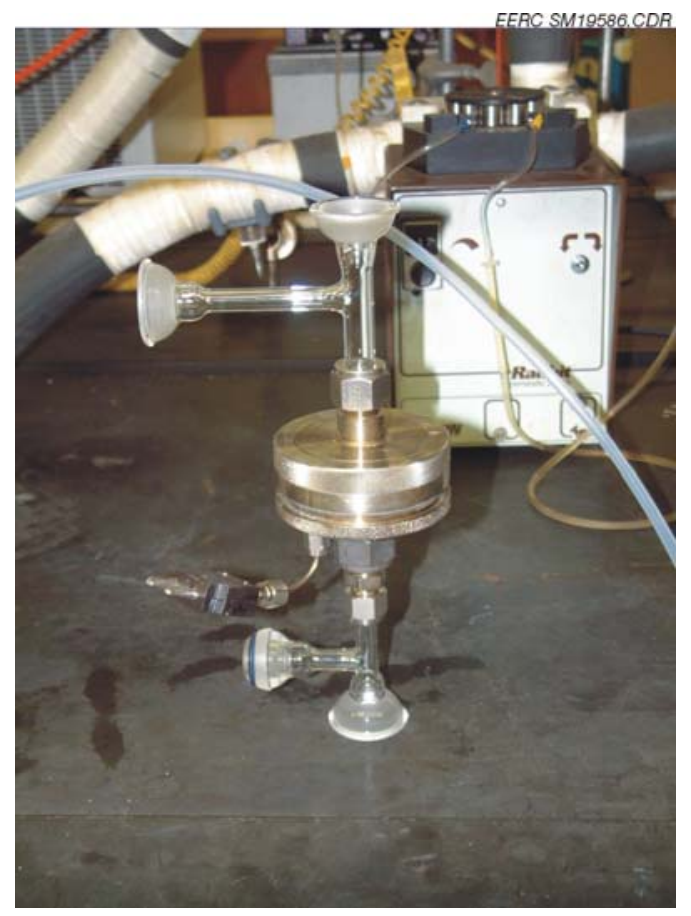

Figure 4.14. Fixed-bed filter holder.

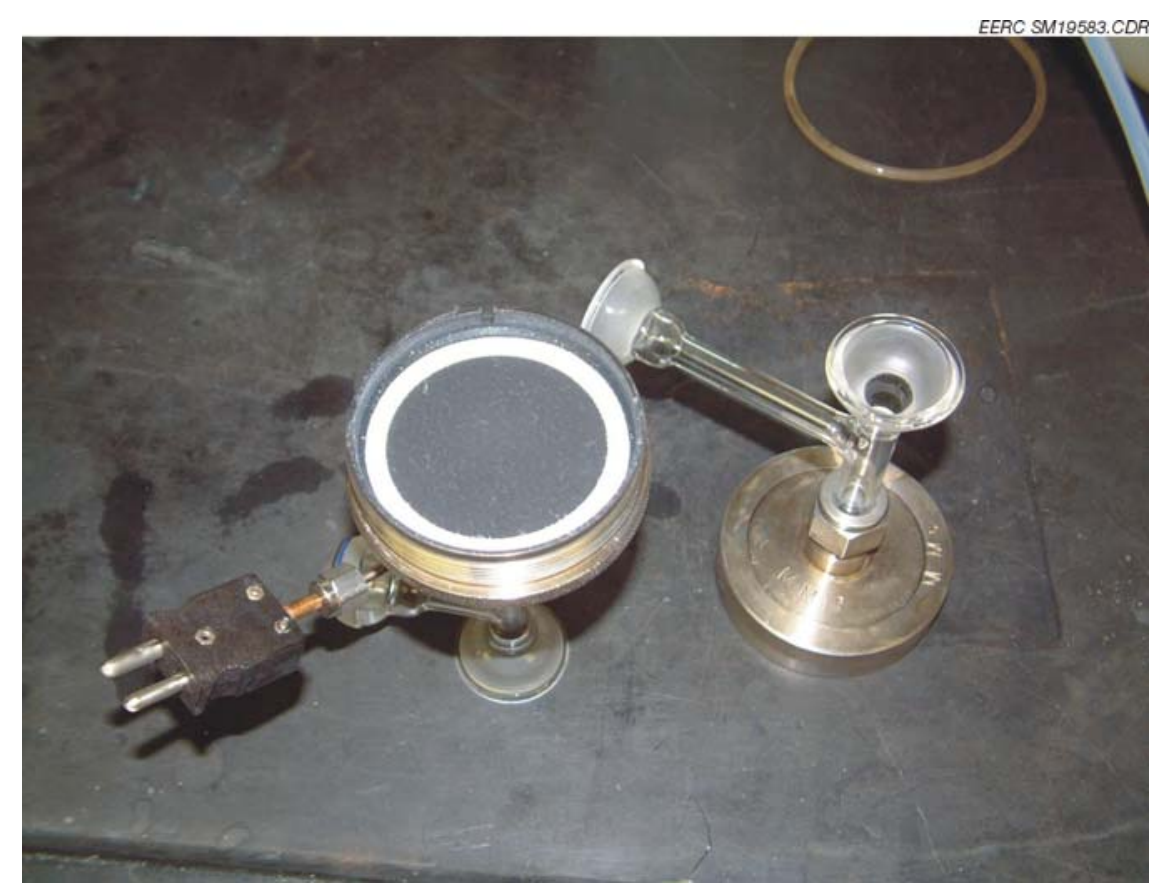

Figure 4.1.5. Carbon fixed bed. 


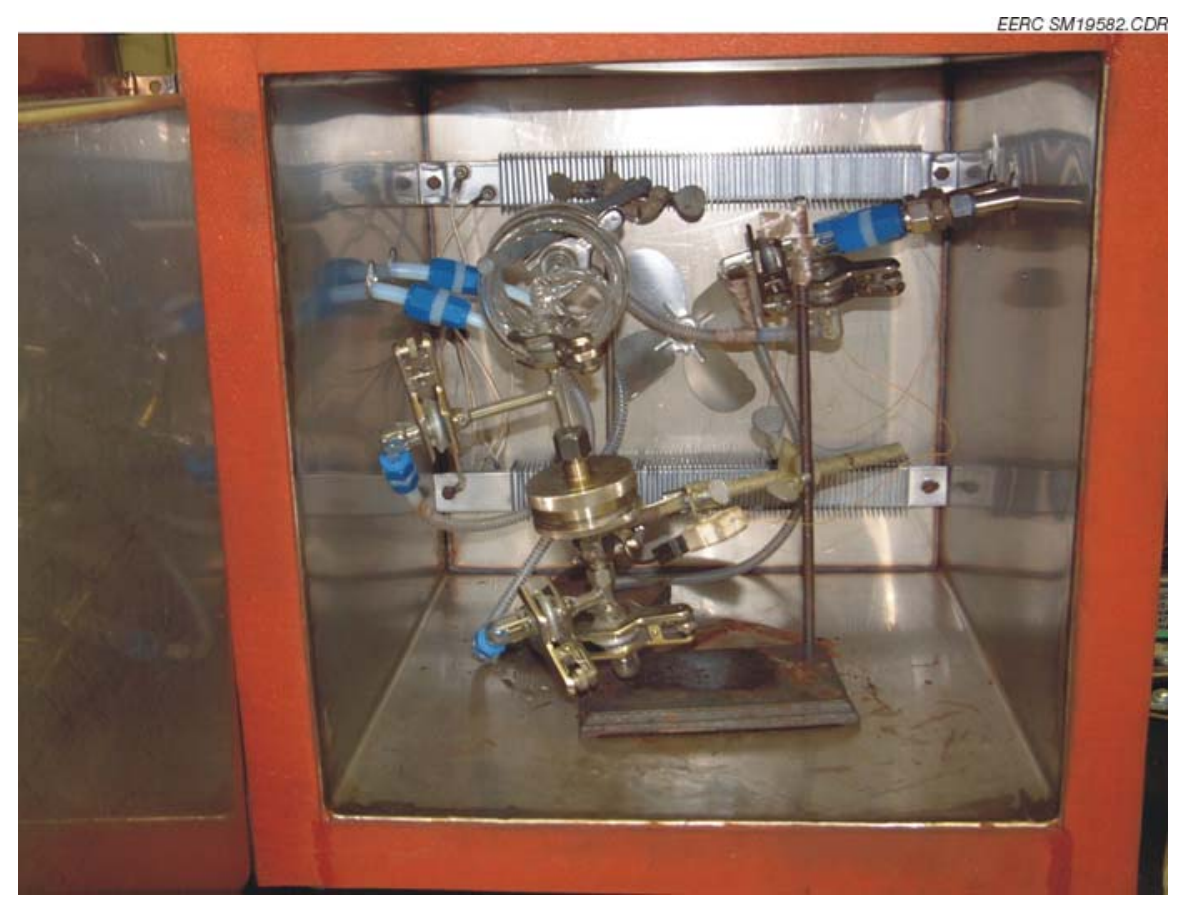

Figure 4.1.6. Fixed-bed oven.

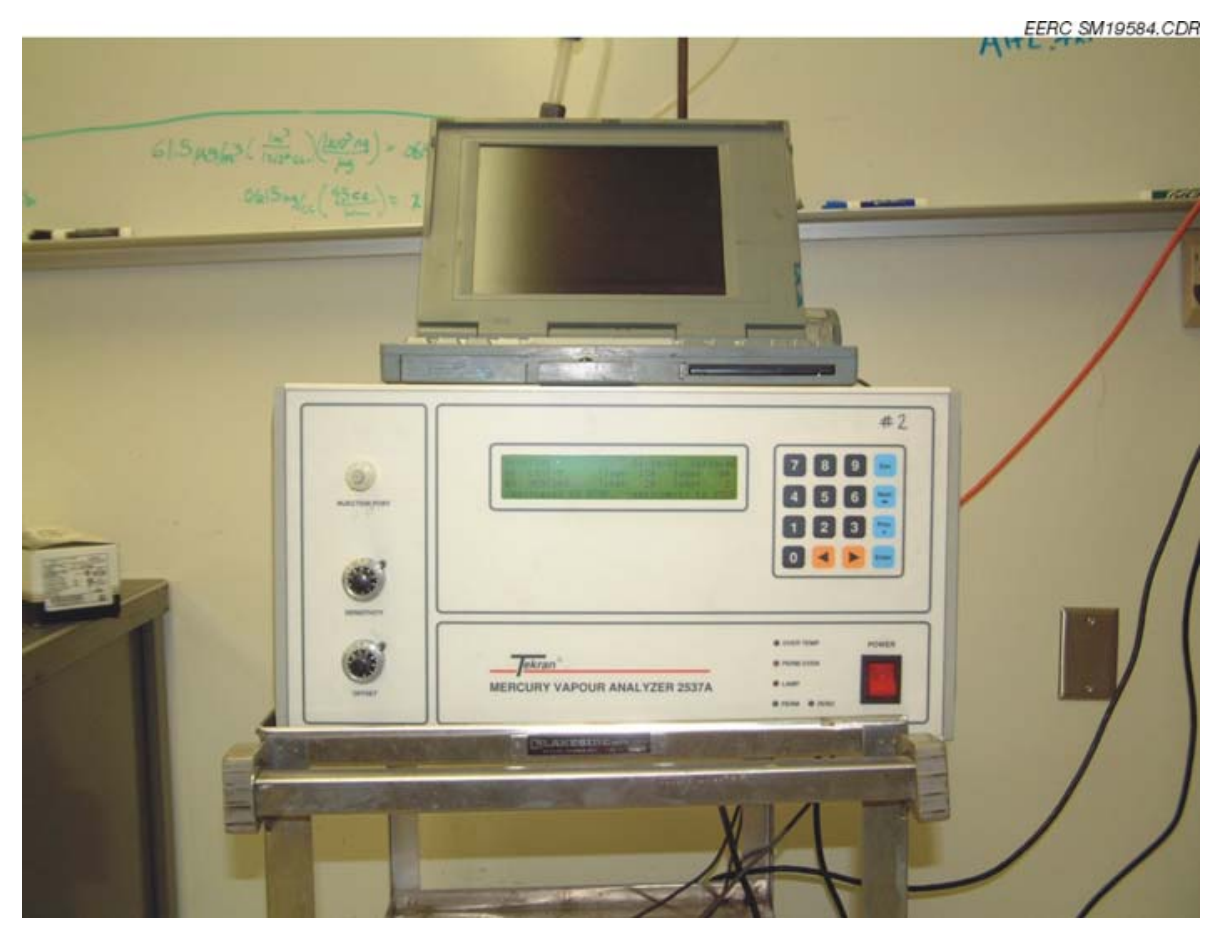

Figure 4.1.7. Tekran mercury instrument. 
to convert all forms of mercury for analysis. The spent sorbent is analyzed for mercury to determine a mass balance, and typically, good mass balance closures in the range from 80 to $120 \%$ are achieved.

The bench-scale results helped us to understand the interactions between sorbent and flue gas constituents, evaluate sorbent performance in different coal combustion flue gases, and link the synthetic gas results to the result with real flue gas.

\section{$4.255-k W(200-a c f m)$ Pilot-Scale Advanced Hybrid ${ }^{\mathrm{TM}}$ Filter Unit at the EERC}

Figure 4.2.1 shows the schematic diagram of the pilot-scale system. A $55-\mathrm{kW}$ (200-acfm) pc-fired combustor was used to produce flue gas from coal combustion. The combustor is oriented vertically to minimize wall deposits. A refractory lining helps to ensure adequate combustion zone temperature for complete combustion of fuel and prevents rapid quenching of the coalescing or condensing fly ash. Based on the superficial gas velocity, the mean residence time of a particle in the combustor is approximately $3 \mathrm{sec}$. The coal nozzle of the unit fires axially upward from the bottom of the combustor, and secondary air is introduced concentrically to the primary air with turbulent mixing. Coal is introduced to the primary air stream via a screw feeder and ejector. An electric air preheater is used for precise control of the combustion air temperature. The temperature in the combustion zone may be over $1500^{\circ} \mathrm{C}\left(2750^{\circ} \mathrm{F}\right)$ depending

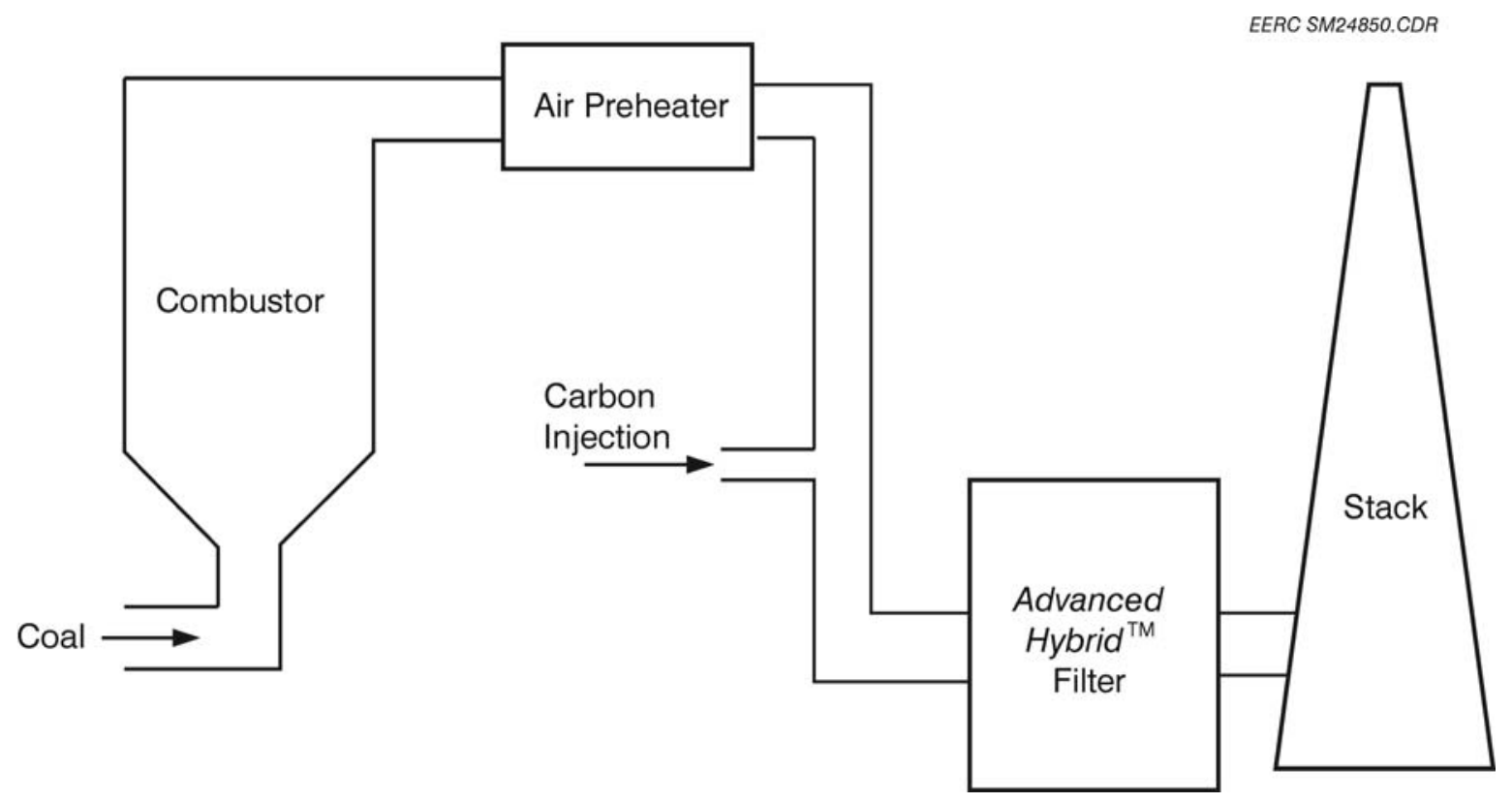

Figure 4.2.1. Schematic drawing of the pilot-scale system. 
on fuel type, but flue gas temperature at the combustor outlet cools to approximately $1000^{\circ} \mathrm{C}$ $\left(1832^{\circ} \mathrm{F}\right)$. The unit was designed to generate fly ash and flue gas representative of that produced in a full-scale utility boiler. The coal combustion flue gas exiting the combustor was further cooled to a temperature of approximately $135^{\circ} \mathrm{C}\left(275^{\circ} \mathrm{F}\right)$ and then introduced into the pilot-scale Advanced Hybrid ${ }^{\mathrm{TM}}$ filter.

As shown in Figure 4.2.2, the 55-kW (200-acfm) combustor has one row of four bags inside the chamber, and perforated plates are placed on each side of the bags to separate the bags from the discharge electrodes. The perforated plates serve as a collection area to capture most of the particulate matter entering the Advanced Hybrid ${ }^{\mathrm{TM}}$ filter unit, and the FF collects the remaining particulate matter when the flue gas flows through the bags. Instrumentation enables the continuous monitoring of system temperature, pressure, flow rates, flue gas constituent concentrations, and particle control device operating data.

A dry powder feeder (TSI 3410 or Palas RBG 2000) was installed at the Advanced Hybrid $^{\mathrm{TM}}$ filter inlet to continuously inject sorbents into the flue gas entering the Advanced Hybrid $^{\mathrm{TM}}$ filter chamber. Two CMMs monitored mercury vapor concentrations at the Advanced

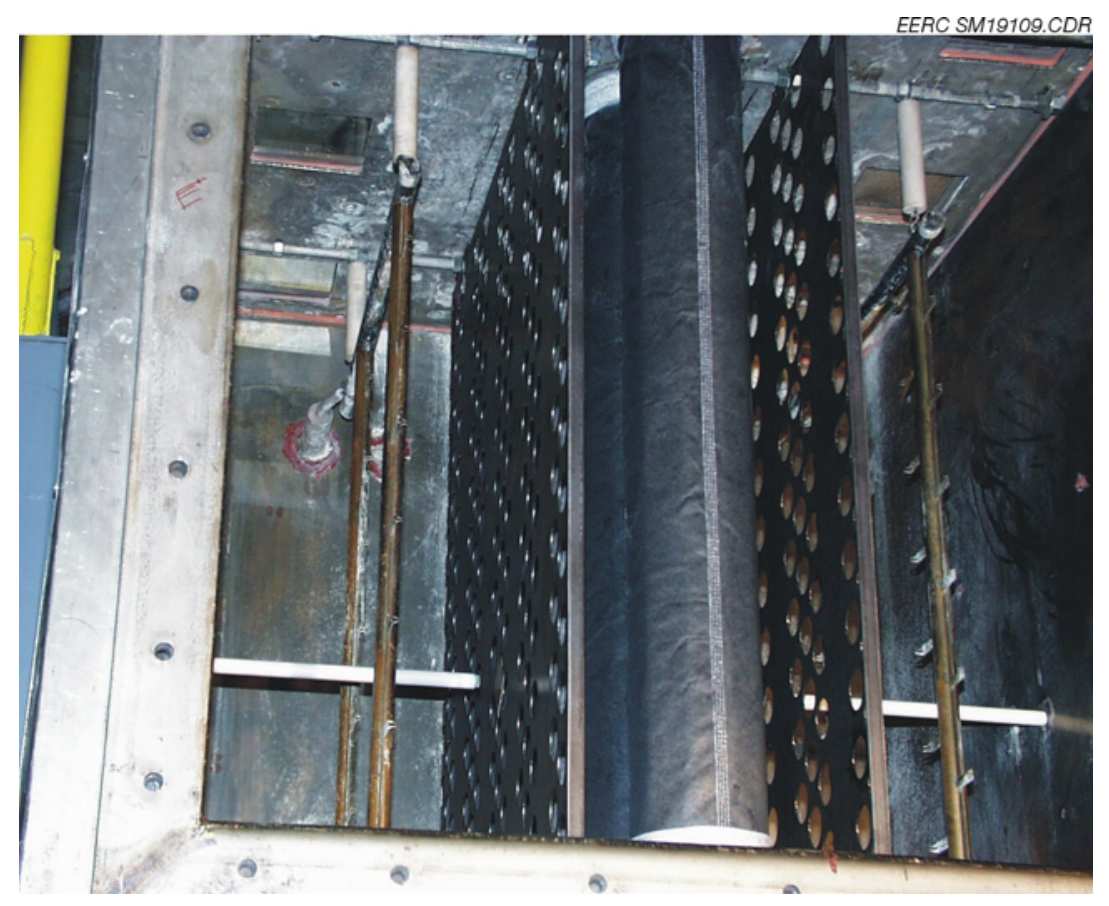

Figure 4.2.2. Front view of the 55-kW (200-acfm) Advanced Hybrid ${ }^{\mathrm{TM}}$ filter at the EERC. 
Hybrid ${ }^{\mathrm{TM}}$ filter inlet and outlet during the testing period. The Ontario Hydro method was also employed to verify the CMM data.

\subsection{5-MW (9000-acfm) Field Demonstration of the Advanced Hybrid ${ }^{\mathrm{TM}}$ Filter Unit at the Big Stone Power Plant}

Funded by a previous DOE project, the EERC designed and installed a 2.5-MW (9000-acfm) slipstream Advanced Hybrid ${ }^{\mathrm{TM}}$ filter unit at the Big Stone Power Plant (Figure 4.3.1). Figure 4.3.2 shows a top-view schematic diagram of the perforated plate Advanced Hybrid $^{\mathrm{TM}}$ filter at the Big Stone Power Plant. Perforated plates with approximately $45 \%$ open area are placed in front of the filter bags to serve as the primary collection surface and as a protective grid for the bags. The perforated plates provide enough collection area for fly ash precipitation while not restricting the flue gas flow through the filter bags. During the pulse cleaning of the bags, most of the re-entrained dust from the bags is forced back through the perforated plates into the ESP zone. Figure 4.3.3 shows a top view of the Advanced Hybrid ${ }^{\mathrm{TM}}$ filter at the Big Stone Power Plant during installation, without the tube sheet or filter bags.

A K-Tron dual-screw feeder was used to continuously inject sorbents into the flue gas entering the Advanced Hybrid ${ }^{\mathrm{TM}}$ filter chamber. The carbon feeder was located in the enclosed area of the Advanced Hybrid ${ }^{\mathrm{TM}}$ filter below the hopper (Figures 4.3.4 and 4.3.5). From the feeder, the sorbent was introduced into an Air-Vac eductor that was driven by compressed air. From the outlet of the eductor, the sorbent was then transported approximately $6.1 \mathrm{~m}(20.0 \mathrm{ft})$ through $0.019 \mathrm{~m}(0.062 \mathrm{ft})$ stainless steel tubing to the elbow location of the inlet piping (Figure

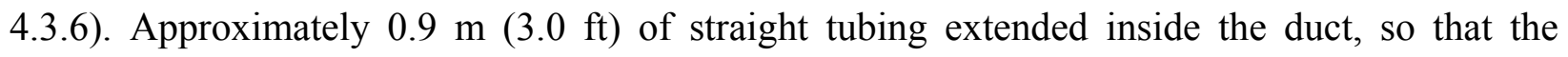
carbon was injected directly upstream at a single point in the center of the $0.61-\mathrm{m}(2.0-\mathrm{ft})-$ diameter inlet pipe.

Two CMMs monitored mercury vapor concentrations at the Advanced Hybrid ${ }^{\mathrm{TM}}$ filter inlet and outlet during the testing periods. The Ontario Hydro method was also performed to verify the CMM data.

\subsection{Experimental Setup of Mercury Stability Tests}

\subsubsection{Synthetic Groundwater Leaching Procedure and Long-Term Leaching}

The SGLP batch-leaching procedure is a relatively simple test that follows many of the conditions of the toxicity characteristic leaching procedure (TCLP). The test utilizes a 20:1 


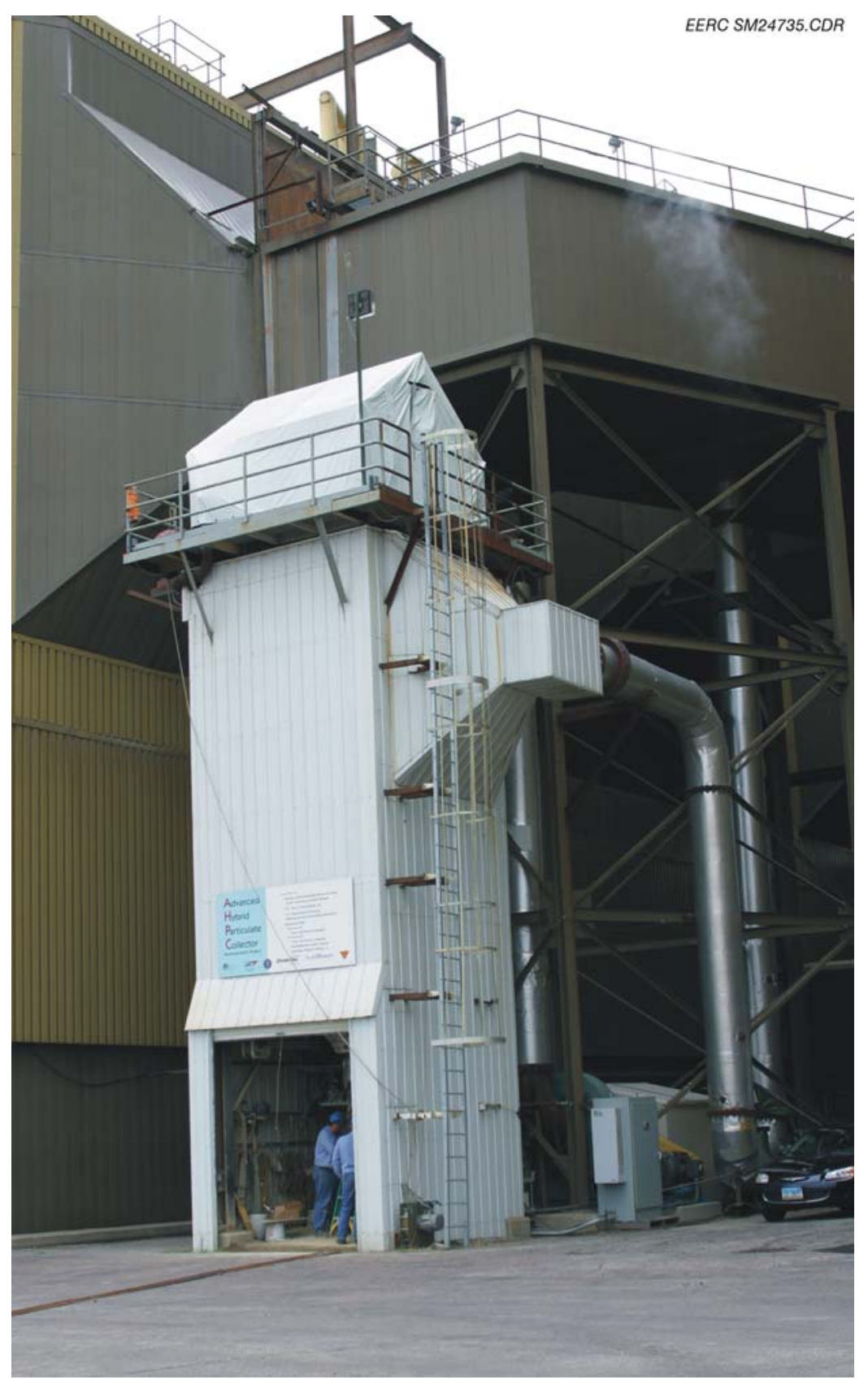

Figure 4.3.1. Demonstration-scale Advanced Hybrid ${ }^{\mathrm{TM}}$ filter at the Big Stone Power Plant. 


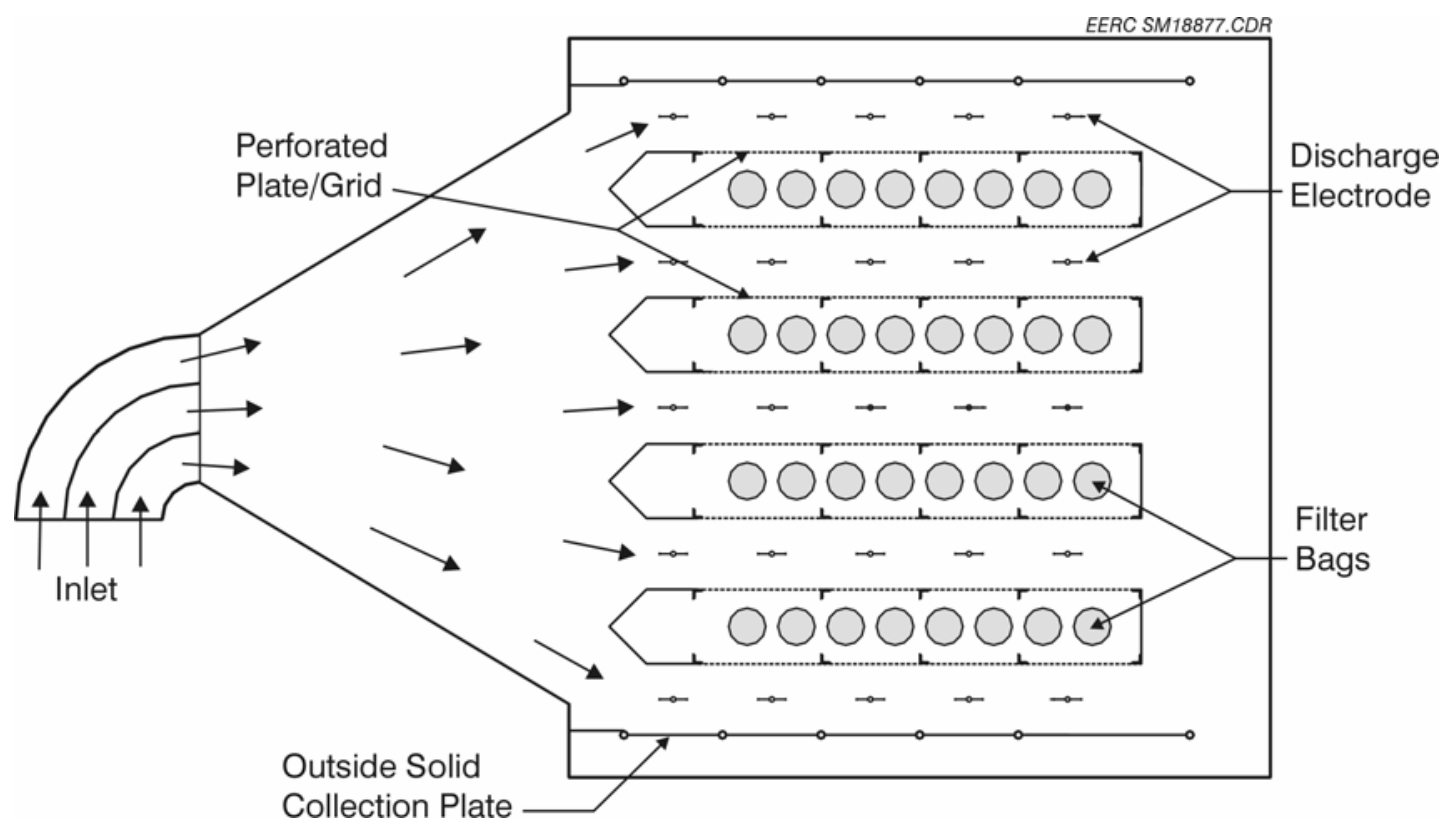

Figure 4.3.2. Top-view schematic diagram of the perforated plate 2.5-MW (9000-acfm) Advanced Hybrid ${ }^{\mathrm{TM}}$ filter.

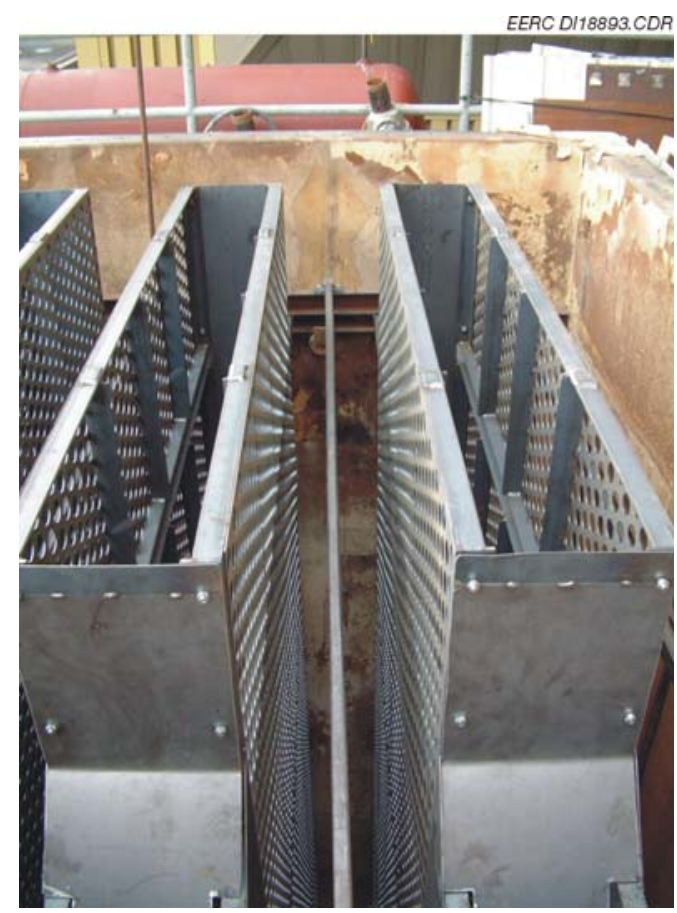

Figure 4.3.3. Top view of the 2.5-MW (9000-acfm) Advanced Hybrid ${ }^{\mathrm{TM}}$ filter at the Big Stone Power Plant during installation. 


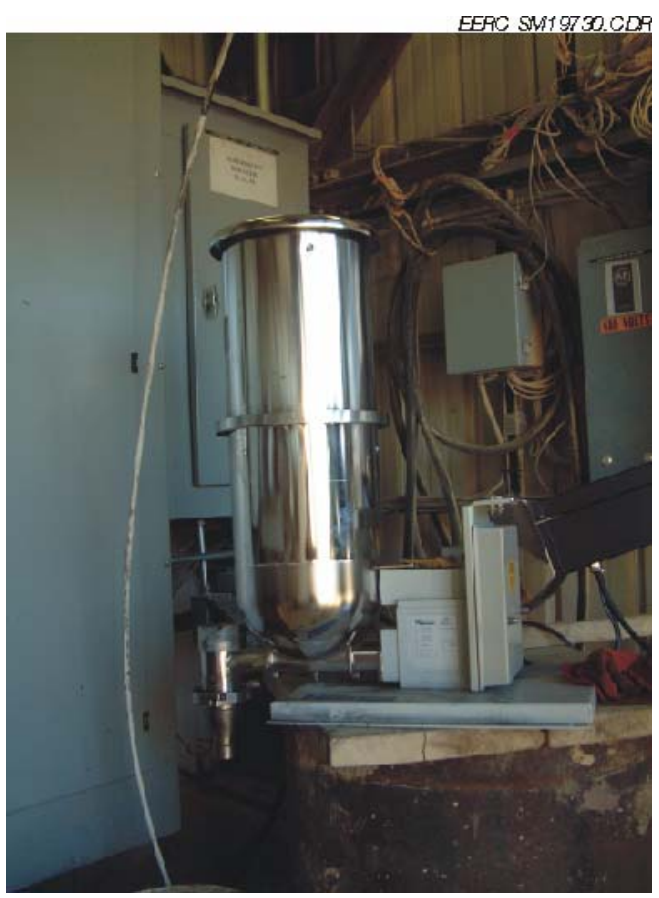

Figure 4.3.4. Overview of the carbon injection system.

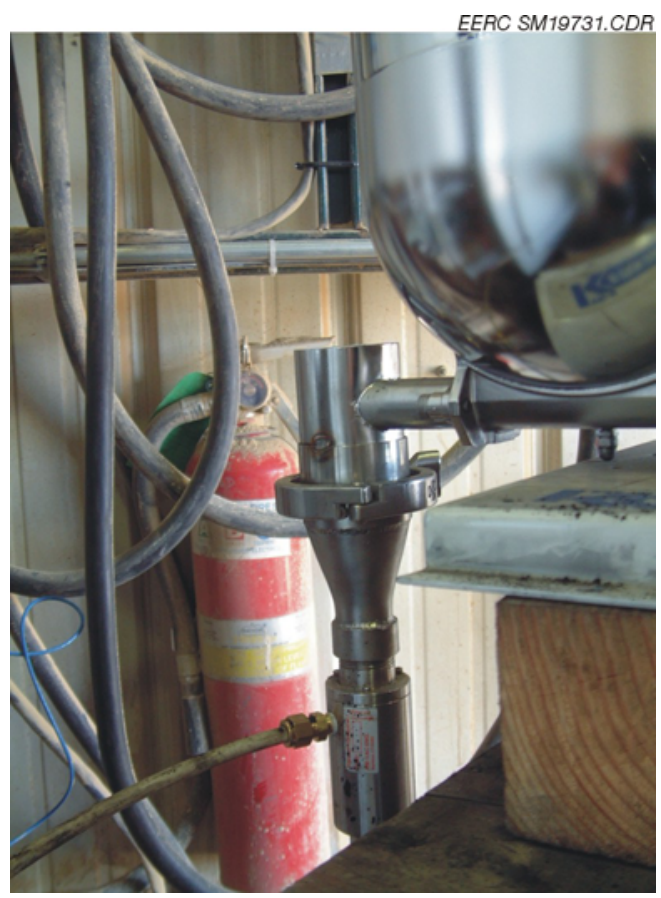

Figure 4.3.5. Air-Vac eductor of the carbon injection system. 


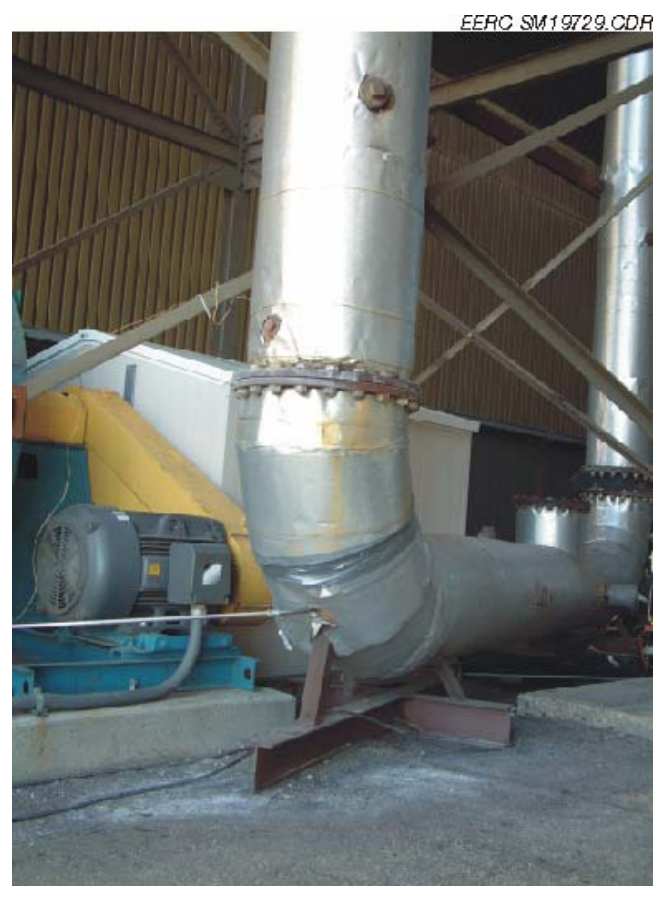

Figure 4.3.6. Carbon-injecting location.

liquid-to-solid ratio, end-over-end agitation at approximately $30 \mathrm{rpm}$, an 18-hr equilibration time, and usually employs a leaching solution consisting of water from the site, water that has been prepared in the lab similar to water likely to contact the ash, or distilled deionized water. Distilled deionized water was used in this effort. For the long-term component of this procedure, multiple bottles are set up and analyzed at different time intervals. A typical SGLP and LTL test might consist of 18-hr, 30-day, and 60-day equilibration times. Although 60 days is often not long enough to have achieved complete equilibrium, it is generally long enough to determine the concentration evolution of individual parameters. The most important factor when performing LTL is to have at least three equilibration times to determine a true trend.

Leachates were filtered through $0.45-\mu \mathrm{m}$ filter paper and analyzed for total mercury. Mercury leachate concentrations were determined using cold-vapor atomic absorption (CVAAS) and cold-vapor atomic fluorescence spectrometry (CVAFS) techniques.

\subsubsection{Microbiological Releases}

The apparatus used to conduct microbiologically mediated vapor-phase mercury release testing is shown in Figure 4.4.1. A $250-\mathrm{mL}$ Erlenmeyer flask was fitted with an impinger inlet/outlet tube with the inlet center shortened to $6 \mathrm{~cm}$ below the standard taper. Cylinder gas 
was passed through several sets of gold-coated quartz traps for mercury removal and admitted to each of the flasks through a gas distribution manifold that routed the gas through $0.23-\mathrm{mm}$ gas chromatography (GC) capillary tubing to each of the individual flasks. A GC capillary length of approximately $60 \mathrm{~cm}$, when pressurized to between 1 and 2 psig through a gas distribution manifold, provided a convenient means of regulating gas flow to approximately $2 \mathrm{~cm}^{3} / \mathrm{min}$. The gas passed mercury vapor from the headspace of the flasks to a mercury vapor collection system at the outlet of the flasks, consisting of two traps. The nearest trap contained Supelco Carbotrap $^{\mathrm{TM}}$, which collected organomercury compounds, followed by a gold-coated quartz trap, which collected elemental mercury.

The flasks were placed on a 16-flask wrist-action shaker. The experimental matrix consisted of eight flasks under anaerobic conditions (using argon) and eight flasks under aerobic conditions (using breathing-quality air). In each set of eight flasks, two contained only buffer, three contained the fly ash with buffer (starved), and three contained the fly ash with buffer and glucose (fed). An 80-gram aliquot of fly ash was placed in the flasks, and $100 \mathrm{~mL}$ of a phosphate buffer (with or without glucose as appropriate) was added to create a neutral $\mathrm{pH}$. The fly ash-

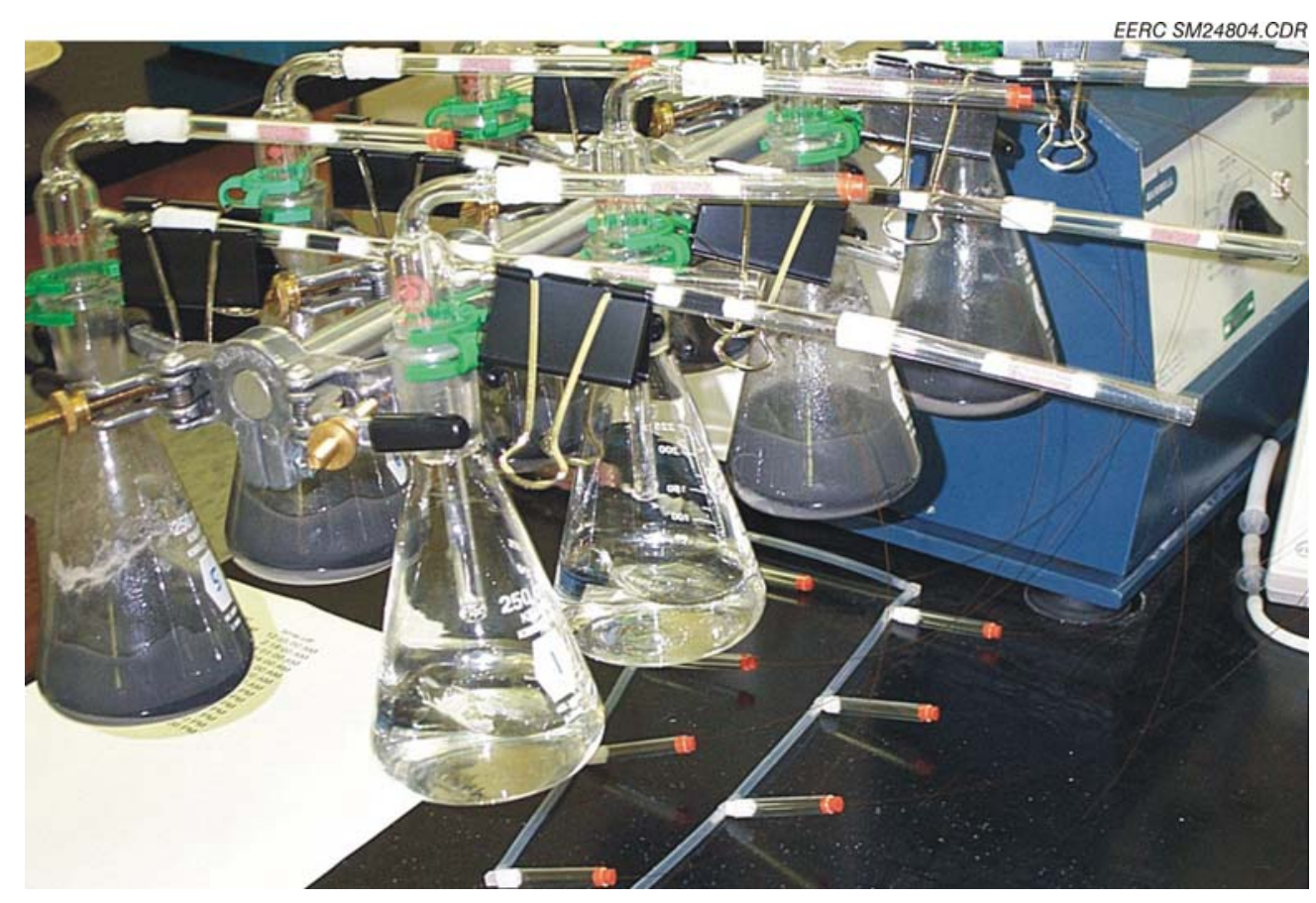

Figure 4.4.1. Microbiologically mediated mercury vapor-phase collection apparatus. 
containing flasks also had $100 \mu \mathrm{L}$ of mixed bacterial culture added. The source of bacteria was a mixed bacterial inoculum from a brackish wetland.

Mercury vapor was collected for 35 days. The gold-coated quartz collection traps were desorbed for analysis by heating to approximately $500^{\circ} \mathrm{C}\left(932^{\circ} \mathrm{F}\right)$, and the mass of mercury released was determined using atomic fluorescence (AF). The Carbotrap ${ }^{\mathrm{TM}}$ collection traps were analyzed for total mercury by heating the trap to approximately $300^{\circ} \mathrm{C}\left(572^{\circ} \mathrm{F}\right)$, passing the released organomercury through a tube at about $800^{\circ} \mathrm{C}\left(1472^{\circ} \mathrm{F}\right)$, and collecting the mercury vapor on a gold-coated quartz trap, which was analyzed as described above.

Bacterial counts were performed upon completion of the 35-day period. A 1-mL aliquot of solution was taken from each flask. The aqueous supernate was serially diluted in $0.1 \%$ sodium pyrophosphate buffer $(\mathrm{pH} 7.0)$ and then used to inoculate a series of tubes containing $1 \%$ PTYG (peptone, tryptone, yeast extract, glucose) broth. The tubes were incubated at $30^{\circ} \mathrm{C}\left(86^{\circ} \mathrm{F}\right)$ and growth, as turbidity, was monitored over a 3-week period.

\subsubsection{Long-Term Ambient Temperature Release}

A 150-gram aliquot of ash was placed into $250-\mathrm{mL}$ tall wide-mouth bottles with bonded Teflon liner caps. The caps were drilled with two holes to accommodate a silicone tube for gas inlet and a Teflon outlet bulkhead fitting. Two samples of each ash were set up for duplicate analyses. Breathing-quality air from a cylinder was passed through several sets of gold-coated quartz traps for mercury removal and admitted to each of the bottles through a gas distribution manifold that routed the gas through $0.23-\mathrm{mm}-\mathrm{ID}$ GC capillary tubing to each of the individual bottles. The pressure drop across the GC capillary tubing allowed for the regulation of air flow through each bottle by simply adjusting the length of tubing to each bottle. The length of tubing was a nominal $65 \mathrm{~cm}$. This length of tubing, when pressurized to between 1 and 2 psig through a gas distribution manifold, provided a convenient means of regulating gas flow to approximately $2 \mathrm{~cm}^{3} / \mathrm{min}$. Because of the variability of particle sizes between different ash samples, the sample with the initial highest gas flow was left with a $65-\mathrm{cm}$ length of GC tubing, and other samples had their tubing lengths shortened until all samples had approximately the same flow rate. The air exiting the GC tubing was given a final scrubbing to remove mercury vapor using goldcoated quartz just prior to entering the bottle containing the ashes. After entering the bottles, the air passed through the ash and exited to a central mercury collection tube containing two separate gold-coated quartz traps. The gold-coated quartz nearest the exit bulkhead fitting was analyzed 
after one 7-day period and two 90-day periods to determine the mass of mercury vapor released from the ashes while the top trap, in the same tube, was present to prevent mercury contamination from atmospheric mercury. This setup is illustrated in Figure 4.4.2.

Mercury collection was carried out for a total of 187 days in this experiment. The goldcoated quartz collection tubes were desorbed for analysis by heating to approximately $500^{\circ} \mathrm{C}$ $\left(932^{\circ} \mathrm{F}\right)$. The mass of mercury released was determined using AF.

\subsubsection{Thermal Desorption at Elevated Temperatures}

A schematic for the controlled thermal desorption of mercury and mercury compounds was assembled and is shown schematically in Figure 4.4.3. The apparatus was constructed using an atomic absorption (AA) spectrophotometer for mercury detection and included a small tube furnace and temperature controller for thermal desorption. A Hewlett Packard 3395 integrator was used for data collection. Detection of thermally desorbed mercury and mercury compounds was done in an electrically heated quartz cell operated at $800^{\circ} \mathrm{C}\left(1472^{\circ} \mathrm{F}\right)$. The use of a heated

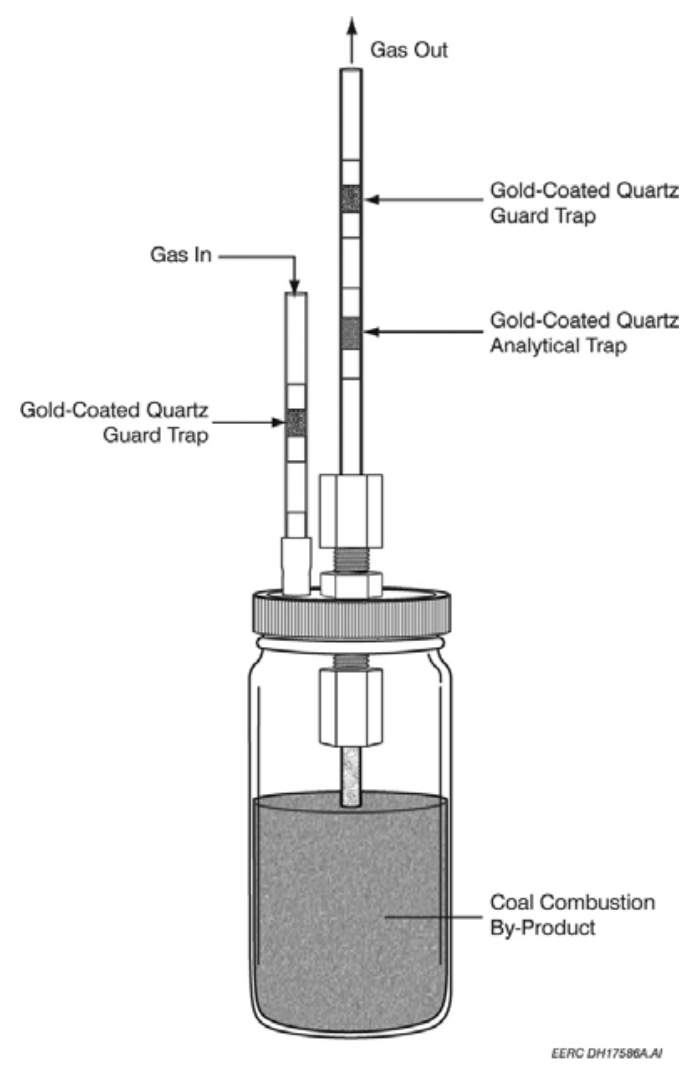

Figure 4.4.2. Mercury vapor release collection apparatus. 


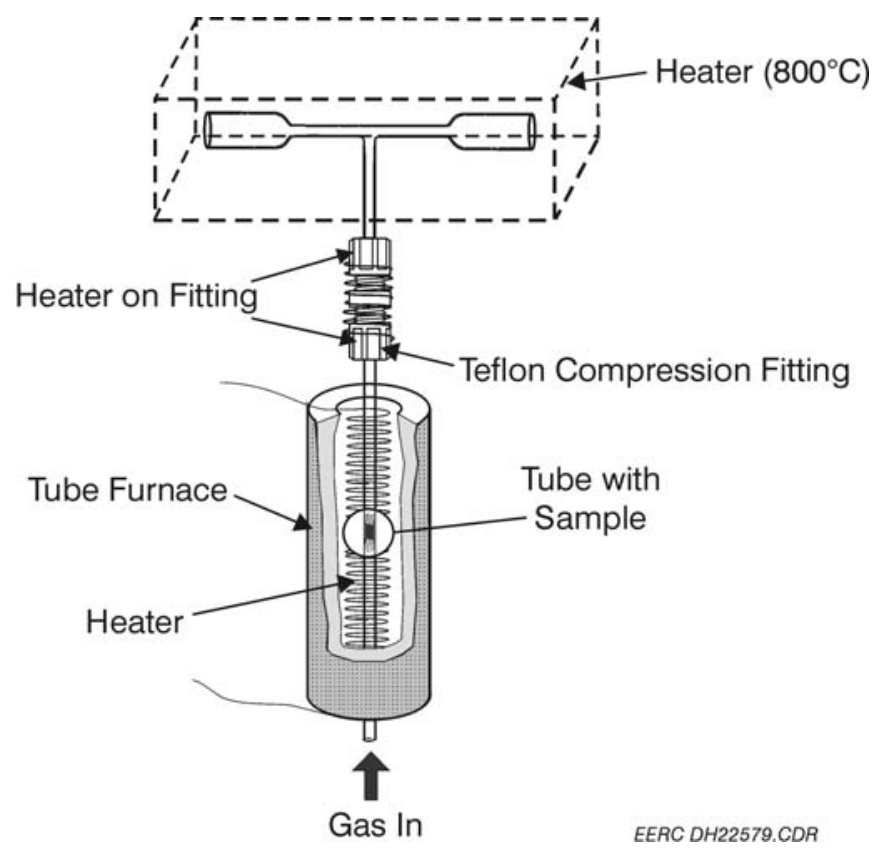

Figure 4.4.3. Mercury thermal desorption apparatus.

cell allowed detection of mercury compounds by thermally decomposing compounds to form elemental mercury, which can be detected by AA. Gas flow was $10 \mathrm{~cm}^{3} / \mathrm{min}$ of nitrogen. The temperature controller was ramped from ambient temperature to $750^{\circ} \mathrm{C}\left(1382^{\circ} \mathrm{F}\right)$ at a rate of $25^{\circ} \mathrm{C}\left(45^{\circ} \mathrm{F}\right)$ per minute.

\subsection{5-kW (200-acfm) Pilot-Scale SDA/PJBH at the EERC}

Figure 4.5.1 is a schematic diagram of the pilot-scale SDA/PJBH configuration. The selected additives were blended with coal and cofired in the combustion unit. The generated flue gas passed through the SDA and PJBH and NORIT FGD carbon was injected into the flue gas upstream of the SDA. Mercury samples were taken both at the SDA inlet and PJBH outlet to determine mercury capture efficiency across the system.

The SDA, Model I provided by Niro Inc., is shown schematically in Figure 4.5.2. The drying chamber is $1.2 \mathrm{~m}(3.9 \mathrm{ft})$ in diameter, with a $0.75-\mathrm{m}(2.5-\mathrm{ft})$ cylindrical height and a $60^{\circ}$ conical bottom. The inner shell is constructed of 2-mm stainless steel, Type AISI 316, with a 220 -grit finish. A Niro Inc. Type FS-1 rotary atomizer, capable of speeds ranging from 10,500 to 30,000 rpm, was used for atomizing lime slurry. An air disperser, supplied with the rotary atomizer, was used to introduce the proper heated $\left(149^{\circ} \mathrm{C}, 300^{\circ} \mathrm{F}\right)$ airflow pattern throughout the 


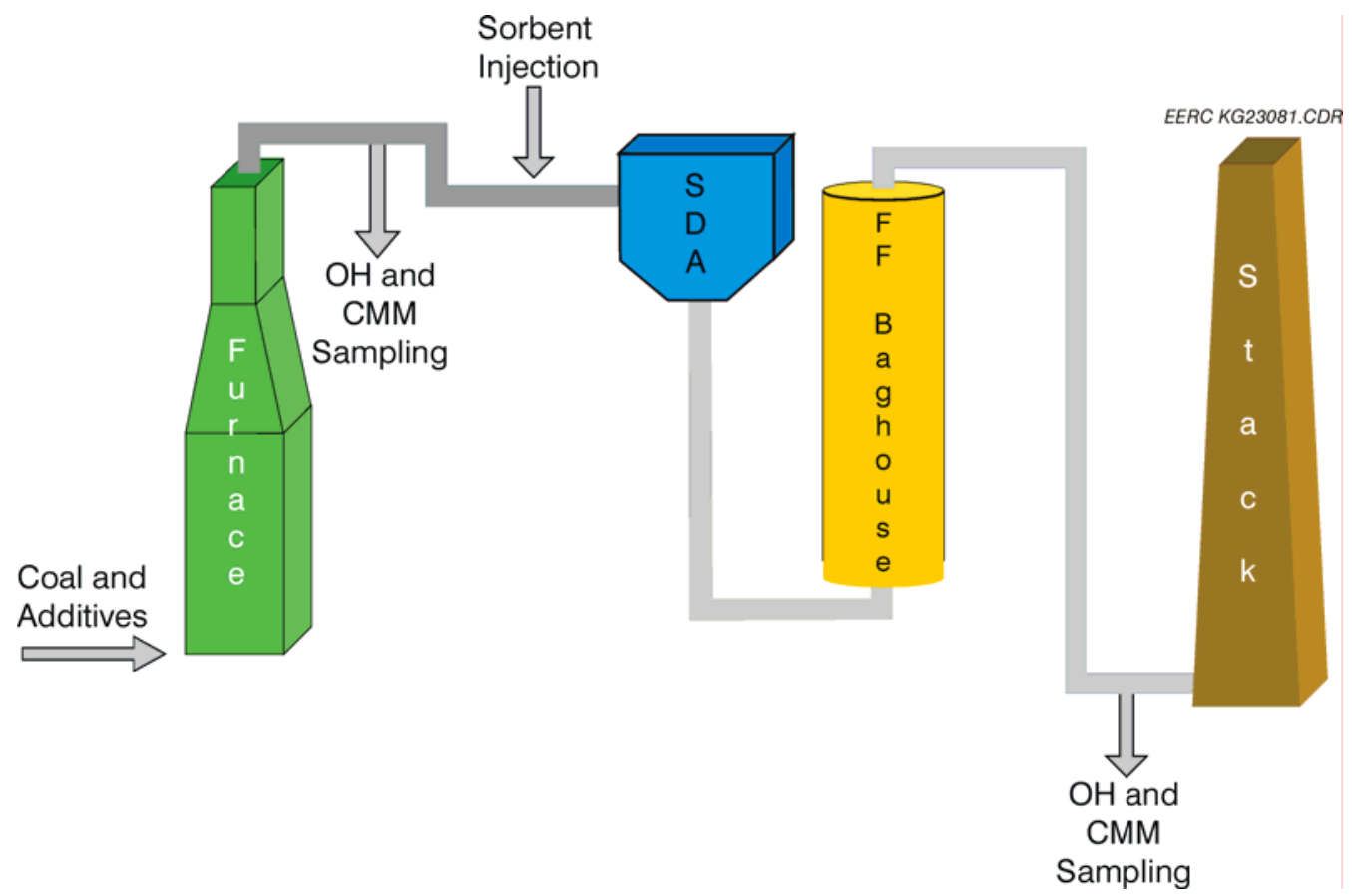

Figure 4.5.1. Schematic diagram of pilot-scale SDA/PJBH configuration.

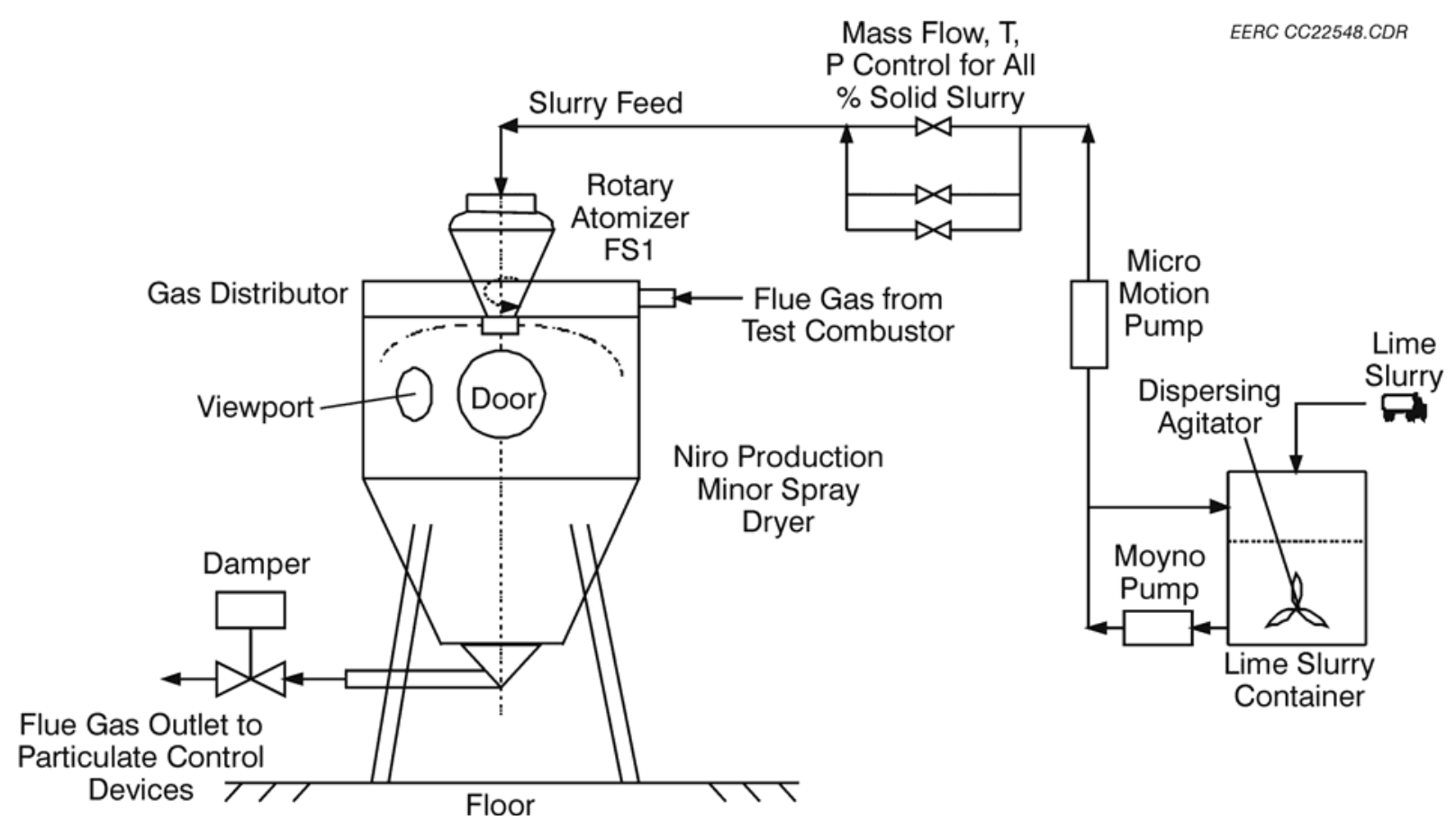

Figure 4.5.2. The SDA, Model I provided by Niro Inc. 
chamber. The lime slurry for the SDA was prepared by adding deionized distilled water to slaked lime and fly ash obtained from the Antelope Valley Station in North Dakota. High-purity water was used to avoid the unintended introduction of chlorine into the system via a chlorinated water supply. Lime slurry compositions are presented in Table 4.5.1. The solid contents of the prepared slurries averaged $38 \mathrm{wt} \%$ on December 8 and 9 and $33 \mathrm{wt} \%$ on December 10 and 11.

Table 4.5.1. Lime Slurry Compositions, wt \%

\begin{tabular}{lcc}
\hline Component & December 8 and 9, 2003 & December 10 and 11, 2003 \\
\hline $\mathrm{Ca}(\mathrm{OH})_{2}$ & 4 & 4 \\
Fly Ash & 34 & 29 \\
Distilled Water & 62 & 67 \\
\hline
\end{tabular}




\subsection{MERCURY MEASUREMENT}

\subsection{Description of Ontario Hydro Method}

ASTM Method D6784-02 (Ontario Hydro method) was extensively used in this project to measure directly $\mathrm{Hg}^{0}, \mathrm{Hg}^{2+}, \mathrm{Hg}(\mathrm{p})$, and $\mathrm{Hg}(\mathrm{g})$ in coal combustion flue gas. For this method, a sample is withdrawn from the flue gas stream isokinetically through a filter, which is followed by a series of impingers in an ice bath. A schematic of the sample train is shown in Figure 5.1.1, and Table 5.1.1 presents a list of sample train components. Particulate-bound mercury is collected on the front filter; oxidized mercury is collected in impingers containing $1 \mathrm{~N}$ potassium

chloride solution; and elemental mercury is collected in one impinger containing a $5 \%$ nitric acid and $10 \%$ peroxide solution and in three impingers containing a solution of $10 \%$ sulfuric acid and $4 \%$ potassium permanganate. An impinger containing silica gel collects any remaining moisture. Quartz fiber filters were used as the filter media for the testing, and the filter holder was glass. A heated Teflon line was used between the probe and impinger train.

Figure 5.1.2 is a schematic of the sample recovery procedure for the impinger train. The samples were recovered into precleaned glass bottles with vented Teflon-lined lids for submission to the laboratory. The following sample fractions were recovered (specific rinse solutions are contained in the method):

- Container 1 - sample filter

- Container 2 - front-half rinse (includes all surfaces upstream of the filter)

- Container 3 - Impingers 1 through 3 ( $\mathrm{KCl}$ impingers) and rinses

- Container 4 - Impinger $4\left(\mathrm{HNO}_{3}-\mathrm{H}_{2} \mathrm{O}_{2}\right.$ impinger $)$ and rinses

- Container 5 - Impingers 5 through $7\left(\mathrm{H}_{2} \mathrm{SO}_{4}-\mathrm{KMnO}_{4}\right.$ impingers $)$ and rinse

- Silica Gel-Impinger 8 (silica gel impinger) (note that this sample is weighed for moisture determination and is not included in the mercury analysis)

The sample fractions were prepared and analyzed as specified in the method and summarized as follows:

- Ash Sample (Containers 1 and 2) - The particulate catch was digested and analyzed using EPA Method 3051 with subsequent analysis using EPA Method 7471A.

- $\mathrm{KCl}$ Impingers (Container 3) - The impingers were prepared using $\mathrm{H}_{2} \mathrm{SO}_{4}, \mathrm{HNO}_{3}$, and $\mathrm{KMnO}_{4}$ solutions as specified in the method. 


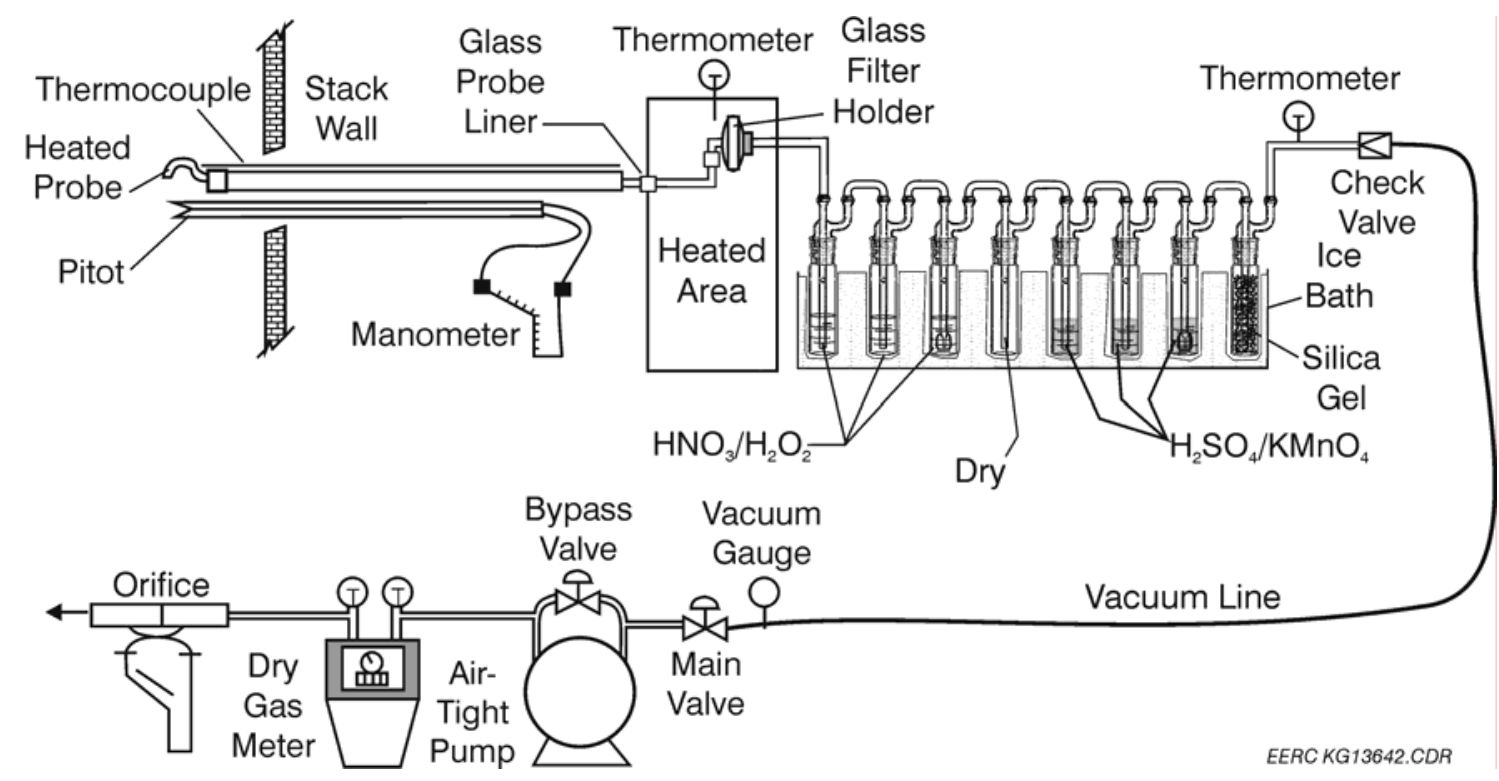

Figure 5.1.1. Schematic of the sample train.

- $\mathrm{HNO}_{3}-\mathrm{H}_{2} \mathrm{O}_{2}$ (Container 4) - The impinger solution was prepared using $\mathrm{HCl}$ and $\mathrm{KMnO}_{4}$ solutions as specified in the method.

- $\mathrm{H}_{2} \mathrm{SO}_{4}-\mathrm{KMnO}_{4}$ Impingers (Container 5) - The impinger solution was prepared using hydroxylamine sulfate as specified in the method.

Table 5.1.1. Sample Train Components-EPA Method 17 Configuration

\begin{tabular}{ll}
\hline Component & Quartz \\
\hline Nozzle & Quartz in glass \\
Filter & Quartz heated to a minimum temperature of $120^{\circ} \mathrm{C}\left(338^{\circ} \mathrm{F}\right)$ \\
Probe & Teflon line used to connect from probe to impingers - heated to \\
Connector Line & a minimum of $120^{\circ} \mathrm{C}\left(338^{\circ} \mathrm{F}\right)$ \\
& $1 \mathrm{~N} \mathrm{KCl}$ solution; modified Smith Greenburg $(\mathrm{SG})$ impinger \\
Impingers 1 and 2 & $1 \mathrm{~N} \mathrm{KCl}$ solution; standard SG impinger \\
Impinger 3 & $5 \%$ nitric acid-10\% hydrogen peroxide; modified SG impinger \\
Impinger 4 & $10 \%$ sulfuric acid-4\% potassium permanganate; modified SG \\
Impingers 5 and 6 & impinger \\
& $10 \%$ sulfuric acid-4\% potassium permanganate; standard SG \\
Impinger 7 & impinger \\
Impinger 8 & Silica gel; modified SG impinger \\
\hline
\end{tabular}


1. Rinse filter holder and connector with $0.1 \mathrm{~N} \mathrm{HNO}_{3}$.

2. Add $5 \% \mathrm{w} / \mathrm{KMnO}_{4}$ to each impinger bottle until purple color remains.

3. Rinse with $10 \% \mathrm{v} / \mathrm{v} \mathrm{HNO}_{3}$.

4. Rinse with a very small amount of $10 \% \mathrm{w} / \mathrm{v}$ $\mathrm{NH}_{2} \mathrm{OH} \cdot \mathrm{H}_{2} \mathrm{SO}_{4}$ if brown residue remains.

5. Final rinse with $10 \% \mathrm{v} / \mathrm{v} \mathrm{HNO}_{3}$.

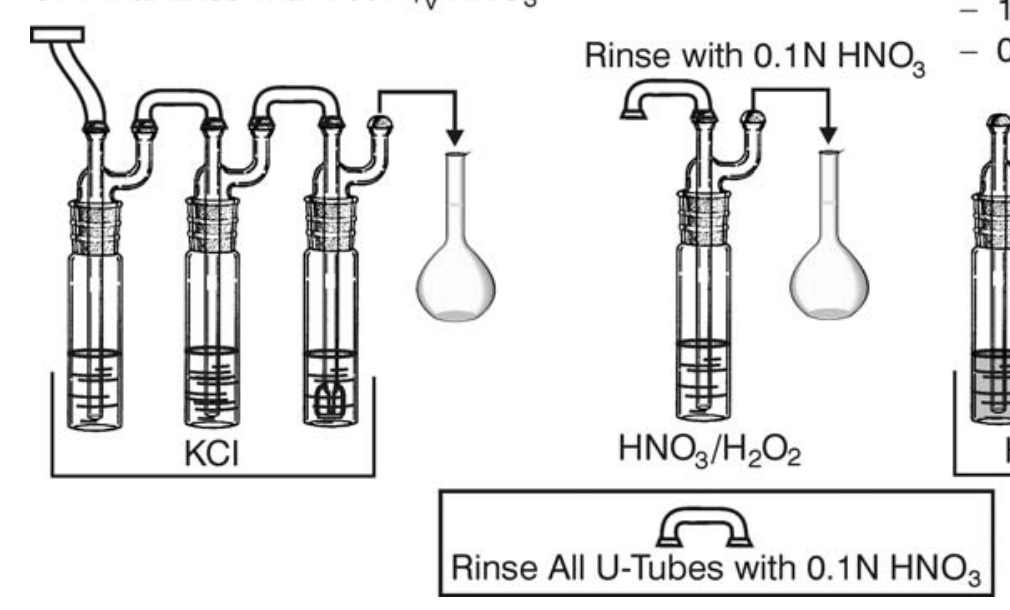

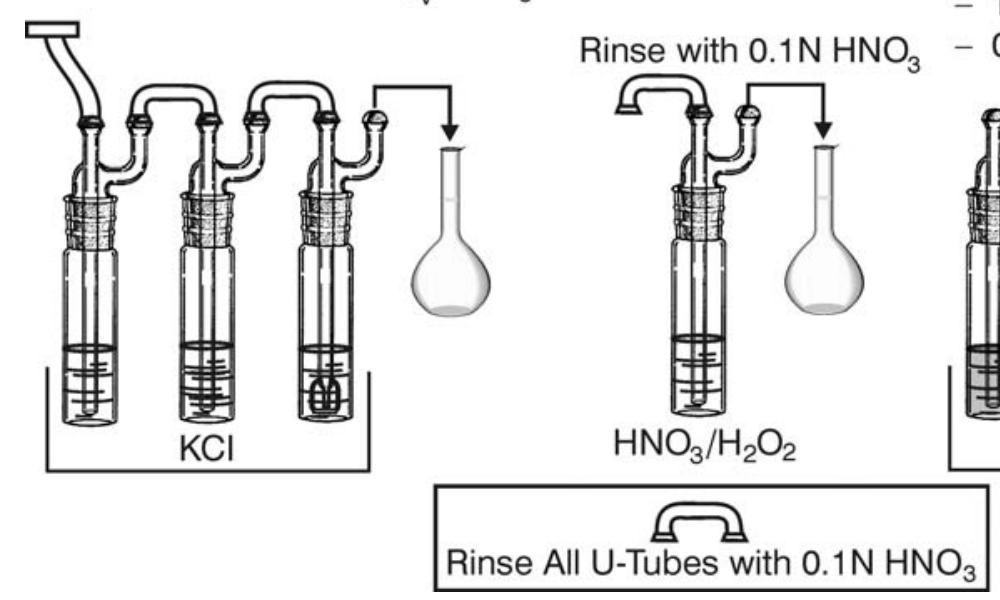

Rinse Bottles Sparingly with

$-0.1 \mathrm{~N} \mathrm{HNO}_{3}$

$-10 \% \mathrm{w} / \mathrm{v} \mathrm{NH}_{2} \mathrm{OH} \cdot \mathrm{H}_{2} \mathrm{SO}_{4}$

$-0.1 \mathrm{~N} \mathrm{HNO}_{3}$

Figure 5.1.2. Sample recovery scheme for the mercury speciation sampling train.

Each prepared fraction was analyzed for total mercury by CVAAS, a method based on the absorption of radiation at $253.7 \mathrm{~nm}$ by mercury vapor. The mercury is reduced to the elemental state and aerated from solution in a closed system. The mercury vapor passes through a cell positioned in the light path of an atomic absorption spectrometer. Mercury concentration is proportional to the indicated absorbance. A soda-lime trap and a magnesium perchlorate trap were used to precondition the gas before it entered the absorption cell.

\subsection{Description of Continuous Mercury Monitor}

CMMs were also widely used in this project to provide continuous gaseous mercury species measurement in coal combustion flue gas, and they are based on the principle of either AA or AF, which provides an inherently more sensitive signal than AA.

Tekran mercury vapor analyzer (2537A) is one of the typical CMMs used in the tests. The instrument samples and traps mercury vapor into a cartridge containing an ultrapure gold adsorbent. The amalgamated mercury is thermally desorbed and detected using CVAFS. A dual-cartridge design allows alternate sampling and desorption, resulting in continuous mercury measurement. 
Sir Galahad is another typical CMM used, requiring a four-step process to obtain flue gas mercury measurement. In the first step, $2 \mathrm{~L}$ of flue gas is pumped through a gold trap, which is maintained at a constant temperature. Before the mercury is desorbed from the gold trap, a flushing step is initiated to remove any flue gas that may be present because it has a damping effect on the mercury fluorescence. When this is completed, the analysis step begins. The heating coil is activated, and the gold trap is heated to approximately $500^{\circ} \mathrm{C}\left(932^{\circ} \mathrm{F}\right)$. This desorbs the mercury from the trap, and the mercury is carried into the fluorescence detector. The gold trap is rapidly cooled by pumping argon over it, in preparation for the next sample. The total time for the entire process is about $5 \mathrm{~min}$ per sample.

All of the CMMs were calibrated using $\mathrm{Hg}^{0}$ as the primary standard. The $\mathrm{Hg}^{0}$ is contained in a closed vial which is held in a thermostatic bath. The temperature of the mercury is monitored, and the amount of mercury is calculated using vapor pressure calculations. Typically, the calibration of the unit has proven stable over a 24-hour period.

Whether the CMM uses AA or AF to measure mercury, some form of gas pretreatment is necessary before accurate measurement of total mercury (or speciated mercury) can be accomplished. For the AA-type systems, only $\mathrm{Hg}^{0}$ can be directly analyzed. Therefore, all mercury forms in the flue gas must be converted to $\mathrm{Hg}^{0}$. For the AF CMMs, a pretreatment/conversion system is also needed, but for a different reason. Both $\mathrm{Hg}^{+}$and $\mathrm{Hg}^{0}$ collect on the gold trap; however, if $\mathrm{HCl}$ and $\mathrm{NO}_{2}$ are present in the flue gas, the gold trap is permanently poisoned. To prevent this, since the $\mathrm{HCl}$ is much easier to remove than $\mathrm{NO}_{2}$, the $\mathrm{HCl}$ is removed prior to the flue gas passing through the gold trap. Also, if the instrument is to be used to provide mercury speciation data, then the $\mathrm{Hg}^{+}$must be removed from the gas stream so that the $\mathrm{Hg}^{0}$ concentration can be measured.

For several years, the EERC has been working on the development of pretreatmentconversion systems for both AA- and AF-type mercury CMMs. The system that is currently used by the EERC consists of three primary parts:

1. An acid gas trap that removes the $\mathrm{SO}_{2}$ and $\mathrm{HCl}$ without removing any of the mercury

2. A $\mathrm{SnCl}_{2}$ gas-liquid separator to convert all $\mathrm{Hg}^{+}$to $\mathrm{Hg}^{0}$

3. A gas-liquid separator that removes $\mathrm{Hg}^{+}$without removing $\mathrm{Hg}^{0}$

Depending on which side of the pretreatment system the flue gas is passed through, either only $\mathrm{Hg}^{0}$ or total mercury is measured. 
The reliability of CMM measurements were evaluated using the Ontario Hydro method. All measurements of mercury in flue gas streams that are reflected in this report have been normalized and corrected to dry conditioning at $3 \% \mathrm{O}_{2}$ and $20^{\circ} \mathrm{C}\left(68^{\circ} \mathrm{F}\right)$. 


\subsection{RESULTS AND DISCUSSION}

\subsection{Bench-Scale Experimental Results}

The bench-scale tests were for the purpose of verifying previous results, expanding on the $\mathrm{SO}_{2}$ and $\mathrm{NO}_{2}$ concentration effect, linking the synthetic gas results to the results with real flue gas, and screening sorbents.

\subsubsection{Series 1 Bench-Scale Tests}

The purpose of the first series of tests was to ensure that results obtained by the EERC and others could be duplicated and, second, to include $\mathrm{SO}_{2}$ and $\mathrm{NO}_{2}$ as variables. Table 6.1.1.1 lists the test matrix completed in Series $1 . \mathrm{SO}_{2}$ and $\mathrm{NO}_{2}$ concentrations were varied to establish their individual and combined effects on mercury capture with NORIT FGD carbon in a fixed bed reactor.

The flue gas concentrations for the Series 1 bench-scale tests are given in Table 6.1.1.2. Both $\mathrm{SO}_{2}$ and $\mathrm{NO}_{2}$ were varied as part of the tests.

Table 6.1.1.1. Bench-Scale Series $1-\mathrm{SO}_{2}$ and $\mathrm{NO}_{2}$ Concentration

\begin{tabular}{lcccccccc}
\hline $\begin{array}{l}\text { Test } \\
\text { No. }\end{array}$ & $\begin{array}{c}\text { Sorbent } \\
\text { Type }\end{array}$ & $\begin{array}{c}\text { Temp., }{ }^{\circ} \mathrm{C} \\
\left({ }^{\circ} \mathrm{F}\right)\end{array}$ & $\begin{array}{c}\text { Sorbent } \\
\text { Concentration, } \mathrm{mg}\end{array}$ & $\begin{array}{c}\text { Flue } \\
\text { Gas }\end{array}$ & $\begin{array}{c}\mathrm{SO}_{2}, \\
\mathrm{ppm}\end{array}$ & $\begin{array}{c}\mathrm{HCl}, \\
\mathrm{ppm}\end{array}$ & $\begin{array}{c}\mathrm{NO}, \\
\mathrm{ppm}\end{array}$ & $\begin{array}{c}\mathrm{NO}_{2}, \\
\mathrm{ppm}\end{array}$ \\
\hline 1 & FGD & $135(275)$ & 150 & Simulated & 1600 & 50 & 400 & 20 \\
2 & FGD & $135(275)$ & 150 & Simulated & 500 & 50 & 400 & 20 \\
3 & FGD & $135(275)$ & 150 & Simulated & 200 & 50 & 400 & 20 \\
4 & FGD & $135(275)$ & 150 & Simulated & 1600 & 50 & 400 & 10 \\
5 & FGD & $135(275)$ & 150 & Simulated & 500 & 50 & 400 & 10 \\
6 & FGD & $135(275)$ & 150 & Simulated & 200 & 50 & 400 & 10 \\
7 & FGD & $135(275)$ & 150 & Simulated & 1600 & 50 & 400 & 5 \\
8 & FGD & $135(275)$ & 150 & Simulated & 500 & 50 & 400 & 5 \\
9 & FGD & $135(275)$ & 150 & Simulated & 200 & 50 & 400 & 5 \\
\hline
\end{tabular}

Table 6.1.1.2. Baseline Flue Gas Concentrations

\begin{tabular}{lc}
\hline $\mathrm{Hg}^{0}$ & $15 \mu \mathrm{g} / \mathrm{m}^{3}$ \\
$\mathrm{O}_{2}$ & $6 \%$ \\
$\mathrm{CO}_{2}$ & $12 \%$ \\
$\mathrm{H}_{2} \mathrm{O}$ & $8 \%$ \\
$\mathrm{~N}_{2}$ & Balance \\
$\mathrm{HCl}$ & $50 \mathrm{ppm}$ \\
$\mathrm{NO}$ & $400 \mathrm{ppm}$ \\
$\mathrm{NO}_{2}$ & Varied \\
$\mathrm{SO}_{2}$ & Varied \\
\hline
\end{tabular}


The nine breakthrough curves for these tests are presented at constant $\mathrm{SO}_{2}$ concentration with varying $\mathrm{NO}_{2}$ and at constant $\mathrm{NO}_{2}$ concentration with varying $\mathrm{SO}_{2}$ concentration in Figures 6.1.1.1-6.1.1.6. For comparison, all nine are shown in Figure 6.1.1.7.

The breakthrough graphs show several effects of $\mathrm{SO}_{2}$ and $\mathrm{NO}_{2}$ concentration. First, the time until initial breakthrough decreased significantly with increasing $\mathrm{SO}_{2}$ and $\mathrm{NO}_{2}$ concentrations. At the higher concentrations, breakthrough occurred after about $30 \mathrm{~min}$, and at the lower concentrations, breakthrough occurred after about $2.5 \mathrm{hr}$. This implies that a sorbent at the lower concentrations would have five times the mercury capacity of a sorbent exposed to the higher concentrations. This range is significant enough that it might dictate whether mercury control with carbon is practical for a given set of conditions. Since these are fixed-bed tests, the cumulative carbon-to-mercury ratio was infinite at the start of the test and decreased with exposure time. After $3 \mathrm{hr}$ of exposure, the calculated ratio was approximately 3700 , which is considered a reasonable value for control. However, after only $30 \mathrm{~min}$, the cumulative ratio was 22,200 , which is likely too high to be considered for economical mercury control. If these data can be shown to be indicative of sorbent performance in real systems, they would appear to be valuable for initial screening of potential sorbents for a known set of flue gas conditions. At high

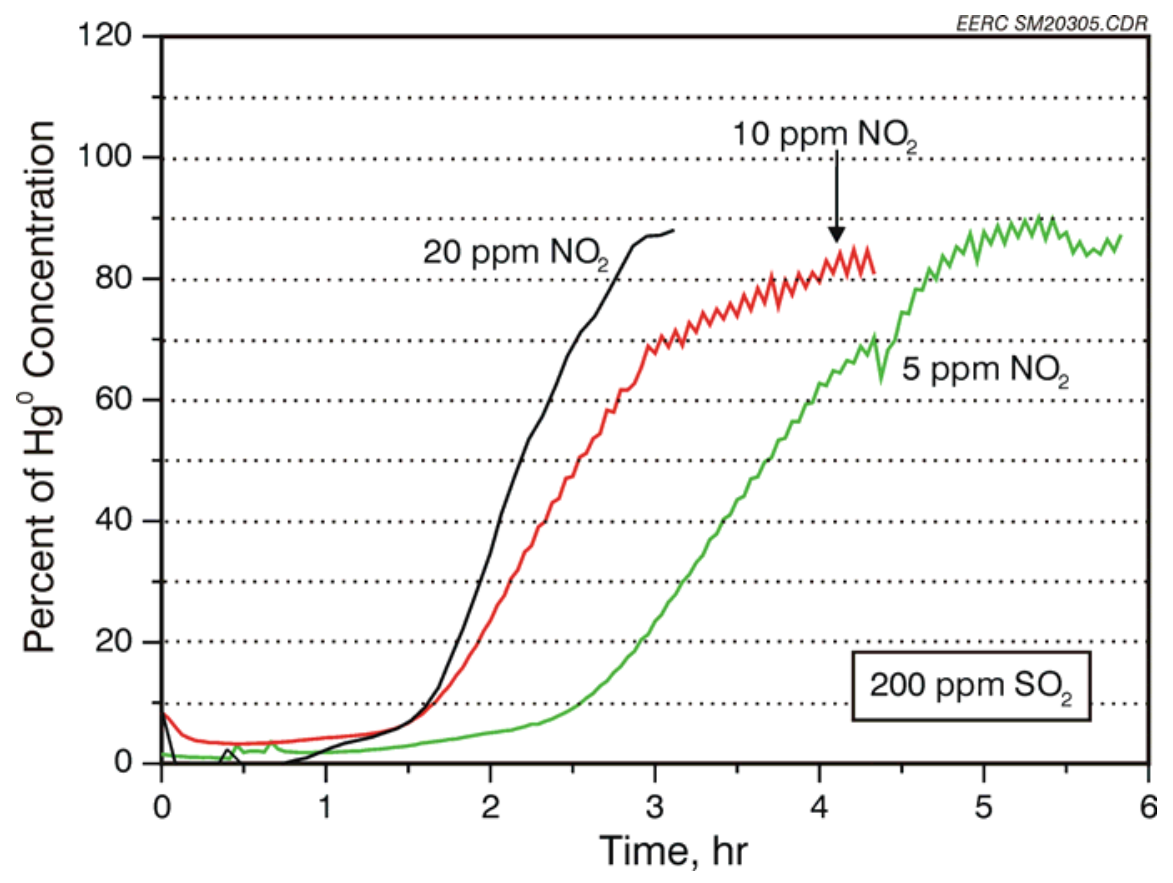

Figure 6.1.1.1. Mercury breakthrough curves at $200 \mathrm{ppm} \mathrm{SO}_{2}$ with varied $\mathrm{NO}_{2}: 5,10,20 \mathrm{ppm}$. 


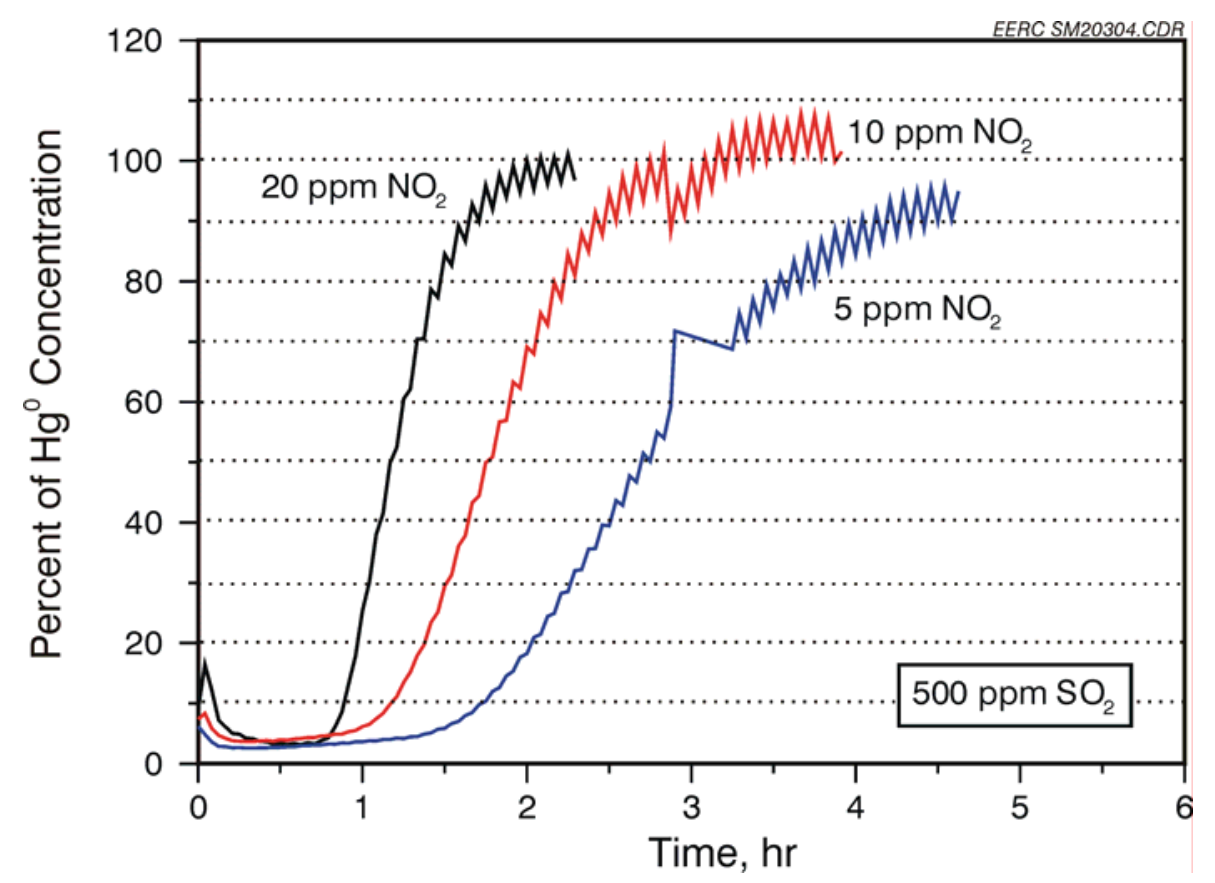

Figure 6.1.1.2. Mercury breakthrough curves at $500 \mathrm{ppm} \mathrm{SO}_{2}$ with varied $\mathrm{NO}_{2}: 5,10,20 \mathrm{ppm}$.

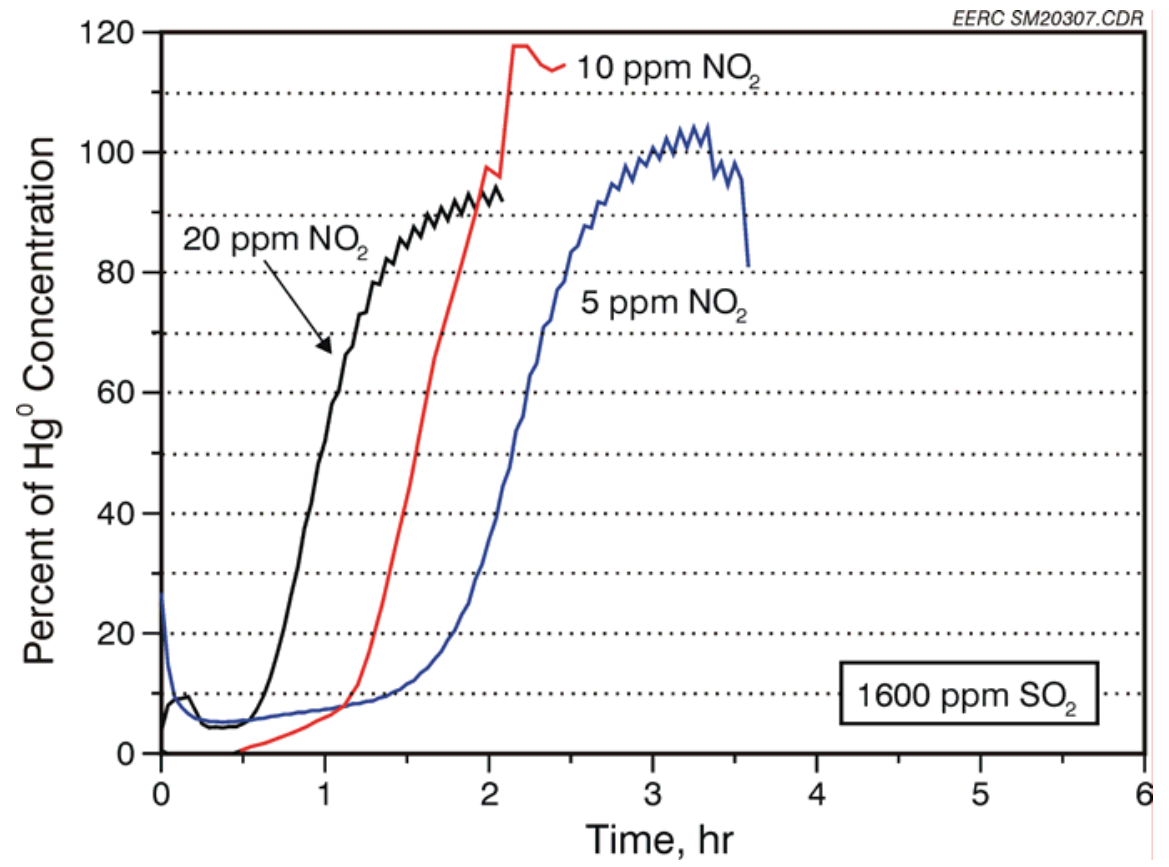

Figure 6.1.1.3. Mercury breakthrough curves at $1600 \mathrm{ppm} \mathrm{SO}_{2}$ with varied $\mathrm{NO}_{2}: 5,10,20 \mathrm{ppm}$. 


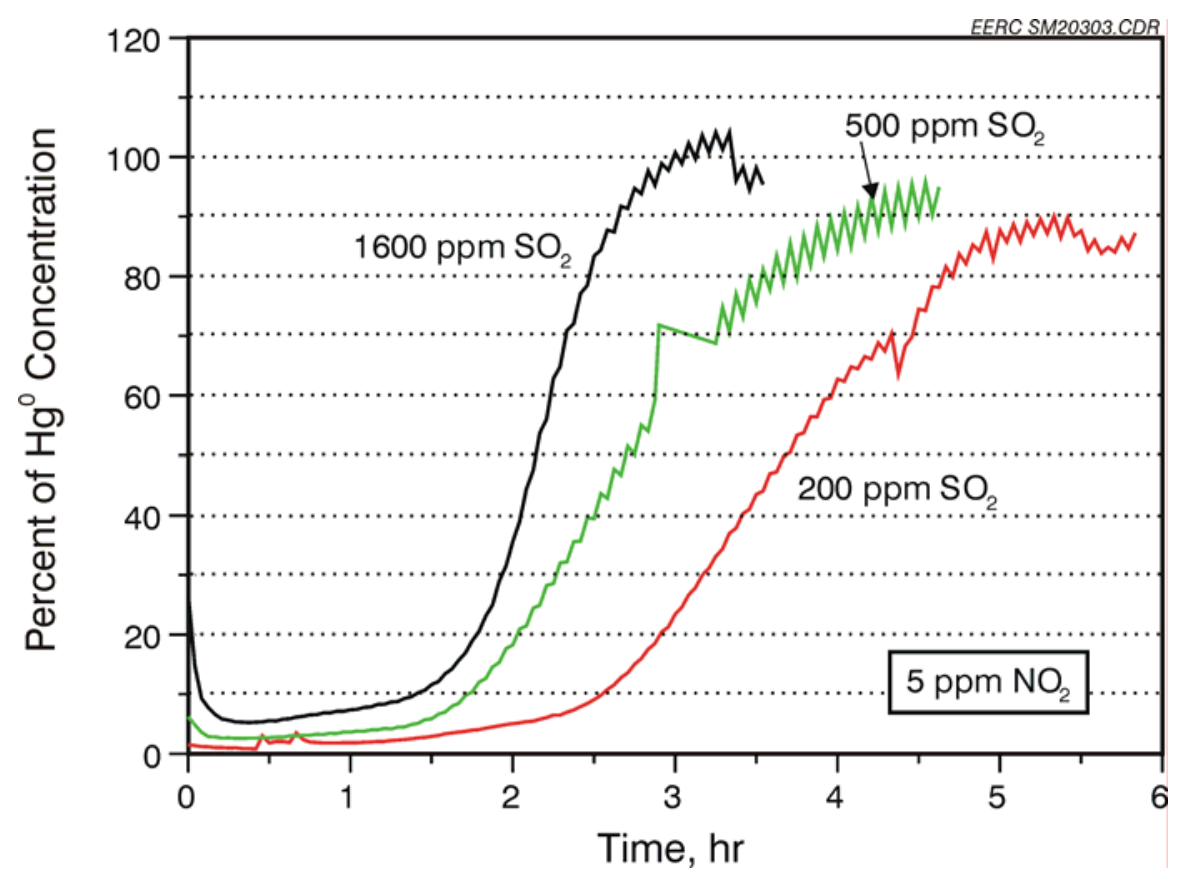

Figure 6.1.1.4. Mercury breakthrough curves at 5 ppm $\mathrm{NO}_{2}$ with varied $\mathrm{SO}_{2}: 200,500,1600$ ppm.

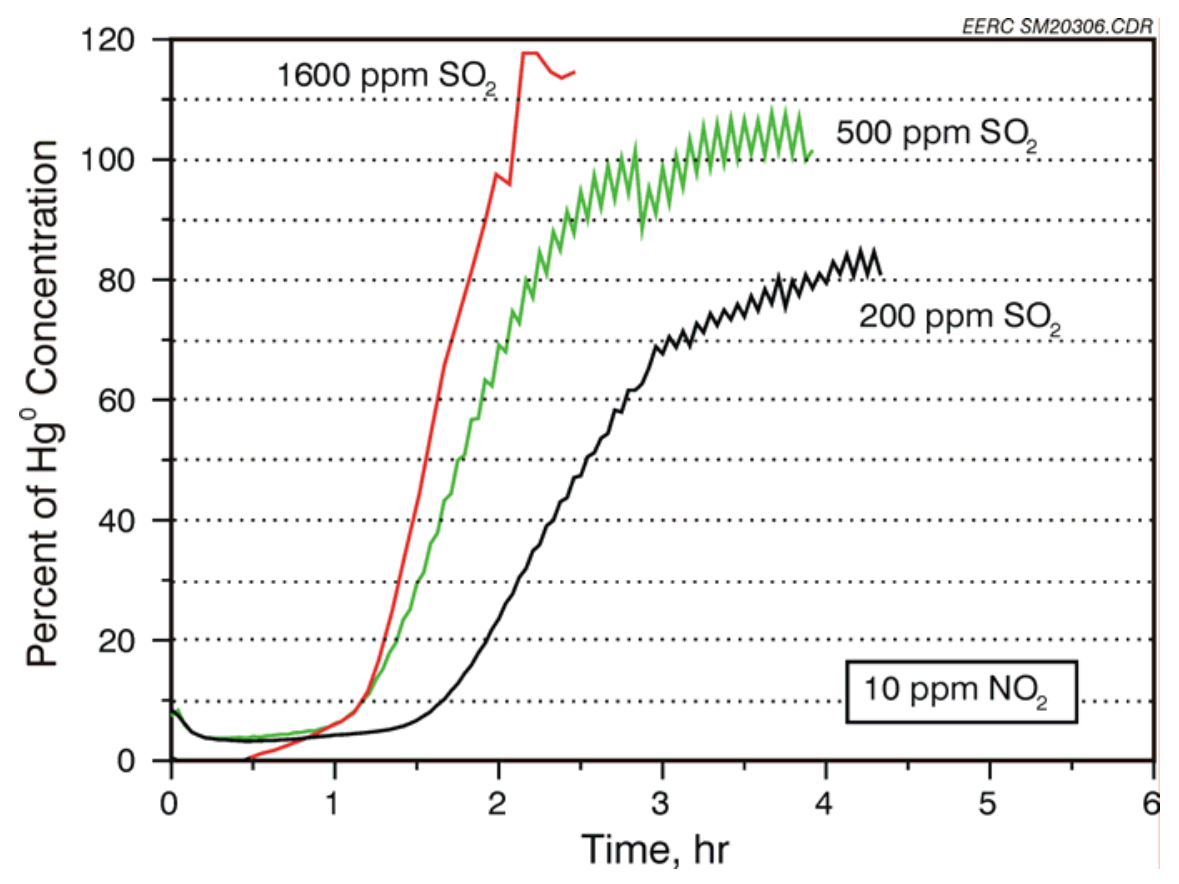

Figure 6.1.1.5. Mercury breakthrough curves at $10 \mathrm{ppm} \mathrm{NO}$ with varied $\mathrm{SO}_{2}: 200,500$, $1600 \mathrm{ppm}$. 


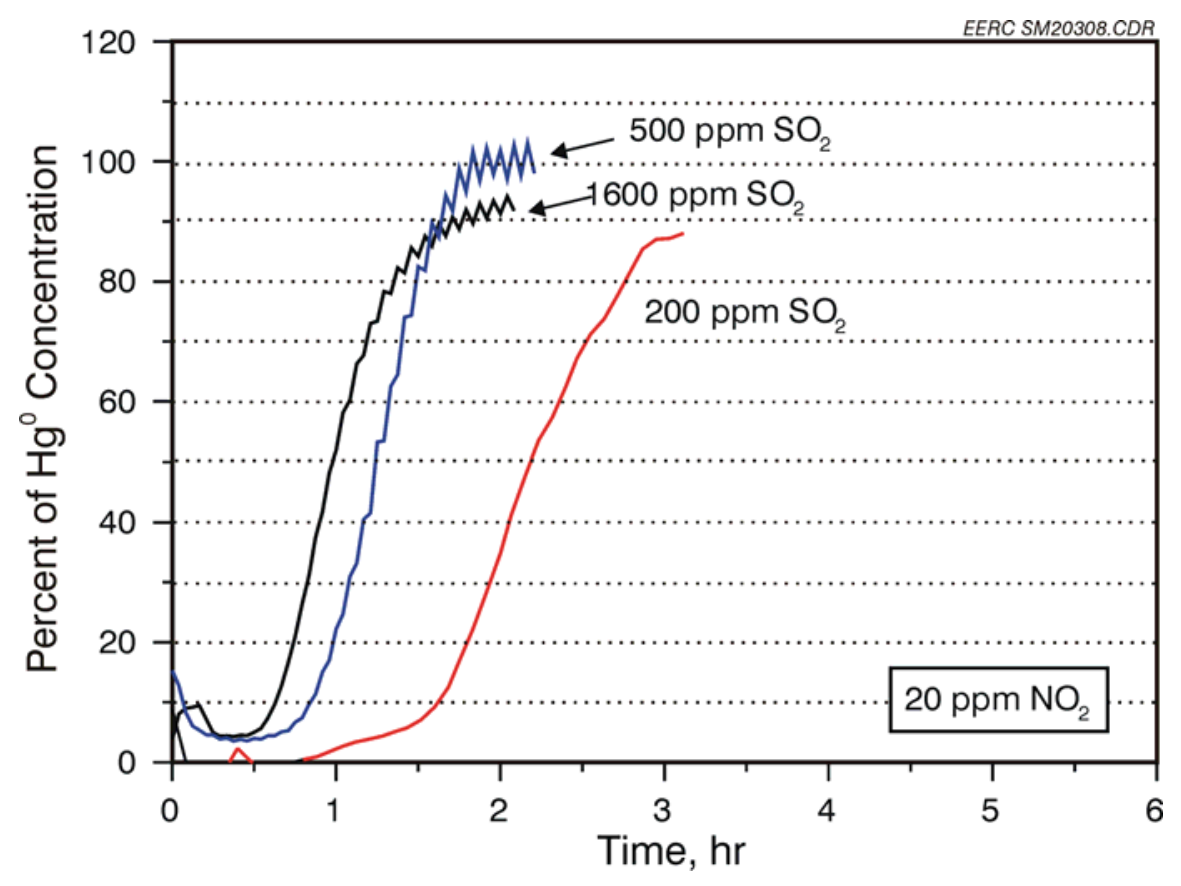

Figure 6.1.1.6. Mercury breakthrough curves at 20 ppm $\mathrm{NO}_{2}$ with varied $\mathrm{SO}_{2}: 200,500$, $1600 \mathrm{ppm}$.

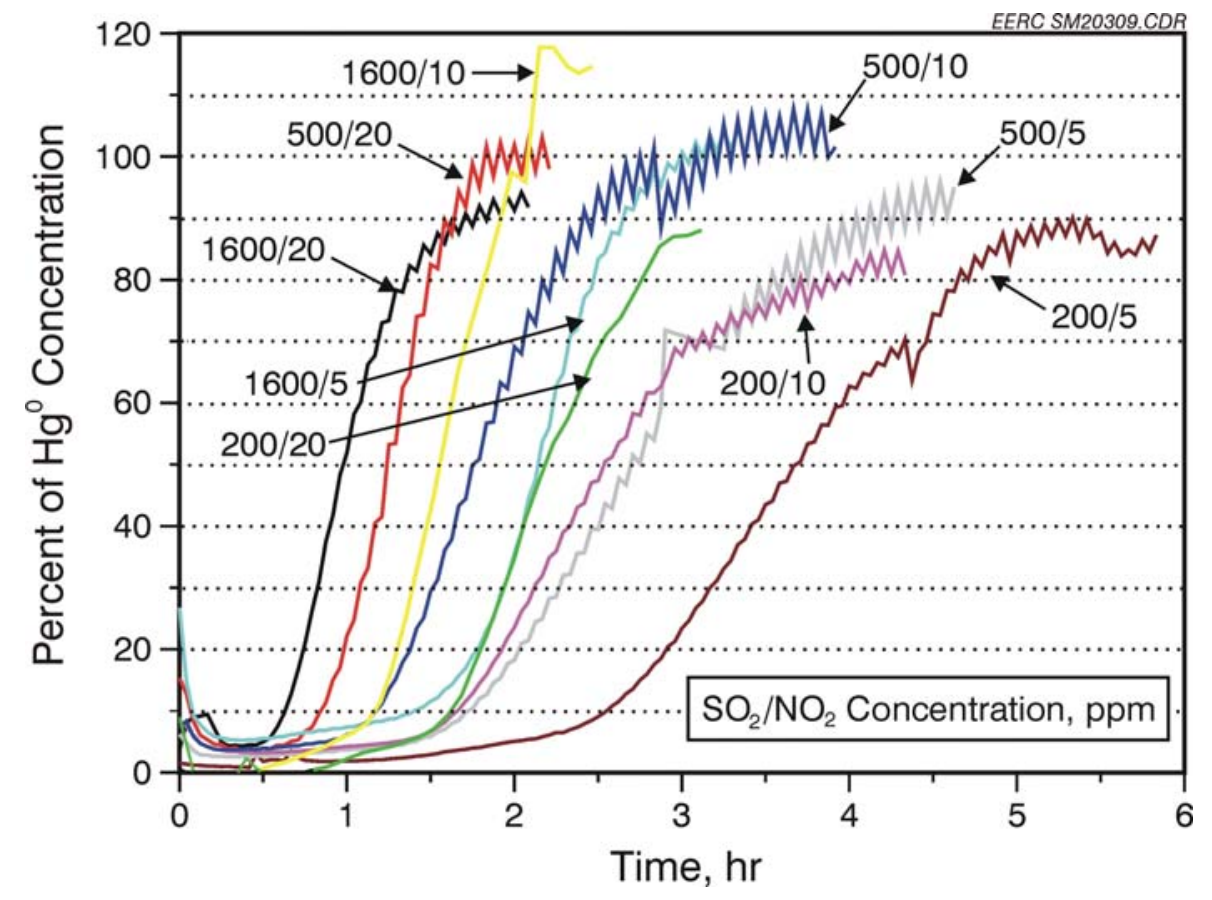

Figure 6.1.1.7. Summary of $\mathrm{Hg}$ breakthrough curves at varied $\mathrm{NO}_{2}$ and $\mathrm{SO}_{2}$. 
$\mathrm{SO}_{2}$ and $\mathrm{NO}_{2}$ concentrations, the data suggest that effective elemental mercury control would be difficult to achieve at a reasonable carbon-to-mercury ratio.

The second obvious $\mathrm{SO}_{2}$ and $\mathrm{NO}_{2}$ concentration effect is that at lower concentrations the slope of the breakthrough curves is more gradual. This suggests that there is some additional sorbent capacity available for the lower $\mathrm{SO}_{2}$ and $\mathrm{NO}_{2}$ concentrations. However, even at the very lowest concentrations tested, the time from initial breakthrough until $50 \%$ breakthrough was extended by only about $1 \mathrm{hr}$, which upon integration yielded only about a $20 \%$ increase in sorbent capacity.

A third conclusion from these tests is that both $\mathrm{SO}_{2}$ and $\mathrm{NO}_{2}$ concentration have a significant effect on breakthrough capacity and that the combined effect of both of these gases is additive, at least within the range of concentrations tested. These breakthrough tests are highly repeatable and appear to be quantitative to the extent that all of the midpoint tests fell between the respective low- and high-concentration test results.

These Series 1 tests are in agreement with previous bench-scale work conducted for other projects that shows the significance of $\mathrm{SO}_{2}$ and $\mathrm{NO}_{2}$ concentration on the elemental mercury capture ability of various sorbents (11). Most of the previous tests were completed with either a $\mathrm{HCl}$ concentration of $50 \mathrm{ppm}$, which would match a medium-chlorine bituminous coal, or with no $\mathrm{HCl}$. The effect of $\mathrm{NO}_{2}$ and $\mathrm{SO}_{2}$ concentration at much lower $\mathrm{HCl}$ levels of 1-5 ppm, which are more typical of WSB coals, has not previously been tested. While previous results have shown that higher $\mathrm{NO}_{2}$ and $\mathrm{SO}_{2}$ concentrations lead to poorer sorbent performance, the presence of $50 \mathrm{ppm} \mathrm{HCl}$ was shown to be beneficial to mercury capture. Even though low $\mathrm{SO}_{2}$ and $\mathrm{NO}_{2}$ concentrations with a subbituminous coal would be expected to result in good sorbent performance, the lower $\mathrm{HCl}$ may lead to poorer performance.

\subsubsection{Series 2 Bench-Scale Tests}

The second series of bench-scale tests was completed to evaluate FGD performance on mercury capture in a fixed-bed reactor using real coal combustion flue gases to compare to those obtained with simulated flue gases. The simulated flue gas concentrations were based on the actual concentrations measured in the combustion tests. The real flue gas tests were part of the pilot-scale tests in Task 3, using a slipstream bench-scale system sampling flue gas from the PTC. 
Table 6.1.2.1 lists a summary test matrix including the concentrations of key acid gases. A total of three bench-scale breakthrough tests were completed on three different days of operation using the real flue gas from a combustion of WSB coal with the 55-kW unit at the EERC. The simulated flue gas concentrations were set according to the actual measured concentrations from the coal-fired test. Table 6.1.2.2 lists the flue gas concentrations (in addition to the acid gases) for the breakthrough test. The real flue gas testing results are shown in Figure 6.1.2.1 along with the simulated flue gas testing data.

From Figure 6.1.2.1, the simulated flue gas testing data are in good agreement with the results upon exposure to real flue gas since the simulated flue gas curve is within the range of the three actual flue gas curves. The results are also in reasonable agreement with the case of nearest $\mathrm{SO}_{2}$ and $\mathrm{NO}_{2}$ concentrations (500 ppm $\mathrm{SO}_{2}$ and 5 ppm NO $\mathrm{N}_{2}$ ) from the Series 1 tests, even though the mercury concentration and speciation were somewhat different. For the Series 1 bench-scale tests, the mercury concentration was $15 \mu \mathrm{g} / \mathrm{m}^{3}$ of elemental mercury. The inlet mercury concentration from the pilot-scale tests averaged $11 \mu \mathrm{g} / \mathrm{m}^{3}$, with about $75 \%$ elemental mercury. For the comparative simulated bench-scale test from Series 2, the mercury was set at $10 \mu \mathrm{g} / \mathrm{m}^{3}$ but included only elemental mercury. Decreasing the mercury from 15 to $10 \mu \mathrm{g} / \mathrm{m}^{3}$ would be expected to extend the time until breakthrough by 50\%. For the Series 1 test at $500 \mathrm{ppm} \mathrm{SO}_{2}$ and 5 ppm $\mathrm{NO}_{2}$, breakthrough occurred after about $1.75 \mathrm{hr}$ (see Figure 6.1.1.4), and for the simulated Series 2 test, breakthrough occurred at about $2.25 \mathrm{hr}$. The $2.25 \mathrm{hr}$ is somewhat less than the $50 \%$ increase expected, but the lower $\mathrm{HCl}$ value for the Series 2 test may be the reason. Considering all of these effects, the simulated flue gas breakthrough curves appear to be in good agreement with results from real flue gas.

Table 6.1.2.1. Bench-Scale Series 2 - Real Flue Gas Comparison

\begin{tabular}{|c|c|c|c|c|c|c|c|c|}
\hline $\begin{array}{l}\text { Test } \\
\text { No. }\end{array}$ & $\begin{array}{c}\text { Sorbent } \\
\text { Type }\end{array}$ & $\begin{array}{l}\text { Temp., } \\
{ }^{\circ} \mathrm{C}\left({ }^{\circ} \mathrm{F}\right)\end{array}$ & $\begin{array}{c}\text { Sorbent } \\
\text { Concentration, mg }\end{array}$ & $\begin{array}{l}\text { Flue } \\
\text { Gas }\end{array}$ & $\begin{array}{l}\mathrm{SO}_{2} \\
\mathrm{ppm} \\
\end{array}$ & $\begin{array}{l}\mathrm{HCl}, \\
\mathrm{ppm}\end{array}$ & $\begin{array}{l}\mathrm{NO}, \\
\mathrm{ppm}\end{array}$ & $\begin{array}{l}\mathrm{NO}_{2}, \\
\mathrm{ppm}\end{array}$ \\
\hline$\overline{10}$ & FGD & $135(275)$ & 150 & Real & \multicolumn{4}{|c|}{ Flue gas from western coal } \\
\hline 11 & FGD & $135(275)$ & 150 & Real & \multicolumn{4}{|c|}{ Duplicate test of western coal } \\
\hline 12 & FGD & $135(275)$ & 150 & Real & \multicolumn{4}{|c|}{ Duplicate test of western coal } \\
\hline 13 & FGD & $135(275)$ & 150 & Simulated & 267 & 3 & 598 & 5 \\
\hline
\end{tabular}




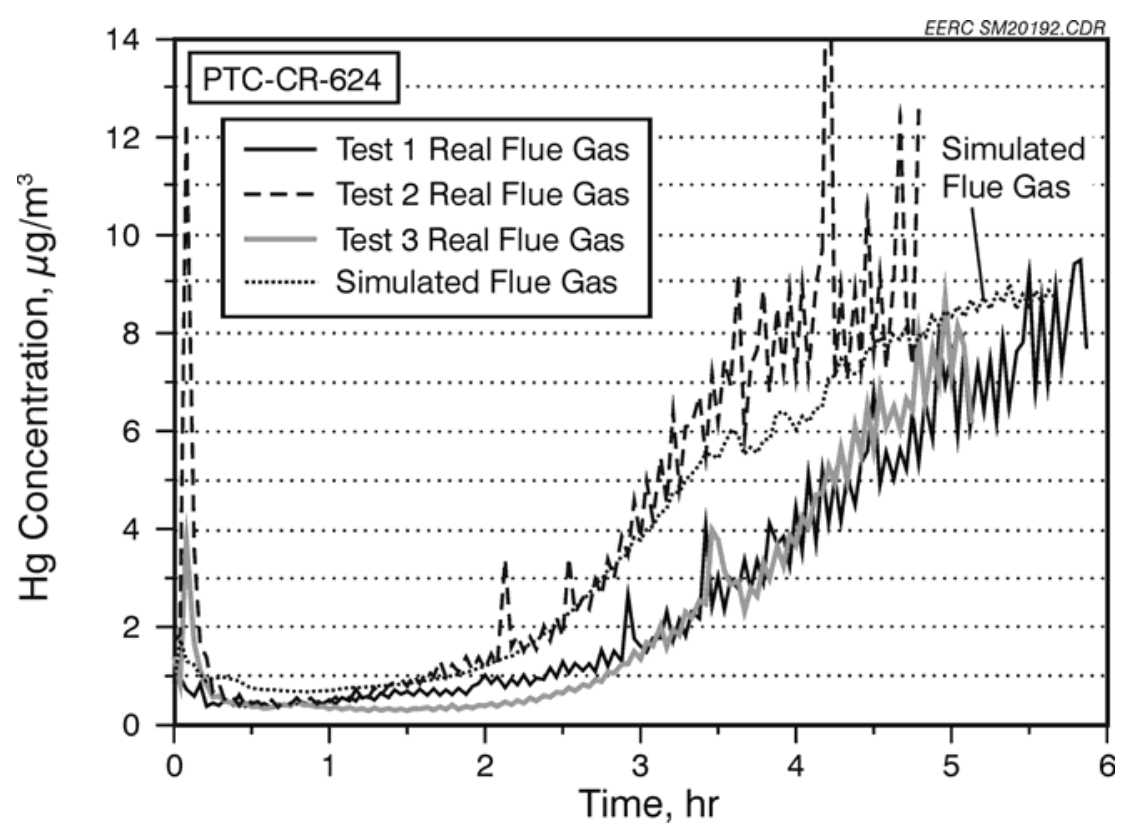

Figure 6.1.2.1. Real flue gas testing results.

Table 6.1.2.2. Flue Gas Concentrations for Bench-Scale Breakthrough Tests

\begin{tabular}{cc}
\hline $\mathrm{Hg}$ (total) & $10 \mu \mathrm{g} / \mathrm{m}^{3}$ \\
\hline $\mathrm{O}_{2}$ & $5 \%$ \\
$\mathrm{CO}_{2}$ & $12 \%$ \\
$\mathrm{H}_{2} \mathrm{O}$ & $10 \%$ \\
$\mathrm{~N}_{2}$ & Balance \\
\hline
\end{tabular}

\subsection{Experimental Results of the Pilot-Scale 55-kW (200-acfm) Advanced Hybrid ${ }^{\mathrm{TM}}$ Filter Unit at the EERC \\ 6.2.1 Summary of the Pilot-Scale Testing with the 55-kW (200-acfm) Advanced Hybrid $^{\mathrm{TM}}$ Unit}

Eight weeks of tests were completed with the 55-kW Advanced Hybrid ${ }^{\mathrm{TM}}$ filter pilot-scale unit at the EERC in this project. The primary goal was to evaluate the effectiveness of carbon injection on mercury control with the Advanced Hybrid ${ }^{\mathrm{TM}}$ filter for both bituminous and subbituminous coal flue gases and compare the Advanced Hybrid ${ }^{\mathrm{TM}}$ filter performance with a PJBH. Operating parameters such as injection rate, injection mode, sorbent residence time, and corona current were evaluated to understand their impacts on mercury removal. Several alternate mercury control technologies including amended silicate developed by ADA, iodineimpregnated carbon by Barneby \& Sutcliffe, and pleated cartridge filter developed by W.L. Gore 
were tested in real coal combustion flue gases to determine their mercury removal efficiencies with the Advanced Hybrid ${ }^{\mathrm{TM}}$ filter. Cofiring TDF and coal along with FGD carbon injection was tested to evaluate the beneficial effect of TDF cofiring on mercury control with the Advanced Hybrid $^{\mathrm{TM}}$ filter. At the end of this project, an added pilot-scale test was completed to evaluate mercury capture on the perforated plates of the Advanced Hybrid ${ }^{\mathrm{TM}}$ filter. Table 6.2.1 summarizes the 8 weeks of testing at the EERC.

\subsubsection{PTC-CR-624}

\subsubsection{Test Conditions}

A 4-day test was completed January 7-10, 2002, with the EERC PTC and pilot-scale 55-kW (200-acfm) Advanced Hybrid ${ }^{\mathrm{TM}}$ filter. The run was designated as PTC-CR-624, where CR refers to the Cordero Rojo Complex Powder River Basin (PRB) subbituminous coal burned in this test, which was the same coal burned at the Big Stone Power Plant during November 2001. The system was continuously operated during the 4-day test to provide baseline mercury speciation data for WSB flue gas with both the Advanced Hybrid ${ }^{\mathrm{TM}}$ filter and a PJBH, with several different cleaning cycle configurations. The test also provided real flue gas for some of the bench-scale tests.

In the Day 1 test, the Advanced Hybrid ${ }^{\mathrm{TM}}$ filter was set at 4.0-mA corona current with a 30-min bag-cleaning interval. During this time period, the perforated plates, electrodes, and outside wall collection surface were rapped every $30 \mathrm{~min}$, and the hopper ash was also emptied once per 30 min to maintain the ash at a constant residence time level.

The unit was switched to pulsing upon reaching a pressure drop of $2.0 \mathrm{kPa}(8.0 \mathrm{in}$. W.C.) in Days 2 and 3, while the current level was still kept at $4.00 \mathrm{~mA}$. The bag-cleaning intervals increased to $4-6 \mathrm{hr}$ as the result of pulse cleaning at $2.0 \mathrm{kPa}(8.0 \mathrm{in}$. W.C.) of pressure drop across the filter bags. During the test period, the hopper ash was emptied twice, providing approximately 17-22 $\mathrm{hr}$ of residence time of ash in the system.

The unit was next operated in a pulse-jet mode with a pulse trigger pressure of $2.0 \mathrm{kPa}$ (8.0 in. W.C.). Because of the high $\mathrm{A} / \mathrm{C}$ ratio of $3.7 \mathrm{~m} / \mathrm{min}(12 \mathrm{ft} / \mathrm{min})$ and no electric field to precollect any of the dust, the bag-cleaning interval was only $3 \mathrm{~min}$. The hopper ash was emptied once every $30 \mathrm{~min}$. 
Table 6.2.1. Pilot-Scale Testing

\begin{tabular}{|c|c|c|c|c|c|c|}
\hline Week/ & & & Collection & & $\mathrm{C}: \mathrm{Hg}$ & Injection \\
\hline Test & Purpose & Coal & Device & Sorbent Type & Ratio & Method \\
\hline $1-1$ & Baseline & WSB & PJBH & None & $\mathrm{NA}^{1}$ & NA \\
\hline $1-2$ & Baseline & WSB & $\begin{array}{l}\text { Advanced } \\
\text { Hybrid } \\
\text { filter }\end{array}$ & None & NA & NA \\
\hline $2-1$ & Baseline & EB & PJBH & None & NA & NA \\
\hline $2-2$ & Baseline & EB & $\begin{array}{l}\text { Advanced } \\
\text { Hybrid } \\
\text { filter }\end{array}$ & None & NA & NA \\
\hline $3-1$ & Hg capture, collection device & WSB & PJBH & FGD & $3000^{2}$ & Continuous \\
\hline $3-2$ & Hg capture, collection device & WSB & $\begin{array}{c}\text { Advanced } \\
\text { Hybrid } \\
\text { filter }\end{array}$ & FGD & $3000^{2}$ & Continuous \\
\hline $4-1$ & Hg capture, residence time & WSB & $\begin{array}{l}\text { Advanced } \\
\text { Hybrid } \\
\text { filter }\end{array}$ & FGD & $3000^{2}$ & Continuous \\
\hline $4-2$ & Hg capture, residence time & WSB & $\begin{array}{c}\text { Advanced } \\
\text { Hybrid } \\
\text { filter }\end{array}$ & FGD & $3000^{2}$ & Batch \\
\hline $5-1$ & Hg capture, residence time & EB & $\begin{array}{l}\text { Advanced } \\
\text { Hybrid }^{\mathrm{TM}} \\
\text { filter }\end{array}$ & FGD & $3000^{2}$ & Continuous \\
\hline $5-2$ & Hg capture, residence time & EB & $\begin{array}{l}\text { Advanced } \\
\text { Hybrid } \\
\text { filter }\end{array}$ & FGD & $3000^{2}$ & Batch \\
\hline $6-1$ & $\begin{array}{l}\text { Sorbent type and } \\
\text { concentration }\end{array}$ & WSB & $\begin{array}{c}\text { Advanced } \\
\text { Hybrid } \\
\text { filter }\end{array}$ & $\begin{array}{c}\text { TDF } \\
\text { cofiring /FGD }\end{array}$ & $3000^{2}$ & Continuous \\
\hline $6-2$ & $\begin{array}{l}\text { Sorbent type and } \\
\text { concentration }\end{array}$ & WSB & $\begin{array}{l}\text { Advanced } \\
\text { Hybrid }^{\mathrm{TM}} \\
\text { filter }\end{array}$ & IAC & $3000^{2}$ & Continuous \\
\hline 7 & $\begin{array}{l}\text { Sorbent type and } \\
\text { concentration }\end{array}$ & WSB & $\begin{array}{l}\text { Advanced } \\
\text { Hybrid } \\
\text { filter }\end{array}$ & Gore $^{3}$ & NA & NA \\
\hline $8^{4}$ & Plate capture vs. total capture & WSB & $\begin{array}{l}\text { Advanced } \\
\text { Hybrid } \\
\text { filter }\end{array}$ & FGD & $3000^{2}$ & Continuous \\
\hline
\end{tabular}

${ }^{1}$ Not applicable.

${ }^{2}$ Nominal concentrations; actual concentrations were varied for specific tests.

${ }^{3}$ Bag insert within the Advanced Hybrid ${ }^{\mathrm{TM}}$ filter.

${ }^{4}$ Newly added test. 
Table 6.2.2.1. Summary of Mercury, Gas, and Solids Samples Taken

Ontario Hydro

Day 1 - One pair of simultaneous inlet and outlet

Days 2-4 - Two pairs of simultaneous inlet and outlet

Method 101A

Day 1 - One pair of simultaneous inlet and outlet

$\mathrm{HCl}$

Two Method 26A inlet samples on Days 2 and 4

$\mathrm{SO}_{2}, \mathrm{NO}, \mathrm{NO}_{2}, \mathrm{CO}, \mathrm{CO}_{2}, \mathrm{O}_{2}$

Sampling at both inlet and outlet with portable Ecom gas analyzer Days 2 and 4

Coal

One sample a day

Advanced Hybrid ${ }^{\mathrm{TM}}$ filter hopper ash

One sample a day

Table 6.2.2.1 summarizes the sampling schedule for mercury, hopper ash, and flue gases. During the Day 1 test, one pair of Method 101A and one pair of Ontario Hydro measurements were completed at the Advanced Hybrid ${ }^{\mathrm{TM}}$ filter inlet and outlet. A total of four Ontario Hydro mercury measurements were taken for each day during the rest of the test.

\subsubsection{Coal and Flue Gas Analyses}

Approximate $2485 \mathrm{~kg}(5478 \mathrm{lb})$ of Cordero Rojo Complex was burned during the 4-day test. Table 6.2.2.2 shows the proximate and ultimate analysis results of the coal samples collected during the test. The mercury content in the raw coal samples (also listed in Table 6.2.2.2) had a mean value of $0.108 \mu \mathrm{g} / \mathrm{g}$. From a combustion calculation based on the proximate and ultimate analysis results, the coal should produce $2.74 \mathrm{scm}$ (96.8 acf) of dry flue gas per $\mathrm{lb}$ normalized to $3.0 \%$ oxygen, which corresponds to a theoretical inlet mercury concentration of $13.4 \mu \mathrm{g} / \mathrm{m}^{3}$ of dry flue gas at $3.0 \% \mathrm{O}_{2}$. The theoretical inlet mercury value is somewhat higher than the 9.2 to $12.1 \mu \mathrm{g} / \mathrm{m}^{3}$ inlet total mercury concentrations measured by the Ontario Hydro method. Possible reasons for the small difference are discussed later in this report.

Table 6.2.2.3 lists daily averaged flue gas compositions of $\mathrm{O}_{2}, \mathrm{CO}_{2}, \mathrm{CO}, \mathrm{NO}, \mathrm{NO}_{2}$, and $\mathrm{SO}_{2}$. Because of the low-sulfur Cordero Rojo coal, the $\mathrm{SO}_{2}$ concentration in the flue gas was at a low level, ranging from 260 to $330 \mathrm{ppm}$. The $\mathrm{NO}$ and $\mathrm{NO}_{2}$ concentrations in the flue gas were 549-695 ppm for $\mathrm{NO}$ and only 4-7 ppm for $\mathrm{NO}_{2}$, respectively. The $\mathrm{O}_{2}$ concentration was slightly increased from the inlet to the outlet because of minor air leakage in the system. Two EPA Method 26 samples were collected at the Advanced Hybrid ${ }^{\mathrm{TM}}$ filter inlet at Days 2 and 4 to determine $\mathrm{HCl}$ concentration in flue gas, and the results are shown in Table 6.2.2.3. 
Table 6.2.2.2. Coal Analysis for the PTC-CR-624 Test

\begin{tabular}{lcc}
\hline & As Sampled & Moisture-Free \\
\hline Proximate Analysis, wt $\%$ & & \\
Moisture Content & 23.1 & NA \\
Volatile Matter & 36.43 & 47.37 \\
Fixed Carbon & 35.42 & 46.06 \\
Ash & 5.05 & 6.57 \\
Ultimate Analysis, wt $\%$ & & \\
Hydrogen & 6.12 & 4.62 \\
Carbon & 52.53 & 68.31 \\
Nitrogen & 0.78 & 1.02 \\
Sulfur & 0.24 & 0.31 \\
Oxygen & 35.27 & 19.17 \\
Ash & 5.05 & 6.57 \\
Heating Value, Btu/lb & 9023 & 11,733 \\
Chlorine in Coal, dry basis, $\mu \mathrm{g} / \mathrm{g}$ & & 14.7 \\
Mercury in Coal, dry basis, $\mu \mathrm{gg} / \mathrm{g}$ & & 0.114 \\
Days 1-3 & & 0.103 \\
Day 4 & & 0.108 \\
Mean & & \\
\hline
\end{tabular}

\subsubsection{Mercury Species in Cordero Rojo Complex Flue Gas and Mercury \\ Transformation Across the Advanced Hybrid ${ }^{\mathrm{TM}}$ filter/PJBH Unit}

Mercury concentrations in the flue gas were normalized to a moisture-free basis and $3 \% \mathrm{O}_{2}$ level. Figure 6.2.2.1 shows speciated mercury concentrations in the flue gas at the Advanced Hybrid $^{\mathrm{TM}}$ filter inlet and outlet when the unit was operated under Advanced Hybrid ${ }^{\mathrm{TM}}$ filter mode, with a 30-min bag-cleaning interval. The collection plates and electrodes were rapped every $30 \mathrm{~min}$, and the hopper ash was also emptied every half hour during the testing period to keep the residence time of the fly ash in the chamber to a maximum of $30 \mathrm{~min}$. At the Advanced

Table 6.2.2.3. Summary of Flue Gas Compositions During PTC-CR-624 Sampling, dry basis

\begin{tabular}{llccccccc}
\hline & & $\mathrm{O}_{2}, \%$ & $\mathrm{CO}_{2}, \%$ & $\mathrm{CO}, \mathrm{ppm}$ & $\mathrm{NO}, \mathrm{ppm}$ & $\mathrm{NO}_{2}, \mathrm{ppm}$ & $\mathrm{SO}_{2}, \mathrm{ppm}$ & $\mathrm{HCl}, \mathrm{ppm}$ \\
\hline Day 1 & In & 4.5 & 13.4 & 7.0 & 653 & - & 299 & - \\
& Out & 5.2 & - & - & 601 & - & 269 & - \\
Day 2 & In & 4.4 & 14.7 & 6.6 & 693 & 4 & 306 & 3.4 \\
& Out & 5.2 & - & - & 614 & 3 & 267 & \\
Day 3 & In & 4.6 & 15.1 & 37.1 & 695 & - & 293 & - \\
& Out & 5.3 & & & 624 & - & 260 & - \\
Day 4 & In & 4.4 & 15.1 & 43.5 & 630 & 5 & 331 & 2.4 \\
& Out & 5.1 & - & - & 549 & 7 & 271 & - \\
\hline
\end{tabular}




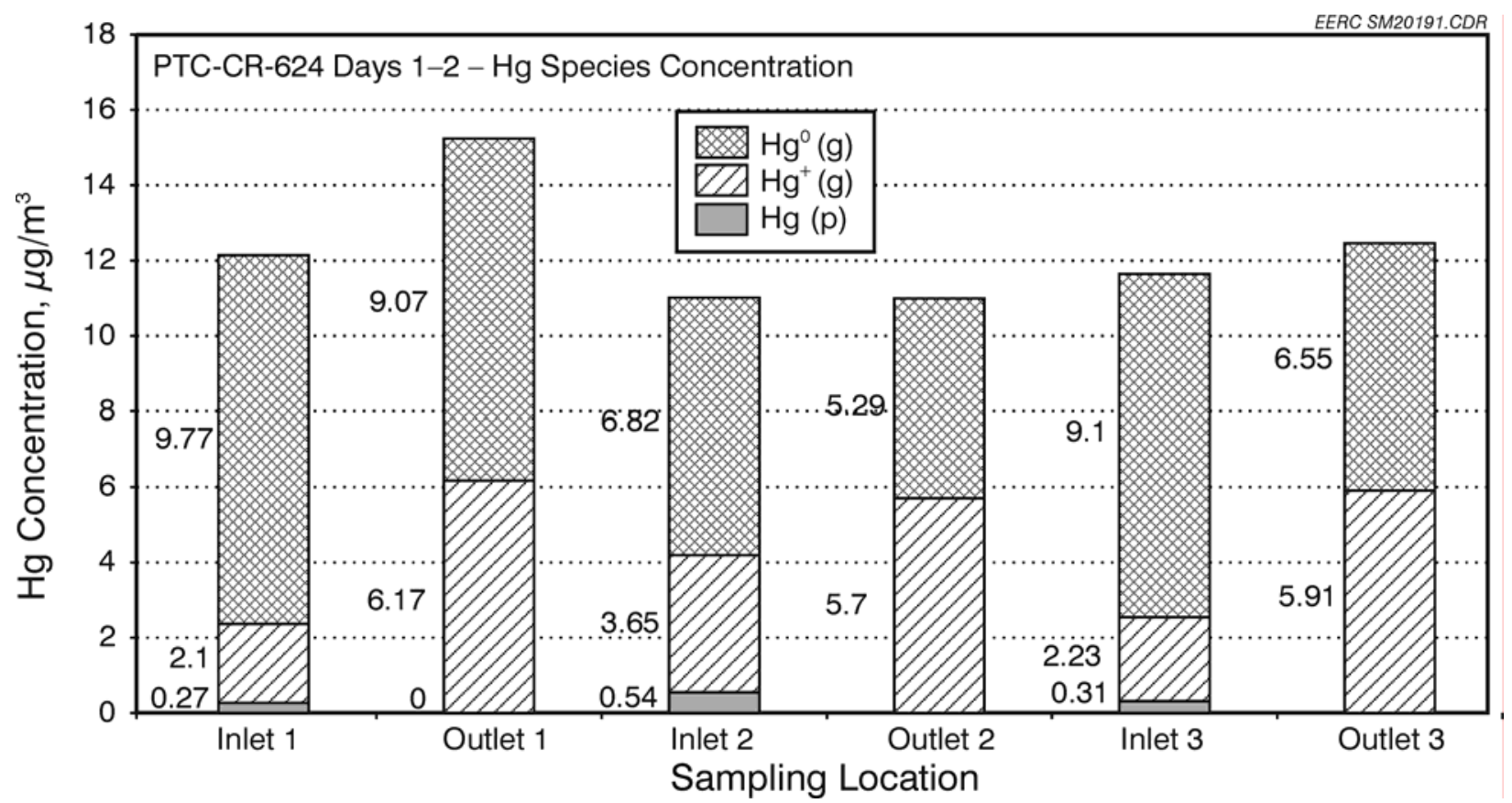

Figure 6.2.2.1. Speciated mercury concentrations in flue gas at the Advanced Hybrid ${ }^{\mathrm{TM}}$ filter inlet and outlet.

Hybrid $^{\mathrm{TM}}$ filter inlet, oxidized mercury vapor varied from 2.1 to $3.7 \mu \mathrm{g} / \mathrm{m}^{3}$, while the elemental mercury vapor was in the range of $6.8-9.8 \mu \mathrm{g} / \mathrm{m}^{3}$. Mercury species associated with particulate was at a low level, ranging from $0.3-0.5 \mu \mathrm{g} / \mathrm{m}^{3}$. There was no particulate-associated mercury at the Advanced Hybrid ${ }^{\mathrm{TM}}$ filter outlet flue gas because of the excellent fly ash capture efficiency of the Advanced Hybrid ${ }^{\mathrm{TM}}$ filter. The total gas-phase mercury was the same for both the Advanced Hybrid $^{\mathrm{TM}}$ filter inlet and outlet. However, the oxidized mercury vapor concentration at the Advanced Hybrid ${ }^{\mathrm{TM}}$ filter outlet was higher than the corresponding oxidized mercury at the Advanced Hybrid ${ }^{\mathrm{TM}}$ filter inlet, indicating additional mercury oxidation across the Advanced Hybrid $^{\mathrm{TM}}$ filter unit.

To better clarify the transformation of mercury species across the Advanced Hybrid ${ }^{\mathrm{TM}}$ filter unit, the average normalized mercury species concentrations at the Advanced Hybrid ${ }^{\mathrm{TM}}$ filter inlet are plotted in Figure 6.2.2.2, showing 75.3\% of elemental mercury, 21.7\% of oxidized mercury vapor, and only $3.0 \%$ of fly ash-associated mercury. Since the particulate collection efficiency of the Advanced Hybrid ${ }^{\mathrm{TM}}$ filter was $99.99 \%$, the mercury associated with the inlet fly 


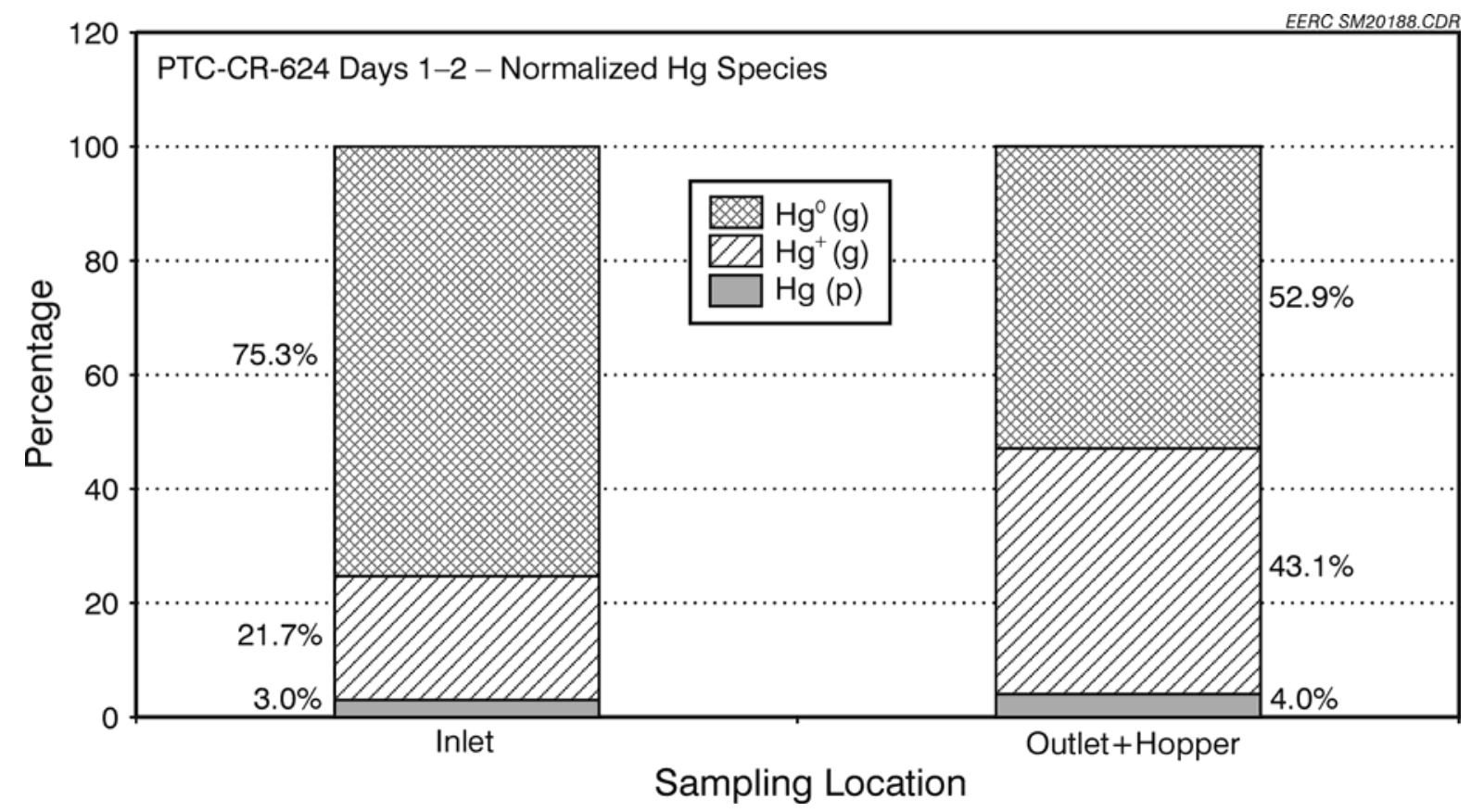

Figure 6.2.2.2. Normalized mercury species at the Advanced Hybrid ${ }^{\mathrm{TM}}$ filter inlet and outlet.

ash was all collected in the hopper. The mercury in the hopper ash was analyzed for comparison with mercury concentration on the Ontario Hydro inlet sampling filters (Table 6.2.2.4). The hopper ash mercury was added to the outlet vapor species and normalized to $100 \%$ for comparison with the inlet (Figure 6.2.2.2). Results show there was an increase in oxidized mercury from $21.7 \%$ to $43.1 \%$ across the Advanced Hybrid ${ }^{\mathrm{TM}}$ filter, while there was a

Table 6.2.2.4. Mercury Concentration in Fly Ash

\begin{tabular}{lccc}
\hline Test Day & Sample Type & Time of Sampling & Hg Concentration, $\mu \mathrm{g} / \mathrm{g}$ \\
\hline Day 1 & Inlet filter & $15: 05-16: 05$ & 0.0595 \\
Day 1 & Inlet filter & $16: 37-17: 37$ & 0.0581 \\
Day 2 & Inlet filter & $11: 00-13: 00$ & 0.109 \\
Day 2 & Inlet filter & $15: 00-17: 00$ & 0.0653 \\
Day 2 & Hopper ash & $17: 00$ & 0.102 \\
Day 3 & Inlet filter & $9: 10-11: 10$ & 0.0311 \\
Day 3 & Inlet filter & $12: 17-14: 17$ & 0.148 \\
Day 3 & Hopper ash & $15: 06$ & 0.182 \\
Day 4 & Inlet filter & $10: 17-12: 17$ & 0.396 \\
Day 4 & Inlet filter & $14: 00-16: 00$ & 0.025 \\
Day 4 & Hopper ash & $19: 30$ & 0.337 \\
Day 4 & Outlet filter & $10: 17-12: 17$ & 0.944 \\
Day 4 & Outlet filter & $14: 00-16: 00$ & 0.233 \\
\hline
\end{tabular}


corresponding decrease in elemental mercury from $75.3 \%$ at the inlet to $52.9 \%$ at the outlet. The results clearly demonstrate that elemental mercury vapor was oxidized across the Advanced Hybrid $^{\mathrm{TM}}$ filter, but very little was captured by the fly ash.

For the Day 3 sampling test, the unit was operated in Advanced Hybrid ${ }^{\mathrm{TM}}$ filter mode with a $2.0-\mathrm{kPa}$ (8.0-in. W.C.) pulse trigger pressure, resulting in longer bag-cleaning intervals ranging from 4 to $6 \mathrm{hr}$. The hopper ash was emptied twice during the testing period, providing approximately 17-22 $\mathrm{hr}$ of residence time of fly ash in the system. Results of two pairs of Ontario Hydro samples collected at the Advanced Hybrid ${ }^{\mathrm{TM}}$ filter inlet and outlet are plotted in Figure 6.2.2.3. The total mercury vapor concentrations at the Advanced Hybrid ${ }^{\mathrm{TM}}$ filter inlet and outlet were at the same level, showing no capture of mercury vapor across the Advanced Hybrid ${ }^{\mathrm{TM}}$ filter unit and a complete removal of mercury associated with fly ash. Again, mercury oxidation occurred across the Advanced Hybrid ${ }^{\mathrm{TM}}$ filter unit.

Figure 6.2.2.4 plots normalized mercury species distributions across the Advanced Hybrid ${ }^{\mathrm{TM}}$ filter unit. The inlet mercury species were $75.4 \%$ elemental mercury, $20.8 \%$ oxidized mercury vapor, and 3.8\% fly ash-associated mercury. The inlet mercury species distribution for the Day 3 test agrees very well with the results obtained for the Day 1-2 test. In the flue gas out

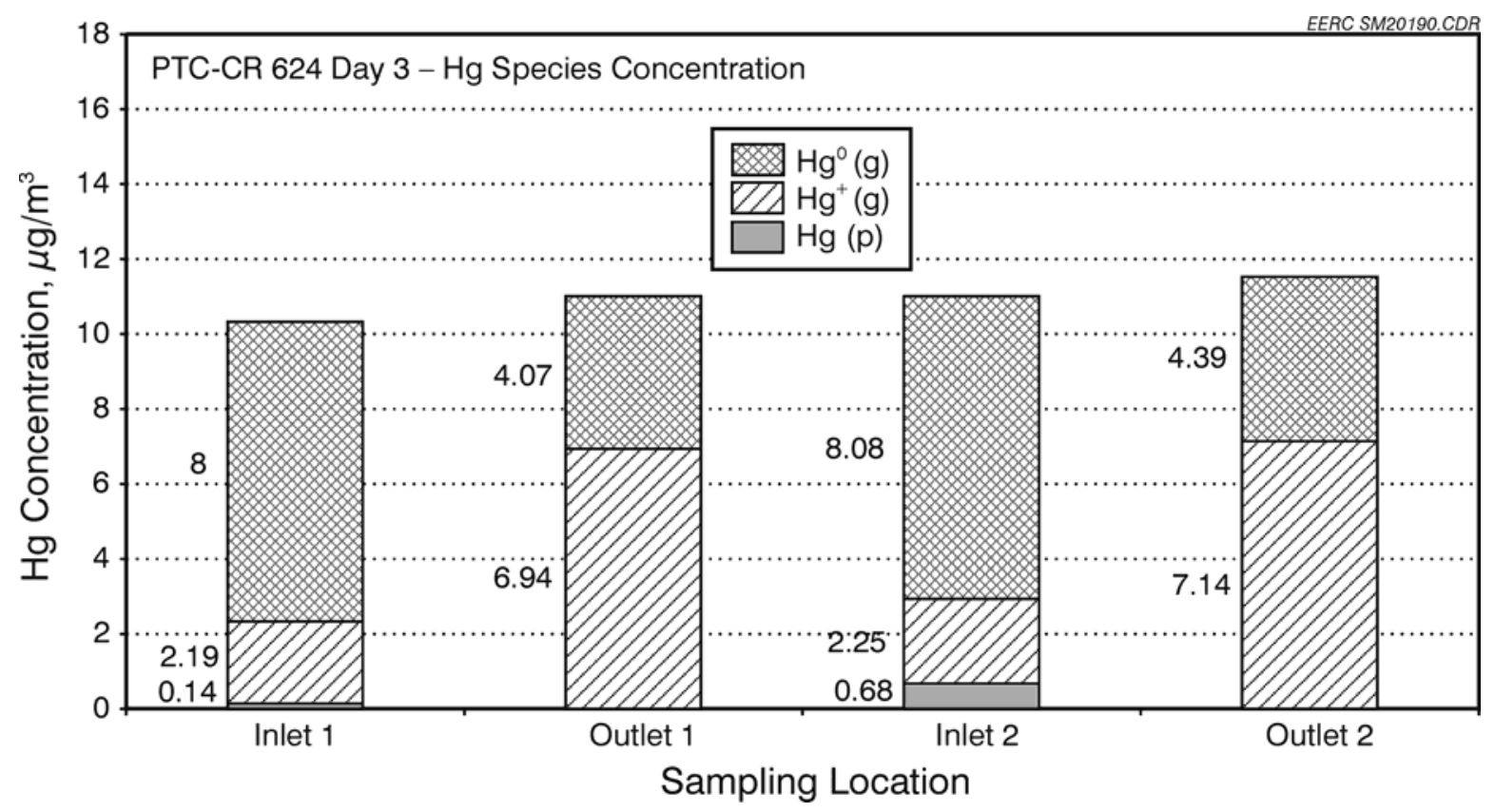

Figure 6.2.2.3. Speciated mercury concentration at the Advanced Hybrid ${ }^{\mathrm{TM}}$ filter inlet and outlet in longer residence time test. 


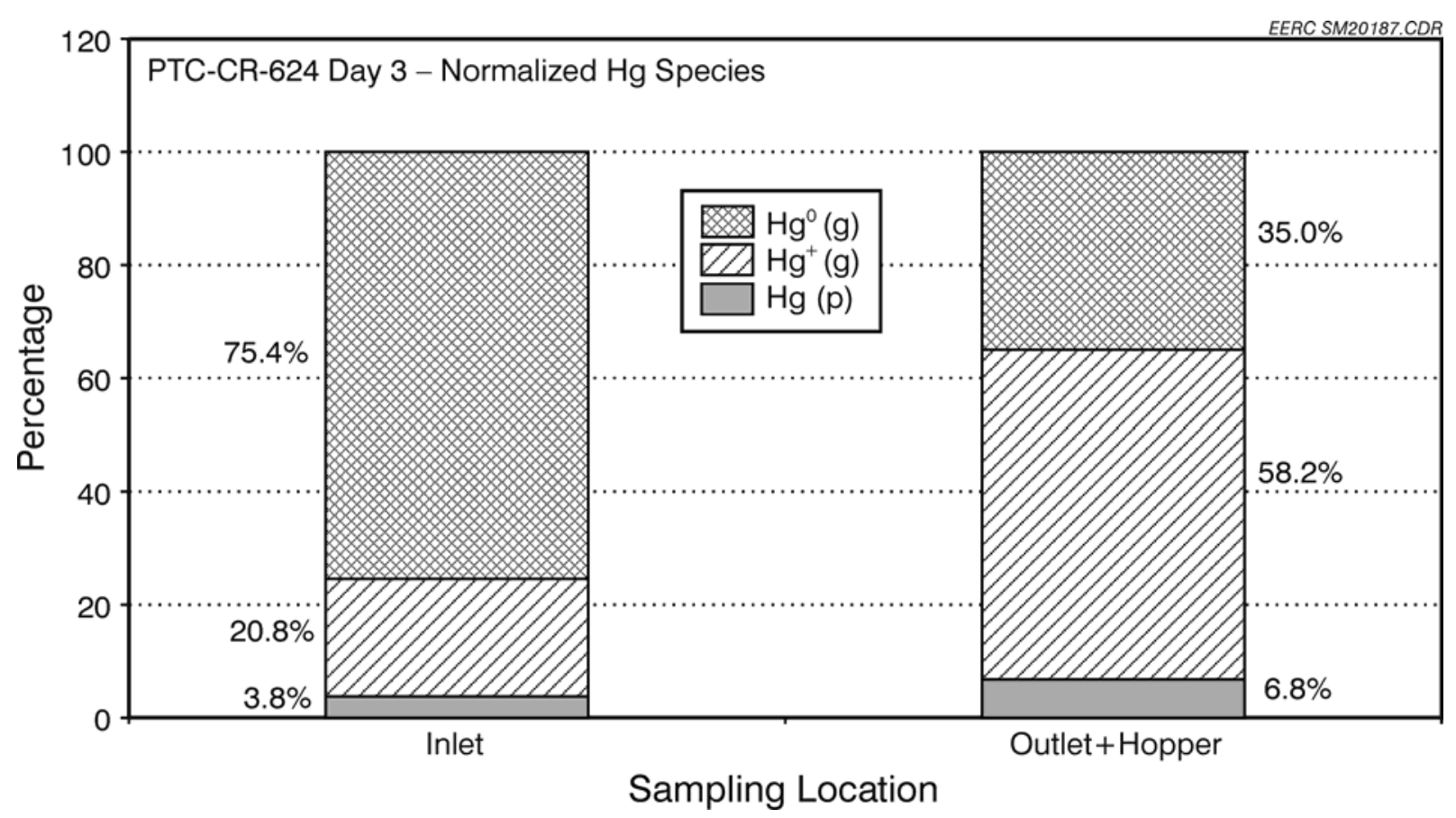

Figure 6.2.2.4. Normalized mercury species distributions across the Advanced Hybrid ${ }^{\mathrm{TM}}$ filter unit in longer residence time test.

of the Advanced Hybrid ${ }^{\mathrm{TM}}$ filter unit, only $35.0 \%$ of the total mercury vapor was in the elemental state, compared to the $52.9 \%$ measured for the Day 1-2 test. The oxidized mercury, on the other hand, increased to $58.2 \%$. The mercury concentration associated with fly ash also increased slightly from $3.8 \%$ at the inlet to $6.8 \%$. The accumulated hopper ash along with the extended residence time of fly ash in the Advanced Hybrid ${ }^{\mathrm{TM}}$ filter unit may have promoted the increased mercury vapor oxidation compared to the Day 1-2 test, where the residence time was limited to $30 \mathrm{~min}$.

The Advanced Hybrid ${ }^{\mathrm{TM}}$ filter unit was then operated as a PJBH (no high-voltage power) for the Day 4 test. The high $\mathrm{A} / \mathrm{C}$ ratio of $3.7 \mathrm{~m} / \mathrm{min}(12 \mathrm{ft} / \mathrm{min})$ resulted in frequent bag pulse cleaning every 3 min caused by the high dust loading to the filter bags and severe fly ash reentrainment. The hopper ash was also emptied every half hour to keep a 30-min maximum residence time of fly ash in the system. The measured mercury species concentrations at the Advanced Hybrid ${ }^{\mathrm{TM}}$ filter inlet and outlet are plotted in Figure 6.2.2.5. The mercury species concentrations at the Advanced Hybrid ${ }^{\mathrm{TM}}$ filter inlet during this testing period showed more 


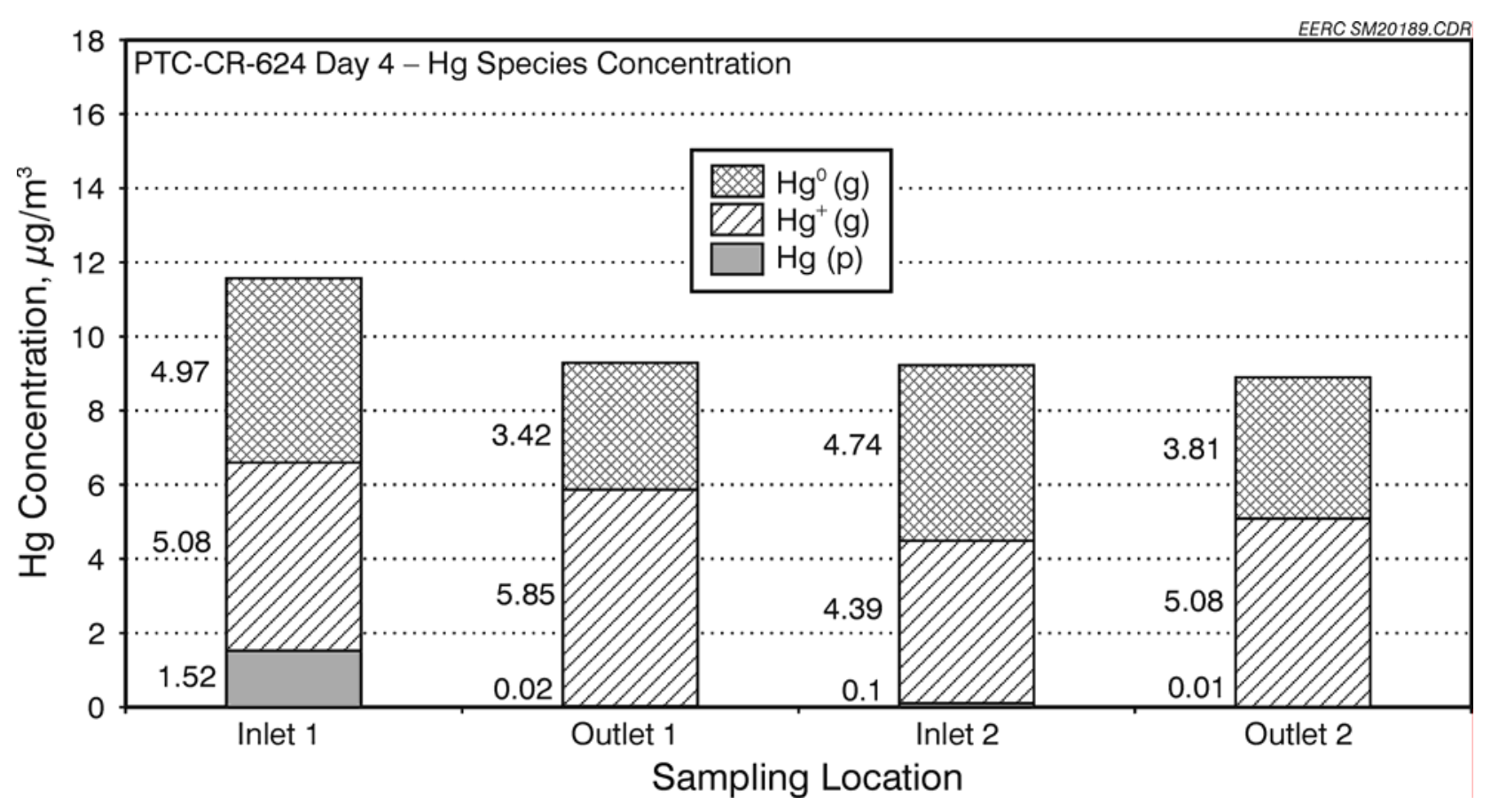

Figure 6.2.2.5. Speciated mercury concentrations at the PJBH inlet and outlet.

oxidized mercury than the previous tests. Because of the frequent bag-cleaning pulsing, a fraction of ultrafine fly ash was measured at the Advanced Hybrid ${ }^{\mathrm{TM}}$ filter outlet. The ultrafine ash was also analyzed for mercury. However, based on the measured dust loading at the Advanced Hybrid ${ }^{\mathrm{TM}}$ filter outlet, mercury associated with fly ash was only $0.01-0.1 \mu \mathrm{g} / \mathrm{m}^{3}$, indicating a very low emission level of particulate mercury.

The normalized mercury distributions at the inlet and outlet plotted in Figure 6.2.2.6 show an increase of oxidized mercury across the PJBH, but not to the extent of the increase noted in either the short-residence-time Advanced Hybrid ${ }^{\mathrm{TM}}$ filter test (Figure 6.2.2.2) or the longresidence-time Advanced Hybrid ${ }^{\mathrm{TM}}$ filter test (Figure 6.2.2.4). However, since the inlet oxidized mercury fraction was higher for the pulse-jet test, no conclusion can be drawn as to the reason. Some variation in inlet speciation is typically seen with the Ontario Hydro method, and the differences seen may simply be the effect of that variability. The data indicate no significant difference between the PJBH and the Advanced Hybrid ${ }^{\mathrm{TM}}$ filter in the level of oxidation of mercury across the device or in the amount of mercury retained by the fly ash. 


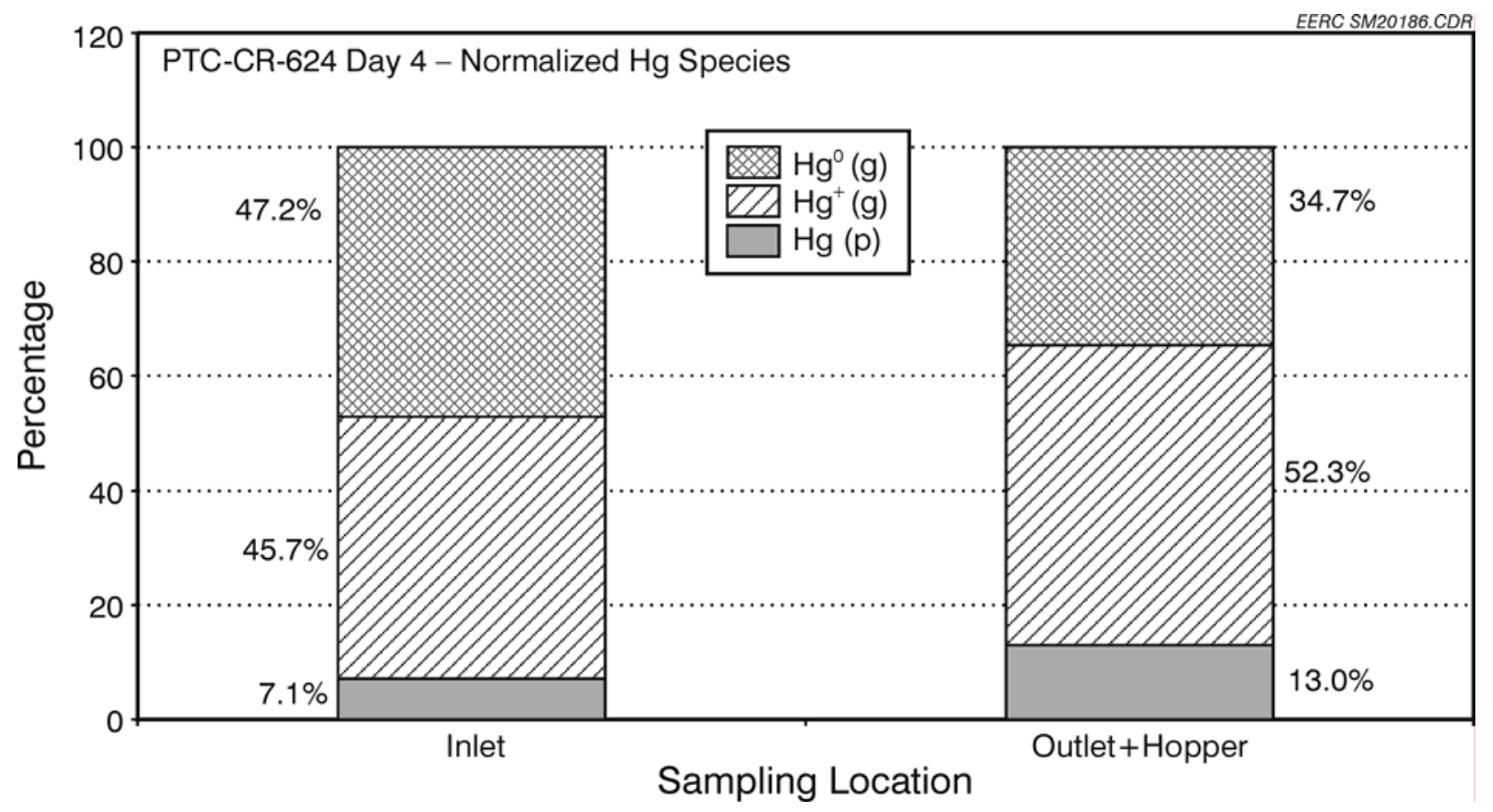

Figure 6.2.2.6. Normalized mercury species distribution across the PJBH.

A summary of Ontario Hydro method mercury analysis results during the 4-day test is listed in Table 6.2.2.5. The total mercury concentration in the flue gas (present as total mercury concentration at the Advanced Hybrid ${ }^{\mathrm{TM}}$ filter inlet) varied from 9.2 to $12.1 \mu \mathrm{g} / \mathrm{m}^{3}$, which is close to a theoretical value of $13.4 \mu \mathrm{g} / \mathrm{m}^{3}$ obtained from the coal combustion calculation based on the coal analysis. The slight difference may be the result of uncertainty in the mercury coal analysis as well as additional process variability.

A pair of Method 101A samples was taken at both the Advanced Hybrid ${ }^{\mathrm{TM}}$ filter inlet and outlet simultaneously in the Day 1 test. The goal was to compare Method 101A with the results from the Ontario Hydro method being performed on the same day. Method 101A provides information on mercury associated with fly ash and total concentration of mercury vapor in flue gas but cannot differentiate mercury species in the vapor phase. As shown in Table 6.2.2.6, mercury species were $11.3 \mu \mathrm{g} / \mathrm{m}^{3}$ of total mercury vapor and $0.3 \mu \mathrm{g} / \mathrm{m}^{3}$ of particulate mercury at the Advanced Hybrid ${ }^{\mathrm{TM}}$ filter inlet and $10.5 \mu \mathrm{g} / \mathrm{m}^{3}$ of mercury vapor at the outlet. The results agree with the data obtained from the Ontario Hydro method. 
Table 6.2.2.5. Summary of Ontario Hydro Mercury Results, dry flue gas at $3.0 \% \mathrm{O}_{2}\left(\mu \mathrm{g} / \mathrm{Nm}^{3}\right)$

\begin{tabular}{llcccc}
\hline & & $\mathrm{Hg}^{0}$ & $\mathrm{Hg}^{+}$ & $\mathrm{Hg}$ (particulate) & $\mathrm{Hg}$ (total) \\
\hline Day 1 & Inlet & 9.8 & 2.1 & 0.3 & 12.1 \\
& Outlet & 9.1 & 6.2 & 0.0 & 15.2 \\
& Inlet & 6.8 & 3.7 & 0.5 & 11.0 \\
Day 2 & & 9.1 & 2.2 & 0.3 & 11.6 \\
& Outlet & 5.3 & 5.7 & 0.0 & 11.0 \\
& & 6.6 & 5.9 & 0.0 & 12.5 \\
& Inlet & 8.0 & 2.2 & 0.1 & 10.3 \\
Day 3 & & 8.1 & 2.3 & 0.7 & 11.0 \\
& Outlet & 4.1 & 6.9 & 0.0 & 11.0 \\
& & 4.4 & 7.1 & 0.0 & 11.5 \\
Day 4 & Inlet & 5.0 & 5.1 & 1.5 & 9.2 \\
& & 4.7 & 4.4 & 0.1 & 9.3 \\
& & 3.4 & 5.9 & 0.0 & 8.9 \\
\hline
\end{tabular}

Day 1 - Advanced Hybrid ${ }^{\mathrm{TM}}$ filter mode, 30-min bag-cleaning interval.

Day 2 - Advanced Hybrid ${ }^{\mathrm{TM}}$ filter mode, 30-min bag-cleaning interval.

Day 3 - Advanced Hybrid ${ }^{\mathrm{TM}}$ filter mode, 8.0-in. W.C. (2.0-kPa) pulse trigger pressure.

Day 4 - Pulse-jet mode, 8.0-in. W.C. (2.0-kPa) pulse trigger pressure.

\subsubsection{Particulate Matter Collection Efficiencies for the Advanced Hybrid ${ }^{\mathrm{TM}}$ Filter and $\mathrm{PJBH}$}

Since the Ontario Hydro method uses isokinetic sampling to measure mercury concentration in fly ash particles, it also provides information on the dust loading in the flue gas. Table 6.2.2.7 lists the measured dust loadings at the Advanced Hybrid ${ }^{\mathrm{TM}}$ filter inlet and outlet and the calculated particle collection efficiencies across the system. The overall particle collection efficiency varied from $99.984 \%$ to $99.996 \%$ during the first 3 days, showing excellent capture of fly ash particles in the Advanced Hybrid ${ }^{\mathrm{TM}}$ filter mode for both a short bag-cleaning interval (30 $\mathrm{min})$ and a long bag-cleaning interval (4-6 hr). When the unit was operated in pulsejet mode for the Day 4 test, the overall particle collection efficiency was reduced to $99.0 \%-$ $99.52 \%$. The reason is that the unit was experiencing frequent pulsing (every 3 min), which caused a high particle penetration through the filter bags as a result of a short particle emission spike after each pulse. The results confirm the Advanced Hybrid ${ }^{\mathrm{TM}}$ filter technology is superior

Table 6.2.2.6. Summary of Method 101A Results, dry flue gas at $3.0 \% \mathrm{O}_{2}$

\begin{tabular}{lcccc}
\hline & & $\mathrm{Hg}, \mathrm{g}$ & $\mathrm{Hg}$ (particulate) & $\mathrm{Hg}$ (total) \\
\hline Day 1 & Inlet & 11.3 & 0.3 & 11.5 \\
& Outlet & 10.5 & 0 & 10.5 \\
\hline
\end{tabular}


Table 6.2.2.7. Dust Loading at the Advanced Hybrid ${ }^{\mathrm{TM}}$ Filter Inlet and Outlet and the Calculated Collection Efficiency

\begin{tabular}{lcccc}
\hline & & $\begin{array}{c}\text { Inlet, g/m } \\
(\mathrm{gr} / \mathrm{dscf})\end{array}$ & $\begin{array}{c}\text { Outlet, g/m } \\
(\mathrm{gr} / \mathrm{dscf})\end{array}$ & Collection Efficiency, \% \\
\hline \multirow{4}{*}{ Advanced } & Day 1-1 & $3.25(1.42)$ & $1.33 \times 10^{-4}\left(5.80 \times 10^{-5}\right)$ & 99.996 \\
Hybrid & Day 1-2 & $3.52(1.54)$ & $1.81 \times 10^{-4}\left(7.90 \times 10^{-5}\right)$ & 99.995 \\
& Day 2-1 & $3.82(1.67)$ & $4.28 \times 10^{-4}\left(1.87 \times 10^{-4}\right)$ & 99.989 \\
& Day 2-2 & $3.64(1.59)$ & $5.70 \times 10^{-4}\left(2.49 \times 10^{-4}\right)$ & 99.984 \\
& Day 3-1 & $3.46(1.51)$ & $2.56 \times 10^{-4}\left(1.12 \times 10^{-4}\right)$ & 99.993 \\
\multirow{2}{*}{ PJBH } & Day 3-2 & $3.56(1.56)$ & $4.26 \times 10^{-4}\left(1.86 \times 10^{-4}\right)$ & 99.988 \\
& Day 4-1 & $3.24(1.42)$ & $1.56 \times 10^{-2}\left(6.80 \times 10^{-3}\right)$ & 99.520 \\
& Day 4-2 & $3.49(1.52)$ & $3.48 \times 10^{-2}\left(1.52 \times 10^{-2}\right)$ & 99.000 \\
\hline
\end{tabular}

to a conventional baghouse and demonstrate that longer bag-cleaning intervals benefit particle emission reduction.

\subsubsection{Mercury Species Comparison Between the PTC-CR-624 Test and Big Stone Field Test (November 2001)}

Figure 6.2.2.7 shows averaged mercury speciation in Advanced Hybrid ${ }^{\mathrm{TM}}$ filter inlet flue gas measured in Big Stone field test (completed in November 2001) and the baseline pilot-scale testing results, and Figure 6.2.2.8 plots corresponding normalized $\mathrm{Hg}$ distributions. Detailed results of the field testing are given later in this report. The total values are similar within the margin of error, but the field results showed $56 \%$ of the mercury was retained by the fly ash, much higher than the $5 \%$ particle-associated mercury in the pilot-scale tests. A second significant difference is that only $6 \%$ of the total mercury was elemental mercury in the field result compared to $67 \%$ elemental mercury in the pilot-scale tests.

A number of differences in conditions between the two tests could be responsible for the significant speciation difference. Big Stone Power Plant cofired a small percentage of waste tires with coal during the November 2001 test, while the pilot-scale coal did not include waste tires. The cofiring of tires may change mercury-flue gas chemistry. For example, the $\mathrm{HCl}$ for the pilotscale tests was measured by Method 26A to be $3 \mathrm{ppm}$ in the flue gas compared to $9 \mathrm{ppm}$ for the field test. However, $9 \mathrm{ppm} \mathrm{HCl}$ is still a fairly low concentration compared to the $50-100 \mathrm{ppm}$ level that is typically seen for bituminous coals. 


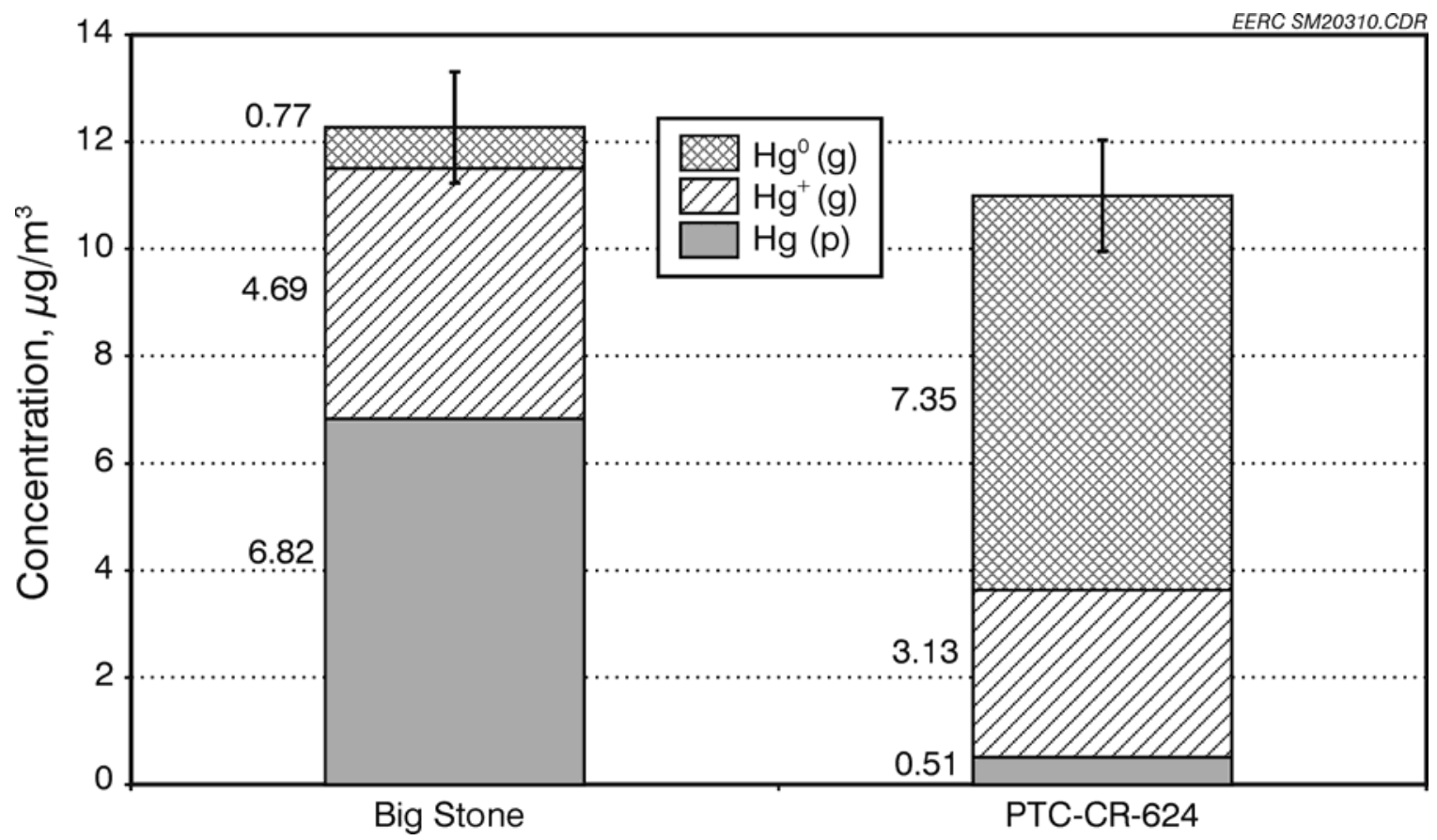

Figure 6.2.2.7. Averaged mercury speciation in Advanced Hybrid ${ }^{\mathrm{TM}}$ filter inlet flue gas measured in Big Stone field test (completed in November 2001) and pilot-scale test.

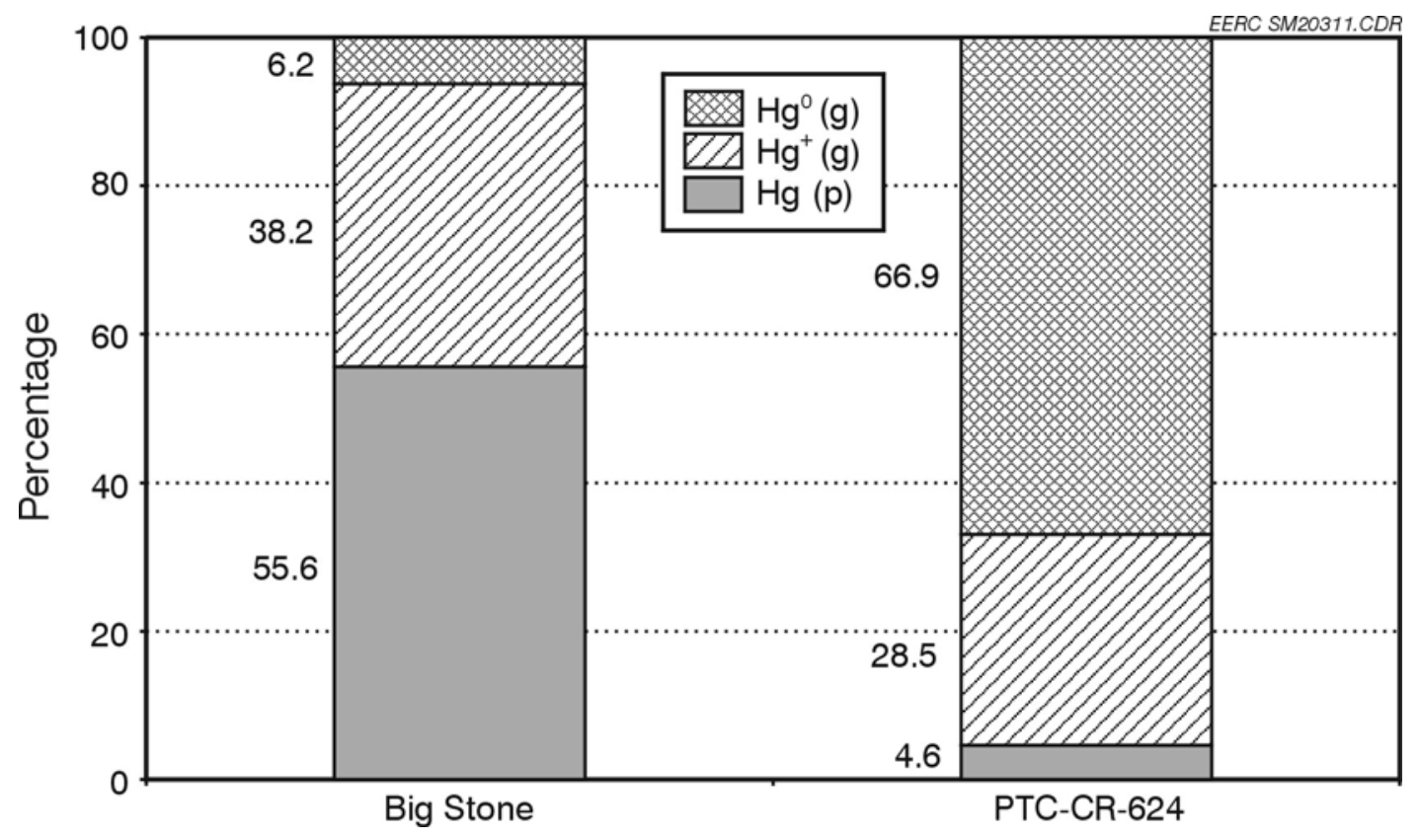

Figure 6.2.2.8. Normalized Hg species distribution in flue gas of Big Stone field test and pilotscale test. 
Another possible reason for the difference is the amount of unburned carbon in the ash, which for the Big Stone baseline tests ranged from $0.5 \%$ to $1.9 \%$ (without carbon injection) compared to only $0.16 \%$ for the pilot-scale tests. Under some conditions, carbon in the ash can be responsible for mercury retention as well as oxidation.

Cyclone firing is known to produce a finer fly ash particle size than pulverized-coal firing, which could also lead to more mercury retention as well as oxidation. Other work has shown that mercury concentration is typically higher in the smaller fly ash fraction, and the higher surface area of the finer particles may also promote more oxidation.

Still further possible contributors to the differences are the longer residence time and exposure of the flue gas to the fly ash for a full-scale boiler and possible differences in the coal. The coal burned in the pilot-scale unit was from the Big Stone Power Plant and was from the same mine, but it was obtained over a month prior to the field test. Further discussion of the effects of cofiring waste tires is given later in this report.

\subsubsection{Conclusions from the PTC-CR-624 Testing Results}

In the pilot-scale tests, a baseline comparison was made between the Advanced HybridTM filter and a PJBH in terms of the mercury speciation change across the device and the amount of mercury retained by the fly ash. Results showed that for both devices there was very little capture of mercury by the fly ash, but there was some increase in oxidized mercury across the device. No significant differences were noted between the Advanced Hybrid ${ }^{\mathrm{TM}}$ filter and the PJBH modes of operation.

The extended residence time of fly ash in the Advanced Hybrid ${ }^{\mathrm{TM}}$ filter chamber may promote slightly more mercury oxidation with the Cordero Rojo complex flue gas.

Even though the same coal was used in the pilot-scale tests and the November 2001 field tests at the Big Stone Power Plant, there was a significant difference in inlet mercury speciation. For the pilot-scale tests, results were more similar to what is typically expected for PRB coals in that most of the mercury was elemental with little mercury capture by the fly ash. In contrast, the field test results show high levels of oxidized and particle-bound mercury. Possible reasons for the difference include higher carbon in the field ash, somewhat higher $\mathrm{HCl}$ in the field flue gas, possible variation in the coal, cyclone firing for the field tests compared to pulverized coal firing for the pilot tests, longer residence time for the field tests, and a finer particle size for the field tests. 


\subsubsection{PTC-BA-628}

\subsubsection{Test Conditions}

Big Stone Power Plant switched coal from Cordero Rojo Complex to Belle Ayr coal, which is another WSB coal from the PRB. This was the coal currently being burned at the Big Stone Power Plant and was the expected coal to be burned at Big Stone during the Advanced Hybrid ${ }^{\mathrm{TM}}$ filter field tests planned for August 2002. Note that this was a different PRB fuel than was burned at the plant during the first field test and the PTC-CR-624 pilot-scale tests. The EERC, therefore, decided to burn the Belle Ayr coal in the pilot-scale test, designated as PTCBA-628. A dry powder disperser system (TSI Model 3410) installed 30 feet upstream of the Advanced Hybrid ${ }^{\mathrm{TM}}$ filter continuously injected NORIT FGD sorbent into the Belle Ayr flue gas entering the Advanced Hybrid ${ }^{\mathrm{TM}}$ filter. Ontario Hydro samples were collected both at the Advanced Hybrid ${ }^{\mathrm{TM}}$ filter inlet and outlet to measure mercury concentrations in the Belle Ayr flue gas across the Advanced Hybrid ${ }^{\mathrm{TM}}$ filter unit.

Table 6.2.3.1 lists five tests that were completed in this testing period. The residence time of the injected sorbent in the unit was either $60 \mathrm{~min}$ or $24 \mathrm{hr}$, controlled by the time interval to empty ash from the hopper. By using the TSI dry powder disperser, the activated carbon was continuously injected into the system at injection rates of $19 \mathrm{mg} / \mathrm{m}^{3}(1.2 \mathrm{lb} / \mathrm{Macf})$ and $38 \mathrm{mg} / \mathrm{m}^{3}(2.4 \mathrm{lb} / \mathrm{Macf})$, corresponding to carbon-to-mercury ratios of 3000:1 and 6000:1,

\section{Table 6.2.3.1. Pilot-Scale Testing Plan for Run PTC-BA-628}

\begin{tabular}{|c|c|c|c|c|c|}
\hline Test No. & Operating Mode & Residence Time & C:Hg Ratio & $\begin{array}{l}\text { Carbon Injectio } \\
\text { Rate, } \mathrm{mg} / \mathrm{m}^{3} \\
\text { (lb/Macf) }\end{array}$ & $\begin{array}{l}\text { Injection } \\
\text { Method }\end{array}$ \\
\hline 1 & $\begin{array}{c}\text { Advanced } \\
\text { Hybrid } \\
4.0 \mathrm{~mA} \text { filter, }\end{array}$ & $60 \mathrm{~min}$ & None & None & NA \\
\hline 2 & $\begin{array}{c}\text { Advanced } \\
\text { Hybrid }{ }^{\mathrm{TM}} \text { filter, } \\
4.0 \mathrm{~mA}\end{array}$ & $60 \mathrm{~min}$ & $3000: 1$ & $19(1.2)$ & Continuous \\
\hline 3 & PJBH & $60 \mathrm{~min}$ & 3000:1 & $19(1.2)$ & Continuous \\
\hline 4 & $\begin{array}{c}\text { Advanced } \\
\text { Hybrid } \\
0.5 \mathrm{~mA} \\
\text { filter, }\end{array}$ & $60 \mathrm{~min}$ & $3000: 1$ & $19(1.2)$ & Continuous \\
\hline 5 & $\begin{array}{c}\text { Advanced } \\
\text { Hybrid } \\
4.0 \mathrm{~mA} \\
\end{array}$ & $24 \mathrm{hr}$ & 6000:1 & $38(2.4)$ & Continuous \\
\hline
\end{tabular}


respectively. The pilot-scale unit was operated either as the Advanced Hybrid ${ }^{\mathrm{TM}}$ filter or a PJBH by shutting off the ESP power.

The purposes of this pilot-scale test were to evaluate NORIT FGD ACI on mercury emission control in the Advanced Hybrid ${ }^{\mathrm{TM}}$ filter, understand the impacts of corona current and residence time of sorbent in the Advanced Hybrid ${ }^{\mathrm{TM}}$ filter, and compare mercury control of the Advanced Hybrid ${ }^{\mathrm{TM}}$ filter with a PJBH for Belle Ayr, a WSB coal.

\subsubsection{Coal and Flue Gas Analyses}

Table 6.2.3.2 lists proximate and ultimate analysis data for the Belle Ayr coal and mercury content from the testing of the Belle Ayr coal. The analysis data show mercury concentrations of $0.077-0.089 \mu \mathrm{g} / \mathrm{g}$ (dry basis), with a mean value of $0.083 \mu \mathrm{g} / \mathrm{g}$ in the raw coal, slightly lower than the Cordero Rojo complex tested in PTC-CR-624. Based on the proximate and ultimate analysis data, $1 \mathrm{lb}$ of Belle Ayr coal would produce $3.04 \mathrm{~m}^{3}(107.3 \mathrm{scf})$ of dry flue gas normalized to $3.0 \%$ oxygen level. Combining the mercury content in raw coal and combustion calculations, the total mercury concentration in the flue gas was expected to be $12.4 \mu \mathrm{g} / \mathrm{m}^{3}$ of dry flue gas (at 3\% oxygen level).

Table 6.2.3.3 summarizes daily average flue gas concentrations of $\mathrm{O}_{2}, \mathrm{CO}_{2}, \mathrm{CO}, \mathrm{NO}, \mathrm{NO}_{2}$, $\mathrm{SO}_{2}$, both at the Advanced Hybrid ${ }^{\mathrm{TM}}$ filter inlet and outlet during the testing period. The

Table 6.2.3.2. Coal Analysis for Run PTC-BA-628

\begin{tabular}{lcc}
\hline Proximate Analysis, wt $\%$ & As Sampled & Moisture Free \\
\hline Moisture Content & 24.8 & NA \\
Volatile Matter & 35.94 & 47.83 \\
Fixed Carbon & 34.42 & 45.74 \\
Ash & 4.83 & 6.43 \\
Ultimate Analysis, wt\% & & \\
Hydrogen & 6.29 & 4.69 \\
Carbon & 51.42 & 68.42 \\
Nitrogen & 0.8 & 1.07 \\
Sulfur & 0.29 & 0.38 \\
Oxygen & 36.37 & 19.01 \\
Ash & 4.83 & 6.43 \\
Heating Value, Btu/lb & 8999 & 11,975 \\
Chlorine in coal, $\mu \mathrm{g} / \mathrm{g}$, dry basis & & 22.5 \\
Mercury in coal, $\mu \mathrm{gg} / \mathrm{g}$, dry basis & & \\
Sample 1 & & 0.077 \\
Sample 2 & & 0.089 \\
Mean & & 0.083 \\
\hline
\end{tabular}


Table 6.2.3.3. Summary of the Flue Gas Compositions During Run PTC-BA-628, dry basis

\begin{tabular}{lllllllll}
\hline & & $\mathrm{O}_{2}, \%$ & $\mathrm{CO}_{2}, \%$ & $\mathrm{CO}, \mathrm{ppm}$ & $\mathrm{NO}, \mathrm{ppm}$ & $\mathrm{NO}_{2}, \mathrm{ppm}$ & $\mathrm{SO}_{2}, \mathrm{ppm}$ & $\mathrm{HCl}, \mathrm{ppm}$ \\
\hline Day 1 & In & 4.8 & 14.3 & 3.9 & 590 & - & 314 & - \\
& Out & 5.13 & 13.5 & - & 537 & - & 307 & - \\
Day 2 & In & 4.5 & 14.3 & 4.5 & 559 & 4 & 306 & 2.7 \\
& Out & 5.2 & - & - & 540 & 3 & 266 & - \\
Day 3 & In & 4.6 & 14.8 & 3.6 & 558 & - & 316 & 3.7 \\
& Out & 5.9 & & & 533 & - & 289 & - \\
Day 4 & In & 4.6 & 14.2 & 3.4 & 571 & - & 312 & 3 \\
& Out & 4.8 & - & - & 547 & - & 289 & - \\
Day 5 & In & 4.4 & 14.9 & 3.51 & 580 & 5 & 331 & - \\
& Out & 5.1 & - & - & 571 & 7 & 291 & - \\
\hline
\end{tabular}

$\mathrm{CO}$ concentration was in the range of 3-5 ppm, indicating complete coal combustion. The lowsulfur Belle Ayr coal produced $\mathrm{SO}_{2}$ in the flue gas ranging from 306 to $331 \mathrm{ppm}$. The NO and $\mathrm{NO}_{2}$ concentrations in the flue gas were 571-590 ppm for $\mathrm{NO}$ and only 4-7 ppm for $\mathrm{NO}_{2}$. The $\mathrm{O}_{2}$ concentration was slightly increased from the inlet to the outlet because of the air leakage in the system. Three U.S. Environmental Protection Agency (EPA) Method 26 samples were collected at the Advanced Hybrid ${ }^{\mathrm{TM}}$ filter inlet, and the results (also listed in Table 6.2.3.3) show low levels of chlorine concentration in the Belle Ayr flue gas. Because of the low levels of CO, $\mathrm{SO}_{2}, \mathrm{NO}, \mathrm{NO}_{2}$, and $\mathrm{HCl}$ in flue gas, most mercury in the flue gas was expected to be in the elemental vapor phase.

\subsubsection{Mercury Results for PTC-BA-628}

\section{Test 1 - Baseline}

Because this was a different coal than that evaluated in PTC-CR-624 baseline test, Test 1 (listed in Table 6.2.3.1) from this run was designated as a baseline to establish the inlet and outlet mercury species concentrations and determine whether there was a change in mercury speciation across the Advanced Hybrid ${ }^{\mathrm{TM}}$ filter unit. In Test 1, the system was operated in Advanced Hybrid $^{\mathrm{TM}}$ filter mode with a corona current of $4.0 \mathrm{~mA}$. The collection plates and electrodes were rapped every 60 minutes followed by a pulse-jet bag cleaning. The hopper ash was then emptied to maintain the residence time of the fly ash in the chamber at approximately 60 min. No activated carbon was injected into the system during the testing period, and a total of three pairs of Ontario Hydro samples were taken out at both the Advanced Hybrid ${ }^{\mathrm{TM}}$ filter inlet and outlet. 


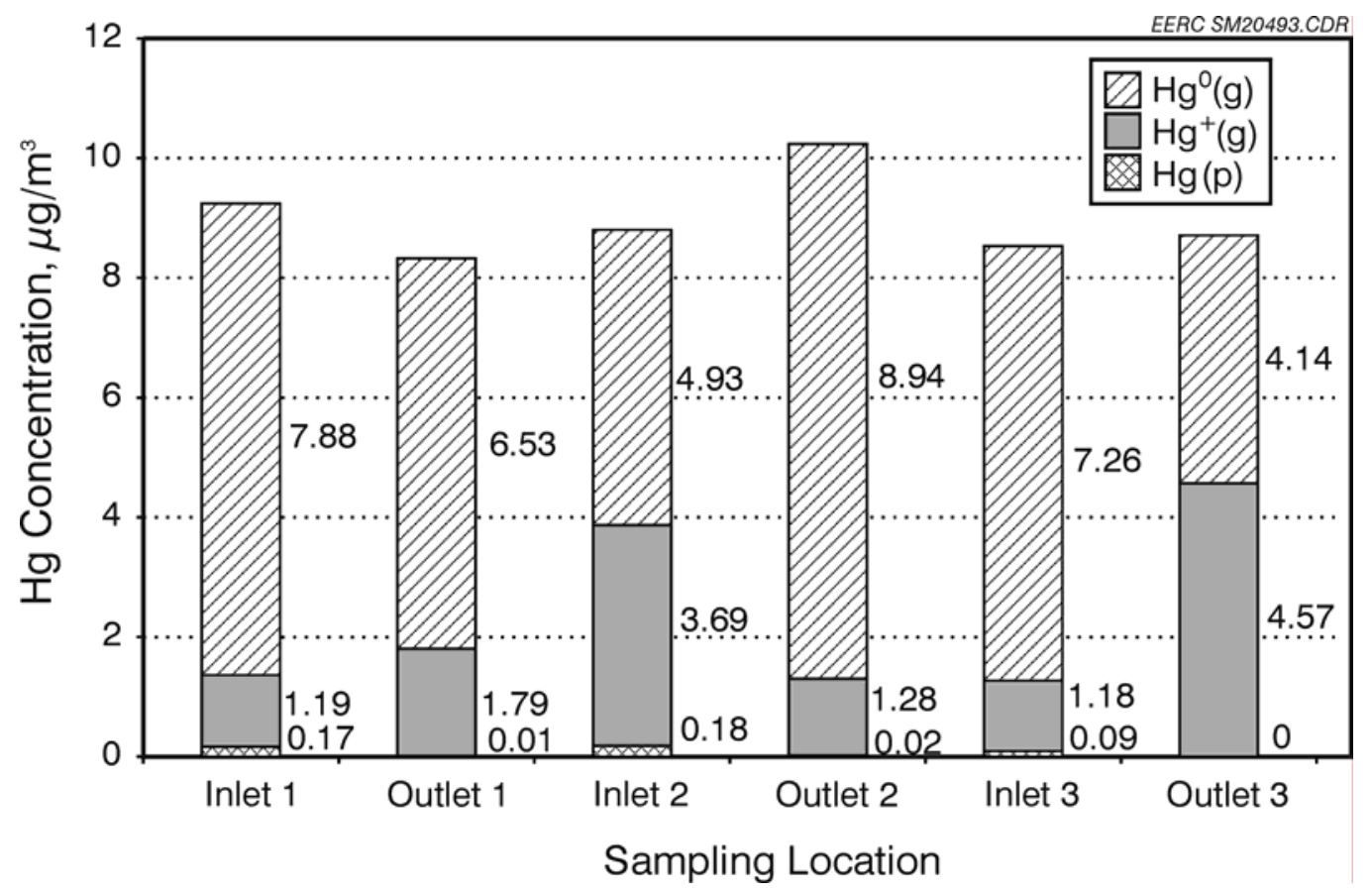

Figure 6.2.3.1. Mercury species concentrations in the Belle Ayr flue gas across the Advanced Hybrid ${ }^{\mathrm{TM}}$ filter in baseline test.

Plotted in Figure 6.2.3.1 are mercury species concentrations in the Belle Ayr flue gas across the Advanced Hybrid ${ }^{\mathrm{TM}}$ filter in baseline test. At the Advanced Hybrid ${ }^{\mathrm{TM}}$ filter inlet, oxidized mercury vapor varied from 1.18 to $3.69 \mu \mathrm{g} / \mathrm{m}^{3}$, while the elemental mercury vapor was dominant, in the range of $4.93-7.88 \mu \mathrm{g} / \mathrm{m}^{3}$. Mercury associated with the particulate was at a very low level, ranging from 0.09 to $0.17 \mu \mathrm{g} / \mathrm{m}^{3}$, showing little capture of mercury by fly ash particles. The total mercury concentration in the flue gas entering the Advanced Hybrid ${ }^{\mathrm{TM}}$ filter varied from 8.83 to $9.24 \mu \mathrm{g} / \mathrm{m}^{3}$, slightly lower than the theoretical value of $12.4 \mu \mathrm{g} / \mathrm{m}^{3}$ obtained from the coal combustion calculation based on the coal analysis. The slight difference may be the result of uncertainty in the mercury analysis as well as additional process variability. Because of the excellent fly ash capture efficiency of the Advanced Hybrid ${ }^{\mathrm{TM}}$ filter, particulate-associated mercury was completely removed from the flue gas. The total mercury in the outlet flue gas (also shown in Figure 6.2.3.1) was about the same as the Advanced Hybrid ${ }^{\mathrm{TM}}$ filter inlet, showing virtually no capture of mercury vapor (including both elemental and oxidized mercury vapor) across the Advanced Hybrid ${ }^{\mathrm{TM}}$ filter. 
To better clarify the transformation of mercury species across the Advanced Hybrid ${ }^{\mathrm{TM}}$ filter unit in the baseline test, the average normalized mercury species distribution at the Advanced Hybrid ${ }^{\mathrm{TM}}$ filter inlet is shown in Figure 6.2.3.2. At the Advanced Hybrid ${ }^{\mathrm{TM}}$ filter inlet, $75.5 \%$ of mercury was in the elemental state, $22.9 \%$ was oxidized mercury vapor, and only $1.6 \%$ of total mercury was associated with fly ash particles. Because of the excellent capture of fly ash by the Advanced Hybrid ${ }^{\mathrm{TM}}$ filter, the mercury associated with fly ash was all collected in the hopper. The mercury in the hopper ash was analyzed, added to the outlet mercury species, and normalized to $100 \%$ for comparison with the inlet. The results show a slight increase in oxidized mercury from $22.9 \%$ to $28.8 \%$ across the Advanced Hybrid ${ }^{\mathrm{TM}}$ filter unit while there was a corresponding decrease in elemental mercury from $75.5 \%$ at the inlet to $71.7 \%$ at the outlet.

\section{Test 2 - $19 \mathrm{mg} / \mathrm{m}^{3}$ (1.2 lb/Macf) Continuous NORIT FGD Injection - Advanced Hybrid $^{\mathrm{TM}}$ Filter with 60-min Residence Time and 4-mA Current}

Figure 6.2.3.3 shows the effect of NORIT FGD carbon injection on mercury emission for the Advanced Hybrid ${ }^{\mathrm{TM}}$ filter (Test 2 in Table 6.2.3.1). The unit was operated in Advanced Hybrid $^{\mathrm{TM}}$ filter mode (Test 2) with a 4.0-mA corona current and a pulse trigger pressure of $2.0 \mathrm{kPa}$ (8.0 in. W.C.). The fly ash and NORIT FGD carbon collected in the hopper were

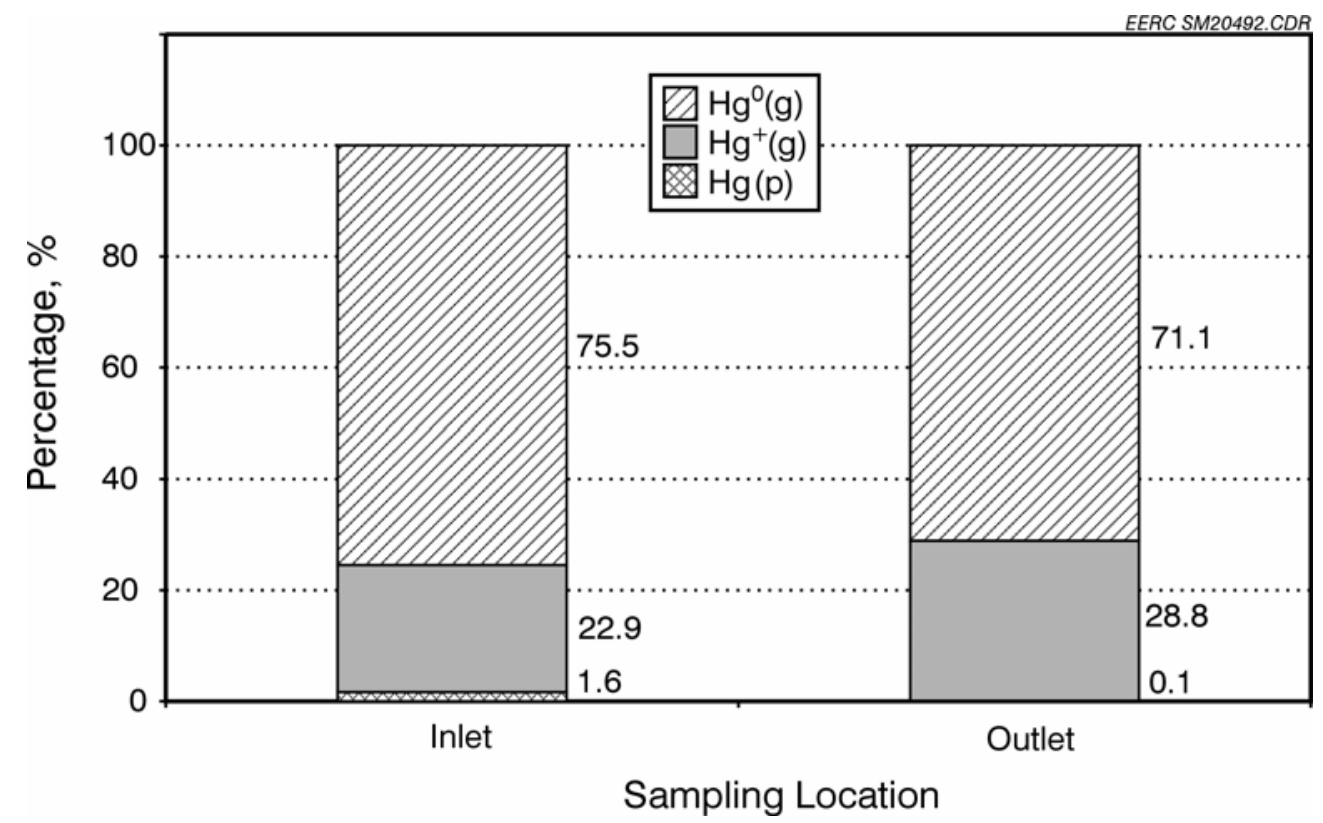

Figure 6.2.3.2. Normalized mercury species distributions across the Advanced Hybrid ${ }^{\mathrm{TM}}$ filter in Belle Ayr coal baseline test. 


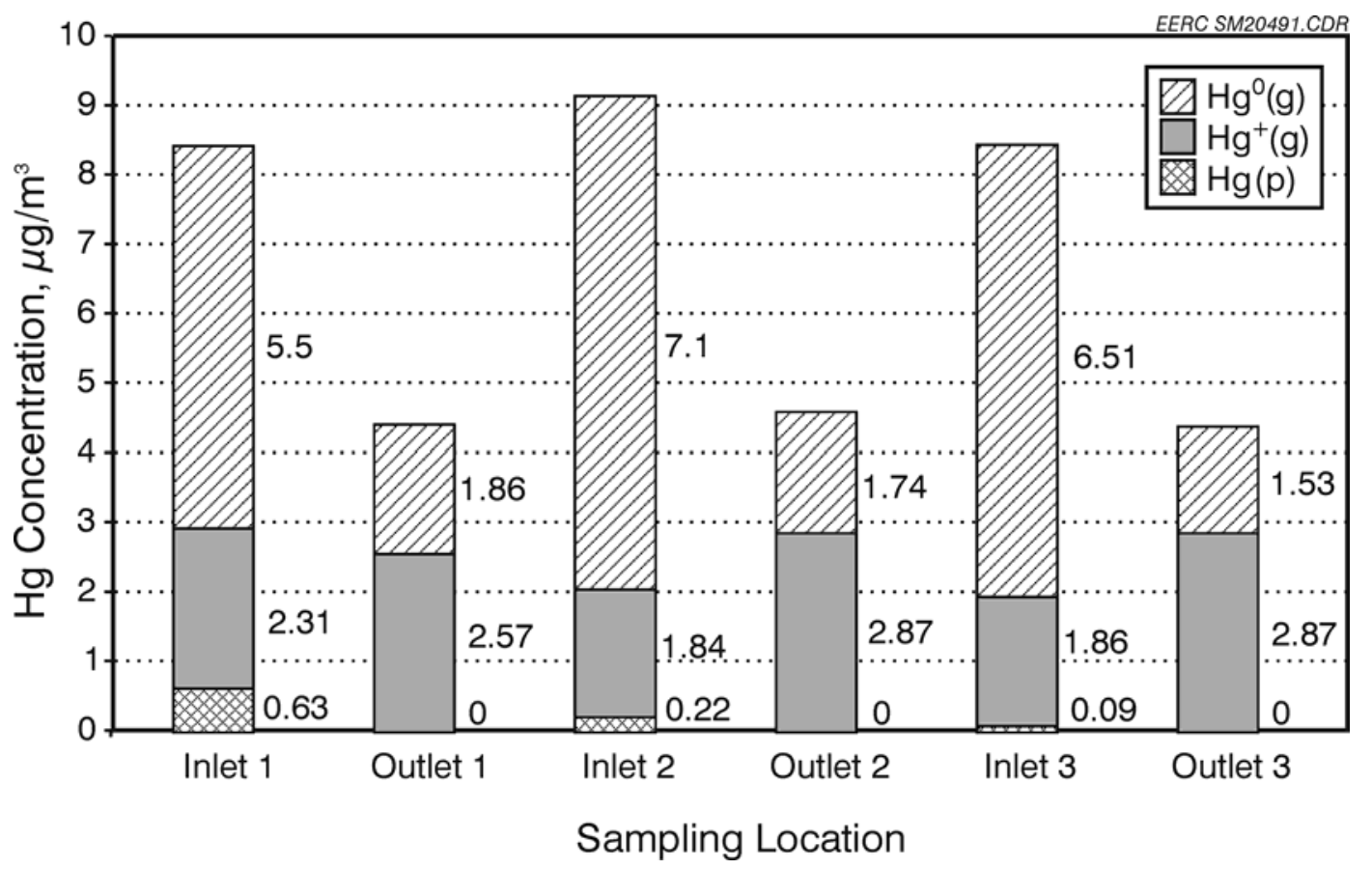

Figure 6.2.3.3. Effect of $19 \mathrm{mg} / \mathrm{m}^{3}$ (1.2 lb/Macf) NORIT FGD carbon injection on mercury emission in the Advanced Hybrid ${ }^{\mathrm{TM}}$ filter.

emptied once every hour to maintain the 1-hr residence time in the system. With continuous 19 $\mathrm{mg} / \mathrm{m}^{3}$ (1.2 lb/Macf) FGD injection into the Advanced Hybrid ${ }^{\mathrm{TM}}$ filter, the mercury outlet emission reduced to approximately $4.48 \mu \mathrm{g} / \mathrm{m}^{3}$ with $38 \%$ of elemental mercury, $62 \%$ of oxidized mercury, and $0 \%$ of particle-bound mercury. Compared to average inlet mercury concentrations of $8.44-9.16 \mu \mathrm{g} / \mathrm{m}^{3}$ with $73.2 \%$ elemental mercury, $23.1 \%$ oxidized mercury, and $3.6 \%$ particulate associated mercury, $19 \mathrm{mg} / \mathrm{m}^{3}(1.2 \mathrm{lb} / \mathrm{Macf})$ NORIT FGD injection resulted in an overall $48.4 \%$ mercury removal in the Advanced Hybrid ${ }^{\mathrm{TM}}$ filter, while there was virtually no inherent mercury capture in the baseline test. The FGD carbon efficiently oxidized mercury: 73\% of the elemental mercury at the Advanced Hybrid ${ }^{\mathrm{TM}}$ filter inlet vs. $38 \%$ of the elemental mercury at the Advanced Hybrid ${ }^{\mathrm{TM}}$ filter outlet. However, the $48.4 \%$ overall mercury removal is lower than expected based on the bench-scale results, likely because some of the activated carbon deposited on the outside walls rather than the perforated plates or the filtration bags, and consequently, some of the carbon was not in full contact with the flue gas. To help minimize this effect, Test 4 was completed later with a reduced corona current. The lower current was still high enough for good operation, but could improve the gas-sorbent contact. 


\section{Test 3 - $19 \mathrm{mg} / \mathrm{m}^{3}$ (1.2 lb/Macf) Continuous NORIT FGD Injection - PJBH with 60-min Residence Time}

In Test 3, the unit was operated in a PJBH mode (without high-voltage power) with a $2.0-\mathrm{kPa}$ (8.0-in. W.C.) pulse trigger pressure. The filter bags were pulse cleaned every 5$7 \mathrm{~min}$ because of the high $\mathrm{A} / \mathrm{C}$ ratio of $3.7 \mathrm{~m} / \mathrm{m}(12 \mathrm{ft} / \mathrm{min})$, high dust loading to the filter bags, and severe fly ash reentrainment. Figure 6.2.3.4 shows measured mercury species concentrations at the Advanced Hybrid ${ }^{\mathrm{TM}}$ filter inlet and outlet during the test. The mercury species concentrations at the Advanced Hybrid ${ }^{\mathrm{TM}}$ filter inlet during this test were somewhat different from the previous tests in that more mercury vapor was already in the oxidized state at the Advanced Hybrid ${ }^{\mathrm{TM}}$ filter inlet: $1.82-4.7 \mu \mathrm{g} / \mathrm{m}^{3}$ of $\mathrm{Hg}^{0}, 1.65-5.03 \mu \mathrm{g} / \mathrm{m}^{3}$ of $\mathrm{Hg}^{+}$, and $0.76-$ $1.09 \mu \mathrm{g} / \mathrm{m}^{3}$ of $\mathrm{Hg}(\mathrm{p})$. The total outlet mercury concentration was reduced to $2-2.17 \mu \mathrm{g} / \mathrm{m}^{3}$ under $19 \mathrm{mg} / \mathrm{m}^{3}$ (1.2 lb/Macf) NORIT FGD injection into the system, reaching a total mercury collection efficiency of $72.7 \%$. Compared to the $48.4 \%$ mercury capture in Advanced Hybrid ${ }^{\mathrm{TM}}$ filter mode, the PJBH mode appeared to provide a higher mercury collection efficiency with the same carbon-to-mercury ratio. However, because of the high levels of oxidized and particlebound mercury in the inlet flue gas during the test, which are typically easier to capture than

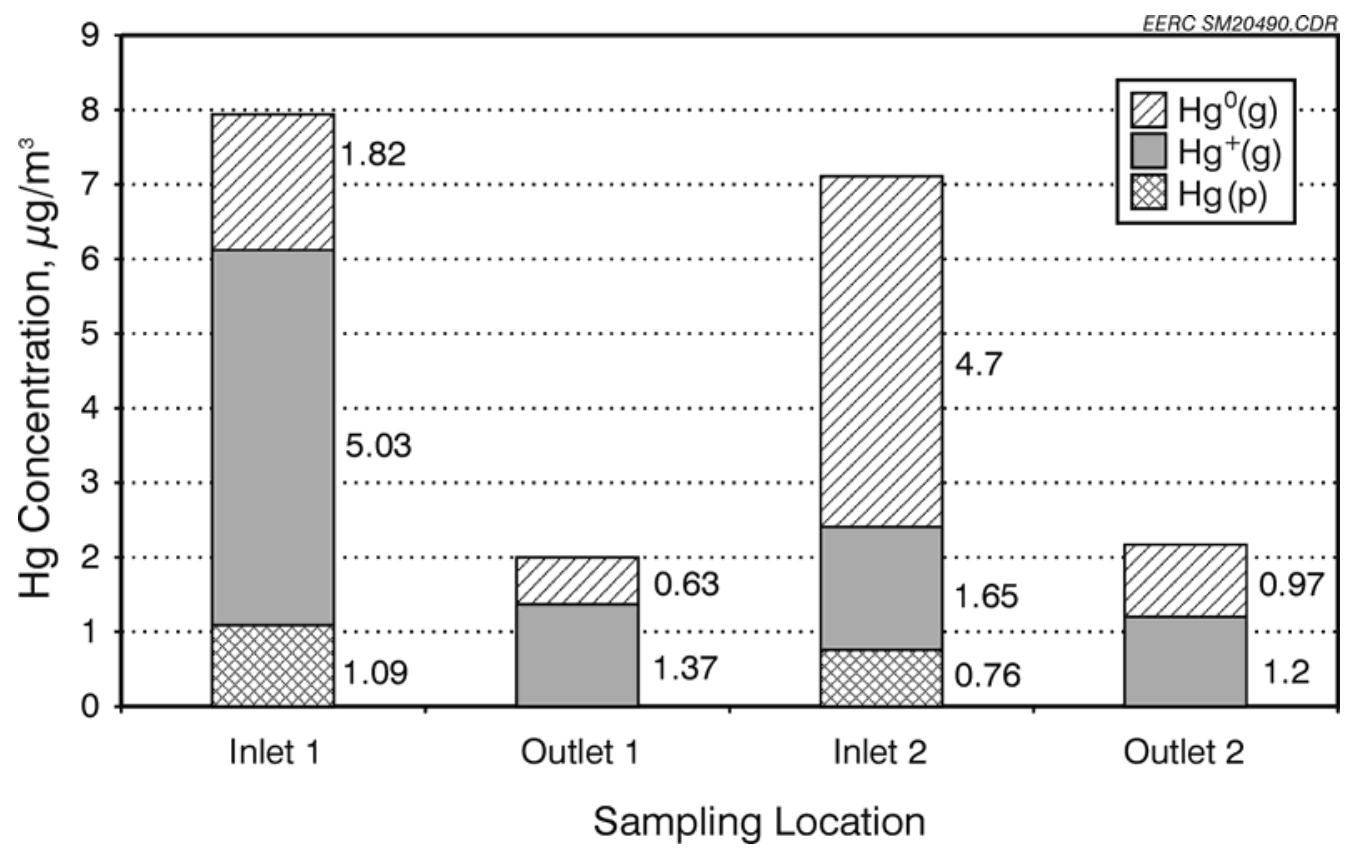

Figure 6.2.3.4. Effect of $19 \mathrm{mg} / \mathrm{m}^{3}$ (1.2-lb/Macf) NORIT FGD injection on mercury emission of PJBH. 
elemental mercury, more tests are needed. So far, both the Advanced Hybrid ${ }^{\mathrm{TM}}$ filter and the PJBH show they can produce good mercury control in a WSB flue gas with low FGD addition.

Test 4 - $19 \mathrm{mg} / \mathrm{m}^{3}$ (1.2 lb/Macf) Continuous NORIT FGD Injection - Advanced Hybrid $^{\mathrm{TM}}$ Filter with 60-min Residence Time and 0.5-mA Current

In Test 4, the system was returned to the Advanced Hybrid ${ }^{\mathrm{TM}}$ filter mode with a reduced 0.5-mA corona current, while the carbon injection rate and residence time of the sorbent were the same as in Test 2. As a result of the reduced corona current, we expected more activated carbon would deposit on the perforated plates and the bag surface instead of the outside wall. The good contact between the flue gas stream and the activated carbons on the perforated plates and filter bags should improve overall mercury capture in the Advanced Hybrid ${ }^{\mathrm{TM}}$ filter. Plotted in Figure 6.2.3.5 are the Ontario Hydro sampling results for the test. Mercury concentration in the inlet flue gas was $7.55 \mu \mathrm{g} / \mathrm{m}^{3}\left(2.58 \mu \mathrm{g} / \mathrm{m}^{3}\right.$ elemental mercury, $4.11 \mu \mathrm{g} / \mathrm{m}^{3}$ oxidized mercury, and $1.06 \mu \mathrm{g} / \mathrm{m}^{3}$ particulate mercury) and was reduced to $3.46 \mu \mathrm{g} / \mathrm{m}^{3}$ in the outlet flue gas. The overall mercury collection efficiency of the Advanced Hybrid ${ }^{\mathrm{TM}}$ filter increased to $54.2 \%$ compared to the $48.4 \%$ obtained in Test 2 , indicating that the reduced corona current appeared to somewhat improve mercury capture, but there was still considerable dust capture on the outside walls.

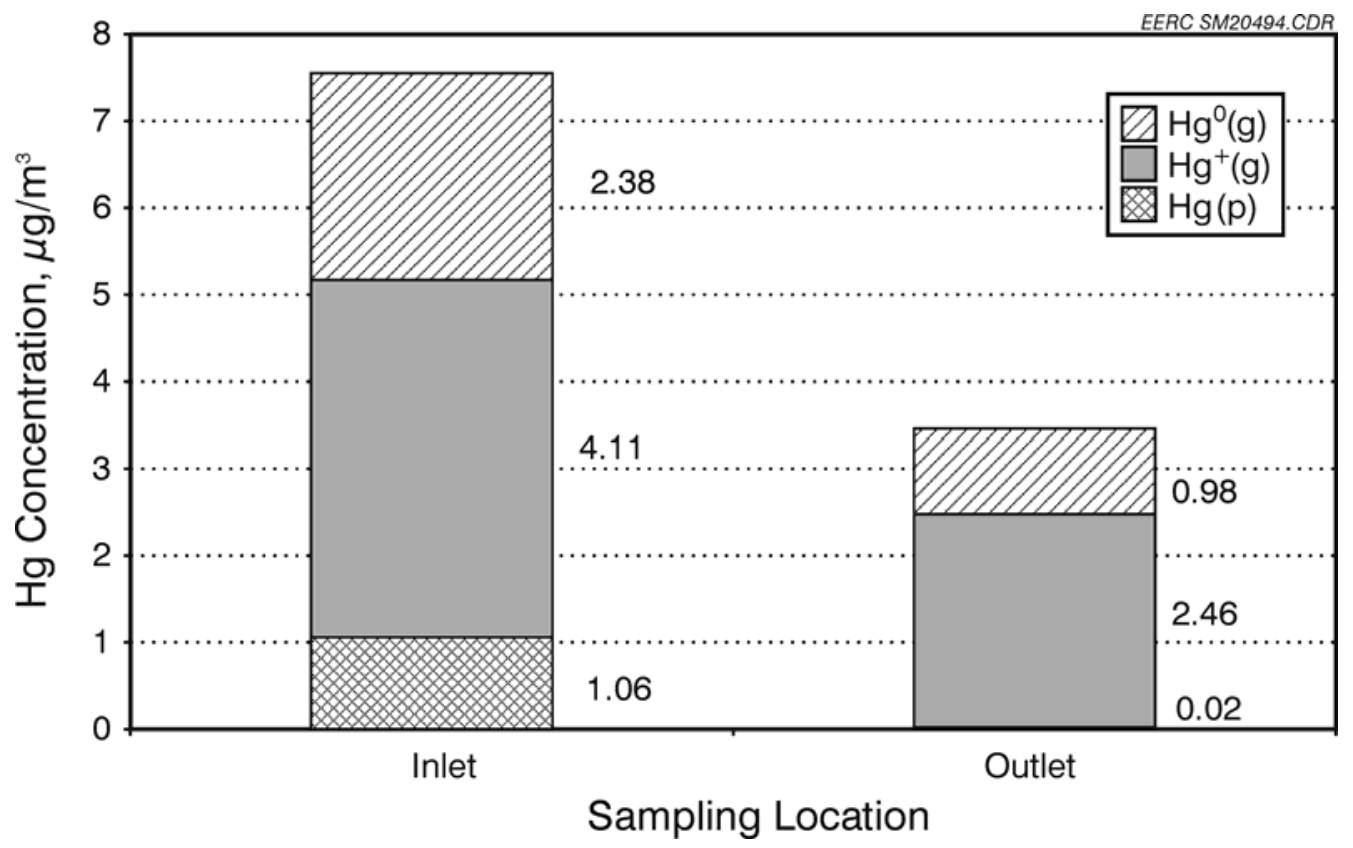

Figure 6.2.3.5. Effect of $19 \mathrm{mg} / \mathrm{m}^{3}$ (1.2-lb/Macf) NORIT FGD injection on $\mathrm{Hg}$ emission of the Advanced Hybrid ${ }^{\mathrm{TM}}$ filter at reduced current. 


\section{Test 5 - $38 \mathrm{mg} / \mathrm{m}^{3}$ (2.4 lb/Macf) Continuous NORIT FGD Injection - Advanced Hybrid $^{\mathrm{TM}}$ Filter with 2-hr Residence Time and 4-mA Current}

In order to achieve a higher mercury capture, the carbon injection rate was doubled to $38 \mathrm{mg} / \mathrm{m}^{3}$ (2.4 lb/Macf) in Test 5, corresponding to a carbon-to-mercury ratio of $6000: 1$. The unit was in Advanced Hybrid ${ }^{\mathrm{TM}}$ filter mode with a $0.5-\mathrm{mA}$ corona current. The residence time of the sorbent in the Advanced Hybrid ${ }^{\mathrm{TM}}$ filter chamber was extended to $24 \mathrm{hr}$. The Ontario Hydro sampling results are shown in Figure 6.2.3.6. Again, all the particulate mercury was removed from the flue gas because of the excellent particle collection efficiency. Most of the elemental mercury vapor $(>80 \%)$ in the flue gas was removed either by direct absorption on the activated carbons or oxidation followed by absorption. The elemental mercury vapor at the outlet was in the range of $0.6-0.97 \mu \mathrm{g} / \mathrm{m}^{3}$, while the oxidized mercury was $0.83-1.76 \mu \mathrm{g} / \mathrm{m}^{3}$. Early in the test, the first pair of Ontario Hydro samples indicated 68\% removal, but the second pair of samples near the end of the test indicated $83 \%$ removal, possibly because of the accumulated sorbent in the Advanced Hybrid ${ }^{\mathrm{TM}}$ filter chamber with extended residence time. However, concern is that if the exposure time is too long, the sorbent may desorb mercury. The bench-scale results indicate this will mostly likely occur in cases with very high $\mathrm{SO}_{2}$ and $\mathrm{NO}_{2}$ concentrations. Even though

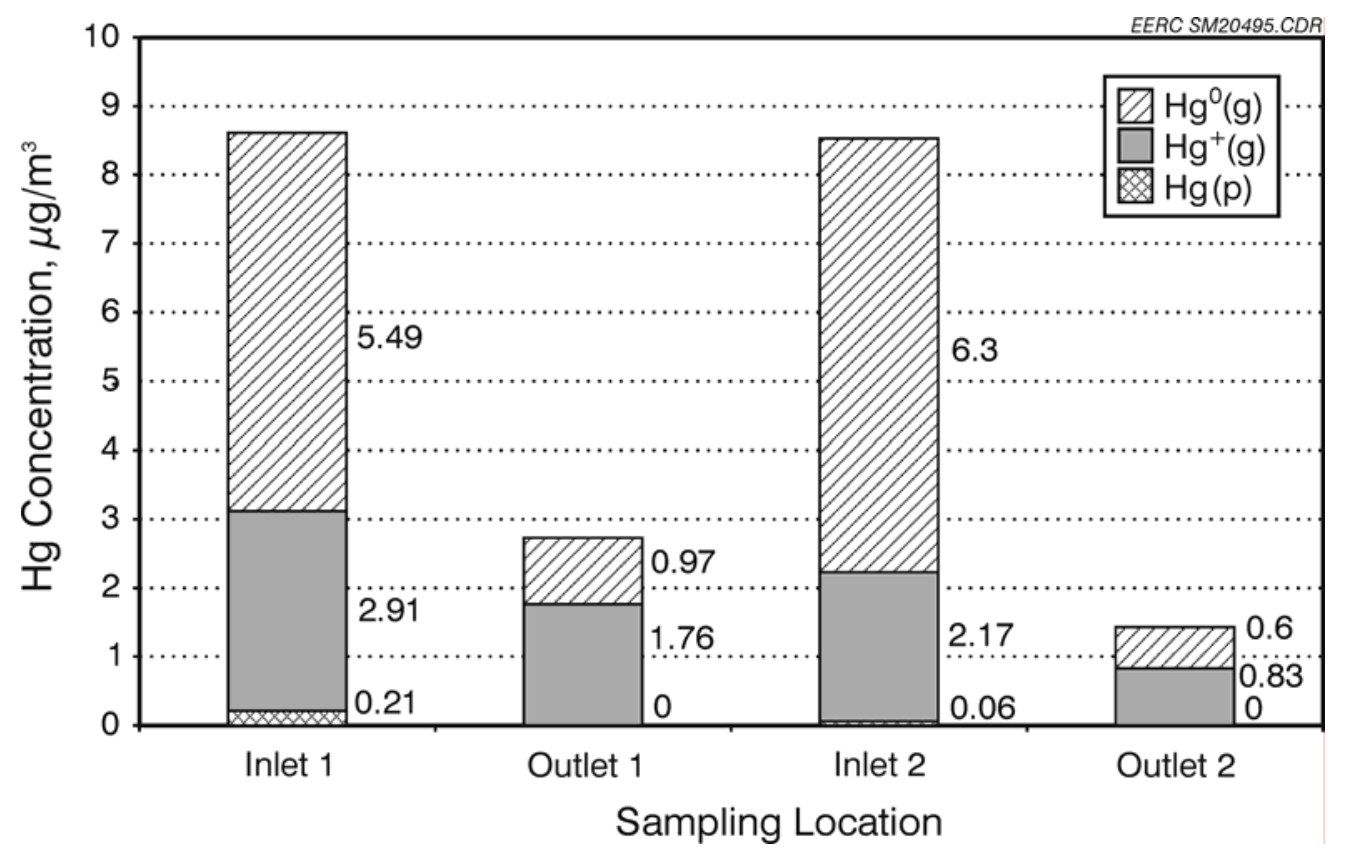

Figure 6.2.3.6. Effect of $38 \mathrm{mg} / \mathrm{m}^{3}$ (2.4-lb/Macf) FGD injection on $\mathrm{Hg}$ emission of the Advanced Hybrid ${ }^{\mathrm{TM}}$ filter. 
the sorbent particles were kept in the Advanced Hybrid ${ }^{\mathrm{TM}}$ filter chamber for $24 \mathrm{hr}$, there was no obvious desorption of mercury from the sorbent. These results are highly encouraging because they are for the difficult scenario with mostly elemental mercury and low levels of particulatebound mercury.

A summary of Advanced Hybrid ${ }^{\mathrm{TM}}$ filter mercury collection efficiency under the different operating conditions is plotted in Figure 6.2.3.7. Without carbon injection, the Belle Ayr coal shows virtually no capture of mercury. At the 3000:1 carbon-to-mercury injection ratio, the Advanced Hybrid ${ }^{\mathrm{TM}}$ filter overall mercury collection efficiency ranged from $48.4 \%$ to $54.2 \%$, depending on the corona current. When the carbon-to-mercury ratio increased from 3000:1 to 6000:1 with the same $0.5-\mathrm{mA}$ corona current and with extended 24-hr residence time, the mercury capture efficiency reached $83 \%$ at the end of the test.

\subsubsection{Particulate Matter Collection Efficiency of Advanced Hybrid ${ }^{\mathrm{TM}}$ Filter and PJBH in PTC-BA-628}

While the focus of these tests was mercury control, the Ontario Hydro samples also provide the particulate collection efficiency as shown in Table 6.2.3.4. The data indicate the

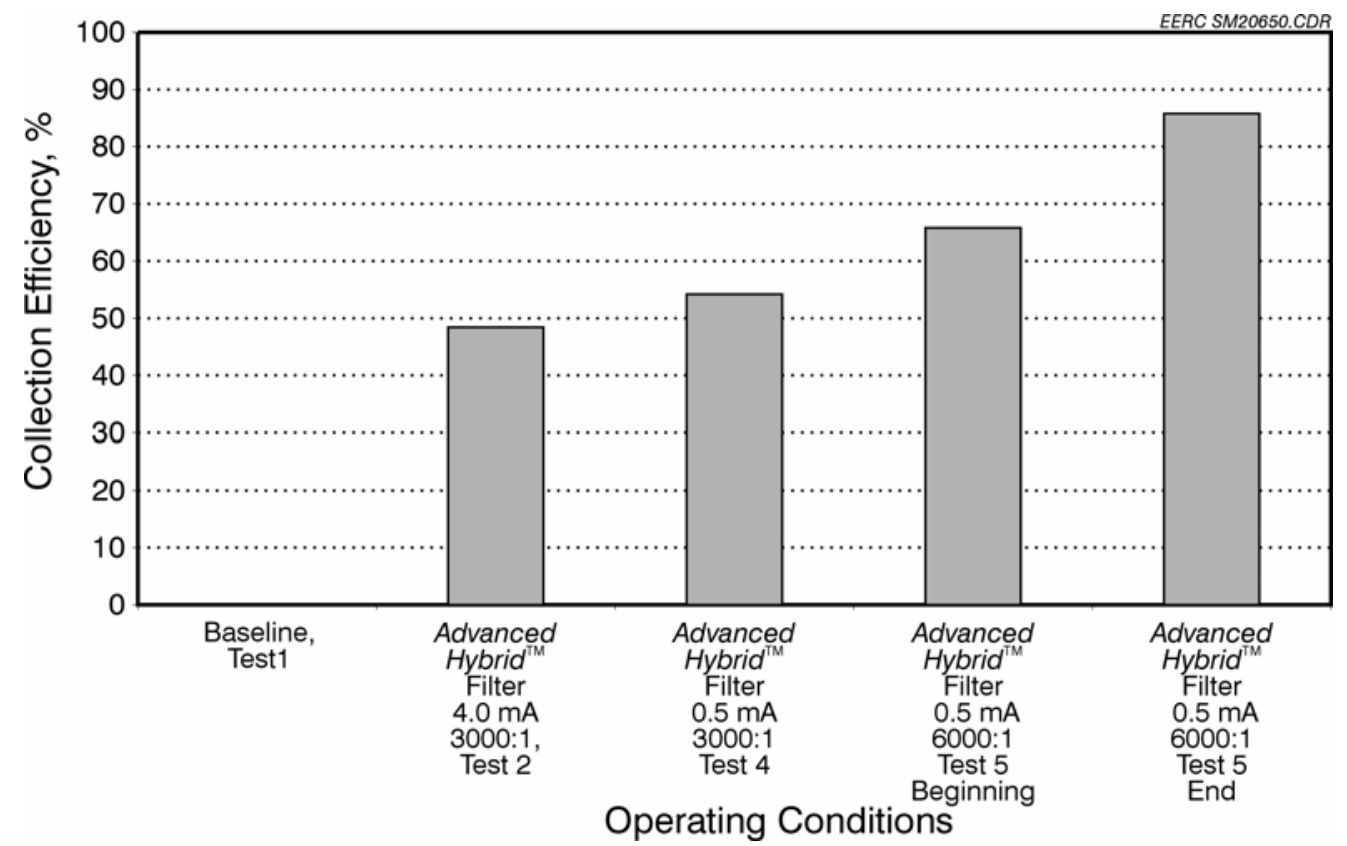

Figure 6.2.3.7. Summary of Advanced Hybrid ${ }^{\mathrm{TM}}$ filter mercury collection efficiency with carbon injection under the different operating conditions. 
Table 6.2.3.4. PTC-BA-628 - Dust Loading at the Advanced Hybrid ${ }^{\mathrm{TM}}$ Filter Inlet and Outlet and the Calculated Collection Efficiency

\begin{tabular}{lccc}
\hline & $\begin{array}{c}\text { Inlet, g/m } \\
(\mathrm{gr} / \mathrm{dscf})\end{array}$ & $\begin{array}{c}\text { Outlet, g/m } \\
(\mathrm{gr} / \mathrm{dscf})\end{array}$ & $\begin{array}{c}\mathrm{C}^{3} \\
\text { Collection Efficiency, \% }\end{array}$ \\
\hline Day 1-1 & $3.09(1.35)$ & $4.58 \times 10^{-3}\left(2.0 \times 10^{-4}\right)$ & 99.985 \\
Day 1-2 & $3.27(1.43)$ & $1.60 \times 10^{-5}\left(7.0 \times 10^{-6}\right)$ & 99.999 \\
Day 2-1 & $3.02(1.32)$ & $2.29 \times 10^{-4}\left(1.0 \times 10^{-3}\right)$ & 99.992 \\
Day 2-2 & $3.48(1.52)$ & $1.60 \times 10^{-5}\left(7.0 \times 10^{-6}\right)$ & 99.999 \\
Day 2-2 & $3.64(1.59)$ & $3.89 \times 10^{-5}\left(1.7 \times 10^{-5}\right)$ & 99.998 \\
Day 3-1 & $2.84(1.24)$ & $0(0)$ & 100.000 \\
Day 3-2 (pulse jet) & $3.39(1.48)$ & $1.83 \times 10^{-3}\left(8.0 \times 10^{-4}\right)$ & 99.945 \\
Day 3-3 (pulse jet) & $3.34(1.46)$ & $1.83 \times 10^{-3}\left(8.0 \times 10^{-4}\right)$ & 99.945 \\
Day 4-1 & $3.43(1.50)$ & $6.86 \times 10^{-5}\left(3.0 \times 10^{-5}\right)$ & 99.998 \\
Day 4-2 & $3.39(1.48)$ & $2.29 \times 10^{-4}\left(1.0 \times 10^{-4}\right)$ & 99.993 \\
Day 4-3 & $3.29(1.44)$ & $0(0)$ & 100.000 \\
Day 5-1 & $3.36(1.47)$ & $4.58 \times 10^{-5}\left(2.0 \times 10^{-5}\right)$ & 99.999 \\
\hline
\end{tabular}

Advanced Hybrid ${ }^{\mathrm{TM}}$ filter consistently had an overall $99.99 \%$ particle collection efficiency, while the PJBH clearly showed some loss in collection efficiency due to no precollection of dust, no enhanced bag cleaning, and much more frequent pulsing than the Advanced Hybrid ${ }^{\mathrm{TM}}$ filter. Even though the bags were the same for all of the tests, the much higher collection efficiency for the Advanced Hybrid ${ }^{\mathrm{TM}}$ filter shows the benefit of the Advanced Hybrid ${ }^{\mathrm{TM}}$ filter for reduced fineparticle emissions.

\subsubsection{Conclusions from the PTC-BA-628 Testing Results}

A number of baseline and carbon injection tests were completed with Belle Ayr PRB subbituminous coal. For the baseline case, approximately $70 \%$ of the inlet mercury was elemental, approximately $23 \%$ oxidized, and $2 \%$ or less was associated with particulate matter. There was very little natural mercury capture across the Advanced Hybrid ${ }^{\mathrm{TM}}$ filter for the baseline tests and only a slight increase in the level of oxidized mercury across the Advanced Hybrid ${ }^{\mathrm{TM}}$ filter during baseline operation.

With carbon injection, a comparison of short and long residence time in the Advanced Hybrid $^{\mathrm{TM}}$ filter showed that somewhat better mercury removal was achieved with longer residence time. No evidence of desorption of mercury from the carbon was seen upon continued exposure to flue gases up to $24 \mathrm{hr}$. This suggests that desorption of captured mercury from the carbon sorbent is not a significant problem under these flue gas conditions with the low-sulfur subbituminous coal. 
At a carbon-to-mercury ratio of 3000:1, approximately 50\% total mercury removal was achieved. When the ratio was increased to $6000: 1$, the removal increased to the range from $65 \%$ to $87 \%$. These results are highly encouraging because this level of control was achieved for the very difficult case with predominantly elemental mercury and very little natural capture of mercury by the fly ash.

Observation of the flow patterns within the pilot-scale Advanced Hybrid ${ }^{\mathrm{TM}}$ filter showed that a significant fraction of the sorbent was collected on the outside walls of the vessel rather than the perforated collection plates and filter bags, resulting in a situation where a fraction of the sorbent was directed away from the main gas flow region. Reducing the corona current somewhat improved the collection efficiency, but collection on the outside walls was still evident. This problem is unique to the small-scale pilot unit with a single row of bags and is not likely to be significant in a larger-scale Advanced Hybrid ${ }^{\mathrm{TM}}$ filter.

\subsubsection{PTC-BA-629}

\subsubsection{Test Conditions}

Another 1-week pilot-scale Advanced Hybrid ${ }^{\mathrm{TM}}$ filter test was completed in May 2002 to further expand on the Advanced Hybrid ${ }^{\mathrm{TM}}$ filter mercury control tests from the previous tests with the same Belle Ayr subbituminous coal. Results from PTC-BA-628 test indicated the carbons were not fully utilized in the Advanced Hybrid ${ }^{\mathrm{TM}}$ filter since some carbon deposited on the outside wall instead of on the perforated plates and filter bags. Therefore, to improve the contact between the injected carbon and the flue gas in the Advanced Hybrid ${ }^{\mathrm{TM}}$ filter, we switched from continuous injection to a batch injection mode, where an amount of carbon is injected every few hours. It is expected that more activated carbon would be on the perforated plates and filter bags, and the longer exposure time of the sorbent to the flue gas may provide better mercury removal than continuous injection. Table 6.2.4.1 lists the seven tests that were completed, including an initial baseline test without carbon injection, three continuous injection tests, and three batch injection tests. The applied corona current was in the range of $0.5-4 \mathrm{~mA}$, and the hopper ash was emptied every $2 \mathrm{hr}$. The carbon injection rates were $19 \mathrm{mg} / \mathrm{m}^{3}$ $(1.2 \mathrm{lb} / \mathrm{Macf})$ and $38 \mathrm{mg} / \mathrm{m}^{3}$ (2.4 lb/Macf), corresponding to carbon-to-mercury ratios of 3000:1 and 6000:1, respectively. 
Table 6.2.4.1. PTC-BA-629 - Summary of the Test Scenarios

\begin{tabular}{|c|c|c|c|c|}
\hline Test No. & $\begin{array}{l}\text { Advanced Hybrid } \\
\text { Filter Current, } \mathrm{mA}\end{array}$ & Residence Time, min & Carbon:Hg Ratio & Injection Mode \\
\hline 1 & 4.0 & 120 & None & \\
\hline 2 & 0.5 & 120 & 6000:1 & Continuous \\
\hline 3 & 3.0 & 120 & 6000:1 & Continuous \\
\hline 4 & 3.0 & 120 & 3000:1 & Batch power off \\
\hline 5 & 3.0 & 120 & 6000:1 & Batch power off \\
\hline 6 & 3.0 & 120 & 6000:1 & Batch power on \\
\hline 7 & 3.0 & 120 & $3000: 1$ & Continuous \\
\hline
\end{tabular}

In addition to Ontario Hydro sampling, CMMs were used at the Advanced Hybrid ${ }^{\mathrm{TM}}$ filter inlet and outlet during the test to track the mercury concentration variations in near-real time. This was especially useful for the batch injection tests, because initially upon injection the mercury quickly dropped to its lowest level and then gradually increased with time.

\subsubsection{Coal and Flue Gas Analyses}

Table 6.2.4.2 summarizes the average flue gas compositions in the Belle Ayr coal flue gas for the tests. Since the coal used in this test is the same as that used in the PTC-BA-628, no proximate and ultimate coal analyses were completed for this test.

\subsubsection{Mercury Results for PTC-BA-629}

\section{Test 1 - Baseline}

Test 1 is a baseline test without carbon injection to establish mercury species in the Belle Ayr coal flue gas. Plotted in Figure 6.2.4.1, the Ontario Hydro results for this test show the inlet flue gas had $11.2 \mu \mathrm{g} / \mathrm{Nm}^{3}$ of total mercury with a dominant $83 \%$ elemental mercury, $13.7 \%$ oxidized mercury, and a low level of $3.2 \%$ particle-bound mercury. Mercury concentration in the outlet flue gas was reduced to $8.8 \mu \mathrm{g} / \mathrm{Nm}^{3}$ of total mercury, indicating approximately $21 \%$ inherent mercury removal across the Advanced Hybrid ${ }^{\mathrm{TM}}$ filter. Figure 6.2.4.2 depicts the temporal variation of mercury species across the system based on the CMM measurements during the baseline test and indicates that there was very low inherent mercury capture with the Advanced Hybrid ${ }^{\mathrm{TM}}$ filter for the Belle Ayr coal flue gas.

Table 6.2.4.2. PTC-BA-629 - Summary of the Flue Gas Compositions During the PilotScale Test, dry basis

\begin{tabular}{cccccccc}
\hline & $\mathrm{O}_{2}, \%$ & $\mathrm{CO}_{2}, \%$ & $\mathrm{CO}, \mathrm{ppm}$ & $\mathrm{NO}, \mathrm{ppm}$ & $\mathrm{NO}_{2}, \mathrm{ppm}$ & $\mathrm{SO}_{2}, \mathrm{ppm}$ & $\mathrm{HCl}, \mathrm{ppm}$ \\
\hline Average Inlet & 4.5 & 14.9 & 4.4 & 637 & 8.5 & 310 & 2.05 \\
\hline
\end{tabular}




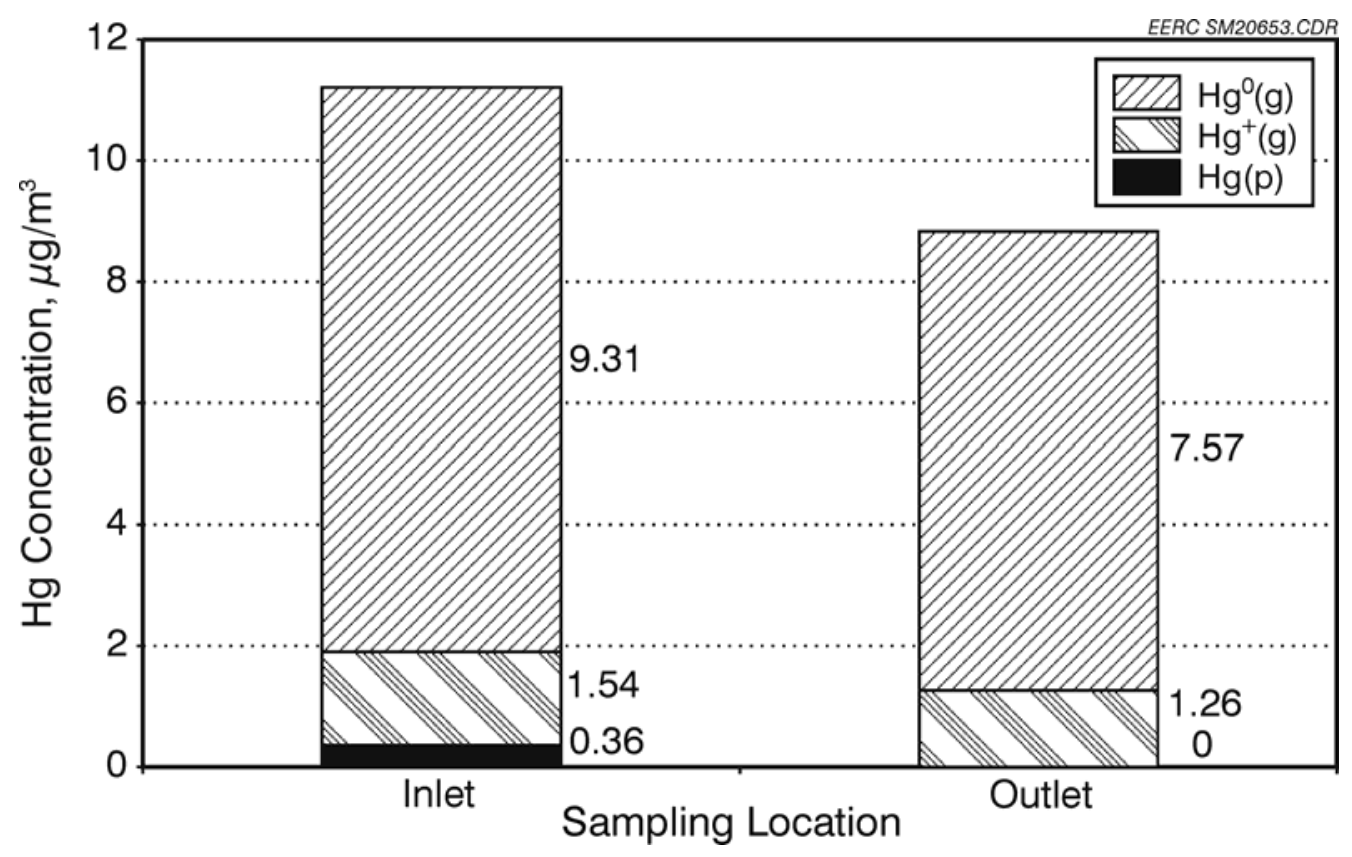

Figure 6.2.4.1. Mercury species across the Advanced Hybrid ${ }^{\mathrm{TM}}$ filter for the baseline test.

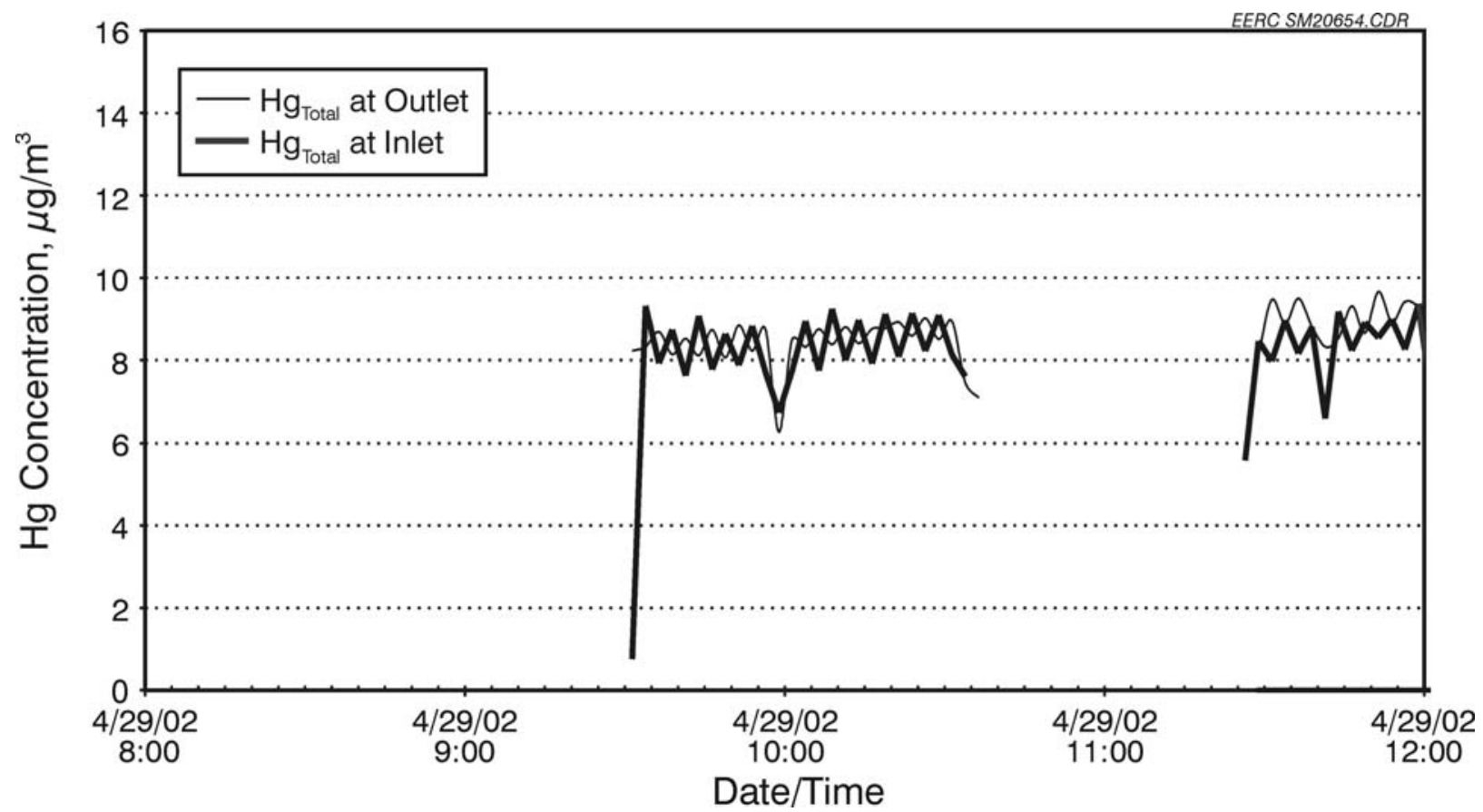

Figure 6.2.4.2. Temporal variation of mercury species across the system based on the CMM measurements during the baseline test. 
Figure 6.2.4.3 plots the six inlet Ontario Hydro sampling results obtained for the PTC-BA629 test along with the average of the six tests. The experimental data show a consistent low level of particle-bound mercury in the inlet flue gas, averaging only $0.2 \mu \mathrm{g} / \mathrm{m}^{3}$, while the average oxidized mercury was $2.8 \mu \mathrm{g} / \mathrm{m}^{3}$ and the average elemental mercury was $6.9 \mu \mathrm{g} / \mathrm{m}^{3}$ for a total average inlet mercury concentration of $9.9 \mu \mathrm{g} / \mathrm{m}^{3}$. The mercury removals were calculated based on the average inlet mercury concentration from all six inlet measurements.

Test 2 - $38 \mathrm{mg} / \mathrm{m}^{3}$ (2.4 lb/Macf) Continuous NORIT FGD Injection - Advanced Hybrid $^{\mathrm{TM}}$ Filter with 120-min Residence Time and 0.5-mA Current

To verify the mercury removal obtained in the PTC-BA-628 test, the Advanced Hybrid TM filter was operated at $0.5-\mathrm{mA}$ corona current and 2-hr residence time with $38 \mathrm{mg} / \mathrm{m}^{3}$ (2.4 lb/Macf) continuous NORIT FGD carbon injection. Mercury measurements for Ontario Hydro sampling and CMMs are plotted in Figures 6.2.4.4 and 6.2.4.5. The CMM data indicate approximately $70 \%$ mercury removal when the system reached equilibrium, which is in reasonable agreement with the $76.3 \%$ mercury capture based on the Ontario Hydro measurement. The mercury removal efficiency under the present operating condition agrees well with the results of PTC-BA-628.

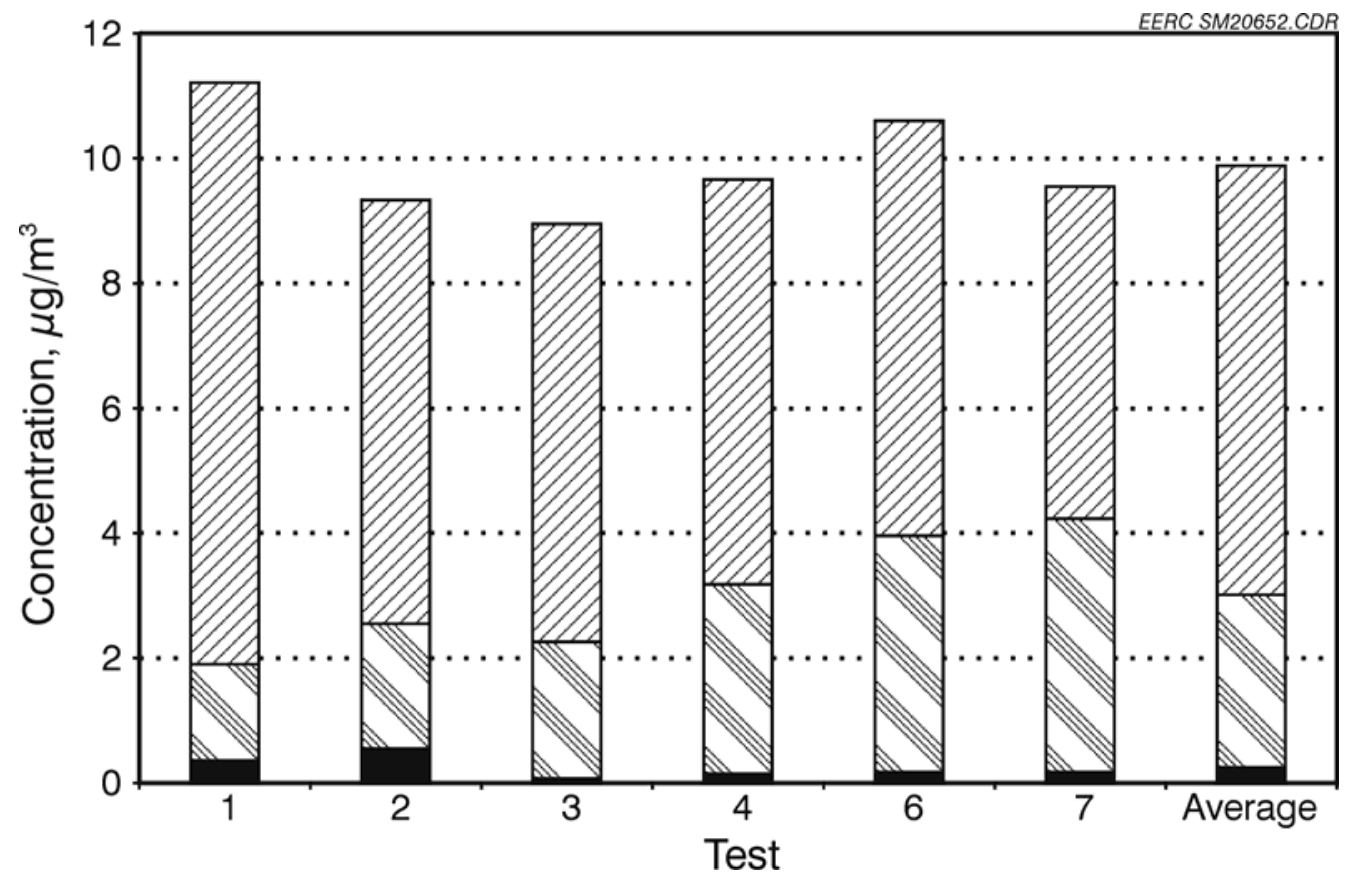

Figure 6.2.4.3. Summary of mercury species in Belle Ayr flue gas for PTC-BA-629 tests. 


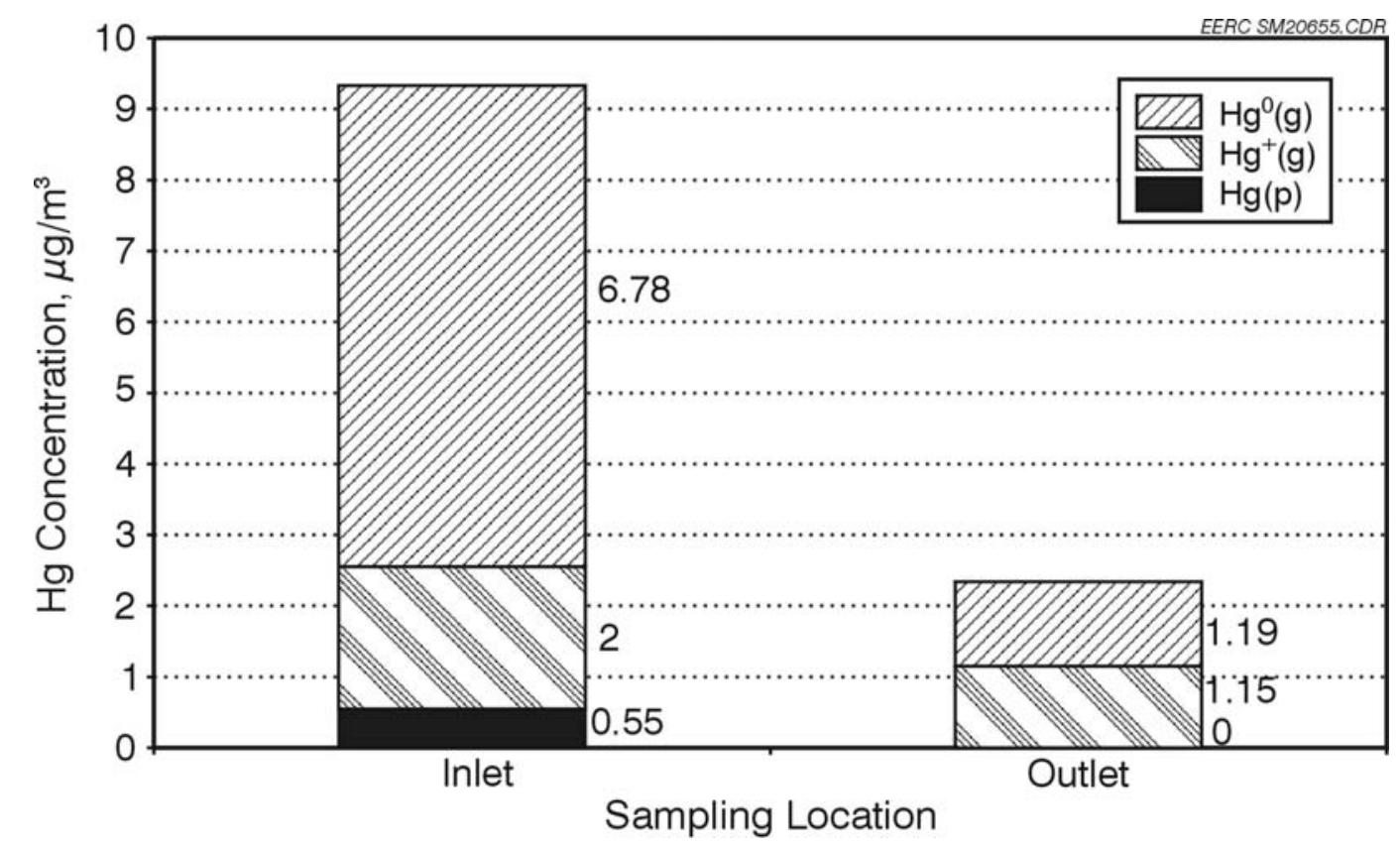

Figure 6.2.4.4. Mercury species across the Advanced Hybrid ${ }^{\mathrm{TM}}$ filter $(0.5 \mathrm{~mA})$ under $38 \mathrm{mg} / \mathrm{m}^{3}$ (2.4-lb/Macf) continuous FGD injection - Ontario Hydro results.

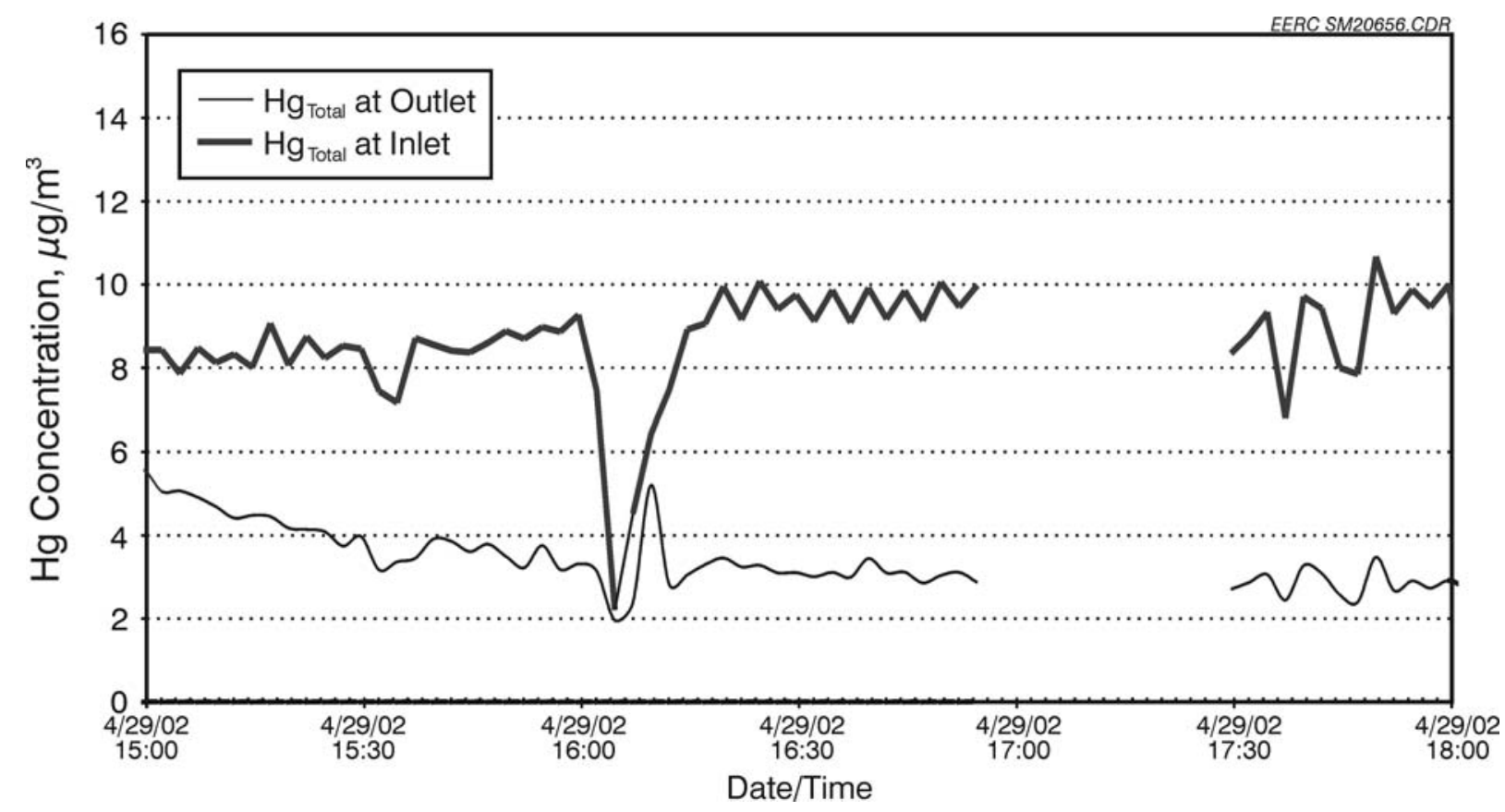

Figure 6.2.4.5. Mercury species across the Advanced Hybrid ${ }^{\mathrm{TM}}$ filter $(0.5 \mathrm{~mA})$ under $38 \mathrm{mg} / \mathrm{m}^{3}$ (2.4-lb/Macf) continuous FGD injection - CMM data. 
Test 3 - $38 \mathrm{mg} / \mathrm{m}^{3}$ (2.4 lb/Macf) Continuous NORIT FGD Injection - Advanced Hybrid $^{\mathrm{TM}}$ Filter with 120-min Residence Time and 3-mA Current

The Advanced Hybrid ${ }^{\mathrm{TM}}$ filter current was increased from 0.5 to $3 \mathrm{~mA}$ to see if the mercury removal would decrease significantly. Results shown in Figures 6.2.4.6 and 6.2.4.7 indicate a slight increase in mercury emissions at the higher current setting. Based the Ontario Hydro data, the removal decreased to $71.5 \%$ at the $3.0-\mathrm{mA}$ corona current compared to $76.3 \%$ at 0.5 -mA current, while the CMM data also indicate a small decrease in mercury capture at the higher current level. Since the Advanced Hybrid ${ }^{\mathrm{TM}}$ filter performed much better in terms of pulse interval and pressure drop control at the higher current, subsequent tests were completed at the higher current setting.

Test 4 - $19 \mathrm{mg} / \mathrm{m}^{3}$ (1.2 lb/Macf) Power-Off Batch NORIT FGD Injection - Advanced Hybrid $^{\mathrm{TM}}$ Filter with 120-min Residence Time and 3-mA Current

A total of $13.3 \mathrm{~g}$ of the NORIT FGD activated carbon was batch-injected into the flue gas entering the Advanced Hybrid ${ }^{\mathrm{TM}}$ filter at a time interval of every $2 \mathrm{hr}$, which corresponds to $19 \mathrm{mg} / \mathrm{m}^{3}$ (1.2 lb/Macf) carbon injection rate and an average carbon:mercury ratio of 3000:1.

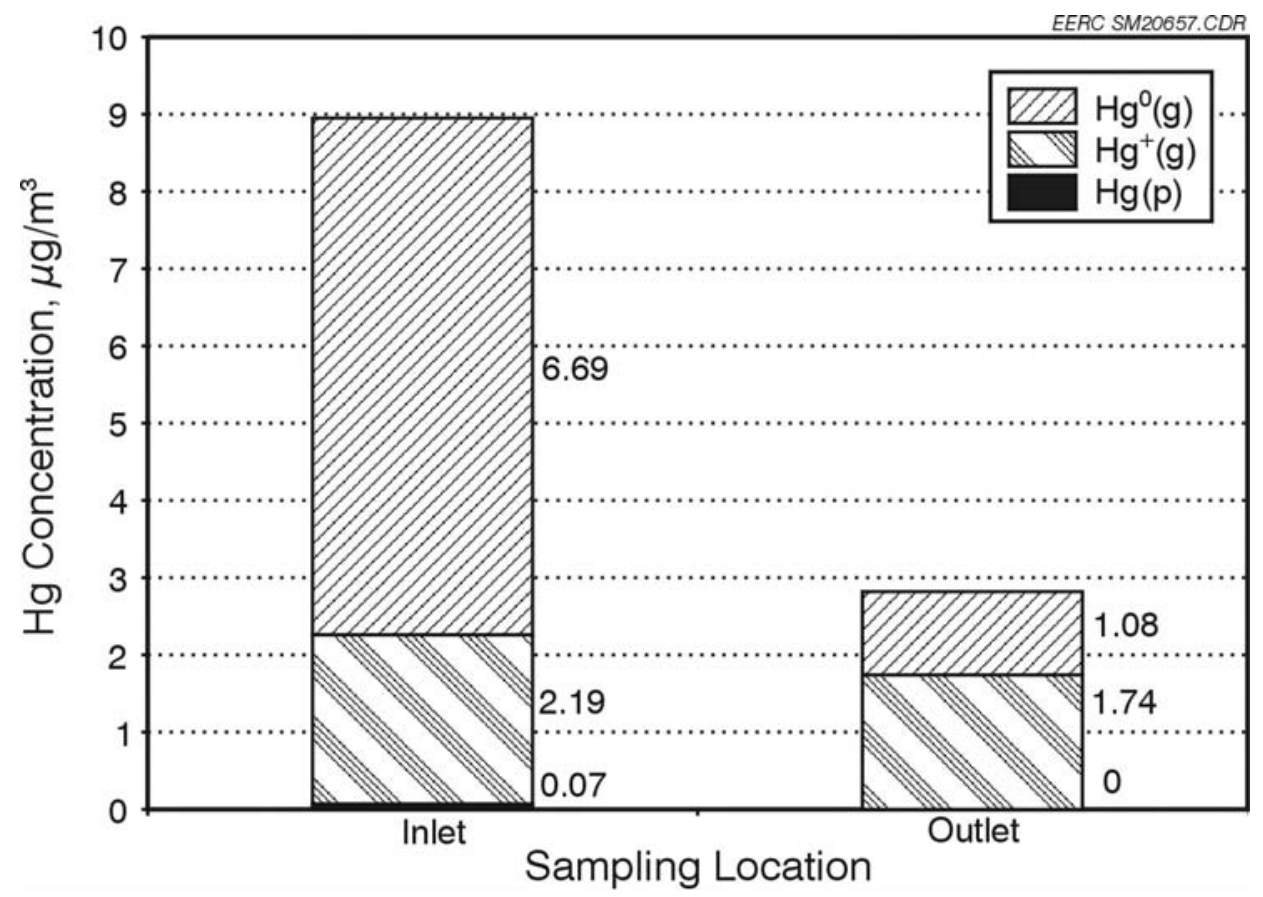

Figure 6.2.4.6. Mercury species across the Advanced Hybrid ${ }^{\mathrm{TM}}$ filter $(3 \mathrm{~mA})$ under $38 \mathrm{mg} / \mathrm{m}^{3}$ (2.4-lb/Macf) FGD continuous injection - Ontario Hydro results. 


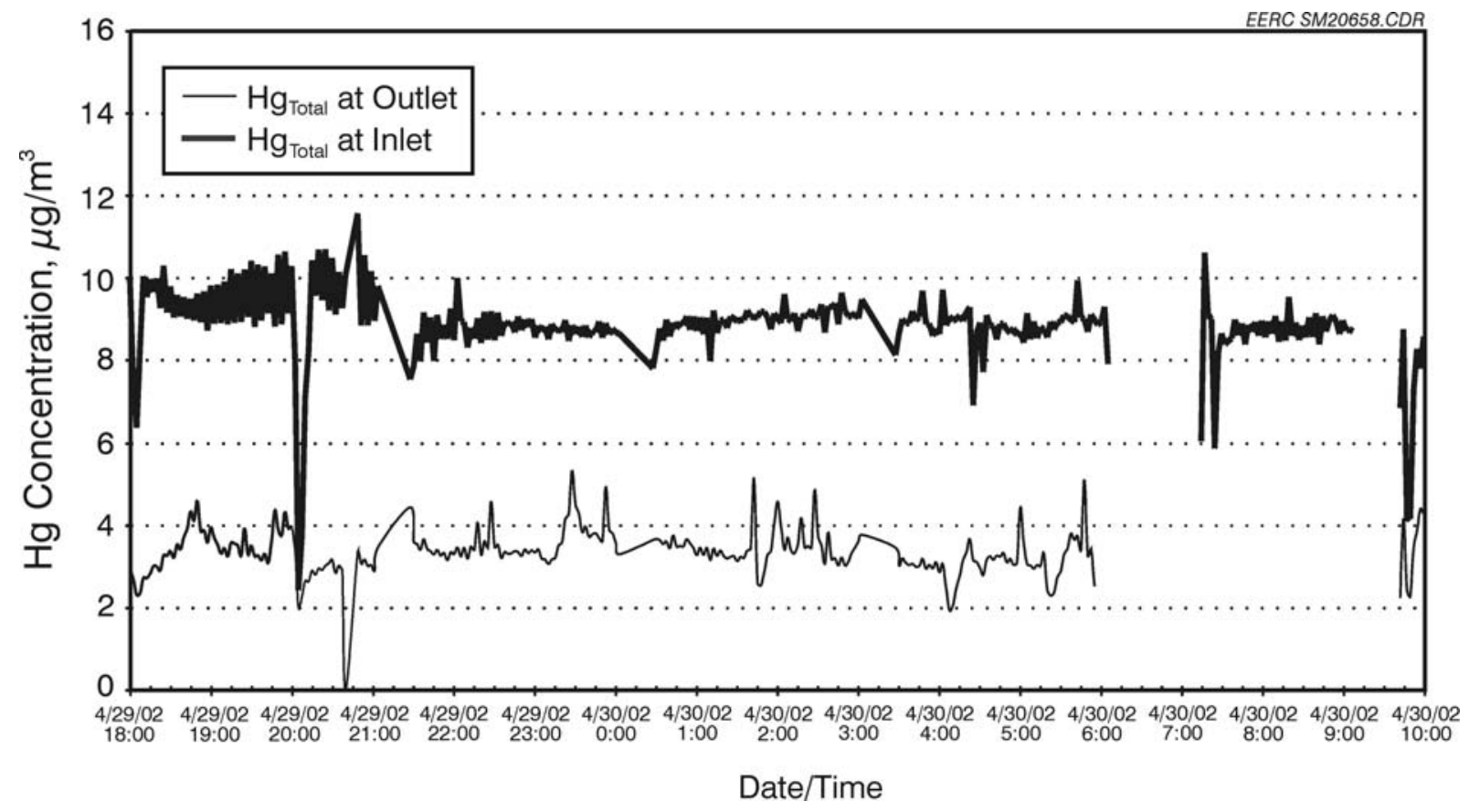

Figure 6.2.4.7. Mercury species across the Advanced Hybrid ${ }^{\mathrm{TM}}$ filter $(3 \mathrm{~mA})$ under $38 \mathrm{mg} / \mathrm{m}^{3}$ (2.4-lb/Macf) FGD continuous injection - CMM data.

During the batch injection, the Advanced Hybrid ${ }^{\mathrm{TM}}$ filter power was momentarily shut off to facilitate the carbon reaching the bags. The pressure drop across the system increased to $0.5 \mathrm{kPa}$ ( 2 in. W.C.) during the power-off batch injection, indicating that most of the carbon deposited on the filter bags where the carbon had good contact with the flue gas.

The CMM data (Figure 6.2.4.8) indicate that, within a few minutes of the power-off batch injection, the outlet mercury level dropped to near zero for approximately $30 \mathrm{~min}$. During this time, total mercury removal was well above $90 \%$. However, after this time, the emission slowly increased until at the end of $2 \mathrm{hr}$ it was close to the inlet level. Two Ontario Hydro samples (Figure 6.2.4.9) were collected at the Advanced Hybrid ${ }^{\mathrm{TM}}$ filter inlet and outlet over a single 2-hr cycle, and the outlet sampling result should represent the average mercury emission during the 2-hr time period. Based on both inlet and outlet Ontario Hydro sampling results, the overall mercury removal was $71.2 \%$ for the $19-\mathrm{mg} / \mathrm{m}^{3}$ (1.2-lb/Macf) power-off batch carbon injection. This represents an improvement in mercury control compared to $48.4 \%$ to $54.2 \%$ of mercury capture under the same carbon injection rate in continuous mode (PTC-BA-628), but it is still 


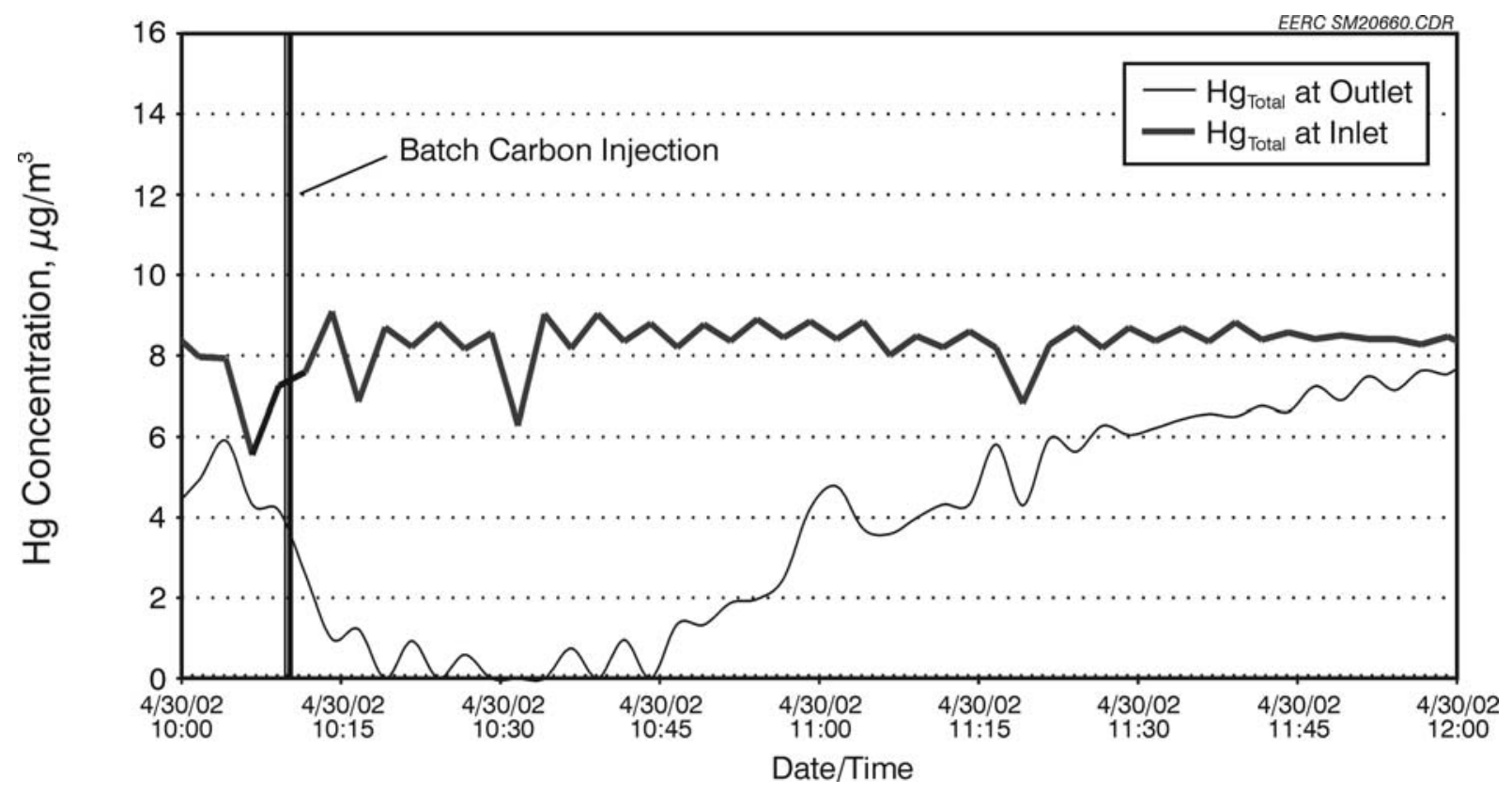

Figure 6.2.4.8. Temporal variation of mercury emission of mercury species across the Advanced Hybrid $^{\mathrm{TM}}$ filter ( $3 \mathrm{~mA}$ ) under $38 \mathrm{mg} / \mathrm{m}^{3}$ (2.4-lb/Macf) FGD continous injection - Ontario Hydro results during the $19 \mathrm{mg} / \mathrm{m}^{3}$ (1.2-lb/Macf) FGD power-off batch injection test.

lower than the goal of $90 \%$ removal. Mercury speciation in the outlet flue gas shows the NORIT FGD carbon efficiently oxidized mercury but could not capture all of it.

Test 5 - $38 \mathrm{mg} / \mathrm{m}^{3}$ (2.4 lb/Macf) Power-Off Batch NORIT FGD Injection - Advanced Hybrid $^{\mathrm{TM}}$ Filter with 120-min Residence Time and 3-mA Current

In Test 5, the amount of carbon injected every $2 \mathrm{hr}$ was increased to $26.6 \mathrm{~g}(0.059 \mathrm{lb})$, equivalent to $38-\mathrm{mg} / \mathrm{m}^{3}$ (2.4-lb/Macf) carbon injection and an average carbon-to-mercury ratio of 6000:1. The Ontario Hydro data (Figure 6.2.4.10) indicate the mercury removal improved to $86.8 \%$, very close to the $90 \%$ removal goal. The CMM data (Figure 6.2.4.11) also show that the time of over $90 \%$ removal increased to about $1 \mathrm{hr}$ after injection. By the end of the 2 -hr interval, the mercury level reached only about $50 \%$ of the inlet level. Again, NORIT FGD carbon demonstrated efficient mercury oxidation, as well as capture. 


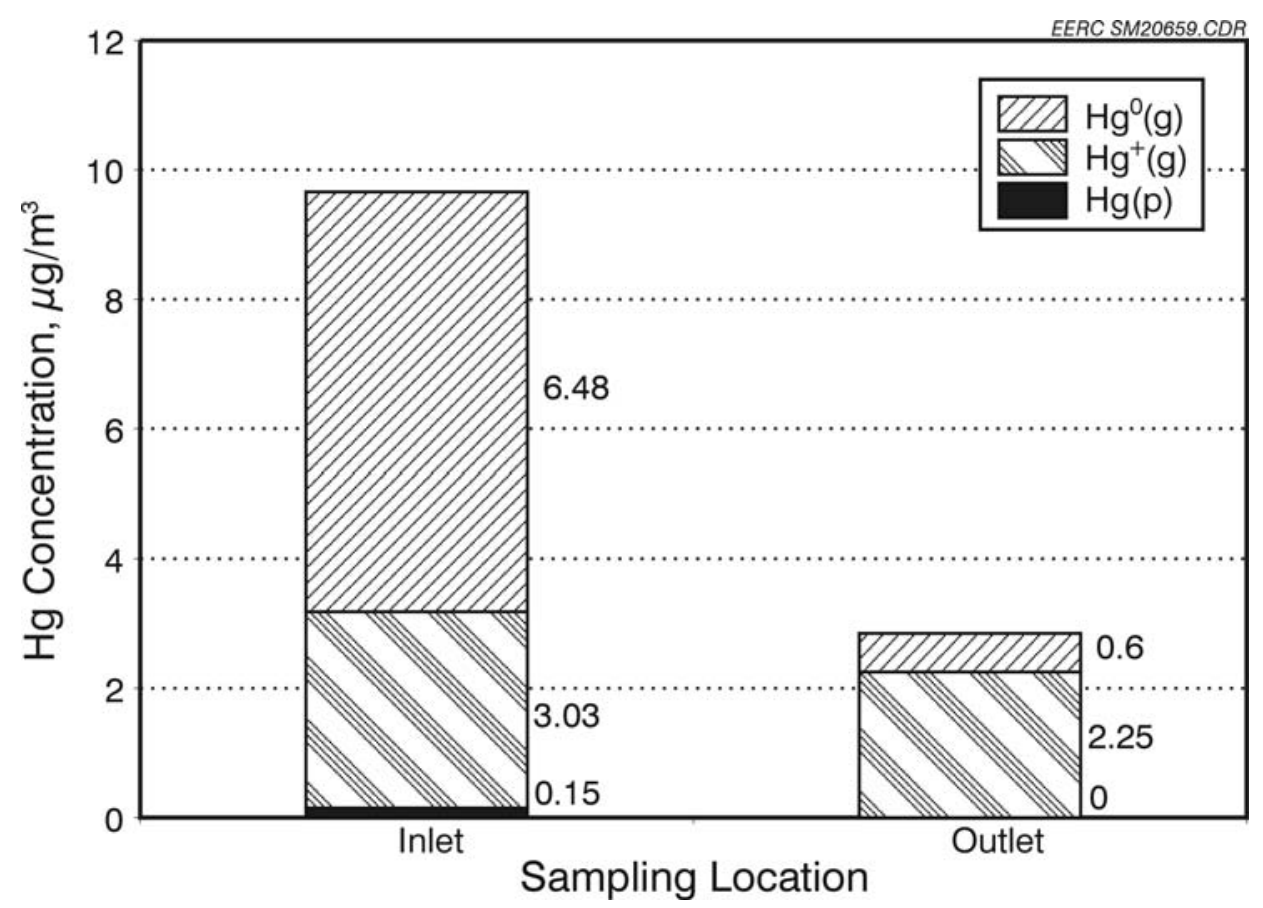

Figure 6.2.4.9. Mercury species across the Advanced Hybrid ${ }^{\mathrm{TM}}$ filter with $19 \mathrm{mg} / \mathrm{m}^{3}$ (1.2-lb/Macf) FGD power-off batch injection.

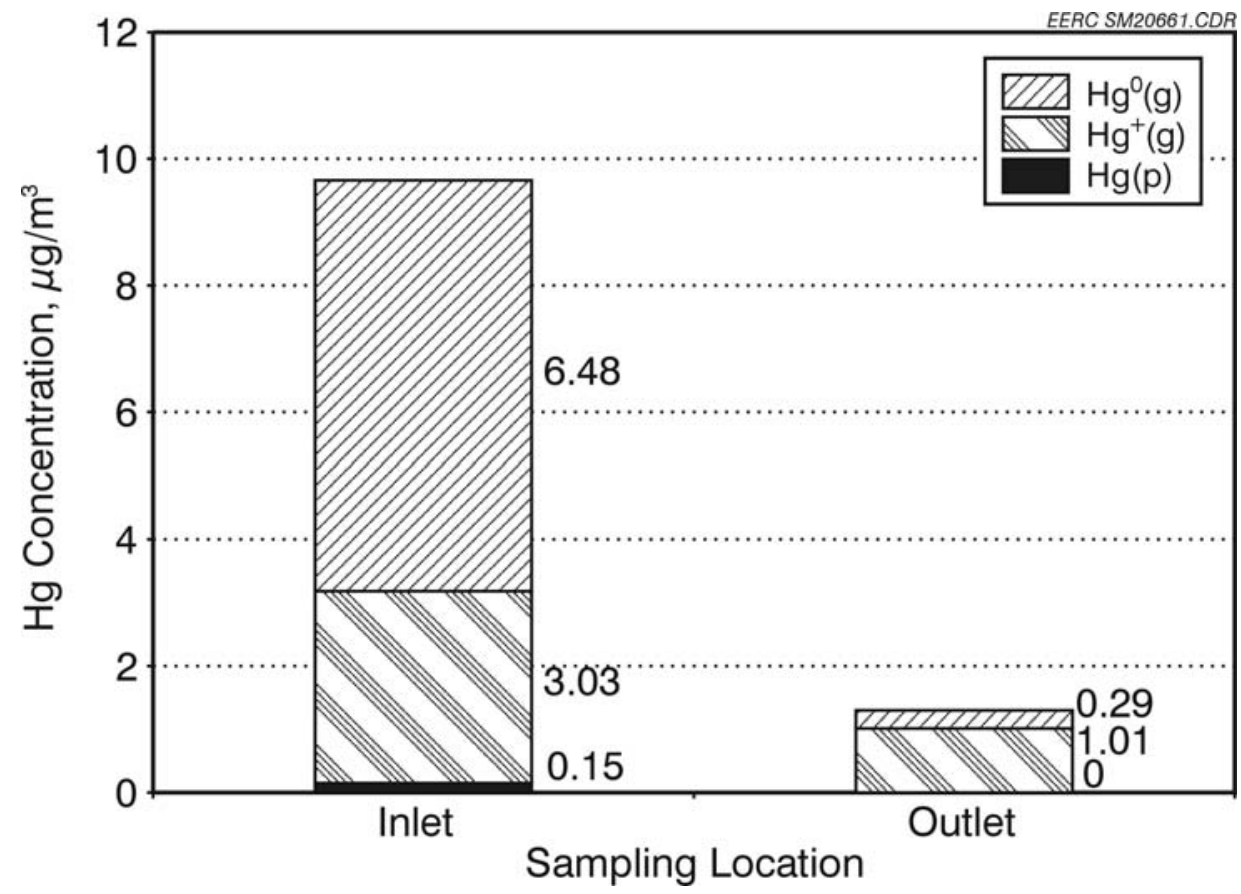

Figure 6.2.4.10. Mercury species across the Advanced Hybrid ${ }^{\mathrm{TM}}$ filter under $38 \mathrm{mg} / \mathrm{m}^{3}$ (2.4-lb/Macf) FGD power-off batch injection. 


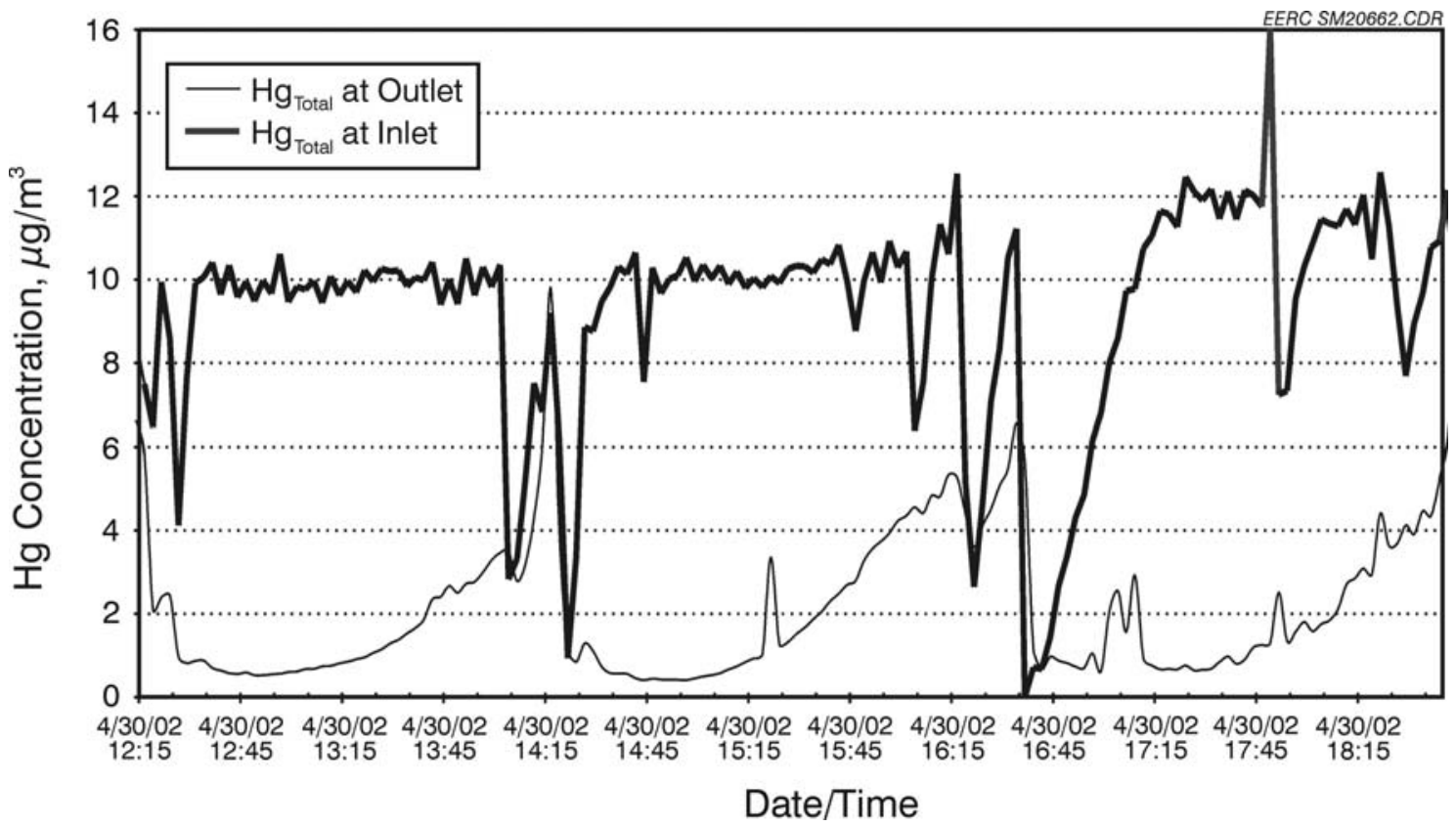

Figure 6.2.4.11. Temporal variations of mercury emission of the Advanced Hybrid ${ }^{\mathrm{TM}}$ filter under $38 \mathrm{mg} / \mathrm{m}^{3}$ (2.4-lb/Macf) FGD power-off batch injection test.

\section{Test 6 - $38 \mathrm{mg} / \mathrm{m}^{3}$ (2.4 lb/Macf) Power-On Batch NORIT FGD Injection - Advanced Hybrid $^{\mathrm{TM}}$ Filter with 120-min Residence Time and 3-mA Current}

The previous two tests clearly showed improved mercury capture with power-off batch injection, but that approach may not be as practical as batch injection while maintaining the Advanced Hybrid ${ }^{\mathrm{TM}}$ filter power. Test 6 was similar to Test 5 except the power remained on during the batch injection. The calculated removal efficiency based on the Ontario Hydro data (Figure 6.2.4.12) was reduced to $75.5 \%$, but was still somewhat better than the $71.5 \%$ removal seen with continuous injection in Test 3 under otherwise similar conditions.

The CMM data (Figure 6.2.4.13) show mercury temporal variation over multiple injection cycles and indicate some differences compared to the power-off batch injection test. After each injection, the mercury emission did not drop as low as in the previous power-off batch injection test, and it started to increase immediately. This suggests that the carbon was not as well exposed to the flue gas as with the power-off batch injection. From inspection through sight ports of the flow patterns and dust deposition in the Advanced Hybrid ${ }^{\mathrm{TM}}$ filter, a significant fraction of the dust deposited on the outside walls away from the main gas flow region. Altering the inlet 


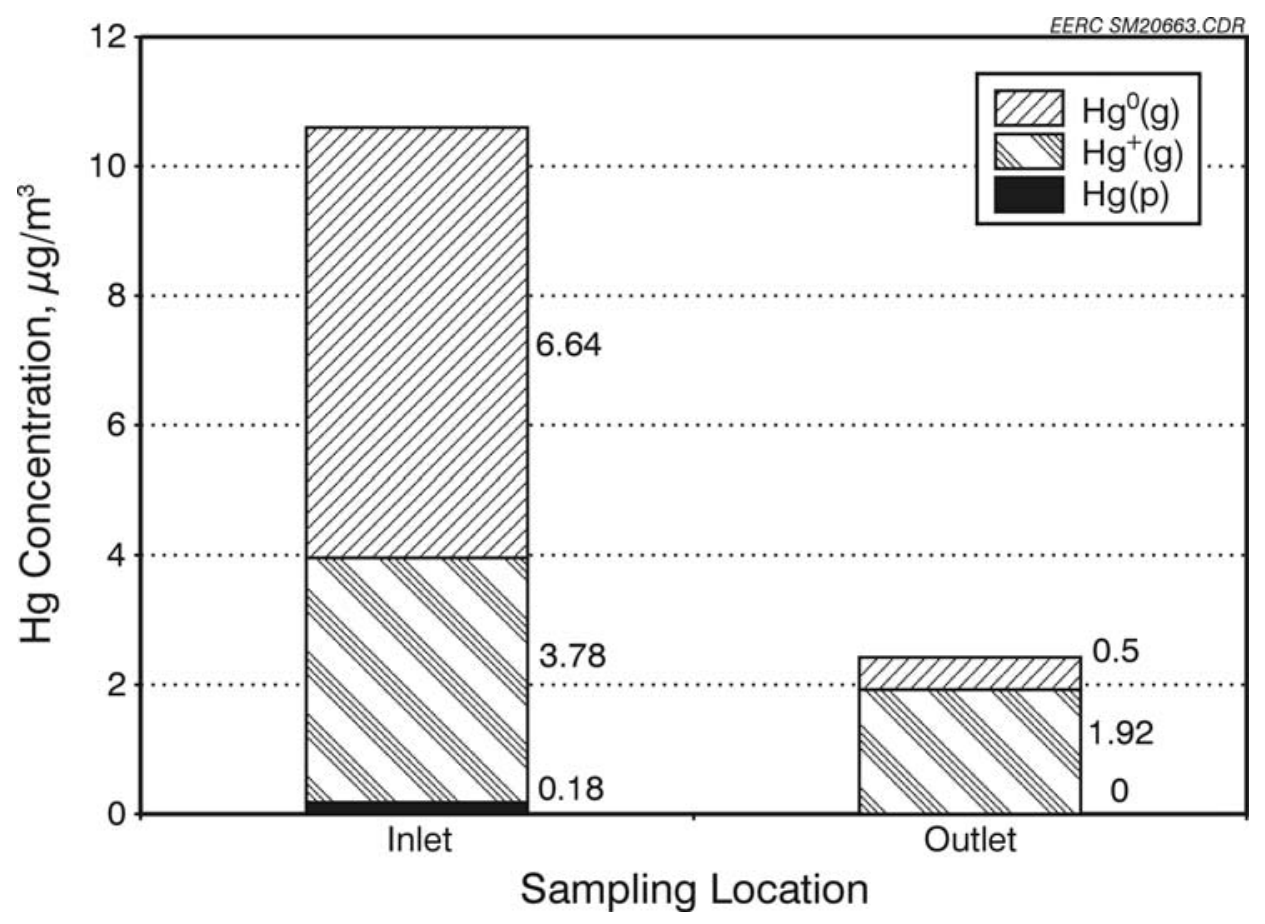

Figure 6.2.4.12. Mercury species across the Advanced Hybrid ${ }^{\mathrm{TM}}$ filter under $38 \mathrm{mg} / \mathrm{m}^{3}$ (2.4-lb/Macf) FGD power-on batch injection.

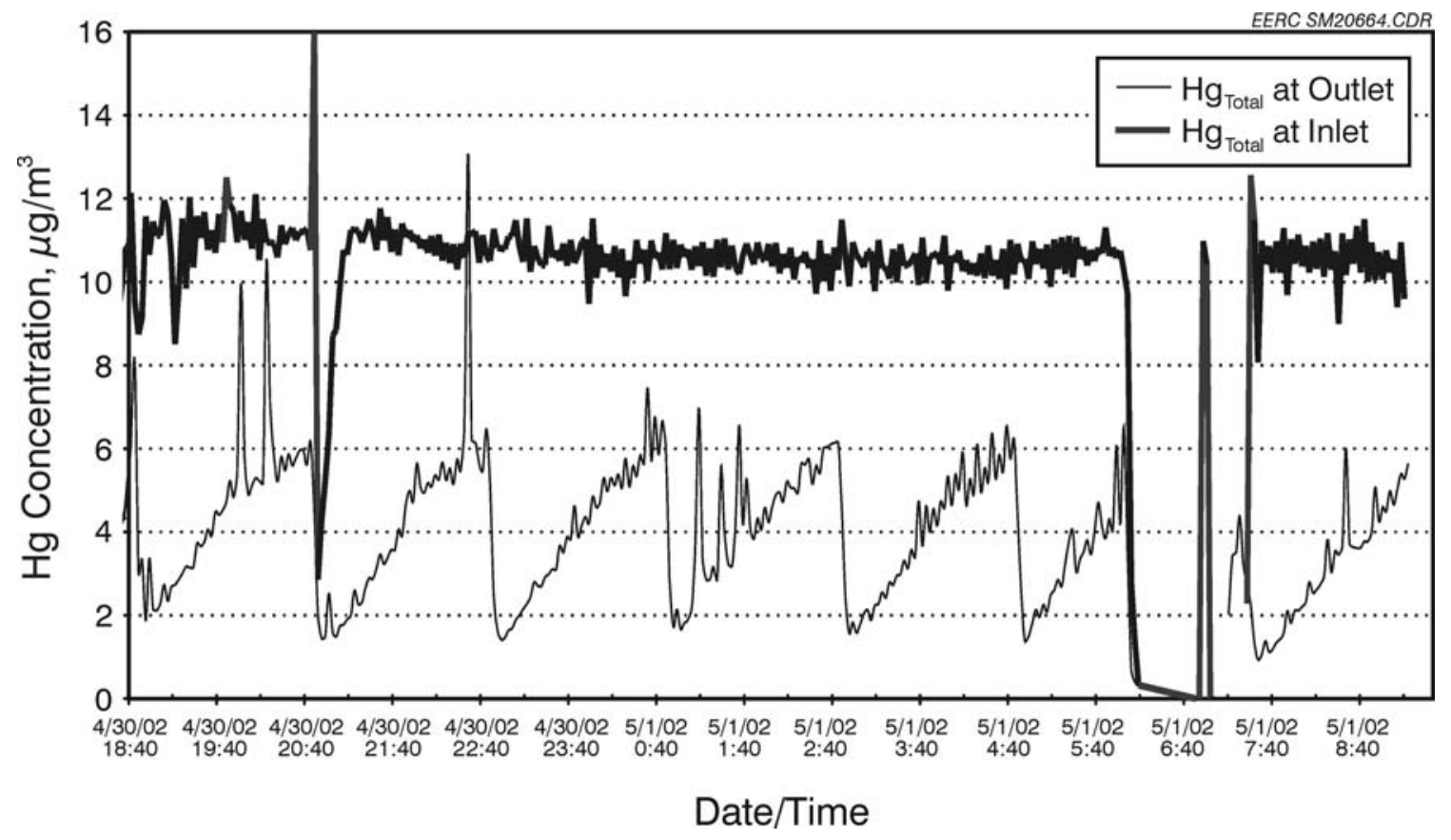

Figure 6.2.4.13. Temporal variations of mercury emission of the Advanced Hybrid ${ }^{\mathrm{TM}}$ filter under $38 \mathrm{mg} / \mathrm{m}^{3}$ (2.4-lb/Macf) FGD power-on batch injection. 
configuration to force the gas flow between the discharge electrodes and perforated plates would likely improve the carbon-flue gas contact.

\section{Test 7 - $19 \mathrm{mg} / \mathrm{m}^{3}$ (1.2 lb/Macf) Continuous NORIT FGD Injection - Advanced Hybrid $^{\mathrm{TM}}$ Filter with 120-min Residence Time and 3-mA Current}

Another test was completed with a continuous $19-\mathrm{mg} / \mathrm{m}^{3}$ (1.2-lb/Macf) NORIT FGD injection, corresponding to carbon-to-mercury ratio of $3000: 1$, to verify the previous results and to determine if extended operational time might result in a gradual increase in mercury removal as a result of carbon buildup in the system. The Ontario Hydro results (Figure 6.2.4.14) indicate only a $41.7 \%$ removal, which is somewhat lower than the results from the previous run (PTCBA-628) under the same carbon injection rate. However, the mercury monitor data (Figure 6.2.4.15) indicate about $60 \%$ removal over an extended time and show the very steady level of control that is maintained with continuous injection.

\subsubsection{Conclusions from the PTC-BA-629 Testing Results}

Figure 6.2.4.16 summarizes mercury removal efficiencies for the seven tests completed in PTC-BA-629. From these data, the removal efficiency of the Advanced Hybrid ${ }^{\mathrm{TM}}$ filter is not only dependent on the carbon addition rate, but can be improved by batch injection. Over 70\%

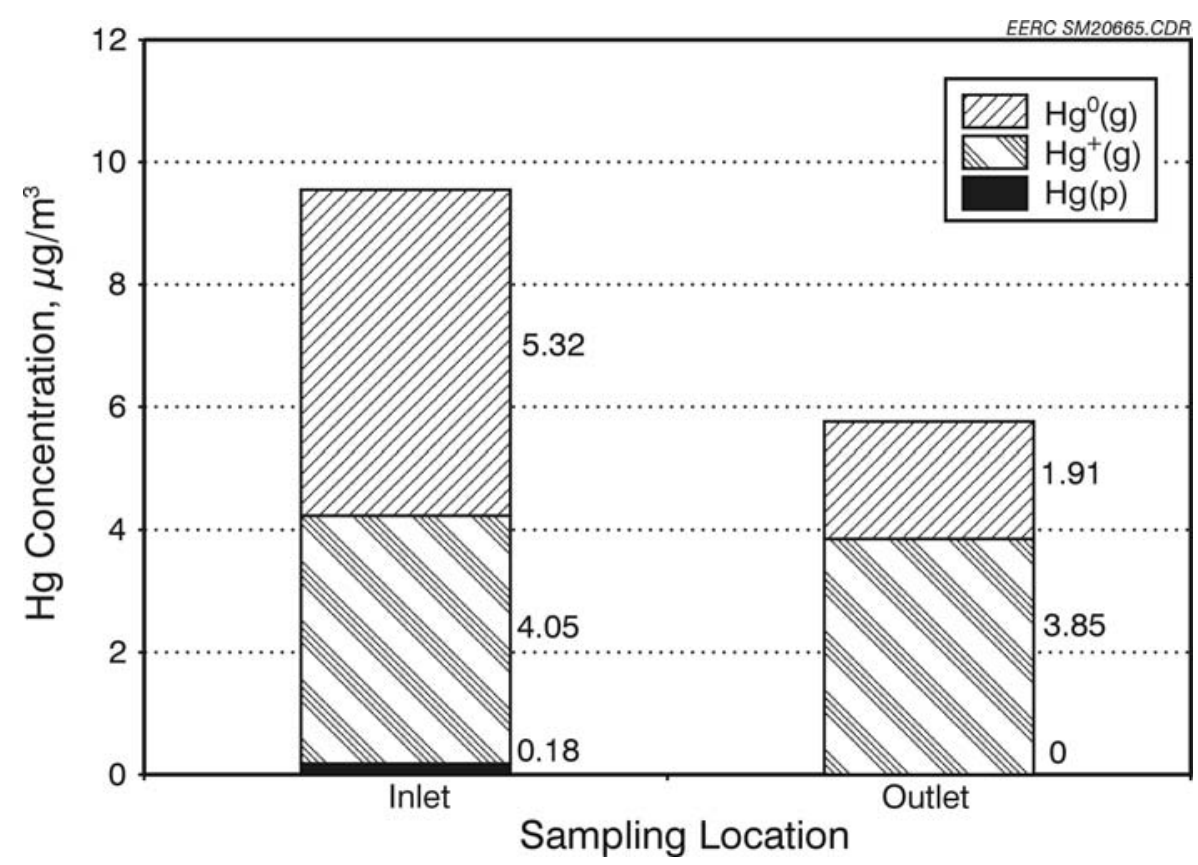

Figure 6.2.4.14. Mercury species across the Advanced Hybrid ${ }^{\mathrm{TM}}$ filter under $19 \mathrm{mg} / \mathrm{m}^{3}$ (1.2-lb/Macf) FGD continuous injection. 


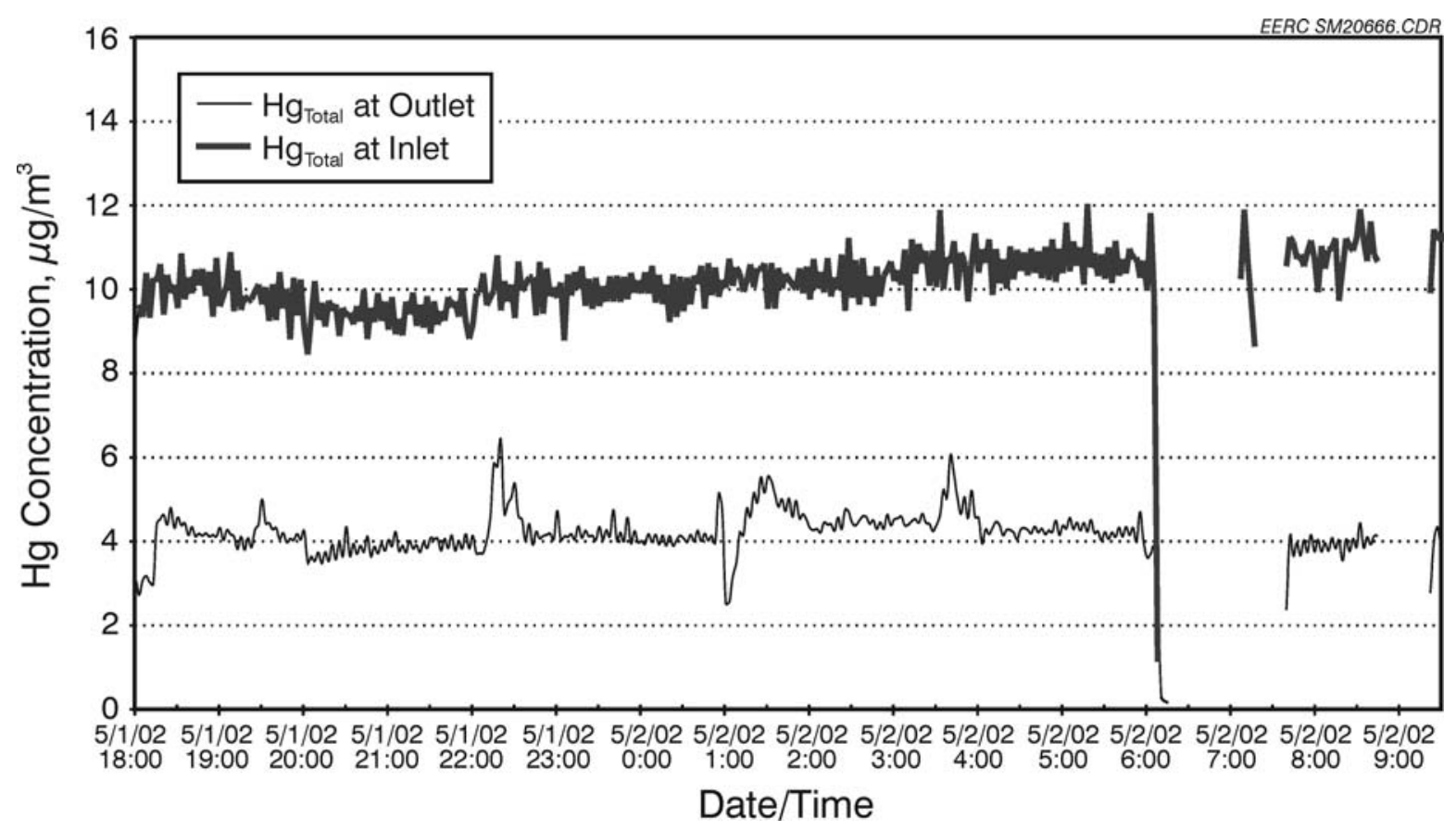

Figure 6.2.4.15. Temporal variations of mercury emission of the Advanced Hybrid ${ }^{\mathrm{TM}}$ filter under $19 \mathrm{mg} / \mathrm{m}^{3}$ (1.2-lb/Macf) FGD continuous injection.

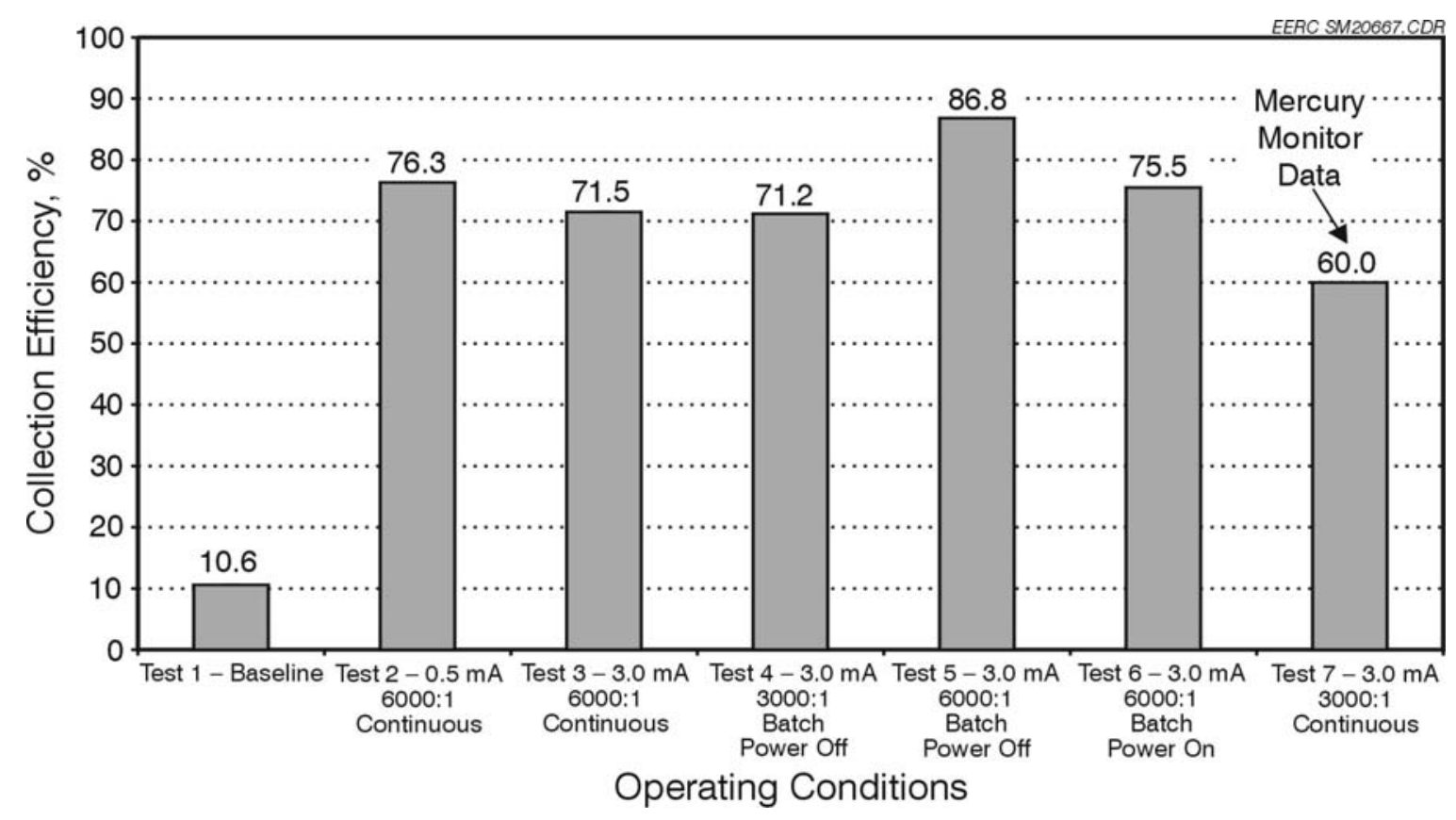

Figure 6.2.4.16. Comparisons of mercury removal with Advanced Hybrid ${ }^{\mathrm{TM}}$ filter under both continuous and batch carbon injection. 
removal was seen for all of the injection tests except for the last test. This suggests that excellent mercury removal can be achieved with the Advanced Hybrid ${ }^{\mathrm{TM}}$ filter, even for the difficult case seen here with very little natural capture of mercury by the fly ash and primarily elemental mercury at the inlet. To increase the capture above the $90 \%$ level will require further optimization of the Advanced Hybrid ${ }^{\mathrm{TM}}$ filter and injection mode and may require a higher carbon addition rate or a more effective sorbent. Modification of the pilot-scale Advanced Hybrid $^{\mathrm{TM}}$ filter inlet configuration is expected to improve mercury capture by keeping more of the carbon in the main flow region within the Advanced Hybrid ${ }^{\mathrm{TM}}$ filter housing.

A comparison of batch injection of sorbent with continuous injection showed that mercury removal was improved with the batch injection. Tests with power-off batch injection compared to power-on injection showed $87 \%$ removal was seen when the power was momentarily shut off during injection, compared to $75 \%$ removal with power-on batch injection. The power-off injection should result in most of the sorbent reaching the filter bag surface where the best gassolid contact occurs. However, during the power-on injection, a fraction of the sorbent collected on the outside walls. With a modified inlet configuration, the benefit of power-off injection may be negligible.

During the power-off batch injection cycles, the mercury removal was well over $90 \%$ for the first half of each cycle. This is encouraging because it indicates that over $90 \%$ removal is possible with the low-cost FGD sorbent and that with further optimization, $90 \%$ control should be achievable, even for a coal that produces mostly elemental mercury and with little natural mercury capture in the fly ash.

\subsubsection{PTC-SC-632}

\subsubsection{Test Conditions}

The primary purpose of this 1-week test was to establish the mercury species baseline across the Advanced Hybrid ${ }^{\mathrm{TM}}$ filter with a bituminous coal flue gas. For this test, Shade Creek bituminous coal was selected and burned in the pilot-scale unit. The run was designated as PTCSC-632, where "SC" refers to the Shade Creek coal burned in this test, Table 6.2.5.1 lists the three tests that were completed. The pilot-scale unit was continuously operated to proved baseline mercury speciation data with the Shade Creek coal flue gas with both the Advanced Hybrid $^{\mathrm{TM}}$ filter and a PJBH. In the Advanced Hybrid ${ }^{\mathrm{TM}}$ filter mode, the corona current was 
Table 6.2.5.1. PTC-SC-632 - Test Parameters

\begin{tabular}{lcc}
\hline Test No. & Mode & Residence Time \\
\hline 1 & Advanced Hybrid ${ }^{\mathrm{TM}}$ Filter $2 \mathrm{~mA}$ & $30 \mathrm{~min}$ \\
2 & Advanced Hybrid & $>24 \mathrm{hr}$ \\
3 & Pulse jet & $30 \mathrm{~min}$ \\
\hline
\end{tabular}

$2 \mathrm{~mA}$, while the fly ash residence time in the hopper was $30 \mathrm{~min}$ and $>24$ hour, respectively, to evaluate the residence time effect on mercury species. Having finished Tests 1 and 2, we switched to the PJBH to compare mercury species between the Advanced Hybrid ${ }^{\mathrm{TM}}$ filter and the PJBH. The PJBH was pulse-cleaned under a trigger pressure of $2.0 \mathrm{kPa}$ (8.0 in. W.C.), and the hopper ash was emptied every $30 \mathrm{~min}$. Ontario Hydro samples were collected at the unit inlet and outlet for each test to determine the mercury species in the flue gas.

\subsubsection{Coal Analysis}

Table 6.2.5.2 lists the analysis results for Shade Creek coal, including proximate and ultimate data, and the mercury and chlorine concentrations in the raw coal. Compared to low levels of chlorine and sulfur in the Cordero Rojo complex $(0.31 \%$ of sulfur and $14.7 \mathrm{ppm}$ of chlorine) and Belle Ayr (0.38\% of sulfur and 22.5 ppm of chlorine), Shade Creek coal has $1.48 \%$ sulfur and $314 \mathrm{ppm}$ of chlorine in raw coal. Based upon the averaged $0.173 \mu \mathrm{g} / \mathrm{g}$ mercury in coal and data from proximate and ultimate analyses, the Shade Creek coal is expected to have $17.6 \mu \mathrm{g} / \mathrm{m}^{3}$ (dry flue gas, $3 \% \mathrm{O}_{2}$ ) of mercury in the flue gas.

\subsubsection{Mercury Results for PTC-SC-632}

Plotted in Figure 6.2.5.1 are one Ontario Hydro result at the unit inlet and two Ontario Hydro results at the unit outlet when the unit was operated in the Advanced Hybrid ${ }^{\mathrm{TM}}$ filter mode with 2.0-mA corona current and 30-min fly ash residence time. The inlet data indicate 15.1 $\mu \mathrm{g} / \mathrm{m}^{3}$ oxidized mercury, $1.3 \mu \mathrm{g} / \mathrm{m}^{3}$ elemental mercury, and $2.9 \mu \mathrm{g} / \mathrm{m}^{3}$ particulate mercury. The two outlet samples indicate the mercury was primarily oxidized with only 1.1 to $1.9 \mu \mathrm{g} / \mathrm{m}^{3}$ of elemental mercury. The $2.9 \mu \mathrm{g} / \mathrm{m}^{3}$ particle-bound mercury for the inlet sample and the evidence that no mercury removal occurred across the Advanced Hybrid ${ }^{\mathrm{TM}}$ filter suggest that some desorption occurred across the Advanced Hybrid ${ }^{\mathrm{TM}}$ filter. However, the $2.9 \mu \mathrm{g} / \mathrm{m}^{3}$ particle-bound mercury may be caused by the additional mercury adsorption on the inlet sampling filter. 
Table 6.2.5.2. PTC-SC-632 - Coal Analysis

\begin{tabular}{lcc}
\hline Proximate Analysis, wt $\%$ & As Sampled & Moisture-Free \\
\hline Moisture Content & 2.1 & $\mathrm{NA}$ \\
Volatile Matter & 23.22 & 23.72 \\
Fixed Carbon & 63.1 & 64.46 \\
Ash & 11.57 & 11.82 \\
\hline Ultimate Analysis, $\mathrm{wt} \%$ & & \\
\hline Hydrogen & 4.46 & 7.32 \\
Carbon & 75.94 & 1.68 \\
Nitrogen & 1.64 & 1.48 \\
Sulfur & 1.45 & 3.14 \\
Oxygen & 4.93 & 11.82 \\
Ash & 11.57 & 13,129 \\
Heating Value, Btu/lb & 12,855 & 314 \\
Chloride Concentration, dry coal basis, $\mu \mathrm{g} / \mathrm{g}$ & & \\
\hline Hg Concentration, dry coal basis, $\mu \mathrm{g} / \mathrm{g}$ & & 0.175 \\
\hline Day 1 & & 0.18 \\
Day 2 & & 0.165 \\
Day 3 & & 0.173 \\
Mean & & \\
\hline
\end{tabular}

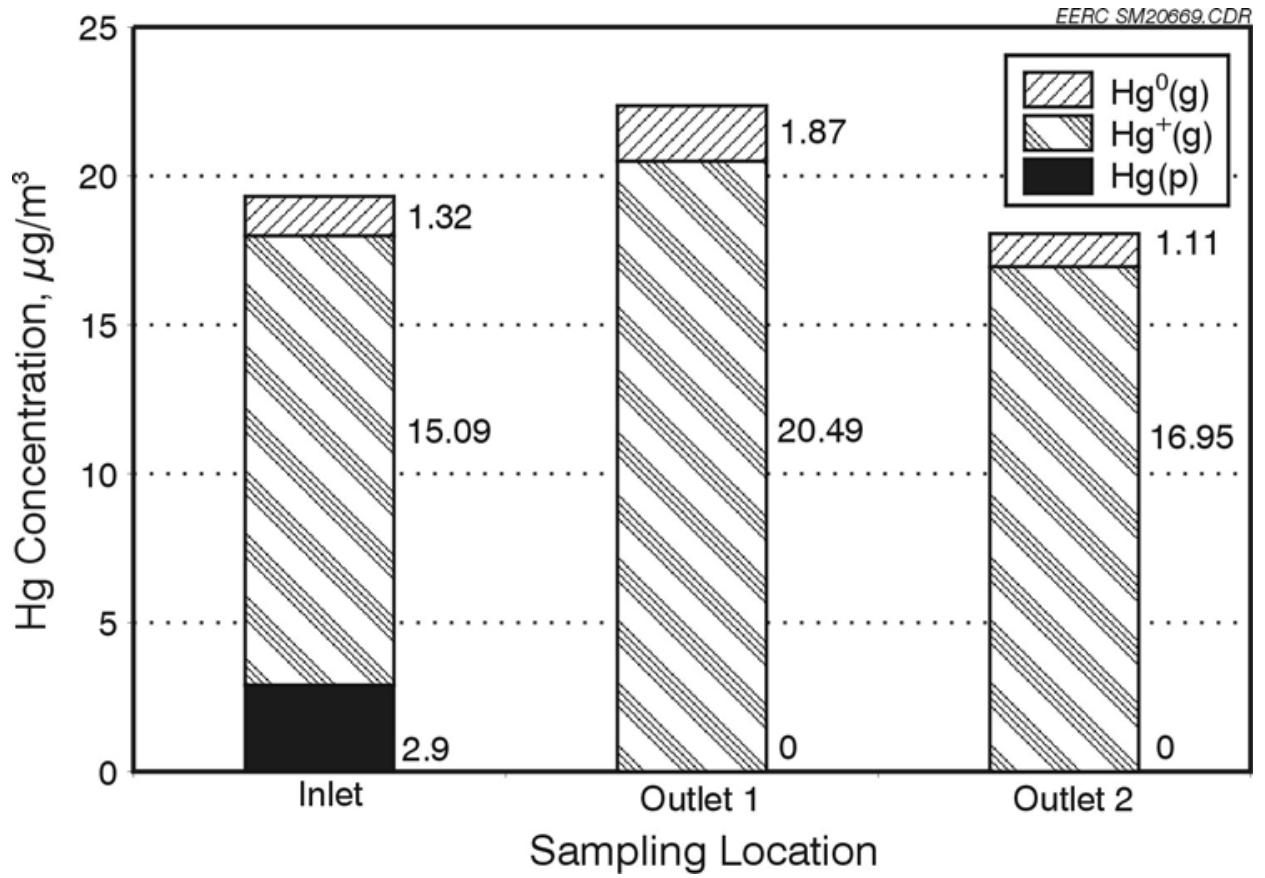

Figure 6.2.5.1. Mercury species across the Advanced Hybrid ${ }^{\mathrm{TM}}$ filter in Shade Creek flue gas 30-min residence time. 
For Test 2, the Advanced Hybrid ${ }^{\mathrm{TM}}$ filter was operated in a similar mode, except the hopper was not emptied for $24 \mathrm{hr}$. The Ontario Hydro data in Figure 6.2.5.2 indicate very different results compared to Test 1 . At the inlet, almost all of the mercury was in particulate form, and there was about $75 \%$ removal of mercury across the Advanced Hybrid ${ }^{\mathrm{TM}}$ filter. If all of the inlet mercury was associated with particulate, it would be expected to be captured in the Advanced Hybrid ${ }^{\mathrm{TM}}$ filter. The $3.8-5.0 \mu \mathrm{g} / \mathrm{m}^{3}$ of mercury emission at the Advanced Hybrid ${ }^{\mathrm{TM}}$ filter unit outlet suggests, again, there may have been desorption of mercury from the inlet ash upon the long exposure to the flue gas, or there was a fair fraction of oxidized mercury in the inlet flue gas, which was adsorbed on the inlet filter.

For Test 3, the unit was operated in pulse-jet mode, and the hopper was emptied every 30 min to maintain a constant half-hour residence time of fly ash in contact with flue gas. The inlet Ontario Hydro data in Figure 6.2.5.3 again show a high level of particulate mercury of $13.7 \mu \mathrm{g} / \mathrm{m}^{3}$, with $2.8 \mu \mathrm{g} / \mathrm{m}^{3}$ of oxidized mercury. The outlet mercury emission was $4.3 \mu \mathrm{g} / \mathrm{m}^{3}$ of

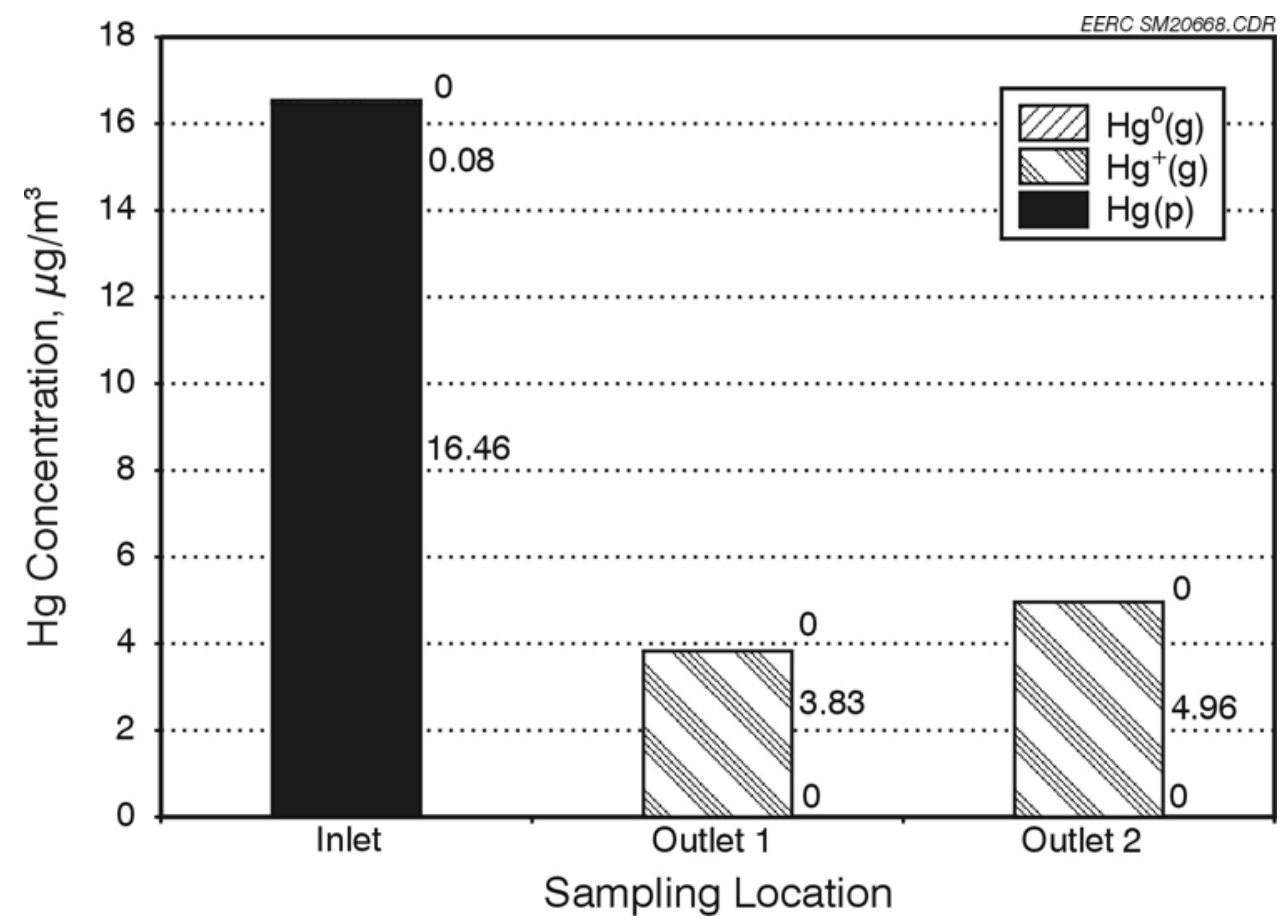

Figure 6.2.5.2. Mercury species across the Advanced Hybrid ${ }^{\mathrm{TM}}$ filter in Shade Creek flue gas 24-hr residence time. 


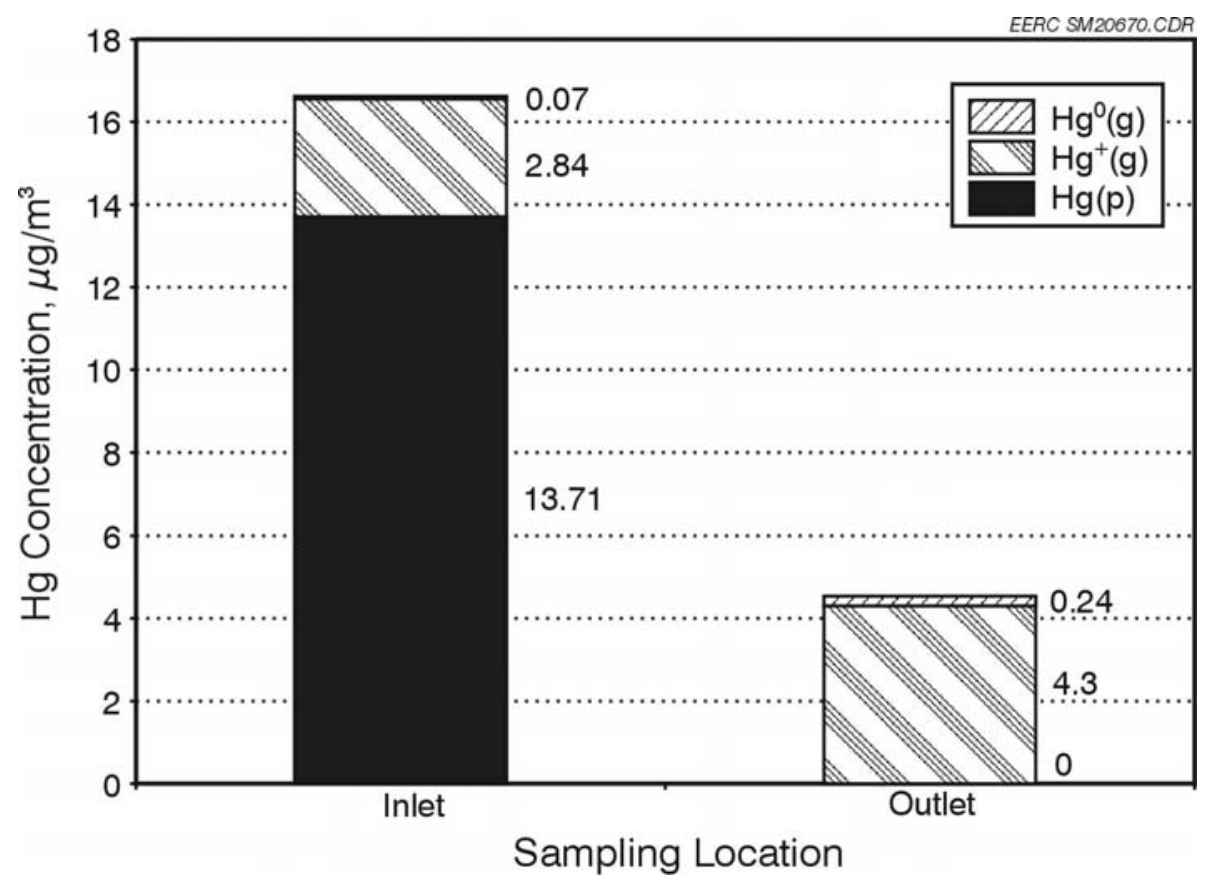

Figure 6.2.5.3. Mercury species across the PJBH in Shade Creek flue gas - 30-min residence time.

oxidized mercury and $0.24 \mu \mathrm{g} / \mathrm{m}^{3}$ of elemental mercury, indicating about $75 \%$ mercury capture across the PJBH.

To further understand the reason for the differences between Test 1 and Tests 2 and 3, the selected hopper ash and inlet filter ash were analyzed for mercury content and LOI, and Table 6.2.5.3 summarizes the analysis results. It became apparent that the differences of mercury species among the inlet Ontario Hydro samples were related to the amount of carbon in the ash. For Test 1 , the first inlet filter and hopper ash had similar mercury concentrations of about $0.35 \mu \mathrm{g} / \mathrm{g}$, and the LOI of the hopper ash was $10.85 \%$ (Table 6.2.5.3). However, the second hopper ash sample had almost five times more mercury, which corresponded to an LOI of $20.33 \%$. For Test 2, again, the inlet filter and hopper samples had high mercury levels corresponding to $20.66 \%$ LOI. For Test 3 , the results were similar, with a high ash mercury level and high LOI in the ash. An interesting result from these tests is the relationship between the carbon content of the ash and the mercury retention. The significant increase of mercury retention in ash when the fly ash LOI increased from $10 \%$ to $20 \%$ suggests that the characteristics of the carbon may be as important as the amount of carbon. 
Table 6.2.5.3. PTC-SC-632 - Mercury Concentration in Fly Ash

\begin{tabular}{lcccc}
\hline Test No. & Sample Type & Time Sample Taken & Hg Concentration, $\mu \mathrm{g} / \mathrm{g}$ & LOI, $\%$ \\
\hline 1 & Inlet filter & $6 / 03 / 0214: 00-16: 00$ & 0.362 & \\
& Hopper ash & $6 / 03 / 0216: 00$ & 0.344 & 10.85 \\
& Hopper ash & $6 / 04 / 027: 00$ & 1.64 & 20.33 \\
2 & Inlet filter & $6 / 05 / 028: 27-10: 27$ & 2.19 & \\
& Hopper ash & $6 / 05 / 0211: 00$ & $1.48-1.63$ & 20.66 \\
3 & Inlet filter & $6 / 05 / 0214: 00-16: 00$ & 1.55 & \\
& Hopper ash & $6 / 05 / 0216: 00$ & & 21.59 \\
\hline
\end{tabular}

The above experimental data indicate that the pilot-scale combustion unit cannot combust the Shade Creek coal completely because of the high carbon and low volatile matter with this coal, resulting in a high $10 \%-20 \%$ LOI in ash instead of $1 \%-5 \%$ LOI in a typical bituminous coal flue gas. Good combustion for this coal in the pilot-scale unit to produce low LOI may be difficult without burner modification.

One purpose of this run was to serve as the source of flue gas for a bench-scale breakthrough test, but because of the high carbon in the ash and varied mercury concentrations at the Advanced Hybrid ${ }^{\mathrm{TM}}$ filter outlet, the fixed-bed tests could not be completed.

\subsubsection{4 - Conclusions from PTC-SC-632 Testing Results}

A baseline test with an EB Shade Creek coal was completed. Fly ash analysis show high levels of LOI from $10 \%$ to $20 \%$ because of incomplete coal combustion.

At the $10 \%$ LOI level, there was minimal capture of mercury by the fly ash, but at $20 \%$ LOI, most of the mercury was retained by the fly ash. This suggests that the relationship between the amount of carbon in the ash and the level of mercury capture is complex and may depend more on critical carbon characteristics than on the amount of carbon present.

\subsubsection{PTC-SF-635}

\subsubsection{Test Conditions}

Results from the previous bituminous coal test (PTC-SC-632) indicate that the pilot-scale combustor cannot completely combust Shade Creek coal because of its high carbon level and low level of volatile matter. Therefore, we switched to Springfield coal, another bituminous coal, and evaluated mercury control technology with the Advanced Hybrid ${ }^{\mathrm{TM}}$ filter with this highsulfur EB coal flue gas. Care was taken to maintain good combustion conditions to avoid generating significant amounts of $\mathrm{CO}$ and to minimize the amount of unburned carbon in the ash. 
The planned variables to be evaluated included residence time of the ash in the Advanced Hybrid $^{\mathrm{TM}}$ filter chamber, activated carbon feed rate, and carbon injection method. Amended silicate developed by ADA, referred to as Sorbent $\mathrm{X}$ in this test, was an alternative sorbent tested for its effectiveness on mercury removal in the Advanced Hybrid ${ }^{\mathrm{TM}}$ filter. An additional unplanned variable tested included the Advanced Hybrid ${ }^{\mathrm{TM}}$ filter temperature. Because of the very poor mercury removal results seen at $135^{\circ} \mathrm{C}\left(275^{\circ} \mathrm{F}\right)$, additional tests were completed at $160^{\circ} \mathrm{C}\left(320^{\circ} \mathrm{F}\right)$. At the measured $\mathrm{SO}_{3}$ level of $31.7 \mathrm{ppm}, 135^{\circ} \mathrm{C}\left(275^{\circ} \mathrm{F}\right)$ is below the acid dew point. There was concern that operation below the acid dew point might be the cause of the poor mercury removal, so some tests were repeated at $160^{\circ} \mathrm{C}\left(320^{\circ} \mathrm{F}\right)$, which is well above the acid dew point for $31.7 \mathrm{ppm} \mathrm{SO}_{3}$. At the end of the testing period, limestone mixed with NORIT FGD was injected into the Advanced Hybrid ${ }^{\mathrm{TM}}$ filter to determine the combined effect on mercury removal. Table 6.2.6.1 is a summary of the tests completed.

Two CMMs monitored mercury species in flue gas at the Advanced Hybrid ${ }^{\mathrm{TM}}$ filter inlet and outlet continuously over the entire testing period. Ontario Hydro samples were collected for the selected tests to verify CMM measurements. The mercury sampling schedule is also listed in Table 6.2.6.1.

\subsubsection{Coal and Flue Gas Analyses}

Table 6.2.6.2 lists coal analysis data including proximate-ultimate analysis and concentrations of mercury and chlorine for the Springfield coal. The Springfield coal has 3.1\% of sulfur, $350 \mathrm{ppm}$ of chlorine, and $0.11 \mu \mathrm{g} / \mathrm{g}$ mercury. Combining a combustion calculation based on proximate and ultimate analysis results with mercury content in the raw coal, mercury concentration in the Springfield coal flue gas is expected to be $13.9 \mu \mathrm{g} / \mathrm{m}^{3}$ (dry flue gas, at $3.0 \%$ $\mathrm{O}_{2}$ ). Also included in Table 6.2.6.2 are the concentrations of the major and minor elements in the Springfield ashed coal as measured by x-ray fluorescence (XRF). Average flue gas concentrations for the test are shown in Table 6.2.6.3. The Springfield coal flue gas had a higher level of $\mathrm{NO}_{\mathrm{x}}$ than might be seen in full-scale boilers, especially with the implementation of low$\mathrm{NO}_{\mathrm{x}}$ burners. The high $\mathrm{NO}_{\mathrm{x}}$ level of $>1300 \mathrm{ppm}$ seen here is the result of trying to maintain very hot flame conditions with sufficient excess air to ensure good carbon burnout. Compared to the lower levels of chlorine and sulfur in WSB coal flue gases measured in previous pilot-scale tests, 
Table 6.2.6.1. Summary of the Test Scenarios for PTC-SF-635

\begin{tabular}{|c|c|c|c|c|c|c|}
\hline \multirow[b]{2}{*}{ Test } & \multirow[b]{2}{*}{ Description } & \multirow[b]{2}{*}{ Test Time } & \multirow[b]{2}{*}{ Mode } & \multirow[b]{2}{*}{ Temp, ${ }^{\circ} \mathrm{C}\left({ }^{\circ} \mathrm{F}\right)$} & \multicolumn{2}{|c|}{ Ontario Hydro Sample Times } \\
\hline & & & & & Inlet & Outlet \\
\hline 1 & Baseline, 30-min & Dec. $9,8: 42-16: 40$ & Advanced & $135(275)$ & $11: 05-13: 05$ & $11: 05-13: 05$ \\
\hline & residence time & & Hybrid ${ }^{\mathrm{TM}}$ Filter & & & $13: 45-15: 15$ \\
\hline 2 & Baseline, 24-hr residence & Dec. 9, 16:40-Dec.10, 17:04 & Advanced & $135(275)$ & $8: 36-10: 16$ & $8: 36-10: 16$ \\
\hline & time & & Hybrid $^{\mathrm{TM}}$ Filter & & & $13: 25-14: 55$ \\
\hline 3 & FGD, $7.5 \mathrm{~g} / \mathrm{hr}$ & Dec. 10, 17:04-18:20 & Advanced & $135(275)$ & $9: 46-10: 30$ & $9: 46-10: 30$ \\
\hline & & Dec. 10, 19:12-Dec.11 12:41 & Hybrid ${ }^{\mathrm{TM}}$ Filter & & & \\
\hline 4 & FGD, $37.5 \mathrm{~g} / \mathrm{hr}$ & Dec. 10, 18:20-18:32 & $\begin{array}{c}\text { Advanced } \\
\text { Hybrid }{ }^{\mathrm{TM}} \text { Filter }\end{array}$ & $135(275)$ & & \\
\hline 5 & FGD $37.5 \mathrm{~g} / \mathrm{hr}$ & Dec. 10, 18:32-18:57 & PJBH & $135(275)$ & & \\
\hline 6 & FGD $15 \mathrm{~g}$ power-off batch & Dec. $10,18: 57-19: 12$ & Advanced & $135(275)$ & & \\
\hline & & & Hybrid ${ }^{\mathrm{TM}}$ Filter & & & \\
\hline 7 & $\begin{array}{c}\text { FGD } 22.5 \text { g power-off } \\
\text { batch }\end{array}$ & Dec. $11,12: 41-13: 25$ & $\begin{array}{c}\text { Advanced } \\
\text { Hybrid }{ }^{\mathrm{TM}} \text { Filter }\end{array}$ & $135(275)$ & & \\
\hline 8 & FGD, $7.5 \mathrm{~g} / \mathrm{hr}$ & Dec. 11, 19:51-20:42 & Advanced & $160(320)$ & $9: 45-10: 45$ & $9: 45-10: 45$ \\
\hline & & Dec. 11, 22:12-Dec.12 10:30 & Hybrid ${ }^{\mathrm{TM}}$ Filter & & & \\
\hline 9 & $\mathrm{FGD}, 30 \mathrm{~g} / \mathrm{hr}$ & Dec. $11,20: 42-22: 12$ & $\begin{array}{c}\text { Advanced } \\
\text { Hybrid }{ }^{\mathrm{TM}} \text { Filter }\end{array}$ & $160(320)$ & & \\
\hline 10 & FGD, $7.5 \mathrm{~g} / \mathrm{hr}$ & Dec. $12,10: 30-10: 45$ & PJBH & $160(320)$ & & \\
\hline 11 & FGD $30 \mathrm{~g} / \mathrm{hr}$ & Dec. $12,10: 45-11: 05$ & PJBH & $160(320)$ & & \\
\hline 12 & Sorbent X $15 \mathrm{~g} / \mathrm{hr}$ & Dec. $12,13: 23-14: 27$ & $\begin{array}{c}\text { Advanced } \\
\text { Hybrid }{ }^{\mathrm{TM}} \text { Filter }\end{array}$ & $160(320)$ & & \\
\hline 13 & $\begin{array}{c}\text { Sorbent X } 15 \mathrm{~g} \text { power-off } \\
\text { batch }\end{array}$ & Dec. $12,14: 37-15: 01$ & $\begin{array}{c}\text { Advanced } \\
\text { Hybrid }{ }^{\mathrm{TM}} \text { Filter }\end{array}$ & $160(320)$ & & \\
\hline 14 & $\begin{array}{c}\text { Limestone } 15 \text { g power-off } \\
\text { batch }\end{array}$ & Dec. $12,15: 01-5: 30$ & $\begin{array}{c}\text { Advanced } \\
\text { Hybrid }{ }^{\mathrm{TM}} \text { Filter }\end{array}$ & $160(320)$ & & \\
\hline 15 & $\begin{array}{l}15 \mathrm{~g} \text { limestone }+15 \mathrm{~g} \\
\text { FGD, power-off batch }\end{array}$ & Dec. $12,15: 30-6: 09$ & $\begin{array}{c}\text { Advanced } \\
\text { Hybrid }{ }^{\mathrm{TM}} \text { Filter }\end{array}$ & $160(320)$ & & \\
\hline
\end{tabular}




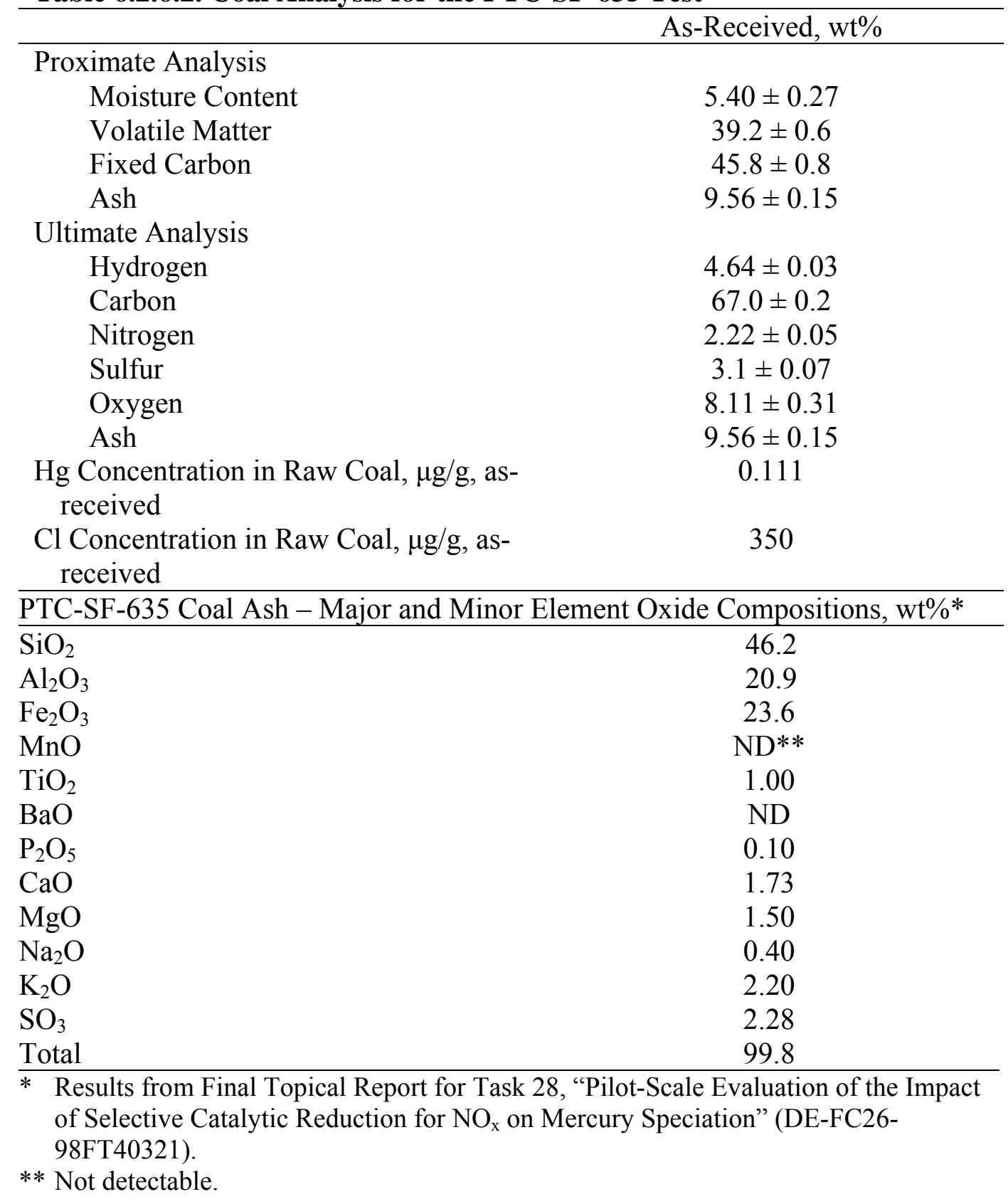

Table 6.2.6.3. Characteristics of Flue Gas for the PTC-SF-635 Test, dry basis

\begin{tabular}{lc}
\hline $\mathrm{O}_{2}, \%$ & 4.6 \\
\hline $\mathrm{CO}_{2}, \%$ & 14.3 \\
$\mathrm{CO}, \mathrm{ppm}$ & 5.3 \\
$\mathrm{NO}, \mathrm{ppm}$ & 1334 \\
$\mathrm{NO}_{2}, \mathrm{ppm}$ & 8.5 \\
$\mathrm{SO}_{2}, \mathrm{ppm}$ & $2000-2300$ \\
$\mathrm{HCl}_{1}, \mathrm{ppm}$ & $32.0-42.9$ \\
$\mathrm{SO}_{3}, \mathrm{ppm}$ & 31.7 \\
\hline
\end{tabular}


the EB Springfield coal flue gas has much higher concentrations of $\mathrm{SO}_{2}(2000-2300 \mathrm{ppm})$ and $\mathrm{HCl}$ (32.4-42.9 ppm). The high concentration of $\mathrm{SO}_{2}(2000-2300 \mathrm{ppm})$ may have a negative impact on carbon sorbent performance for mercury capture, while $\mathrm{HCl}$ would benefit mercury oxidation and possibly enhance carbon reactivity with mercury. Note that the $\mathrm{SO}_{3}$ level was also fairly high at $31.7 \mathrm{ppm}$.

\subsubsection{Mercury Results for PTC-SF-635}

\section{Tests 1 and 2 - Baseline Comparison for 30-min and 24-hr Residence Time}

Since this coal was not previously tested in the pilot-scale Advanced Hybrid ${ }^{\mathrm{TM}}$ filter unit, Tests 1 and 2 were completed to establish mercury baselines across the Advanced Hybrid ${ }^{\mathrm{TM}}$ filter and to evaluate whether the residence time of the ash in the Advanced Hybrid ${ }^{\mathrm{TM}}$ filter chamber had any effect on mercury retention by the fly ash or oxidation of mercury across the Advanced Hybrid $^{\mathrm{TM}}$ filter. For Test 1, there was no carbon injection, and the Advanced Hybrid ${ }^{\mathrm{TM}}$ filter was operated with a timed-pulse interval of $30 \mathrm{~min}$. The plates were also rapped every 30 min to remove the deposited fly ash, and the hopper was emptied every hour. For Test 2, the pulse pressure set point was $2.0 \mathrm{kPa}$ (8 in. W.C.), which resulted in a pulse interval of about $1 \mathrm{hr}$, and the plates were rapped every $3 \mathrm{hr}$. Ash was allowed to accumulate in the hopper for $24 \mathrm{hr}$ before it was emptied.

Figure 6.2.6.1 plots Ontario Hydro results of mercury species across the Advanced Hybrid $^{\mathrm{TM}}$ filter unit during Tests 1 and 2 and indicates no significant mercury capture for the baseline condition. The inlet flue gas of Test 1 had a high level of $12.5 \mu \mathrm{g} / \mathrm{m}^{3}$ oxidized mercury, $0.87 \mu \mathrm{g} / \mathrm{m}^{3}$ elemental mercury, and a very low level of particle-bound mercury of $0.02 \mu \mathrm{g} / \mathrm{m}^{3}$. With the 30-min fly ash residence time in the Advanced Hybrid ${ }^{\mathrm{TM}}$ filter hopper, the outlet flue gas of Test 1 had almost the same level of total mercury as the inlet, but it did show a slight increase of oxidized mercury at the Advanced Hybrid ${ }^{\mathrm{TM}}$ filter outlet.

For Test 2, there was a significant increase in oxidized mercury across the Advanced Hybrid $^{\mathrm{TM}}$ filter. However, since the amount of elemental mercury at the outlet is similar to Test 1, this increase in oxidation cannot be attributed to residence time alone. The Test 2 Ontario Hydro data indicate somewhat higher total outlet mercury than the inlet. This difference may be within the normal variability of the measurements, but the CMM data also show higher outlet than inlet mercury concentrations near the end of the 24-hr residence time (Figure 6.2.6.2). 


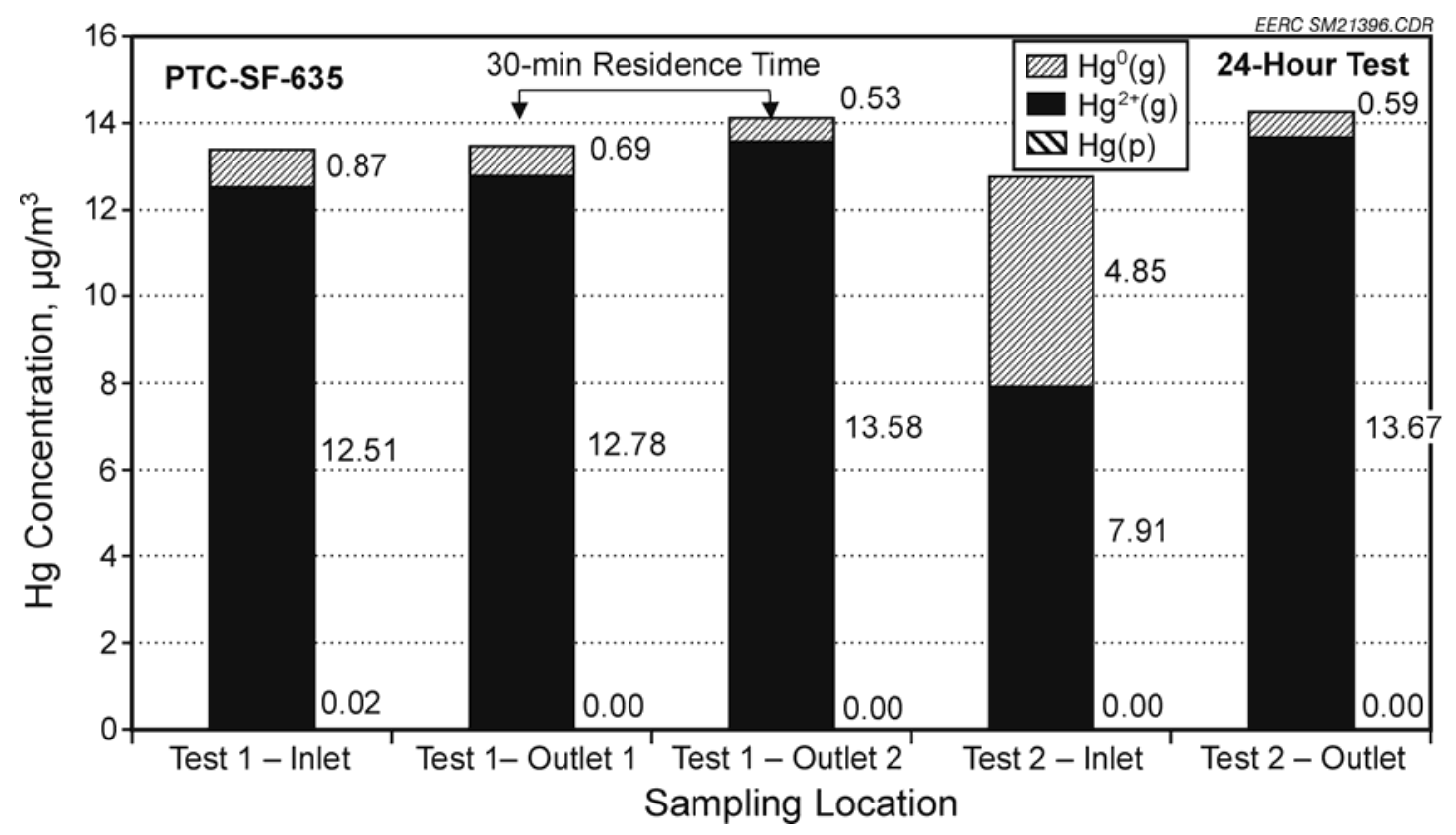

Figure 6.2.6.1. Ontario Hydro results of mercury species across the Advanced Hybrid ${ }^{\mathrm{TM}}$ filter unit during Tests 1 and 2.

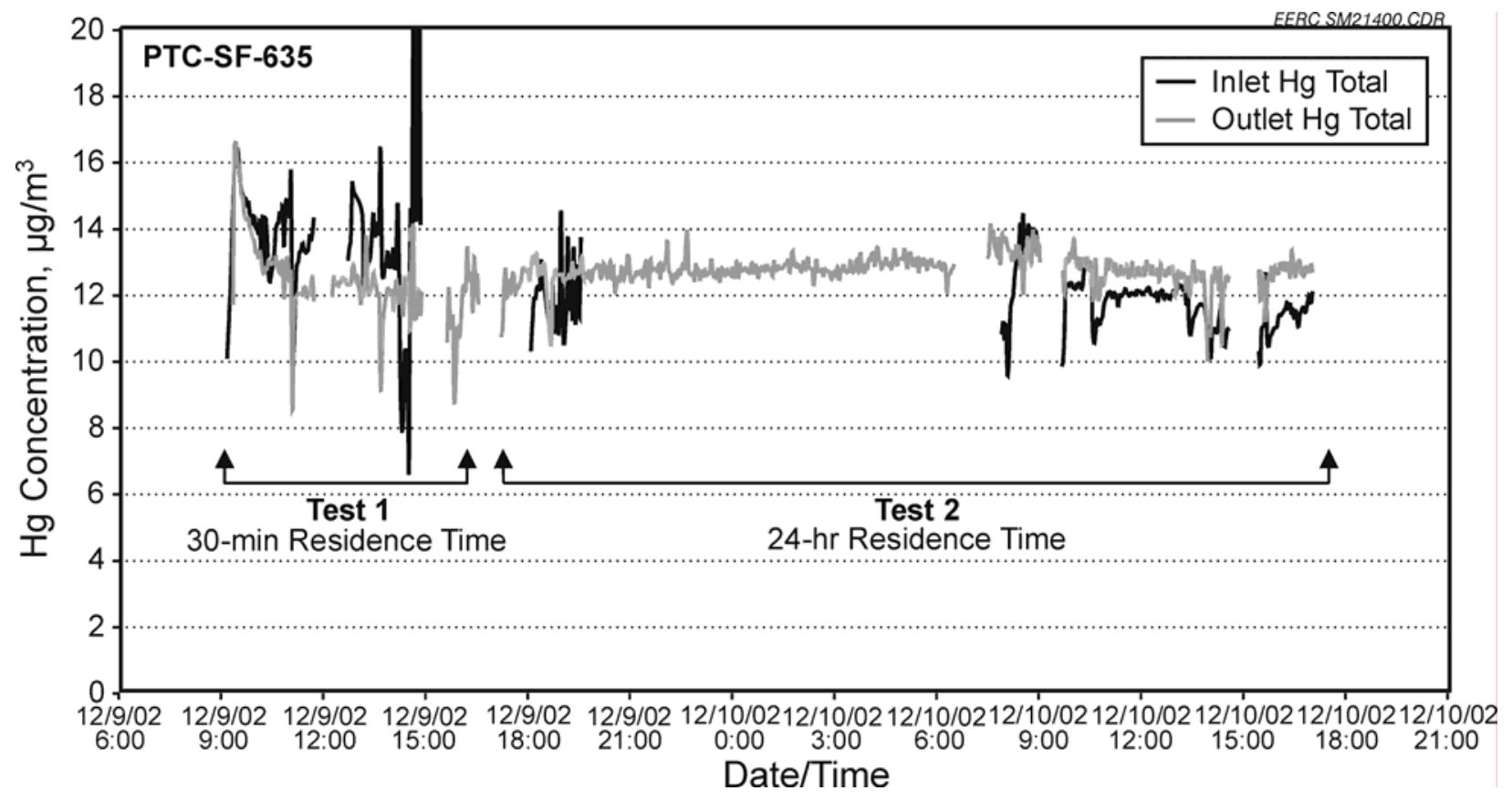

Figure 6.2.6.2. Temporal variations of gaseous mercury across the Advanced Hybrid ${ }^{\mathrm{TM}}$ filter in Springfield coal baseline test. 
Again, the difference could be within the variability of the instruments, but a comparison of the mercury in the hopper ash shows that the mercury concentration after $24 \mathrm{hr}$ of exposure to flue gas was 7 times lower $(0.00490 \mu \mathrm{g} / \mathrm{g}$ compared to $0.34 \mu \mathrm{g} / \mathrm{g}$ for the $30-\mathrm{min}$ residence time sample). From previous bench-scale work, high $\mathrm{SO}_{2}$ and $\mathrm{NO}_{\mathrm{x}}$ concentrations led to the most significant desorption of mercury from activated carbon, so the same mechanism could be responsible for desorption of mercury from fly ash. The Test 3 data also indicate that desorption may be occurring with the activated carbon.

Figure 6.2.6.3 summarizes four Ontario Hydro inlet mercury samples completed during the entire PTC-SF-635 testing period, showing predominantly oxidized mercury and almost an undetectable amount of particulate mercury in the Springfield coal flue gas. Interestingly, even though the Springfield coal flue gas has very high concentrations of all of the acid gases, including $\mathrm{SO}_{2}, \mathrm{NO}_{\mathrm{x}}$, and $\mathrm{HCl}$, there is still some elemental mercury present. The total average inlet mercury is in good agreement with the CMM inlet data, which typically was in the range from 12 to $14 \mu \mathrm{g} / \mathrm{m}^{3}$. In cases with little particulate mercury, it is usually possible to get good agreement between the CMM and Ontario Hydro measurements.

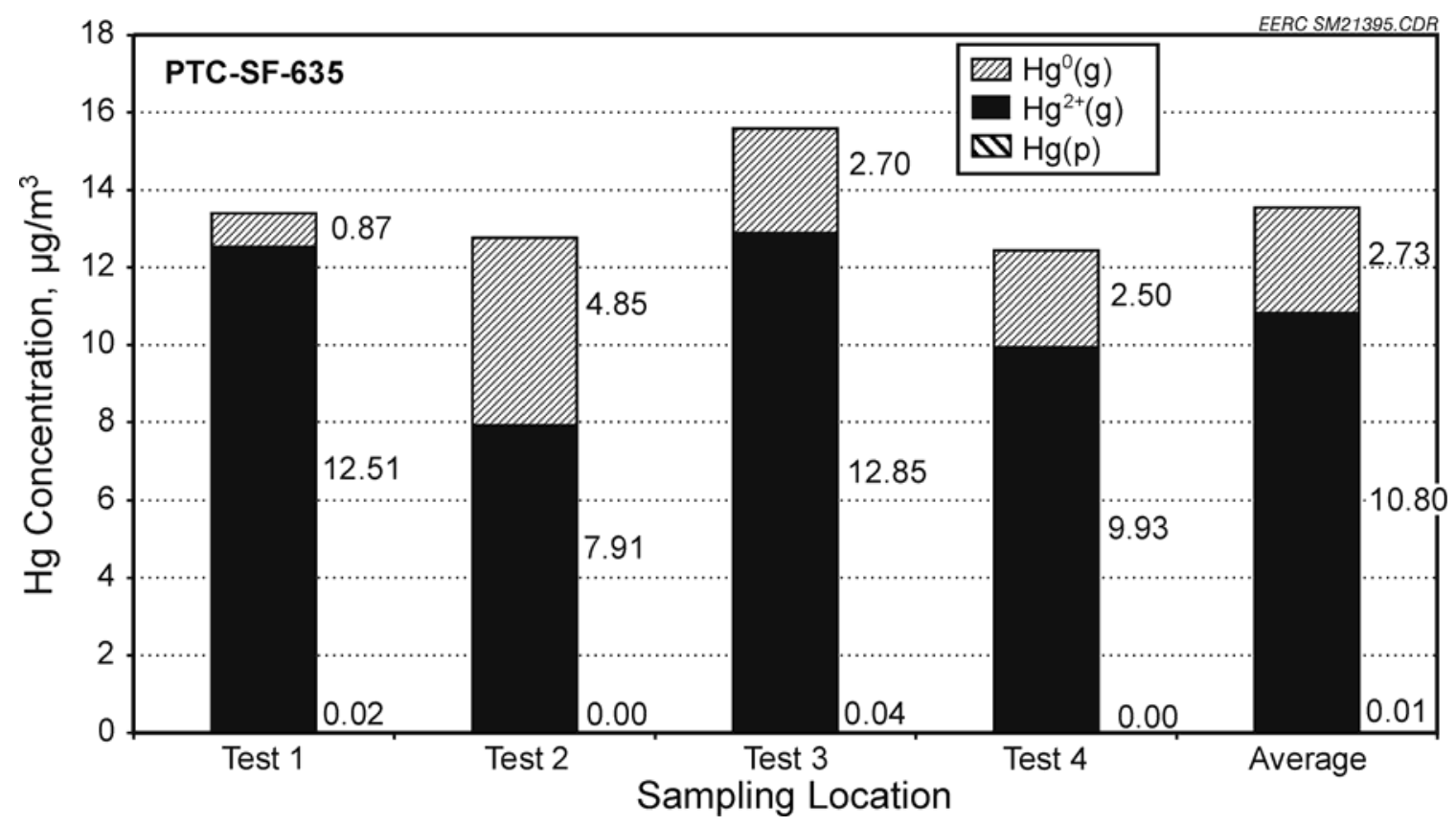

Figure 6.2.6.3. Four Ontario Hydro inlet mercury samples completed during the PTC-SF-635 testing period. 


\section{Tests 3-7 NORIT FGD Activated Carbon Injection at $135^{\circ} \mathrm{C}\left(275^{\circ} \mathrm{F}\right)$}

Two CMMs monitored the mercury species in flue gas across the Advanced Hybrid ${ }^{\mathrm{TM}}$ filter during the short-term activated carbon injection tests, and the measurements are plotted in Figure 6.2.6.4. With an activated carbon injection of $7.5 \mathrm{~g} / \mathrm{hr}(1.5 \mathrm{lb} / \mathrm{Macf})$, which was equivalent to a carbon-to-mercury ratio of about 3000:1, there was no detectable reduction in mercury emissions. The inlet and outlet Ontario Hydro data (Figure 6.2.6.5) also indicate less than 10\% mercury removal in the Advanced Hybrid ${ }^{\mathrm{TM}}$ filter with the $7.5 \mathrm{~g} / \mathrm{hr}(1.5 \mathrm{lb} / \mathrm{Macf})$ NORIT FGD carbon injection. The predominant oxidized mercury in the Springfield flue gas is thought to be easily captured with activated carbon, but both CMM and Ontario Hydro data indicate otherwise. One possible reason is that the overwhelmingly high $\mathrm{SO}_{2}$ in flue gas poisons the activated carbon sites, either to prevent mercury adsorption on the carbon or to form a volatile mercury compound that reenters the flue gas. The carbon feed rate was increased to $37.5 \mathrm{~g} / \mathrm{hr}(7.5 \mathrm{lb} / \mathrm{Macf})$ to see if better mercury capture would occur. CMM data in Figure 6.2.6.4 indicate only a 15\% mercury removal at the higher carbon feed rate. The high-voltage power to the Advanced Hybrid ${ }^{\mathrm{TM}}$ filter was then turned off to determine mercury removal in the PJBH when all of the carbon reached

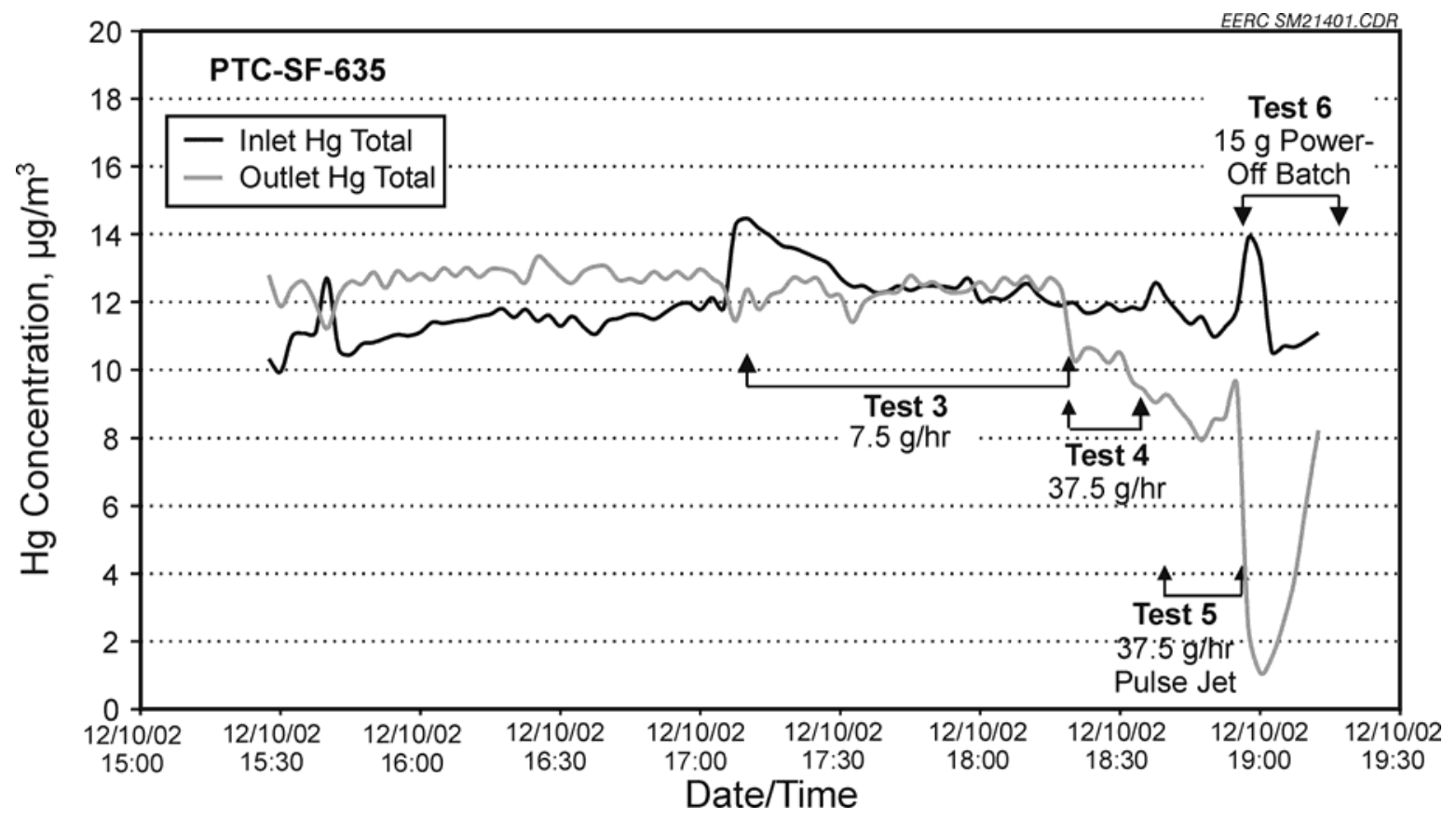

Figure 6.2.6.4. Temporal variations of gaseous mercury in the Advanced Hybrid ${ }^{\mathrm{TM}}$ filter inlet and outlet flue gas with FGD injection at $135^{\circ} \mathrm{C}\left(275^{\circ} \mathrm{F}\right)$. 


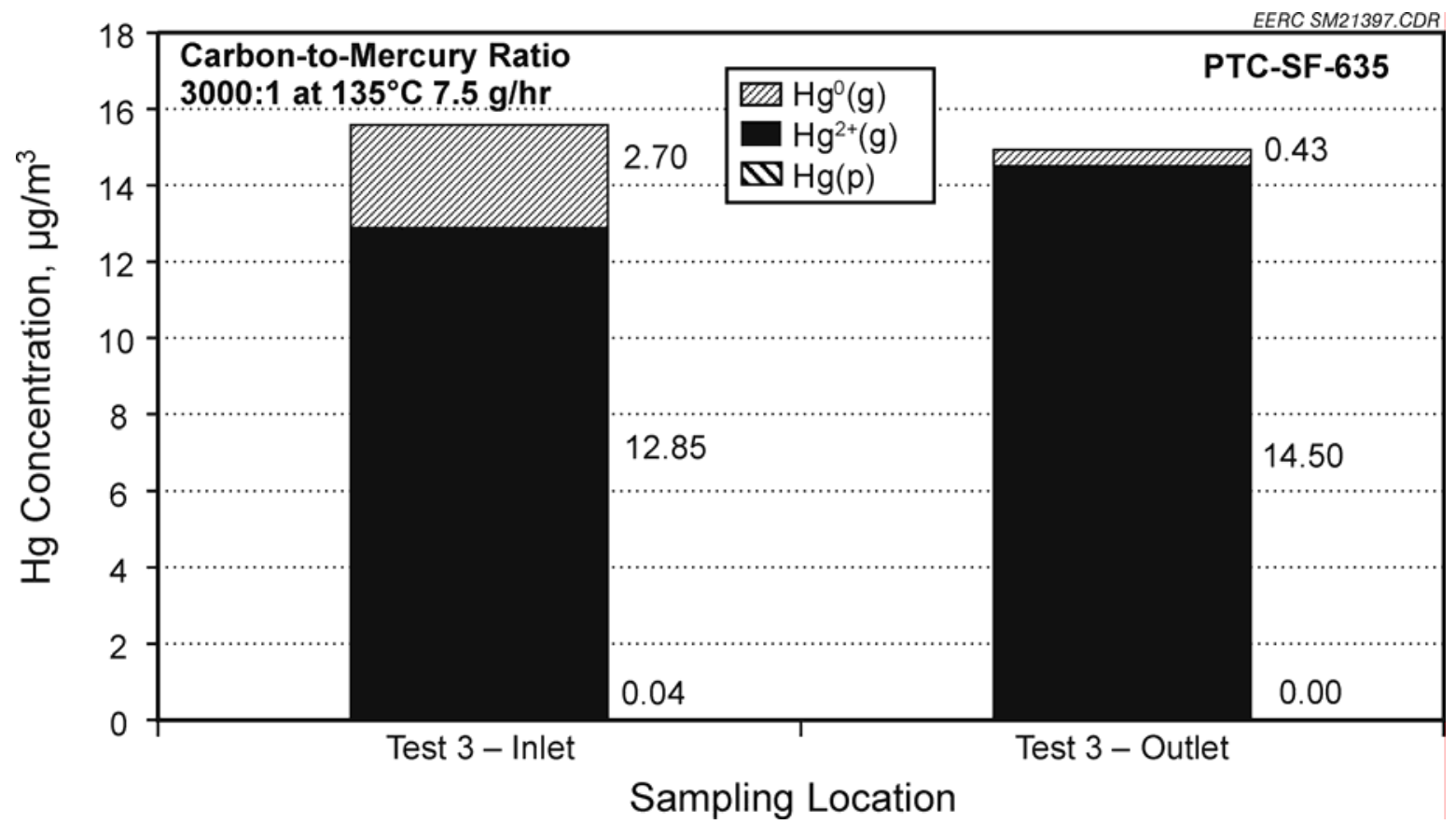

Figure 6.2.6.5. Inlet and outlet Ontario Hydro results with FGD injection at $135^{\circ} \mathrm{C}\left(275^{\circ} \mathrm{F}\right)$.

the bags. The mercury removal with PJBH under the same carbon feed rate of $37.5 \mathrm{~g} / \mathrm{hr}$ (7.5 lb/Macf) was still marginal based on mercury emission data measured by the outlet CMM. A power-off batch of $15 \mathrm{~g}$ of NORIT FGD was then added to see if the mercury level would drop. The outlet CMM data show that the additional batch of carbon did briefly result in a mercury dropping down to $1 \mu \mathrm{g} / \mathrm{m}^{3}$, but it quickly climbed again. These tests all indicated that the FGD carbon was not effective at removing mercury in the Springfield flue gas with either the Advanced Hybrid ${ }^{\mathrm{TM}}$ filter or the $\mathrm{PJBH}$. To further verify the above experimental results, the carbon injection rate was then set back to $7.5 \mathrm{~g} / \mathrm{hr}(1.5 \mathrm{lb} / \mathrm{Macf})$ and operated overnight until noon the next day. The CMM data during this time (Figure 6.2.6.6) showed no mercury removal, which provides further proof of the ineffectiveness of the FGD carbon. One additional power-off batch test was completed by injecting a batch of $22.5 \mathrm{~g}$ of carbon within a minute. This resulted in a brief drop in mercury, but after only 15 min, the mercury rapidly started increasing again. Figure 6.2.6.7 provides more detailed information of this batch injection test. Since the outlet mercury rises above the inlet level after breakthrough, this may indicate desorption of some of 


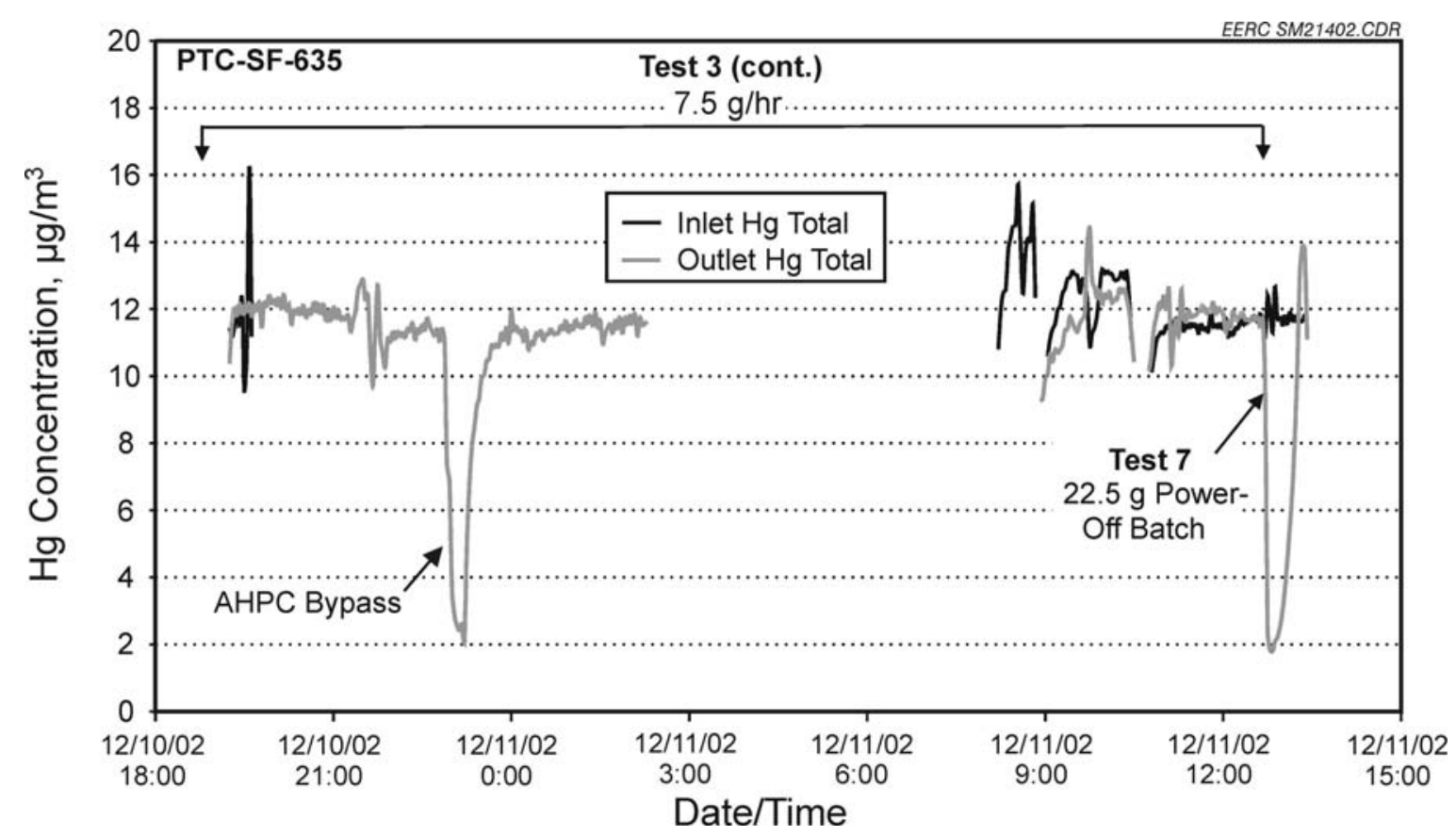

Figure 6.2.6.6. Temporal variations of gaseous mercury in Advanced Hybrid ${ }^{\mathrm{TM}}$ filter inlet and outlet flue gases with FGD injection at $135^{\circ} \mathrm{C}\left(275^{\circ} \mathrm{F}\right)$.

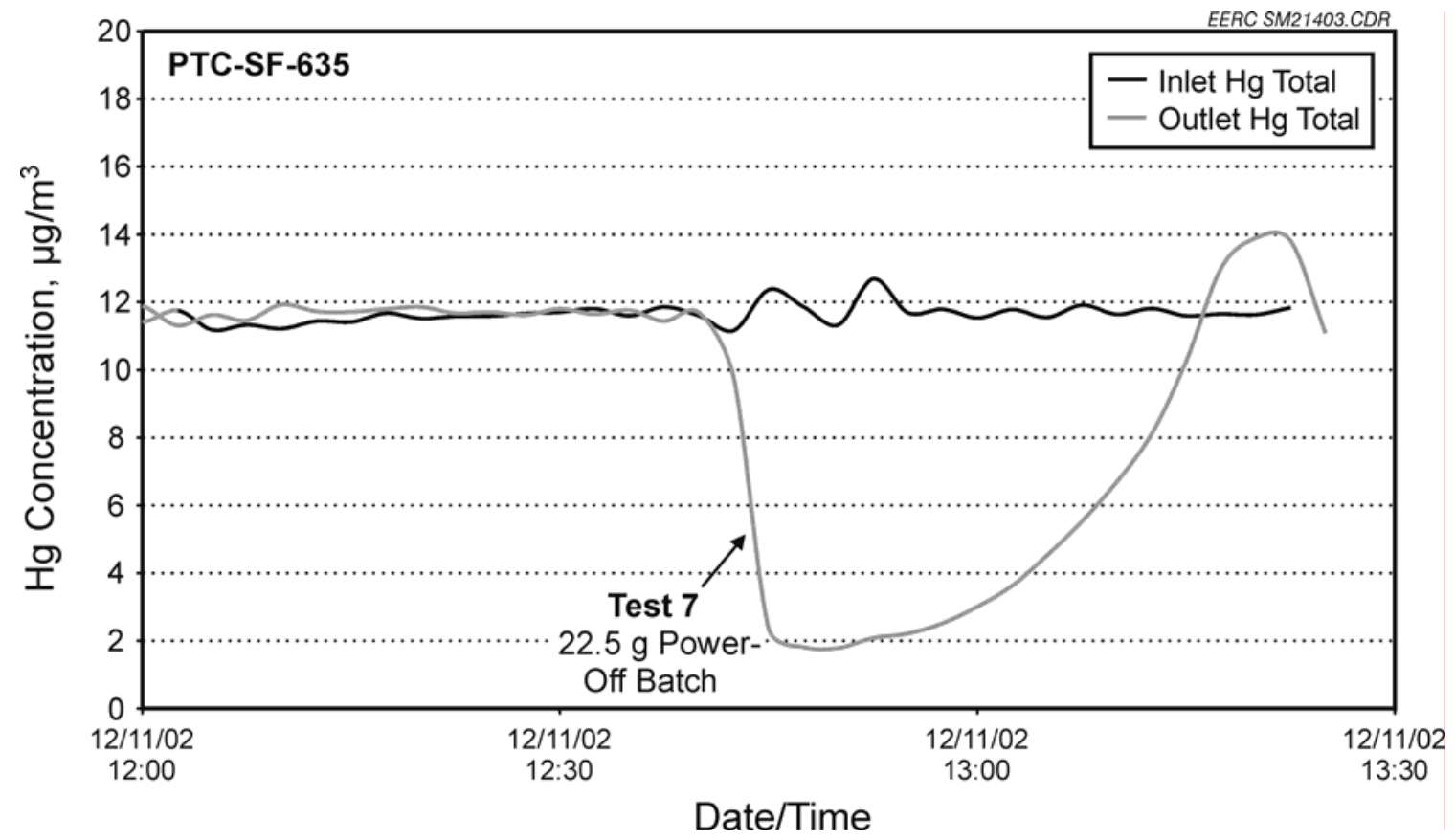

Figure 6.2.6.7. Test 7 - Detailed information of mercury emission of the Advanced Hybrid ${ }^{\mathrm{TM}}$ filter under this batch injection test. 
the previously captured mercury. In previous bench-scale breakthrough tests with a thin fixed bed of carbon, desorption was commonly seen for cases where the flue gas was high in both $\mathrm{NO}_{\mathrm{x}}$ and $\mathrm{SO}_{2}$.

The poor mercury capture by the activated carbon is consistent with previous bench-scale tests, but those bench-scale tests were completed without $\mathrm{SO}_{3}$. These tests were all conducted at a temperature of $135^{\circ} \mathrm{C}\left(275^{\circ} \mathrm{F}\right)$, which is below the acid dew point for the measured $\mathrm{SO}_{3}$ level of $31.7 \mathrm{ppm}$. The possibility was raised that $\mathrm{SO}_{3}$ condensation on the activated carbon might impair mercury capture. To address this concern, further testing was completed after increasing the Advanced Hybrid ${ }^{\mathrm{TM}}$ filter temperature to $160^{\circ} \mathrm{C}\left(320^{\circ} \mathrm{F}\right)$.

\section{Tests 8-11 NORIT FGD Activated Carbon Injection at $160^{\circ} \mathrm{C}\left(320^{\circ} \mathrm{F}\right)$}

With the Advanced Hybrid ${ }^{\mathrm{TM}}$ filter temperature raised to $160^{\circ} \mathrm{C}\left(320^{\circ} \mathrm{F}\right)$, carbon injection was started at a rate of $7.5 \mathrm{~g} / \mathrm{hr}$, increasing to $30 \mathrm{~g} / \mathrm{hr}$ later. CMM outlet data (Figure 6.2.6.8) showed no mercury removal at the $7.5 \mathrm{~g} / \mathrm{hr}$ injection and less than $10 \%$ mercury removal across the Advanced Hybrid ${ }^{\mathrm{TM}}$ filter at the increased rate of $30 \mathrm{~g} / \mathrm{hr}$. The carbon injection was

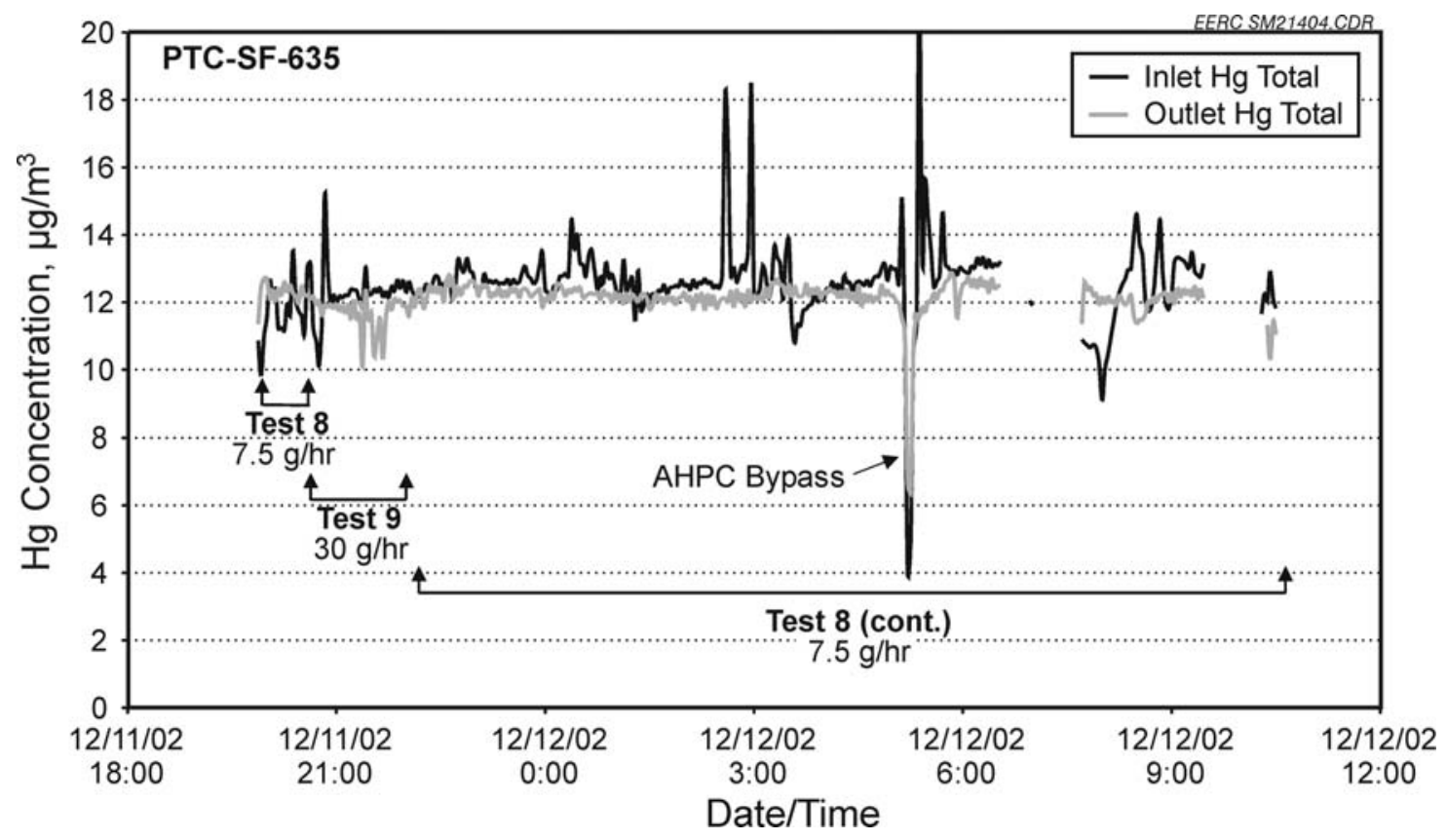

Figure 6.2.6.8. Tests 8 and 9 - Temporal variations of gaseous mercury in the Advanced Hybrid $^{\mathrm{TM}}$ filter inlet and outlet flue gas with FGD injection at $160^{\circ} \mathrm{C}\left(320^{\circ} \mathrm{F}\right)$. 
then scaled back to $7.5 \mathrm{~g} / \mathrm{hr}$ for a longer-term test overnight. The inlet and outlet CMM data in Figure 6.2.6.8 and the Ontario Hydro measurements (Figure 6.2.6.9) showed no mercury removal during this time.

To provide final proof that the poor mercury removal was due to the carbon sorbent rather than a limitation of the Advanced Hybrid ${ }^{\mathrm{TM}}$ filter, the high-voltage power was again shut off, and short-term tests were completed with the PJBH at a carbon injection of 7.5 and $30 \mathrm{~g} / \mathrm{hr}$, respectively. CMM outlet data in Figure 6.2.6.10 showed that even with no high-voltage power and the high carbon addition rate, mercury removal was in the range from $0 \%$ to $10 \%$.

Since very poor mercury capture was seen at $160^{\circ} \mathrm{C}\left(320^{\circ} \mathrm{F}\right)$ as well as at $135^{\circ} \mathrm{C}\left(275^{\circ} \mathrm{F}\right)$, the reason appeared to be something other than an acid dew point problem. Apparently, in the temperature range from $135^{\circ}$ to $160^{\circ} \mathrm{C}\left(275^{\circ}\right.$ to $\left.320^{\circ} \mathrm{F}\right)$ with these flue gas concentrations, the FGD sorbent is ineffective at mercury capture.

\section{Tests 12-15 Alternative Sorbent Injection at $160^{\circ} \mathrm{C}$}

Before Tests 12-15 were begun, all of the carbon-laden ash was removed from the Advanced Hybrid ${ }^{\mathrm{TM}}$ filter hopper, and the system was allowed to return to baseline conditions.

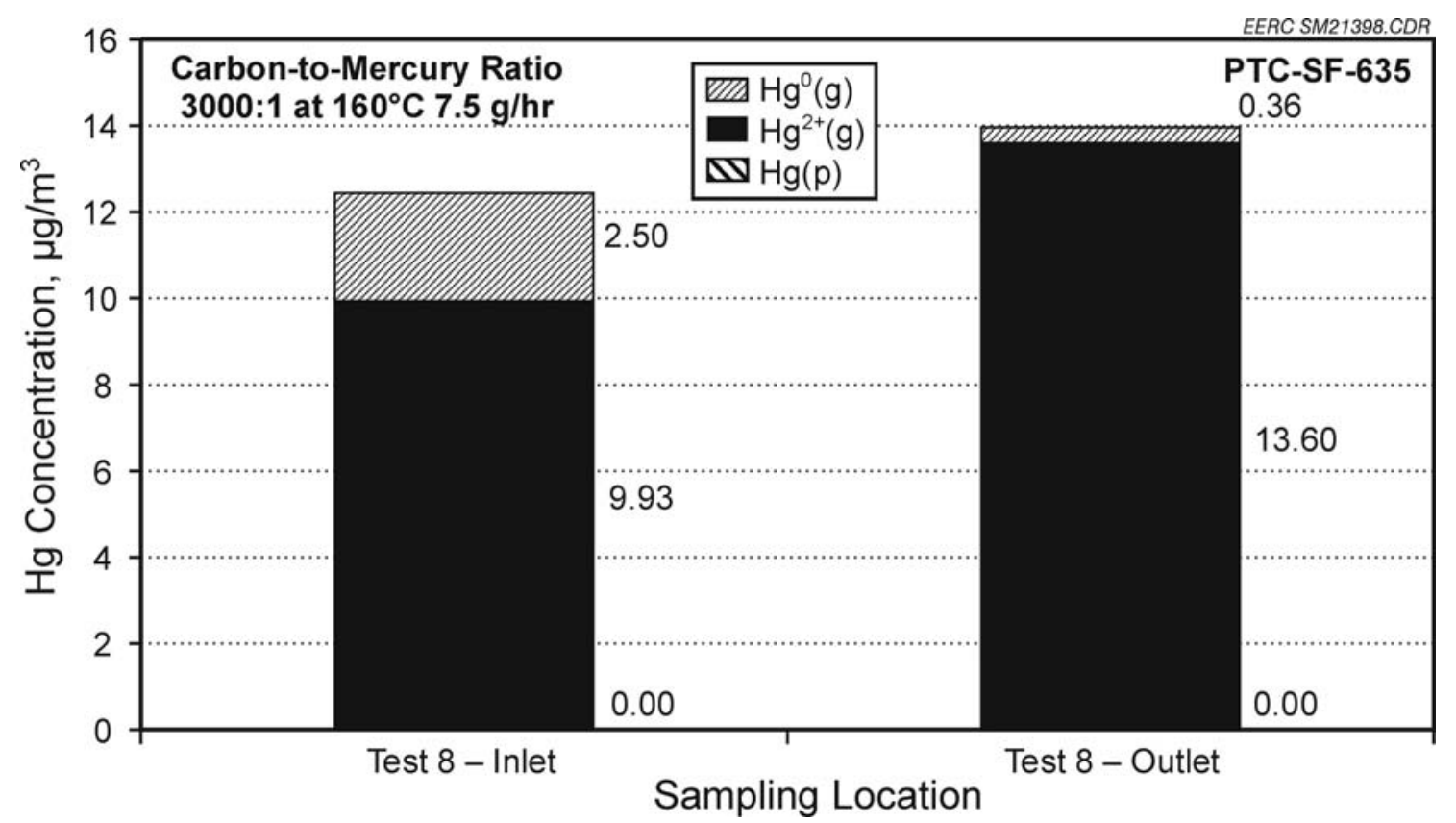

Figure 6.2.6.9. Advanced Hybrid ${ }^{\mathrm{TM}}$ filter inlet and outlet Ontario Hydro results with FGD injection at $160^{\circ} \mathrm{C}\left(320^{\circ} \mathrm{F}\right)$. 


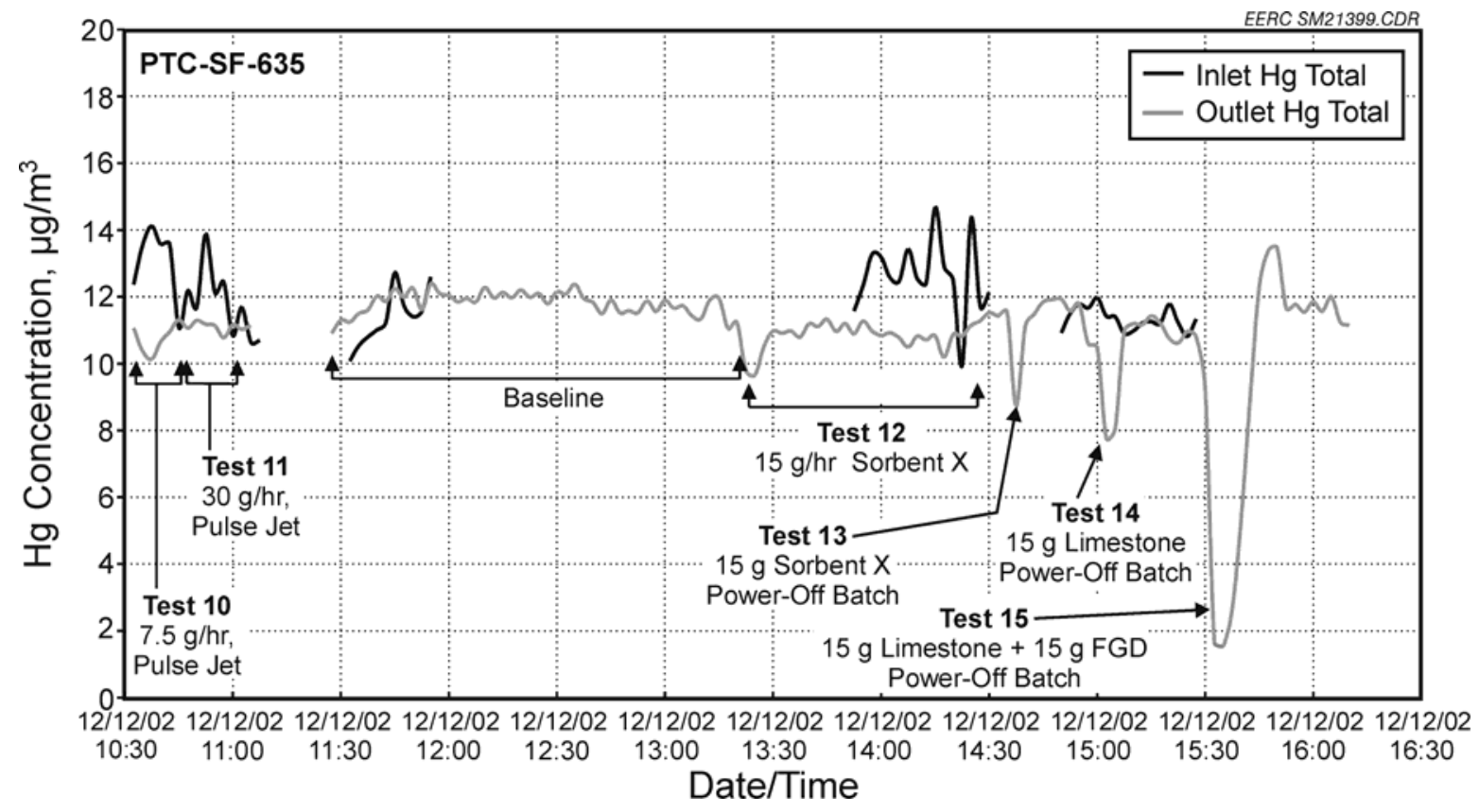

Figure 6.2.6.10. Tests 10-15 - Temporal variations of gaseous mercury in the Advanced Hybrid $^{\mathrm{TM}}$ filter inlet and outlet flue gas with FGD injection at $160^{\circ} \mathrm{C}\left(320^{\circ} \mathrm{F}\right)$.

Next, a non-carbon-based alternative sorbent (Sorbent X) was injected, first continuously at 15 $\mathrm{g} / \mathrm{hr}$ and then in a power-off batch mode. This sorbent also was ineffective at mercury capture (Figure 6.2.6.10). Two additional short-term batch injection tests were completed, first with straight limestone powder followed by a combination of $15 \mathrm{~g}$ of limestone and $15 \mathrm{~g}$ of the NORIT FGD carbon. As seen in the Figure 6.2.6.10 data, these tests were marginal in mercury removal effectiveness, and the combination of limestone and FGD carbon was no better than the previous batch FGD carbon injection tests.

\subsubsection{Conclusions from PTC-SF-635 Testing Results}

The Springfield bituminous coal flue gas has high levels of the acid gases, and most of the inlet mercury was in oxidized form.

A number of short- and longer-term tests with NORIT FGD carbon injection at both $135^{\circ}$ and $160^{\circ} \mathrm{C}\left(275^{\circ}\right.$ and $\left.320^{\circ} \mathrm{F}\right)$ with both the Advanced Hybrid ${ }^{\mathrm{TM}}$ filter and the PJBH showed that this sorbent was completely ineffective at mercury control for the Springfield coal flue gas. The data are consistent with previous bench-scale testing showing that flue gas conditions are critical to the mercury capture ability of an activated carbon. 
The amended silicate developed by ADA also showed ineffectiveness in mercury capture for this Springfield coal flue gas.

\subsubsection{PTC-BA-636}

\subsubsection{Test Conditions}

The November 2001 field test at Big Stone Power Plant demonstrated over 90\% mercury removal with the Advanced Hybrid ${ }^{\mathrm{TM}}$ filter with injection of $0.29 \mathrm{~kg} / \mathrm{hr}(1.2 \mathrm{lb} / \mathrm{Macf})$ NORIT FGD combined with 90-250 tons/day of TDF cofiring. During the start of the August 2002 field test at the Big Stone Power Plant, the tire feed was deliberately stopped to evaluate mercury control with TDF cofiring, showing an overall 63\% mercury removal across the Advanced Hybrid $^{\mathrm{TM}}$ filter field unit with $0.26 \mathrm{~kg} / \mathrm{hr}(1.1 \mathrm{lb} / \mathrm{Macf})$ FGD carbon injection. When TDF cofiring was started August 12, 2002, at 23 ton/day, much lower than the 90-250-ton/day rate during the November 2001 test, $68 \%$ mercury capture was achieved.

All the field demonstrations showed there was a correlation between oxidized mercury concentration in the flue gas and the amount of TDF fed into the boilers, suggesting that the low rate of TDF cofiring resulted in some improvement in mercury collection with the Advanced Hybrid $^{\mathrm{TM}}$ filter. However, because of the variability of the TDF feed rate, it was difficult to quantify the TDF effect on mercury removal. Subsequently, a 1-week pilot-scale test was designed and conducted on the 55-kW (200-acfm) pilot-scale Advanced Hybrid ${ }^{\mathrm{TM}}$ filter where the coal feed rate and the TDF feed rate were precisely controlled.

Belle Ayr coal was used in this test. The Advanced Hybrid ${ }^{\mathrm{TM}}$ filter unit was operated at 24-mA corona current, pulse-cleaned at trigger pressures of $2.0-2.5 \mathrm{kPa}$ (8-10 in. W.C.), and kept at approximately $135^{\circ} \mathrm{C}\left(275^{\circ} \mathrm{F}\right)$ across the Advanced Hybrid ${ }^{\mathrm{TM}}$ filter. To confirm and clarify the TDF effect on mercury species in flue gas, TDF was used as a supplemental fuel to cofire with the Belle Ayr coal. The TDF was preshredded by the supplier to -20 mesh. This material was then screened to -40 mesh at the EERC. The TDF was then fed with a separate feeder directly into the pneumatic coal feed line at rates of 1.4 and $2.7 \mathrm{~kg} / \mathrm{hr}$, corresponding to $5 \%$ and $10 \%$ of the feed coal (mass-based), respectively. The NORIT FGD injection rate was set at $24 \mathrm{mg} / \mathrm{m}^{3}$ (1.5 lb/Macf), corresponding to 3000:1 carbon-to-mercury ratio. By combining cofiring TDF with NORIT FGD injection, a series of tests were completed to evaluate the beneficial effect of TDF cofiring on mercury removal with the Advanced Hybrid ${ }^{\mathrm{TM}}$ filter. At the end of this 1-week 
test, an iodine-treated carbon was also tested for its effectiveness on mercury capture in the Advanced Hybrid ${ }^{\mathrm{TM}}$ filter. Table 6.2.7.1 lists the nine tests completed during this period.

Two CMMs monitored the mercury species across the Advanced Hybrid ${ }^{\mathrm{TM}}$ filter, and Ontario Hydro samples were collected at Advanced Hybrid ${ }^{\mathrm{TM}}$ filter inlet and outlet to verify mercury species in the flue gas. EPA Method 26 sampling was conducted to determine the increase of $\mathrm{HCl}$ in the flue gas with TDF cofiring. The sampling schedule is also included in Table 6.2.7.1.

\subsubsection{Coal and Flue Gas Analyses}

Since the Belle Ayr coal used in this test was the same as in previous tests (PTC-BA-628 and 629) and the general information on this coal was known, no additional coal analysis was performed. Listed in Table 6.2.7.2 are the analysis results of the TDF, including proximateultimate data and chlorine content, indicating a high carbon content and heating value. The

\section{Table 6.2.7.1. Summary of the Test Conditions for PTC-BA}

\begin{tabular}{|c|c|c|c|}
\hline Test & Time & Test Conditions & $\mathrm{OH}$ and $\mathrm{HCl}$ Sampling \\
\hline \multirow[t]{2}{*}{1} & Feb. 10, 10:24-16:20 & Baseline & $\mathrm{OH}(13: 31-14: 31)$ \\
\hline & & & M26 (15:07-16:07) \\
\hline \multirow[t]{3}{*}{2} & Feb. 10, 16:20-Feb.11, 11:35 & $1.4 \mathrm{~kg} / \mathrm{hr}$ & $\mathrm{OH}^{1}(17: 44-19: 44)$ \\
\hline & & $(3 \mathrm{lb} / \mathrm{hr}) \mathrm{TDF}$ & $\mathrm{OH}^{2}(9: 05-10: 05)$ \\
\hline & & & M26 (10:30-11:30) \\
\hline \multirow[t]{3}{*}{3} & Feb. 11, 11:47-15:34; 15:49- & $1.4 \mathrm{~kg} / \mathrm{hr}$ & $\mathrm{OH}(13: 27-15: 29)$ \\
\hline & Feb. $12,1: 08 ; 1: 18-7: 13,7: 21-$ & $(3 \mathrm{lb} / \mathrm{hr}) \mathrm{TDF}+$ & $\mathrm{OH}(8: 57-9: 58)$ \\
\hline & $11: 14$ & 3000:1 FGD carbon & M26 (10:20-11:14) \\
\hline \multirow[t]{2}{*}{4} & Feb. 12, 12:15-13:28, 14:11- & 3000:1 FGD carbon & $\mathrm{OH}(14: 28-15: 29)$ \\
\hline & $17: 10$ & & M26 (16:00-17:00) \\
\hline \multirow[t]{2}{*}{5} & Feb. 12, 17:12-18:30, 19:15- & $2.7 \mathrm{~kg} / \mathrm{hr}$ & \\
\hline & $\begin{array}{c}23: 08,23: 18-F e b .13,0: 23 \\
0: 43-3: 25\end{array}$ & $\begin{array}{c}(6 \mathrm{lb} / \mathrm{hr}) \mathrm{TDF}+ \\
\text { 3000:1 FGD carbon }\end{array}$ & \\
\hline \multirow[t]{2}{*}{6} & Feb. 13, 10:16-14:34 & $2.7 \mathrm{~kg} / \mathrm{hr}(6 \mathrm{lb} / \mathrm{hr})$ & $\mathrm{OH}(11: 11-12: 11)$ \\
\hline & & TDF, bigger size & M26 (12:33-13:33) \\
\hline \multirow[t]{3}{*}{7} & Feb. 13, 14:35-18:07 & $2.7 \mathrm{~kg} / \mathrm{lb}$ & $\mathrm{OH}(17: 01-18: 01)$ \\
\hline & & $(6 \mathrm{lb} / \mathrm{hr}) \mathrm{TDF}+$ & \\
\hline & & 3000:1 FGD carbon & \\
\hline 8 & Feb. 13, 18:36-Feb. 14, 8:45 & Baseline & \\
\hline \multirow[t]{2}{*}{9} & Feb. 14, 8:45-13:33 & 4700:1 IAC carbon & OH (10:01-11:01) \\
\hline & & & M26 (11:26-12:40) \\
\hline
\end{tabular}




\section{Table 6.2.7.2. Analysis for the TDF}

\begin{tabular}{lc}
\hline & As-Received, $\mathrm{wt} \%$ \\
\hline Proximate Analysis & \\
Moisture Content & 0.6 \\
Volatile Matter & 66.22 \\
Fixed Carbon & 28.06 \\
Ash & 5.12 \\
Ultimate Analysis & \\
Hydrogen & 7.58 \\
Carbon & 83.23 \\
Nitrogen & 0.80 \\
Sulfur & 2.69 \\
Oxygen & 0.58 \\
Ash & 5.12 \\
Heating Value, Btu/lb & 16,485 \\
Cl Concentration in TDF, $\mu \mathrm{g} / \mathrm{g}$, as received & 598 \\
\hline
\end{tabular}

$598 \mu \mathrm{g} / \mathrm{g}$ of chlorine in the TDF is much higher than the $22.5 \mu \mathrm{g} / \mathrm{g}$ of chlorine in the Belle Ayr coal, which may enhance mercury oxidation in the coal flue gas.

\subsubsection{Mercury Results for PTC-BA-636}

\section{Test 1 - Baseline Test}

A short-term 6-hr baseline test was completed without any carbon or TDF to establish mercury species in the Belle Ayr coal flue gas. One pair of $\mathrm{OH}$ samples was collected at the Advanced Hybrid ${ }^{\mathrm{TM}}$ filter inlet and outlet to determine whether there was a change in mercury speciation across the Advanced Hybrid ${ }^{\mathrm{TM}}$ filter unit. The results are plotted in Figure 6.2.7.1. Based on Ontario Hydro results, the flue gas entering the Advanced Hybrid ${ }^{\mathrm{TM}}$ filter contained $13.1 \mu \mathrm{g} / \mathrm{m}^{3}$ of elemental mercury, $3.07 \mu \mathrm{g} / \mathrm{m}^{3}$ of oxidized mercury, and a very low level of $0.04 \mu \mathrm{g} / \mathrm{m}^{3}$ of particle-bound mercury. Since all of the particulate-associated mercury was captured in the Advanced Hybrid ${ }^{\mathrm{TM}}$ filter, the outlet flue gas had $8.1 \mu \mathrm{g} / \mathrm{m}^{3}$ of elemental mercury and $4.6 \mu \mathrm{g} / \mathrm{m}^{3}$ of oxidized mercury. The total mercury concentration of $16.2 \mu \mathrm{g} / \mathrm{m}^{3}$ in the inlet flue gas was reduced to $12.6 \mu \mathrm{g} / \mathrm{m}^{3}$ at the Advanced Hybrid ${ }^{\mathrm{TM}}$ filter outlet, showing $22.2 \%$ mercury capture across the Advanced Hybrid ${ }^{\mathrm{TM}}$ filter. Compared in Figure 6.2.7.2 are normalized mercury species distributions in Belle Ayr coal flue gas obtained in the current and previous tests. The results show very consistent mercury species distributions for the Belle Ayr coal flue gas during the three individual tests: $75.5 \%-83.1 \% \mathrm{Hg}^{0}, 13.7 \%-22.8 \% \mathrm{Hg}^{2+}$, and $0.24 \%-3.21 \%$ 


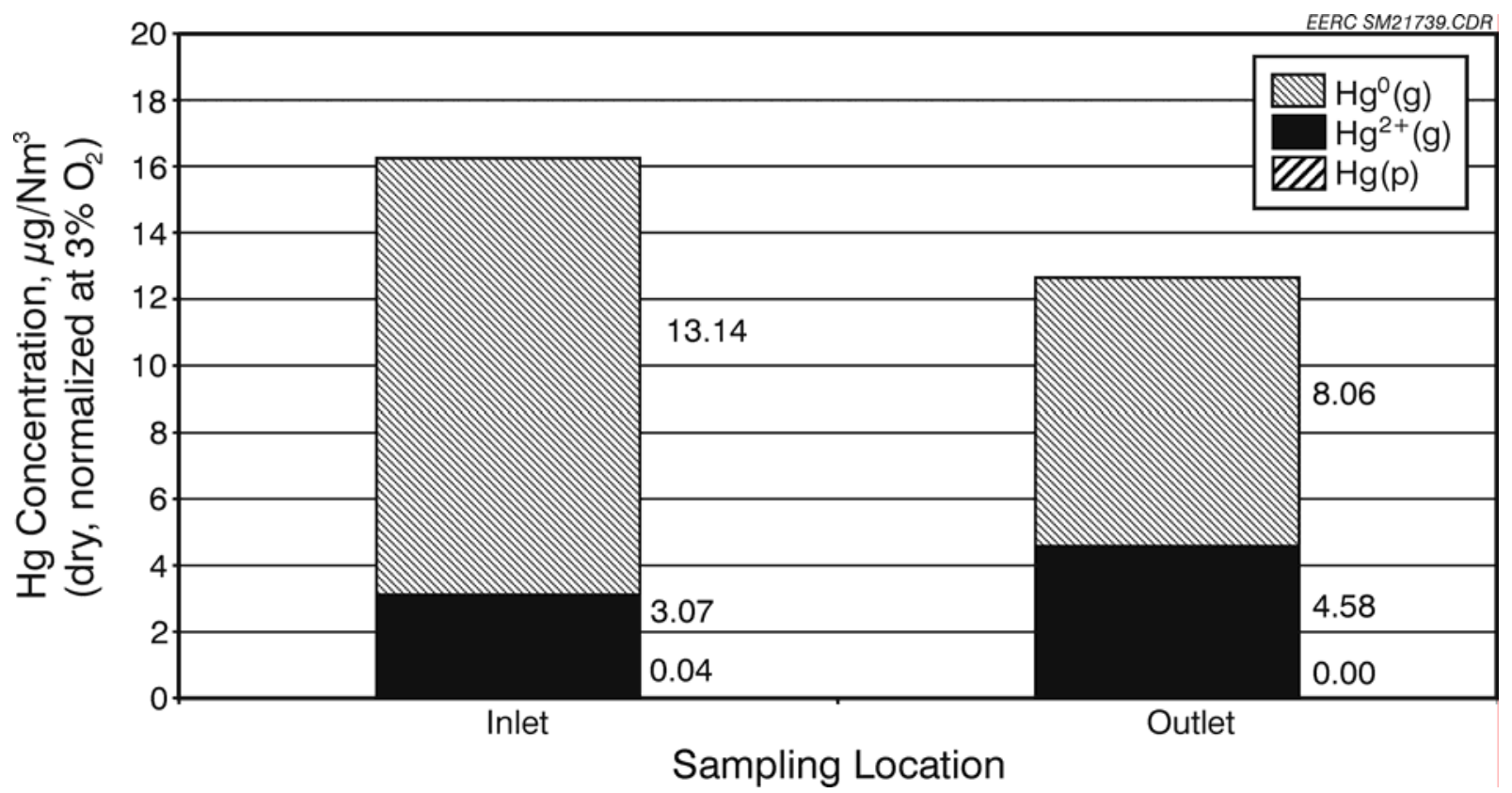

Figure 6.2.7.1. Mercury species across the Advanced Hybrid ${ }^{\mathrm{TM}}$ filter in the Belle Ayr baseline test.

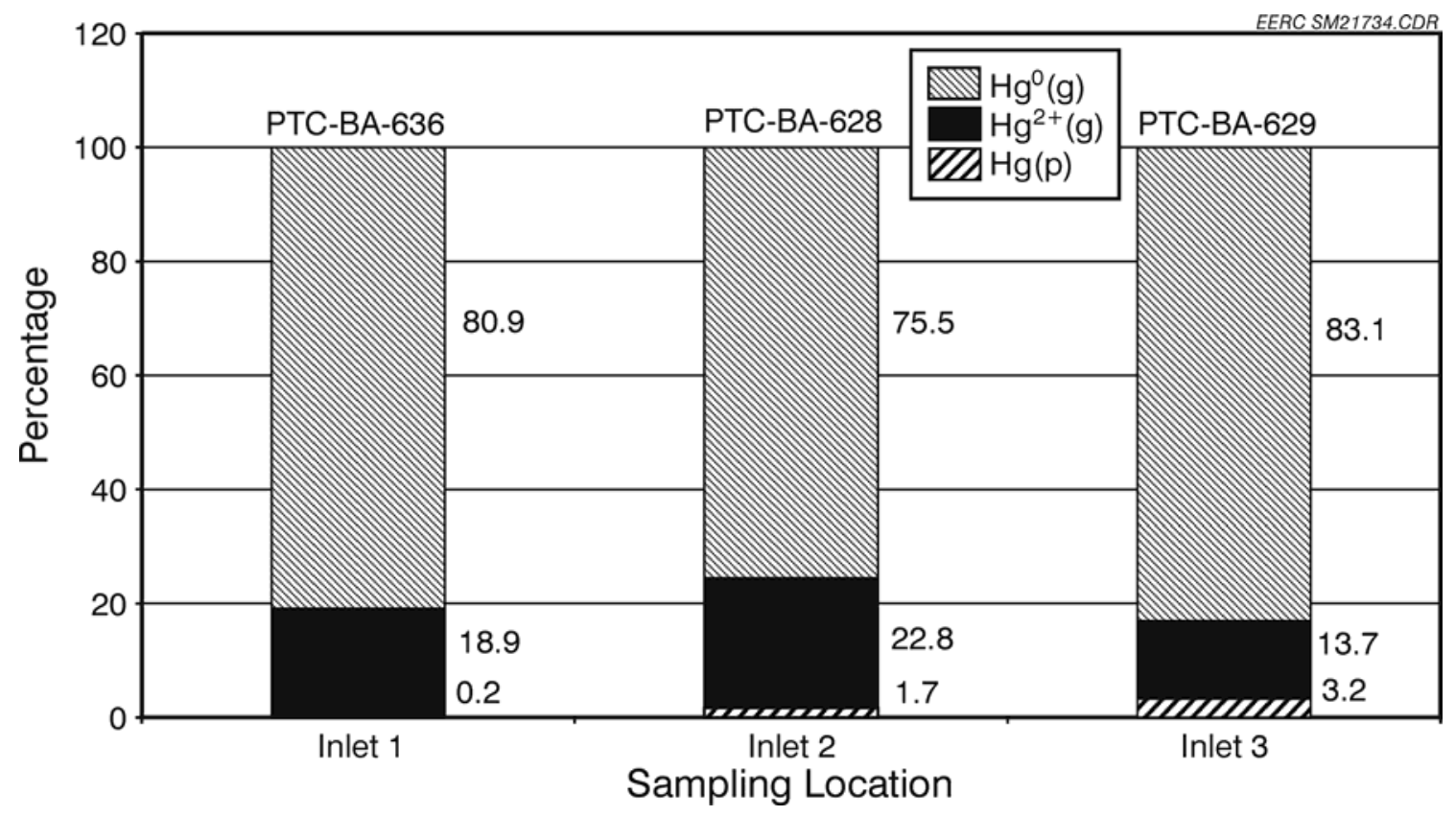

Figure 6.2.7.2. Comparison of normalized mercury species distributions in Belle Ayr coal flue gas obtained in the current and previous tests. 
$\mathrm{Hg}(\mathrm{p})$, indicating a representative and repeatable coal combustion performance for the pilot-scale Advanced Hybrid ${ }^{\mathrm{TM}}$ filter system. At the same time, two CMMs monitored temporal variations of mercury vapor species in the flue gas across the Advanced Hybrid ${ }^{\mathrm{TM}}$ filter, and the data (Figure 6.2.7.3) showed almost the same level of mercury in the inlet and outlet flue gases during the baseline test. Both Ontario Hydro and CMM data showed that a $33 \% \mathrm{Hg}^{0}$ to $\mathrm{Hg}^{2+}$ and $\mathrm{Hg}(\mathrm{p})$ conversion occurred across the filter bags.

\section{Test 2 - 1.4-kg/hr (3-lb/hr) TDF Cofiring}

The TDF is suspected to be the reason for the high levels of particulate-bound and oxidized mercury observed in the November 2001 and August 2002 field demonstrations. The mechanisms, however, are not quite understood and may be attributed to the additional chlorine or other substance in the TDF, the unburned carbon from the TDF combustion, or other unknown factors. Therefore, to further confirm and clarify the TDF effect on mercury species in flue gas, Test 2 included the TDF as a supplemental fuel at a feed rate of $1.4 \mathrm{~kg} / \mathrm{hr}(3 \mathrm{lb} / \mathrm{hr})$ (corresponding to 5\% coal mass-based) to cofire with the Belle Ayr coal. Two pairs of Ontario Hydro samples were taken at the Advanced Hybrid ${ }^{\mathrm{TM}}$ filter inlet and outlet, and the mercury vapor species across the Advanced Hybrid ${ }^{\mathrm{TM}}$ filter unit were monitored by two CMMs. The inlet

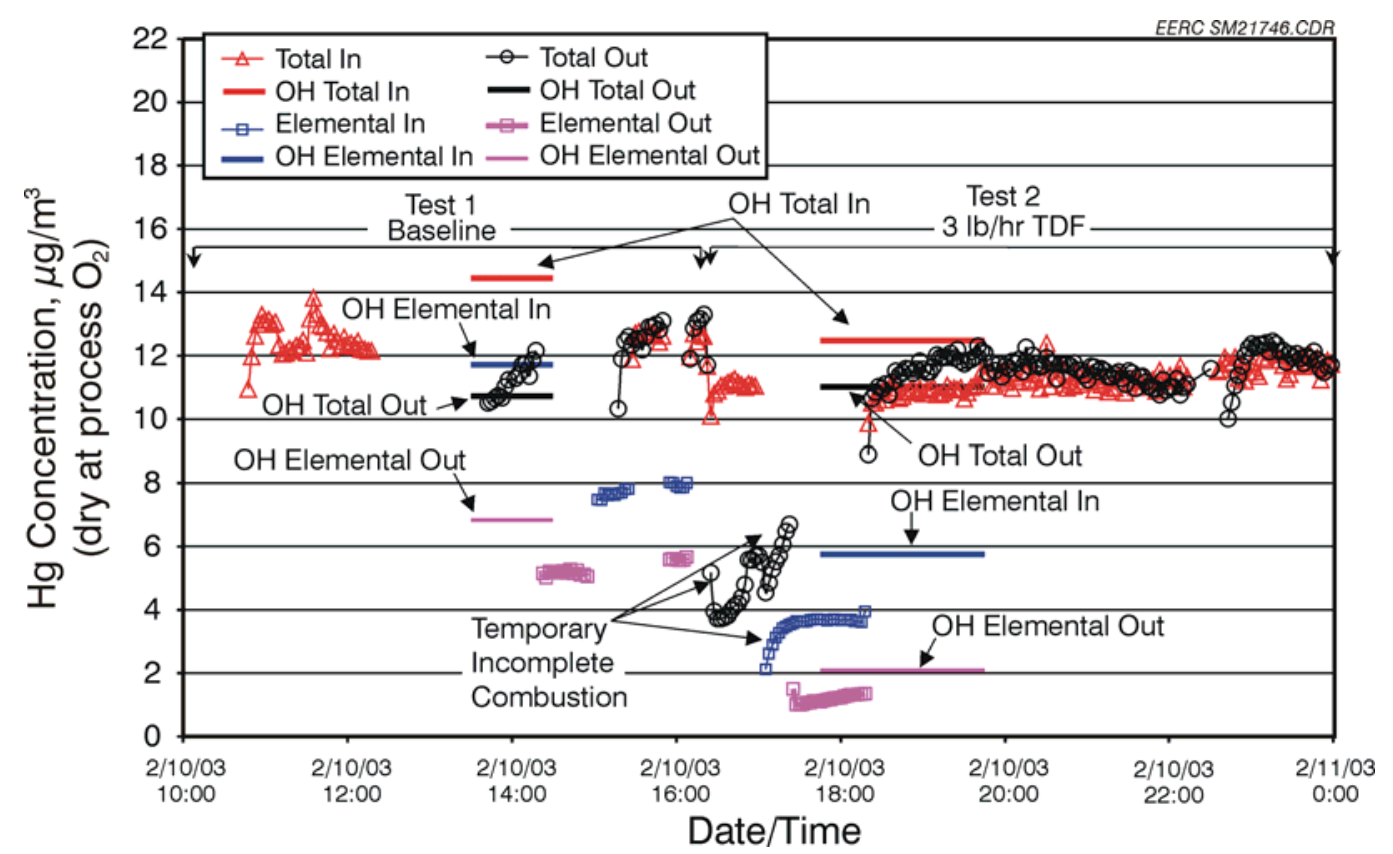

Figure 6.2.7.3. Temporal variations of gaseous mercury across the Advanced Hybrid ${ }^{\mathrm{TM}}$ filter in the Belle Ayr baseline test. 
Ontario Hydro results indicate $13-14 \mu \mathrm{g} / \mathrm{m}^{3}$ of total mercury in the flue gas (shown in Figure 6.2.7.4, slightly lower than the $16.2 \mu \mathrm{g} / \mathrm{m}^{3}$ without TDF cofiring. Part of the reason for lower inlet mercury could be the reduced coal feed rate with supplemental TDF.

The CMM data (Figure 6.2.7.3) were quite consistent with the Ontario Hydro results, and they both showed more oxidized mercury in the flue gas while cofiring TDF and Belle Ayr coal than firing Belle Ayr coal alone: $47.5 \%$ of oxidized mercury with TDF cofiring flue gas compared to $18.9 \%$ without TDF cofiring, indicating additional oxidation occurred upstream of the Advanced Hybrid ${ }^{\mathrm{TM}}$ filter inlet sampling port. In the Advanced Hybrid ${ }^{\mathrm{TM}}$ filter outlet flue gas, $79.2 \%$ of the total mercury emission was oxidized mercury, and only $20.8 \%$ was elemental mercury. The conversion of $\mathrm{Hg}^{0}$ to $\mathrm{Hg}^{2+}$ and $\mathrm{Hg}(\mathrm{p})$ across the Advanced Hybrid ${ }^{\mathrm{TM}}$ filter was $65 \%$, compared to $33 \%$ in the baseline test. The mercury emission, nevertheless, was around $12 \mu \mathrm{g} / \mathrm{m}^{3}$ : only a $10 \%-20 \%$ capture efficiency.

The above experimental data indicate that TDF enhances mercury oxidation, which may start in the combustion zone and continue in the Advanced Hybrid ${ }^{\mathrm{TM}}$ filter unit. One hypothesis

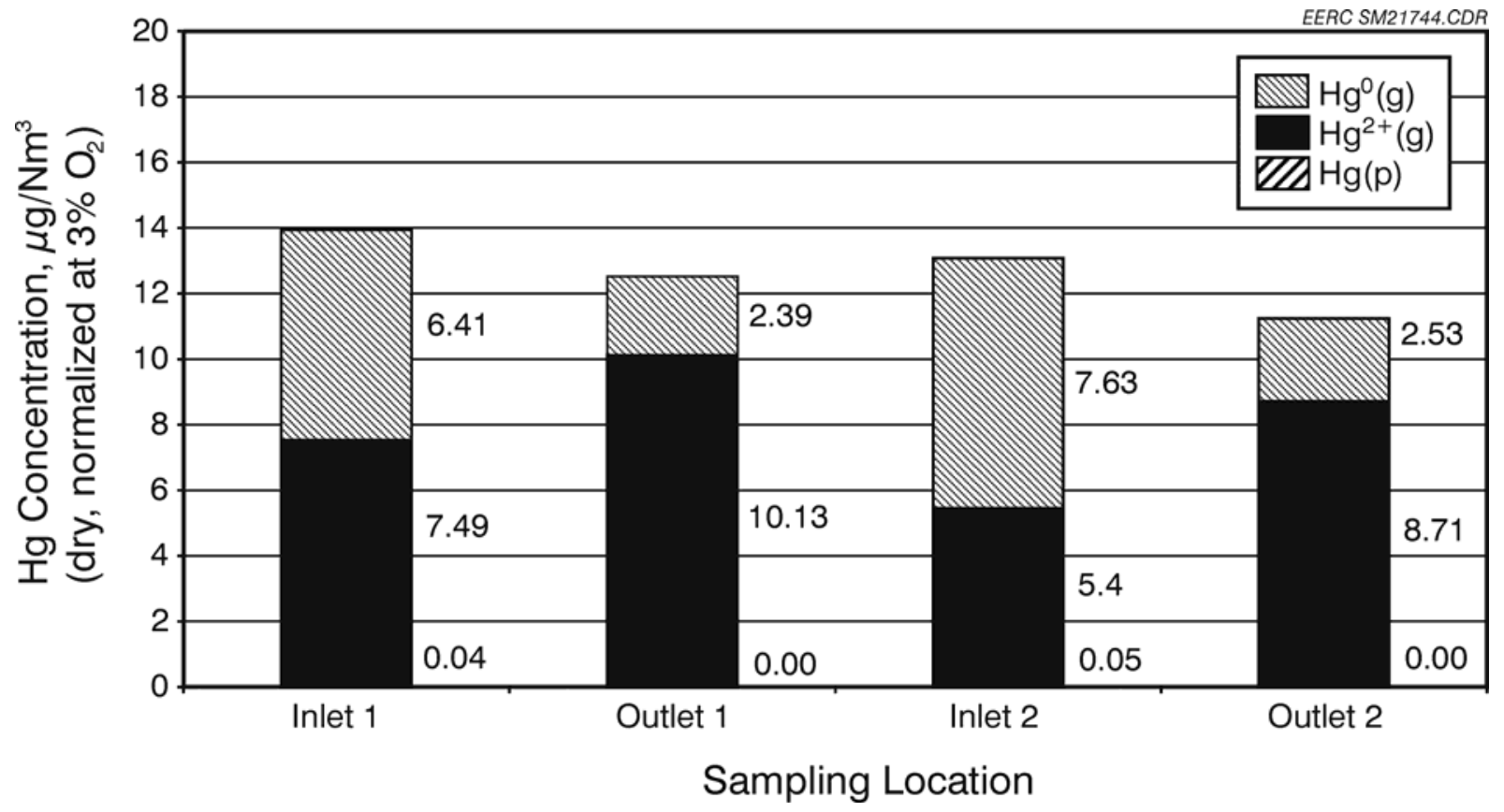

Figure 6.2.7.4. Test 2 - Ontario Hydro results in the Advanced Hybrid ${ }^{\mathrm{TM}}$ filter inlet and outlet flue gas with 1.4-kg/hr (3-lb/hr) TDF cofiring. 
is that the additional chlorine from the TDF caused the enhanced oxidation. A Method 26 sample collected in the inlet flue gas showed a $\mathrm{HCl}$ concentration in flue gas of $2.54 \mathrm{ppm}$ with TDF cofiring compared to $0.75 \mathrm{ppm}$ measured in the baseline test (listed in Table 6.2.7.3). The 2.54-ppm $\mathrm{HCl}$ in flue gas is still low, but the TDF combustion may enhance the formation of atomic chlorine, which is considered the chlorine species responsible for oxidation.

The CMM data in Figure 6.2.7.3 indicated a dramatic decrease of mercury emission in the outlet flue gas when TDF cofiring started: the total mercury concentration in the Advanced Hybrid $^{\mathrm{TM}}$ filter outlet flue gas decreased to less than $4 \mu \mathrm{g} / \mathrm{m}^{3}$. It took nearly $3 \mathrm{hr}$ to return to the same level as at the inlet concentration. The flue gas concentrations of $\mathrm{O}_{2}, \mathrm{CO}, \mathrm{CO}_{2}, \mathrm{NO}_{\mathrm{x}}$, and $\mathrm{SO}_{2}$ during this period are shown in Figure 6.2.7.5. The $\mathrm{O}_{2}$ concentration was momentarily decreased to $3.5 \%$ during 16:20-16:30, with a corresponding $\mathrm{CO}_{2}$ spike at the combustor outlet, indicating temporary incomplete fuel combustion when TDF addition was started. Possibly, unburned carbon was generated and attached to the filter bags, where mercury was subsequently captured.

At the end of the test, the hopper ash with a residence time of $18 \mathrm{hr}$ was collected for LOI analysis. Table 6.2.7.4 lists the analysis result with a comparison to the LOI level in the baseline ash. The LOI levels in both ash samples are very close: $0.16 \%$ and $0.14 \%$ for the baseline and $1.4 \mathrm{~kg} / \mathrm{hr}(3 \mathrm{lb} / \mathrm{hr})$ for the tire addition test, respectively, indicating, in general, good combustion and no significant carbon residue in the ash.

Test 3 - 1.4-kg/hr (3-lb/hr) TDF Cofiring Combined with 1.5-lb/Macf NORIT FGD

\section{Carbon Injection}

With TDF cofiring, FGD carbon injection was started at a rate of $24 \mathrm{mg} / \mathrm{m}^{3}(1.5 \mathrm{lb} / \mathrm{Macf})$, corresponding to a carbon-to-mercury ratio of 3000:1. The CMM data (Figures 6.2.7.6 and 6.2.7.7) indicated the temporal variations of mercury species in the flue gas under TDF cofiring combined with NORIT FGD injection. Upon the injection of $24 \mathrm{mg} / \mathrm{m}^{3}$ (1.5 lb/Macf) NORIT FGD into the system, the mercury emissions in the Advanced Hybrid ${ }^{\mathrm{TM}}$ filter outlet dropped from 10 to $1.1-1.9 \mu \mathrm{g} / \mathrm{m}^{3}$ with only $0.07-0.25 \mu \mathrm{g} / \mathrm{m}^{3}$ elemental mercury. CMM data in Figure 6.2.7.7

Table 6.2.7.3. Chloride Concentrations in Flue Gas, ppmv, dry basis, $3 \%$

\begin{tabular}{ccccc}
\hline Baseline & $\begin{array}{c}1.4-\mathrm{kg} / \mathrm{hr} \\
(3-\mathrm{lb} / \mathrm{hr}) \mathrm{TDF}\end{array}$ & $\begin{array}{c}3000: 1 \\
\text { Carbon }\end{array}$ & $\begin{array}{c}2.7-\mathrm{kg} / \mathrm{hr} \\
(6-\mathrm{lb} / \mathrm{hr}) \mathrm{TDF}\end{array}$ & $\begin{array}{c}1.4-\mathrm{kg} / \mathrm{hr}(3-\mathrm{lb} / \mathrm{hr}) \mathrm{TDF}+ \\
3000: 1 \mathrm{Carbon}\end{array}$ \\
\hline $0-0.75$ & 2.54 & 0 & 2.47 & 2.47 \\
\hline
\end{tabular}




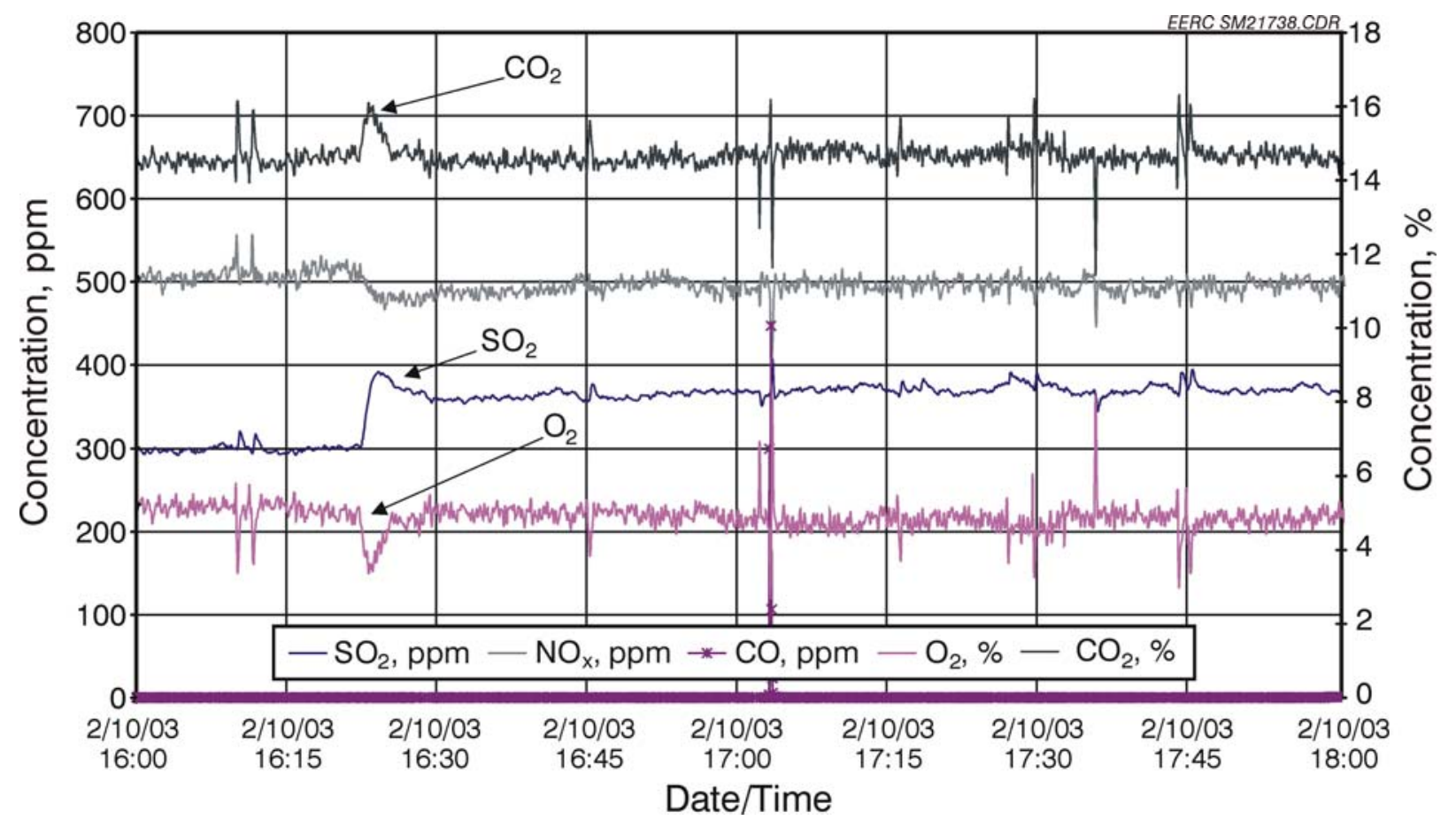

Figure 6.2.7.5. Flue gas concentrations for PTC-BA-636.

Table 6.2.7.4. LOI in the Advanced Hybrid ${ }^{\mathrm{TM}}$ Filter Hopper Ash, \%

\begin{tabular}{lcccccc}
\hline & $1.4 \mathrm{~kg} / \mathrm{hr}$ & $1.4 \mathrm{~kg} / \mathrm{hr}$ & \multicolumn{3}{c}{$2.7 \mathrm{~kg} / \mathrm{hr}$} & $2.7 \mathrm{~kg} / \mathrm{hr}$ \\
& $(3 \mathrm{lb} / \mathrm{hr})$ & $(3 \mathrm{lb} / \mathrm{hr}) \mathrm{TDF}+$ & $3000: 1$ & $(6 \mathrm{lb} / \mathrm{hr}) \mathrm{TDF}+$ & $(6 \mathrm{lb} / \mathrm{hr})$ & $4400: 1$ \\
Baseline & TDF & $3000: 1$ Carbon & Carbon & $3000: 1 \mathrm{Carbon}$ & $\mathrm{TDF}$ & $\mathrm{IAC}$ \\
\hline 0.16 & 0.14 & 0.58 & 0.68 & 0.77 & 0.48 & 1.31 \\
\hline
\end{tabular}

show a quick recovery of mercury emission when carbon injection was accidentally shut down, which further confirms the fact that TDF cofiring results in oxidation rather than capture of the mercury.

Plotted in Figure 6.2.7.8 are the Ontario Hydro results during this test. The total mercury (44.7\%-67.4\%) in the inlet flue gas, based on the Ontario Hydro data shown in Figure 6.2.7.4, had already been oxidized as a result of TDF cofiring. After contacting the FGD carbon, the total mercury emission at the Advanced Hybrid ${ }^{\mathrm{TM}}$ filter outlet was dramatically decreased to $1.72-$ $1.90 \mu \mathrm{g} / \mathrm{Nm}^{3}$ with only $1.43-1.61 \mu \mathrm{g} / \mathrm{Nm}^{3}$ of oxidized mercury vapor and virtually no elemental mercury. Total mercury collection efficiency in this test was about 88\%. Both CMM and Ontario Hydro data were in good agreement with total mercury vapor concentration. The 


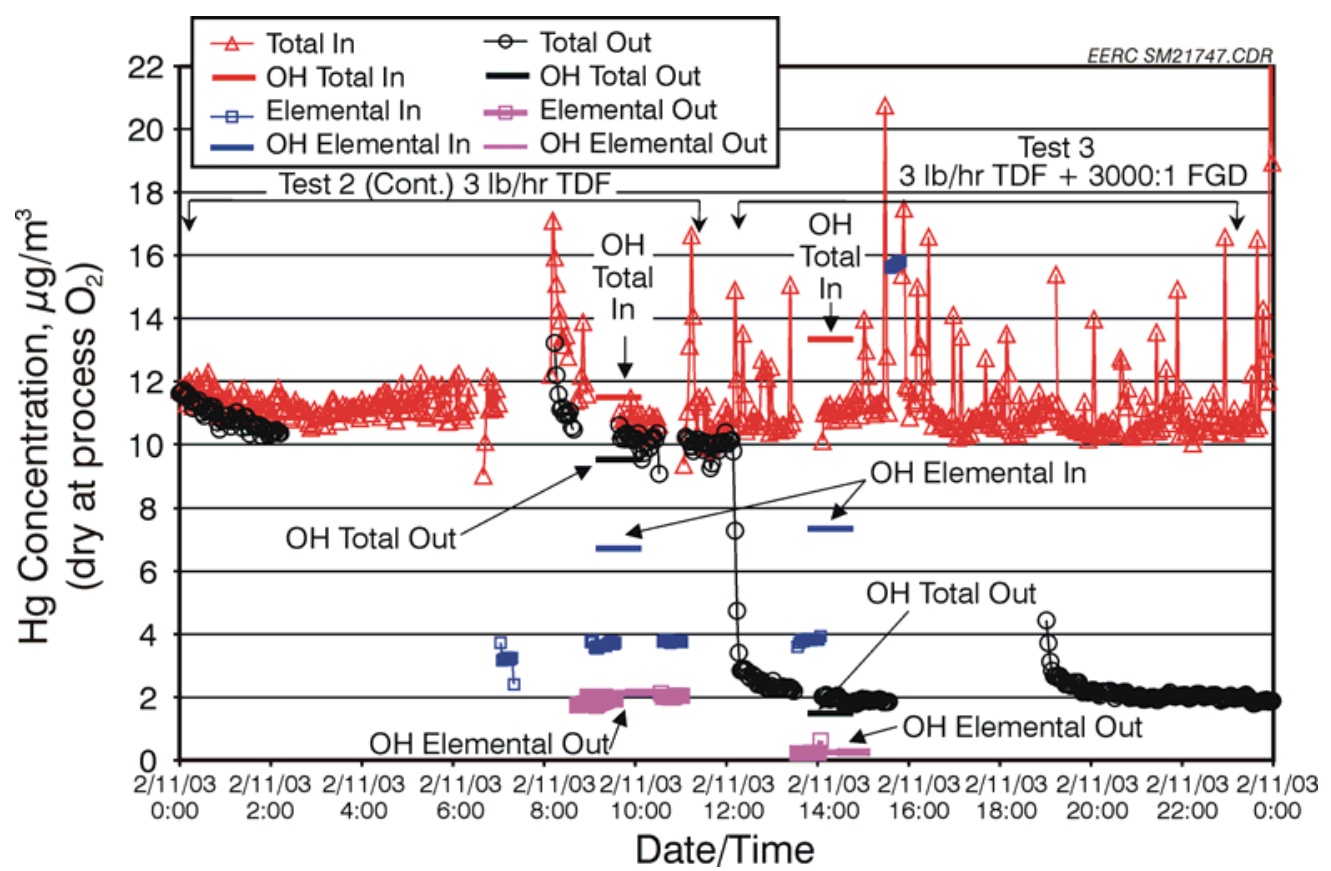

Figure 6.2.7.6. Temporal variations of gaseous mercury across the Advanced Hybrid ${ }^{\mathrm{TM}}$ filter in Day 2 test.

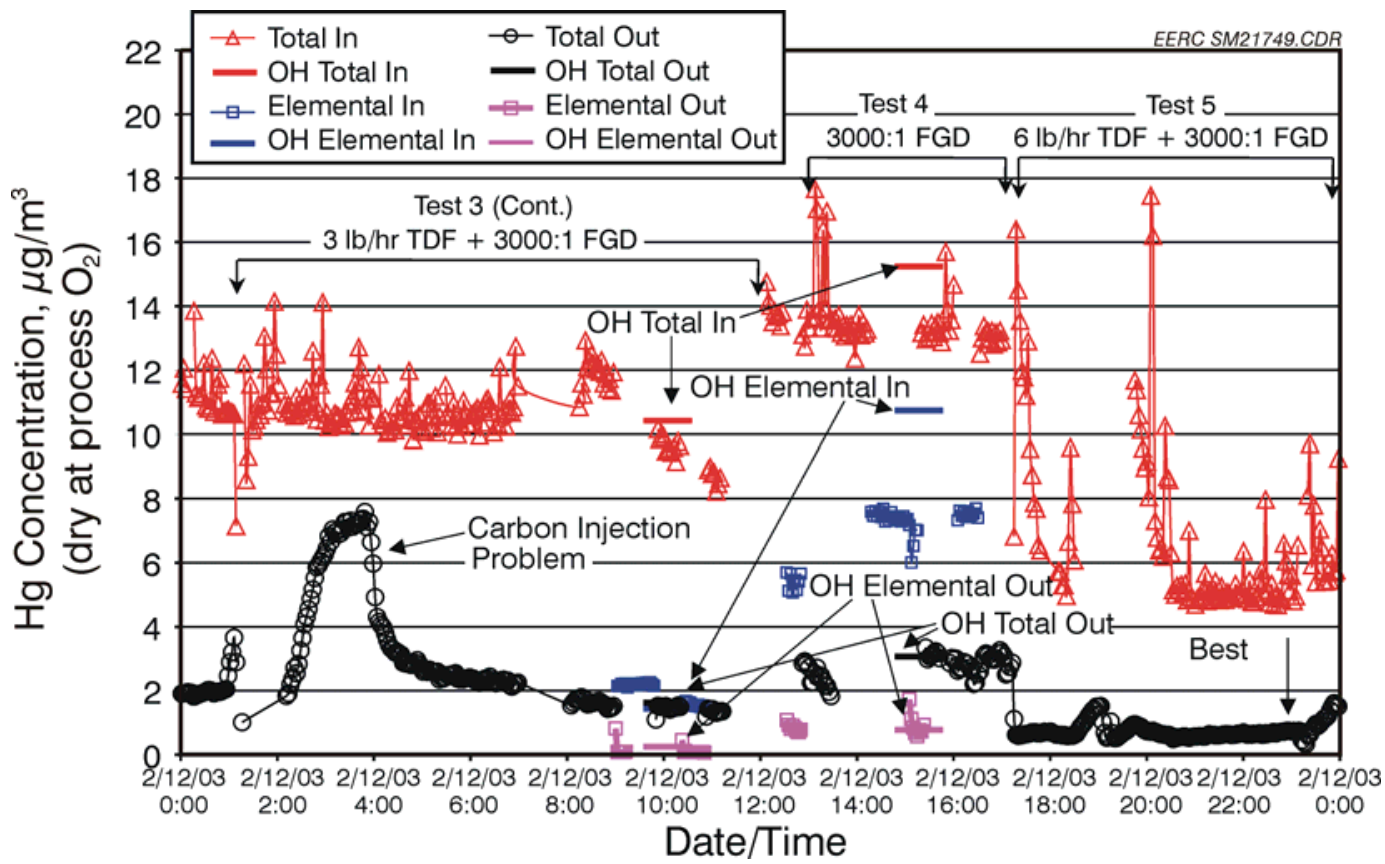

Figure 6.2.7.7. Temporal variations of gaseous mercury across the Advanced Hybrid ${ }^{\mathrm{TM}}$ filter in

Day 3 test. 


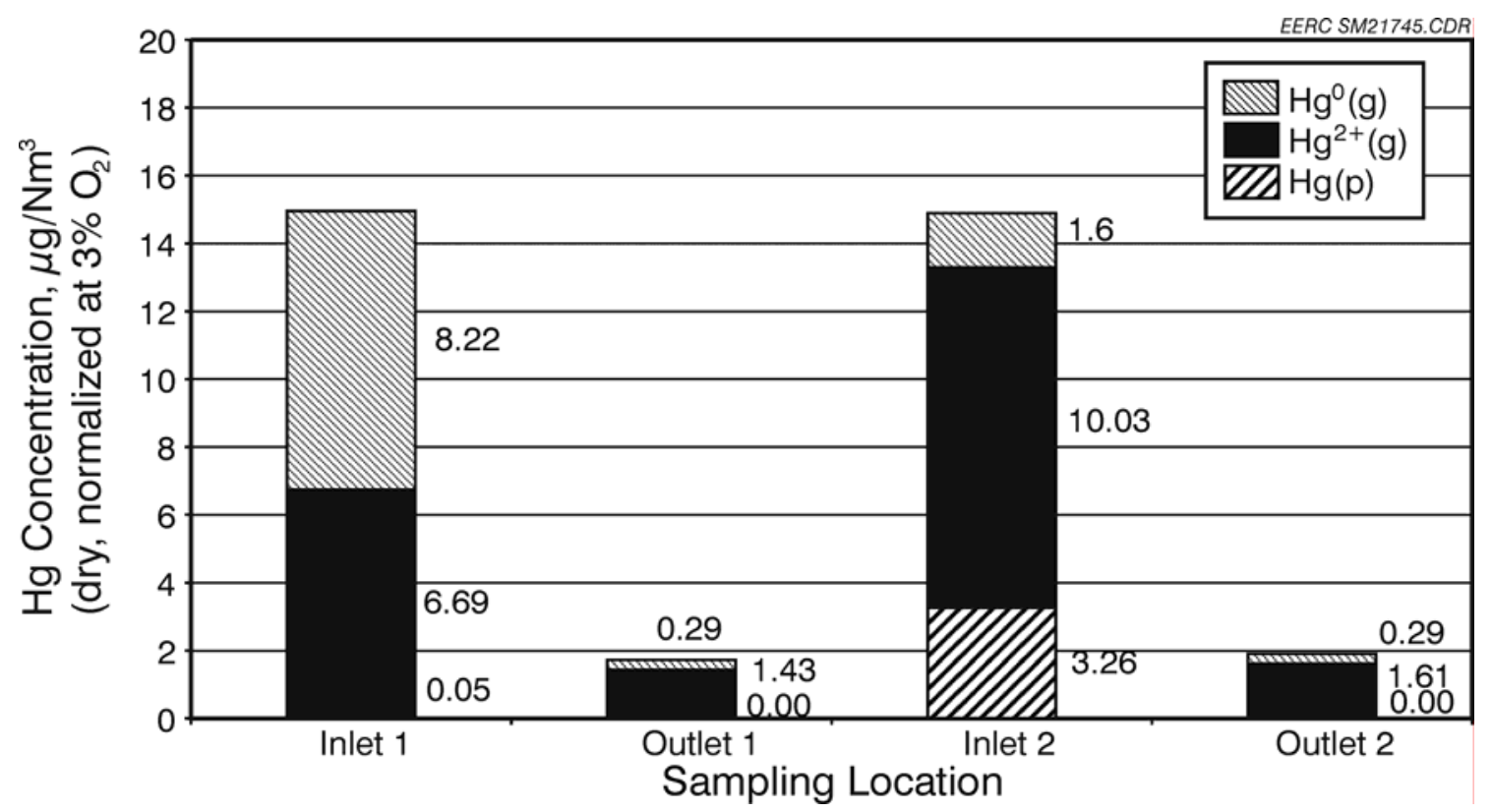

Figure 6.2.7.8. Ontario Hydro results in the Advanced Hybrid ${ }^{\mathrm{TM}}$ filter inlet and outlet flue gas under 3-lb/hr TDF cofiring combined with 1.5-lb/Macf FGD injection.

inlet elemental mercury measured by CMM was slightly lower than the corresponding Ontario Hydro data, which may be the result of some mercury capture on the sampling filter before the flue gas entered the CMM.

The $0.58 \%$ LOI in hopper ash was higher than that in Tests 1 and 2, which is expected because of FGD carbon injection. The chlorine concentration was $2.47 \mathrm{ppm}$, the same as the $2.54 \mathrm{ppm}$ in Test 2 since the TDF injection rate was maintained at $1.4 \mathrm{~kg} / \mathrm{hr}(3 \mathrm{lb} / \mathrm{hr})$.

\section{Test 4 - 24 mg/m ${ }^{3}$ (1.5 lb/Macf) NORIT FGD Carbon Injection}

To confirm the improved mercury removal efficiency by TDF cofiring combined with NORIT FGD injection, the TDF feeder was shut off while carbon injection was maintained into the Advanced Hybrid ${ }^{\mathrm{TM}}$ filter. CMM data in Figure 6.2.7.7 indicated the temporal variation of mercury species across the Advanced Hybrid ${ }^{\mathrm{TM}}$ filter during the test. Once the TDF feeding was stopped, the gaseous mercury in the inlet flue gas was around $13-14 \mu \mathrm{g} / \mathrm{m}^{3}$, while the elemental mercury in the inlet flue gas gradually increased and reached $7.5 \mu \mathrm{g} / \mathrm{m}^{3}$, accounting for approximately $60 \%$ of the total mercury in the inlet flue gas. Without TDF cofiring, the mercury species in the Belle Ayr coal flue gas were almost at the same level as in the baseline test. Total 
mercury emission at the Advanced Hybrid ${ }^{\mathrm{TM}}$ filter outlet recovered to approximately $3.0 \mu \mathrm{g} / \mathrm{m}^{3}$ with $1.2 \mu \mathrm{g} / \mathrm{m}^{3}$ of elemental mercury under NORIT FGD injection alone.

The corresponding mercury removal efficiency was $78 \%$, somewhat higher than the previous data in PTC-BA-628 and-629 tests, although the operating conditions were the same. One pair of Ontario Hydro samples was collected at the inlet and outlet to verify the CMM measurement, and the analysis results (Figure 6.2.7.9) indicated the same level of mercury removal.

The flue gas compositions, including $\mathrm{SO}_{2}, \mathrm{NO}_{\mathrm{x}}, \mathrm{O}_{2}, \mathrm{CO}$, and $\mathrm{CO}_{2}$, were very similar among the three tests; the only obvious difference was the $17.3 \mu \mathrm{g} / \mathrm{m}^{3}$ of total mercury present in the flue gas compared to $10 \mu \mathrm{g} / \mathrm{m}^{3}$ from previous PTC-BA-628 and 629 tests. The higher mercury concentration in the flue gas resulted in a greater concentration difference between the mercury vapor in the bulk gas phase and the mercury on the FGD carbon. This imposed a greater driving force from bulk phase to carbon surface, and might lead to a higher percentage of mercury capture. The conversion of $\mathrm{Hg}^{0}$ to $\mathrm{Hg}^{2+}$ and $\mathrm{Hg}(\mathrm{p})$ across the Advanced Hybrid ${ }^{\mathrm{TM}}$ filter

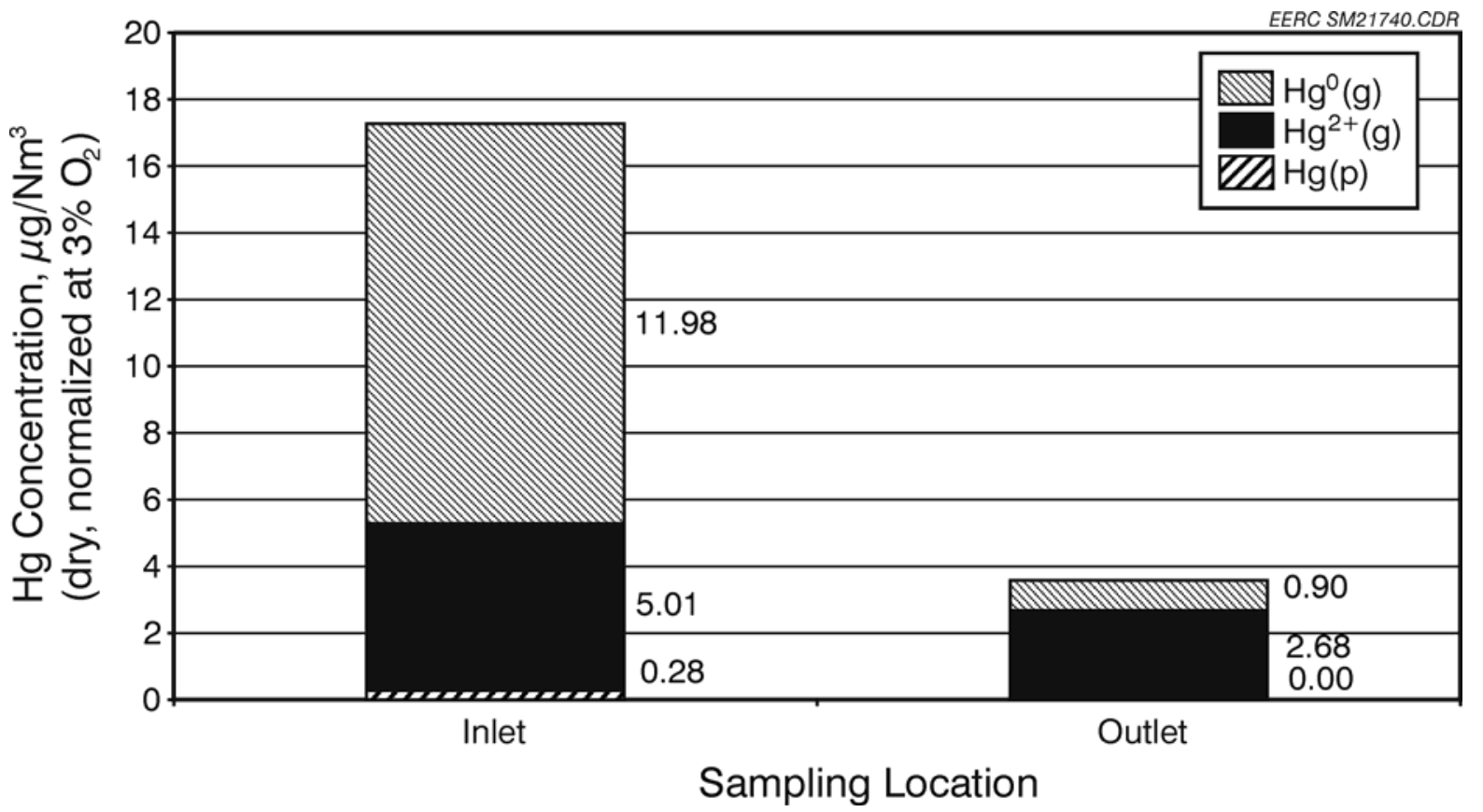

Figure. 6.2.7.9. Ontario Hydro sample collected at the Advanced Hybrid ${ }^{\mathrm{TM}}$ filter inlet and outlet with $24-\mathrm{mg} / \mathrm{m}^{3}$ (1.5-lb/Macf) FGD injection. 
was $93 \%$ in this test, almost the same level as that in Test 3 and higher than the $60 \%-75 \%$ in the PTC-BA-628 and -629 tests. It is possible that there was a residual effect from TDF cofiring which caused both higher mercury oxidation and capture. Nevertheless, FGD carbon combined with TDF cofiring provided better mercury capture than FGD alone.

Analysis results from Method 26 (listed in Table 6.2.7.3) indicate that chloride concentration in the flue gas during this time was virtually zero without TDF injection. The LOI in the hopper ash was $0.68 \%$, the same level as in Test 3 , since they both had the same carbon injection rate.

\section{Test 5 - 2.7-kg/hr (6-lb/hr) TDF Cofiring Combined with 24-mg/m ${ }^{3}$ (1.5-lb/Macf) NORIT FGD Carbon Injection}

To enhance the carbon reactivity with mercury species in the coal flue gas, TDF cofiring was restarted and the feed rate increased from 1.4 to $2.7 \mathrm{~kg} / \mathrm{hr}$ ( 3 to $6 \mathrm{lb} / \mathrm{hr}$ ). The CMM data (Figures 6.2.7.7 and 6.2.7.10) showed that total mercury vapor at the Advanced Hybrid ${ }^{\mathrm{TM}}$ filter inlet during this test temporarily dropped to $5 \mu \mathrm{g} / \mathrm{Nm}^{3}$ while the coal feed rate was stable and

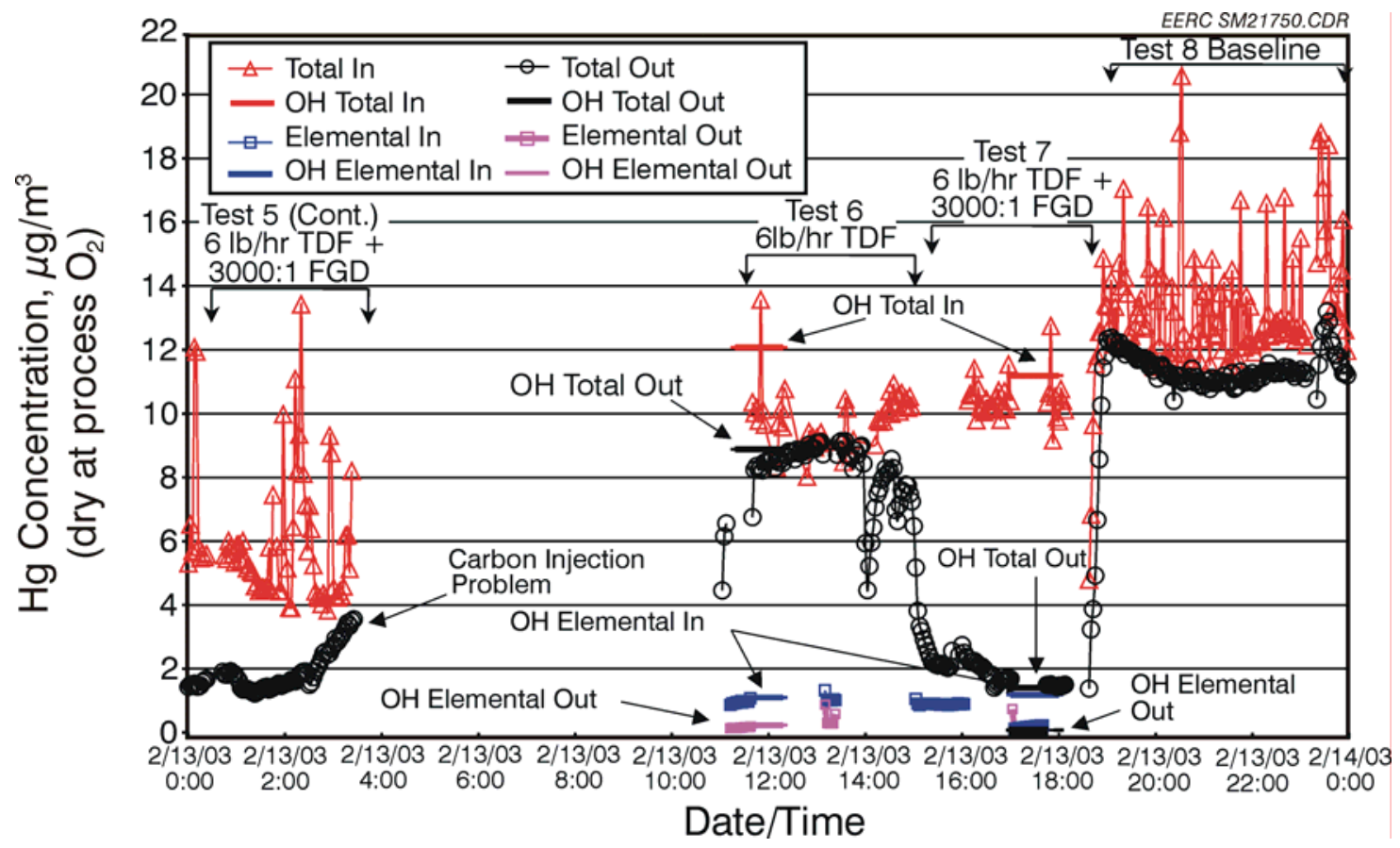

Figure 6.2.7.10. Temporal variations of gaseous mercury across the Advanced Hybrid ${ }^{\mathrm{TM}}$ filter in Day 4 tests. 
consistent. The possible reason is that some of the mercury vapor was captured in the inlet filter as a result of the higher TDF feed rate. At the same time, the total mercury emission level at the Advanced Hybrid ${ }^{\mathrm{TM}}$ filter outlet was around $0.6 \mu \mathrm{g} / \mathrm{Nm}^{3}$. Since no Ontario Hydro sampling was completed at that time, a total mercury concentration of $12 \mu \mathrm{g} / \mathrm{Nm}^{3}$ in flue gas is assumed, corresponding to a capture efficiency of $95 \%$, which was the best achieved so far.

\section{Test 6 - 2.7-kg/hr Larger-Sized TDF Cofiring}

To clarify the benefit from the $2.7-\mathrm{kg} / \mathrm{hr}$ TDF cofiring on mercury oxidation and capture across the Advanced Hybrid ${ }^{\mathrm{TM}}$ filter unit, the NORIT FGD carbon was stopped during this test, while the TDF was still fed into the furnace. However, the TDF included larger (-20-mesh) material rather than the -40 -mesh size TDF for the previous tests. The chloride concentration in the flue gas was 2.48 ppmv compared to zero without TDF cofiring.

The CMM data (Figure 6.2.7.10) showed that the gaseous mercury concentrations in the Advanced Hybrid ${ }^{\mathrm{TM}}$ filter inlet and outlet flue gases were the same at $8-9 \mu \mathrm{g} / \mathrm{Nm}^{3}$, and most of the mercury vapor $(85 \%)$ had already been oxidized because of the TDF cofiring before it entered the Advanced Hybrid ${ }^{\mathrm{TM}}$ filter. The total mercury concentration including the particulateassociated mercury (Figure 6.2.7.11) in the inlet flue gas, measured by the Ontario Hydro method, was $14.7 \mu \mathrm{g} / \mathrm{Nm}^{3}$, higher than the CMM measured gaseous mercury concentration value because of the particle-bound mercury in flue gas. The mercury capture efficiency was $29.4 \%$, slightly higher than the inherent capture efficiency of $22.1 \%$ in the baseline test, showing that cofiring TDF not only enhances mercury vapor oxidation, but also somewhat improves gaseous mercury conversion to the particulate phase. The low LOI of $0.48 \%$ obtained in this test indicates that the larger-size TDF burned as well as the smaller-size TDF.

\section{Test 7 - 2.7-kg/hr TDF Cofiring Combined with 1.5-lb/Macf FGD Carbon Injection}

This test is a repeat of Test 5 to verify mercury collection efficiency with the Advanced Hybrid $^{\mathrm{TM}}$ filter with $2.7-\mathrm{kg} / \mathrm{hr}$ TDF cofiring combined with $24 \mathrm{mg} / \mathrm{m}^{3}$ (1.5 lb/Macf) NORIT FGD carbon injection. One pair of Ontario Hydro samples was collected in the Advanced Hybrid $^{\mathrm{TM}}$ filter inlet and outlet flue gases, and Figure 6.2.7.12 plots the analysis results. In the inlet flue gas, there was only approximately $1 \mu \mathrm{g} / \mathrm{m}^{3}$ of elemental mercury vapor due to the $2.7-\mathrm{kg} / \mathrm{hr}$ TDF cofiring compared to $4-8 \mu \mathrm{g} / \mathrm{Nm}^{3}$ of elemental mercury under $1.4-\mathrm{kg} / \mathrm{hr}$ TDF 


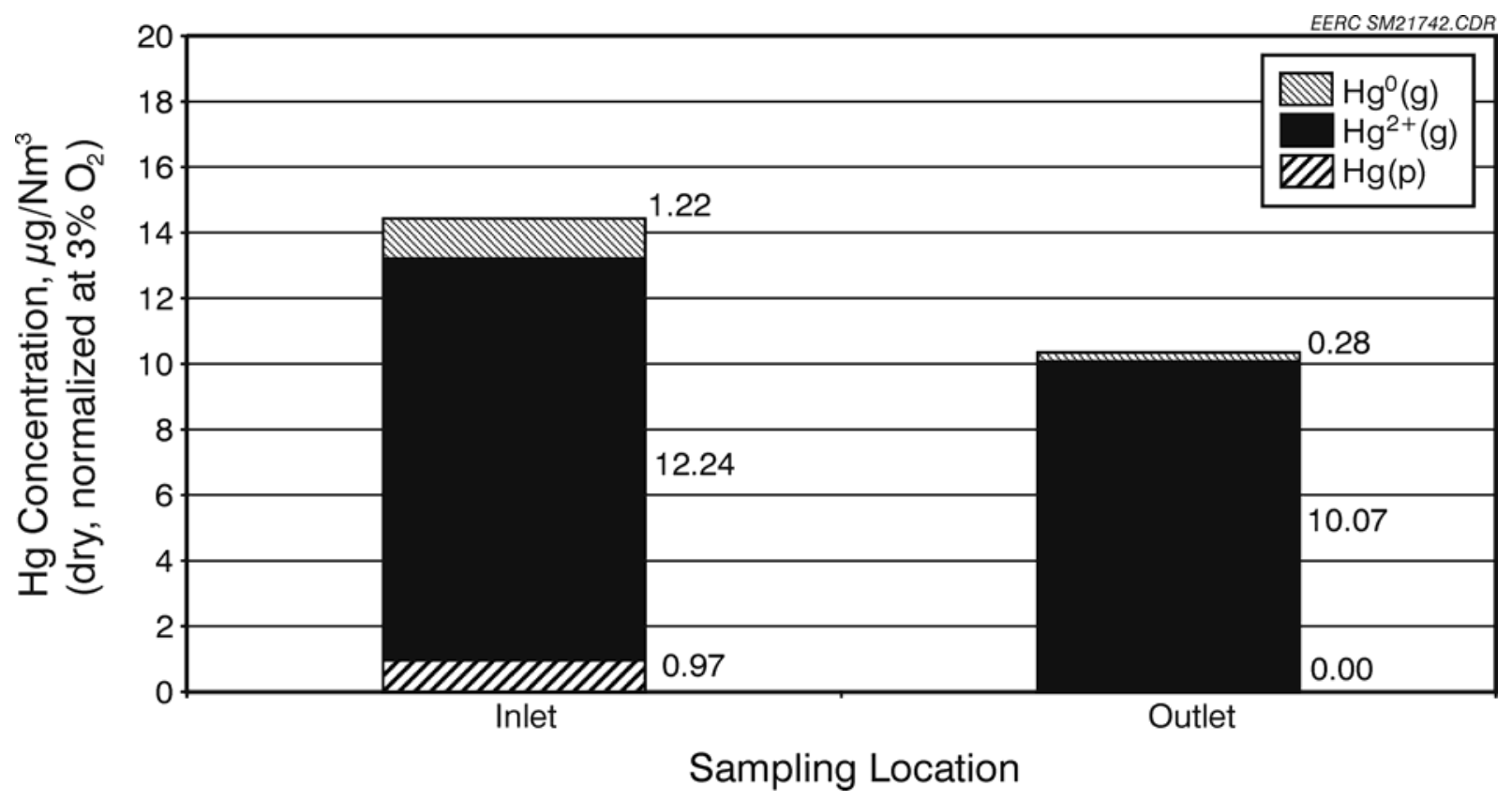

Figure 6.2.7.11. Ontario Hydro results in the Advanced Hybrid ${ }^{\mathrm{TM}}$ filter inlet and outlet flue gases under $2.7-\mathrm{kg} / \mathrm{hr}(6-\mathrm{lb} / \mathrm{hr}) \mathrm{TDF}$ cofiring.

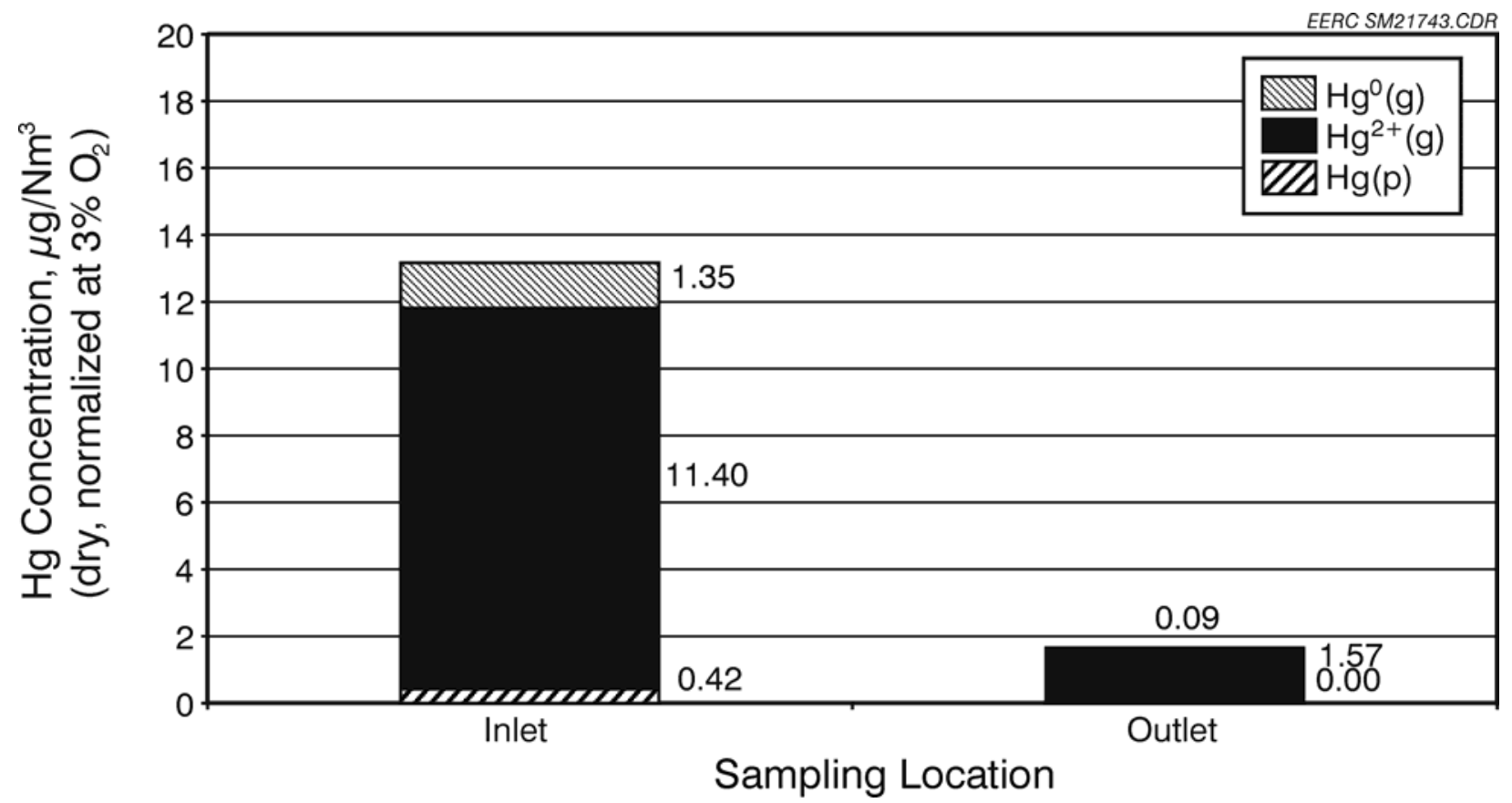

Figure 6.2.7.12. Ontario Hydro result from the Advanced Hybrid ${ }^{\mathrm{TM}}$ filter inlet and outlet flue gases with 2.7-kg/hr (6-lb/hr) TDF cofiring and 24-mg/m³ (1.5-lb/Macf) FGD injection. 
cofiring. Most mercury was oxidized, accounting for around $86.5 \%$ of the total mercury in the flue gas. The total mercury concentration in the flue gas was around $13.2 \mu \mathrm{g} / \mathrm{m}^{3}$, partly because of the decreased coal feed rate. Mercury emission in the Advanced Hybrid ${ }^{\mathrm{TM}}$ filter outlet flue gas was $1.66 \mu \mathrm{g} / \mathrm{m}^{3}$ (Ontario Hydro results) with $1.57 \mu \mathrm{g} / \mathrm{m}^{3}$ of oxidized mercury and virtually no elemental mercury. The CMM data during this testing period (plotted in Figure 6.2.7.10) matched very well with Ontario Hydro results.

The mercury capture efficiency with the Advanced Hybrid ${ }^{\mathrm{TM}}$ filter, based on Ontario Hydro results, was $87.4 \%$, very close to the $95 \%$ mercury removal in Test 5 under the same rates of TDF cofiring and NORIT FGD injection. Compared to $88 \%$ of mercury capture at $1.4-\mathrm{kg} / \mathrm{hr}$ (3-lb/hr) TDF cofiring combined with $24-\mathrm{mg} / \mathrm{m}^{3}$ (1.5-lb/Macf) NORIT FGD injection, there is no significant improvement in mercury removal by increasing the TDF cofiring rate. More carbon is needed to further improve mercury capture.

\section{Test 8 - Baseline Reestablishment}

Both NORIT FGD and TDF were off during this testing period to reestablish baseline conditions. The CMM data (Figures 6.2.7.10 and 6.2.7.13) showed that the total mercury vapor

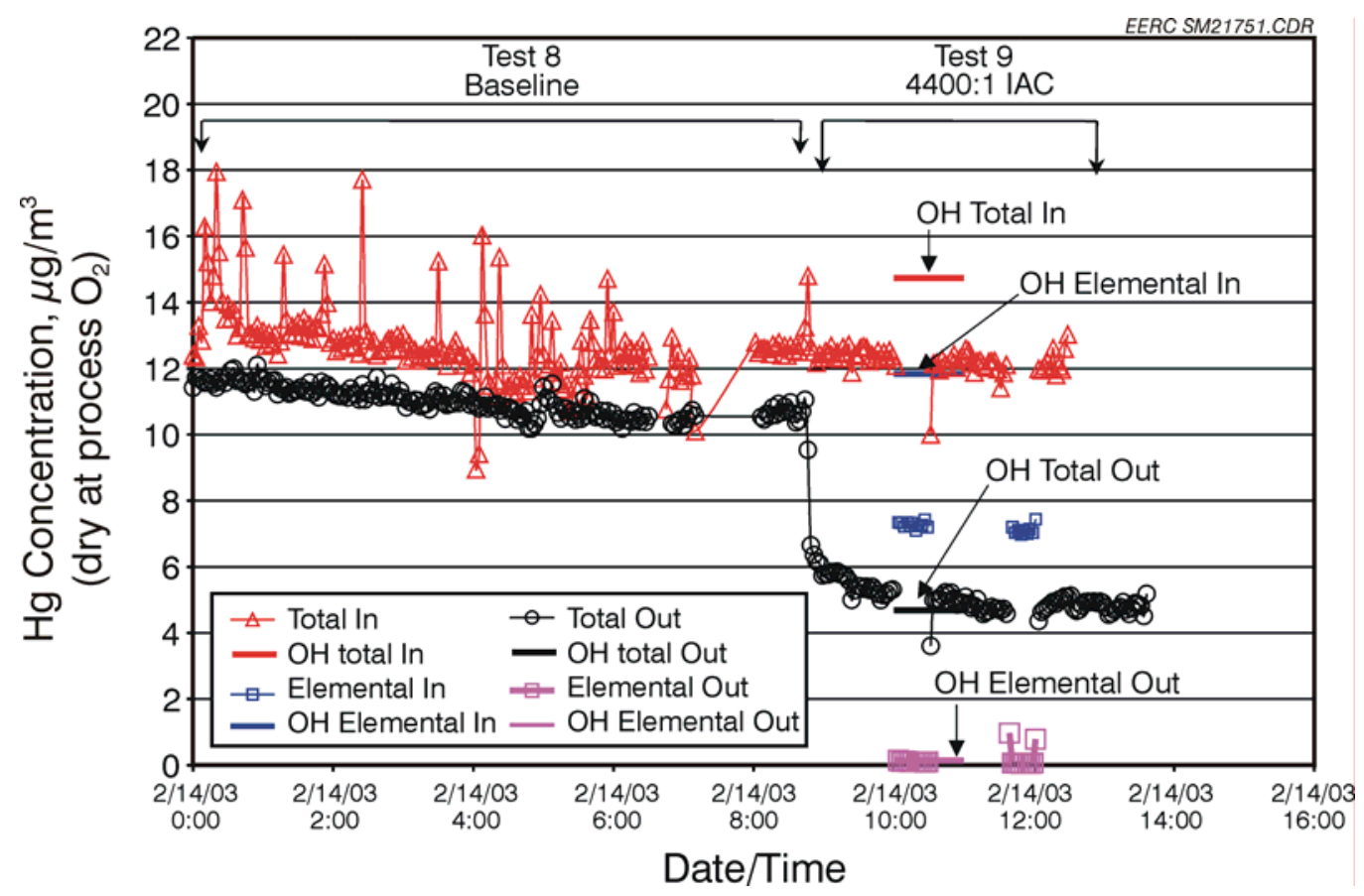

Figure 6.2.7.13. Temporal variations of gaseous mercury across the Advanced Hybrid ${ }^{\mathrm{TM}}$ filter in Day 5 tests. 
concentration at the outlet was returned to the same level as the inlet mercury concentration, indicating a fully recovered baseline condition.

\section{Test 9 - 41.6-mg/m³ (2.6-lb/Macf) Iodine-Treated Carbon Injection}

After reestablishing the baseline, an IAC, commercially available from Barnebey and Sutcliffe, was tested to examine its ability to remove mercury with the Advanced Hybrid ${ }^{\mathrm{TM}}$ filter in the Belle Ayr coal flue gas. Because of the bulk density difference between the FGD carbon and IAC, the actual IAC injection rate was $41.6 \mathrm{mg} / \mathrm{m}^{3}$ (2.6 lb/Macf), corresponding to a carbonto-mercury mass ratio of 4400:1.

The mercury species in the inlet flue gas (Figure 6.2.7.14) were $13.2 \mu \mathrm{g} / \mathrm{Nm}^{3}$ of $\mathrm{Hg}^{0}$, $3.23 \mu \mathrm{g} / \mathrm{Nm}^{3}$ of $\mathrm{Hg}^{2+}$, and $0.04 \mu \mathrm{g} / \mathrm{Nm}^{3}$ of $\mathrm{Hg}(\mathrm{p})$, almost the same as in the baseline tests. At the Advanced Hybrid ${ }^{\mathrm{TM}}$ filter outlet, both the CMM and Ontario Hydro experimental data (Figure 6.2.7.13 and 6.2.7.14) showed the IAC completely oxidized the mercury. Virtually no elemental mercury exited the Advanced Hybrid ${ }^{\mathrm{TM}}$ filter unit when $7-11 \mu \mathrm{g} / \mathrm{Nm}^{3}$ of elemental mercury, accounting for $60 \%-80 \%$ of the total mercury, entered the Advanced Hybrid ${ }^{\mathrm{TM}}$ filter unit. The

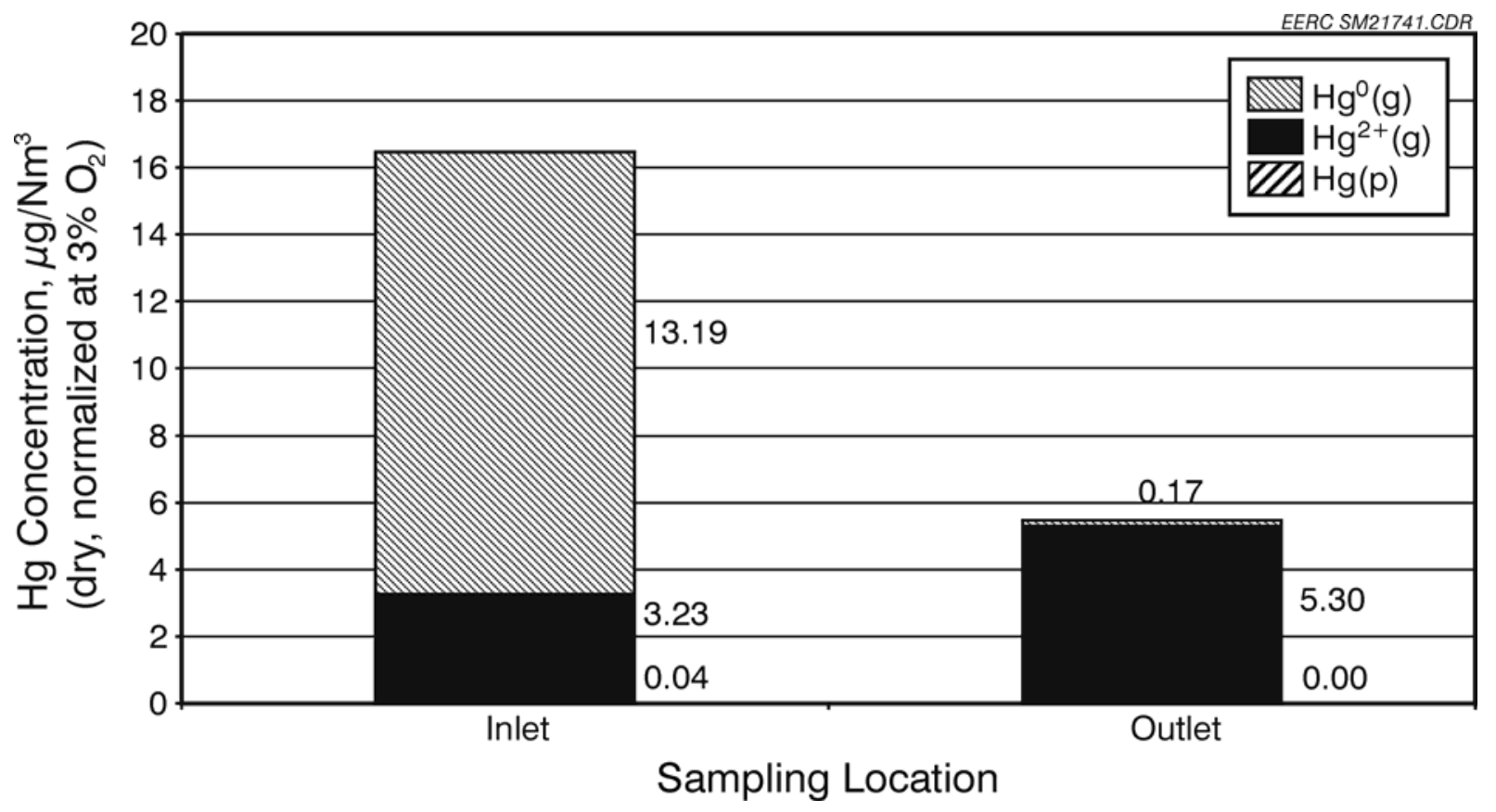

Figure 6.2.7.14. Ontario Hydro results in the Advanced Hybrid ${ }^{\mathrm{TM}}$ filter inlet and outlet flue gases under $42 \mathrm{mg} / \mathrm{m}^{3}$ (2.6-lb/Macf) IAC injection. 
total mercury emission at the Advanced Hybrid ${ }^{\mathrm{TM}}$ filter outlet was still maintained at a relatively high level of $5 \mu \mathrm{g} / \mathrm{Nm}^{3}$, mainly in the oxidized form, which indicates the IAC may face a capacity limit for mercury capture rather than oxidation with the Belle Ayr coal flue gas.

The overall mercury capture efficiency was $66.8 \%$ based on the Ontario Hydro data, similar to what has previously been achieved with the NORIT FGD carbon.

\section{Effect of TDF Cofiring on Carbon Performance for Mercury Oxidation and Capture}

Figure 6.2.7.15 summarizes mercury capture with the Advanced Hybrid ${ }^{\mathrm{TM}}$ filter in Belle Ayr coal flue gas under TDF cofiring combined with carbon injection. With 1.4-kg/hr TDF cofiring with Belle coal, there was no significant improvement on mercury removal compared to the inherent mercury removal with the Advanced Hybrid ${ }^{\mathrm{TM}}$ filter in the baseline test, although the TDF cofiring effectively enhanced mercury oxidation in the flue gas. Only $28.9 \%$ mercury removal was obtained at the $2.7-\mathrm{kg} / \mathrm{h}(6-\mathrm{lb} / \mathrm{hr})$ TDF addition test compared to $0 \%-22 \%$ inherent mercury capture for baseline tests.

For the $24-\mathrm{mg} / \mathrm{m}^{3}(1.5-\mathrm{b} / \mathrm{Macf})$ NORIT FGD carbon injection test, since the $78 \%$ mercury capture efficiency is suspected to be overestimated, $48.4 \%-71.2 \% \mathrm{Hg}$ capture efficiency in PTC-

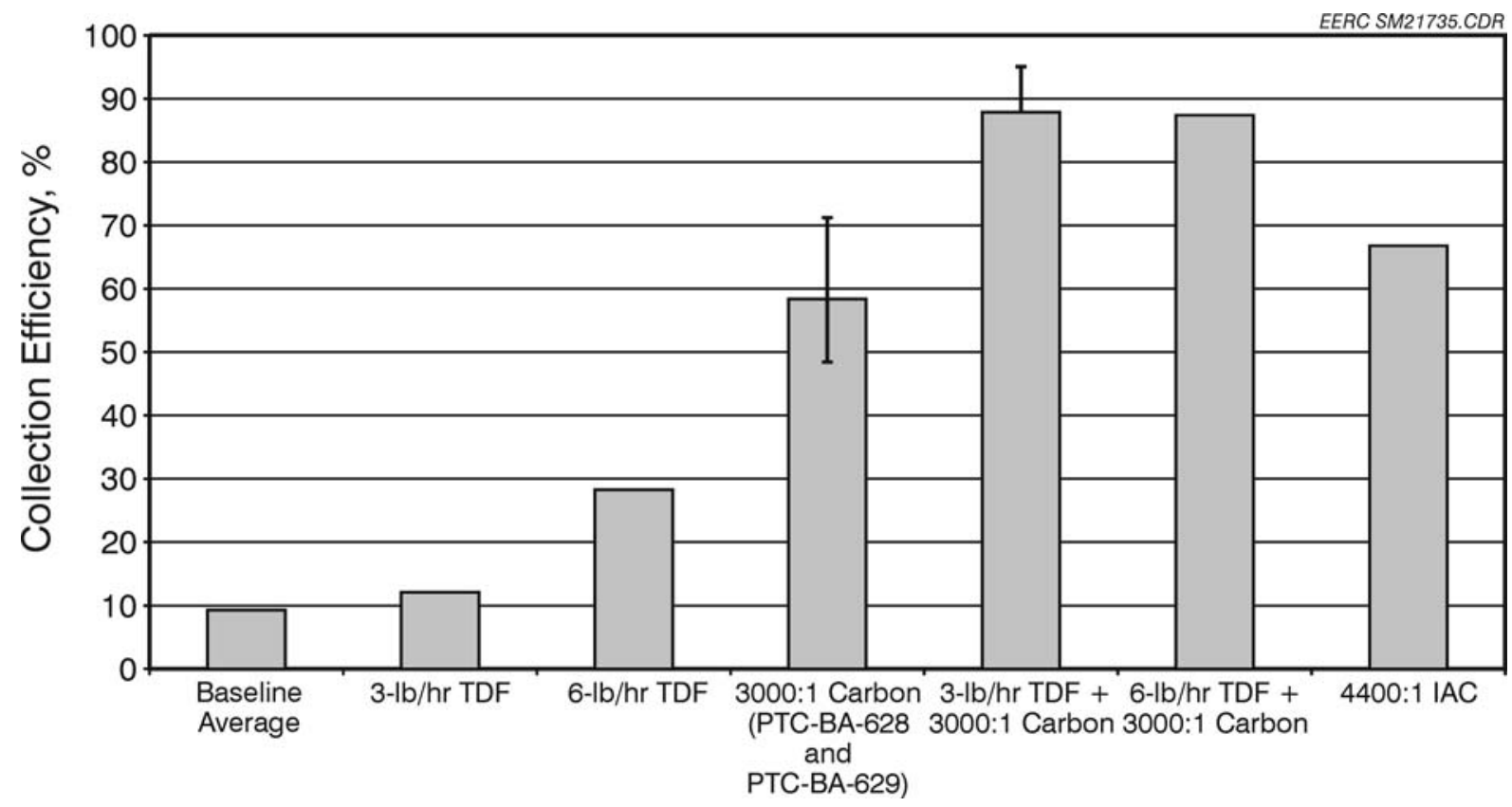

Figure 6.2.7.15. Summary of mercury capture with the Advanced Hybrid ${ }^{\mathrm{TM}}$ filter in Belle Ayr coal flue gas under TDF cofiring combined with carbon injection. 
BA-628 and -629 tests is plotted in Figure 6.2.7.15. When 24-mg/ $\mathrm{m}^{3}$ (1.5-lb/Macf) NORIT FGD and $1.4-\mathrm{kg} / \mathrm{hr}$ TDF were injected simultaneously, the overall mercury removal efficiency was increased to $88 \%-95 \%$, showing TDF cofiring does benefit mercury capture in the Advanced Hybrid ${ }^{\mathrm{TM}}$ filter because of more $\mathrm{Hg}^{2+}$ in the flue gas. The FGD has a better ability to capture $\mathrm{Hg}^{2+}$ than $\mathrm{Hg}^{0}$ because the capture process only involves adsorption instead of oxidation and adsorption. There was no further improvement in mercury capture by increasing the TDF cofiring rate.

Table 6.2.7.5 lists the calculated capacity of NORIT FGD carbon for different conditions. With NORIT FGD carbon injection alone, the capacity of NORIT FGD was $125 \mu \mathrm{g} \mathrm{Hg} / \mathrm{g}$ carbon in the pilot-scale test, very close to the $161 \mu \mathrm{g} \mathrm{Hg} / \mathrm{g}$ carbon obtained in the bench-scale test under the same condition, indicating that the carbon was efficiently utilized in the Advanced Hybrid ${ }^{\mathrm{TM}}$ filter unit.

With the added TDF, much higher capacity was seen compared to the NORIT FGD carbon injection alone test. The TDF not only promotes mercury oxidation but also enhances mercury reactivity with activated carbon, resulting in improved carbon capacity.

Plotted in Figure 6.2.7.16 are normalized mercury species distributions in the Advanced Hybrid $^{\mathrm{TM}}$ filter inlet flue gas for the baseline and TDF cofiring tests. The data clearly show a significant effect of TDF cofiring on mercury oxidation upstream of the Advanced Hybrid ${ }^{\mathrm{TM}}$ filter. The outlet mercury speciation data (Figure 6.2.7.17) showed that additional oxidation occurred across the Advanced Hybrid ${ }^{\mathrm{TM}}$ filter with the TDF cofiring. Almost complete mercury oxidation in the Advanced Hybrid ${ }^{\mathrm{TM}}$ filter outlet flue gas was also seen with the IAC injection test.

\subsubsection{4 - Conclusions from PTC-BA-636 Testing Results}

Cofiring of TDF with the subbituminous coal had a significant effect on mercury speciation in the flue gas. When $100 \%$ coal was fired, there was only $19 \%$ oxidized mercury in the flue gas compared to $47 \%$ when cofiring $5 \%$ TDF (mass basis) and $85 \%$ when cofiring $10 \%$

\section{Table 6.2.7.5. Capacity of FGD Carbon, $\mu \mathrm{g} \mathrm{Hg} / \mathrm{g}$}

\begin{tabular}{lccc}
\hline $\begin{array}{l}3000: 1 \text { Carbon } \\
\text { Injection }\end{array}$ & $\begin{array}{c}3000: 1 \mathrm{Carbon}+ \\
1.4-\mathrm{kg} / \mathrm{hr}(3-\mathrm{lb} / \mathrm{hr}) \mathrm{TDF}^{2}\end{array}$ & $\begin{array}{c}3000: 1 \mathrm{Carbon}+ \\
2.7-\mathrm{kg} / \mathrm{hr}(6-\mathrm{lb} / \mathrm{hr}) \mathrm{TDF}^{2}\end{array}$ & $\begin{array}{c}\text { Capacity from } \\
\text { Bench Scale }\end{array}$ \\
\hline 125 & 236 & 206 & 161 \\
\hline 1 & &
\end{tabular}




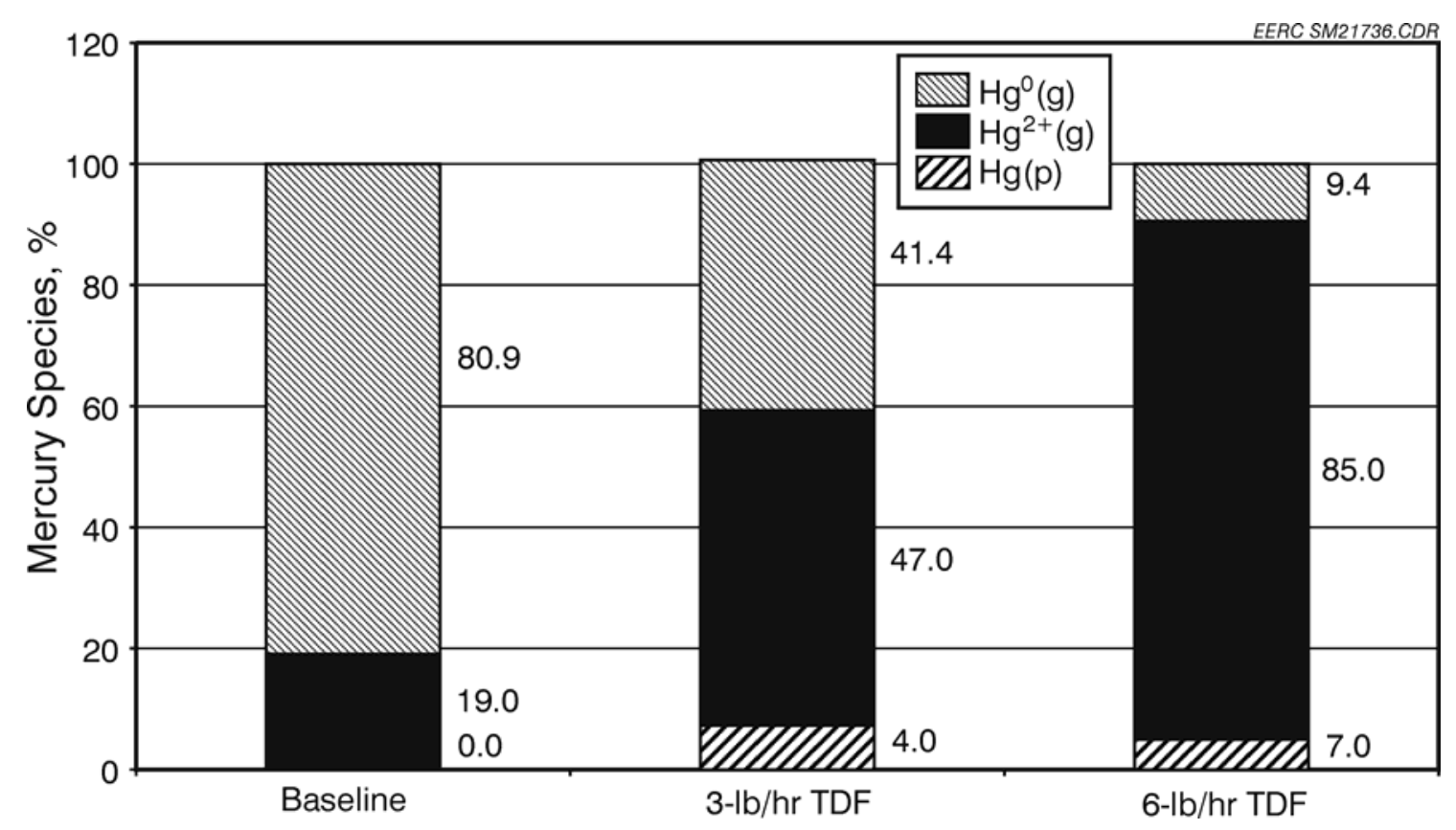

Figure 6.2.7.16. Effect of TDF cofiring on mercury species distributions in the Advanced Hybrid ${ }^{\mathrm{TM}}$ filter inlet flue gases for the baseline and TDF cofiring tests.

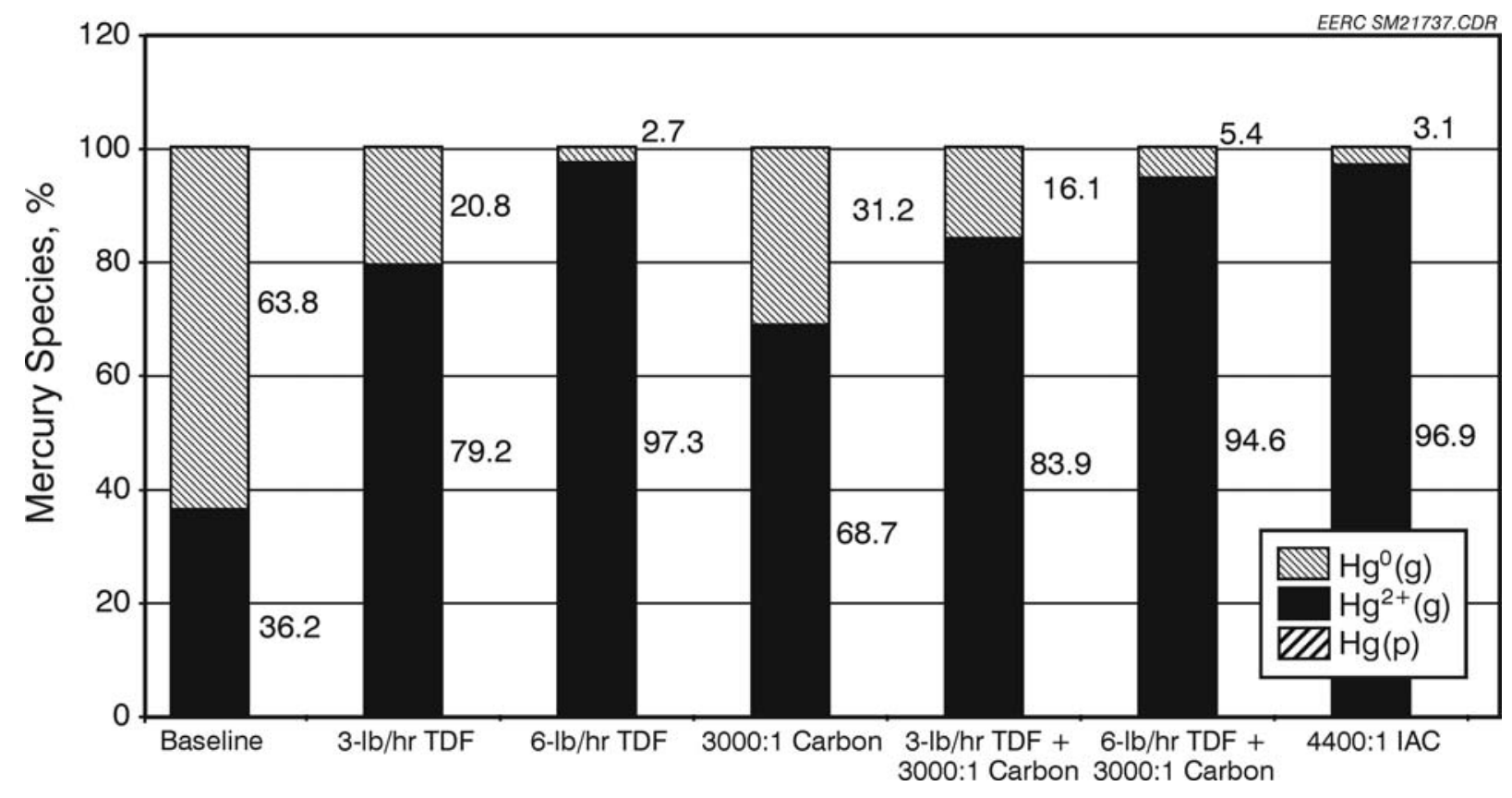

Figure 6.2.7.17. Effects of TDF cofiring combined with carbon injects on mercury oxidation in the Advanced Hybrid ${ }^{\mathrm{TM}}$ filter outlet flue gas. 
TDF. The significant increase in oxidized mercury may be partly the result of increased $\mathrm{HCl}$ in the flue gas with the TDF. However, since the actual increase of measured $\mathrm{HCl}$ was only a few ppm, other changes in combustion conditions or flue gas components may also be responsible for the increase in oxidized mercury.

TDF not only enhanced mercury oxidation in the flue gas but also improved mercury capture when it was combined with FGD carbon injection. With $100 \%$ coal, test results have shown from $48 \%$ to $78 \%$ mercury removal at a relatively low FGD carbon addition rate of $24 \mathrm{mg} / \mathrm{m}^{3}$ (1.5 lb/Macf). With 5\%-10\% TDF cofiring, results showed from $88 \%$ to $95 \%$ total mercury removal with the same carbon addition rate. These results are consistent with results from the 2.5-MW (9000-acfm) Advanced Hybrid ${ }^{\mathrm{TM}}$ filter presented later in this report.

The IAC provided no better mercury removal than the FGD carbon. However, with the IAC, a larger fraction of mercury was oxidized across the Advanced Hybrid ${ }^{\mathrm{TM}}$ filter. This suggests that the IAC effectiveness is also highly dependent on flue gas conditions, similar to the FGD. The mechanisms of oxidation and capture for the two carbons may be different, but the exact conditions where the IAC may provide better mercury control than the FGD carbon are not known.

\subsubsection{PTC-BA-637}

\subsubsection{Test Conditions}

W.L. Gore has developed a cartridge filter for mercury emission control designed to fit inside the cage of a conventional filter bag. Two different cartridge filters (Inserts A and B) were tested separately with the EERC 55-kW (200-acfm) Advanced Hybrid ${ }^{\mathrm{TM}}$ filter unit with Belle Ayr coal flue gas. The cartridge filters were installed inside of the four cylindrical all-PTFE bags of the pilot-scale Advanced Hybrid ${ }^{\mathrm{TM}}$ filter unit. The four all-PTFE bags would remove all the fly ash, and the cartridge filter would capture the gaseous mercury that penetrates the all-PTFE bags in a fly ash-free environment.

The unit was operated as a PJBH with varied A/C ratios of $0.015 \mathrm{~m} / \mathrm{s}(3 \mathrm{ft} / \mathrm{min})$ and $0.03 \mathrm{~m} / \mathrm{s}(6 \mathrm{ft} / \mathrm{min})$. The flue gas temperature across the unit was varied at $124^{\circ} \mathrm{C}\left(255^{\circ} \mathrm{F}\right), 149^{\circ} \mathrm{C}$ $\left(300^{\circ} \mathrm{F}\right)$, and $193^{\circ} \mathrm{C}\left(380^{\circ} \mathrm{F}\right)$ to evaluate the temperature dependence of the cartridge filter on mercury removal with the subbituminous coal flue gas. The filter bags were pulse-cleaned under a trigger pressure of $2.0 \mathrm{kPA}$ ( $8.0 \mathrm{in.}$ W.C.) and had a bag-cleaning interval of 20-30 min during the test. 
One CMM was used to monitor the mercury concentrations in the inlet and outlet flue gases. Pairs of Ontario Hydro samples were collected at the inlet and outlet to verify the CMM measurement and determine the overall mercury removal with the cartridge filters with the Belle Ayr coal flue gas.

\subsubsection{Coal and Flue Gas Analyses}

The Belle Ayr coal used in this testing period was well characterized in previous tests. Therefore, no proximate and ultimate analyses were performed, but a mercury content analysis of the testing coal was done showing $0.115 \mu \mathrm{g} / \mathrm{g}$ of mercury content, which agrees with previous analytical data.

\subsubsection{Mercury Results for PTC-BA-637}

\section{Test 1 - Cartridge A in PJBH at $0.03 \mathrm{~m} / \mathrm{s}(6 \mathrm{ft} / \mathrm{min})$ Face Velocity and $149^{\circ} \mathrm{C}\left(300^{\circ} \mathrm{F}\right)$}

For this test, four Cartridge A filters were installed inside of the four PTFE membrane bags, and the pilot-scale unit was operated as a $\mathrm{PJBH}$ with an $\mathrm{A} / \mathrm{C}$ ratio of $0.03 \mathrm{~m} / \mathrm{s}(6 \mathrm{ft} / \mathrm{min})$. With the flue gas flowing through the system, the temperature across the unit stabilized around $149^{\circ} \mathrm{C}\left(300^{\circ} \mathrm{F}\right)$. $\mathrm{CMM}$ data in Figures 6.2.8.1 and 6.2.8.2 show the gaseous mercury concentrations in the inlet flue gas and mercury emissions of the $\mathrm{PJBH}$ installed with Cartridge A for the $149^{\circ} \mathrm{C}\left(300^{\circ} \mathrm{F}\right)$ Belle Ayr coal flue gas. In the inlet flue gas, the total gaseous mercury was in the range of $10.8-13.5 \mu \mathrm{g} / \mathrm{m}^{3}$ with approximately $8 \mu \mathrm{g} / \mathrm{m}^{3}$ of elemental mercury, indicating a very representative mercury species partition for the Belle Ayr coal flue gas. Mercury emission at the PJBH outlet started at $1.1 \mu \mathrm{g} / \mathrm{m}^{3}$ with $0.5 \mu \mathrm{g} / \mathrm{m}^{3} \mathrm{Hg}^{0}$ and gradually increased to $3.0 \mu \mathrm{g} / \mathrm{m}^{3}$ after $8 \mathrm{hr}$ of operation, indicating approximately $30 \%$ breakthrough.

To confirm the outlet CMM measurement, natural gas was temporarily fired instead of the Belle Ayr coal to determine if the mercury emission would drop to zero. With natural gas combustion, the gaseous mercury concentration in the inlet flue gas (Figure 6.2.8.1) decreased to

$0.2 \mu \mathrm{g} / \mathrm{m}^{3}$ immediately, while the mercury emission at the outlet gradually decreased to $0.6 \mu \mathrm{g} / \mathrm{m}^{3}$ after $2 \mathrm{hr}$, meaning mercury desorbed either from the cartridge filters or the residual ash in the pipe. The results from the natural gas combustion test indicate the CMM responded to mercury variation in the flue gas promptly and accurately.

The pilot-scale unit was returned to Belle Ayr coal firing, and the CMM data (Figures 6.2.8.1 and 6.2.8.2) showed a continuous increase of mercury emission. After approximately 


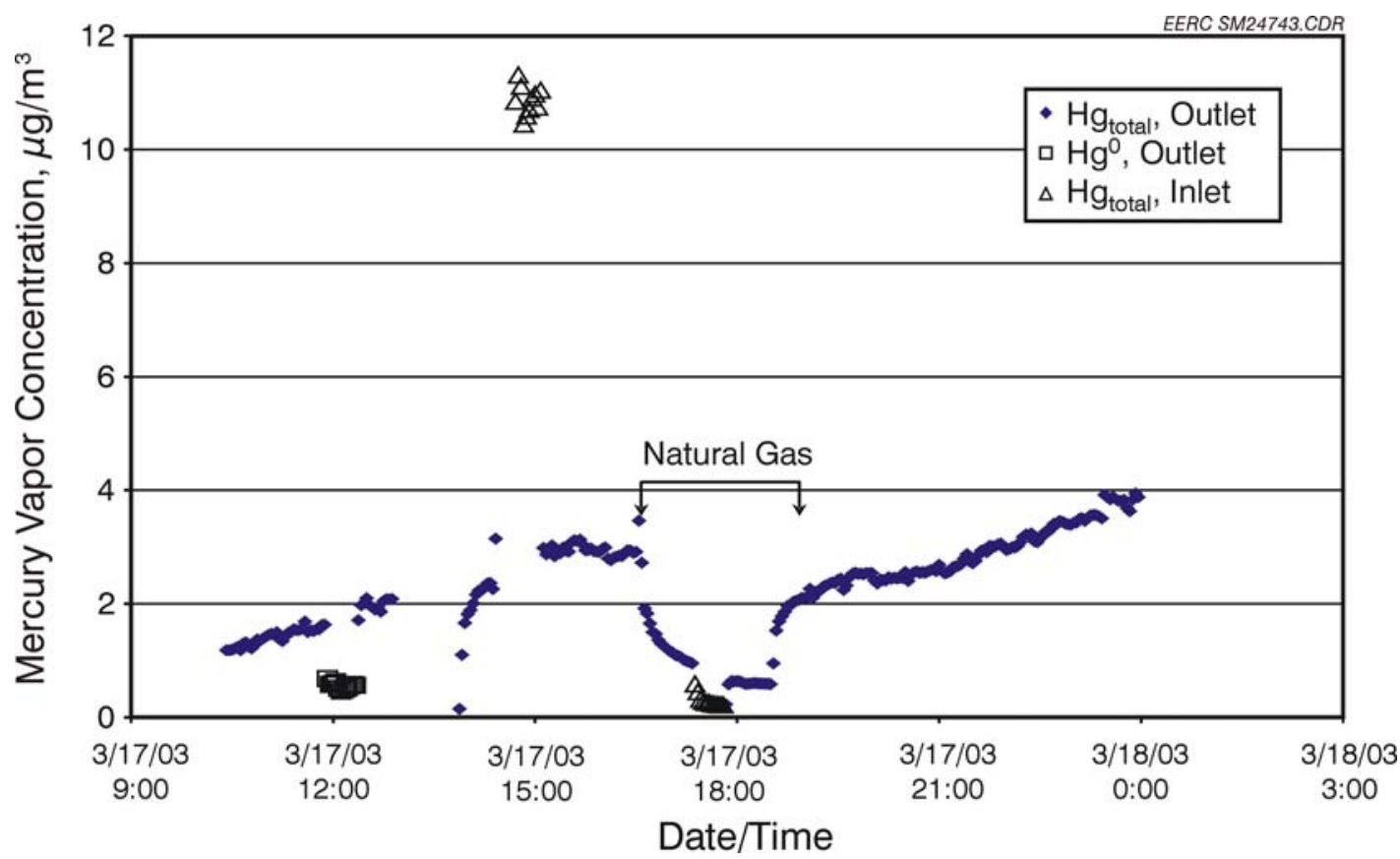

Figure 6.2.8.1. Gaseous mercury across $\mathrm{PJBH}$ equipped with Cartridge A filters $-149^{\circ} \mathrm{C}$ $\left(300^{\circ} \mathrm{F}\right)$ test.

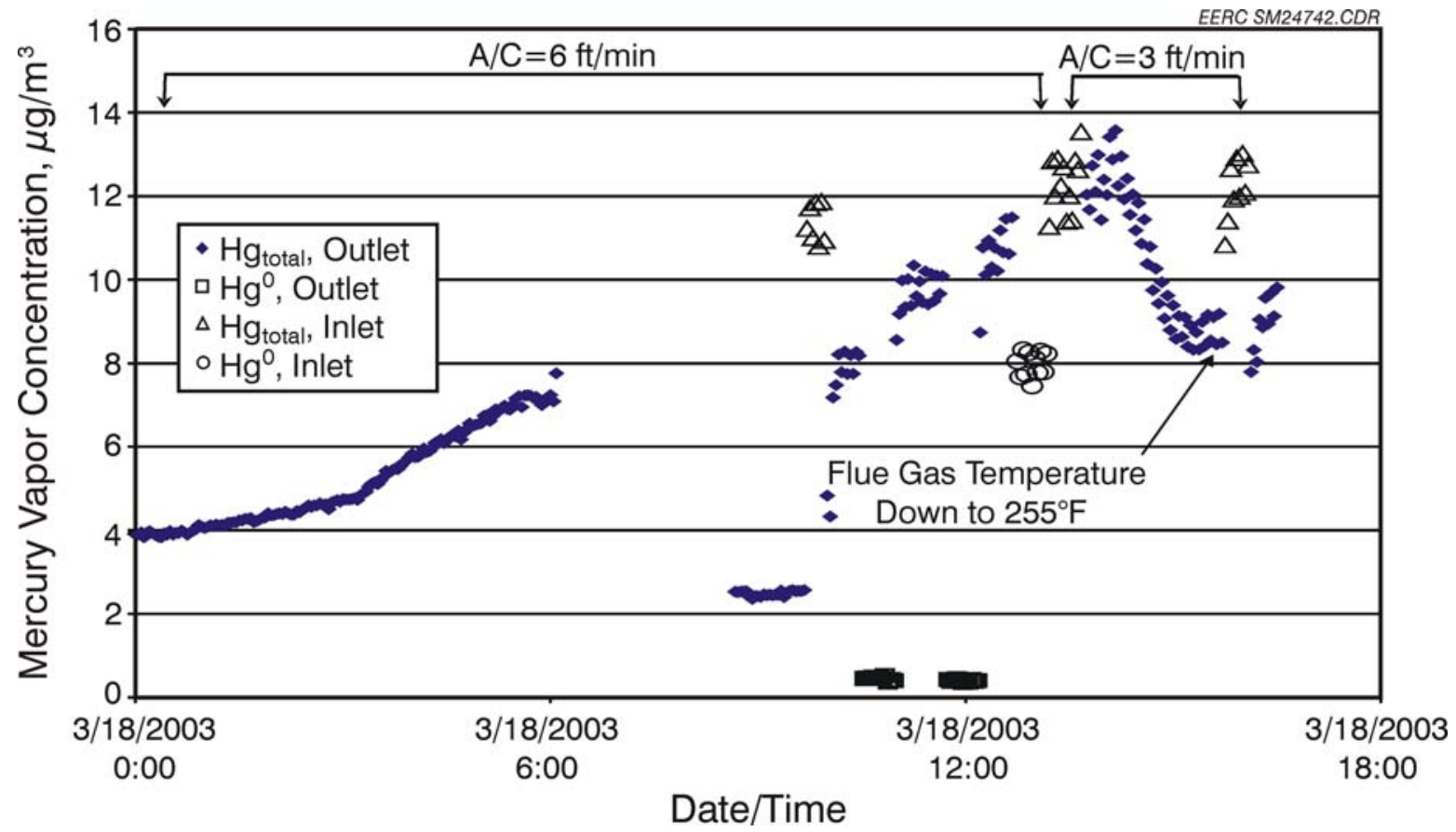

Figure 6.2.8.2. Gaseous mercury across the PJBH equipped with Cartridge A filters $149^{\circ} \mathrm{C}\left(300^{\circ} \mathrm{F}\right)$ and $124^{\circ} \mathrm{C}\left(255^{\circ} \mathrm{F}\right)$ tests. 
$26 \mathrm{hr}$ of operation with Cartridge A, the gaseous mercury concentration in the outlet flue gas reached $10.1-11.5 \mu \mathrm{g} / \mathrm{m}^{3}$, and most of the mercury was in an oxidized state, with only $0.45 \mu \mathrm{g} / \mathrm{m}^{3}$ of elemental mercury. One pair of Ontario Hydro samples was taken at the inlet and outlet at the end of this test to verify the complete breakthrough based on CMM data, and Figure 6.2.8.3 plots the analysis results.

Mercury in the flue gas was primarily elemental mercury at $11.3 \mu \mathrm{g} / \mathrm{m}^{3}, \mathrm{Hg}^{2+}$ at $2.1 \mu \mathrm{g} / \mathrm{m}^{3}$, and $\mathrm{Hg}(\mathrm{p})$ virtually undetectable. The total mercury emission at the outlet was $13 \mu \mathrm{g} / \mathrm{m}^{3}$, very close to the $13.6 \mu \mathrm{g} / \mathrm{m}^{3}$ measured at the inlet. In the outlet flue gas, almost all of the mercury was in oxidized form.

The Ontario Hydro results agree very well with the corresponding CMM measurements. They both indicate that the Cartridge A was capable of oxidizing mercury efficiently but had a $100 \%$ breakthrough after $26 \mathrm{hr}$ of operation with the Belle Ayr coal flue gas. The overall mercury capture was initially $91.8 \%$ but dropped to almost zero after $26 \mathrm{hr}$ of operation.

Test 2 - Cartridge A in PJBH at $0.015 \mathrm{~m} / \mathrm{s}(3 \mathrm{ft} / \mathrm{min})$ Face Velocity and $124^{\circ} \mathrm{C}\left(255^{\circ} \mathrm{F}\right)$

In this test, the performance of Cartridge A for mercury removal was evaluated for a reduced face velocity of $0.015 \mathrm{~m} / \mathrm{s}(3 \mathrm{ft} / \mathrm{min})$ and operating temperature of $124^{\circ} \mathrm{C}\left(255^{\circ} \mathrm{F}\right)$.

Plotted CMM data (Figure 6.2.8.2) shows that although the gaseous mercury in the inlet flue gas stayed around $11-13 \mu \mathrm{g} / \mathrm{m}^{3}$, the same as in Test 1 , the mercury emissions at the outlet gradually decreased from the $100 \%$ percent mercury breakthrough with the reducing operating temperature. The gaseous mercury concentration in the outlet flue gas decreased with decreasing temperature and stabilized around $8.8 \mu \mathrm{g} / \mathrm{m}^{3}$ when the operating temperature leveled off at $124^{\circ} \mathrm{C}\left(255^{\circ} \mathrm{F}\right)$. The short-term testing data indicate better mercury capture as a result of the reduced operating temperature and lower $\mathrm{A} / \mathrm{C}$ ratio.

\section{Test 3 - Cartridge B with a PJBH at $0.03 \mathrm{~m} / \mathrm{s}(6 \mathrm{ft} / \mathrm{min})$ Face Velocity and $149^{\circ} \mathrm{C}$} $\left(300^{\circ} \mathrm{F}\right)$

Since Cartridge A did not demonstrate efficient long-term mercury removal in the above tests, a different cartridge filter, referred to as Cartridge B, was installed and tested with the $\mathrm{PJBH}$ at a $0.03 \mathrm{~m} / \mathrm{s}(6 \mathrm{ft} / \mathrm{min}) \mathrm{A} / \mathrm{C}$ ratio and $149^{\circ} \mathrm{C}\left(300^{\circ} \mathrm{F}\right)$ operating temperature.

The outlet CMM data (Figure 6.2.8.4) showed, initially, a very low gaseous mercury concentration of $0.4 \mu \mathrm{g} / \mathrm{m}^{3}$ with virtually no elemental mercury, while gaseous mercury in the inlet flue gas was $9-10 \mu \mathrm{g} / \mathrm{m}^{3}$ with $7-8 \mu \mathrm{g} / \mathrm{m}^{3}$ of elemental mercury. 


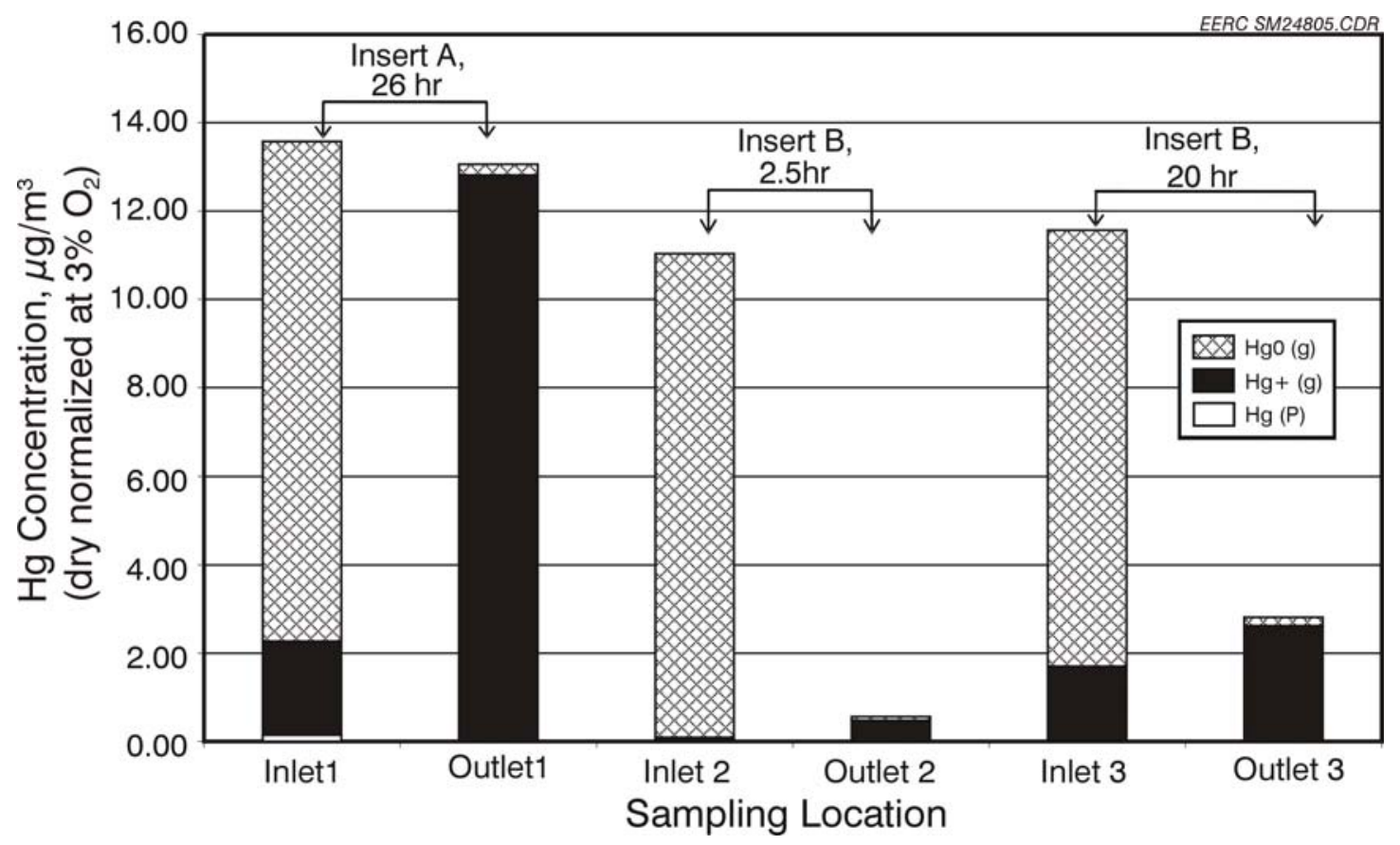

Figure 6.2.8.3. Ontario Hydro results in the inlet and outlet flue gas during PTC-BA-637.

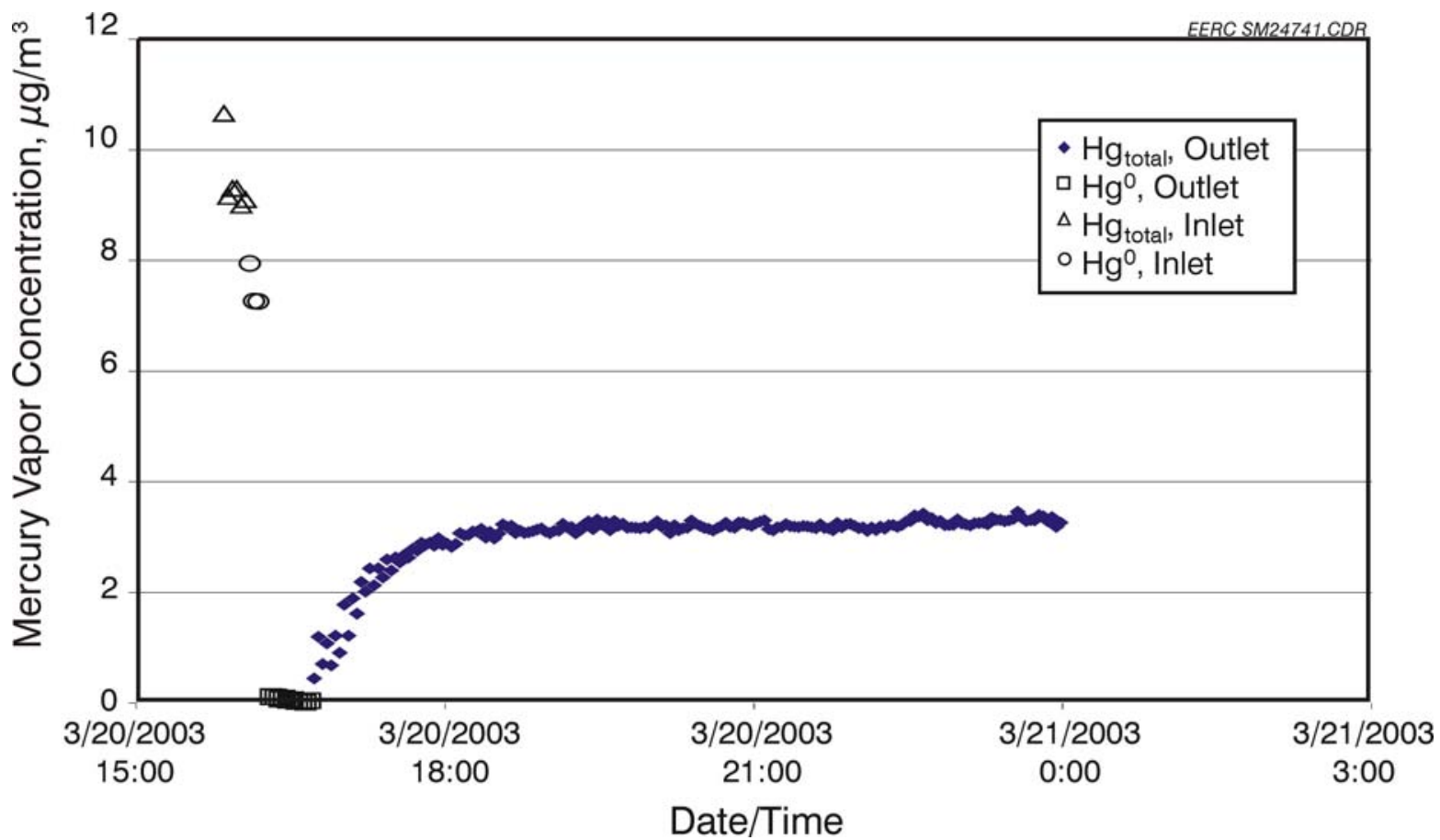

Figure 6.2.8.4. Gaseous mercury across the PJBH equipped with Cartridge B filter $-149^{\circ} \mathrm{C}$ $\left(300^{\circ} \mathrm{F}\right)$ test. 
One pair of Ontario Hydro samples was taken at the inlet and outlet to verify CMM measurement and determine overall mercury collection efficiency with Cartridge B after the 2.5-hr testing, and analysis results are plotted in Figure 6.2.8.3. The mercury in the inlet flue gas was $10.9 \mu \mathrm{g} / \mathrm{m}^{3}$ of elemental mercury, $0.1 \mu \mathrm{g} / \mathrm{m}^{3}$ of oxidized mercury, and $0.04 \mu \mathrm{g} / \mathrm{m}^{3}$ of particle-bound mercury, and the total mercury emission in the outlet flue gas was only $0.6 \mu \mathrm{g} / \mathrm{m}^{3}$. Both the CMM data and Ontario Hydro result are in good agreement, and the overall mercury capture efficiency with Cartridge B was $94.5 \%$ after $2.5 \mathrm{hr}$ of operation.

With extended exposure time, the CMM data (Figures 6.2.8.4 and 6.2.8.5) indicated a gradual increase of mercury concentration in the outlet flue gas. The mercury emission reached $5.7 \mu \mathrm{g} / \mathrm{m}^{3}$ after approximately $20 \mathrm{hr}$ of operation with no elemental mercury in the flue gas. The results of the second pair of Ontario Hydro samples (Figure 6.2.8.3) confirm the CMM measurement, showing a total of $2.8 \mu \mathrm{g} / \mathrm{m}^{3}$ mercury emission after $20 \mathrm{hr}$ of operation of Cartridge B with only $2.6 \mu \mathrm{g} / \mathrm{m}^{3}$ of oxidized mercury and $0.2 \mu \mathrm{g} / \mathrm{m}^{3}$ of elemental mercury. The overall mercury collection efficiency of Cartridge B was $75 \%$ after $20 \mathrm{hr}$ of operation, which was much better than Cartridge A.

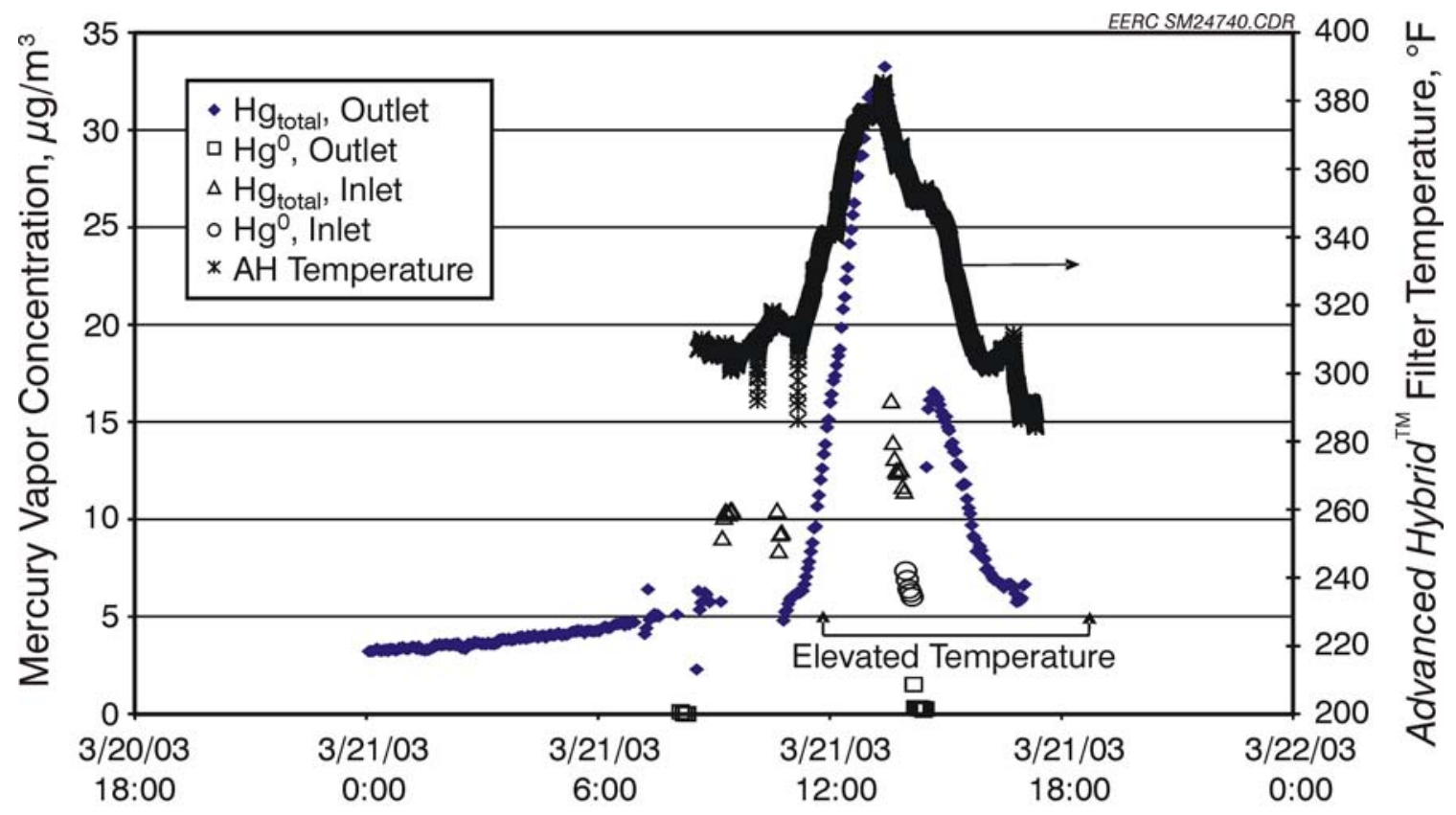

Date/Time

Figure 6.2.8.5. Gaseous mercury across the PJBH equipped with Cartridge B filter $-149^{\circ} \mathrm{C}$ $\left(300^{\circ} \mathrm{F}\right)$ and $193^{\circ} \mathrm{C}\left(380^{\circ} \mathrm{F}\right)$ tests. 
The mercury emission response of Cartridge B was different from Cartridge A, which showed continuously and steadily increasing mercury emission as a function of operating time. For Cartridge B, an initial transition zone existed where the mercury emission increased very fast. Mercury emission then reached the second phase where the mercury concentration at the outlet slowly increased until the flue gas chemistry changed. It is hypothesized that the capacity limit is the controlling factor for Cartridge A, while reactivity is the limit for Cartridge B.

\section{Test 4 - Cartridge B with PJBH at $0.03 \mathrm{~m} / \mathrm{s}(6 \mathrm{ft} / \mathrm{min})$ Face Velocity and $193^{\circ} \mathrm{C}\left(3_{80}^{\circ} \mathrm{F}\right)$}

Near the end of testing, the flue gas temperature was increased to $193^{\circ} \mathrm{C}\left(380^{\circ} \mathrm{F}\right)$ to examine mercury removal with Cartridge $\mathrm{B}$ at an elevated temperature. The outlet CMM data (Figure 6.2.8.5) indicate that, upon increasing the flue gas temperature, mercury concentration in the outlet flue gas increased significantly. A mercury vapor concentration of $32 \mu \mathrm{g} / \mathrm{m}^{3}$ was measured in the outlet flue gas when flue gas temperature reached $193^{\circ} \mathrm{C}\left(380^{\circ} \mathrm{F}\right)$. Compared to the $10 \sim 12 \mu \mathrm{g} / \mathrm{m}^{3}$ of total mercury vapor concentration in the inlet flue gas, the much higher mercury emission indicates significant mercury desorption from the cartridge filters at the elevated temperature.

Also plotted in Figure 6.2.8.5 is the average flue gas temperature across the filter during the testing period as a function of time. The desorption took place once the flue gas temperature was higher than $159^{\circ} \mathrm{C}\left(318^{\circ} \mathrm{F}\right)$. After the flue gas temperature cooled, mercury emissions also decreased. The total mercury emission was back to $5.9 \mu \mathrm{g} / \mathrm{Nm}^{3}$ when the flue gas temperature was returned to $141^{\circ} \mathrm{C}\left(285^{\circ} \mathrm{F}\right)$. The experimental data demonstrate that Cartridge $\mathrm{B}$ is very temperature-dependent for mercury capture.

\subsubsection{Conclusions from PTC-BA-637 Testing Results}

Cartridges A and B showed excellent (over 98\%) mercury oxidation, and Cartridge B attained $75 \%$ overall mercury removal efficiency with the Belle Ayr coal flue gas after $20 \mathrm{hr}$ of operation.

The mercury capture performance of the cartridge filter was highly temperature-dependent. The best operating temperature is in the range of $124^{\circ} \sim 149^{\circ} \mathrm{C}\left(255^{\circ} \sim 300^{\circ} \mathrm{F}\right)$. 


\subsubsection{PTC-BA-650}

\subsubsection{Test Conditions}

Previous results with both the 55-kW (200-acfm) pilot-scale Advanced Hybrid ${ }^{\mathrm{TM}}$ filter and the 2.5-MW (9000-acfm) field Advanced Hybrid ${ }^{\mathrm{TM}}$ filter showed that, over a range of conditions, from $50 \%$ to $95 \%$ mercury control could be achieved. Based on the rate of pressure drop increase in comparative tests without high-voltage power, the particulate collection efficiency of the perforated-plate ESP portion of the Advanced Hybrid ${ }^{\mathrm{TM}}$ filter was calculated to be about $95 \%$. If the injected carbon is collected at the same efficiency as the fly ash, then it can be assumed that most of the carbon was also collected on the plates rather than on the bags. It is important to show that good mercury control can be achieved by collection of the carbon on the perforated plates, because then the carbon addition rate can be adjusted as necessary to achieve the target mercury control level without concern of the effect of carbon injection on pressure drop. While it could be inferred from previous tests that most of the mercury capture occurred before the flue gas reached the bags, the uncertainty over the exact amount of fly ash and injected carbon collected on the perforated plates made the conclusion tentative. The primary purpose of this pilot-scale test with the modified 55-kW (200-acfm) Advanced Hybrid ${ }^{\mathrm{TM}}$ filter unit was to determine the amount of mercury control across the perforated plates alone.

The 55-kW (200-acfm) pilot-scale Advanced Hybrid ${ }^{\mathrm{TM}}$ filter was set up with perforated plates surrounding the bag area. The plates had approximately 50\% open area with $0.019-\mathrm{m}$ (0.75-in.)-diameter holes. Directional discharge electrodes pointing toward the perforated plates were used to minimize any unwanted collection on the outside walls of the Advanced Hybrid ${ }^{\mathrm{TM}}$ filter housing. To further facilitate collection of the dust on the plates rather than the housing walls, the distance from the discharge electrodes to the plates was set at $0.13 \mathrm{~m}$ (5.25 in.), while the distance from the discharge points to the outside housing walls was $0.21 \mathrm{~m}$ (8.25 in.). Flue gas was introduced into the Advanced Hybrid ${ }^{\mathrm{TM}}$ filter housing in the area between the discharge electrodes and the outside walls to make sure that all of the gas would pass through the plane of the discharge electrodes before reaching the perforated plates (see Figures 6.2.9.1 and 6.2.9.2).

To minimize collection of any ash or carbon downstream from the perforated plates, the bags were removed. After the gas passed through the perforated plates, it exited through the open holes in the tube sheet into the clean air plenum and then out of the Advanced Hybrid ${ }^{\mathrm{TM}}$ filter housing. 


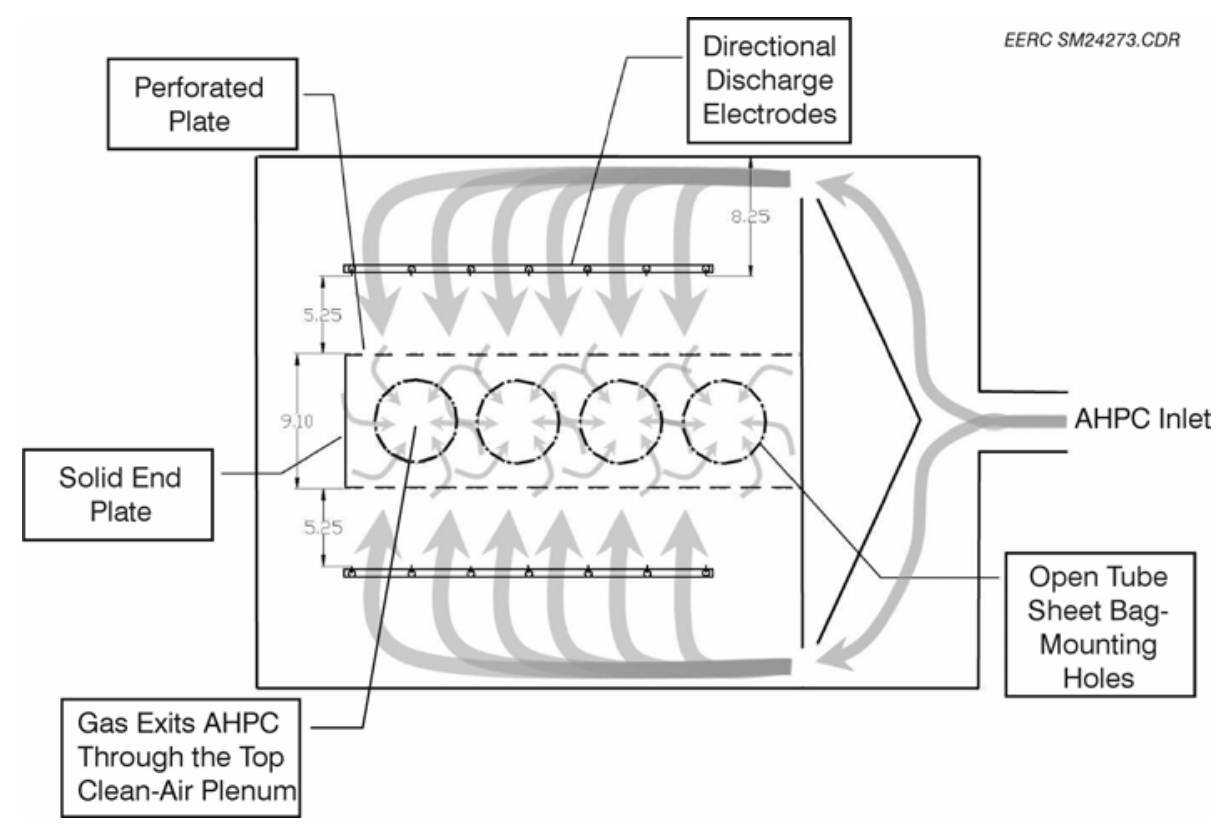

Figure 6.2.9.1. Top-view schematic of the Advanced Hybrid ${ }^{\mathrm{TM}}$ filter (perforated plate only).

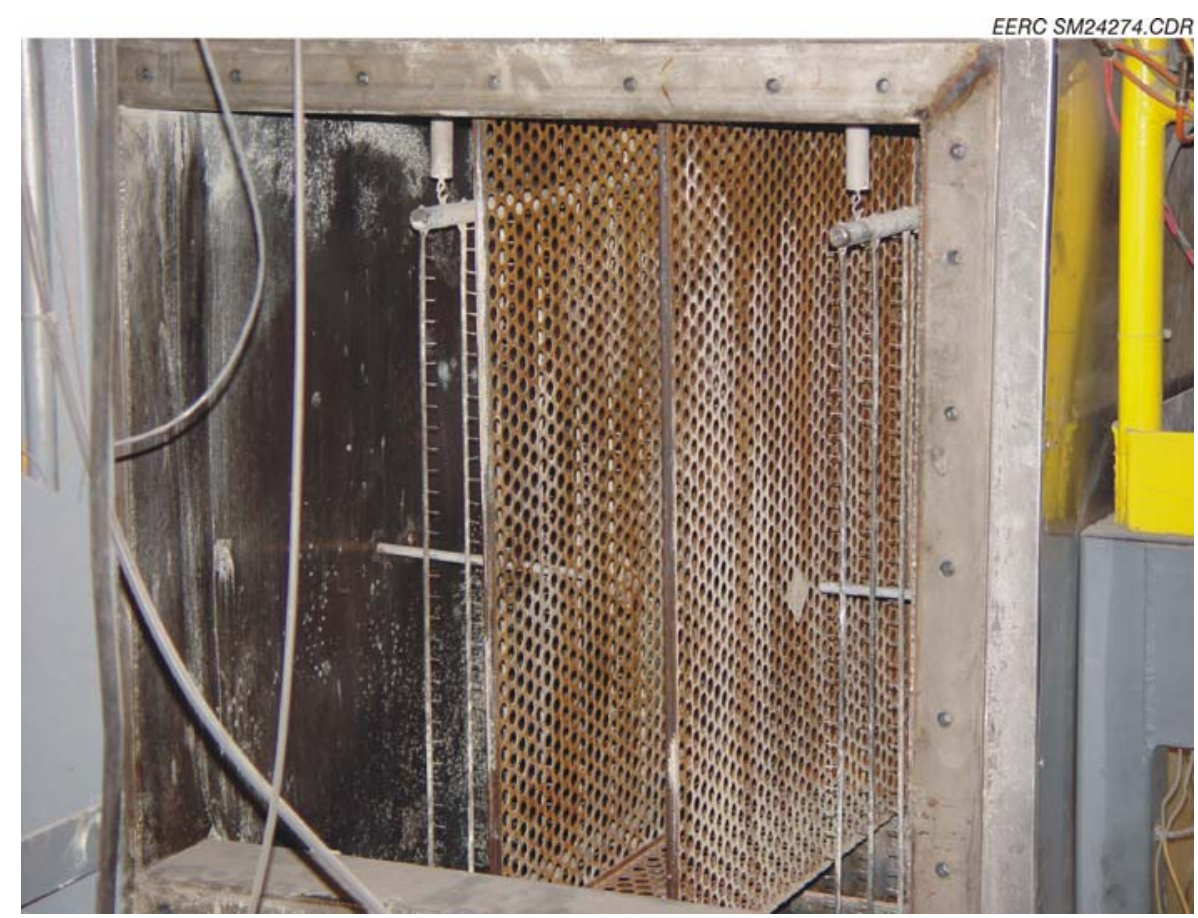

Figure 6.2.9.2. Front view of the Advanced Hybrid ${ }^{\mathrm{TM}}$ filter (perforated plate only) with inlet cover removed. 
Three test conditions were evaluated with this configuration: 1) baseline tests before each of the carbon injection tests, 2) the NORIT FGD carbon injection test, and 3) the treated-NORIT FGD carbon injection test. The coal for the tests was Belle Ayr, which is one of the PRB subbituminous coals burned at the Big Stone Power Plant and which was used for previous pilotscale tests. Gaseous mercury was measured with two PS Analytical CMMs: one at the inlet upstream of the point of carbon injection and one at the Advanced Hybrid ${ }^{\mathrm{TM}}$ filter outlet. Outlet particulate dust loadings were determined with EPA Method 5 during each of the two carbon injection tests.

\subsubsection{Coal and Flue Gas Analyses}

Since the Belle Ayr coal used in this test is the same as in previous tests (PTC-BA-628, 629,636 , and 637) and the general information on this coal was known, no additional coal analysis was completed.

\subsubsection{Mercury Results for PTC-BA-650}

Plotted in Figure 6.2.9.3 are the mercury emissions from the perforated plate-only Advanced Hybrid ${ }^{\mathrm{TM}}$ filter unit during the testing period. Mercury concentration in the outlet flue gas in the baseline test was around $10-11 \mu \mathrm{g} / \mathrm{m}^{3}$ (dry gas corrected to $3 \% \mathrm{O}_{2}$ ), which is the expected inlet concentration based on previous tests with this coal. When the NORIT FGD carbon was injected just upstream of the Advanced Hybrid ${ }^{\mathrm{TM}}$ filter at a rate of $32 \mathrm{mg} / \mathrm{m}^{3}$ ( $2 \mathrm{lb} / \mathrm{Macf}$ ), the outlet mercury concentration quickly dropped to $3-4 \mu \mathrm{g} / \mathrm{m}^{3}$, corresponding to an average of $66 \%$ removal compared to $0.95 \%$ inherent mercury capture in the baseline test (Figure 6.2.9.4).

This level of removal was similar to previous results with the Advanced Hybrid ${ }^{\mathrm{TM}}$ filter and higher than the ESP configuration using the NORIT FGD carbon at the same injection rate, which indicates that reasonably good mercury control can be achieved with carbon collected on the perforated plates alone. However, there was still the question of whether the mercury control was limited by the gas-solid contact geometry or by the mercury sorption ability of the injected carbon. During this test, the outlet dust loading measurement showed that the total particulate control removal across the perforated plates was $98.3 \%$, so very little carbon bypassed the perforated plates (Figure 6.2.9.5). 


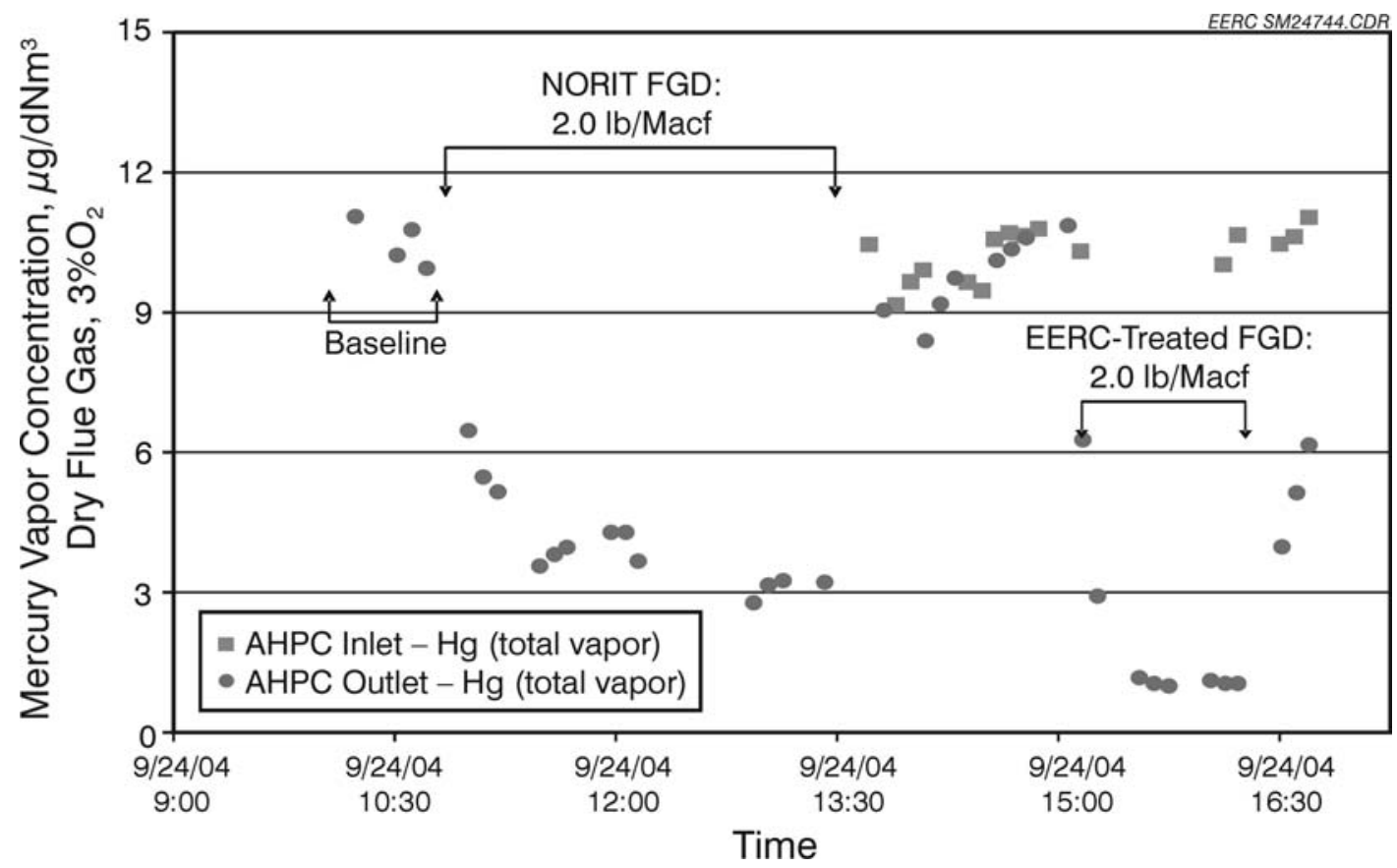

Figure 6.2.9.3. Mercury emissions from the perforated plate-only Advanced Hybrid ${ }^{\mathrm{TM}}$ filter unit under carbon injection.

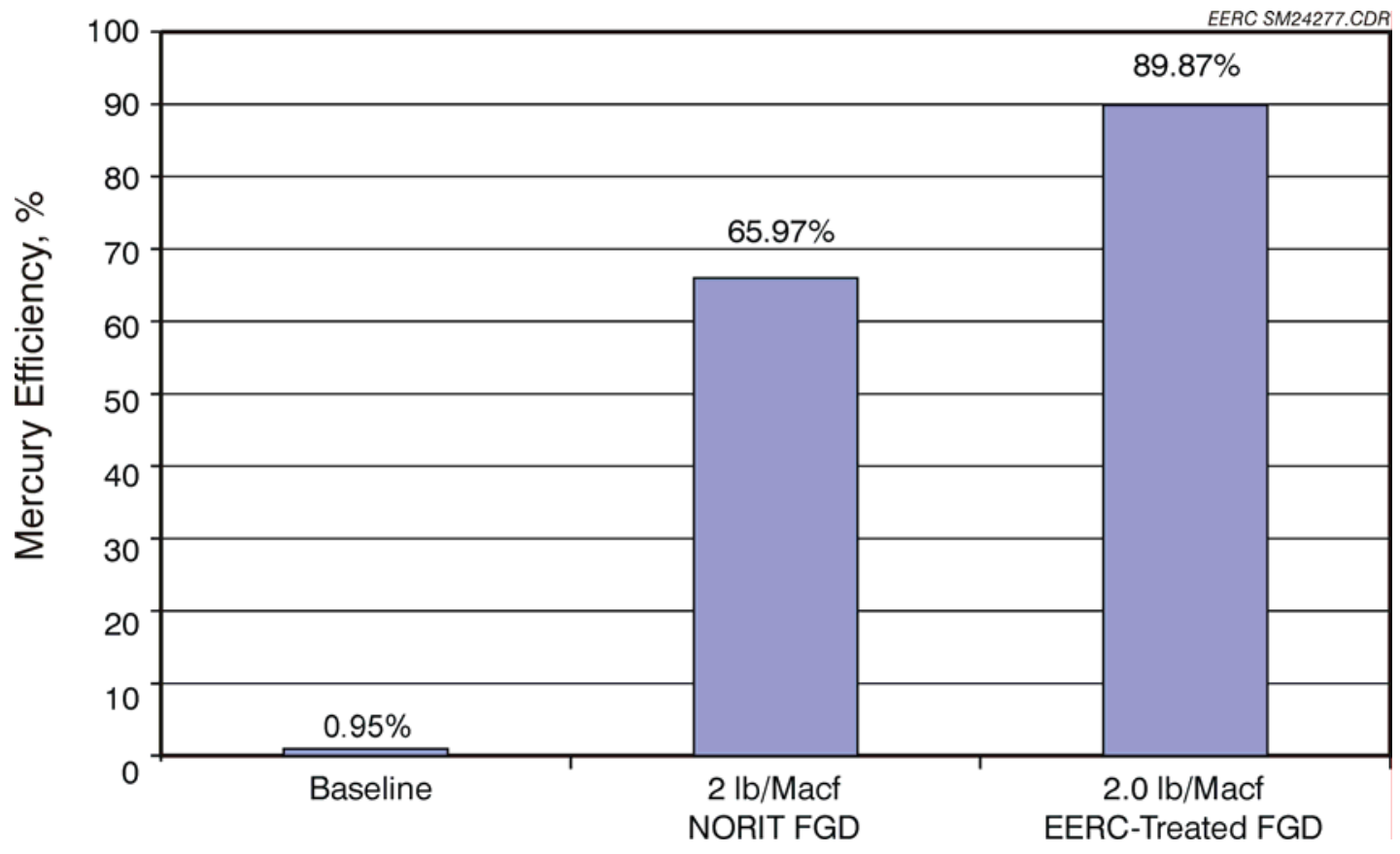

Figure 6.2.9.4. Average gaseous mercury removals for baseline and carbon injection tests. 
To further evaluate the level of mercury control across the perforated plates, a second carbon injection test was conducted using a treated NORIT FGD carbon developed by the EERC. After reestablishing the baseline, the treated carbon was injected upstream of the Advanced Hybrid ${ }^{\mathrm{TM}}$ filter at the same carbon injection rate as in the FGD test. Immediately after starting injection, the outlet mercury dropped to about $1 \mu \mathrm{g} / \mathrm{m}^{3}$, corresponding to an average mercury removal of 89.9\% (Figures 6.2.9.3 and 6.2.9.4). Since the carbon injection rate and the particulate collection efficiency (Figure 6.2.9.5) were the same for both tests, the better mercury removal for the treated carbon is attributed to superior mercury capture ability of the carbon rather than any difference in gas-solid contact exposure. These results provide convincing evidence that the geometry of the Advanced Hybrid ${ }^{\mathrm{TM}}$ filter allows sufficient gas-solid contact for achieving excellent mercury control when most of the carbon is collected on the perforated plates. The data represent the minimum level of mercury control that would be expected. Any carbon that reaches the bags would only enhance the gas-solid contact and further improve total mercury capture.

\subsubsection{Conclusions from PTC-BA-650 Testing Results}

The last planned experimental work for the project was a test to measure the amount of mercury collected by the perforated plates in the Advanced Hybrid ${ }^{\mathrm{TM}}$ filter apart from any mercury control on the filter bags. To address this question, the 55-kW (200-acfm) pilot-scale

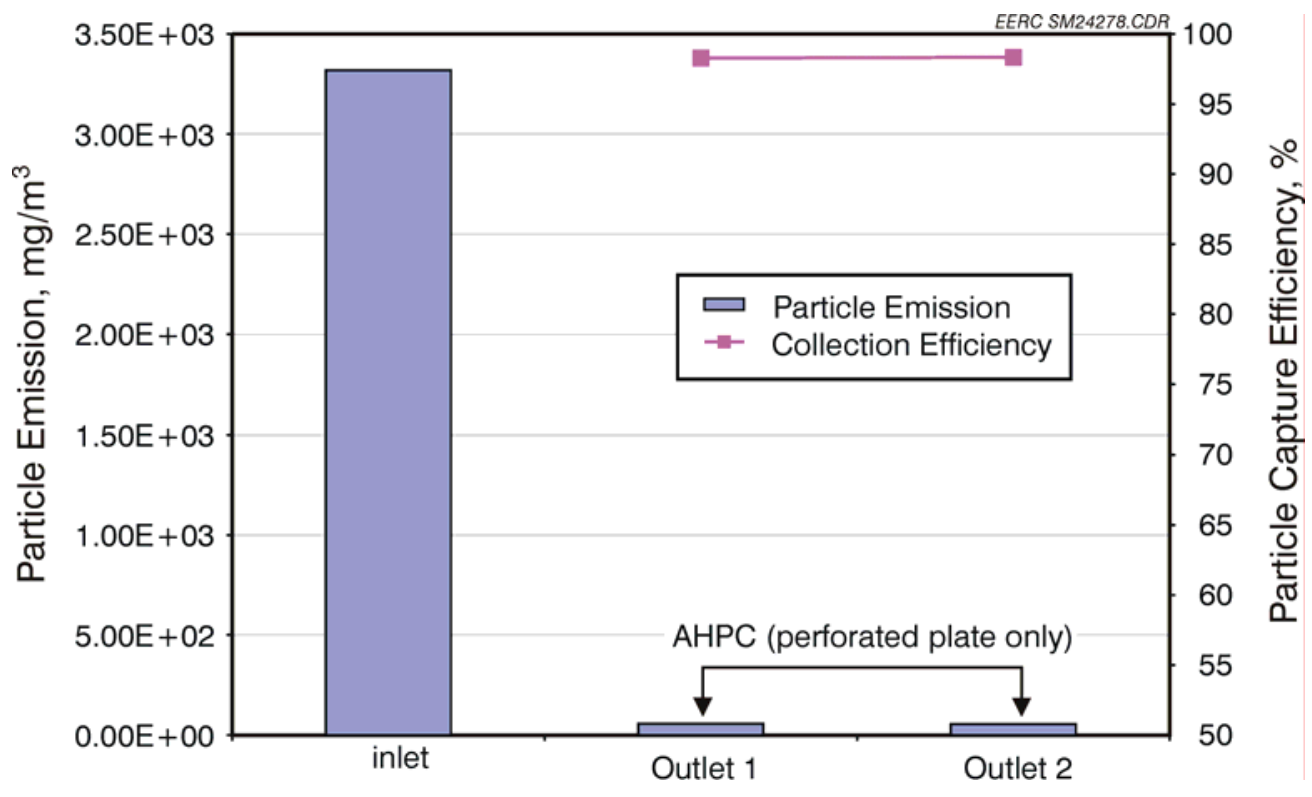

Figure 6.2.9.5. Particle emissions from the Advanced Hybrid ${ }^{\mathrm{TM}}$ filter - perforated plate only. 
Advanced Hybrid ${ }^{\mathrm{TM}}$ filter was modified so that it included perforated plates totally surrounding the normal bag area, but with the filter bags removed. Mercury removal with this configuration using NORIT FGD carbon injected at $32 \mathrm{mg} / \mathrm{m}^{3}$ (2 lb/Macf) was similar to previous results with the Advanced Hybrid ${ }^{\mathrm{TM}}$ filter when filter bags were installed. These results indicate that good mercury control can be achieved with carbon collected on the perforated plates alone. However, using an EERC proprietary sorbent at the same carbon addition rate, the mercury collection efficiency improved to $90 \%$. For both tests, the particulate collection efficiency of the perforated plates alone was $98 \%$. These results are even more convincing because they prove that good gassolid contact leading to excellent mercury removal can be achieved by collection of the activated carbon on the perforated plates alone, without a significant fraction of the carbon reaching the bags. It is important to show that good mercury control can be achieved by collection of the carbon on the perforated plates, because then the carbon addition rate can be adjusted as necessary to achieve the target mercury control level without concern of the effect of carbon injection on pressure drop. These results are consistent with previous pilot-scale and field data that have consistently shown that carbon injected upstream of the Advanced Hybrid ${ }^{\mathrm{TM}}$ filter for mercury control has little or no effect on pressure drop.

\subsection{Field Demonstration at the 2.5-MW (9000-acfm) Advanced Hybrid ${ }^{\mathrm{TM}}$ Filter Unit at the Big Stone Power Plant}

\subsubsection{Short-Term Field Test During November 5-10, 2001}

\subsubsection{Test Conditions}

According to the planned work, testing with the 2.5-MW (9000-acfm) Advanced Hybrid ${ }^{\mathrm{TM}}$ filter at the Big Stone Power Plant was not scheduled to begin until early 2002 after completion of the first pilot-scale tests. However, the project team decided to conduct an initial field test the first week of November 2001 prior to the pilot-scale tests at the EERC. There were several reasons for performing an initial early test:

- Delay in implementing the overall program by 5 months resulted in moving the whole schedule back by 5 months. With the original proposed work, the field testing would have begun in the summer. This would have prevented some of the weather problems associated with mercury sampling in the winter. By doing initial testing in November, we avoided beginning the mercury sampling in the worst part of the winter. It was expected that the mercury control testing at Big Stone would then resume in the spring 
of 2002, and the completion of the field testing within the planned schedule would still be possible.

- A full-scale retrofit of an Advanced Hybrid ${ }^{\mathrm{TM}}$ filter at Big Stone was announced by DOE as one of the projects selected under the DOE Power Plant Improvement Initiative. Because design of this project needed to begin immediately, it was imperative to have as much information available as possible. By completing this initial field test early, additional information on Advanced Hybrid ${ }^{\mathrm{TM}}$ filter performance with carbon injection would facilitate final design of the full-scale Big Stone Advanced Hybrid ${ }^{\mathrm{TM}}$ filter.

- Since no mercury sampling was previously completed at the Big Stone Power Plant, early baseline data on the actual inlet mercury concentration and speciation would help in finalizing the EERC pilot plant testing. For example, if higher-than-expected fly ash capture of mercury were seen at Big Stone, that would have to be considered in planning the pilot plant tests.

The field test at Big Stone was completed the week of November 5-10, 2001, with baseline testing on the first day, followed by NORIT FGD carbon injection in both Advanced Hybrid $^{\mathrm{TM}}$ filter and pulse-jet operational modes for the remainder of the week. The starting carbon addition rate was set at $24 \mathrm{mg} / \mathrm{m}^{3}(1.5 \mathrm{lb} / \mathrm{Macf})$.

During the baseline test, the Advanced Hybrid ${ }^{\mathrm{TM}}$ filter was operated at a constant $\mathrm{A} / \mathrm{C}$ ratio of $3.0 \mathrm{~m} / \mathrm{min}$ (10 ft/min), the bags were cleaned on a constant timed 20-min interval, and the ash hopper was emptied once an hour.

For the second day, conditions were identical except for carbon addition at a rate of $24 \mathrm{mg} / \mathrm{m}^{3}$ (1.5 lb/Macf). The DARCO FGD carbon used was obtained from NORIT Americas and is commercially available. The carbon addition was controlled with a K-Tron powder feeder and was injected pneumatically at a single point into the center of the $0.610-\mathrm{m}$ (24-in)-diameter inlet duct.

For the third day, the Advanced Hybrid ${ }^{\mathrm{TM}}$ filter was operated as a $\mathrm{PJBH}$ at an $\mathrm{A} / \mathrm{C}$ ratio of $1.5 \mathrm{~m} / \mathrm{min}(5 \mathrm{ft} / \mathrm{min})$ with carbon injection. To keep the same carbon-to-flue gas ratio of $24 \mathrm{mg} / \mathrm{m}^{3}$ (1.5 lb/Macf), the carbon feed rate was set to half the previous level.

The fourth day was a repeat of Day 2, where the unit was again operated in Advanced Hybrid $^{\mathrm{TM}}$ filter mode with carbon injection at $24 \mathrm{mg} / \mathrm{m}^{3}$ (1.5 lb/Macf). 
For the fifth day of testing, the unit was operated with carbon injection in both Advanced Hybrid $^{\mathrm{TM}}$ filter and PJBH modes, but with both at an $\mathrm{A} / \mathrm{C}$ ratio of $1.5 \mathrm{~m} / \mathrm{min}(5 \mathrm{ft} / \mathrm{min})$. This test was completed to allow for a valid comparison between the Advanced Hybrid ${ }^{\mathrm{TM}}$ filter and pulsejet modes without changing the residence time or temperature.

For all of the tests with carbon, the sorbent was injected only during the day, and after the mercury sampling was completed, the carbon was shut off overnight to allow the unit to return to baseline conditions prior to starting carbon injection the next day.

A total of four Ontario Hydro samples were taken for each day, including both at the inlet and outlet of the Advanced Hybrid ${ }^{\mathrm{TM}}$ filter. Two mercury CMMs provided gaseous mercury species for both inlet and outlet flue gases during the last 3 days of testing. A summary of the mercury, solids, and flue gas sampling is given in Table 6.3.1.1.

\subsubsection{Big Stone Fuel Records and Analyses}

Table 6.3.1.2 lists the fuel burn record of the Big Stone Power Plant November 5-10, 2001. During the testing period, the plant mainly fired coals from either Cordero or Caballo Mines in the PRB with supplemental fuels of TDF and waste seeds.

\section{Table 6.3.1.1. Summary of Mercury, Gas, and Solids Samples Taken}

Ontario Hydro

Day 1 - Two Pairs of Simultaneous Inlet and Outlets

Days 2-4 - One Inlet and Three Outlets

Day 5 - Two Pairs of Simultaneous Inlet and Outlets

CMM

Continuous Sampling with Two PS Analytical Mercury CMMs on Days 3-5 $\mathrm{SO}_{3}$

Three Inlets Total $\mathrm{HCl}$

Three Inlets Total $\mathrm{SO}_{2}, \mathrm{NO}, \mathrm{NO}_{2}, \mathrm{CO}, \mathrm{CO}_{2}, \mathrm{O}_{2}$ Coal

Select Sampling Each Day at Both Inlet and Outlet with Portable Ecom Gas Analyzer

One Sample a Day

Advanced Hybrid ${ }^{\mathrm{TM}}$ Filter Hopper Ash

Day 1 - Three Total

Days 2-4 - One Baseline Before Starting Carbon Injection and Three Corresponding to the End of Each Outlet Ontario Hydro Sample

Day 5 - One Baseline Before Starting Carbon Injection and Two Corresponding to the End of Each Outlet OH Sample 
Table 6.3.1.2. Big Stone Fuel Record November 5-10, 2001

\begin{tabular}{lccll}
\hline Date & Coal Mine & Coal, tons & TDF, tons & Waste Seeds, tons \\
\hline November 5, 2001 & Cordero & 4695 & 140 & 100 \\
November 6, 2001 & Cordero & 6117 & 200 & 100 \\
November 7, 2001 & Caballo & 6104 & 150 & 120 \\
November 8, 2001 & Caballo & 6296 & 90 & 100 \\
November 9, 2001 & Caballo & 6024 & 250 & 80 \\
November 10, 2001 & Caballo & 5344 & 200 & 30 \\
\hline
\end{tabular}

A 4-L (1-gallon) grab sample of coal was collected each day from the coal feed conveyor by Big Stone Power Plant personnel. Table 6.3.1.3 lists proximate and ultimate analysis results of the testing coal, showing a low level of sulfur in the raw coal. Mercury analysis for the five coal samples (Table 6.3.1.3) indicates a consistent mercury content in the range of $0.105-0.149 \mu \mathrm{g} / \mathrm{g}$ with a mean value of $0.126 \mu \mathrm{g} / \mathrm{g}$, while a single analysis of the waste corn seed indicates almost no mercury originated from the corn. The chlorine analyses show the coal had a

Table 6.3.1.3. Coal Analysis for the Big Stone Power Plant

\begin{tabular}{lcc}
\hline Proximate Analysis & \% As-Sampled & \% Moisture-Free \\
\hline Moisture Content & 29.3 & NA \\
Volatile Matter & 33.92 & 47.96 \\
Fixed Carbon & 31.57 & 44.67 \\
Ash & 5.21 & 7.37 \\
Ultimate Analysis & & \\
$\quad$ Hydrogen & 6.48 & 4.57 \\
Carbon & 49.46 & 69.93 \\
Nitrogen & 0.77 & 1.09 \\
Sulfur & 0.38 & 0.54 \\
Oxygen & 37.69 & 16.50 \\
Ash & 5.21 & 7.37 \\
Heating Value, Btu/lb & 8607 & 12,174 \\
Mercury Analysis, $\mu \mathrm{g} / \mathrm{g}$ & & \\
Coal Day 1 Sample & & 0.127 \\
Coal Day 2 Sample & & 0.122 \\
Coal Day 3 Sample & & 0.105 \\
Coal Day 4 Sample & & 0.149 \\
Coal Day 5 Sample & & 0.125 \\
Mean & & 0.126 \\
Corn Screened from Feed Coal & & $<0.001$ \\
Chlorine Analysis, $\mu \mathrm{g} / \mathrm{g}$ & & 8.72 \\
Coal & & 577 \\
Corn & & 741 \\
TDF & &
\end{tabular}


very low level of $8.7 \mu \mathrm{g} / \mathrm{g}$ of chlorine; in contrast, the corn and TDF had quite a high chlorine level of 577 and $741 \mu \mathrm{g} / \mathrm{g}$, respectively. Although the feed rates of corn and TDF were approximately only $1.5 \%$ and $3 \%$ of the coal feed rate, the high chlorine contents may alter mercury-flue gas chemistry.

From the combustion calculation based on proximate-ultimate analyses and mercury content in raw coal, the test coal is expected to produce $15.1 \mu \mathrm{g} / \mathrm{m}^{3}$ (dry basis, $3 \% \mathrm{O}_{2}$ ) of mercury in flue gas.

\subsubsection{Flue Gas Analysis}

Flue gas composition was measured each day both at the Advanced Hybrid ${ }^{\mathrm{TM}}$ filter inlet and outlet by using a portable Ecom gas analyzer which provides the concentrations of $\mathrm{O}_{2}, \mathrm{CO}_{2}$, $\mathrm{CO}, \mathrm{NO}, \mathrm{NO}_{2}$, and $\mathrm{SO}_{2}$ in the flue gas on a dry basis. The results of the 5-day test are listed in Table 6.3.1.4. Because of the use of the low-sulfur coal, the $\mathrm{SO}_{2}$ concentration in the flue gas was low, ranging from 165 to $299 \mathrm{ppm}$. The $\mathrm{NO}$ and $\mathrm{NO}_{2}$ concentrations in the flue gas were 499-575 ppm for $\mathrm{NO}$ and only 1-4 ppm for $\mathrm{NO}_{2}$. Three $\mathrm{SO}_{3}$ samples (by using selective condensation method) and three $\mathrm{HCl}$ samples (using EPA Method 26) were collected at the Advanced Hybrid ${ }^{\mathrm{TM}}$ filter inlet during the 5-day test. The analysis results were normalized to $3 \%$ $\mathrm{O}_{2}$ dry flue gas and are summarized in Table 6.3.1.5. The coal flue gas had low levels of $\mathrm{HCl}$ and $\mathrm{SO}_{3}$ during the testing period.

Table 6.3.1.4. Summary of the Flue Gas Compositions During the 5-day Sampling, dry basis

\begin{tabular}{lccccccc}
\hline & & $\mathrm{O}_{2}, \%$ & $\mathrm{CO}_{2}, \%$ & $\mathrm{CO}, \mathrm{ppm}$ & $\mathrm{NO}, \mathrm{ppm}$ & $\mathrm{NO}_{2}, \mathrm{ppm}$ & $\mathrm{SO}_{2}, \mathrm{ppm}$ \\
\hline \multirow{2}{*}{ Day 1} & In & 6.2 & 13.1 & 1 & 509 & 4 & 165 \\
& Out & 5.1 & 14.1 & 1 & 543 & 3 & 238 \\
Day 2 & In & 4.9 & 14.3 & - & 545 & 2 & 252 \\
& Out & 5.0 & 14.2 & 10 & 531 & 2 & 247 \\
Day 3 & In & 5.3 & 13.9 & 2 & 575 & 2 & 251 \\
& Out & 5.3 & 13.9 & 1 & 514 & 3 & 248 \\
Day 4 & In & 5.2 & - & - & 545 & 2 & 260 \\
& Out & 5.3 & - & 4 & 499 & 1 & 299 \\
Day 5 & In & 5.1 & 14.1 & 2 & 541 & 2 & 226 \\
& Out & 5.5 & 13.8 & 1 & 523 & 3 & 201 \\
\hline
\end{tabular}

Table 6.3.1.5. $\mathrm{HCl}$ and $\mathrm{SO}_{3}$ Analysis in the Flue Gas, ppm dry at $3 \% \mathrm{O}_{2}$

\begin{tabular}{lccc}
\hline Gas, ppm & Sample 1 & Sample 2 & Sample 3 \\
\hline $\mathrm{HCl}$ & 9.12 & 10.12 & 9.95 \\
$\mathrm{SO}_{3}$ & 0.41 & 0.61 & 0.65 \\
\hline
\end{tabular}




\subsubsection{4 - Mercury Results for November 5-10, 2001, Field Test}

Ontario Hydro sampling trains were set up at the Advanced Hybrid ${ }^{\mathrm{TM}}$ filter inlet and outlet to measure mercury species concentrations in the flue gas. Figure 6.3.1.1 shows the inlet

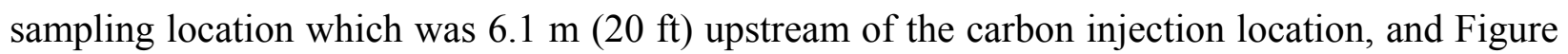
6.3.1.2 shows the outlet sampling location that was just before the flue gas entered the fan. The Ontario Hydro method provides mercury species information in flue gas as elemental mercury vapor, oxidized mercury, and mercury associated with particulate matter. All of the results are presented in the form of $\mu \mathrm{g} / \mathrm{m}^{3}$ based on the CVAA analysis results of the impinger solutions, sampled flue gas volume, and dust loading. All of the measured mercury concentrations in the flue gas were corrected to a moisture-free $3 \% \mathrm{O}_{2}$ level to allow a valid comparison at varying $\mathrm{O}_{2}$ levels.

During the Day 1 baseline test, the Advanced Hybrid ${ }^{\mathrm{TM}}$ filter unit was operated at an $\mathrm{A} / \mathrm{C}$ ratio of $3.0 \mathrm{~m} / \mathrm{min}(10 \mathrm{ft} / \mathrm{min})$ without carbon injection. Plotted in Figure 6.3.1.3 are mercury species in the Advanced Hybrid ${ }^{\mathrm{TM}}$ filter inlet and outlet flue gas. At the Advanced Hybrid ${ }^{\mathrm{TM}}$ filter inlet, the mercury associated with particulate was $5.91-7.12 \mu \mathrm{g} / \mathrm{m}^{3}$, and the oxidized mercury was $5.2-6.55 \mu \mathrm{g} / \mathrm{m}^{3}$, while the elemental mercury vapor was at a surprisingly low level of

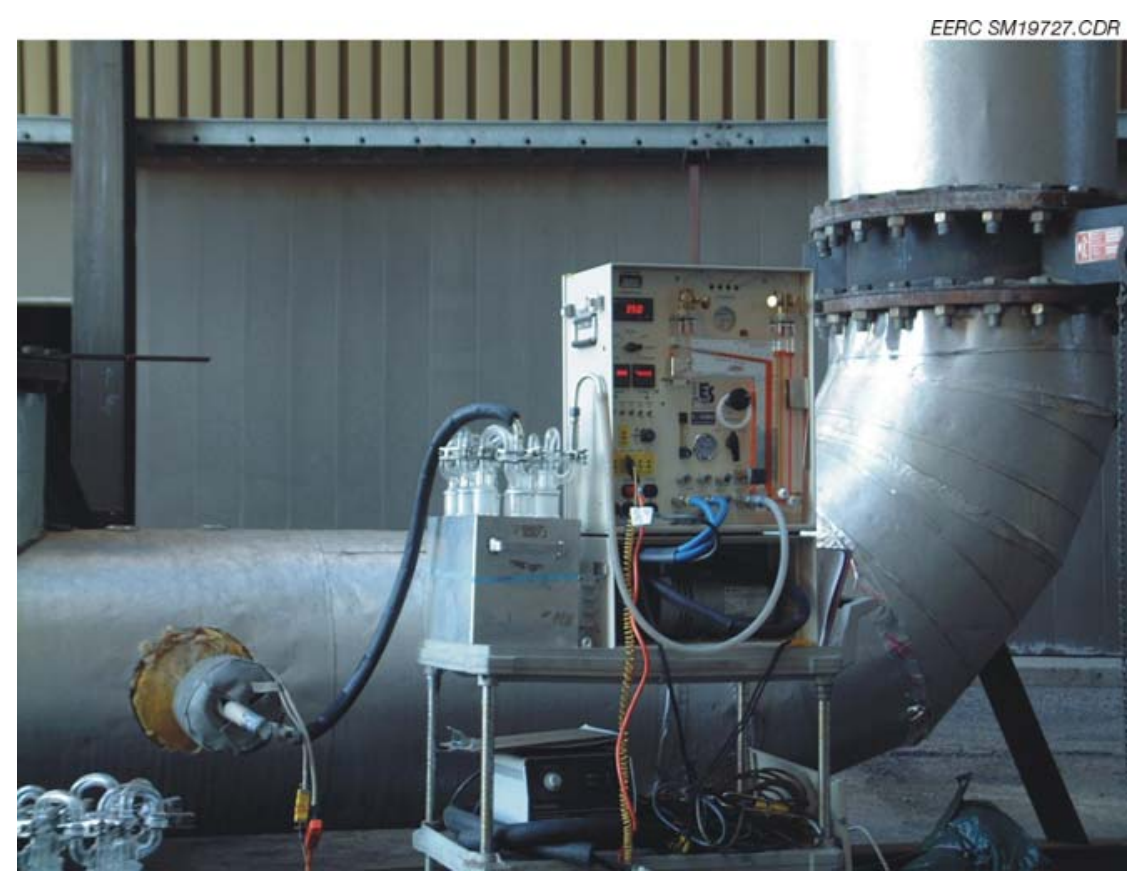

Figure 6.3.1.1. Inlet sampling location. 


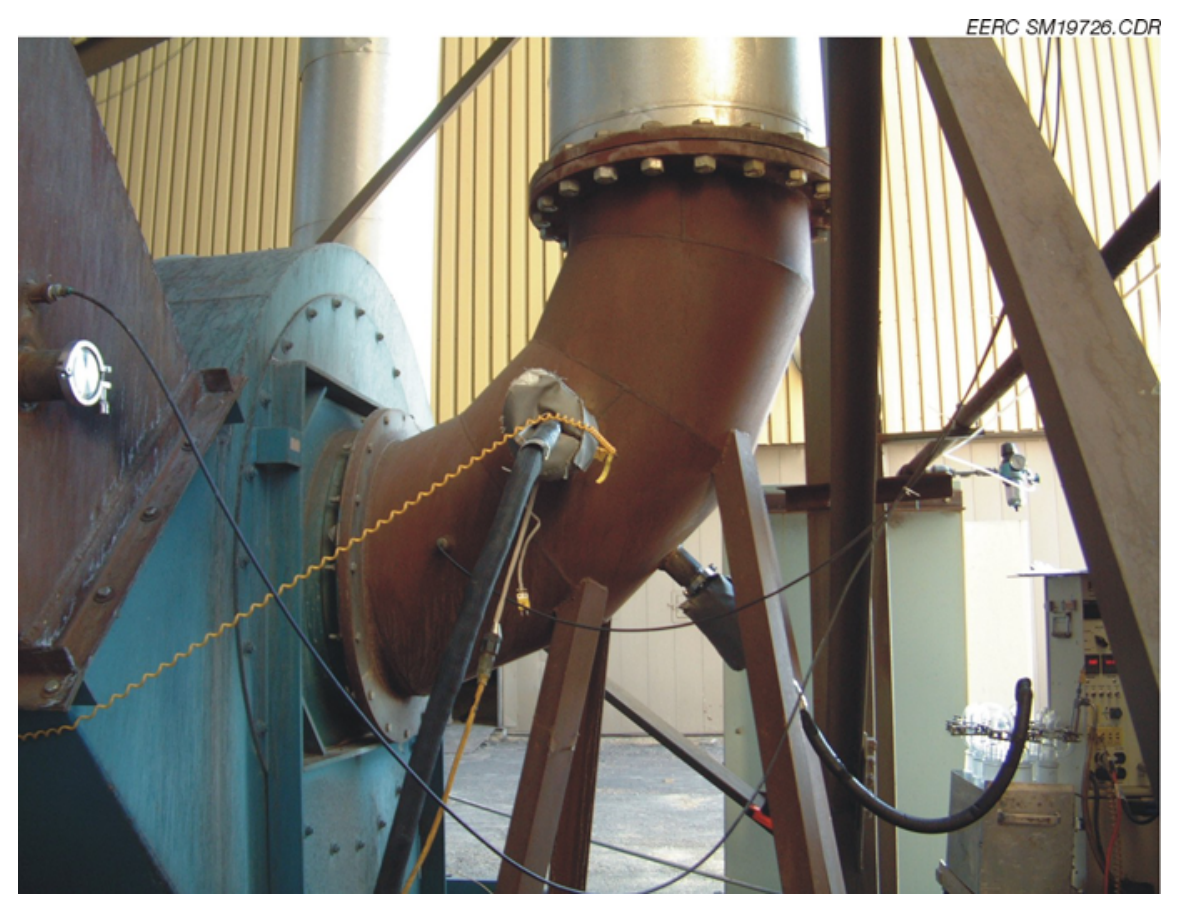

Figure 6.3.1.2. Outlet sampling location just before flue gas entered the fan.

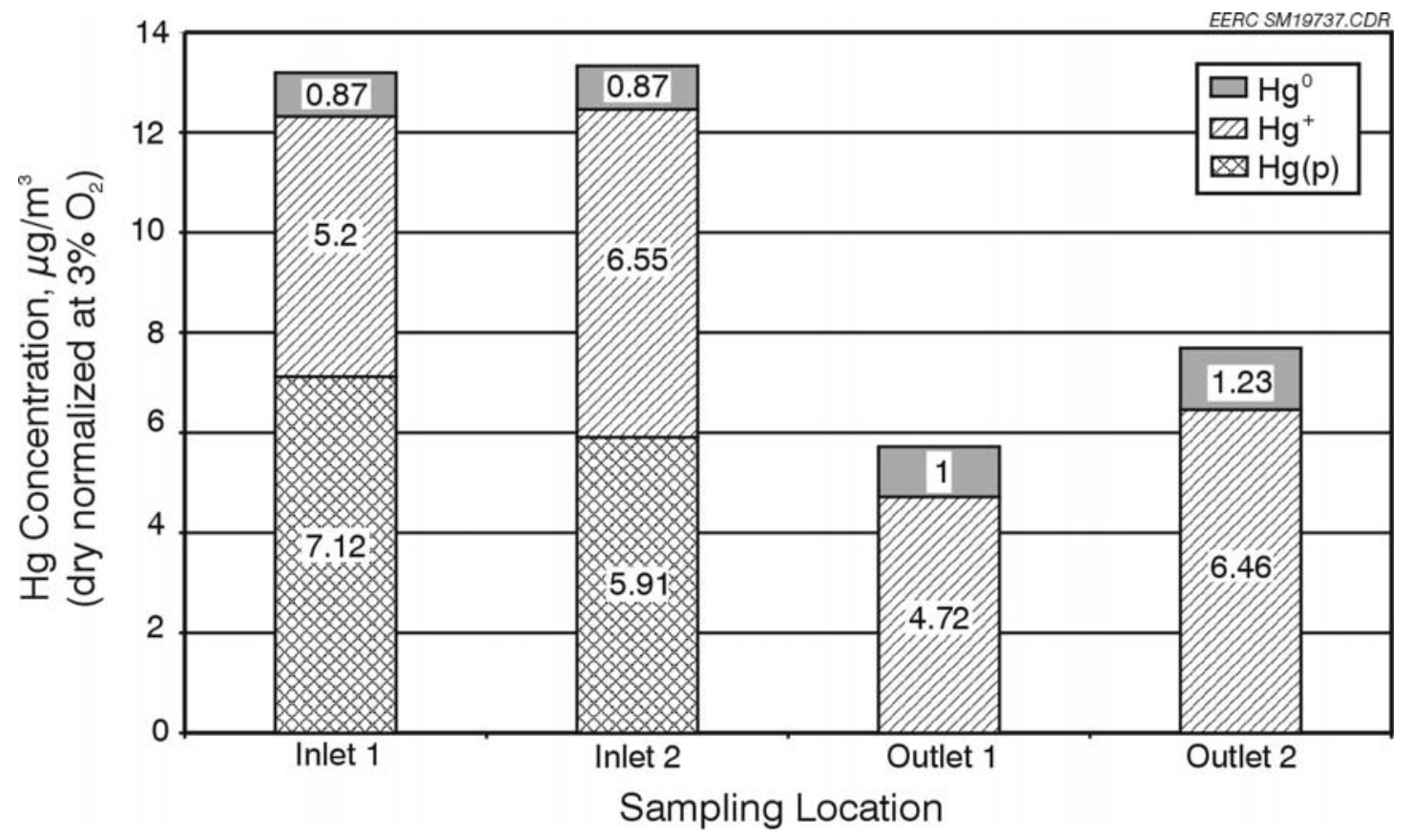

Figure 6.3.1.3. Baseline mercury species in the Advanced Hybrid ${ }^{\mathrm{TM}}$ filter inlet and outlet flue gas. 
$0.87 \mu \mathrm{g} / \mathrm{Nm}^{3}$. Mercury concentration at the Advanced Hybrid ${ }^{\mathrm{TM}}$ filter outlet was $1-1.23 \mu \mathrm{g} / \mathrm{m}^{3}$, of elemental mercury, $4.72-6.46 \mu \mathrm{g} / \mathrm{m}^{3}$ of oxidized mercury, no particle-bound mercury. The sampling data indicate an excellent removal of particle-associated mercury and virtually no additional capture of gaseous mercury (including elemental and oxidized mercury) across the Advanced Hybrid ${ }^{\mathrm{TM}}$ filter unit under the baseline testing conditions.

Mercury species in the inlet and outlet flue gases are normalized and replotted in Figure 6.3.1.4 to further clarify mercury transformation across the Advanced Hybrid ${ }^{\mathrm{TM}}$ filter system. In the inlet flue gas, around $50 \%$ of total mercury had already been associated with fly ash, another $43 \%$ of total mercury was in the oxidized state, and only about $7 \%$ was in the elemental state. At the Advanced Hybrid ${ }^{\mathrm{TM}}$ filter outlet, only elemental (16-17.5\%) and oxidized (82.5-84\%) mercury were in the flue gas since all the particle-bound mercury had been captured with the Advanced Hybrid ${ }^{\mathrm{TM}}$ filter. The overall mercury removal with Advanced Hybrid ${ }^{\mathrm{TM}}$ filter under the baseline test was approximately $49.4 \%$, mainly due to the capture of particle-bound mercury in the coal flue gas.

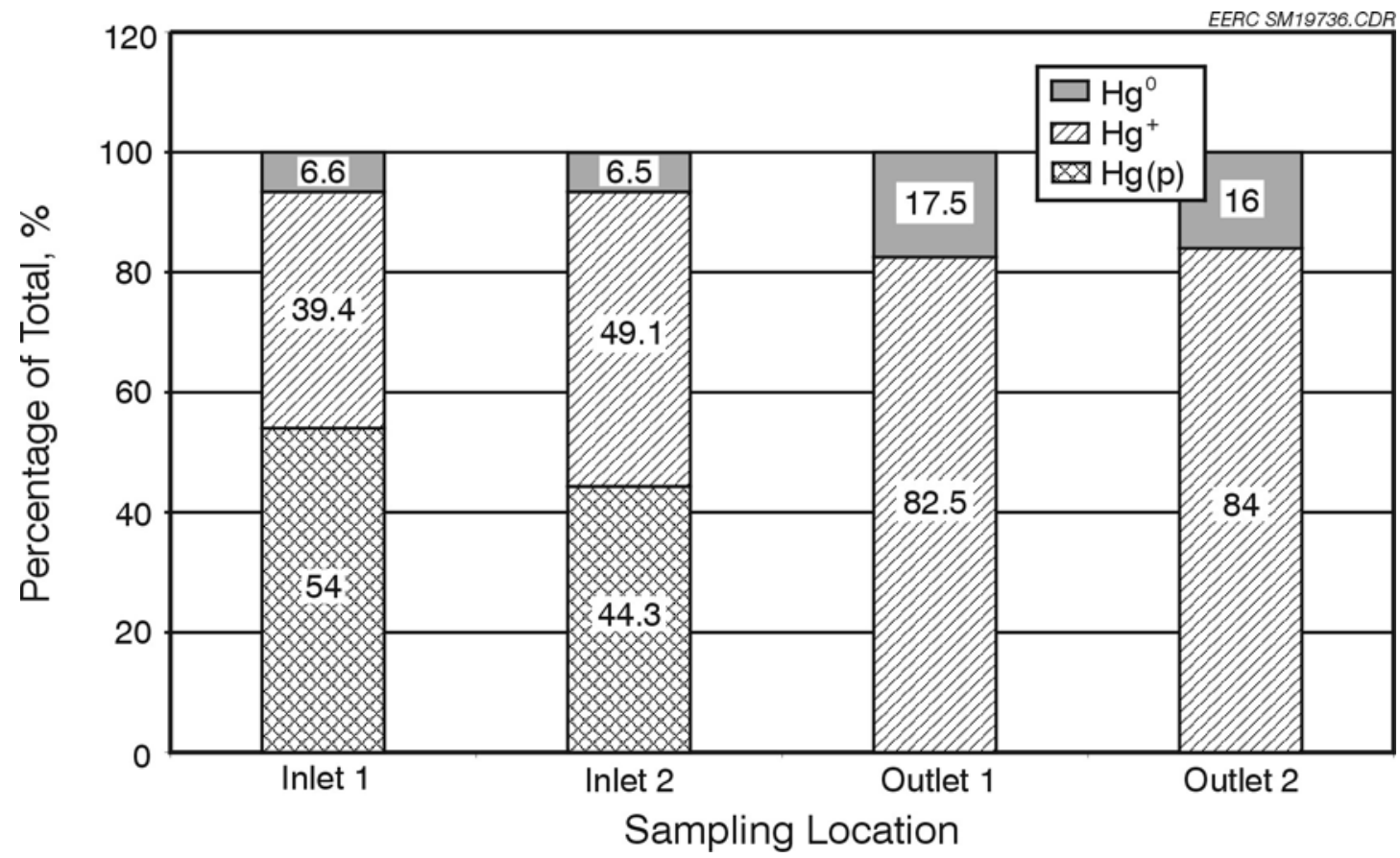

Figure 6.3.1.4. Normalized baseline mercury species distributions in the inlet and outlet flue gases. 
On Day 2 (November 7, 2001), the Advanced Hybrid ${ }^{\mathrm{TM}}$ filter was operated at $3.0 \mathrm{~m} / \mathrm{min}$ $(10 \mathrm{ft} / \mathrm{min}) \mathrm{A} / \mathrm{C}$ ratio, $70 \mathrm{~mA}, 58 \mathrm{kV}$, and $0.29 \mathrm{~kg} / \mathrm{hr}(0.64 \mathrm{lb} / \mathrm{hr})$ carbon injection rate, corresponding to $24 \mathrm{mg} / \mathrm{m}^{3}$ (1.5 $\left.\mathrm{lb} / \mathrm{Macf}\right)$. One inlet Ontario Hydro sample and three outlet Ontario Hydro samples were collected during the test, and the results are plotted in Figure 6.3.1.5. In the inlet flue gas, there was high level of particle-bound mercury of $6.5 \mu \mathrm{g} / \mathrm{m}^{3}$, $3.0 \mu \mathrm{g} / \mathrm{m}^{3}$ of oxidized mercury, and only $1.04 \mu \mathrm{g} / \mathrm{m}^{3}$ of elemental mercury. With the carbon injection, mercury emission in the outlet flue gas decreased to $0.75-1.42 \mu \mathrm{g} / \mathrm{m}^{3}$ with 0 $0.55 \mu \mathrm{g} / \mathrm{m}^{3}$ oxidized mercury and $0.74-0.85 \mu \mathrm{g} / \mathrm{m}^{3}$ elemental mercury. The overall mercury removal with the Advanced Hybrid ${ }^{\mathrm{TM}}$ filter at the carbon injection rate of $24 \mathrm{mg} / \mathrm{m}^{3}(1.5 \mathrm{lb} / \mathrm{Macf})$ was $90.6 \%$ compared to $49 \%$ without carbon injection. The injected carbon efficiently adsorbed oxidized mercury vapor and part of the elemental mercury in the flue gas and then was removed from the flue gas by the injected carbon.

Figure 6.3.1.6 plots the Ontario Hydro results of the Day 3 test where the Advanced Hybrid $^{\mathrm{TM}}$ filter was operated as a PJBH with a 20-min bag-cleaning interval (BCI). In order to keep the pressure drop across the system at a reasonable level, the $\mathrm{A} / \mathrm{C}$ ratio was reduced to

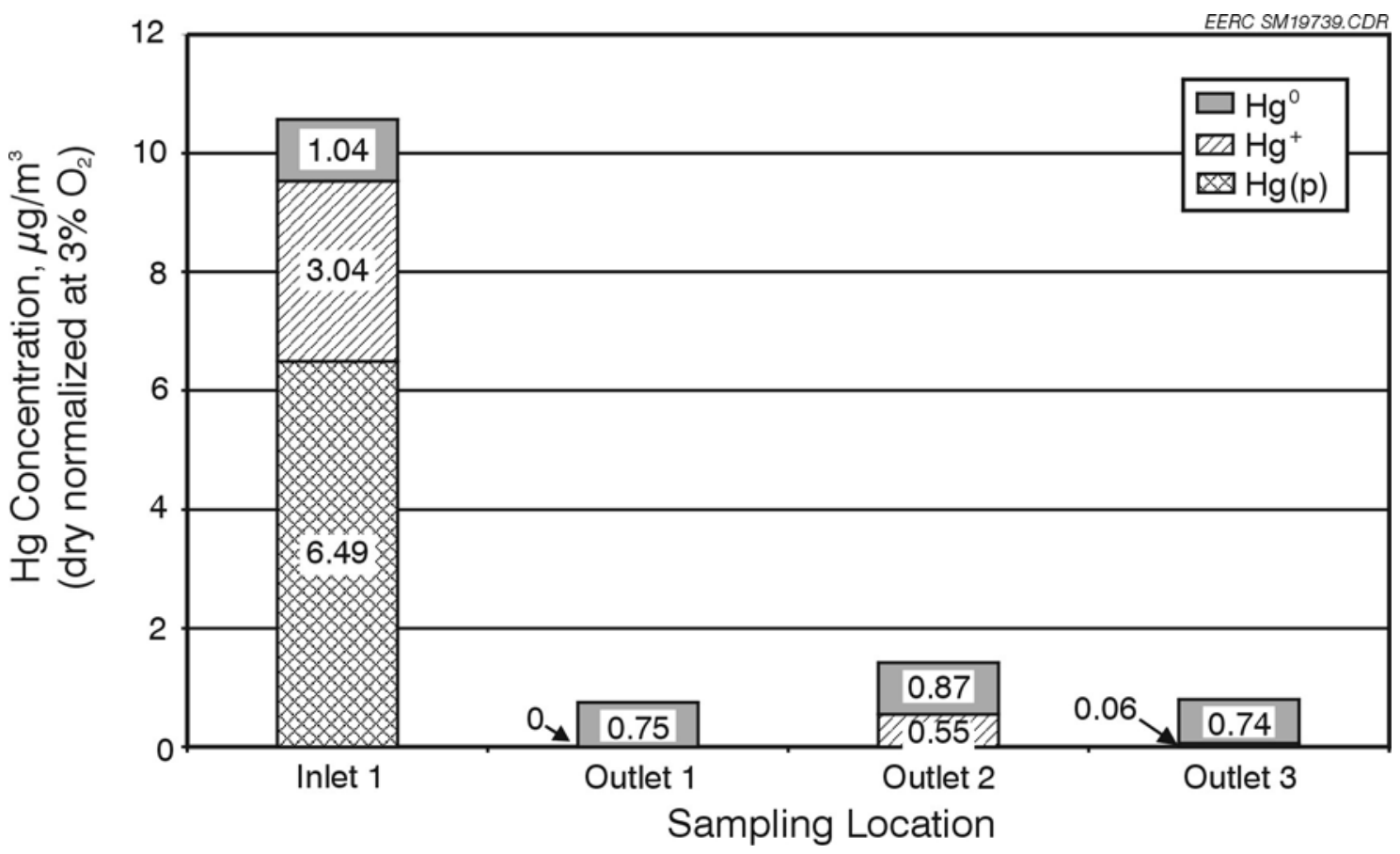

Figure 6.3.1.5. Ontario Hydro results in the Advanced Hybrid ${ }^{\mathrm{TM}}$ filter inlet and outlet flue gas at $24-\mathrm{mg} / \mathrm{m}^{3}$ (1.5-lb/Macf) FGD injection. 


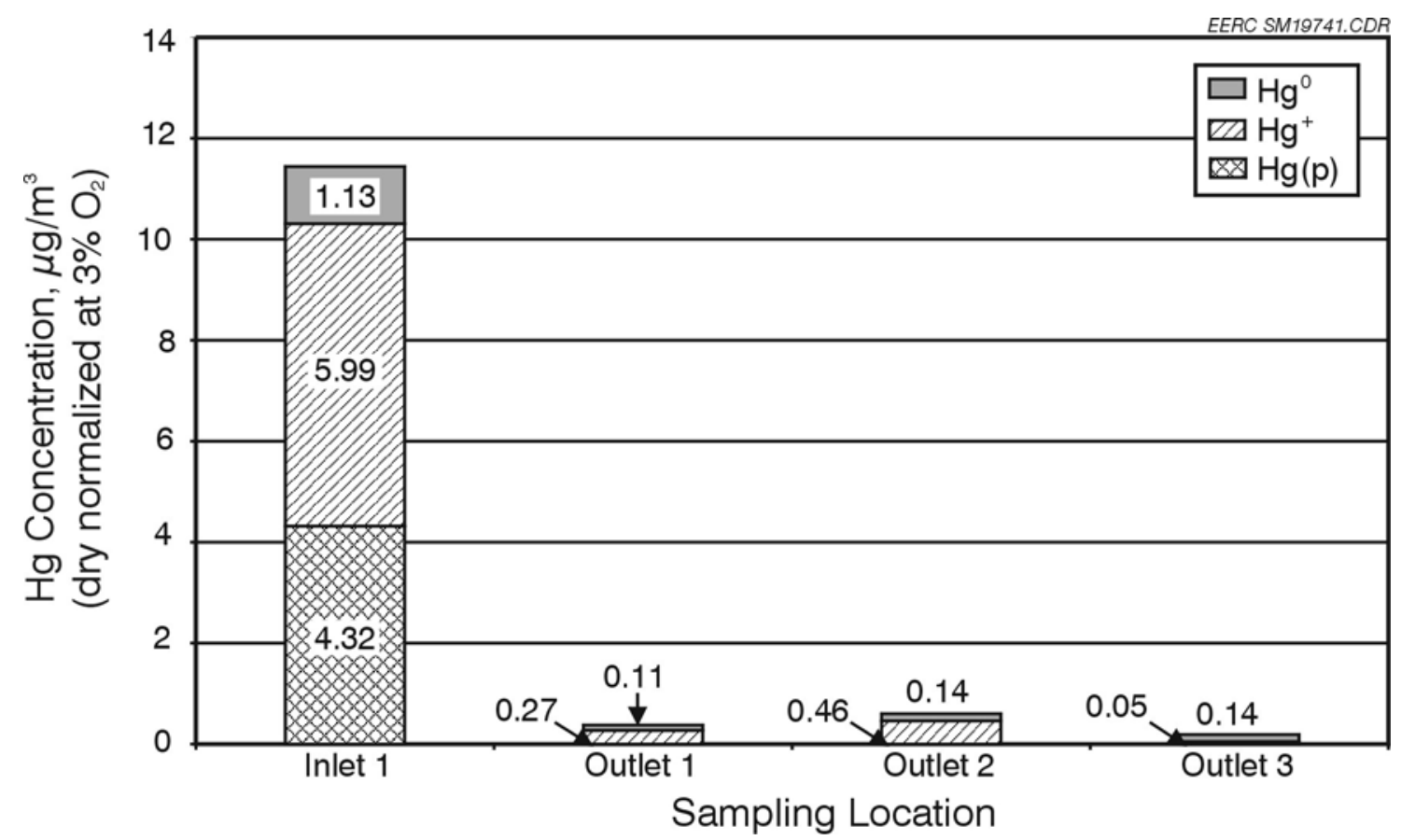

Figure 6.3.1.6. Ontario Hydro results in the PJBH inlet and outlet flue gas under $24-\mathrm{mg} / \mathrm{m}^{3}$ (1.5-lb/Macf) FGD injection.

$1.5 \mathrm{~m} / \mathrm{min}$ ( $5 \mathrm{ft} / \mathrm{min}$ ), and the carbon injection rate was correspondingly reduced to $0.15 \mathrm{~kg} / \mathrm{hr}$ $(0.33 \mathrm{lb} / \mathrm{hr})$ to keep the same carbon-to-flue gas ratio of $24 \mathrm{mg} / \mathrm{m}^{3}(1.5 \mathrm{lb} / \mathrm{Macf})$. The inlet mercury species distribution was similar to the previous 2 days. The outlet mercury emission with carbon injection was $0 \mu \mathrm{g} / \mathrm{m}^{3}$ particle-associated mercury, $0.07-0.46 \mu \mathrm{g} / \mathrm{m}^{3}$ oxidized mercury, and $0.11-0.14 \mu \mathrm{g} / \mathrm{m}^{3}$ elemental mercury vapor.

Two CMMs monitored elemental and total mercury concentrations in the inlet and outlet flue gases during the test. Figure 6.3.1.7 plots the temporal variation of mercury species in flue gas in the testing period. The inlet elemental mercury was around $0.39 \mu \mathrm{g} / \mathrm{m}^{3}$, only accounting for $8.4 \%$ of the $4.62 \mu \mathrm{g} / \mathrm{m}^{3}$ gaseous mercury, which agreed with the Ontario Hydro results. With NORIT FGD carbon injection into the Advanced Hybrid ${ }^{\mathrm{TM}}$ filter chamber, the total mercury concentration at the outlet reduced to $0.54 \mu \mathrm{g} / \mathrm{m}^{3}$, and the elemental mercury concentration in the flue gas was below the CMM detection limit. Having the carbon injection shut down, the outlet mercury emission gradually increased and reached the same level as that of the inlet. The 


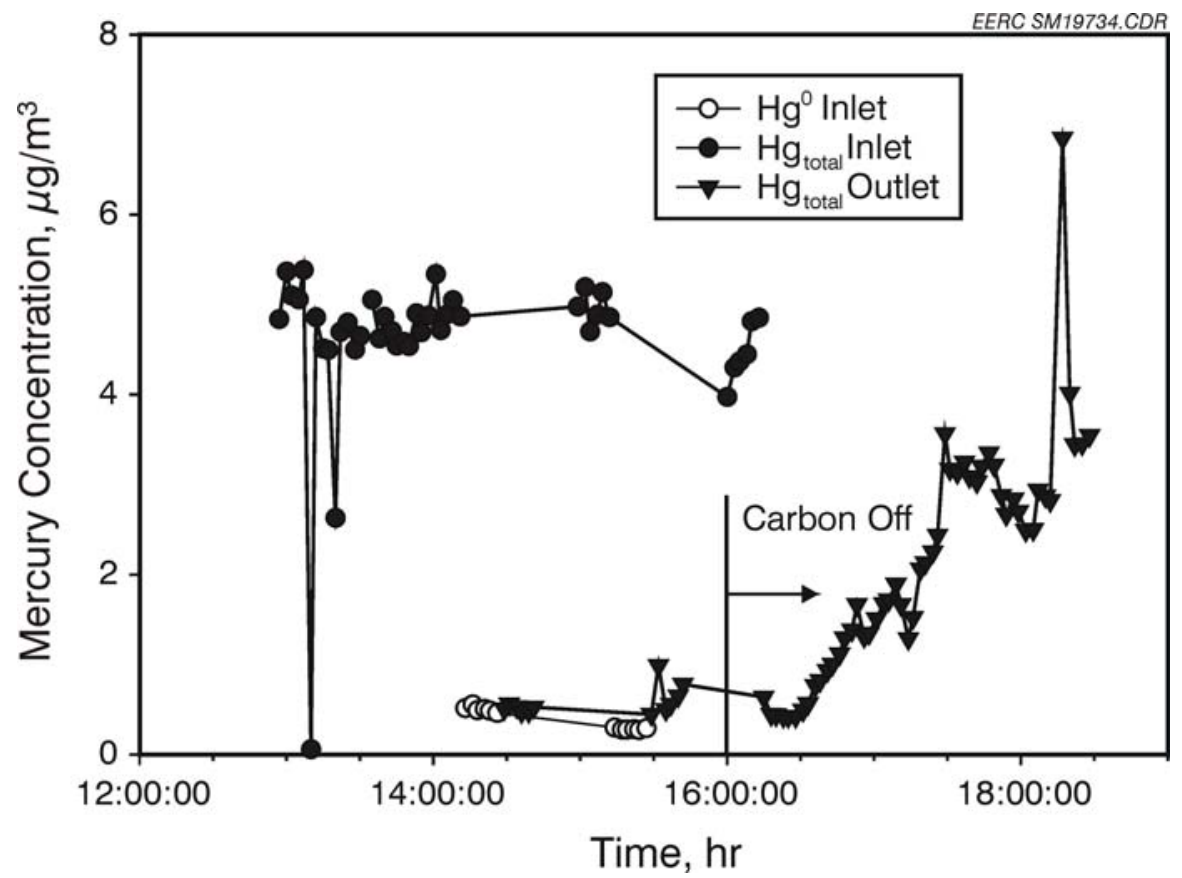

Figure 6.3.1.7. Temporal variation of mercury species in flue gas across the PJBH with $24-\mathrm{mg} / \mathrm{m}^{3}$ (1.5-lb/Macf) FGD injection.

observed slow increase of mercury concentration at the outlet was likely caused by the residual activated carbon in the Advanced Hybrid ${ }^{\mathrm{TM}}$ filter chamber.

Both Ontario Hydro results and CMM data showed that most of the inlet mercury vapor in the flue gas was in the oxidized state and there was excellent mercury capture with the PJBH at $24 \mathrm{mg} / \mathrm{m}^{3}$ (1.5 lb/Macf) of carbon injection. The corresponding overall mercury collection efficiency of $\mathrm{PJBH}$ was $96.6 \%$, which is somewhat better than the $90.6 \%$ of the Advanced Hybrid $^{\mathrm{TM}}$ filter achieved in the Day 2 sampling test. Longer residence time at the reduced $\mathrm{A} / \mathrm{C}$ ratio of $1.5 \mathrm{~m} / \mathrm{min}(5 \mathrm{ft} / \mathrm{min})$ and a lower temperature may have contributed to the somewhat lower mercury emissions compared to Day 2.

The Day 4 sampling test was a repeat of the Day 2 test (Advanced Hybrid ${ }^{\mathrm{TM}}$ filter mode, 20-min BCI, $3.0 \mathrm{~m} / \mathrm{min}$ [10 ft/min] A/C ratio, and $0.29 \mathrm{~kg} / \mathrm{hr}[0.65 \mathrm{lb} / \mathrm{hr}]$ carbon injection rate). Plotted in Figures 6.3.1.8 and 6.3.1.9 are the Ontario Hydro results and CMM data, respectively. The CMM data (Figure 6.3.1.9) show the total inlet mercury vapor concentration varied from 2.78 to $3.54 \mu \mathrm{g} / \mathrm{m}^{3}$, with an average value of $3.09 \mu \mathrm{g} / \mathrm{m}^{3}$, which was very close to the 


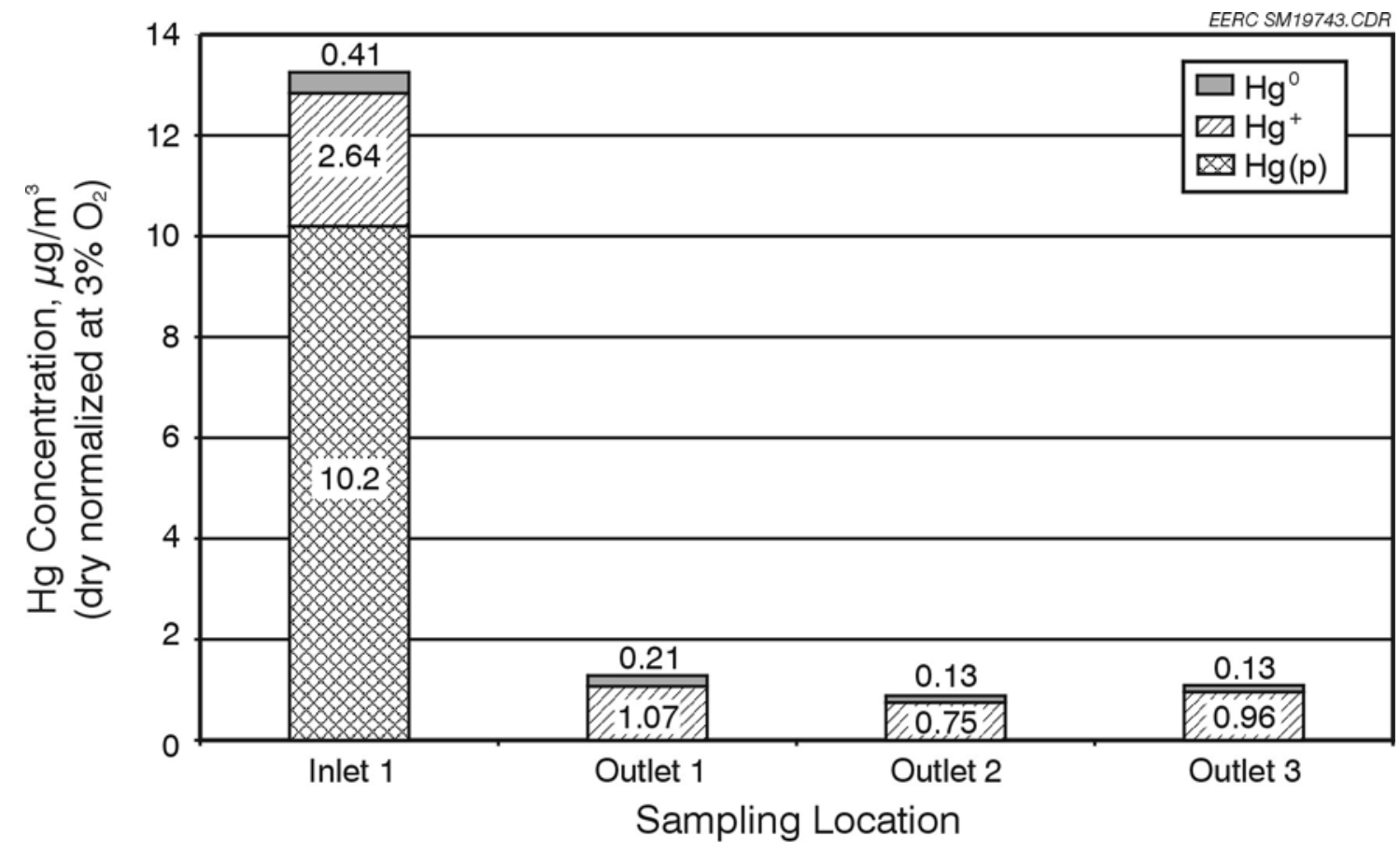

Figure 6.3.1.8. Ontario Hydro results in the Advanced Hybrid ${ }^{\mathrm{TM}}$ filter inlet and outlet flue gases with 24-mg/m³ (1.5-lb/Macf) FGD injection for Day 4.

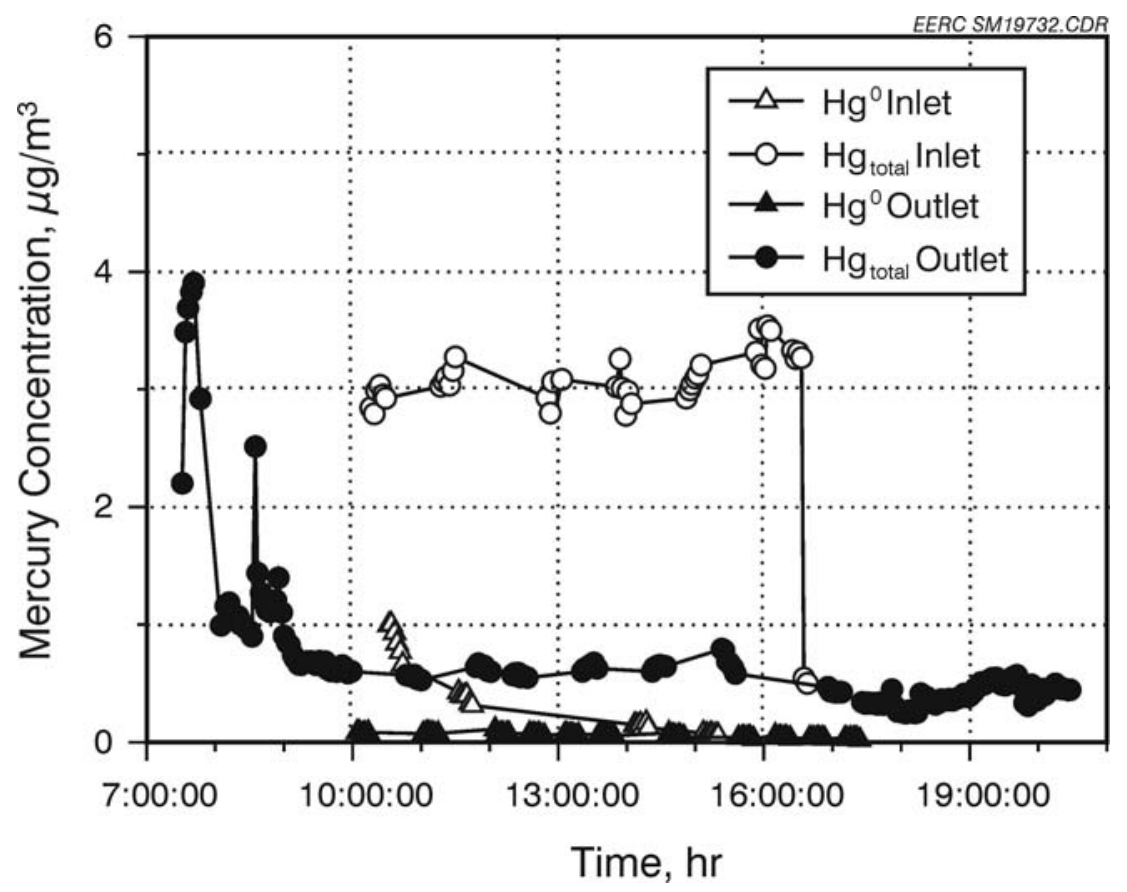

Figure 6.3.1.9. Temporal variations of gaseous mercury across the Advanced Hybrid ${ }^{\mathrm{TM}}$ filter with 24-mg $/ \mathrm{m}^{3}$ (1.5-lb/Macf) FGD injection for Day 4. 
$3.05 \mu \mathrm{g} / \mathrm{Nm}^{3}$ from Ontario Hydro analysis (Figure 6.3.1.8). Again, a very low percentage of elemental mercury was observed at the Advanced Hybrid ${ }^{\mathrm{TM}}$ filter inlet. Both Ontario Hydro and CMM data indicated mercury emission in the outlet flue gas was in the range of $0.6-1.28 \mu \mathrm{g} / \mathrm{m}^{3}$.

For Day 5, the unit was operated as both an Advanced Hybrid ${ }^{\mathrm{TM}}$ filter and a PJBH at the same $\mathrm{A} / \mathrm{C}$ ratio of $1.5 \mathrm{~m} / \mathrm{min}(5 \mathrm{ft} / \mathrm{min})$ with the same carbon injection rate of $24 \mathrm{mg} / \mathrm{m}^{3}$ $(1.5 \mathrm{lb} / \mathrm{Macf})$ to compare mercury removals. The tests provided a better comparison between the two operating modes because the residence time and temperature were constant. The measured mercury species concentrations in flue gas for the two operating modes are plotted in Figure 6.3.1.10 (Ontario Hydro results) and Figure 6.3.1.11 (CMM data).

The total inlet mercury concentration was $11.98 \mu \mathrm{g} / \mathrm{m}^{3}$ in the Advanced Hybrid ${ }^{\mathrm{TM}}$ filter mode and $12.13 \mu \mathrm{g} / \mathrm{m}^{3}$ in the PJBH, indicating constant inlet conditions. Both Ontario Hydro and CMM data confirmed the same levels of outlet mercury emissions for the Advanced Hybrid ${ }^{\mathrm{TM}}$ filter and the PJBH operating modes. The total mercury collection efficiency was $93.8 \%$ for the Advanced Hybrid ${ }^{\mathrm{TM}}$ filter and $94.8 \%$ for the PJBH. Since each test only lasted for $2 \mathrm{hr}$, more long-term experiments are necessary to verify these results.

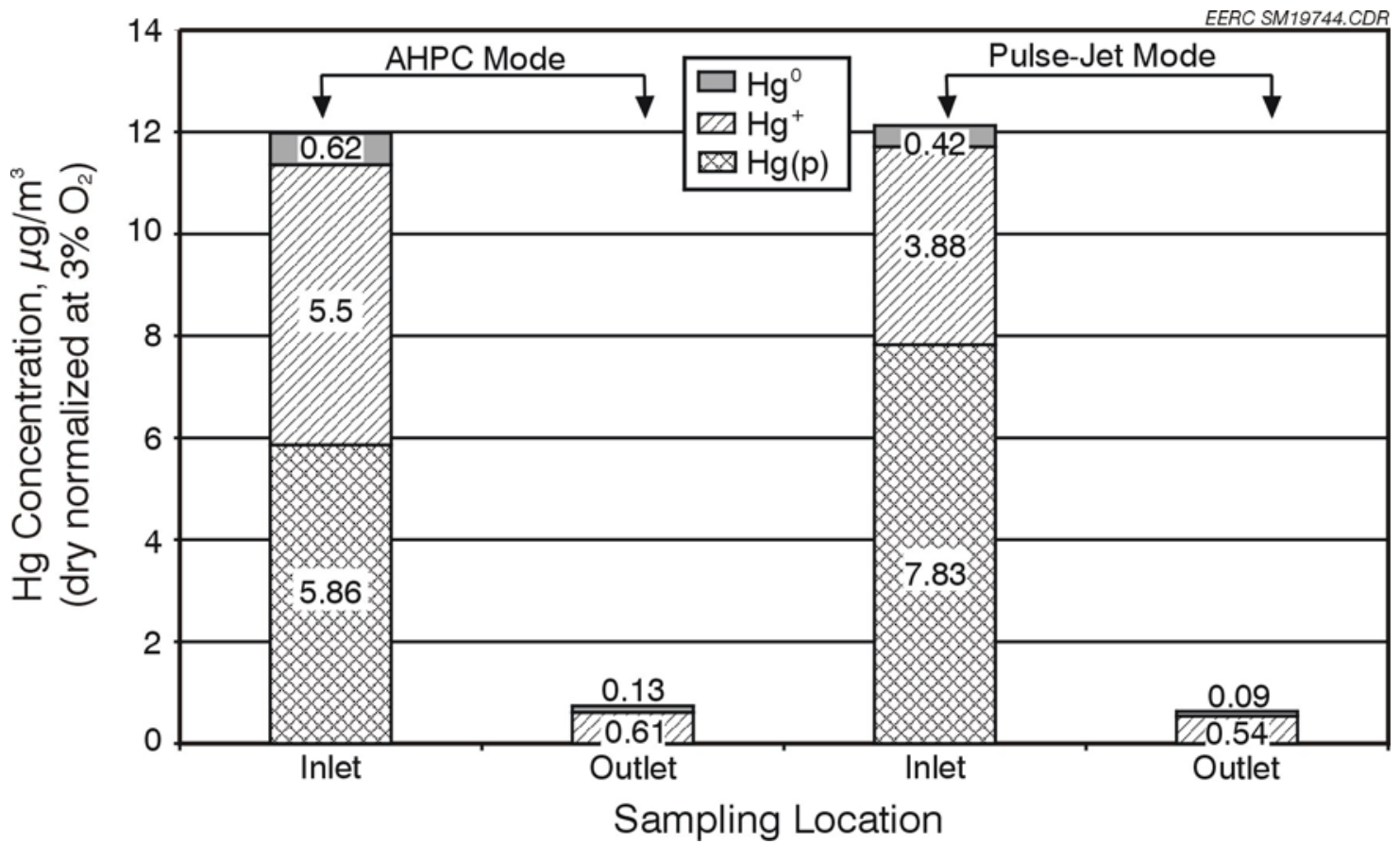

Figure 6.3.1.10. Comparison of mercury species concentration in both the Advanced Hybrid ${ }^{\mathrm{TM}}$ filter and PJBH inlet and outlet flue gas with 24-mg $/ \mathrm{m}^{3}$ (1.5-lb/Macf) FGD injection for Day 5. 


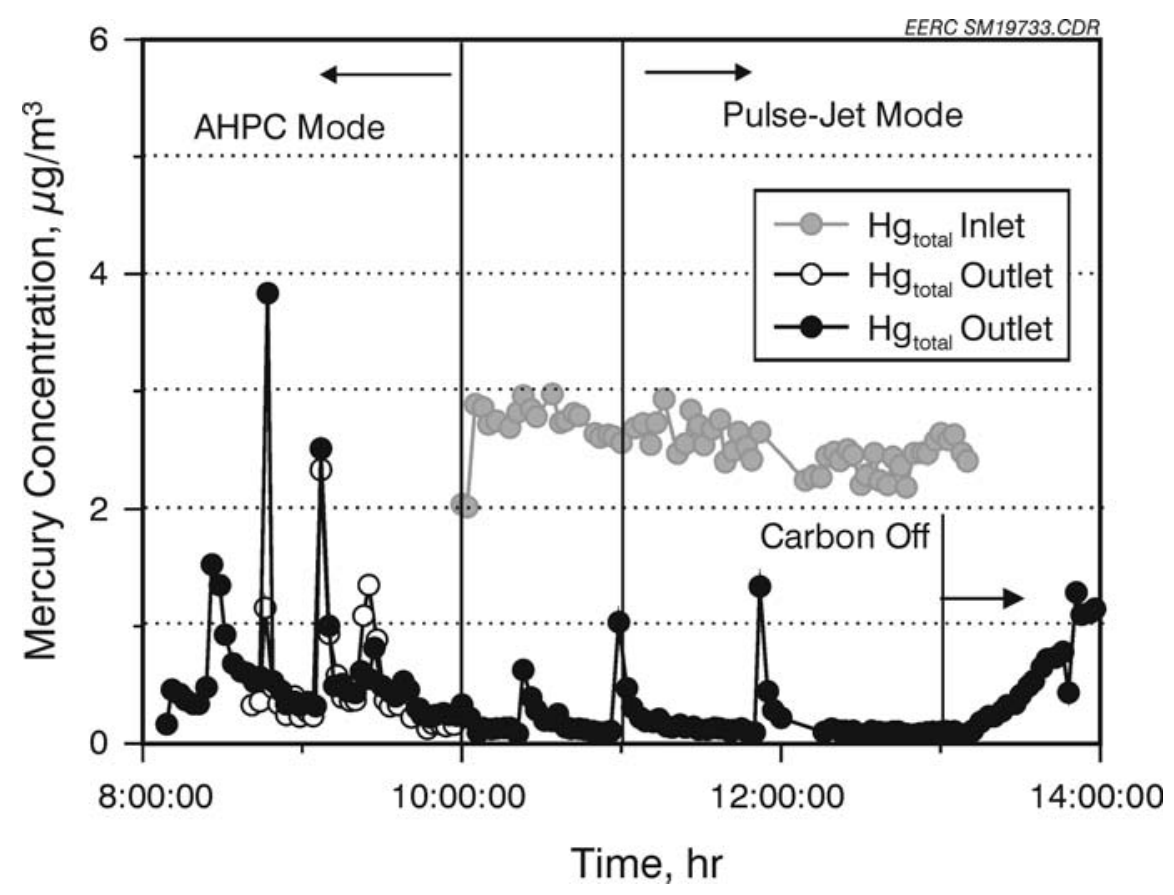

Figure 6.3.1.11. Temporal variations of gaseous mercury across the Advanced Hybrid ${ }^{\mathrm{TM}}$ filter or PJBH with 24-mg/m³ (1.5-lb/Macf) FGD injection for Day 5.

Table 6.3.1.6 summarizes the Ontario Hydro results collected during the entire 5-day test. The total mercury concentration in the flue gas (present as total mercury concentration at the Advanced Hybrid ${ }^{\mathrm{TM}}$ filter inlet) ranged from 10.6 to $13.2 \mu \mathrm{g} / \mathrm{Nm}^{3}$, which is slightly lower than the theoretical value of $15.1 \mu \mathrm{g} / \mathrm{Nm}^{3}$ obtained from the coal combustion calculation based on the coal analysis. A possible reason is the underestimated inlet dust loading. However, considering the complexity of mercury analysis, the measured mercury results are close to the theoretical value.

During the week, the sorbent was injected only during the day, and after the mercury sampling was completed, the carbon injection was shut off overnight to allow the unit to return to baseline conditions. Four hopper ash samples were collected each day except for the first and the fifth day when two samples and three samples were collected, respectively. The first sample usually was regarded as baseline ash, and the rest represented ash samples from the carbon injection tests. The hopper ash samplers were then acid-digested and measured for mercury concentration. The results are presented in Table 6.3.1.7. For comparison, the filter ash mercury 
Table 6.3.1.6. Summary of Ontario Hydro Mercury Results, dry flue gas at $3.0 \% \mathrm{O}_{2}$ $\left(\mu \mathrm{g} / \mathrm{Nm}^{3}\right)$

\begin{tabular}{|c|c|c|c|c|c|}
\hline & & $\mathrm{Hg}^{0}$ & $\mathrm{Hg}^{+}$ & $\mathrm{Hg}$ (particulate) & $\mathrm{Hg}$ (total) \\
\hline \multirow{4}{*}{ Day 1} & \multirow{2}{*}{ Inlet } & 0.87 & 5.2 & 7.12 & 13.19 \\
\hline & & 0.87 & 6.55 & 5.91 & 13.33 \\
\hline & \multirow{2}{*}{ Outlet } & 1.0 & 4.72 & 0 & 5.72 \\
\hline & & 1.23 & 6.46 & 0 & 7.69 \\
\hline \multirow{5}{*}{ Day 2} & \multirow[t]{2}{*}{ Inlet } & 1.04 & 3.04 & 6.49 & 10.57 \\
\hline & & 0.75 & 0 & 0 & 0.75 \\
\hline & \multirow[t]{2}{*}{ Outlet } & 0.87 & 0.55 & 0 & 1.42 \\
\hline & & 0.74 & 0.06 & 0 & 0.80 \\
\hline & \multirow[t]{2}{*}{ Inlet } & 1.13 & 5.99 & 4.32 & 11.44 \\
\hline \multirow{3}{*}{ Day 3} & & 0.11 & 0.27 & 0 & 0.38 \\
\hline & \multirow[t]{2}{*}{ Outlet } & 0.14 & 0.46 & 0 & 0.6 \\
\hline & & 0.14 & 0.05 & 0 & 0.19 \\
\hline \multirow{4}{*}{ Day 4} & \multirow[t]{2}{*}{ Inlet } & 0.41 & 2.64 & 10.2 & 13.25 \\
\hline & & 0.21 & 1.07 & 0 & 1.28 \\
\hline & \multirow[t]{2}{*}{ Outlet } & 0.13 & 0.75 & 0 & 0.88 \\
\hline & & 0.13 & 0.96 & 0 & 1.09 \\
\hline \multirow[t]{2}{*}{ Day 5} & Inlet & 0.62 & 5.5 & 5.86 & 11.98 \\
\hline & Outlet & 0.13 & 0.61 & 0 & 0.74 \\
\hline \multirow[t]{2}{*}{ Day 5} & Inlet & 0.42 & 3.88 & 7.83 & 12.13 \\
\hline & Outlet & 0.09 & 0.54 & 0 & 0.63 \\
\hline
\end{tabular}

Day 1 - No carbon injection, Advanced Hybrid ${ }^{\mathrm{TM}}$ filter, $3.0 \mathrm{~m} / \mathrm{min}(10 \mathrm{ft} / \mathrm{min})$.

Day 2 - Carbon: $0.65 \mathrm{lb} / \mathrm{hr}$, Advanced Hybrid ${ }^{\mathrm{TM}}$ filter, $3.0 \mathrm{~m} / \mathrm{min}(10 \mathrm{ft} / \mathrm{min})$.

Day 3 - Carbon: $0.33 \mathrm{lb} / \mathrm{hr}$, pulse jet, $1.5 \mathrm{~m} / \mathrm{min}(5 \mathrm{ft} / \mathrm{min})$.

Day 4 - Carbon: $0.65 \mathrm{lb} / \mathrm{hr}$, Advanced Hybrid ${ }^{\mathrm{TM}}$ filter, $3.0 \mathrm{~m} / \mathrm{min}(10 \mathrm{ft} / \mathrm{min})$.

Day 5 - Carbon: $0.33 \mathrm{lb} / \mathrm{hr}$, Advanced Hybrid ${ }^{\mathrm{TM}}$ filter, $1.5 \mathrm{~m} / \mathrm{min}(5 \mathrm{ft} / \mathrm{min})$.

Day 5 - Carbon: $0.33 \mathrm{lb} / \mathrm{hr}$, pulse jet, $1.5 \mathrm{~m} / \mathrm{min}(5 \mathrm{ft} / \mathrm{min})$.

from the inlet Ontario Hydro samples is also reported in Table 6.3.1.7. For the Day 1 baseline test, both the inlet filter ash and hopper ash had almost the same mercury concentration at approximately the same operating time. With carbon injection, the mercury concentration in the hopper ash gradually increased, showing the mercury vapor was absorbed on the activated carbon and removed from the flue gas by the Advanced Hybrid ${ }^{\mathrm{TM}}$ filter. A fly ash sample collected in the thimble filter used in CMM sampling at the inlet location was also analyzed for mercury concentration and is shown in Table 6.3.1.7. The mercury concentration of $8.22 \mu \mathrm{g} / \mathrm{Nm}^{3}$ on the CMM filter fly ash was much higher than that of the hopper ash. One possible reason could be that the sampling nozzle was pointing downstream so the fine fly ash collected in the filter by nonisokinetic sampling had a greater enrichment of mercury compared to that of larger- 
Table 6.3.1.7. Mercury Concentration and LOI in Fly Ash

\begin{tabular}{|c|c|c|c|c|}
\hline Test Day & Sample Type & Time Sample Taken & Hg Concentration, $\mu \mathrm{g} / \mathrm{g}$ & $\%$ LOI \\
\hline Day 1 & Hopper ash baseline & $11: 01$ & 1.84 & \\
\hline Day 1 & Hopper ash baseline & 14:00 & 1.53 & 0.48 \\
\hline Day 1 & Inlet filter & $9: 20-11: 20$ & 1.98 & \\
\hline Day 1 & Inlet filter & $12: 05-14: 05$ & 1.58 & \\
\hline Day 2 & Hopper ash baseline & $7: 10$ & 1.34 & 0.79 \\
\hline Day 2 & $\begin{array}{c}\text { Carbon injection } \\
\text { Advanced Hybrid } \\
\mathrm{T}^{\mathrm{M}} \text { filter }\end{array}$ & 10:02 & 2.58 & \\
\hline Day 2 & $\begin{array}{c}\text { Carbon injection } \\
\text { Advanced Hybrid }{ }^{\mathrm{TM}} \text { filter }\end{array}$ & 12:01 & 2.74 & \\
\hline Day 2 & $\begin{array}{c}\text { Carbon injection } \\
\text { Advanced Hybrid } \\
\mathrm{TM}^{\mathrm{TM}} \text { filter }\end{array}$ & 14:00 & 3.06 & 1.56 \\
\hline Day 2 & Inlet filter & 8:00-10:00 & 1.67 & \\
\hline Day 3 & Hopper ash baseline & $7: 18$ & 1.67 & 1.86 \\
\hline Day 3 & Carbon injection pulse jet & 11:00 & 3.58 & \\
\hline Day 3 & Carbon injection pulse jet & 14:04 & 3.94 & \\
\hline Day 3 & Carbon injection pulse jet & $16: 01$ & 3.62 & 2.15 \\
\hline Day 3 & Inlet filter & $10: 23-12: 23$ & 1.59 & \\
\hline Day 4 & Hopper ash baseline & $7: 20$ & 1.64 & 0.71 \\
\hline Day 4 & $\begin{array}{c}\text { Carbon injection } \\
\text { Advanced Hybrid } \\
\mathrm{T}^{\mathrm{TM}} \text { filter }\end{array}$ & 11:01 & 2.71 & \\
\hline Day 4 & $\begin{array}{c}\text { Carbon injection } \\
\text { Advanced Hybrid }{ }^{\mathrm{TM}} \text { filter }\end{array}$ & 13:04 & 2.80 & \\
\hline Day 4 & $\begin{array}{c}\text { Carbon injection } \\
\text { Advanced Hybrid } \\
\mathrm{TM} \text { filter }\end{array}$ & 16:01 & 3.36 & 1.90 \\
\hline Day 4 & Inlet filter & 9:00-11:00 & 2.89 & \\
\hline Day 5 & Hopper ash baseline & $7: 18$ & 3.09 & 1.67 \\
\hline Day 5 & $\begin{array}{c}\text { Carbon injection } \\
\text { Advanced Hybrid } \\
\mathrm{T}^{\mathrm{MM}} \text { filter }\end{array}$ & $10: 01$ & 3.46 & \\
\hline Day 5 & Carbon injection pulse jet & 13:01 & 3.90 & 2.45 \\
\hline Day 5 & Inlet filter & $8: 00-10: 00$ & 2.18 & \\
\hline Day 5 & Inlet filter & $11: 00-13: 00$ & 2.89 & \\
\hline Day 4 & Inlet filter from CMM & $8: 00-19: 00$ & 8.22 & \\
\hline
\end{tabular}

sized fly ash particles. Another factor could be that this filter was continually used over a whole day, so the extended exposure time may lead to higher mercury adsorption.

The mercury concentrations for the Advanced Hybrid ${ }^{\mathrm{TM}}$ filter hopper ash samples along with percent LOI shown in Table 6.3.1.7 indicate a general trend of increasing values with carbon injection, as would be expected. However, because of the varying baseline values, it is not possible to complete a good mass balance. For the measured inlet dust loading, the expected increase in carbon in the fly ash (for the given carbon injection rate) is about $1.6 \%$. The LOI data 
from Days 4 and 5 are in reasonable agreement with this level of increase. The varying baseline LOI levels and the short-term tests do not allow for a better mass balance closure. The morning baseline ash samples were collected after a time without carbon injection, but no attempt was made to clean the Advanced Hybrid ${ }^{\mathrm{TM}}$ filter hopper of residual ash between tests, so some mixing of the hopper ash from different tests could have occurred.

\subsubsection{Summary of Advanced Hybrid ${ }^{\mathrm{TM}}$ Filter Performance for the First Field Test}

During the 5-day sampling test, the Advanced Hybrid ${ }^{\mathrm{TM}}$ filter unit was set up at a fixed 20 -min BCI with an $\mathrm{A} / \mathrm{C}$ ratio of either $1.5 \mathrm{~m} / \mathrm{min}(5 \mathrm{ft} / \mathrm{min})$ or $3.0 \mathrm{~m} / \mathrm{min}(10 \mathrm{ft} / \mathrm{min})$. The carbon injection rate of $24 \mathrm{mg} / \mathrm{m}^{3}(1.5 \mathrm{lb} / \mathrm{Macf})$ is equivalent to a dust inlet loading of 0.023 $\mathrm{g} / \mathrm{actual} \mathrm{m}^{3}$ or $0.034 \mathrm{~g} / \mathrm{standard} \mathrm{m}^{3}(0.01 \mathrm{gr} / \mathrm{acf}$ or $0.015 \mathrm{gr} / \mathrm{scf})$. Compared to the average inlet fly ash dust loading of $2.2 \mathrm{~g} /$ standard $\mathrm{m}^{3}(0.96 \mathrm{gr} / \mathrm{scf})$, this represents $1.6 \%$ of the dust loading and would not be expected to affect the Advanced Hybrid ${ }^{\mathrm{TM}}$ filter pressure drop. From the pressure drop and drag data with and without carbon injection, there was no effect of the carbon injection on Advanced Hybrid ${ }^{\mathrm{TM}}$ filter operation.

The dust loadings in the inlet and outlet flue gases (obtained from the Ontario Hydro method) are listed in Table 6.3.1.8, and the corresponding particle collection efficiencies are also calculated and presented in Table 6.3.1.8. The particle collection efficiency ranged from $99.972 \%$ to $100 \%$, which represents the level of accuracy that can be achieved by this method with a 2-hr sample. Earlier tests on the Big Stone Advanced Hybrid ${ }^{\mathrm{TM}}$ filter where the outlet was sampled for over $15 \mathrm{hr}$ indicated dust loadings in the range of 0.00009 to $0.0002 \mathrm{~g} / \mathrm{m}^{3}$ (0.00004 to $0.00009 \mathrm{gr} / \mathrm{dscf}$ ). Independent measurements with real-time particle analyzers have also proven the collection efficiency to be better than $99.99 \%$.

\subsubsection{6 - Conclusions from the First Field Test}

The average inlet total mercury concentration was $12.3 \mu \mathrm{g} / \mathrm{Nm}^{3}$ with $55.4 \%$ particulate-bound, $38.1 \%$ oxidized, and $6.4 \%$ elemental mercury. The high level of particulatebound mercury and oxidized mercury was somewhat surprising because for western PRB coals lower levels of particulate-bound mercury and oxidized mercury are more typical. Possible factors that determine the level of particulate-bound and oxidized mercury include coal type, boiler type, $\mathrm{HCl}$ (as well as other flue gases), temperature, and amount of carbon in the fly ash. For this test, the supplemental TDF was suspected to be reason for the high levels of particle-bound and oxidized mercury. 
Table 6.3.1.8. Dust Loadings at the Advanced Hybrid ${ }^{\mathrm{TM}}$ Filter Inlet and Outlet and the Calculated Collection Efficiency

\begin{tabular}{lccc}
\hline & Inlet, gr/dscf & Outlet, gr/dscf & Collection Efficiency, \% \\
\hline Day 1-1 & 1.169 & 0.000250 & 99.978 \\
Day 1-2 & 1.235 & 0.000191 & 99.984 \\
Day 2-1 & 1.324 & 0.000363 & 99.972 \\
Day 4-1 & 1.189 & $1.760 \mathrm{E}-06$ & 99.999 \\
Day 5-1 & 0.909 & 0 & 100.000 \\
\hline
\end{tabular}

With $1.5 \mathrm{lb} /$ Macf carbon injection rate, total mercury removal with the Advanced Hybrid ${ }^{\mathrm{TM}}$ filter was $91 \%-97 \%$ compared to $49 \%$ removal for the baseline case. Even though the carbon addition rate was low, the carbon was highly effective at removing mercury. The data show that the carbon was effective at removing both elemental and oxidized mercury.

Mercury removal with carbon injection in the Advanced Hybrid ${ }^{\mathrm{TM}}$ filter mode was 91\% and $92 \%$ on Days 2 and 4 compared to $97 \%$ on Day 4 PJBH test. The difference in mercury removals was possibly caused by the longer residence time and lower flue gas temperature in PJBH. On Day 5, the unit was operated in both modes at the same flow rate, which resulted in 94\% capture in the Advanced Hybrid ${ }^{\mathrm{TM}}$ filter mode and 95\% capture in PJBH. It can be concluded that there was no significant difference in mercury capture between the Advanced Hybrid $^{\mathrm{TM}}$ filter and the PJBH during this testing period.

These short-term tests are highly encouraging because they prove that excellent mercury removal can be achieved with very low addition rates of carbon injected upstream of the Advanced Hybrid ${ }^{\mathrm{TM}}$ filter. Further testing is needed to demonstrate that the high level of mercury removal can be maintained over the longer term and that the carbon injection will not have any adverse effect on the longer-term operation of the Advanced Hybrid ${ }^{\mathrm{TM}}$ filter. Since the conditions that lead to good mercury capture with carbon are not well known, at this point the results should not be generalized to other coals or plants.

\subsubsection{Long-Term Field Test June 28-September 6, 2002}

\subsubsection{Test Conditions}

A 2-month field test was completed with the 2.5-MW (9000-acfm) field Advanced Hybrid $^{\mathrm{TM}}$ filter from June 28 through September 6, 2002. From June 28 to August 6, the Advanced Hybrid ${ }^{\mathrm{TM}}$ filter was operated without carbon injection to establish baseline conditions. Carbon injection and CMM measurements were continuous (24 hr a day) from August 6 to September 6, except during an unplanned plant outage from August 29 to September 2. The 
primary goal of the work was to demonstrate longer-term mercury control with the Advanced Hybrid ${ }^{\mathrm{TM}}$ filter and evaluate the effect of carbon injection on the Advanced Hybrid ${ }^{\mathrm{TM}}$ filter operational performance.

During the November 2001 test, the Big Stone Power Plant was burning approximately $3 \%-5 \%$ waste tires, which was suspected to be the reason for the unexpectedly high levels of particle-bound and oxidized mercury in the flue gas. Therefore, another goal of this test was to evaluate the effect of supplemental TDF cofiring on the level of mercury capture for comparison with results from the previous test completed in November 2001. During the start of the August test, the TDF feed was deliberately stopped to evaluate mercury control without tire feed. The plan was then to start the tire feed again during the monthlong test. However, because of an unsteady supply of the waste tires, the tire feed rate was lower and more intermittent than the amount burned previously.

During the week of testing from August 5 to 9 and on August 26 and 27, Ontario Hydro samples were collected at both the Advanced Hybrid ${ }^{\mathrm{TM}}$ filter inlet and outlet. Several Method 26A samples were also taken during those days to determine $\mathrm{HCl}$ concentrations in flue gas. The inlet and outlet mercury concentrations were also monitored by a CMM. For the majority of the time, the mercury monitor sampled at the outlet, but several times a day it was switched to the inlet for a short time to document the inlet concentration. On the days when Ontario Hydro samples were not taken, the CMM was operated continuously for $24 \mathrm{hr}$ a day. The CMM was normally set up to measure the outlet total vapor-phase mercury, but during the day for several hours, it was manually switched to measure both the total and elemental vapor-phase mercury at the inlet as well as the elemental mercury at the outlet.

\subsubsection{Big Stone Fuel Record}

The fuel burn record from the plant data for the field test last November and the August 5September 6, 2002, test is shown in Table 6.3.2.1. In November 2001, the coal was from either the Cordero or Caballo Mines in the PRB. For the August 5-September 6 test, the coal was from the Belle Ayr and Eagle Butte Mines. Both coals are similar low-sulfur subbituminous fuels from the PRB. The amounts of TDF and waste seed fuel burned during this time are also listed in Table 6.3.2.1. Waste tires are known to be a source of chlorine and thought to be the reason for the higher $\mathrm{HCl}$ seen in the flue gas last November. Waste corn seed may also be a source of 
Table 6.3.2.1. Big Stone Fuel Record

\begin{tabular}{|c|c|c|c|c|}
\hline Date & Coal Mine & Coal, tons & TDF, tons & Waste Seeds, tons \\
\hline November 5, 2001 & Cordero & 4695 & 140 & 100 \\
\hline November 6, 2001 & Cordero & 6117 & 200 & 100 \\
\hline November 7, 2001 & Caballo & 6104 & 150 & 120 \\
\hline November 8, 2001 & Caballo & 6296 & 90 & 100 \\
\hline November 9, 2001 & Caballo & 6024 & 250 & 80 \\
\hline August 5, 2002 & Belle Ayr & 5947 & 0 & 18 \\
\hline August 6, 2002 & Belle Ayr & 5945 & 0 & 0 \\
\hline August 7, 2002 & Belle Ayr & 6096 & 0 & 46 \\
\hline August 8, 2002 & Belle Ayr & 6312 & 0 & 0 \\
\hline August 9, 2002 & Belle Ayr & 6135 & 16 & 157 \\
\hline August 10, 2002 & Belle Ayr & 6473 & 0 & 0 \\
\hline August 11,2002 & Belle Ayr & 6242 & 0 & 0 \\
\hline August 12,2002 & Belle Ayr & 6418 & 23 & 92 \\
\hline August 13, 2002 & Belle Ayr & 5531 & 23 & 88 \\
\hline August 14, 2002 & Belle Ayr & 5525 & 22 & 64 \\
\hline August 15, 2002 & Eagle Butte & 5793 & 25 & 50 \\
\hline August 16, 2002 & Eagle Butte & 5867 & 0 & 69 \\
\hline August 17, 2002 & Eagle Butte & 5344 & 0 & 0 \\
\hline August 18, 2002 & Eagle Butte & 5278 & 0 & 0 \\
\hline August 19, 2002 & Eagle Butte & 5121 & 20 & 24 \\
\hline August 20, 2002 & Eagle Butte & 5895 & 51 & 33 \\
\hline August 21, 2002 & Eagle Butte & 5951 & 177 & 0 \\
\hline August 22, 2002 & Eagle Butte & 5771 & 150 & 0 \\
\hline August 23, 2002 & Eagle Butte & 5827 & 0 & 169 \\
\hline August 24, 2002 & Belle Ayr & 6100 & 0 & 0 \\
\hline August 25, 2002 & Belle Ayr & 5878 & 0 & 0 \\
\hline August 26, 2002 & Belle Ayr & 6040 & 0 & 92 \\
\hline August 27, 2002 & Belle Ayr & 5862 & 24 & 116 \\
\hline August 28, 2002 & Belle Ayr & 2488 & 0 & 0 \\
\hline September 3, 2002 & Eagle Butte & 5996 & 23 & 0 \\
\hline September 4, 2002 & Belle Ayr & 6298 & 0 & 0 \\
\hline September 5, 2002 & Belle Ayr & 6336 & 0 & 0 \\
\hline September 6, 2002 & Eagle Butte & 6186 & 45 & 24 \\
\hline
\end{tabular}

some additional chlorine, but the amount of inorganic material in the corn is expected to be less than in TDF.

\subsubsection{Mercury Results for August 6-September 6, 2002, Field Test}

Mercury Species in the Inlet Flue Gas

Figures 6.3.2.1 and 6.3.2.2 summarize mercury species in the Big Stone Power Plant flue gas based on Ontario Hydro samples collected in August 5-9 and August 26-27, respectively. 


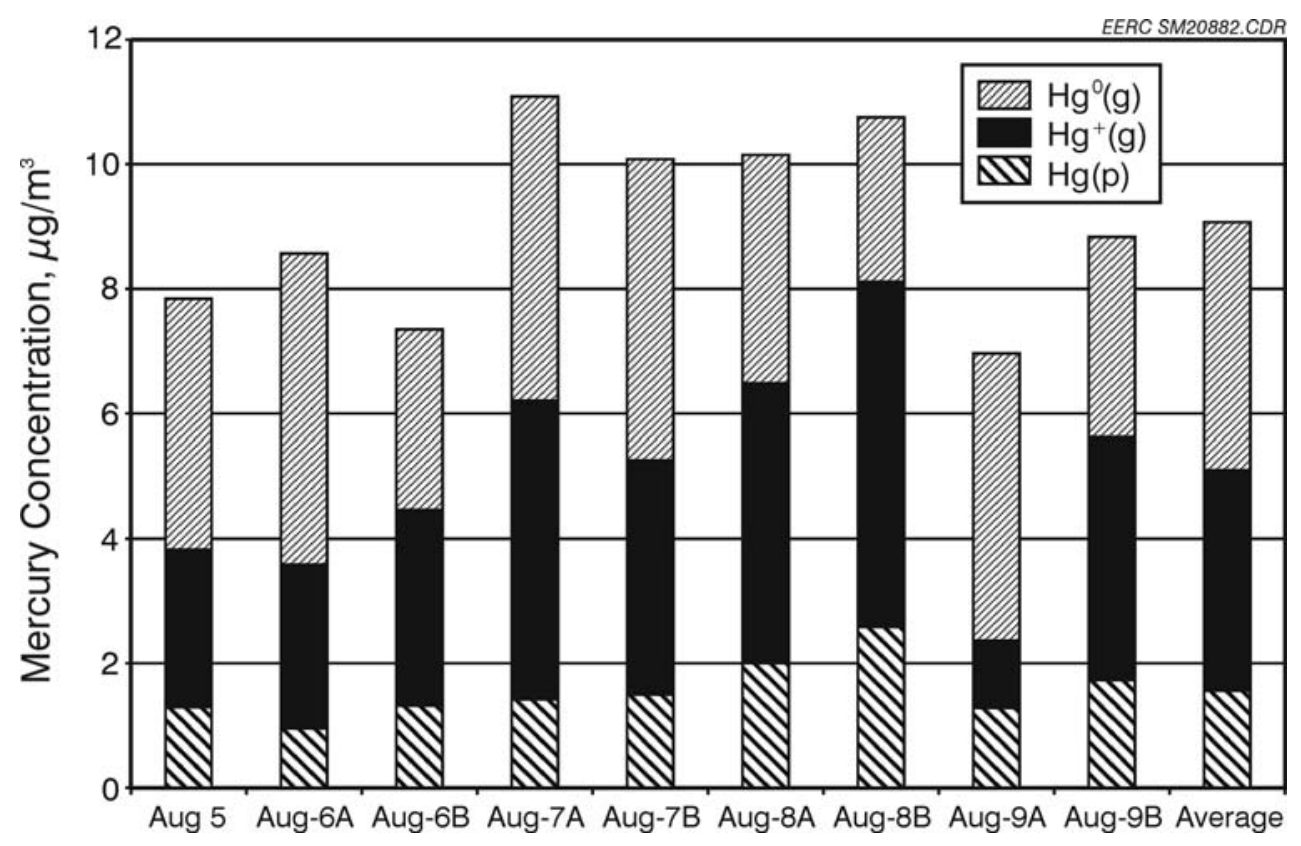

Figure 6.3.2.1. Mercury species in the Big Stone Power Plant flue gas based on Ontario Hydro samples collected August 5-9, 2002.

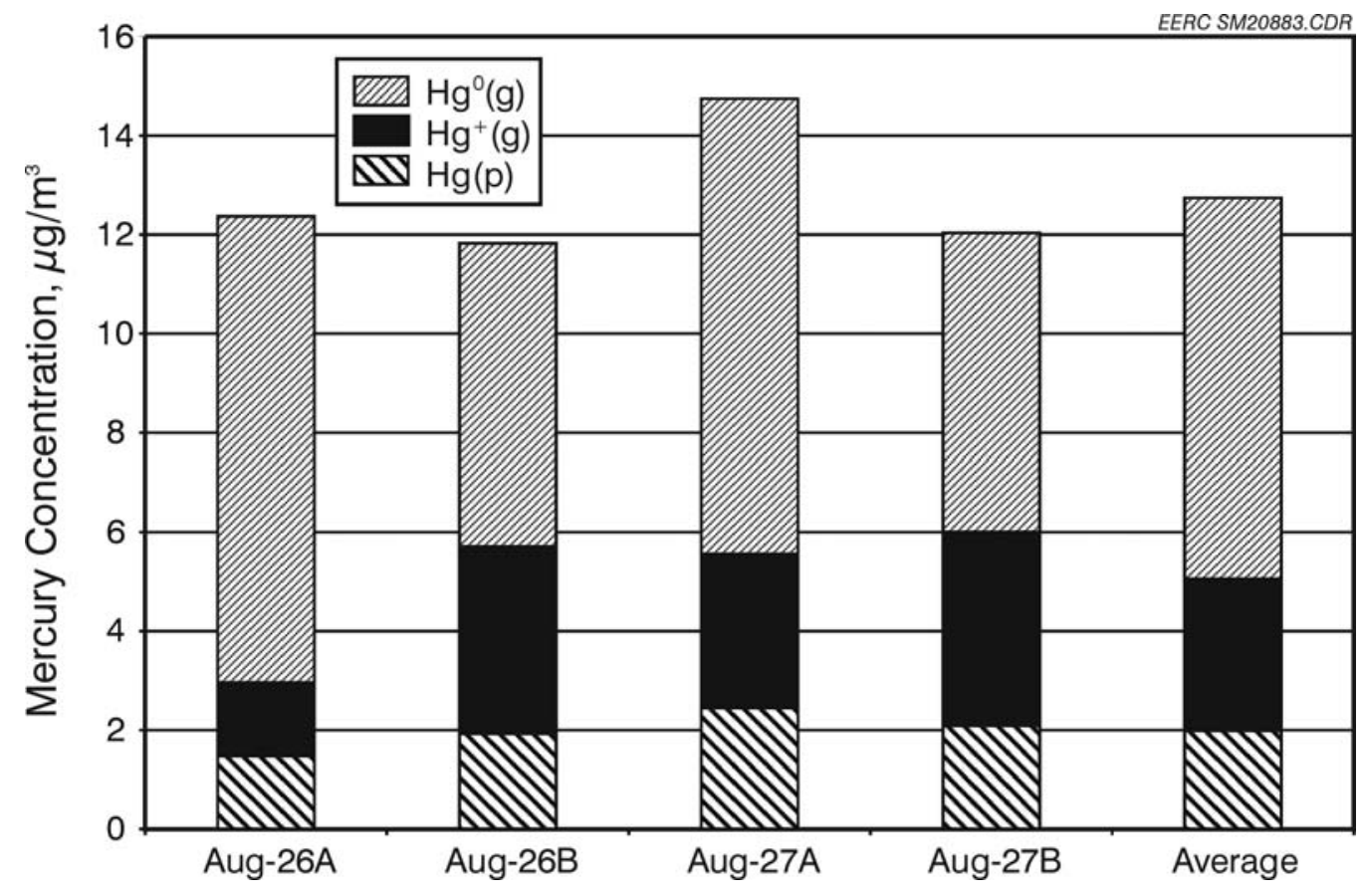

Figure 6.3.2.2. Mercury species in the Big Stone Power Plant flue gas based on Ontario Hydro samples collected in August 26-27, 2002. 
During most of the sampling time period, the Big Stone Power Plant burned Belle Ayr coal, except on August 9 and 27 when the plant cofired small amounts of TDF and waste seeds. While there is some variability in the coal as well as analytical uncertainty, the data indicate fairly consistent mercury speciation. The averaged mercury concentration in the coal combustion flue gas was $9.1 \mu \mathrm{g} / \mathrm{m}^{3}$ during August $5-9$ and $12.7 \mu \mathrm{g} / \mathrm{m}^{3}$ for August 26-27, respectively, showing approximately $16.4 \% \mathrm{Hg}(\mathrm{p}), 31.6 \% \mathrm{Hg}^{++}$, and $52 \% \mathrm{Hg}^{0}$.

Compared in Figure 6.3.2.3 are the Ontario Hydro results with CMM data collected during the same sampling time. No particulate mercury for the CMM is shown because the gas is sampled through a filter with a probe pointed downstream to minimize any gas-particulate contact. In contrast, the Ontario Hydro samples are collected isokinetically, and the particulate fraction is captured on a filter. The particulate mercury may have existed in the duct or could have been absorbed on the particulate during sampling. Some of the particulate mercury in the Ontario Hydro method may be measured as vapor-phase mercury with the CMM. In spite of this difference, the CMM data, in most cases, are in good agreement with the Ontario Hydro data.

Figure 6.3.2.4 plots the daily average of gaseous mercury (CMM data) in the flue gas over the 1-month testing period. The total gaseous mercury varied from 8 to $14 \mu \mathrm{g} / \mathrm{m}^{3}$, and the

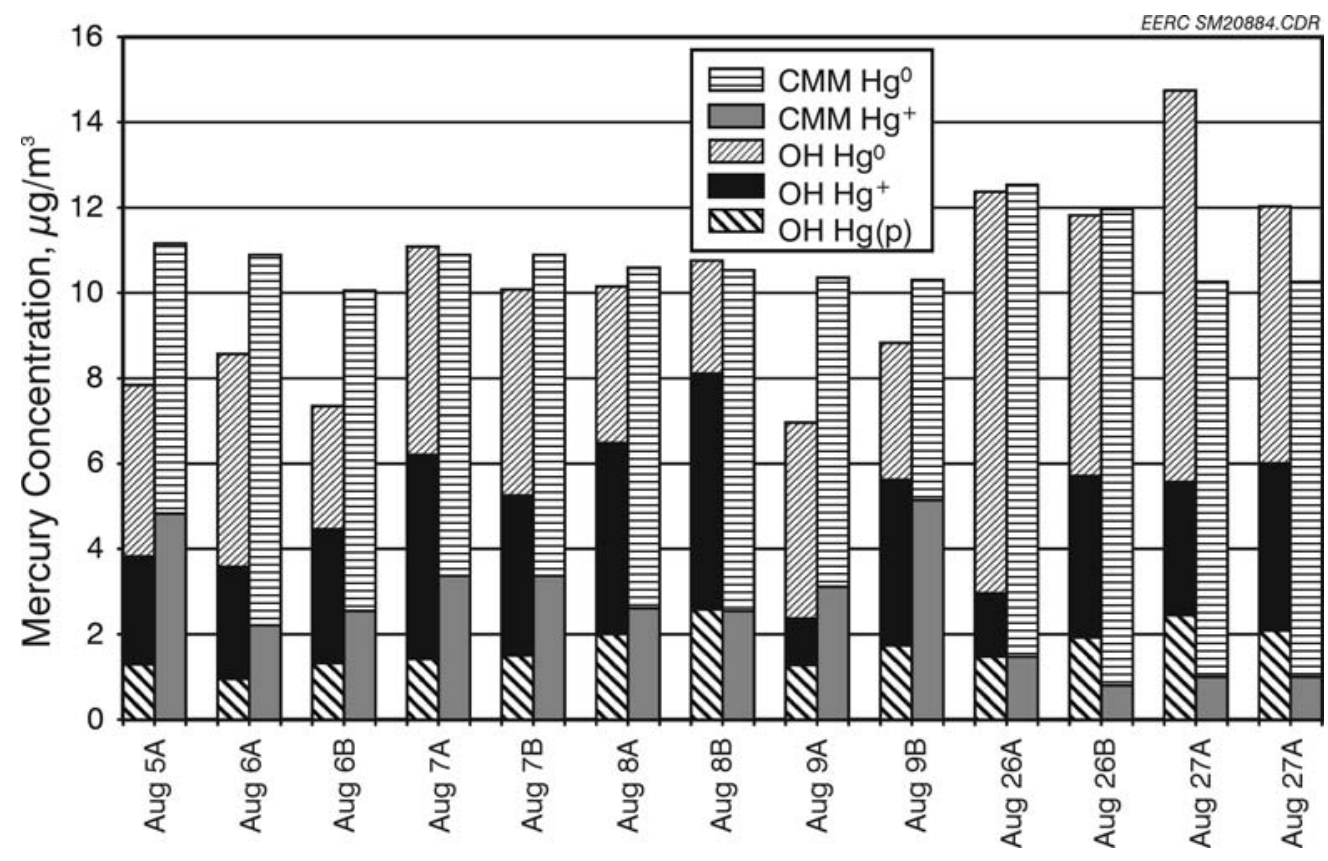

Figure 6.3.2.3. Comparison of Ontario Hydro results with CMM data. 


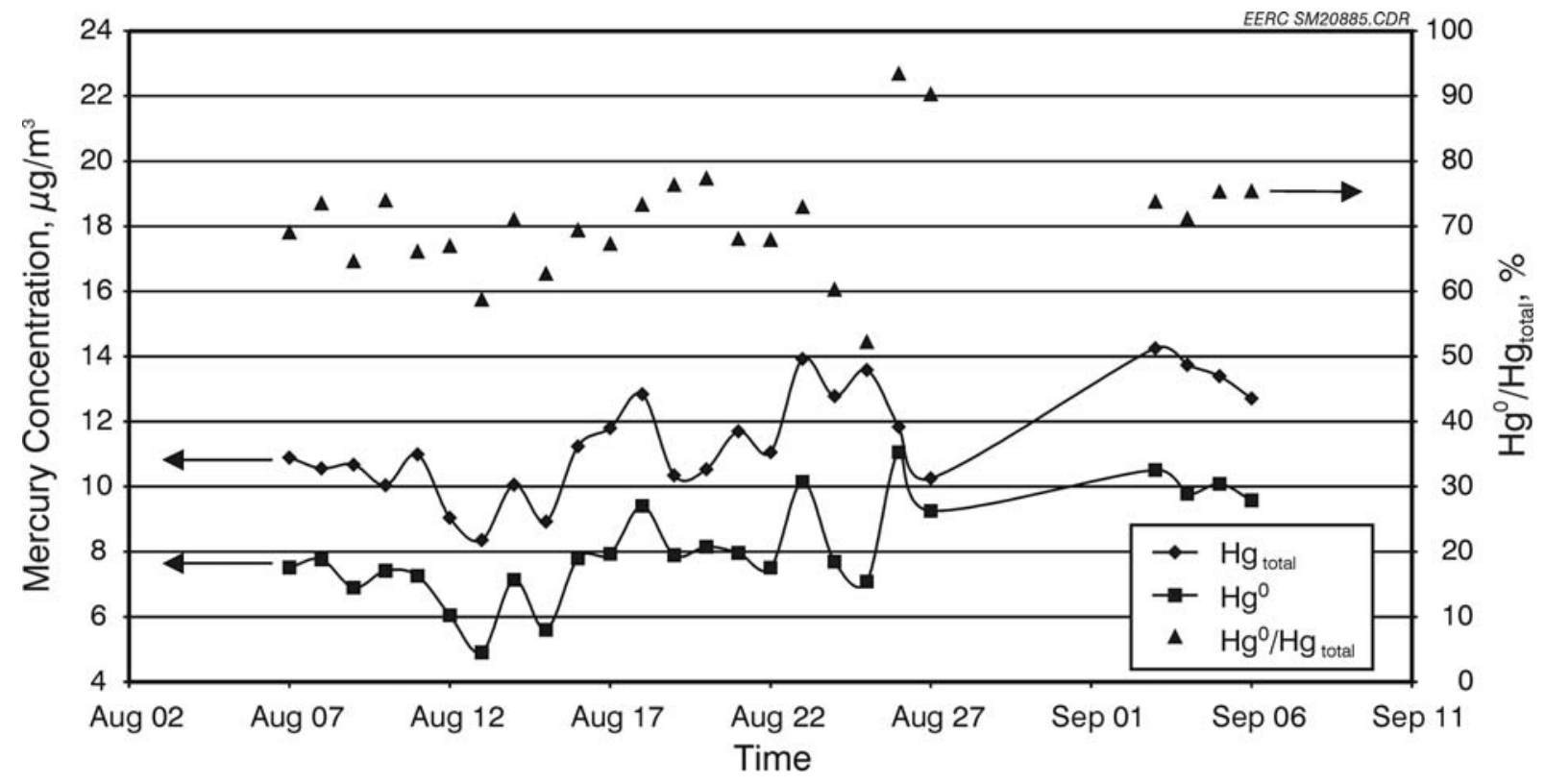

Figure 6.3.2.4. Daily average of gaseous mercury (CMM data) in the flue gas over the 1-month testing period.

elemental mercury tracked with the total gaseous mercury consistently between $60 \%$ and $80 \%$. Comparing the mercury concentration when the two coals were burned (see Figure 6.3.2.4 and Table 6.3.2.1) does not indicate any clear effect of coal type beyond the day-to-day variability in the data.

The inlet mercury speciation may depend on a number of factors such as the amount of carbon in the fly ash, chlorine level in the coal, firing mode, contact with fly ash, and residence time. However, the current level of understanding of how these variables affect mercury speciation does not allow accurate prediction. In general, high-chlorine EB fuels tend to produce flue gas with more oxidized mercury and low-chlorine WSB coals tend to produce more elemental mercury. Data also show that contact between the fly ash and flue gas promotes mercury oxidation for some coals.

Compared in Figure 6.3.2.5 are the inlet Ontario Hydro mercury speciation data for the November 2001 field test, January 2002 EERC pilot-scale data burning the same fuel, EERC pilot-scale data burning the Belle Ayr coal from April to May, 2002, and August 5-9 and August 26-27, 2002, field test data with the Belle Ayr fuel. The error bars represent plus and minus one standard deviation. 


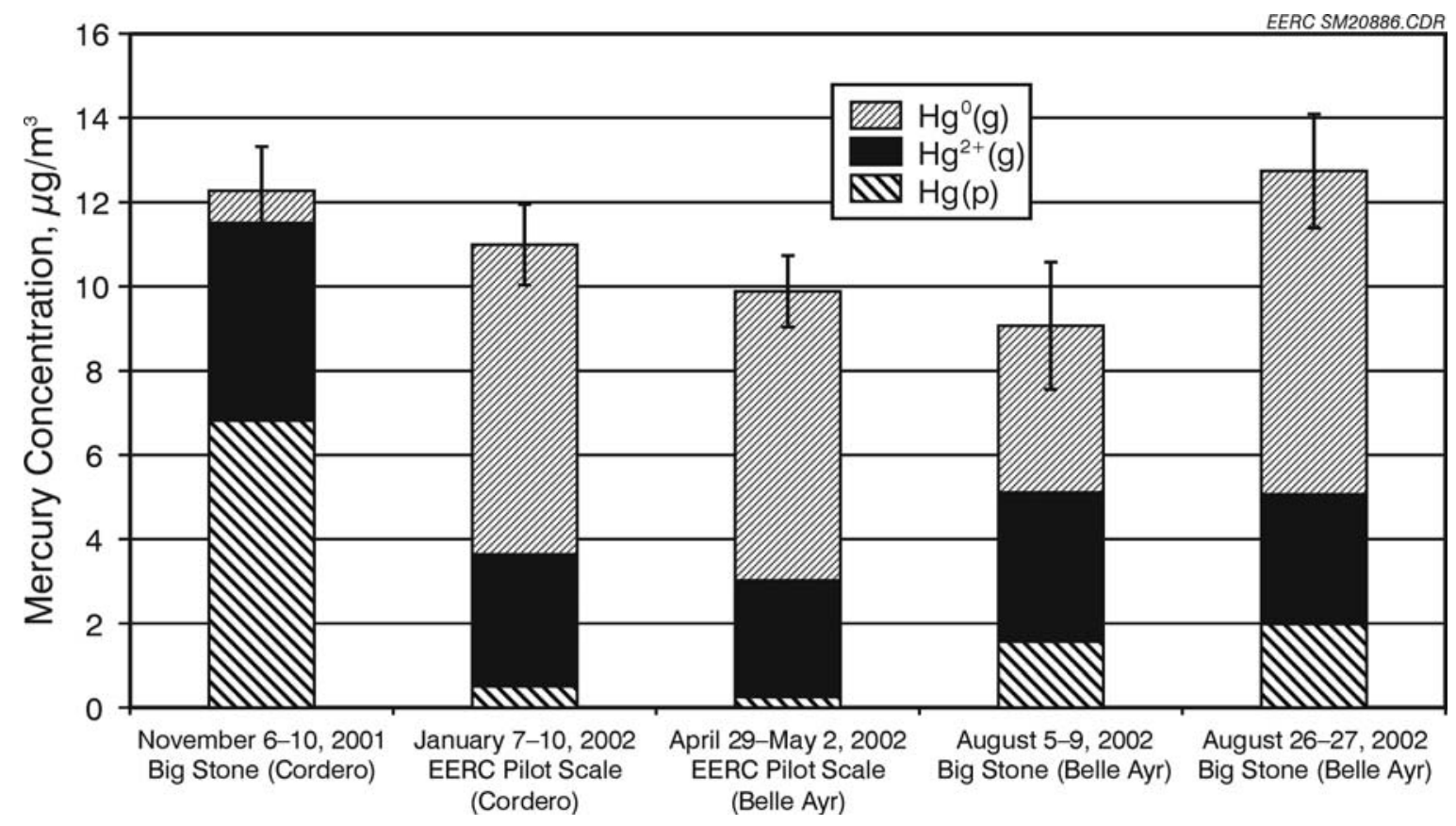

Figure 6.3.2.5. Comparisons of mercury species distribution in the Advanced Hybrid ${ }^{\mathrm{TM}}$ filter Big Stone field tests and EERC pilot-scale tests.

For the November 2001 field test and the January 2002 pilot-scale baseline test, the mercury speciation in flue gas revealed two significant differences although they both burned the same Cordero complex coal. For the field results, an average of $56 \%$ of the mercury was retained by the fly ash compared to only $5 \%$ for the pilot-scale tests. A second significant difference is the vapor-phase speciation. There was $38 \%$ of the total mercury as oxidized mercury and only $6 \%$ as elemental mercury, compared to $29 \%$ oxidized and $67 \%$ elemental for the pilot-scale tests.

A number of differences in conditions between the two tests could be responsible for the significant speciation difference. The $\mathrm{HCl}$ for the pilot-scale tests measured by Method 26A was 1-2 ppm in the flue gas compared to about $10 \mathrm{ppm}$ for the November 2001 field test (Table 6.3.2.2). The additional $\mathrm{HCl}$ in the field tests is likely the result of the small percentage of waste tires that were cofired with coal at the Big Stone Power Plant during the November test. However, $10 \mathrm{ppm} \mathrm{HCl}$ is still a fairly low concentration compared to the 50-100 ppm level that is typically seen for bituminous coals. 
Table 6.3.2.2. Chlorine Concentration in Flue Gas at Big Stone Power Plant

\begin{tabular}{lr}
\hline Date & $\mathrm{HCl}, \mathrm{ppm}$ \\
\hline November 7, 2001 & 9.1 \\
November 8, 2001 & 10.1 \\
November 9, 2001 & 10.0 \\
August 5, 2002 & 1.0 \\
August 7, 2002 & 0.9 \\
August 8, 2002 & 1.2 \\
August 26, 2002 & 0.5 \\
August 27, 2002 & 1.4 \\
August 28, 2002 & 1.2 \\
\hline
\end{tabular}

Another possible reason for the difference is the amount of unburned carbon in the ash, which for the Big Stone baseline tests ranged from $0.5 \%$ to $1.9 \%$ (without carbon injection) compared to only $0.16 \%$ for the pilot-scale tests. Under some conditions, carbon in the ash can be responsible for mercury retention and for promoting oxidation.

Cyclone firing is known to produce a finer fly ash particle size than pulverized-coal firing, which could also lead to more mercury retention as well as oxidation. Other work has shown that mercury concentration is typically higher in the smaller fly ash fraction, and the higher surface area of the finer particles may also promote more oxidation.

Comparison of the EERC pilot-scale data between the Cordero and Belle Ayr coals (shown in Figure 6.3.2.5) suggests that there was no significant difference in mercury species as a result of coal type. The mercury speciation data for the EERC pilot-scale tests with the Belle Ayr coal are also similar to the Big Stone field data with the same coal when TDF was not being cofired. However, the Big Stone data do show somewhat more particulate-bound mercury than the pilotscale data. A possible reason for this difference is the slightly higher carbon content in the Big Stone ash.

The higher August 26-27 total mercury than the August 5-9 data is consistent with the CMM data and is likely due to somewhat higher mercury in the coal. The significant difference in mercury speciation between the August field data and the November field data, however, is likely the effect of cofiring the coal and TDF, since the pilot-scale data indicated no difference between the two coals when they were burned without TDF.

Baseline Test

Three pairs of Ontario Hydro samples were collected at the inlet and outlet of the field Advanced Hybrid ${ }^{\mathrm{TM}}$ filter unit during August 5-6, 2002, to establish mercury species under 
baseline conditions without carbon injection and TDF cofiring. The Ontario Hydro results (Figure 6.3.2.6) show the same levels of total mercury in the inlet and outlet flue gases, indicating no mercury capture. It does appear, however, that there is an increase in the fraction of oxidized mercury across the Advanced Hybrid ${ }^{\mathrm{TM}}$ filter. Another baseline test was conducted August 19-20 while the plant was burning the Eagle Butte coal with a small amount of TDF. The $\mathrm{CMM}$ data for those tests indicated from $5 \%$ to $10 \%$ mercury capture without any carbon injection. Both of these baseline results are significantly different than the November tests with a much higher TDF cofiring rate, where 49\% mercury capture was seen for the baseline conditions. Again, the most likely explanation is the much higher TDF cofiring rate and higher $\mathrm{HCl}$ in the flue gas for the November test.

\section{NORIT FGD Carbon Continuous Injection Without Cofiring TDF}

During the testing period, a K-Tron dual-screw feeder continuously fed NORIT FGD carbon at a starting rate of $24 \mathrm{mg} / \mathrm{m}^{3}$ (1.5-lb/Macf), which corresponds to $0.29 \mathrm{~kg} / \mathrm{hr}(0.65 \mathrm{lb} / \mathrm{hr})$ at an $\mathrm{A} / \mathrm{C}$ ratio of $3.0 \mathrm{~m} / \mathrm{min}(10 \mathrm{ft} / \mathrm{min})$. This is equivalent to a carbon-to-mercury ratio of 3000:1 for an inlet mercury concentration of $14 \mu \mathrm{g} / \mathrm{m}^{3}$. The carbon feeder was located in the

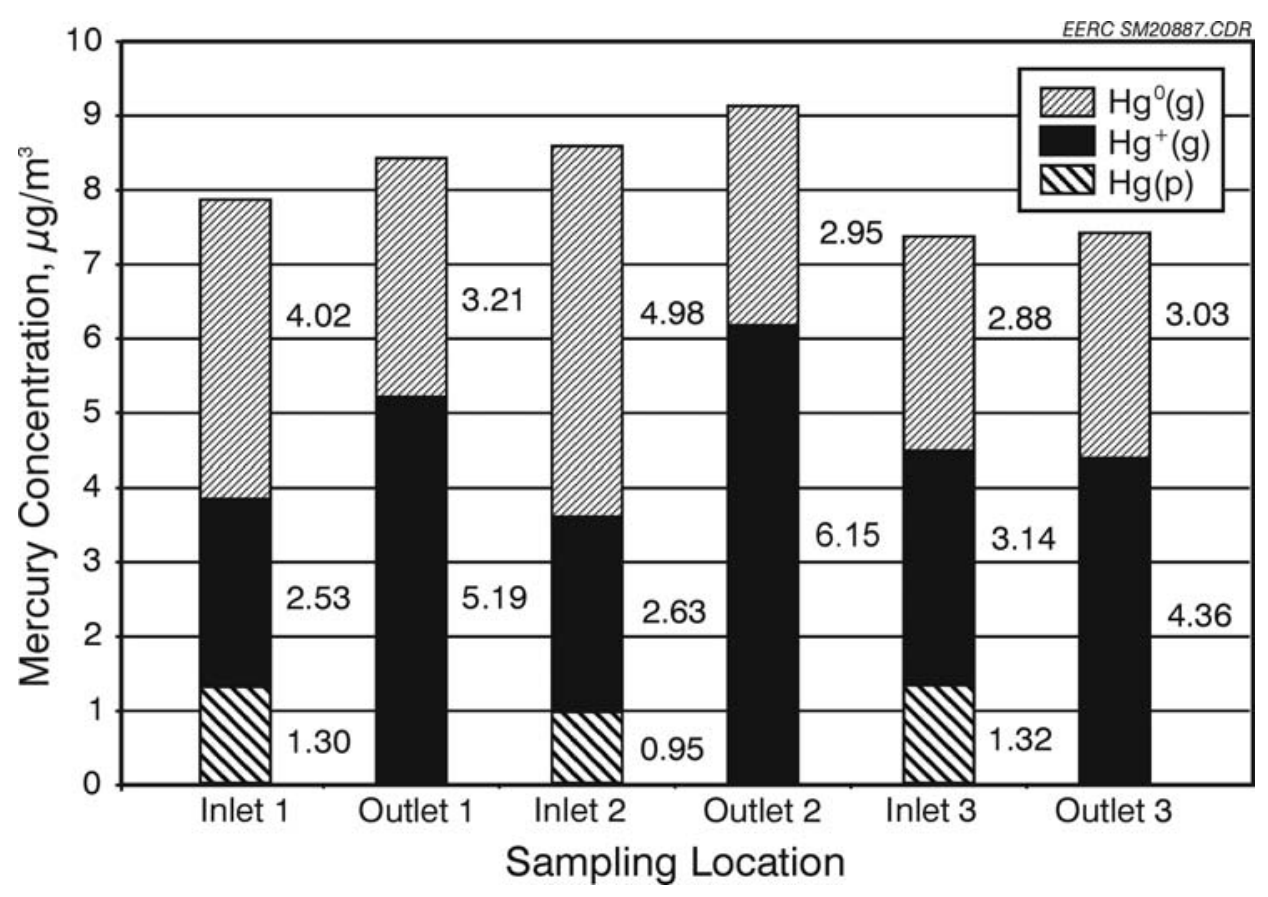

Figure 6.3.2.6. Inlet and outlet Ontario Hydro mercury speciation for the Advanced Hybrid ${ }^{\mathrm{TM}}$ filter baseline test at Big Stone, August 5-6, 2002. 
enclosed area of the Advanced Hybrid ${ }^{\mathrm{TM}}$ filter below the hopper. From the screw feeder, the carbon was introduced into an Air-Vac eductor that was driven by compressed air. From the

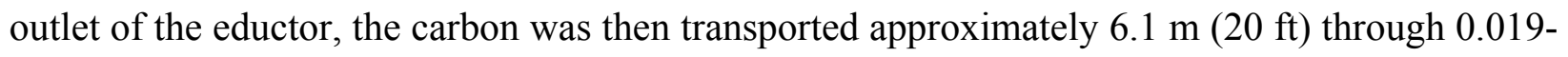
$\mathrm{m}(0.75$-in.) stainless steel tubing to the elbow location of the inlet piping. Approximately $0.9 \mathrm{~m}$ (3 ft) of straight tubing extended inside the duct so that the carbon was injected directly upstream at a single point in the center of the 0.610-m (24-in.)-diameter inlet pipe.

The feeder was calibrated prior to the start of carbon injection. In addition, the weight of carbon added during a day was divided by the time of injection to provide an average feed rate. According to the calibration data and weight-of-added-carbon data, the feeder appeared to provide a very steady and consistent feed rate within a few percent of the target rate. The carbon feed and injection system worked very well, and there were no problems with inconsistent feeding or plugging of the feeder or injection system. Other Advanced Hybrid ${ }^{\mathrm{TM}}$ filter operating conditions are given in Table 6.3.2.3.

With no TDF cofiring on August 7, two sorbent injection tests with feed rates of $0.29 \mathrm{~kg} / \mathrm{hr}$ $(0.65 \mathrm{lb} / \mathrm{hr})$ and $0.58 \mathrm{~kg} / \mathrm{hr}(1.28 \mathrm{lb} / \mathrm{hr})$ were completed. Figure 6.3.2.7 plots both the Ontario Hydro results and CMM data during the tests, and the two methods provided very consistent mercury species in the inlet and outlet flue gases. Most of the mercury in the inlet flue gas was gaseous mercury with a fair fraction of elemental mercury. At the lower feed rate of $0.29 \mathrm{~kg} / \mathrm{hr}$ $(0.65 \mathrm{lb} / \mathrm{hr})$, mercury removal was $54 \%$ with $5 \mu \mathrm{g} / \mathrm{m}^{3}$ mercury emission, and at doubled the feed rate, it increased marginally to $61 \%$. The outlet mercury emission was slightly down to $4.8 \mu \mathrm{g} / \mathrm{m}^{3}$. Since doubling the carbon feed rate did not significantly improve mercury capture, the decision was made to do further testing at the lower carbon feed rate. Two additional Ontario Hydro tests were completed at $0.29 \mathrm{~kg} / \mathrm{hr}(0.65 \mathrm{lb} / \mathrm{hr}$ ) on August 8 (Figure 6.3.2.8). Again, the Ontario Hydro and CMM results were in good agreement and indicated 63\%-68\% removal, slightly better than the August 7 test. On August 9 and 26, tests were repeated at the same carbon injection rate of $24 \mathrm{mg} / \mathrm{m}^{3}$ (1.5lb/Macf), and four pairs of Ontario Hydro samples were taken to determine the overall mercury removal in the Advanced Hybrid ${ }^{\mathrm{TM}}$ filter. Figure 6.3.2.9 summarizes the mercury collection efficiencies with the Advanced Hybrid ${ }^{\mathrm{TM}}$ filter at the 
Table 6.3.2.3. Standard Operating Conditions During August 5-September 6, 2002

\begin{tabular}{ll}
\hline A/C Ratio & $10 \mathrm{ft} / \mathrm{min}(3 \mathrm{~m} / \mathrm{min})$ \\
\hline Pulse Pressure & $70 \mathrm{psi}(482 \mathrm{kPa})$ \\
Pulse Duration & $200 \mathrm{~ms}$ \\
Pulse Sequence & $87654321($ multibank $)$ \\
Pulse Trigger & $8.0 \mathrm{in} . \mathrm{W} . \mathrm{C} .(2.0 \mathrm{kPa})$ \\
Pulse Interval & $260-400 \mathrm{~min}$ \\
Temperature & $127^{\circ}-160^{\circ} \mathrm{C}\left(260^{\circ}-320^{\circ} \mathrm{F}\right)$ \\
Rapping Interval & $15-20 \mathrm{~min}$ \\
Voltage & $58-62 \mathrm{kV}$ \\
Current & $55 \mathrm{~mA}$
\end{tabular}

$24 \mathrm{mg} / \mathrm{m}^{3}$ (1.5 lb/Macf) carbon injection during the August 2002 field test. From these results, it appears that a fairly low carbon addition rate of $24 \mathrm{mg} / \mathrm{m}^{3}$ (1.5 lb/Macf) can provide from $60 \%$ to $70 \%$ mercury control with the Advanced Hybrid ${ }^{\mathrm{TM}}$ filter in subbituminous coal flue gas. This is lower than the $91 \%$ removal seen last November but similar to the $50 \%-60 \%$ removal seen with EERC pilot-scale tests completed earlier 2002. This suggests that the higher removal seen November 2001 was because of the much higher TDF feed rate and higher $\mathrm{HCl}$ in the flue gas.

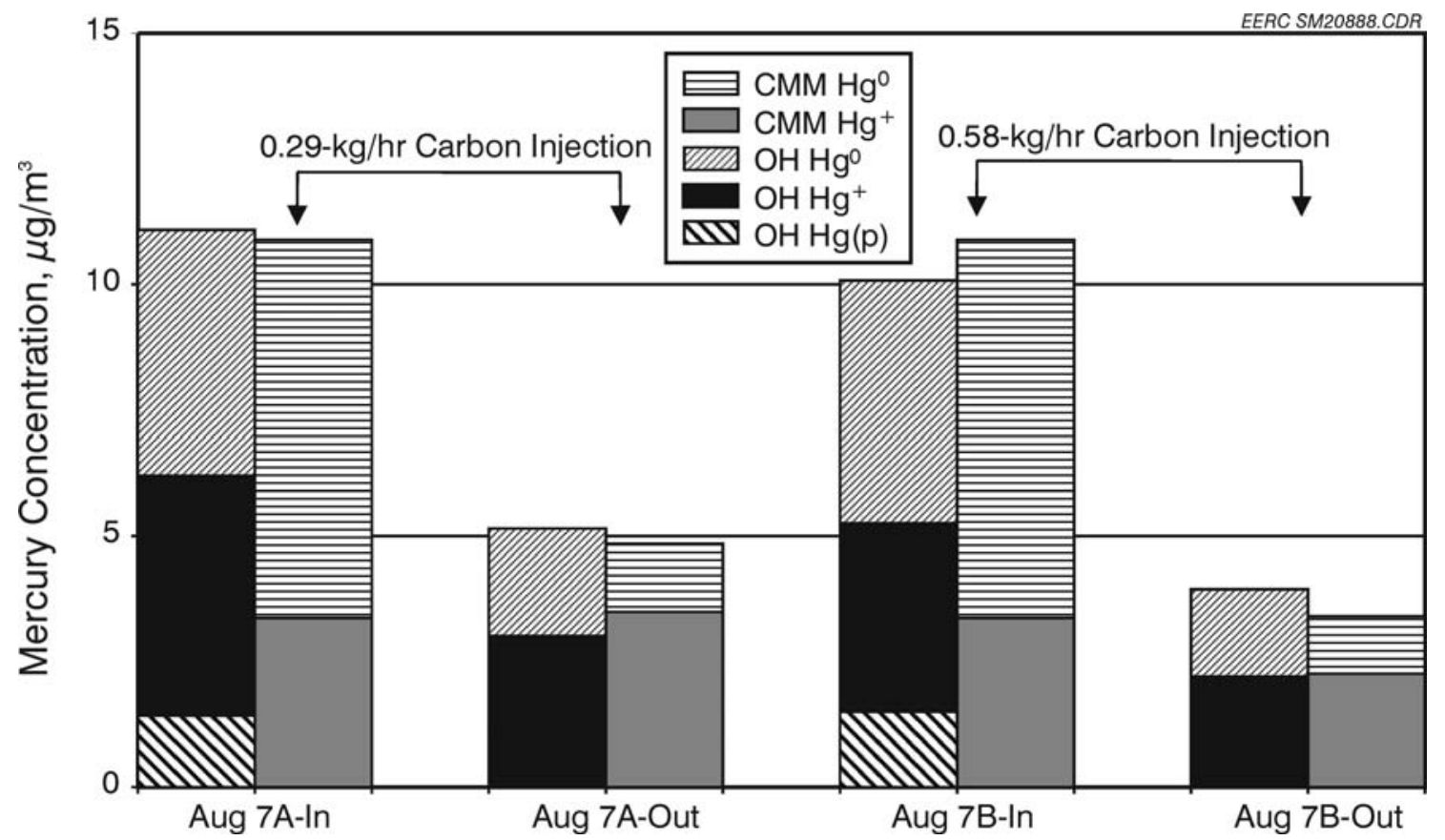

Figure 6.3.2.7. Mercury species concentration in flue gas at the Advanced Hybrid ${ }^{\mathrm{TM}}$ filter inlet and outlet under two FGD injection rates. 


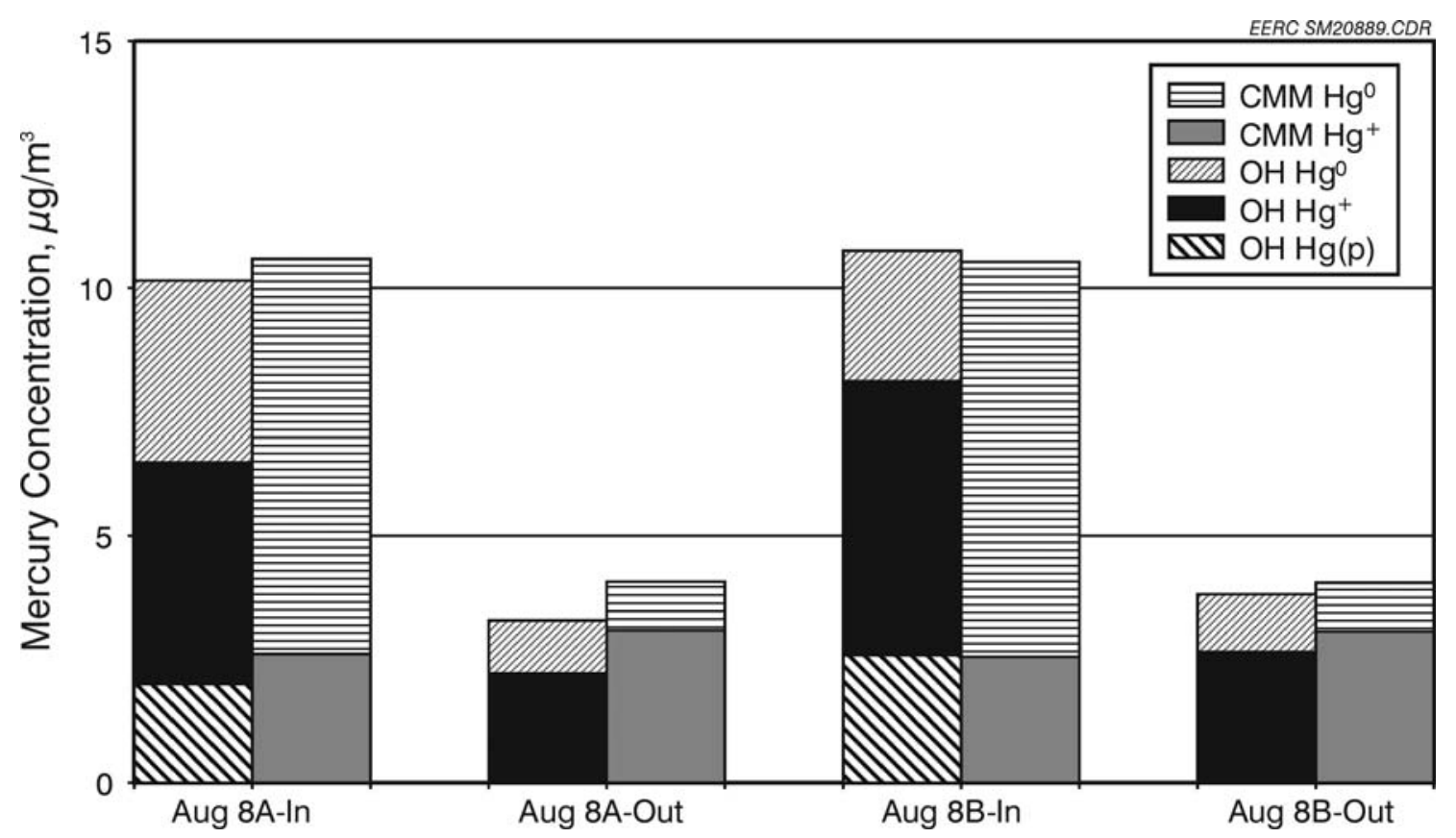

Figure 6.3.2.8. Advanced Hybrid ${ }^{\mathrm{TM}}$ filter inlet and outlet mercury species at $24-\mathrm{mg} / \mathrm{m}^{3}(1.5$ lb/Macf) FGD injection.

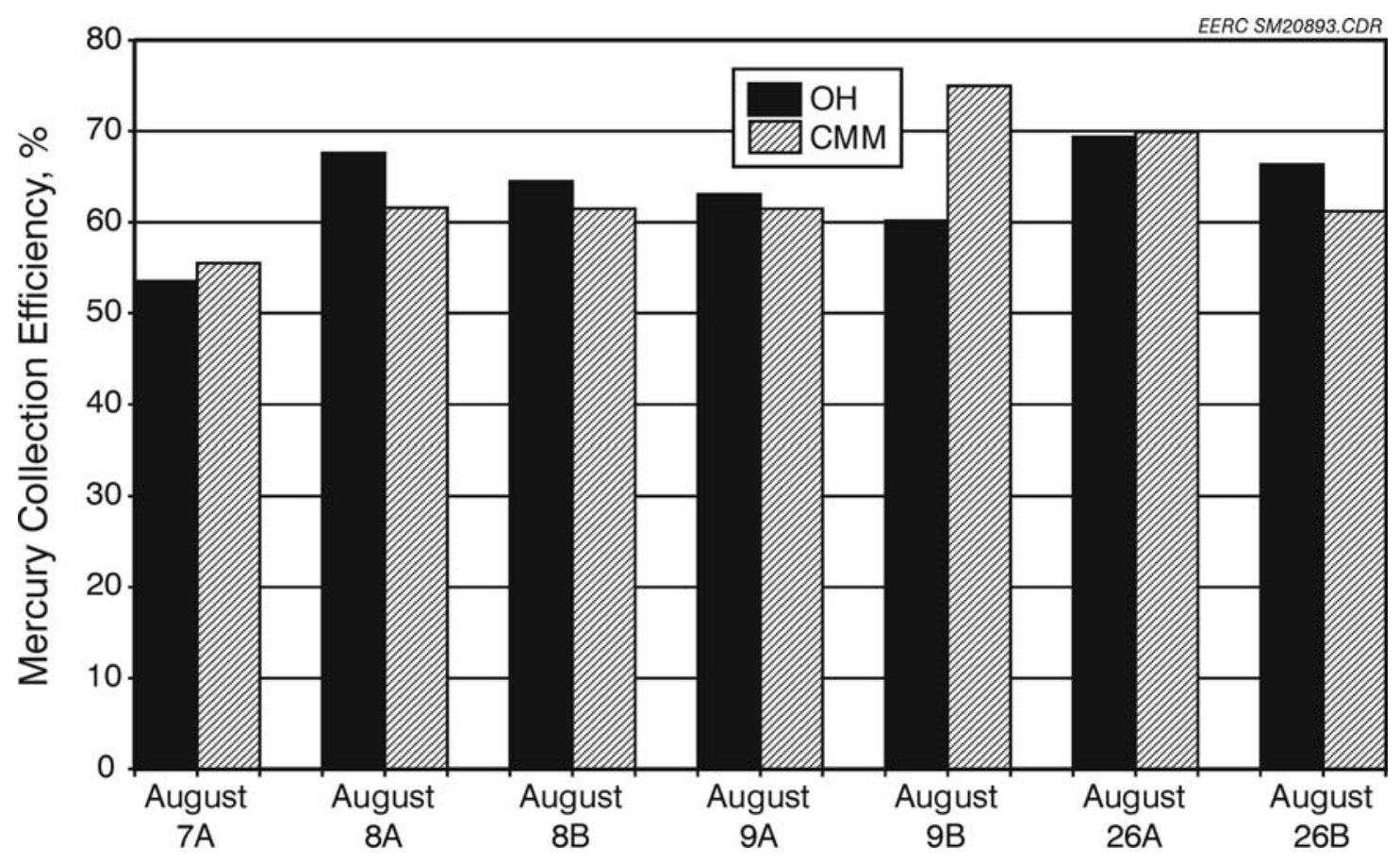

Figure 6.3.2.9. Mercury collection efficiencies with the Advanced Hybrid ${ }^{\mathrm{TM}}$ filter at $24-\mathrm{mg} / \mathrm{m}^{3}$ (1.5-lb/Macf) carbon injection. 
Also included in Figure 6.3.2.9 are the mercury removals based on the CMM data. With the exception of the August 9 data, the Ontario Hydro and CMM data are in excellent agreement. This provides confidence that the CMM data for the rest of the month are reliable even though Ontario Hydro samples were not taken.

\section{Batch NORIT FGD Carbon Injection Tests}

On August 27, a batch injection test was completed with high-voltage power on and another where the high voltage was briefly shut off during injection. For both tests, $0.91 \mathrm{~kg}$ $(2.0 \mathrm{lb})$ of carbon was injected in about $1 \mathrm{~min}$. The Ontario Hydro sampling was then started a half hour after injection for a period of $2 \mathrm{hr}$. The outlet Ontario Hydro results represented averaged mercury emission during the $2.5-\mathrm{hr}$ period after the carbon was batched into the system. Plotted in Figure 6.3.2.10 are the inlet and outlet mercury speciation results of the batch injection tests along with the continuous injection tests completed the previous day at $0.29 \mathrm{~kg} / \mathrm{hr}$ $(0.65 \mathrm{lb} / \mathrm{hr})$. The calculated mercury removal efficiencies are shown in Figure 6.3.2.11. The data indicate that the batch power-on removal was comparable to the continuous injection results, but the power-off batch injection improved the collection efficiency to $82.5 \%$. This suggests that it might be possible to optimize the overall collection efficiency by modifying the injection approach.

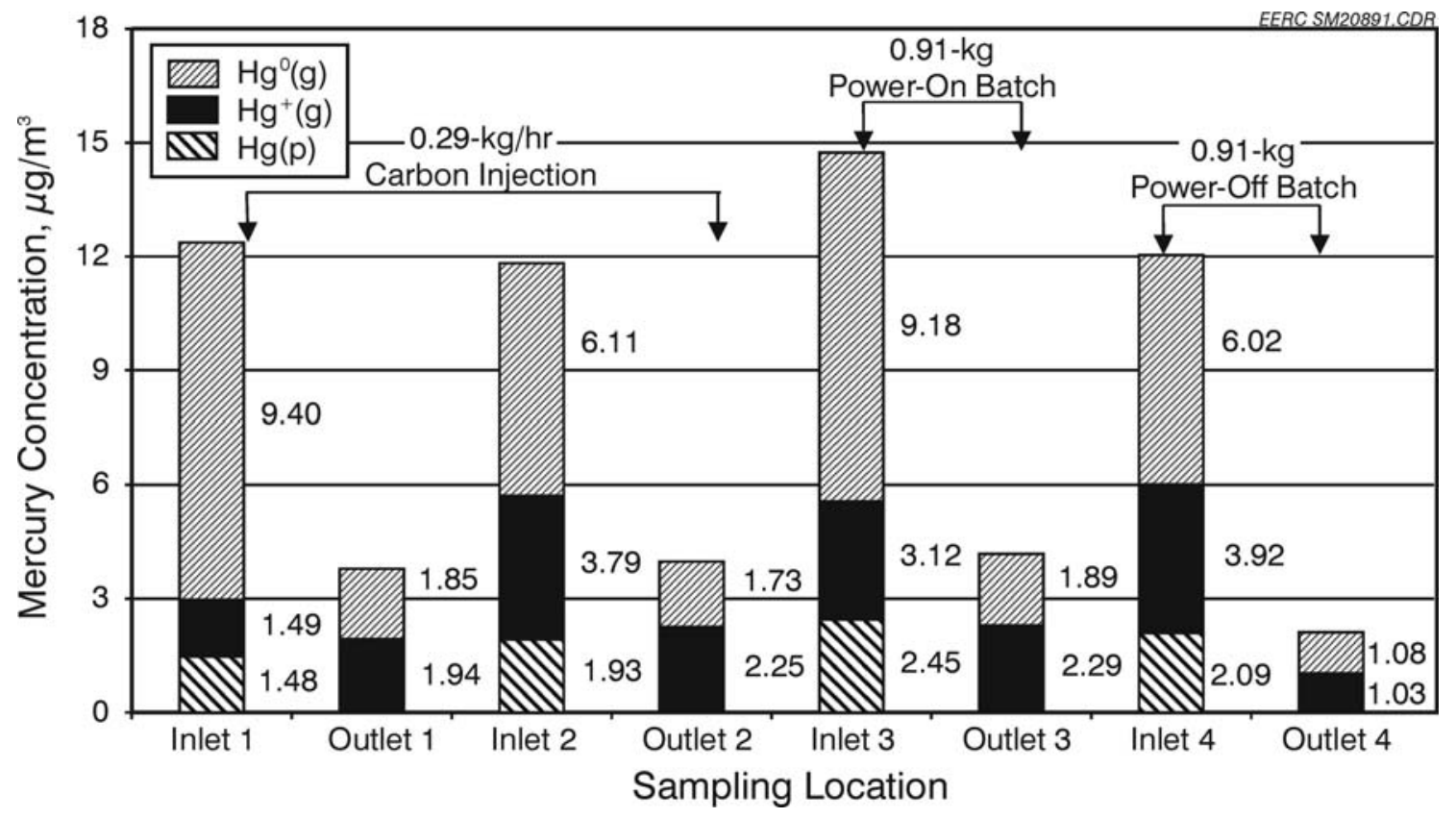

Figure 6.3.2.10. Inlet and outlet mercury speciation results of the batch injection tests. 


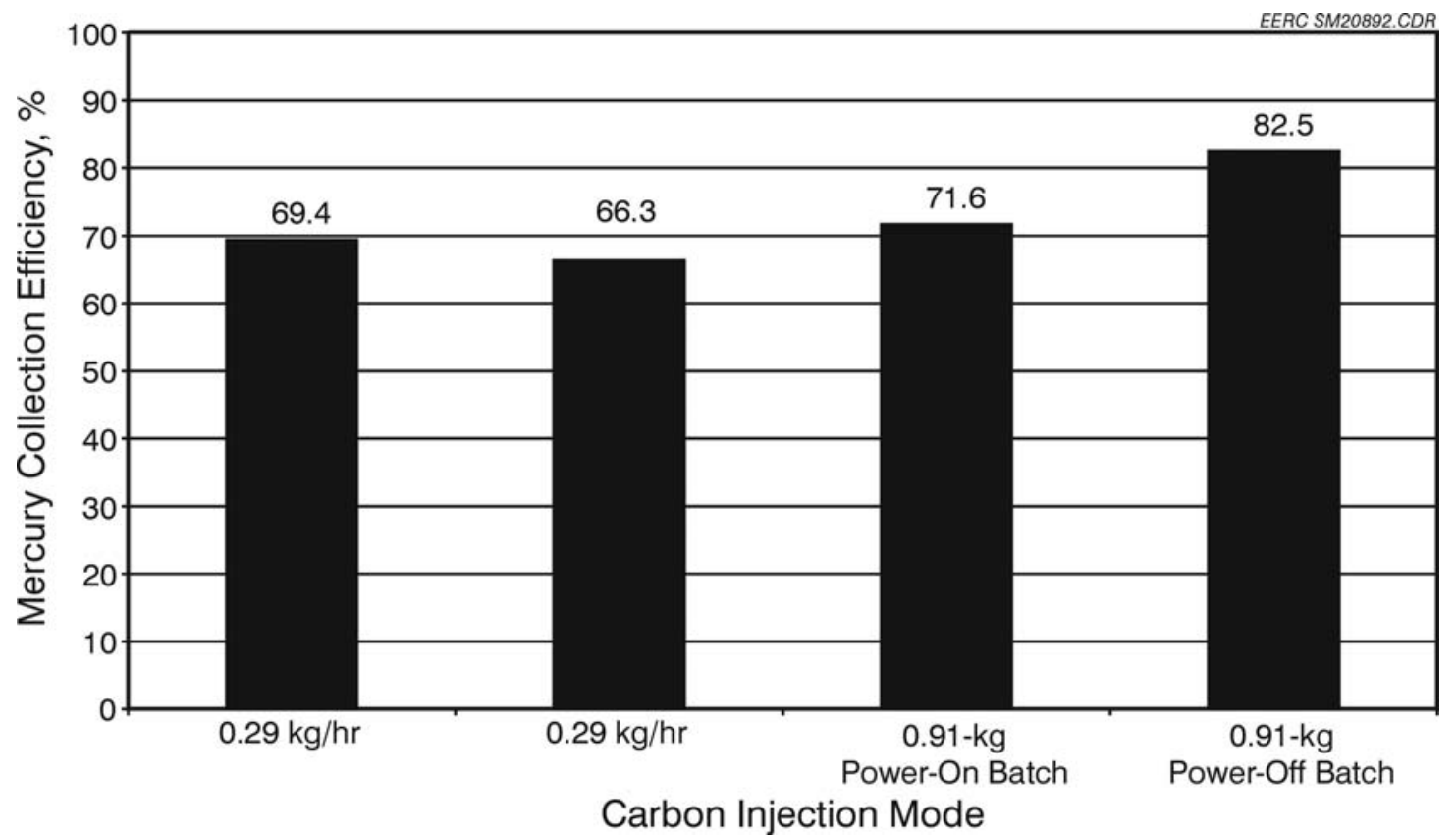

Figure 6.3.2.11. Mercury removal efficiencies for continuous and batch FGD injection tests.

However, on a larger scale, power-off batch injection would likely not be as practical as continuous injection. Another batch injection test was completed where the batch amount was increased to $1.82 \mathrm{~kg}(4.0 \mathrm{lb})$ with only the CMM measurement. In this case, the outlet mercury was near zero for over $2 \mathrm{hr}$ before it slowly started to increase, and even after $3 \mathrm{hr}$, the integrated average removal was over $90 \%$. This implies that all of the flue gas was effectively treated and that with a reactive sorbent, it should be possible to achieve over $90 \%$ mercury removal.

\section{Effect of TDF Cofiring on Mercury Removal}

TDF cofiring was started August 12, but at a much lower rate than the 90-250 ton/day rate during the November 2001 test (see Table 6.3.2.1). Subsequently, the effect on mercury removal was small. From the daily averages of the CMM data plotted in Figure 6.3.2.12, it did appear that mercury removal improved from about $63 \%$ on August $9-11$ to about $68 \%$ on August $12-13$ as a result of the TDF cofiring. On August 14 and part of the day on August 15, the carbon feed rate was doubled to $0.58 \mathrm{~kg} / \mathrm{hr}(1.28 \mathrm{lb} / \mathrm{hr})$. At the higher rate on August 14, the removal increased to $77 \%$, and on August 15, it reached 89\%. However, the $89 \%$ removal corresponded to a time of lower plant load where the temperature was about $11^{\circ} \mathrm{C}\left(20^{\circ} \mathrm{F}\right)$ lower than normal. Later on August 15, the carbon feed rate was reduced back to $0.29 \mathrm{~kg} / \mathrm{hr}(0.65 \mathrm{lb} / \mathrm{hr})$, and with a 


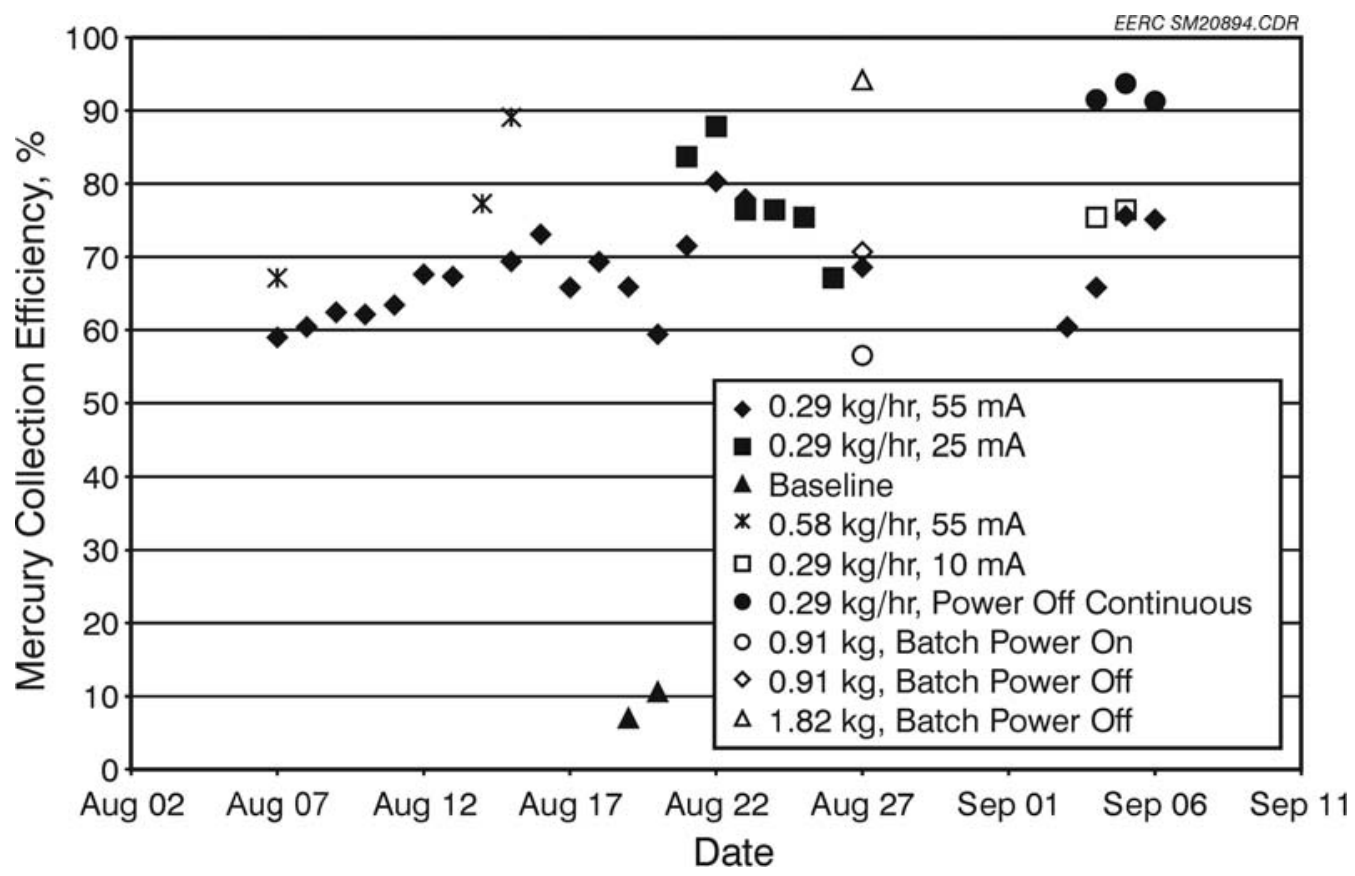

Figure 6.3.2.12. Gaseous mercury capture efficiency at Big Stone field unit during AugustSeptember 2002 (CMM data).

temperature increase, the removal dropped to $69 \%$. This is consistent with the data from August 12-13 and suggests that the small rate of TDF cofiring resulted in some improvement in mercury collection.

The power plant switched to Eagle Butte fuel during August 16-22, 2002, and stopped the TDF cofiring from August 16 to 18, 2002. The coal switch may have also affected the mercury species in flue gas and the capture efficiency with carbon injection. Without TDF cofiring and carbon injection, there was only $5 \%-10 \%$ mercury capture across the Advanced Hybrid ${ }^{\mathrm{TM}}$ filter in the Eagle Butte flue gas. By injecting $0.29 \mathrm{~kg} / \mathrm{hr}(0.65 \mathrm{lb} / \mathrm{hr})$ NORIT FGD without TDF cofiring, the overall removal was $66 \%-73 \%$.

On August 20-22, there was a high TDF cofiring rate (Table 6.3.2.1), and the high-voltage power supply current was decreased to $25 \mathrm{~mA}$ from the standard condition of $55 \mathrm{~mA}$. The data from Figure 6.3.2.12 indicated the mercury removal improved to $84 \%-88 \%$ during this time which corresponded to the 2 days when the TDF was high. The next day on August 23 when the TDF was stopped, the mercury removal dropped to $76 \%$. This indicated that the $84 \%-88 \%$ removal seen the previous 2 days was partly due to the higher TDF cofiring rate. 


\section{Effect of Corona Current on Mercury Removal}

Reducing the current of the Advanced Hybrid ${ }^{\mathrm{TM}}$ filter unit will increase the amount of carbon that reaches the bags and subsequently produce better gas-sorbent contact. A closer examination of the immediate effect of a change in current is shown in Figure 6.3.2.13 during August 21-23 based on CMM measurements. During this time, whenever the current was changed, there was an immediate effect. On August 21 at 12:00, the reduce in current from 55 to $25 \mathrm{~mA}$ resulted in an immediate decrease in outlet mercury emission from 2.3 to $1.7 \mu \mathrm{g} / \mathrm{m}^{3}$; on August 22 at noon, a current increase from 25 to $55 \mathrm{~mA}$ resulted in an increase in mercury emission from 1.2 to $1.7 \mu \mathrm{g} / \mathrm{m}^{3}$; and on August 23 at noon, a current change back to $25 \mathrm{~mA}$ brought a decrease of mercury in outlet flue gas from 2.9 to $2.0 \mu \mathrm{g} / \mathrm{m}^{3}$. These data indicate better mercury removals under the reduced current condition. Operational data indicate that there would be some compromise in Advanced Hybrid ${ }^{\mathrm{TM}}$ filter performance, because the bag pulse cleaning interval was $150 \mathrm{~min}$ at the $25 \mathrm{~mA}$ compared to about $300 \mathrm{~min}$ at $55 \mathrm{~mA}$. However, in both cases, the Advanced Hybrid ${ }^{\mathrm{TM}}$ filter pressure drop was readily controlled at about $1.5 \mathrm{kPa}$ (6 in. W.C.).

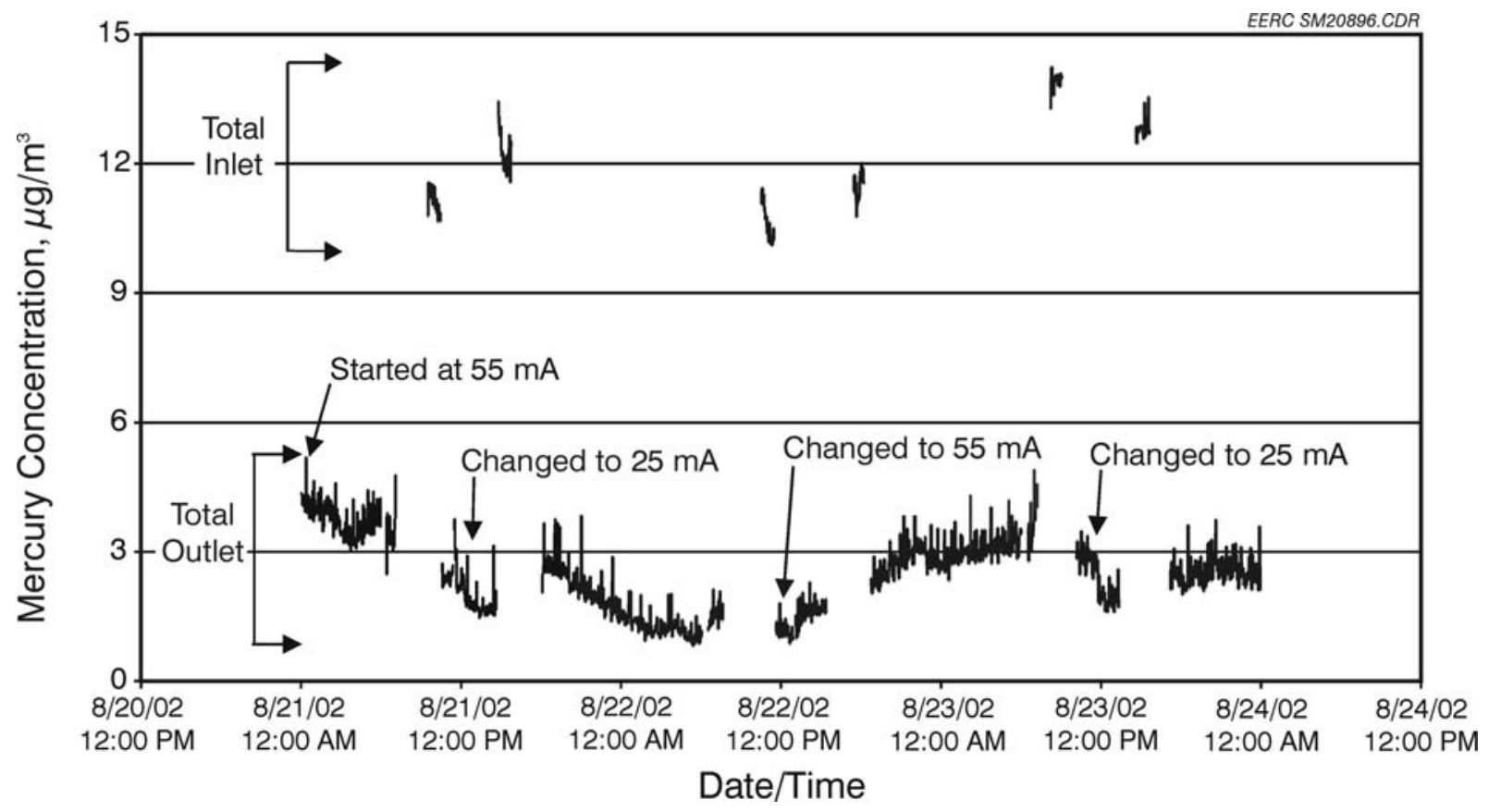

Figure 6.3.2.13. Effect of change in current on mercury emission from the Advanced Hybrid ${ }^{\mathrm{TM}}$ filter field unit. 


\subsubsection{Comparison of Mercury Removals of the Advanced Hybrid ${ }^{\mathrm{TM}}$ Filter and the $\mathrm{PJBH}$}

On September 5-6, several additional tests were completed where the current was reduced to $10 \mathrm{~mA}$, and in the extreme case, the high-voltage power was shut off completely, switching into a PJBH. The data show that the best removal was seen in short-term tests where the power was off (Figure 6.3.2.12). However, the BCI dramatically reduced to $10 \mathrm{~min}$ for the PJBH compared to $300 \mathrm{~min}$ at $55 \mathrm{~mA}$ with the Advanced Hybrid ${ }^{\mathrm{TM}}$ filter, and the average pressure drop across the filter bags increased. From past experience, pressure drop would not be controlled for long at these operating conditions. However, these CMM data indicate that, in the Advanced Hybrid ${ }^{\mathrm{TM}}$ filter mode, the sorbent-gas contact may not be sufficient to achieve $90 \%$ removal at a low carbon addition rate with the FGD carbon.

Figure 6.3.2.14 shows individual bag flows for one row of the bags over several bagcleaning cycles. Individual bag flow monitors were installed in the 1,3,5, 7, and 8 bag positions for one of the rows. The bags are numbered from the back of the unit to the front, so Bag No. 8 is at the entrance of the Advanced Hybrid ${ }^{\mathrm{TM}}$ filter where the dust loading is highest and No. 1 is at the back where the dust loading is lowest. The data indicate that shortly after a pulse, the flows

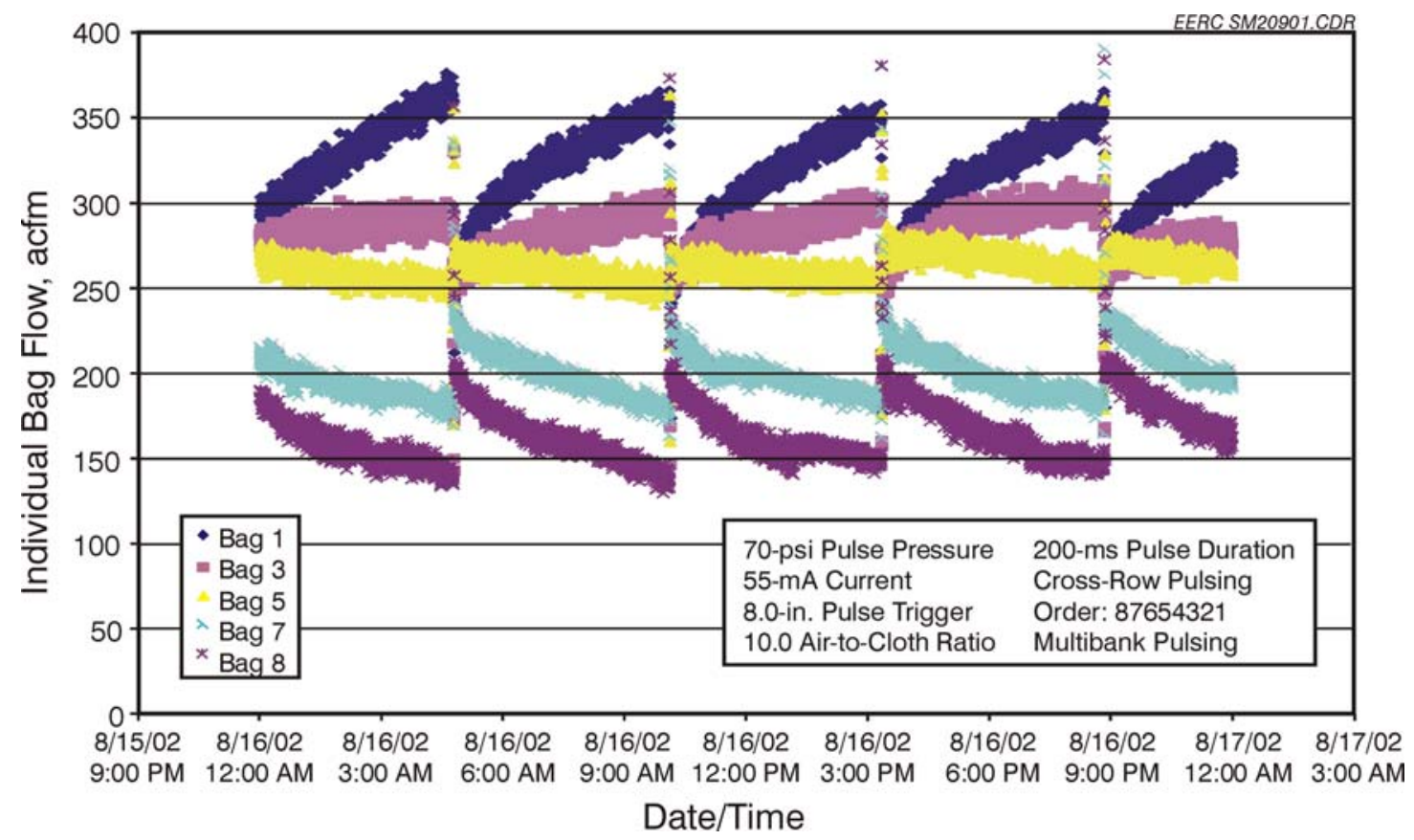

Figure 6.3.2.14. Individual bag flows for one row of the bags over several bag-cleaning cycles. 
through the bags are similar, or with power off, the flows are similar. However, in the operating mode when all of the bags are pulsed when the pressure drop reaches $2.0 \mathrm{kPa}$ ( 8 in. W.C.), a larger fraction of the flow goes through the last bags with increasing time from cleaning. Pulsing the bags more often or in a different sequence could significantly change the flow distribution, possibly resulting in better mercury capture.

\subsubsection{Mercury and Particulate Matter Emissions at Big Stone Stack}

Two Ontario Hydro samples were taken at the middle level of the Big Stone stack on August 6-7, 2002. Figure 6.3.2.15 shows the Ontario Hydro results at the stack. Also included in Figure 6.3.2.15 are the Ontario Hydro data collected at the Advanced Hybrid ${ }^{\mathrm{TM}}$ filter inlet, which are equivalent to the Big Stone ESP inlet. The data indicate little or no change in mercury species or removal across the ESP.

As part of the Ontario Hydro measurements, the measured particulate level at the stack is given in Table 6.3.2.4. Based on inlet measurements from the Advanced Hybrid ${ }^{\mathrm{TM}}$ filter inlet on the same day, the Big Stone ESP collection efficiency was in the range from $99.75 \%$ to $99.77 \%$, which is well within compliance. However, because of the concentration of fine particles exiting the ESP, even at this level of control, a visible plume can frequently be seen at an opacity much less than the $20 \%$ opacity compliance requirement. These particulate emission values served as a

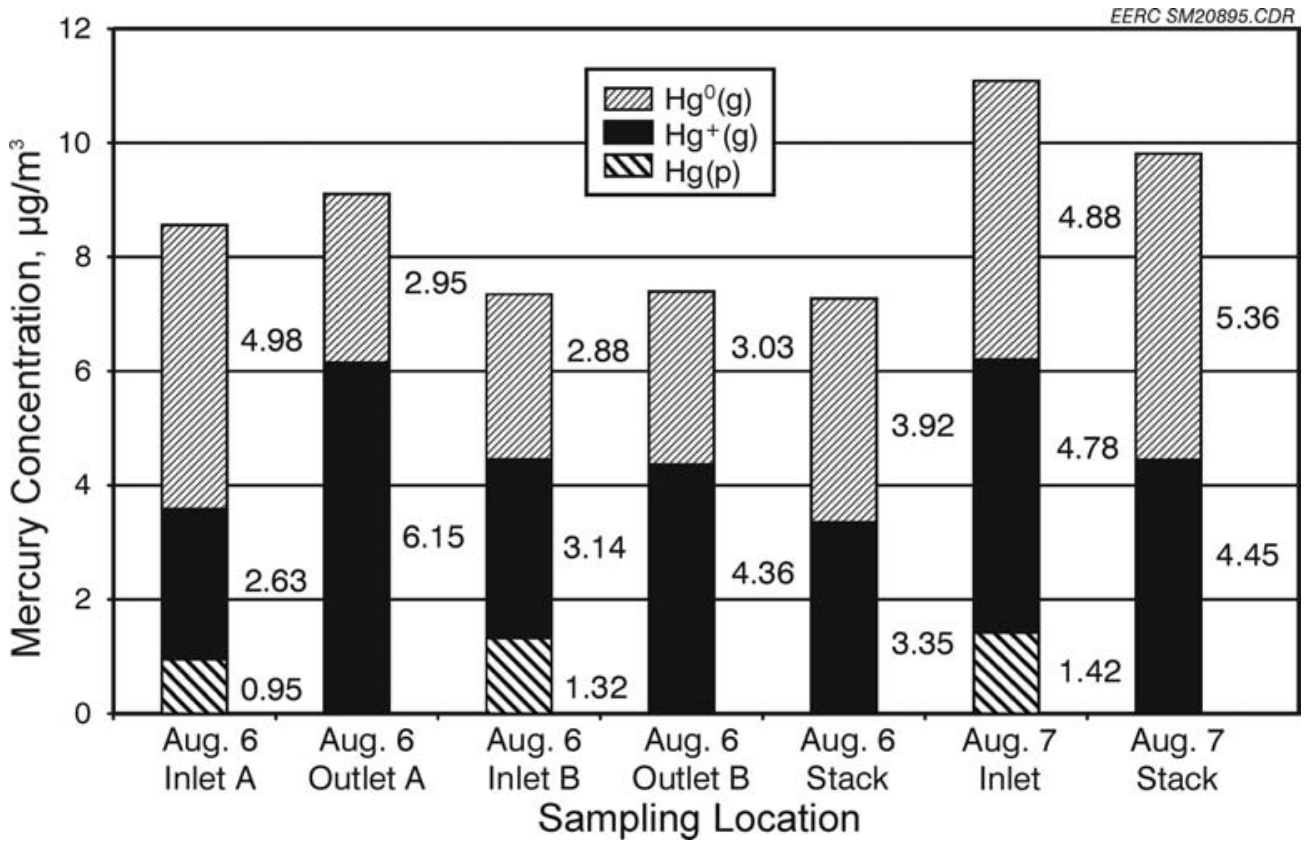

Figure 6.3.2.15. Ontario Hydro results at the Big Stone stack. 
Table 6.3.2.4. Big Stone Power Plant Stack Emissions

\begin{tabular}{ccccc}
\hline Date & & $\begin{array}{c}\text { Advanced Hybrid } \\
\text { Filter Inlet Dust Loading, } \\
\mathrm{mg} / \mathrm{m}^{3}(\mathrm{gr} / \mathrm{scf})\end{array}$ & $\begin{array}{c}\text { Big Stone Stack Dust } \\
\text { Loading, } \mathrm{mg} / \mathrm{m}^{3}(\mathrm{gr} / \mathrm{scf})\end{array}$ & $\begin{array}{c}\text { Big Stone ESP } \\
\text { Collection } \\
\text { Efficiency, \% }\end{array}$ \\
\hline $8-6-02$ & Sample 1 & $0.0021(0.9077)$ & & \\
& Sample 2 & $0.0026(1.1308)$ & $0.0000\left(0.0023^{*}\right)$ & 99.774 \\
& Average & $0.0023(1.0193)$ & & \\
$8-7-02$ & Sample 1 & $0.0027(1.1981)$ & & \\
& Sample 2 & $0.0026(1.1255)$ & $0.0000\left(0.0029^{*}\right)$ & 99.750 \\
\hline
\end{tabular}

* Single stack sample each day.

baseline for comparison with emissions after the Big Stone Power Plant completed installation of a full-scale Advanced Hybrid ${ }^{\mathrm{TM}}$ filter.

\subsubsection{Advanced Hybrid ${ }^{\mathrm{TM}}$ Filter Performance with Carbon Injection}

One of the main objectives of these tests was to evaluate the impact of carbon injection on longer-term Advanced Hybrid ${ }^{\mathrm{TM}}$ filter performance. The Advanced Hybrid ${ }^{\mathrm{TM}}$ filter was started with new bags on June 28 and operated continuously through the entire tests. Figures 6.3.2.166.3.2.19 plot the pressure drop, $\mathrm{BCI}, \mathrm{K}_{2} \mathrm{C}_{\mathrm{i}}$, and residual drag from June 28 to September 3 to see if carbon injection affected the Advanced Hybrid ${ }^{\mathrm{TM}}$ filter operation. The daily average pressure drop data increased slightly with time as would be expected after starting with new bags. When the carbon was started on August 7, there was no perceptible change in pressure drop. The BCI was somewhat variable as a result of temperature and load swings, but, again, there was no increase when the carbon feed was started. The $\mathrm{K}_{2} \mathrm{C}_{\mathrm{i}}$ values are an indication of the amount of dust that reaches the bags and subsequently relate to how well the ESP portion of the Advanced Hybrid $^{\mathrm{TM}}$ filter is working. Again, there was no perceptible change when the carbon was started. The residual drag data indicate how well the bags clean and also did not show any change as a result of the carbon.

Of interest is the effect on these performance parameters with the lower current setting of $25 \mathrm{~mA}$ (see Figures 6.3.2.16-6.3.2.19). At $25 \mathrm{~mA}$, the bag-cleaning interval dropped to about one-half, and the $\mathrm{K}_{2} \mathrm{C}_{\mathrm{i}}$ value approximately doubled. Both of these indicate that about twice as much dust reached the bags at $25 \mathrm{~mA}$ compared to $55 \mathrm{~mA}$. However, almost no effect on 


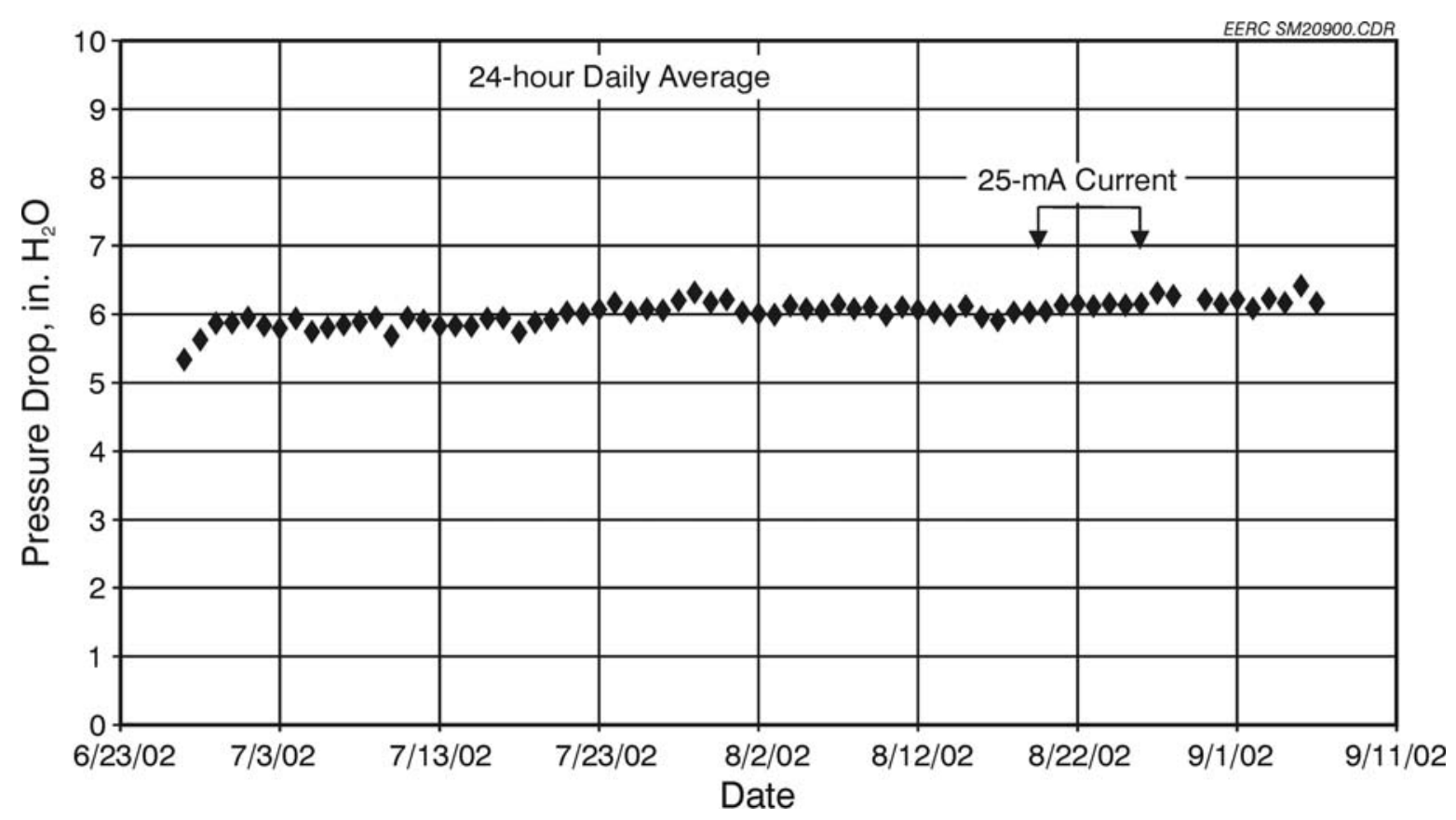

Figure 6.3.2.16. Average daily pressure drop for June 28-September 3, 2002.

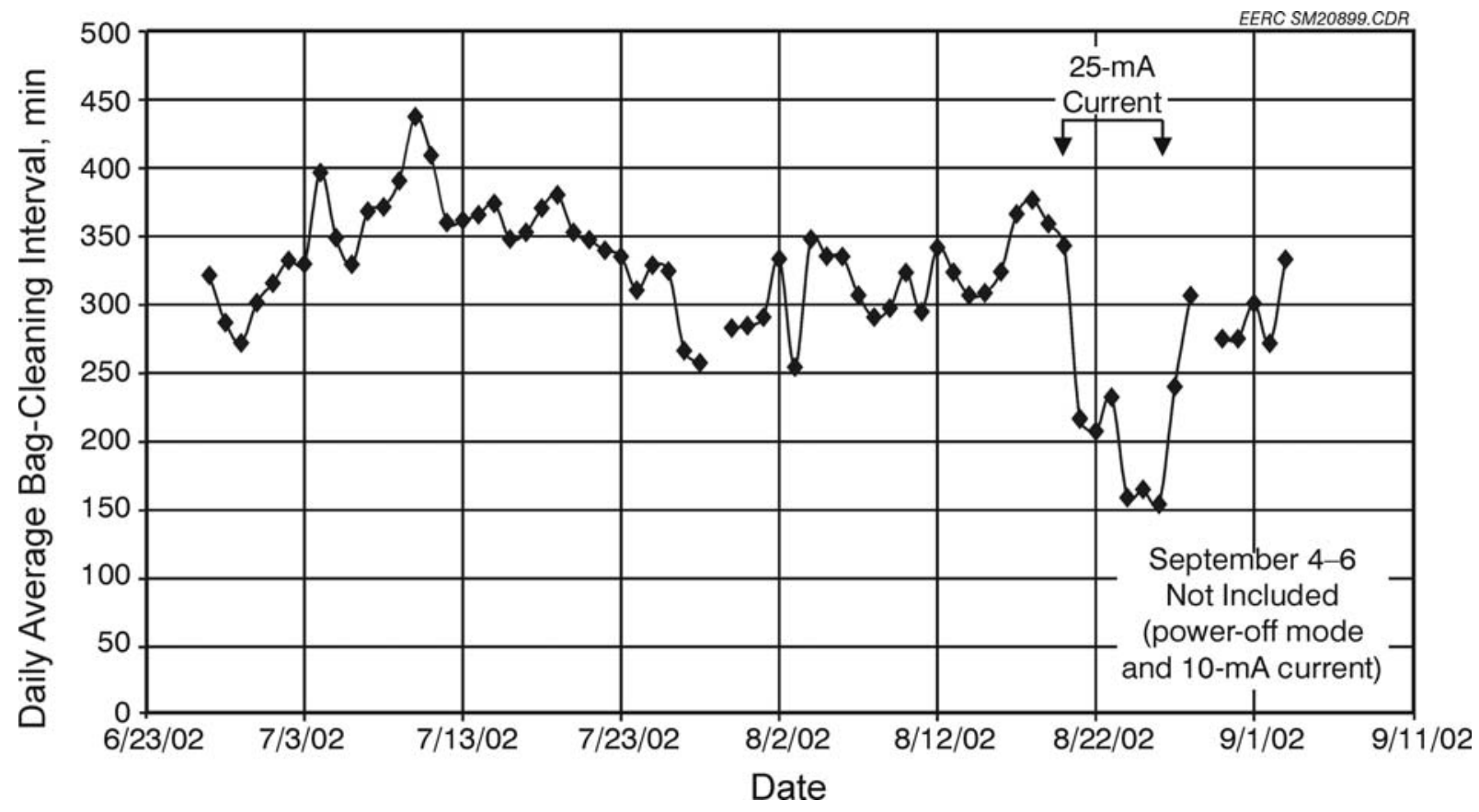

Figure 6.3.2.17. Daily average BCI for June 28-September 3, 2002. 


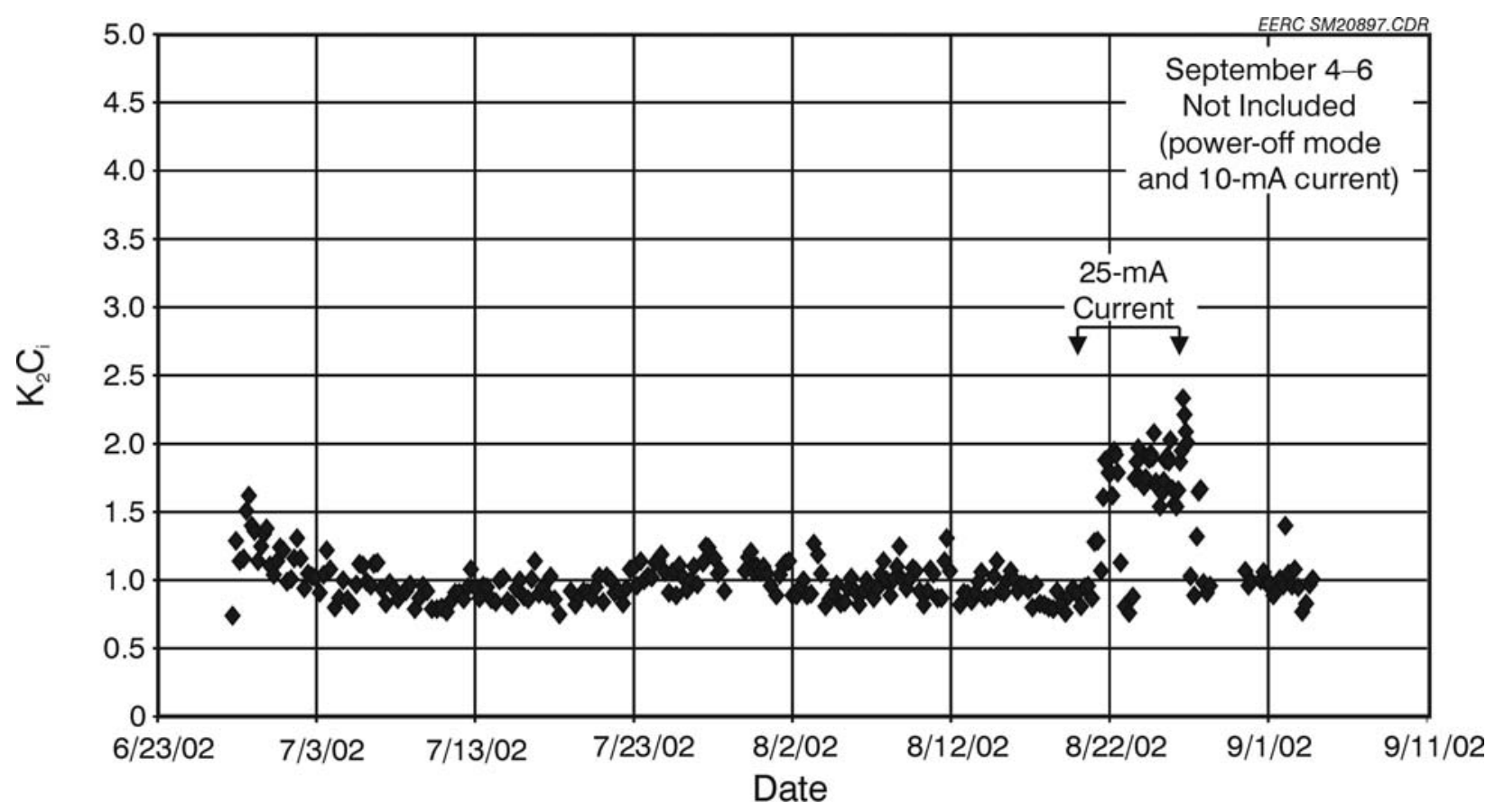

Figure 6.3.2.18. $\mathrm{K}_{2} \mathrm{C}_{\mathrm{i}}$ for June 28-September 3, 2002.

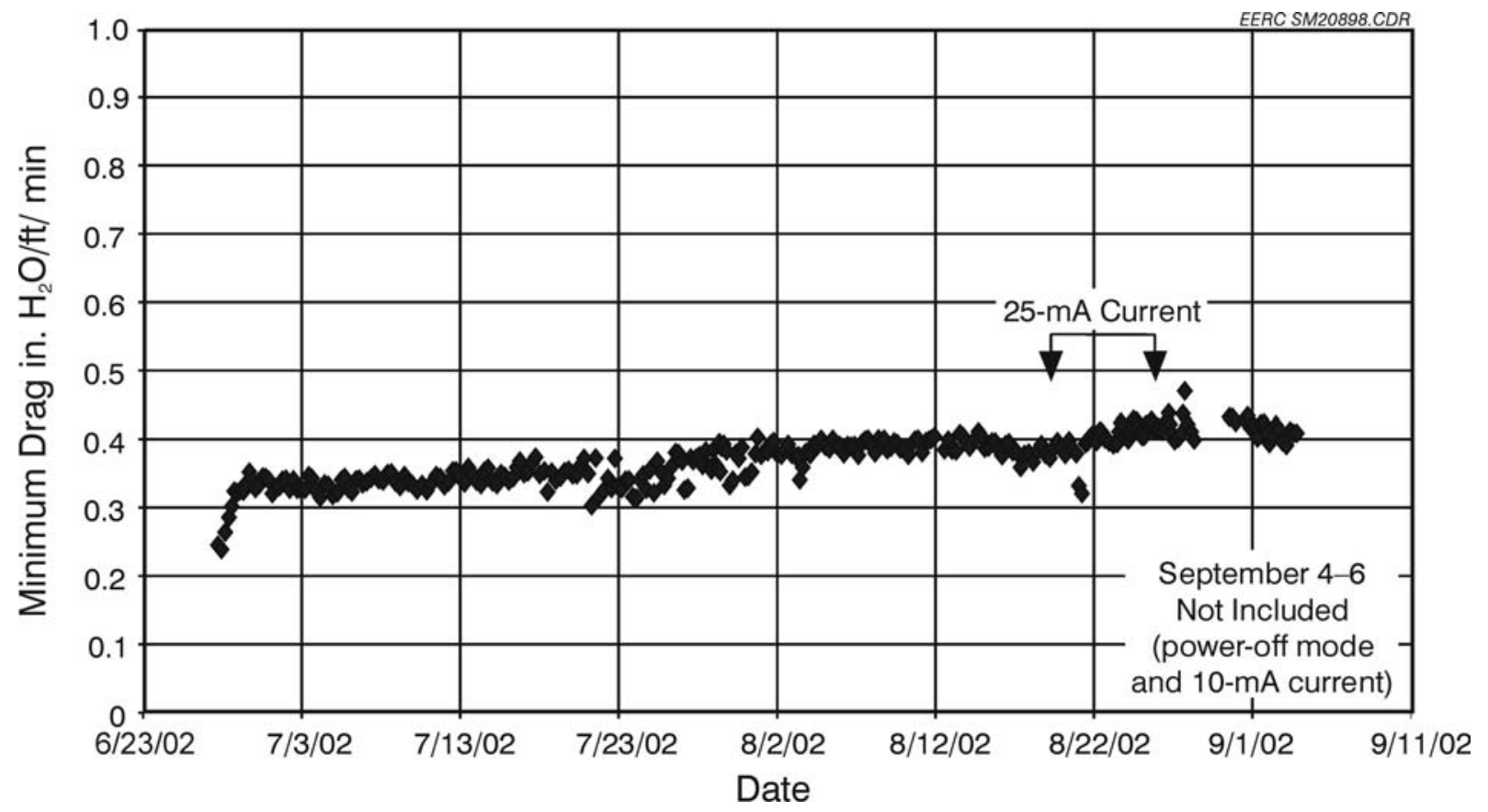

Figure 6.3.2.19. Residual drag for June 28-September 3, 2002. 
pressure drop or residual drag was seen. This implies that it should be possible to optimize Advanced Hybrid ${ }^{\mathrm{TM}}$ filter operational parameters to get the best overall mercury removal while maintaining good Advanced Hybrid ${ }^{\mathrm{TM}}$ filter performance.

\subsubsection{Conclusions}

The average inlet mercury speciation values during the August 2002 tests were 17\% particulate-bound, 32\% oxidized, and 51\% elemental, and the corresponding inherent mercury capture efficiency across the Advanced Hybrid ${ }^{\mathrm{TM}}$ filter was $0 \%-10 \%$. The significant differences of mercury species in flue gas as well as inherent removal between the August 2002 test and November 2001 test are likely caused by high TDF cofiring rates during the November 2001 test.

$1.5 \mathrm{lb} /$ Macf NORIT FGD carbon injection resulted in an average of $63 \%$ mercury removal with the Advanced Hybrid ${ }^{\mathrm{TM}}$ filter in the August tests without any TDF cofiring. A small TDF cofiring rate of about 23 tons per day improved mercury capture to $68 \%$. At the highest TDF rate seen in the August tests of 150-177 tons per day, mercury removal up to $88 \%$ was achieved. Comparing with 91\% removal seen during the November tests when the TDF feed rate was in the range from 90 to 250 tons per day, the field testing results indicate that TDF cofiring benefits mercury control with a low carbon addition rate in the Advanced Hybrid ${ }^{\mathrm{TM}}$ filter.

Possible approaches to improve mercury capture include batch injection of the carbon or reducing the Advanced Hybrid ${ }^{\mathrm{TM}}$ filter current density. At 25-mA current, mercury emissions were from 0.5 to $0.9 \mu \mathrm{g} / \mathrm{m}^{3}$ lower than at the standard current setting of $55 \mathrm{~mA}$. The short-term power-off tests also showed improved mercury capture. These results suggest that modifying the pulsing sequence or interval could change the flow distribution to enhance the gas-solid contact and improve mercury removal.

Based on measured pressure drop across the Advanced Hybrid ${ }^{\mathrm{TM}}$ filter, $\mathrm{BCI}, \mathrm{K}_{2} \mathrm{C}_{\mathrm{i}}$, and residual drag, there was no perceptible effect of the carbon injection on the performance of the Advanced Hybrid ${ }^{\mathrm{TM}}$ filter.

\subsubsection{Short-Term Field Test During November 19-22, 2002}

\subsubsection{Test Conditions}

A short field test was completed with the 2.5-MW (9000-acfm) Advanced Hybrid ${ }^{\mathrm{TM}}$ filter at the Big Stone Power Plant from November 19-22, 2002. This test period was planned to coincide with the first test conducted at the inlet and stack of the full-scale Advanced Hybrid ${ }^{\mathrm{TM}}$ filter after it came online October 26, 2002. From earlier testing results with the 2.5-MW (9000- 
acfm) Advanced Hybrid ${ }^{\mathrm{TM}}$ filter at the Big Stone Power Plant, when the plant was cofiring a small amount of TDF, there was an increase in $\mathrm{HCl}$ in the flue gas and a higher fraction of oxidized mercury. In addition, improved mercury control was seen with the addition of activated carbon when the plant cofired TDF. It is not know whether the better mercury control was the result of more oxidized mercury, higher $\mathrm{HCl}$ in the flue gas, more unburned carbon in the ash or, possibly, a combination of these factors. The primary purpose of the test was to evaluate the effect of injecting a small amount of $\mathrm{HCl}$ into the flue gas along with the activated carbon. Table 6.3.3.1 lists 11 tests completed with the 2.5-MW (9000-acfm) Advanced Hybrid ${ }^{\mathrm{TM}}$ filter during this

Table 6.3.3.1. Summary of Test Matrix for the November 2002 Big Stone Power Plant Field Sampling

\begin{tabular}{|c|c|c|c|c|}
\hline Test & Mode & Carbon Injection & $\mathrm{HCl}$ Injection & Time Frame \\
\hline 1 & $\begin{array}{l}8.0 \text { in. W.C. }(2.0 \mathrm{kPa}) \\
\text { Pulse trigger }\end{array}$ & NA & NA & Nov. $19,8: 00-$ Nov. $20,13: 00$ \\
\hline 2 & $\begin{array}{l}8.0 \text { in. W.C. }(2.0 \mathrm{kPa}) \\
\text { Pulse trigger }\end{array}$ & $\begin{array}{l}0.3 \mathrm{~kg} / \mathrm{hr} \\
(0.66 \mathrm{lb} / \mathrm{hr})\end{array}$ & NA & Nov. 20, 13:00-15:02 \\
\hline 3 & $\begin{array}{l}8.0 \text { in. W.C. }(2.0 \mathrm{kPa}) \\
\text { Pulse trigger }\end{array}$ & $\begin{array}{l}0.3 \mathrm{~kg} / \mathrm{hr} \\
(0.66 \mathrm{lb} / \mathrm{hr})\end{array}$ & $\begin{array}{l}10 \mathrm{ppm} \mathrm{HCl} \text { at } \\
\text { feeder }\end{array}$ & Nov. 20, 15:02-17:00 \\
\hline 4 & $\begin{array}{l}8.0 \text { in. W.C. }(2.0 \mathrm{kPa}) \\
\text { Pulse trigger }\end{array}$ & $\begin{array}{l}0.29 \mathrm{~kg}(2 \mathrm{lb}) \\
\text { power-off batch }\end{array}$ & NA & Nov. $20,17: 11$ \\
\hline 5 & $\begin{array}{l}8.0 \text { in. W.C. }(2.0 \mathrm{kPa}) \\
\text { Pulse trigger }\end{array}$ & $\begin{array}{l}0.3 \mathrm{~kg} / \mathrm{hr} \\
(0.65 \mathrm{lb} / \mathrm{hr})\end{array}$ & NA & Nov. 20, 20:00-Nov. 21, 11:00 \\
\hline 6 & $\begin{array}{l}8.0 \mathrm{in} \text {. W.C. }(2.0 \mathrm{kPa}) \\
\text { Pulse trigger }\end{array}$ & $\begin{array}{l}0.3 \mathrm{~kg} / \mathrm{hr} \\
(0.65 \mathrm{lb} / \mathrm{hr})\end{array}$ & $\begin{array}{l}10 \mathrm{ppm} \mathrm{HCl} \text { at } \\
\text { feeder }\end{array}$ & Nov. 21, 11:00-13:00 \\
\hline 7 & $\begin{array}{l}8.0 \text { in. W.C. }(2.0 \mathrm{kPa}) \\
\text { Pulse trigger }\end{array}$ & $\begin{array}{l}0.3 \mathrm{~kg} / \mathrm{hr} \\
(0.65 \mathrm{lb} / \mathrm{hr})\end{array}$ & NA & Nov. 21, 13:00-15:00 \\
\hline 8 & $\begin{array}{l}8.0 \text { in. W.C. }(2.0 \mathrm{kPa}) \\
\text { Pulse trigger }\end{array}$ & $\begin{array}{l}0.09 \mathrm{~kg} / \mathrm{hr} \\
(0.2 \mathrm{lb} / \mathrm{hr}) \\
\text { due to plug at } \\
\text { feeder }\end{array}$ & $\begin{array}{l}16 \mathrm{ppm} \mathrm{HCl} \text { at } \\
\text { feeder }\end{array}$ & Nov. 21, 15:00-17:00 \\
\hline 9 & 20-min interval & $\begin{array}{l}0.3 \mathrm{~kg} / \mathrm{hr} \\
(0.65 \mathrm{lb} / \mathrm{hr})\end{array}$ & NA & Nov. $21,17: 12-$ Nov. $22,9: 30$ \\
\hline 10 & 20-min interval & $\begin{array}{l}0.3 \mathrm{~kg} / \mathrm{hr} \\
(0.65 \mathrm{lb} / \mathrm{hr})\end{array}$ & $\begin{array}{l}10 \mathrm{ppm} \mathrm{HCl} \text { at } \\
\text { Advanced } \\
\text { Hybrid } \\
\text { inlet pipe }\end{array}$ & Nov. 22, 9:30-11:00 \\
\hline 11 & 20-min interval & $\begin{array}{l}0.6 \mathrm{~kg} / \mathrm{hr} \\
(1.3 \mathrm{lb} / \mathrm{hr})\end{array}$ & NA & Nov. 22, 11:30-13:30 \\
\hline
\end{tabular}


testing period. For the first eight tests, the Advanced Hybrid ${ }^{\mathrm{TM}}$ filter was set to pulse when the pressure drop reached $2.0 \mathrm{kPa}$ (8 in. W.C.), which resulted in a pulse interval of about $3 \mathrm{hr}$ and an average pressure drop of $1.6 \mathrm{kPa}$ (6.5 in. W.C.). Conversely, the remaining three tests had a constant 20-min BCI with an average pressure drop of $1.2 \mathrm{kPa}$ (5.0 in. W.C.).

Since the inlet and stack mercury measurements were being completed for the full-scale Advanced Hybrid ${ }^{\mathrm{TM}}$ filter, no Ontario Hydro samples were taken on the 2.5-MW (9000-acfm) Advanced Hybrid ${ }^{\mathrm{TM}}$ filter. However, two mercury CMMs monitored gaseous mercury concentrations at the inlet and outlet of the 2.5-MW (9000-acfm) Advanced Hybrid ${ }^{\mathrm{TM}}$ filter. Method 29 instead of the Ontario Hydro method was used in the full-scale Advanced Hybrid ${ }^{\mathrm{TM}}$ filter because of the need to measure a number of trace elements in addition to mercury.

\subsubsection{Big Stone Fuel Record for November 2002}

During the test period, the Big Stone Power Plant burned coal from the Belle Ayr Mine. The plant fuel burn record (Table 6.3.3.2) shows that some supplemental TDF and waste seed were cofired on two of the test days, November 19 and 22.

\subsubsection{Mercury Results for November 19-22, 2002, Field Test}

\section{Mercury Stack Emission at Big Stone Flue-Scale Advanced Hybrid ${ }^{\mathrm{TM}}$ Filter November 2002}

Mercury results from three pairs of Method 29 sample collected at plant inlet and stack are shown in Figure 6.3.3.1. Since Method 29 can provide an accurate split between the particulate and vapor-phase mercury but not between oxidized and elemental mercury, the data shown are only with particulate and vapor-phase fractions. The total mercury concentrations in the flue gas were within the range of previously measured inlet values for the $2.5-\mathrm{MW}(9000-\mathrm{acfm})$ Advanced Hybrid ${ }^{\mathrm{TM}}$ filter, but appeared to vary significantly, especially in the particulate-bound fraction. Because of this variability the exact total inlet mercury for specific tests in the 2.5-MW (9000-acfm) Advanced Hybrid ${ }^{\mathrm{TM}}$ filter is somewhat uncertain.

\section{Test 1 - Baseline test}

The 2.5-MW (9000-acfm) Advanced Hybrid ${ }^{\mathrm{TM}}$ filter was operated under baseline conditions without any carbon or $\mathrm{HCl}$ injection from noon on November 19 until 13:00 on November 20. The inlet and outlet mercury CMM data for this time (Figure 6.3.3.2) indicated no vapor-phase mercury capture across the Advanced Hybrid ${ }^{\mathrm{TM}}$ filter unit. For the later part of Test 
Table 6.3.3.2. Big Stone Fuel Record for November 2002

\begin{tabular}{llrrr}
\hline Date & Coal Mine & Coal, tons & TDF, tons & Waste Seeds, tons \\
\hline November 1, 2002 & Eagle Butte & 5988 & 22 & 189 \\
November 2, 2002 & Eagle Butte & 6001 & 0 & 0 \\
November 3, 2002 & Caballo Rojo & 5641 & 0 & 0 \\
November 4, 2002 & Caballo Rojo & 4601 & 90 & 980 \\
November 5, 2002 & Eagle Butte & 5871 & 23 & 36 \\
November 6, 2002 & Eagle Butte & 6182 & 45 & 48 \\
November 7, 2002 & Cordero & 6062 & 0 & 0 \\
November 8, 2002 & Cordero & 5519 & 250 & 98 \\
November 9, 2002 & Eagle Butte & 5418 & 0 & 0 \\
November 10, 2002 & Eagle Butte & 6080 & 0 & 0 \\
November 11, 2002 & Belle Ayr & 6316 & 0 & 0 \\
November 12, 2002 & Belle Ayr & 6170 & 45 & 24 \\
November 13, 2002 & Belle Ayr & 6140 & 92 & 23 \\
November 14, 2002 & Belle Ayr & 6306 & 117 & 49 \\
November 15, 2002 & Belle Ayr & 6202 & 46 & 85 \\
November 16, 2002 & Belle Ayr & 6511 & 0 & 0 \\
November 17, 2002 & Belle Ayr & 6185 & 0 & 0 \\
November 18, 2002 & Belle Ayr & 5797 & 44 & 160 \\
November 19, 2002 & Belle Ayr & 6013 & 23 & 195 \\
November 20, 2002 & Belle Ayr & 6290 & 0 & 0 \\
November 21, 2002 & Belle Ayr & 6365 & 0 & 0 \\
November 22, 2002 & Belle Ayr & 6037 & 139 & 180 \\
November 23, 2002 & Belle Ayr & 4781 & 0 & 0 \\
November 24, 2002 & Belle Ayr & 6276 & 0 & 0 \\
November 25, 2002 & Belle Ayr & 6342 & 23 & 0 \\
November 26, 2002 & Belle Ayr & 6249 & 0 & 0 \\
November 27, 2002 & Belle Ayr & 6152 & 0 & 0 \\
November 28, 2002 & Eagle Butte & 5913 & 0 & 0 \\
November 29, 2002 & Eagle Butte & 5652 & 46 & 0 \\
November 30, 2002 & Caballo Rojo & 6338 & 0 & \\
\hline & & & 0 & 0 \\
\hline
\end{tabular}




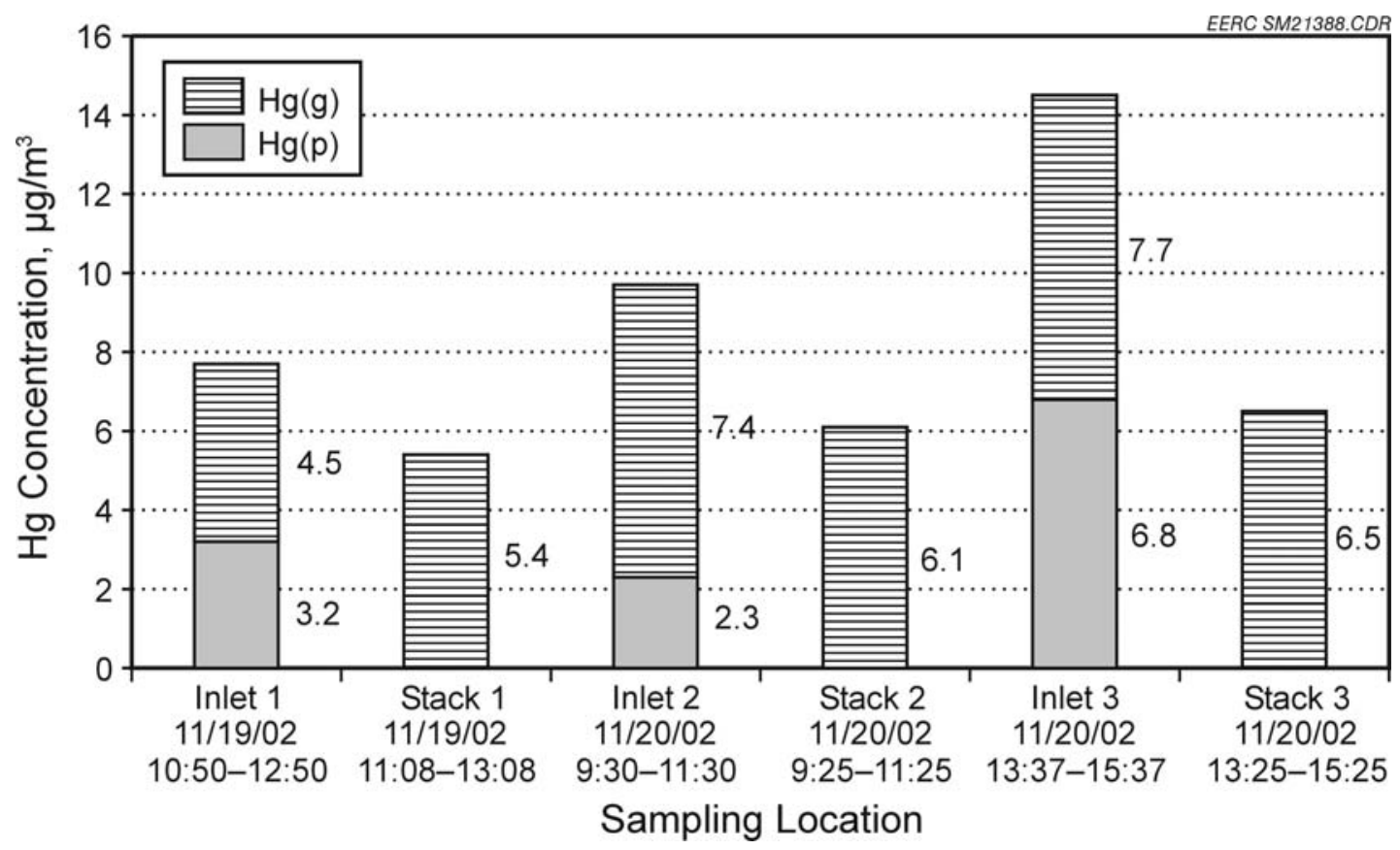

Figure 6.3.3.1. Mercury species concentration at the full-scale Advanced Hybrid ${ }^{\mathrm{TM}}$ filter inlet and stack.

1 (Figure 6.3.3.2), the outlet CMM data were higher than the measured inlet values. From previous work, we know that this is can be caused by accumulation of dust on the inlet sampling filter. In cases where the fly ash has a tendency to capture some of the mercury, this causes a low bias to the measured inlet mercury. Because of this effect, only the outlet CMM data are shown for the remaining tests.

Tests 2-3 0.3-kg/hr (0.65-lb/hr) NORIT FGD Carbon Injection with and Without HCl Addition

From 13:00 to $15: 00$ on November 20, at a carbon injection rate of $0.3 \mathrm{~kg} / \mathrm{hr}(0.65 \mathrm{lb} / \mathrm{hr})$, equivalent to a $24 \mathrm{mg} / \mathrm{m}^{3}(1.5 \mathrm{lb} / \mathrm{Macf})$, the outlet mercury emissions dropped to $3.7 \mu \mathrm{g} / \mathrm{m}^{3}$, which corresponds to $65 \%$ total mercury removal (based on the average inlet total value of $10.6 \mu \mathrm{g} / \mathrm{m}^{3}$ ) (see Figure 6.3.3.3).

While carbon injection was continued, $10 \mathrm{ppm} \mathrm{HCl}$ was injected directly into the carbon feed line just downstream from the carbon feeder. Over the 2-hr test from 15:00 to 17:00 (Figure 6.3.3.3), there was only a slight decrease in outlet mercury to about $3.1 \mu \mathrm{g} / \mathrm{m}^{3}$, corresponding to a $71 \%$ total mercury control. The lower mercury emissions may be attributable to the added $\mathrm{HCl}$. 


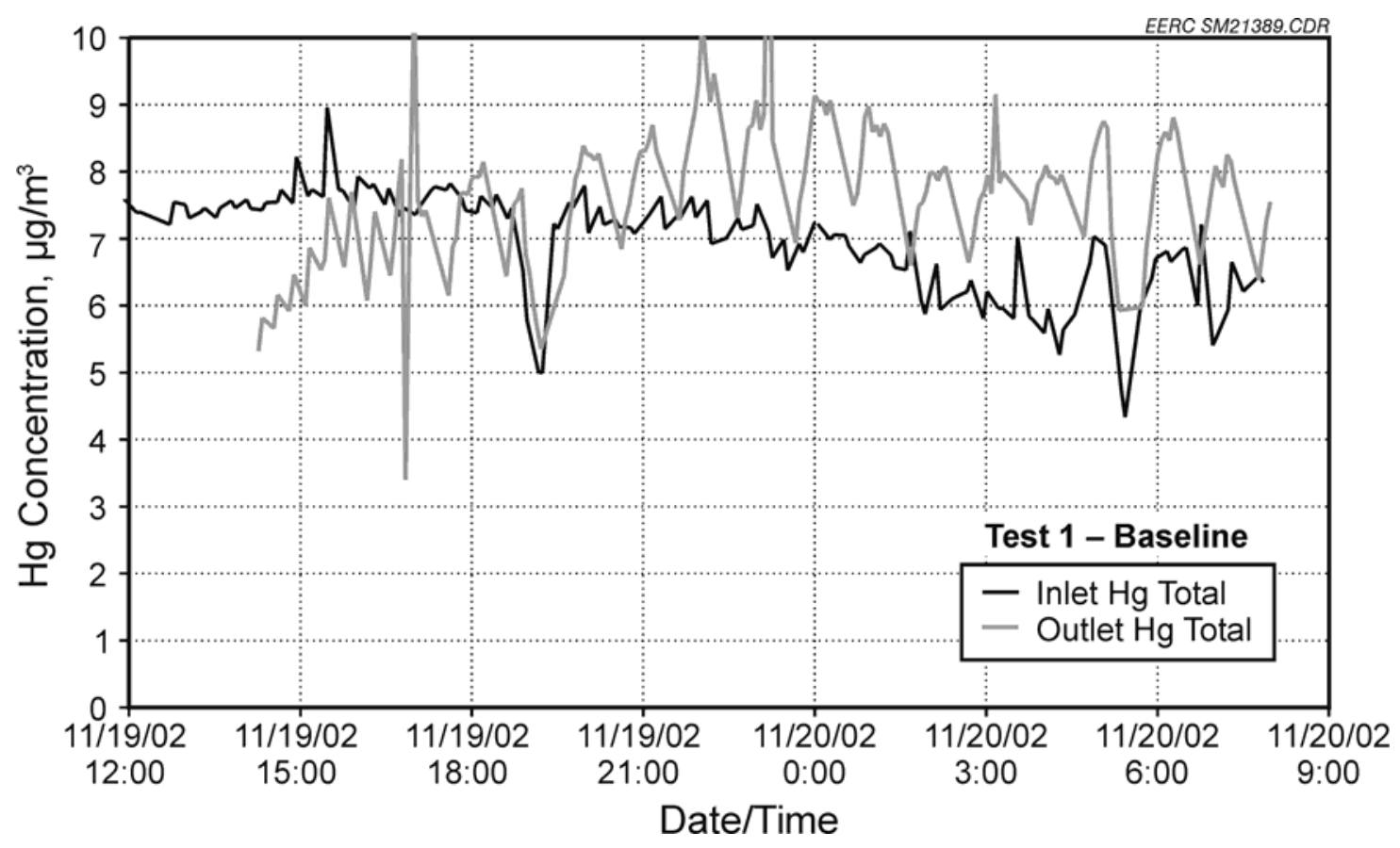

Figure 6.3.3.2. Test 1 Baseline inlet and outlet mercury CMM data for the 2.5-MW (9000-acfm) Advanced Hybrid ${ }^{\mathrm{TM}}$ filter.

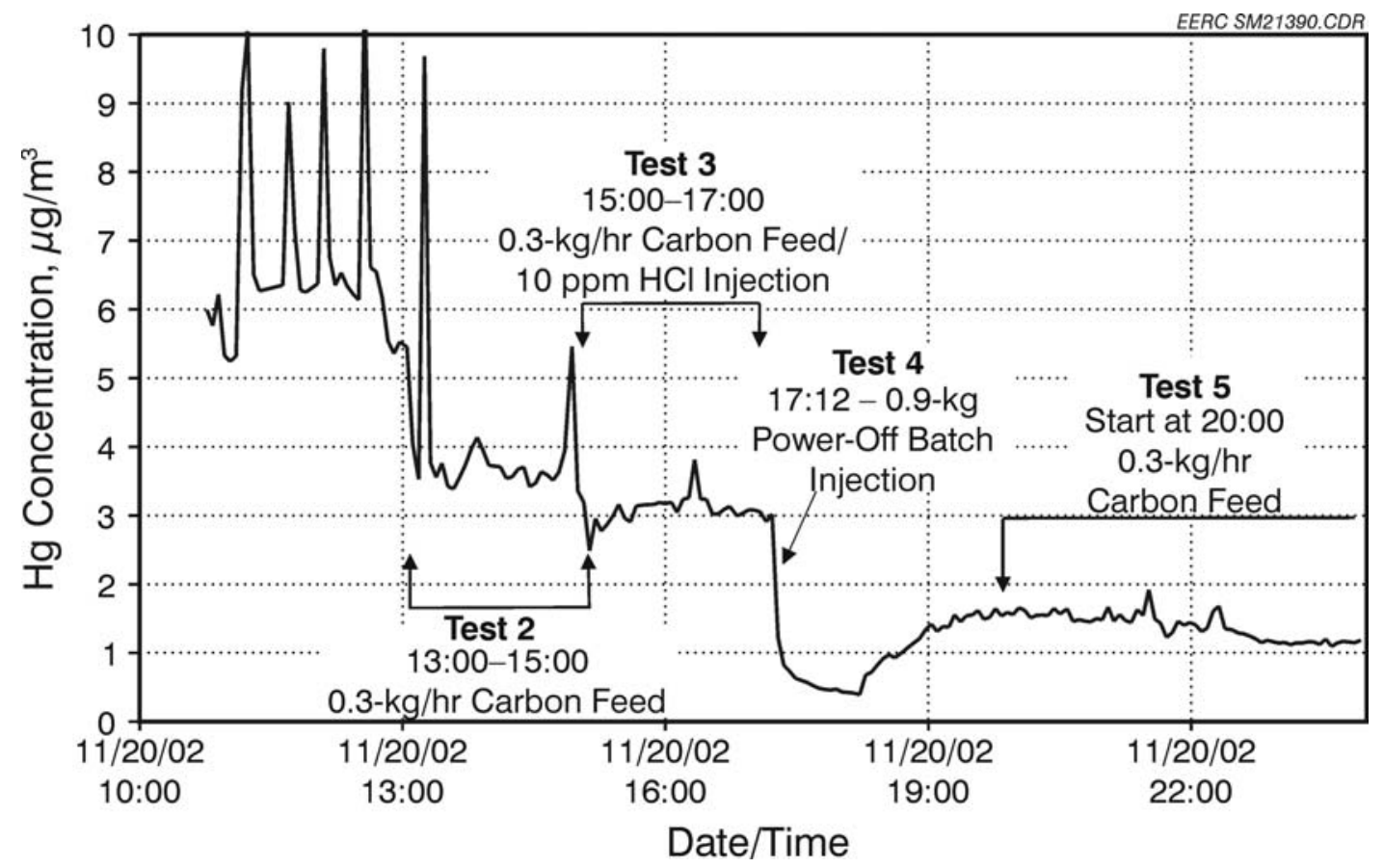

Figure 6.3.3.3. Tests $2-5$ - outlet mercury emission for the $2.5-\mathrm{MW}(9000-\mathrm{acfm})$ Advanced Hybrid ${ }^{\mathrm{TM}}$ filter. 


\section{Test 4 - NORIT FGD Power-Off Batch Injection, No HCl}

There was a concern that the mercury monitor might be biased high. So, at $17: 12,0.9 \mathrm{~kg}$ $(2 \mathrm{lb})$ of carbon was injected into the flue gas within about a minute with the high-voltage power off to verify CMM performance. Based on previous testing data, the outlet mercury concentration would drop to near zero, at least for a short time. From the data in Figure 6.3.3.3, the outlet mercury concentration dropped as low as $0.4 \mu \mathrm{g} / \mathrm{m}^{3}$, which indicated that the mercury monitor was providing valid readings. After $1 \mathrm{hr}$, the mercury started increasing again. During this time, the carbon feeder was at a rate of $0.3 \mathrm{~kg} / \mathrm{hr}(0.65 \mathrm{lb} / \mathrm{hr})$.

\section{Tests 5-8 0.3-kg/hr NORIT FGD Carbon Injection with and Without HCl Additions}

For Test 5 , the carbon remained at a constant $0.3-\mathrm{kg} / \mathrm{hr}(0.65-\mathrm{lb} / \mathrm{hr})$ feed rate while the CMMs monitored mercury emissions overnight to establish mercury removal with $0.3-\mathrm{kg} / \mathrm{hr}$ $(0.65-\mathrm{lb} / \mathrm{hr})$ carbon injection alone. After recovering from the batch carbon injection, the CMM data in Figures 6.3.3.3 and 6.3.3.4 showed the outlet mercury increased only to $1.7 \mu \mathrm{g} / \mathrm{m}^{3}$ and then slowly dropped to $1.0 \mu \mathrm{g} / \mathrm{m}^{3}$ by $01: 00$ on the next day where it remained until $05: 30$. This corresponds to a total mercury removal of $91 \%$ without any supplemental $\mathrm{HCl}$ injection.

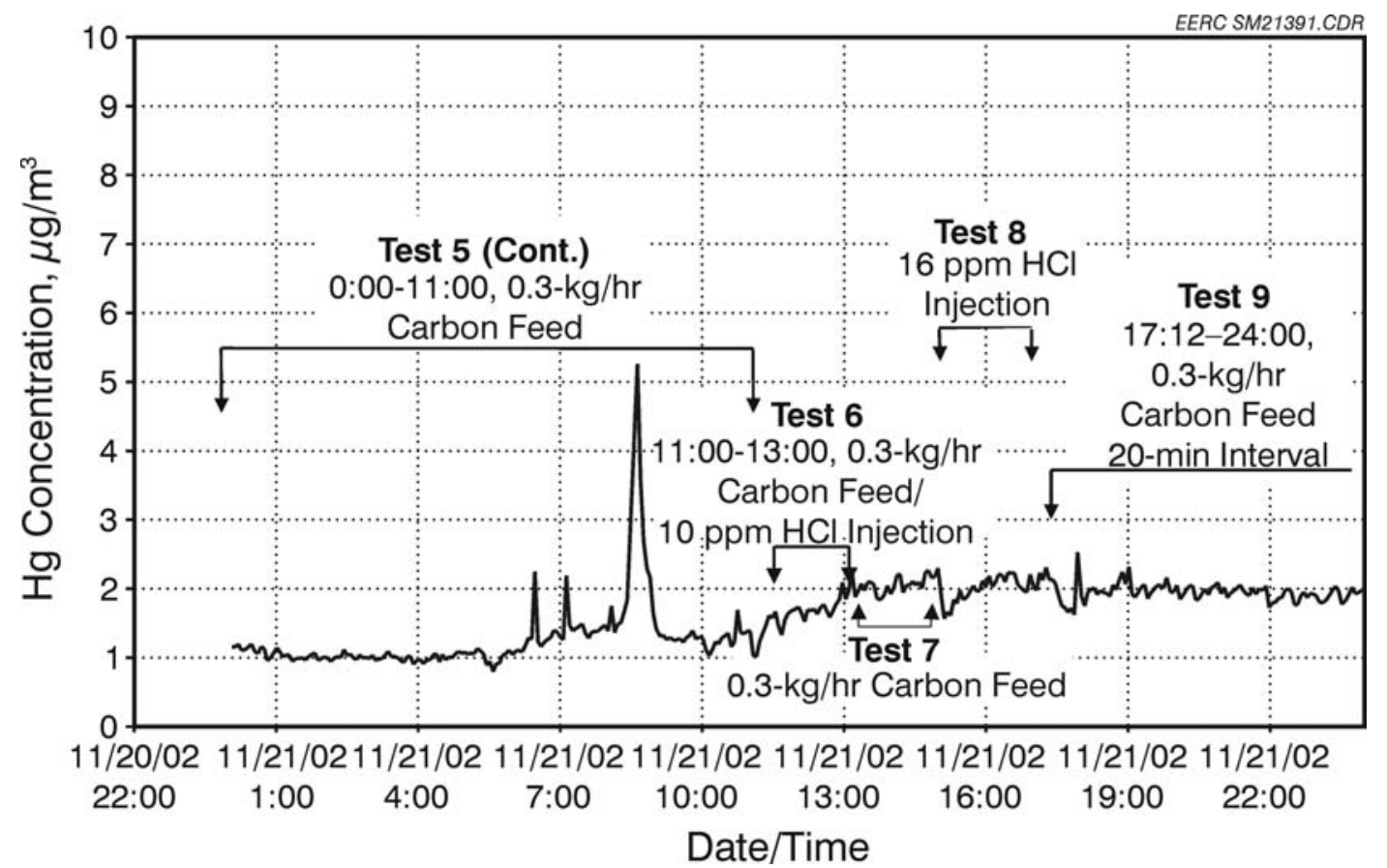

Figure 6.3.3.4. Tests 5-9-Outlet mercury emission for the 2.5-MW (9000-acfm) Advanced Hybrid $^{\mathrm{TM}}$ filter. 
Interestingly, during this time there was also no cofiring of TDF. The plant load (Figure 6.3.3.5 was reduced slightly from midnight until 06:00 on November 21, but the drop in mercury emission already started before the drop in plant load. The Advanced Hybrid ${ }^{\mathrm{TM}}$ filter inlet and outlet temperatures (Figure 6.3.3.6) did decrease slightly from midnight until 06:00, which may have benefited the mercury retention. It is also expected that with longer-term carbon injection some additional capture of mercury might occur until all of the carbon retained in the unit has reached its maximum capacity. From the time of starting carbon injection on November 20 until 05:30 on November 21, it is possible that some additional carbon buildup would occur and this could account for the gradual drop in mercury emissions. At 05:30, the mercury started to increase again, corresponding to a return to full plant load and a gradual increase in temperature. This suggests that the level of mercury control may be sensitive to even small changes in plant conditions.

Test 6 was a repeat of Test 3 to determine the effect of $\mathrm{HCl}$ combined with carbon injection on mercury removal with the Advanced Hybrid ${ }^{\mathrm{TM}}$ filter. After the outlet mercury was

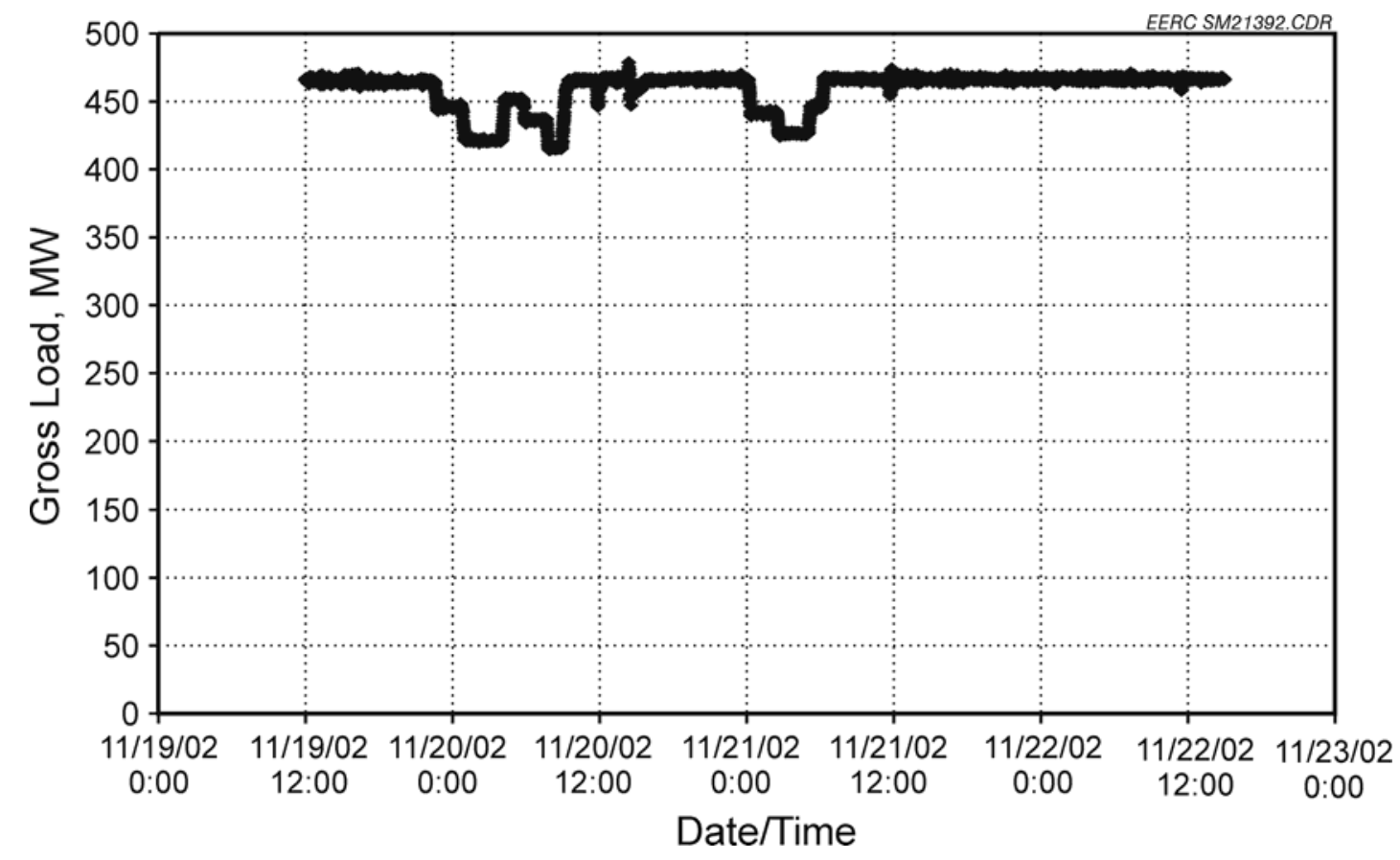

Figure 6.3.3.5. Big Stone Power Plant load during field sampling at the 2.5-MW (9000-acfm) Advanced Hybrid ${ }^{\mathrm{TM}}$ filter. 


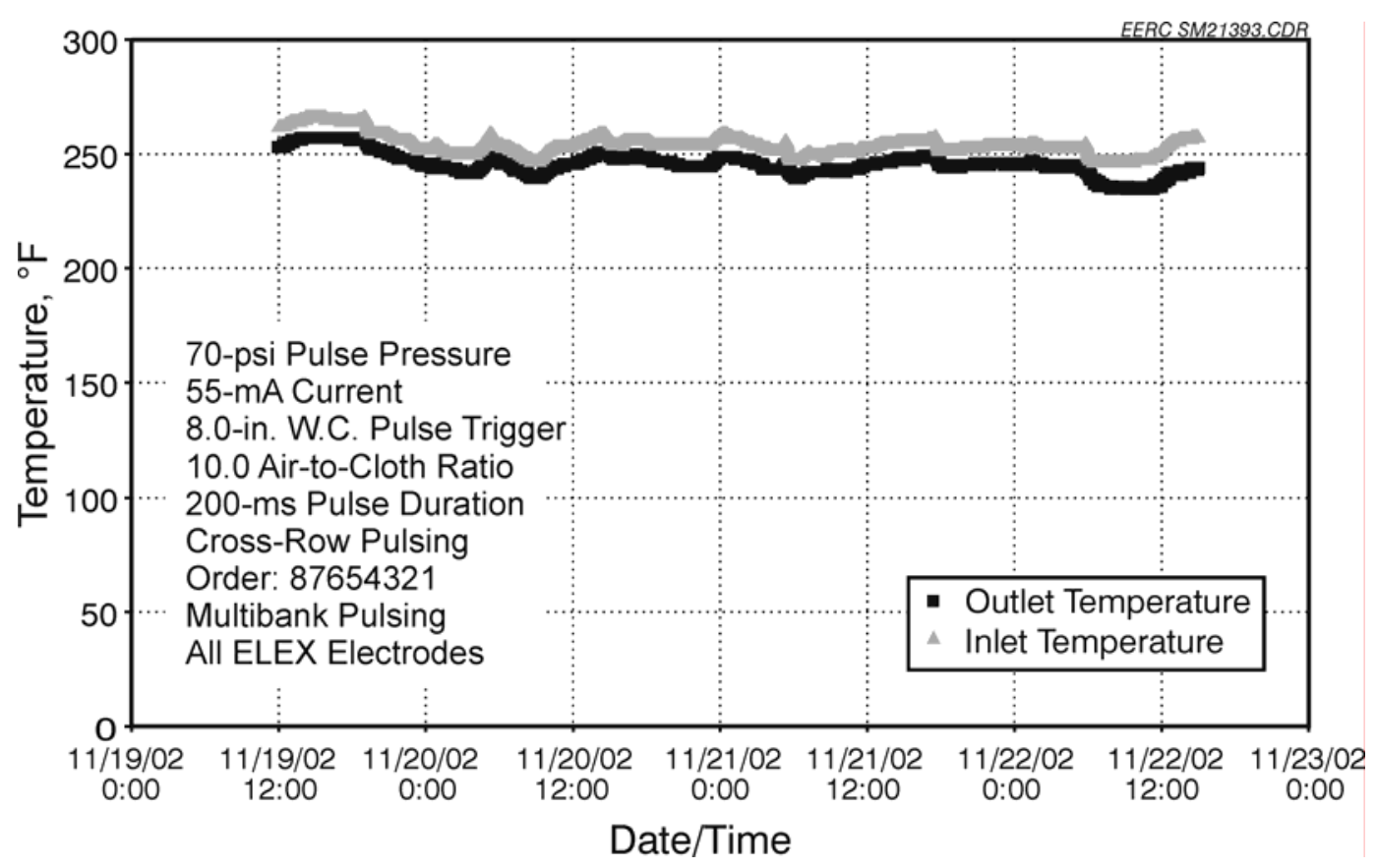

Figure 6.3.3.6. The Advanced Hybrid ${ }^{\mathrm{TM}}$ filter inlet and outlet temperatures.

shown to be fairly steady at about $1.5 \mu \mathrm{g} / \mathrm{m}^{3}, 10 \mathrm{ppm}$ of $\mathrm{HCl}$ was again injected into the carbon feed line from 11:00 to 13:00. However, from the results shown in Figure 6.3.3.4, the outlet mercury actually increased from 1.5 to $2.0 \mu \mathrm{g} / \mathrm{m}^{3}$. During this time, the Advanced Hybrid ${ }^{\mathrm{TM}}$ filter temperature was also increasing somewhat so the increase in mercury is more likely associated with the temperature increase rather than the injected $\mathrm{HCl}$. Another possible reason is that the injected $\mathrm{HCl}$ mobilized mercury captured on carbon which reentered the flue gas. Results from Tests 3 and 6 indicated little or no benefit of adding $10 \mathrm{ppm} \mathrm{HCl}$ directly into the flue gas.

The $\mathrm{HCl}$ was shut off from 13:00 to 15:00, and the mercury emission remained at $2.0 \mu \mathrm{g} / \mathrm{m}^{3}$, which corresponded to a total mercury removal of $81 \%$ (Test 7 ).

For Test $8, \mathrm{HCl}$ was started again from 15:00 to 17:00 and increased to the maximum controller setting which allowed up to $16 \mathrm{ppm} \mathrm{HCl}$. During this time, there was a short-term plug in the carbon feeder which may have contributed to some variability in the outlet mercury, but comparing the mercury concentration while injecting the $\mathrm{HCl}$ with the times before and after the test without $\mathrm{HCl}$ injection indicates little or no effect of the $\mathrm{HCl}$. 


\section{Tests 9-11 Carbon and/or HCl Injections with a 20-min Timed Pulsed Interval}

From 17:12 on November 21 until 09:30 on November 22, the carbon feed was held constant at $0.3 \mathrm{~kg} / \mathrm{hr}(1.5 \mathrm{lb} / \mathrm{Macf})$, but the bag pulse controller was set to a 20 -min timed interval (Test 9) rather than the $2.0 \mathrm{kPa}$ (8 in. W.C.) trigger for all of the previous tests. At the $2.0 \mathrm{kPa}(8 \mathrm{in}$. W.C.) pulse trigger pressure, the bags typically pulsed about every $3 \mathrm{hr}$, which allowed for a fairly long carbon residence time in the Advanced Hybrid ${ }^{\mathrm{TM}}$ filter chamber. A 20-min timed pulse interval possibly could limit the carbon residence time and result in lower mercury capture. However, much of the carbon was likely deposited on the perforated collection plates which were rapped at a constant 40-min interval for all of the tests. CMM data in Figures 6.3.3.4 and 6.3.3.7 indicated no immediate change in the outlet mercury concentration after starting the 20-min timed bag pulsing. The outlet mercury emissions were very steady at about $1.9 \mu \mathrm{g} / \mathrm{m}^{3}$ from 19:00 November 21 to $03: 00$ November 22 and dropped to $0.9 \mu \mathrm{g} / \mathrm{m}^{3}$ during 03:00-06:00. During this time, the plant was at steady full load, and the Advanced Hybrid ${ }^{\mathrm{TM}}$ filter temperatures did not fluctuate. Inspection of the plant fuel burn record shows that supplemental TDF and waste seed burning were started again on November 22, but the exact

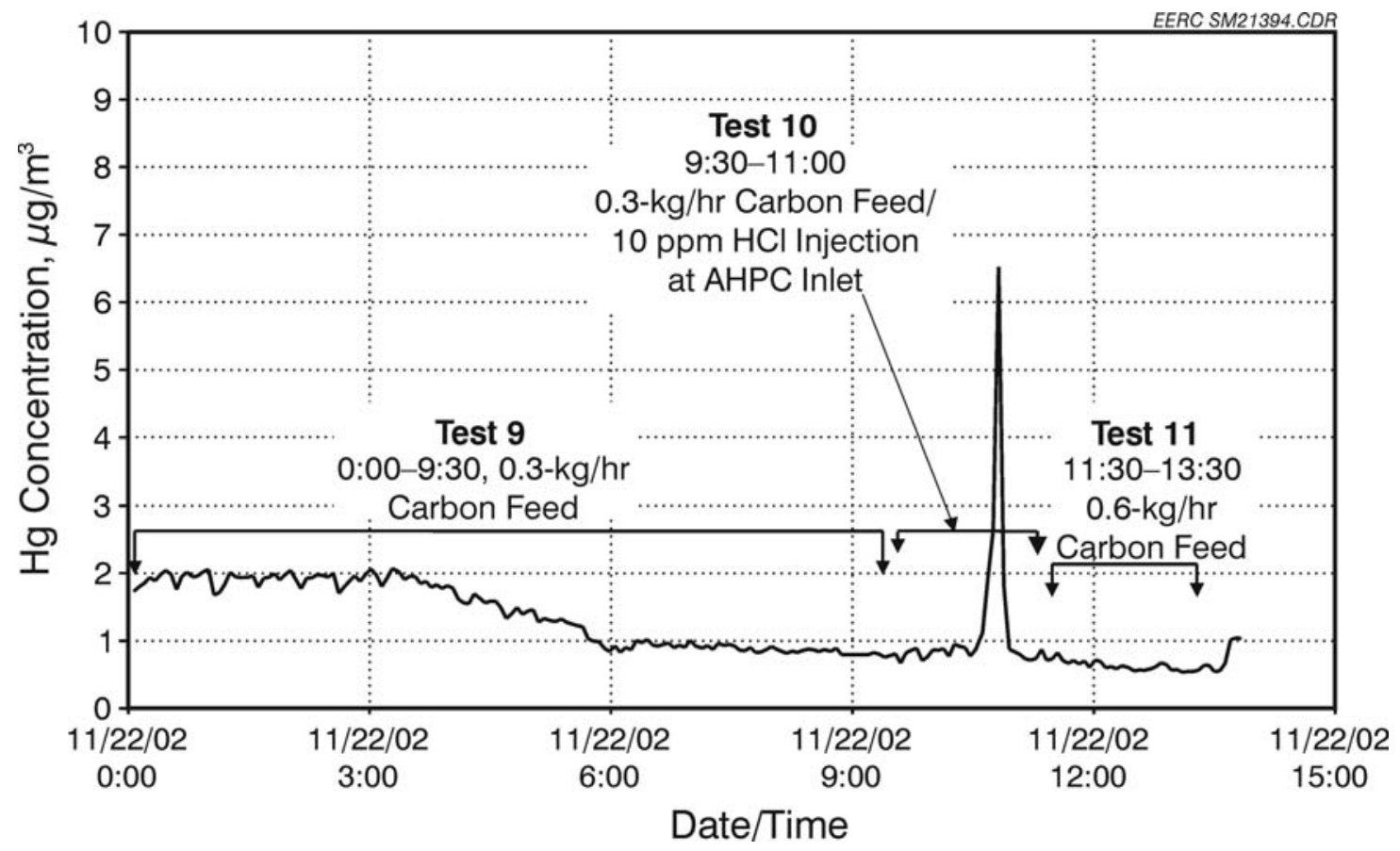

Figure 6.3.3.7. Tests 9-11 - outlet mercury emission for the 2.5-MW (9000-acfm) Advanced Hybrid $^{\mathrm{TM}}$ filter. 
time that the fuels reached the boiler is unknown. From previous tests, similar effects were seen when TDF was started, but the drop could also be the result of variation in the inlet mercury concentration or speciation.

Test 10 was another attempt to determine if supplemental injection of $\mathrm{HCl}$ along with carbon injection would benefit mercury control. In this case, $\mathrm{HCl}$ was injected directly into the Advanced Hybrid ${ }^{\mathrm{TM}}$ filter inlet duct just upstream of the carbon injection location. From the outlet CMM data plotted in Figure 6.3.3.7, there was, again, no obvious decrease of mercury emission as the result of the $\mathrm{HCl}$ injection. However, the mercury removal during the test as well as just before and just after the test was over $90 \%$ so there may have already been a sufficient amount of $\mathrm{HCl}$ in the flue gas. During Test 10, there was a short-term spike in the mercury emission up to $6 \mu \mathrm{g} / \mathrm{m}^{3}$. It is not know whether it was caused by a process upset or some transient condition in the sampling and analytical instrumentation.

Test 11 was completed in which the carbon injection rate was doubled to $1.3 \mathrm{~kg} / \mathrm{hr}$ ( $3 \mathrm{lb} /$ million acf). From the results shown in Figure 6.3.3.7, there was not an immediate drop in outlet mercury, but there did appear to be a gradual decrease in mercury. By the end of the 2-hr test, the mercury was only $0.6 \mu \mathrm{g} / \mathrm{m}^{3}$ which corresponds to $94 \%$ total mercury removal. The excellent mercury removal seen here may have been at least partially due to the burning of TDF on November 22.

\subsubsection{Conclusions}

The November 2002 field testing data show a $24-\mathrm{mg} / \mathrm{m}^{3}$ (1.5-lb/Macf) NORIT FGD carbon injection alone provided $65 \%-90 \%$ mercury removal with the Advanced Hybrid ${ }^{\mathrm{TM}}$ filter for the subbituminous coal flue gas, which is somewhat better than the results from the monthlong continuous field test in August 2002. Part of the reason could be the higher temperatures of $132^{\circ}-143^{\circ} \mathrm{C}\left(270^{\circ}-290^{\circ} \mathrm{F}\right)$ in the Advanced Hybrid ${ }^{\mathrm{TM}}$ filter during August 2002 compared to $121^{\circ} \mathrm{C}\left(250^{\circ} \mathrm{F}\right)$ for the November 2002 tests. These results indicate that the exact level of mercury control that can be achieved with a low carbon addition rate is dependent on many factors and is difficult to predict.

High mercury removal was seen both for the 2.0-kPa (8-in. W.C.) pulse trigger tests, which resulted in a 3 -hr pulse interval and for the 20 -min timed pulse interval tests. This indicates that a long pulse interval is not necessary to achieve good mercury removal. 
The small effect (if any) seen with the supplemental $\mathrm{HCl}$ injection is somewhat surprising because an extensive amount of bench-scale sorbent work demonstrated the benefit of $\mathrm{HCl}$ for capturing elemental mercury in a simulated flue gas over the temperature range from $107^{\circ}$ $188^{\circ} \mathrm{C}\left(225^{\circ}-370^{\circ} \mathrm{F}\right)$. Previous work has also demonstrated that the addition of chlorine compounds into the combustion zone will result in a higher fraction of oxidized mercury. However, the benefit of additional $\mathrm{HCl}$ may be marginal in cases where there is already a sufficient amount of $\mathrm{HCl}$ present to achieve good mercury control.

\subsubsection{Long-Term Field Test During May 6-June 3, 2003}

\subsubsection{Test Conditions}

A 1-month field test was completed with the 2.5-MW (9000-acfm) Advanced Hybrid ${ }^{\mathrm{TM}}$ filter unit from May 6 to June 3, 2003. Carbon injection (NORIT FGD and/or Barneby \& Sutcliffe IAC) was continuous ( $24 \mathrm{hr}$ a day) for the entire month except for a planned plant outage on May 8, 2003, Memorial Day weekend break, and a 1-day shutdown on May 30, 2003. The primary goal of the 1-month test was to demonstrate long-term mercury control with the Advanced Hybrid ${ }^{\mathrm{TM}}$ filter technology by carbon injection. Another goal was to evaluate the impacts of various operating parameters of filtration face velocity, carbon injection rate, and residence time of carbon on mercury control with the Advanced Hybrid ${ }^{\mathrm{TM}}$ filter technology. A summary of the testing parameters is listed in Table 6.3.4.1.

Since previous field testing results (August-November 2002) had proved that CMM instruments were able to precisely measure gaseous mercury species in the flue gas two CMMs were used to continuously monitor mercury concentrations in the inlet and outlet flue gas, over the entire testing period, and no Ontario Hydro sampling was completed. The CMMs were normally set up to measure inlet and outlet total mercury vapor concentrations, but during the day for several hours, they were manually switched to also measure the elemental mercury vapor concentrations at the inlet and outlet.

\subsubsection{Big Stone Fuel Record for May 2003}

Table 6.3.4.2 lists the fuel burn record for Big Stone Power Plant from May 6 - June 3, 2003. During the majority of this test, the coals burned were from the Belle Ayr and Eagle Butte Mines, which are both similar low-sulfur subbituminous fuels from the PRB. On May 31, 2003, another PRB coal, Caballo coal, was burned. The amounts of TDF and waste seed fuel burned during this time are also listed in Table 6.3.4.2. 


\subsubsection{Mercury Results for May 6-June 3, 2003, Field Test}

\section{Baseline Test}

Figure 6.3.4.1 shows daily average mercury vapor concentrations, both total and elemental, in the inlet flue gas for the entire test period. The error bars represent plus and minus one standard deviation. The inlet CMM sampling probe was set up prior to the carbon injection location so that the collected data were reflective of mercury species entering the Advanced Hybrid ${ }^{\mathrm{TM}}$ filter unit. The concentrations of total mercury vapor $\left(\mathrm{Hg}_{\mathrm{gas}}\right)$ in the inlet flue gas varied

Table 6.3.4.1. Testing Parameters During May-June 2003 Test

\begin{tabular}{lc}
\hline Carbon & NORIT FGD Activated Carbon, IAC \\
\hline Filtration Face Velocity, $\mathrm{m} / \mathrm{min}(\mathrm{ft} / \mathrm{min})$ & $1.8,2.4,3.0,3.7,4.3(6,8,10,12,14)$ \\
Carbon Injection Concentration, $\mathrm{mg} / \mathrm{m}^{3}(\mathrm{lb} / \mathrm{Macf})$ & $17,20,3040,48(1.07,1.25,1.88,2.51,3.00)$ \\
Carbon Injection Location & Inlet elbow, inlet transition \\
\hline
\end{tabular}

Table 6.3.4.2. Fuel Burn Record for the Big Stone Power Plant for May 2003

\begin{tabular}{lcccc}
\hline Date & Coal Mine & Coal, tons & TDF, tons & Waste Seed, tons \\
\hline $5 / 6 / 2003$ & Belle Ayr & 5945 & 46 & 0 \\
$5 / 7 / 2003$ & Eagle Butte & 5759 & 0 & 0 \\
$5 / 8 / 2003$ & Eagle Butte & 4741 & 0 & 0 \\
$5 / 9 / 2002$ & Belle Ayr & 6216 & 49 & 46 \\
$5 / 10 / 2003$ & Belle Ayr & 6429 & 0 & 0 \\
$5 / 11 / 2003$ & Belle Ayr & 6585 & 0 & 0 \\
$5 / 12 / 2003$ & Eagle Butte & 6301 & 0 & 0 \\
$5 / 13 / 2003$ & Belle Ayr & 6073 & 22 & 180 \\
$5 / 14 / 2003$ & Belle Ayr & 6003 & 46 & 183 \\
$5 / 15 / 2003$ & Belle Ayr & 6222 & 0 & 0 \\
$5 / 16 / 2003$ & Belle Ayr & 5882 & 27 & 140 \\
$5 / 17 / 2003$ & Belle Ayr & 6158 & 0 & 0 \\
$5 / 18 / 2003$ & Belle Ayr & 6133 & 0 & 0 \\
$5 / 19 / 2003$ & Belle Ayr & 6011 & 69 & 71 \\
$5 / 20 / 2003$ & Belle Ayr & 6156 & 70 & 94 \\
$5 / 21 / 2003$ & Belle Ayr & 6109 & 0 & 48 \\
$5 / 22 / 2003$ & Belle Ayr & 5943 & 22 & 24 \\
$5 / 23 / 2003$ & Belle Ayr & 5777 & 45 & 24 \\
$5 / 27 / 2003$ & Belle Ayr & 5637 & 22 & 0 \\
$5 / 28 / 2003$ & Belle Ayr & 5847 & 45 & 0 \\
$5 / 29 / 2003$ & Belle Ayr & 6051 & 0 & 0 \\
$5 / 31 / 2003$ & Caballo & 5579 & 0 & 0 \\
$6 / 1 / 2003$ & Eagle Butte & 5439 & 0 & \\
$6 / 2 / 2003$ & Eagle Butte & 5564 & 0 & 0 \\
$6 / 3 / 2003$ & Eagle Butte & 4109 & & 0 \\
\hline
\end{tabular}




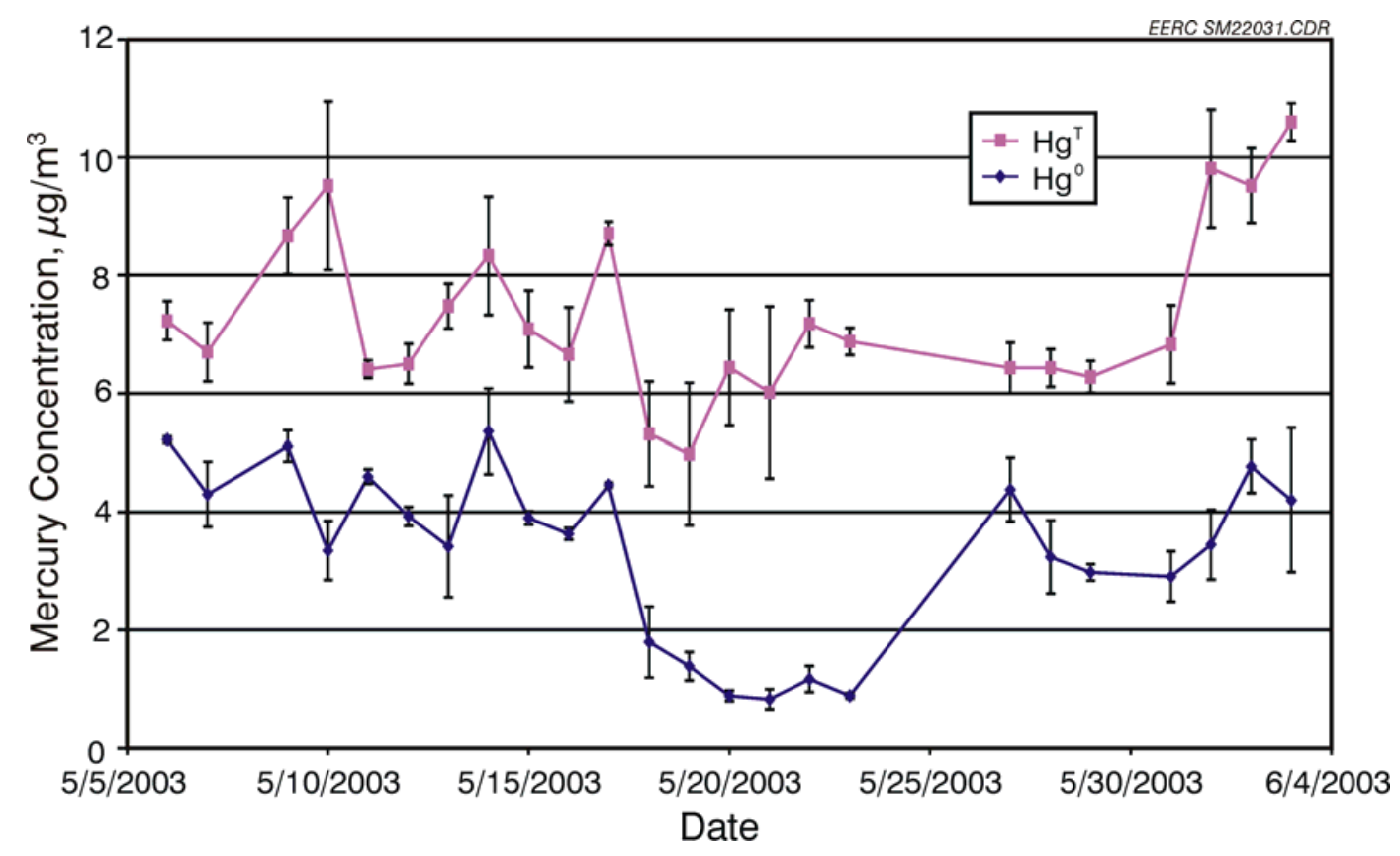

Figure 6.3.4.1. Daily average mercury vapor concentrations, both total and elemental, in the inlet flue gas for the 2.5-MW (9000-acfm) Advanced Hybrid ${ }^{\mathrm{TM}}$ filter.

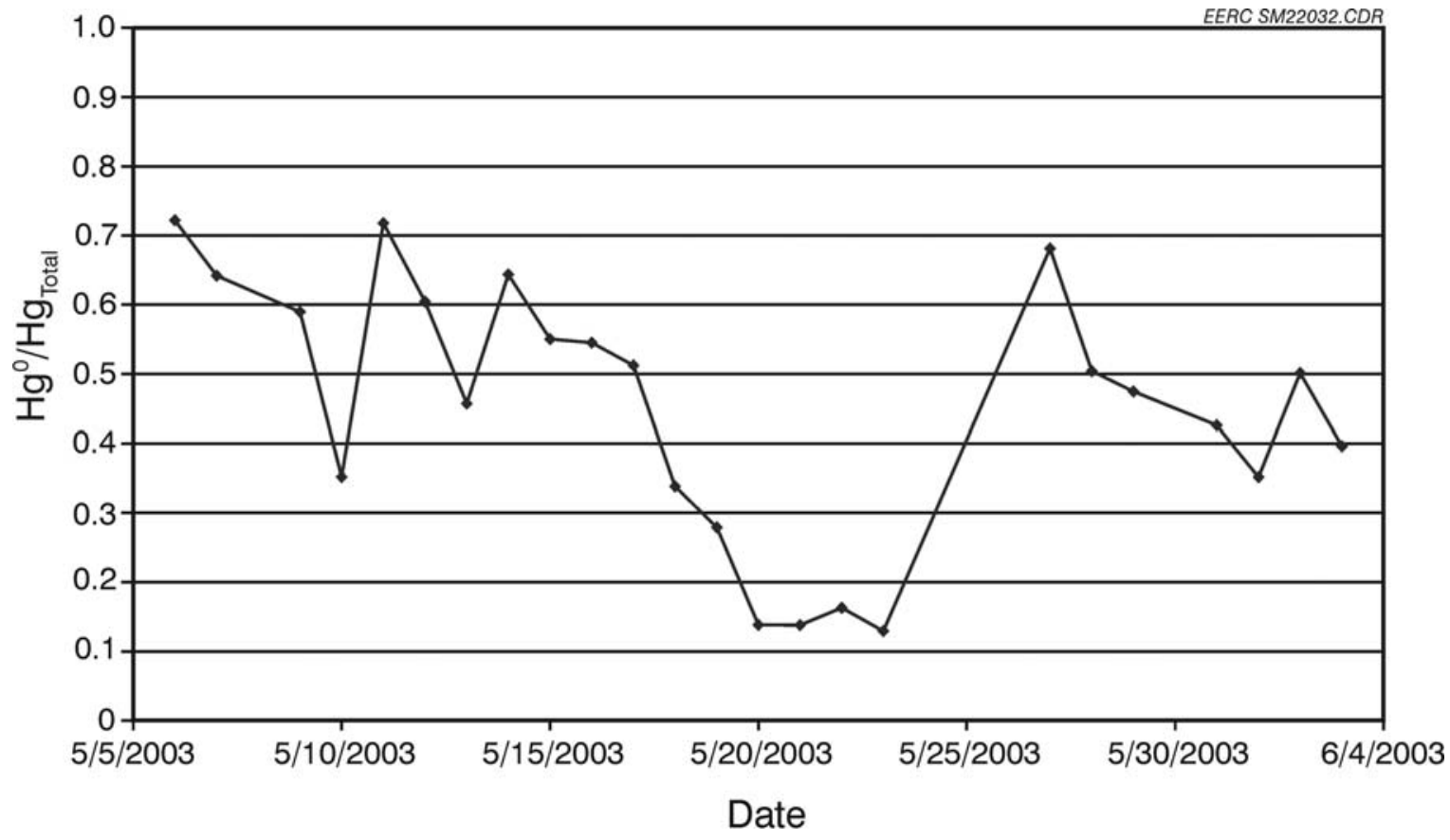

Figure 6.3.4.2. Ratios of $\mathrm{Hg}^{0}$-to- $\mathrm{Hg}_{\text {gas }}$ in the inlet flue gas for the 2.5-MW (9000-acfm) Advanced Hybrid ${ }^{\mathrm{TM}}$ filter. 
from 4.98 to $10.6 \mu \mathrm{g} / \mathrm{m}^{3}$ with 0.83 to $5.36 \mu \mathrm{g} / \mathrm{m}^{3}$ elemental mercury. Figure 6.3 .4 .2 plots the daily ratios of $\mathrm{Hg}^{0}$-to- $\mathrm{Hg}_{\text {gas }}$ based on the daily averaged mercury species in the inlet flue gas, which ranged from 12.9\% to 72.9\%. During the previous field test in August 2002 for the Belle Ayr and Eagle Butte coals, $60 \%-80 \%$ of total mercury vapor in the flue gas was elemental, while $20 \%-40 \%$ was oxidized mercury. The wide variations of $\mathrm{Hg}^{0}$-to- $\mathrm{Hg}_{\text {gas }}$ ratio during this testing period were likely the result of the variation in the coal as well as the intermittent cofiring of TDF and waste seed. By correlating the fuel burn record with mercury species in the flue gas for both field tests, it appeared that the Belle Ayr coal was more sensitive to cofiring TDF and waste seed in that more oxidized mercury in the flue gas was seen under relatively low levels of TDF additions. However, because the TDF and waste seed were fed into the plant intermittently, it is very difficult to precisely estimate the TDF effect on mercury species.

Table 6.3.4.3 lists mercury contents of the three different coals burned during the testing period. Although these coals are from different mines, their mercury contents are quite similar, in the range of 0.0689 to $0.109 \mu \mathrm{g} / \mathrm{g}$. The predicted mercury concentration in the flue gas is in the range of 7.8 to $12.3 \mu \mathrm{g} / \mathrm{m}^{3}$, with an average of $9.85 \mu \mathrm{g} / \mathrm{m}^{3}$. Also included in Table 6.3.4.3 are the mercury analysis results of hopper ash samples collected in baseline tests.

During the test on May 20, 2003, the power plant burned Belle Ayr coal along with 1.1\% TDF (mass basis) and 1.2\% (mass basis) waste seed. The total gaseous mercury in the flue gas during the test was $6.44 \mu \mathrm{g} / \mathrm{m}^{3}$. Based on the measured 0.233-0.256 $\mu \mathrm{g} / \mathrm{g}$ mercury in the Belle Ayr hopper ash collected in the baseline test and a typical dust loading of $2.83 \mathrm{~g} / \mathrm{m}^{3}(1.2 \mathrm{gr} / \mathrm{scf})$, the particle-bound mercury in the flue gas was in the range of $0.66-0.72 \mu \mathrm{g} / \mathrm{m}^{3}$, giving a total mercury concentration of $7.16-7.76 \mu \mathrm{g} / \mathrm{m}^{3}$. Compared to the predicted $9.45 \mu \mathrm{g} / \mathrm{m}^{3}$ total mercury in the Belle Ayr coal flue gas, the discrepancy between the measured and predicted

Table 6.3.4.3. Mercury Content in the Coals and Hopper Ash

\begin{tabular}{lccc}
\hline Coal Samples & Date & Coal Mine & Mercury Content, $\mu \mathrm{g} / \mathrm{g}$, dry basis \\
\hline & $5 / 20 / 03$ & Belle Ayr & 0.0836 \\
& $5 / 31 / 03$ & Caballo & 0.0689 \\
Ash Samples & $6 / 02 / 03$ & Eagle Butte & 0.109 \\
& Date & Mercury Content, $\mu \mathrm{g} / \mathrm{g}$, dry basis \\
& $5 / 09 / 03$ & & 0.256 \\
& $5 / 27 / 03$ & & 0.233 \\
& $5 / 31 / 03$ & 0.438 \\
\hline
\end{tabular}


total mercury concentrations in the flue gas may be the result of analytical uncertainty or could be caused by some mercury collected on the CMM sampling filter, which occurs to greater extent when TDF was cofired.

On the May 31, 2003, baseline test, the power plant burned Caballo coal without any TDF and waste seed added. At the same time, the Advanced Hybrid ${ }^{\mathrm{TM}}$ filter was operated under baseline conditions without additional carbon injection. The mercury in the raw coal and Advanced Hybrid ${ }^{\mathrm{TM}}$ filter hopper ash were 0.0689 and $0.438 \mu \mathrm{g} / \mathrm{g}$, respectively. Assuming a typical dust loading of $2.83 \mathrm{~g} / \mathrm{m}^{3}$ (1.2 gr/scf) in the flue gas (based on previous sampling data), the particle-bound mercury was about $1.13 \mu \mathrm{g} / \mathrm{m}^{3}$ (dry basis). Combined with the averaged gaseous mercury of $6.83 \mu \mathrm{g} / \mathrm{m}^{3}$ in the inlet flue gas, the total mercury concentration in the flue gas was $7.96 \mu \mathrm{g} / \mathrm{m}^{3}$, close to the calculated mercury concentration of $7.8 \mu \mathrm{g} / \mathrm{m}^{3}$ based on the mercury content in the raw coal. This agreement is easier to achieve when no TDF and waste seeds are burned.

The coal burned on June 2, 2003, was Eagle Butte with a mercury concentration of $0.109 \mu \mathrm{g} / \mathrm{g}$, corresponding to a total mercury concentration of $12.3 \mu \mathrm{g} / \mathrm{m}^{3}$, which was higher than the measured $9.8 \mu \mathrm{g} / \mathrm{m}^{3}$. Again, the TDF is a possible reason for the discrepancy.

Since the TDF was added into the plant intermittently during the entire test period, the total mercury vapor concentration measured by the $\mathrm{CMM}$ at the Advanced Hybrid ${ }^{\mathrm{TM}}$ filter inlet may not accurately reflect the real total mercury concentrations in the flue gas. Therefore, the average $9.85 \mu \mathrm{g} / \mathrm{m}^{3}$ from the combustion calculation was used as a typical inlet total mercury concentration in the flue gas for the mercury removal calculation.

Figure 6.3.4.3 summarizes the inherent mercury captures with the Advanced Hybrid ${ }^{\mathrm{TM}}$ filter during several different baseline testing periods when the power plant burned Belle Ayr, Eagle Butte, or Caballo with and/or without cofiring of TDF and waste seed. For the Belle Ayr coal, without cofiring TDF and waste seeds (May 10, 2003), there was virtually no inherent mercury capture by fly ash itself. However, when the power plant was cofiring with TDF as well as waste seed (May 6, 9, 27, and 28, 2003), the inherent mercury removal ranged from $2 \%$ to $18.9 \%$. The above data indicated again the impacts of added TDF and waste seed on mercury species in the flue gas. Somewhat higher inherent mercury capture was seen with the Eagle Butte coal ranging from $24.7 \%$ to $30.5 \%$, but this is somewhat overestimated because the average 


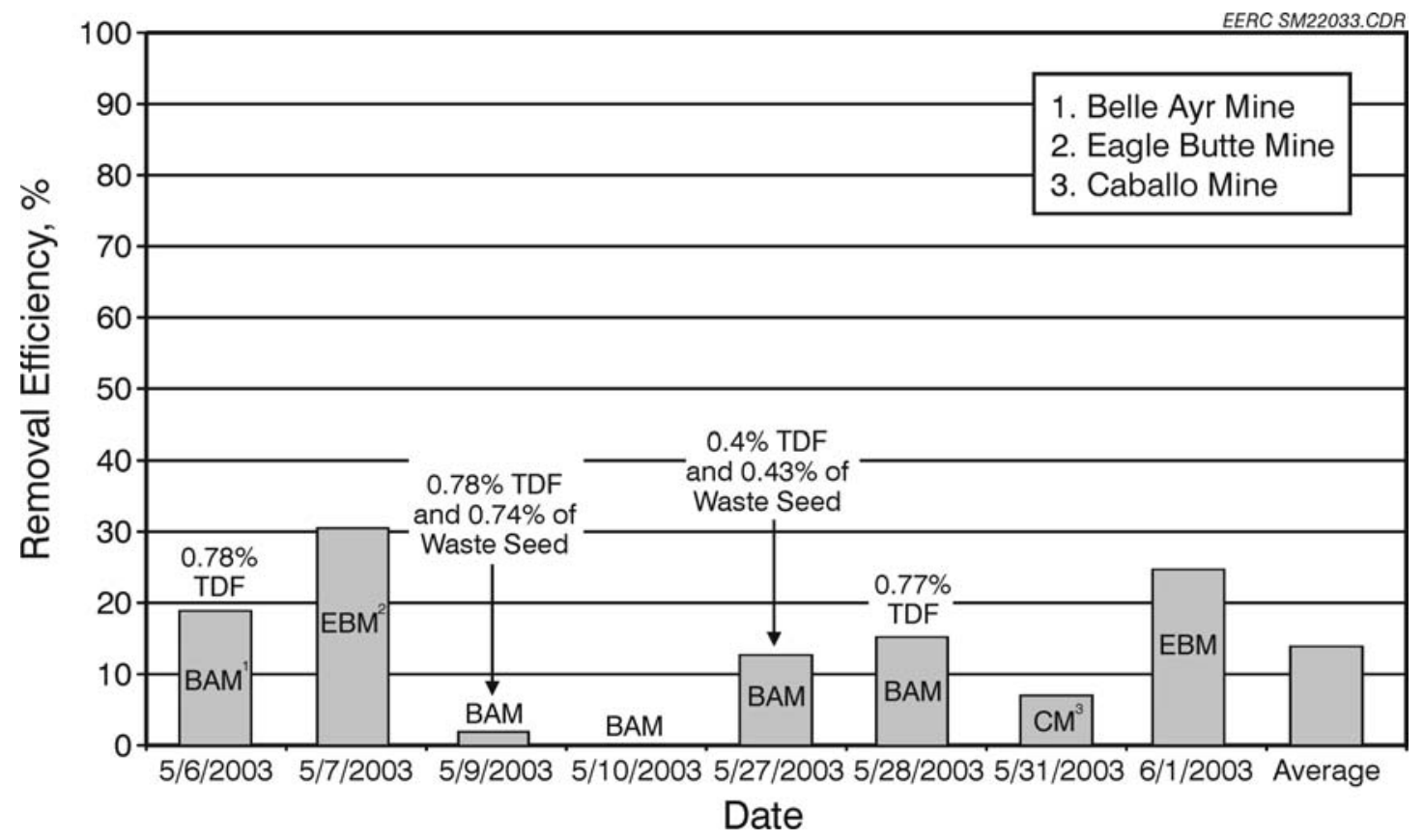

Figure 6.3.4.3. Summary of the inherent mercury captures with the Advanced Hybrid ${ }^{\mathrm{TM}}$ filter during several different baseline testing periods.

$9.85 \mu \mathrm{g} / \mathrm{m}^{3}$ instead of $12.1 \mu \mathrm{g} / \mathrm{m}^{3}$ was used for inherent capture calculation. In summary, the overall inherent mercury removal by the ash was low, with an average of $13.9 \%$ during the 1 month test.

\section{Effect of Filtration Velocity on Mercury Removal with Carbon Injection}

The goal of this test was to understand the impact of filtration velocity on Advanced Hybrid $^{\mathrm{TM}}$ filter mercury capture with carbon injection. By adjusting the Advanced Hybrid ${ }^{\mathrm{TM}}$ filter flue gas flow rate from 122 to $285 \mathrm{~m}^{3} / \mathrm{min}$ (4320 to $10,080 \mathrm{acfm}$ ), the filtration velocity through the bags varied from 2 to $4 \mathrm{~m} / \mathrm{min}$ (6 to $14 \mathrm{ft} / \mathrm{min}$ ), while the carbon injection rate was maintained at $0.3 \mathrm{~kg} / \mathrm{hr}(0.65 \mathrm{lb} / \mathrm{hr})$ during the testing time. When the flue gas flow rate was increased at a constant $0.3 \mathrm{~kg} / \mathrm{hr}(0.65 \mathrm{lb} / \mathrm{hr})$ carbon feed rate, the in-flight mercury-to-carbon adsorption was impeded as results of the diluted carbon-to-mercury ratio and reduced contact time between mercury and the in-flight carbon. However, at higher flow rates, more carbon deposited on the filter bags where they would have the best contact with mercury vapor. The mercury removals were the results of these competing factors. 
The flow rate tests were completed on May 14, 15, and 20, 2003. On May 14, 2003, the Advanced Hybrid ${ }^{\mathrm{TM}}$ filter was initially operated at $3 \mathrm{~m} / \mathrm{min}(10 \mathrm{ft} / \mathrm{min})$ of filtration velocity with a $24 \mathrm{mg} / \mathrm{m}^{3}$ (1.5 $\left.\mathrm{lb} / \mathrm{Macf}\right)$ carbon injection rate. The average mercury collection efficiency (Figure 6.3.4.4) was 55.3\%. The flue gas flow rate through the Advanced Hybrid ${ }^{\mathrm{TM}}$ filter was then reduced to $163 \mathrm{~m}^{3} / \mathrm{min}$ (5760 acfm) for a few hours and further reduced to $1317 \mathrm{~m}^{3} / \mathrm{min}$ $(4320 \mathrm{acfm})$ for the rest of the day $(8 \mathrm{hr})$, resulting in decreased filtration velocities of 1.8 and $2.4 \mathrm{~m} / \mathrm{min}$ ( 6 and $8 \mathrm{ft} / \mathrm{min}$ ) and corresponding increased carbon injection concentrations of 30 and $40 \mathrm{mg} / \mathrm{m}^{3}$ (1.88 and $2.51 \mathrm{lb} /$ Macf), respectively. The subsequent overall mercury removal increased to $63.8 \%$ at $2.4 \mathrm{~m} / \mathrm{min}(8 \mathrm{ft} / \mathrm{min})$ and further to $81.1 \%$ at $1.8 \mathrm{~m} / \mathrm{min}(6 \mathrm{ft} / \mathrm{min})$. The higher mercury removal at the reduced filtration velocity is likely the result of the raised carbonto-mercury ratio combined with better contact of mercury with the in-flight carbon and the carbon on the perforated plates under extended residence times.

On May 15, 2003, the Advanced Hybrid ${ }^{\mathrm{TM}}$ filter was operated at filtration velocities of 1.8, 3.0 , and $3.7 \mathrm{~m} / \mathrm{min}(6,10$ and $12 \mathrm{ft} / \mathrm{min})$. The overall mercury collection efficiency (Figure 6.3.4.5) increased with decreasing filtration velocity from $65.8 \%$ at $3.7 \mathrm{~m} / \mathrm{min}(12 \mathrm{ft} / \mathrm{min})$ to $73.2 \%$ at $3 \mathrm{~m} / \mathrm{min}(10 \mathrm{ft} / \mathrm{min})$ and to $83.1 \%$ at $1.8 \mathrm{~m} / \mathrm{min}(6 \mathrm{ft} / \mathrm{min})$. The better mercury removals

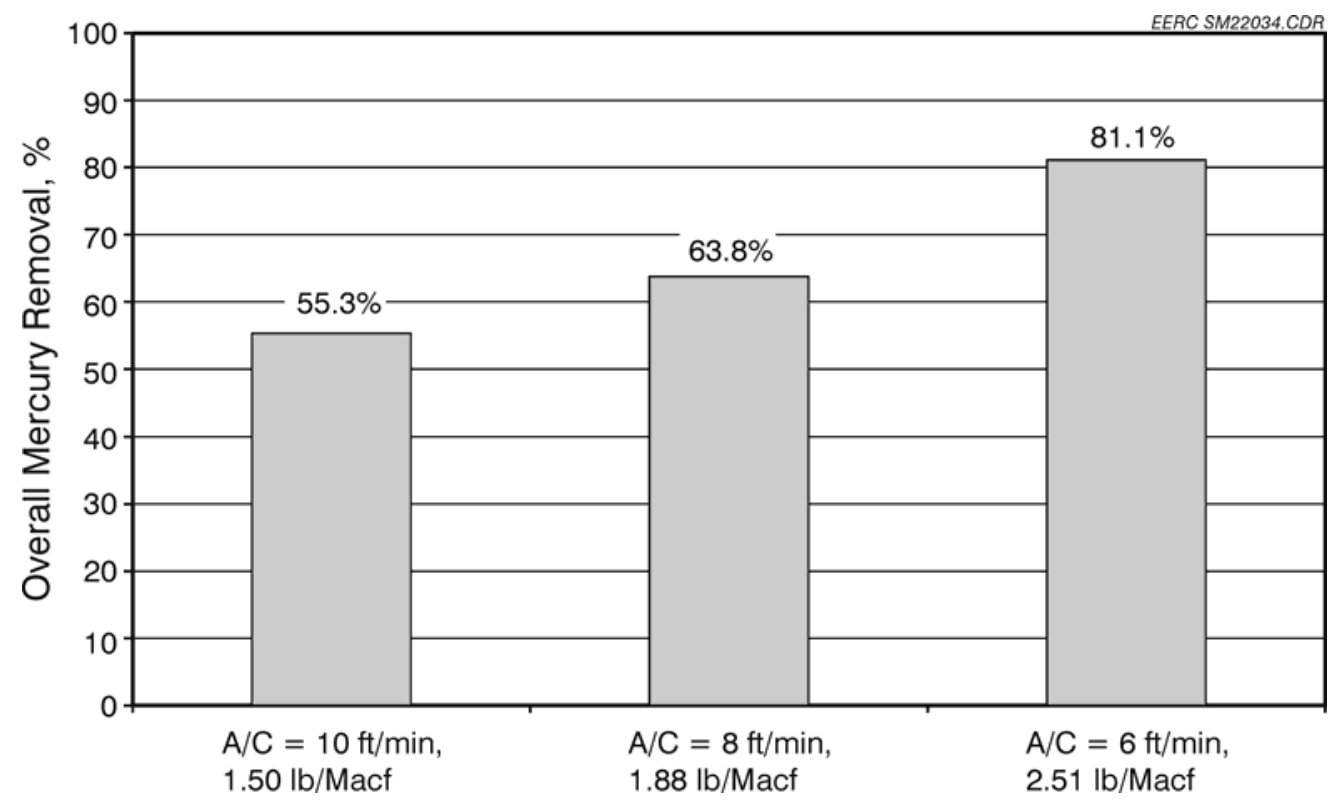

Figure 6.3.4.4. Mercury collection efficiencies under different filtration velocities (May 14, 2003). 


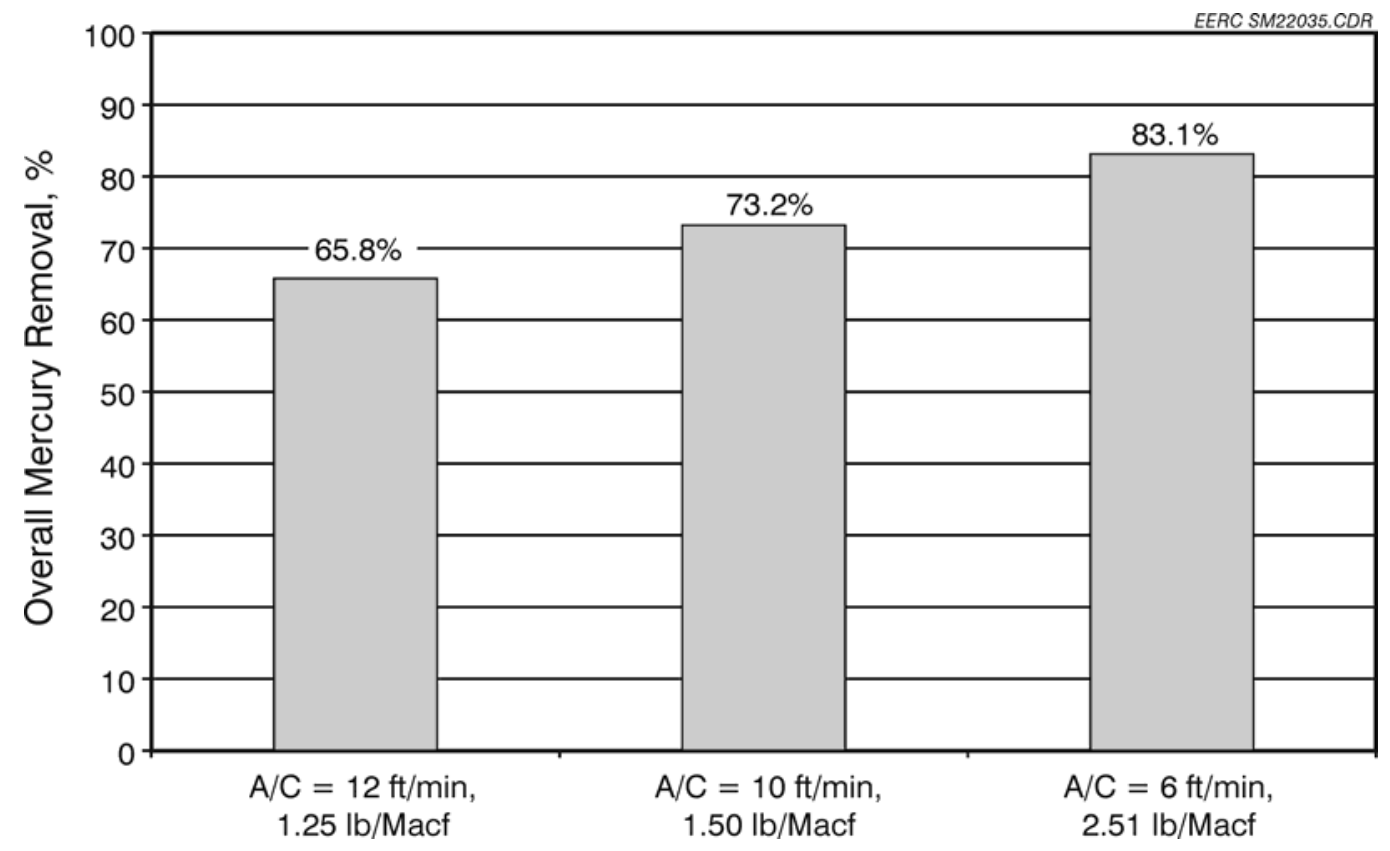

Figure 6.3.4.5. Mercury collection efficiencies under different filtration velocities (May 15, 2003).

at the $3 \mathrm{~m} / \mathrm{min}(10 \mathrm{ft} / \mathrm{min})$ and $1.8 \mathrm{~m} / \mathrm{min}(6 \mathrm{ft} / \mathrm{min})$, compared to May 14, 2003 testing data, may be the result of more oxidized mercury in the flue gas on May 15 (Figures 6.3.4.1 and 6.3.4.2).

To further confirm the filtration velocity effect on mercury removal with carbon injection, another test was conducted on May 20, 2003. Approximately 70 tons of TDF and 70 tons of waste seed (Table 6.3.4.2) were cofiring with the Belle Ayr coal on May 19-20, which resulted in more oxidized mercury in the flue gas. The total mercury collection efficiency (Figure 6.3.4.6) was $76.9 \%$ at $4.3 \mathrm{~m} / \mathrm{min}(14 \mathrm{ft} / \mathrm{min})$, increased to $82 \%$ at $3 \mathrm{~m} / \mathrm{min}(10 \mathrm{ft} / \mathrm{min})$ and $93.9 \%$ at $1.8 \mathrm{~m} / \mathrm{min}$ ( $6 \mathrm{ft} / \mathrm{min})$, again showing the beneficial effect of reducing filtration velocity on mercury removal in the Advanced Hybrid ${ }^{\mathrm{TM}}$ filter. The higher mercury removal in this test compared to the previous two tests was likely because of the high percentage of oxidized mercury and somewhat lower total mercury vapor in the flue gas (Figures 6.3.4.1 and 6.3.4.2).

All three short-term individual tests showed that reducing the filtration velocity at a fixed carbon injection rate of $0.3 \mathrm{~kg} / \mathrm{hr}(0.65 \mathrm{lb} / \mathrm{hr})$ improved mercury removal in the Advanced Hybrid $^{\mathrm{TM}}$ filter. This improvement is likely the result of both increased carbon-to-mercury ratio and better contact between mercury and carbon. 


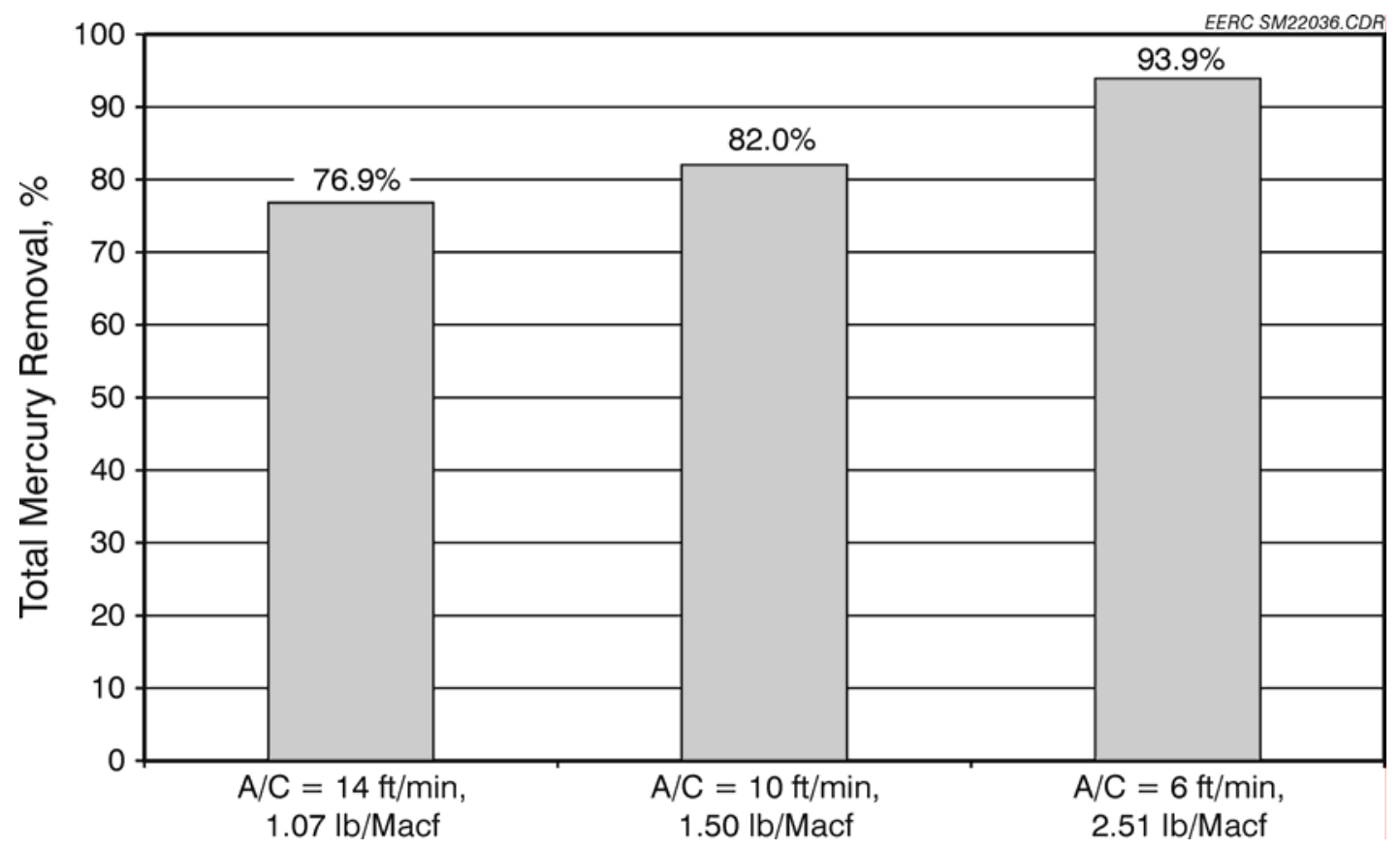

Figure 6.3.4.6. Mercury collection efficiencies under different filtration velocities

(May 20, 2003).

\section{Effect of the Sorbent In-Flight Time on Mercury Removal}

Mercury removal is divided into three stages in the Advanced Hybrid ${ }^{\mathrm{TM}}$ filter configuration: 1) in-flight adsorption by carbon, 2) adsorption by carbon collected on the perforated plates, and 3) fixed-bed adsorption on the filter bag surface. The in-flight mercury adsorption is limited because of a short contact time between the bulk gas-phase mercury in the flue gas and the in-flight carbon. The mercury capture by carbon collected on the perforated plates may be somewhat greater than the in-flight mercury capture because of 1) longer residence time of activated carbon in the Advanced Hybrid ${ }^{\mathrm{TM}}$ filter unit, approximately 30 min or longer, depending on the plate-rapping and bag-cleaning intervals; 2) extended contact time between mercury in the flue gas and sorbent on the perforated plates due to the local recirculation of the flue gas; and 3) enhanced mass transfer from the bulk gas-phase mercury to the carbon surface since the flue gas flows straight toward the perforated plate instead of in a parallel flow with the plates in a conventional ESP. The fixed-bed adsorption on the filter bags is capacity-limited rather than mass transfer-limited. 
To further understand the detailed mercury capture mechanisms in the Advanced Hybrid ${ }^{\mathrm{TM}}$ filter with carbon injection, the carbon injection location was switched from the normal inlet elbow location to the closer inlet transition zone on June 2-3, 2003, while other operating parameters were the same: $3 \mathrm{~m} / \mathrm{min}(10 \mathrm{ft} / \mathrm{min})$ filtration velocity and $0.3 \mathrm{~kg} / \mathrm{hr}(0.65 \mathrm{lb} / \mathrm{hr}) \mathrm{FGD}$ carbon injection rate. Subsequently, the in-flight time of activated carbon was reduced by roughly $50 \%$. Figure 6.3.4.7 plots the measured mercury overall collection efficiencies under the two different in-flight times, showing almost the same levels of mercury capture: $58.4 \%$ at the inlet elbow vs. $60.9 \%$ at the inlet transition. The extended sorbent in-flight time did not benefit mercury capture with the Advanced Hybrid ${ }^{\mathrm{TM}}$ filter. At the end of this test, the ESP power was shut down when carbon was injected from the inlet transition zone, resulting in a $20 \%$ increase of mercury removal. The additional gain was because all of the activated carbon was uniformly collected on the filter bags. This indicates that in-flight mercury capture is not a dominant capture mechanism.

\section{Effect of Carbon Injection Rate on Mercury Removal}

On May 12, 2003, when the FGD carbon injection rate was set as $0.3 \mathrm{~kg} / \mathrm{hr}(0.65 \mathrm{lb} / \mathrm{hr})$, corresponding to $24 \mathrm{mg} / \mathrm{m}^{3}$ (1.5 lb/Macf), the mercury removal efficiency was $71.6 \%$ (Figure

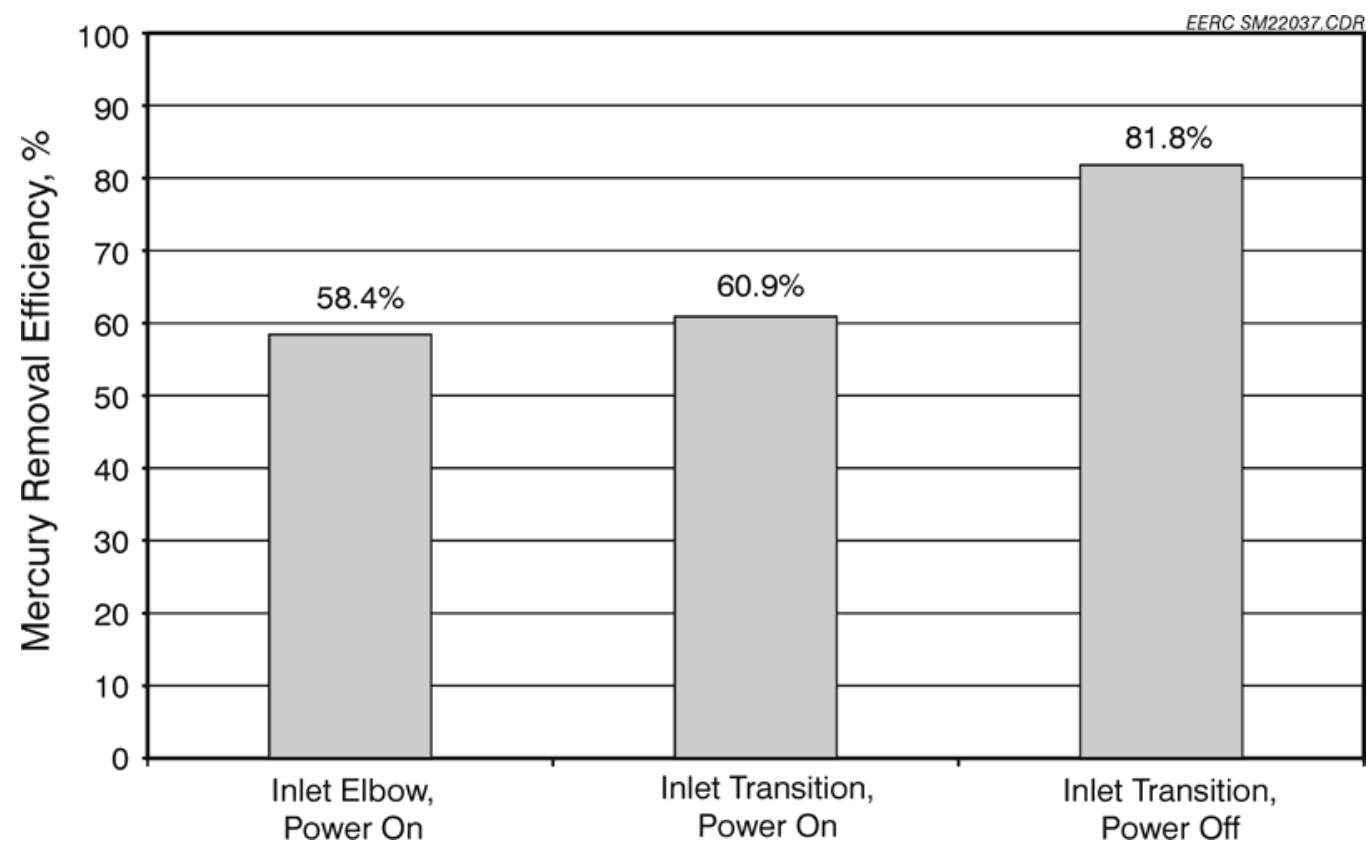

Figure 6.3.4.7. Measured mercury overall collection efficiencies under the two different sorbent in-flight times (June 2-3, 2003). 
6.3.4.8). While keeping all other operating parameters the same, the FGD carbon injection rate was doubled to $0.6 \mathrm{~kg}\left(1.3 \mathrm{lb} / \mathrm{hr}\right.$ ), corresponding to $48 \mathrm{mg} / \mathrm{m}^{3}$ (3 lb/Macf). The overall mercury collection efficiency, however, only slightly increased to $74.0 \%$ (Figure 6.3.4.8), which was somewhat surprising. A possible reason for the marginal benefit gained from the double carbon injection rate is that the effectiveness of activated carbon to capture mercury may be limited by the amount of $\mathrm{HCl}$ in the flue gas.

\section{Effect of ESP Power on Mercury Removal}

During the 1-month test, the ESP power was shut down temporarily several times to confirm the maximum mercury capture efficiency of the NORIT FGD carbon at different filtration velocities. With the high-voltage power off, the Advanced Hybrid ${ }^{\mathrm{TM}}$ filter unit was operated as a PJBH with a BCI of $60 \mathrm{~min}$. Because of the unique geometric configuration of the Advanced Hybrid ${ }^{\mathrm{TM}}$ filter, the flue gas into the Advanced Hybrid ${ }^{\mathrm{TM}}$ filter unit is evenly distributed among all of the filter bags when the unit was operated as a PJBH. However, the side inlet of the unit and the larger spacing between bag rows make gas distribution in the Advanced Hybrid $^{\mathrm{TM}}$ filter without ESP power more ideal than in a conventional PJBH. Therefore, a

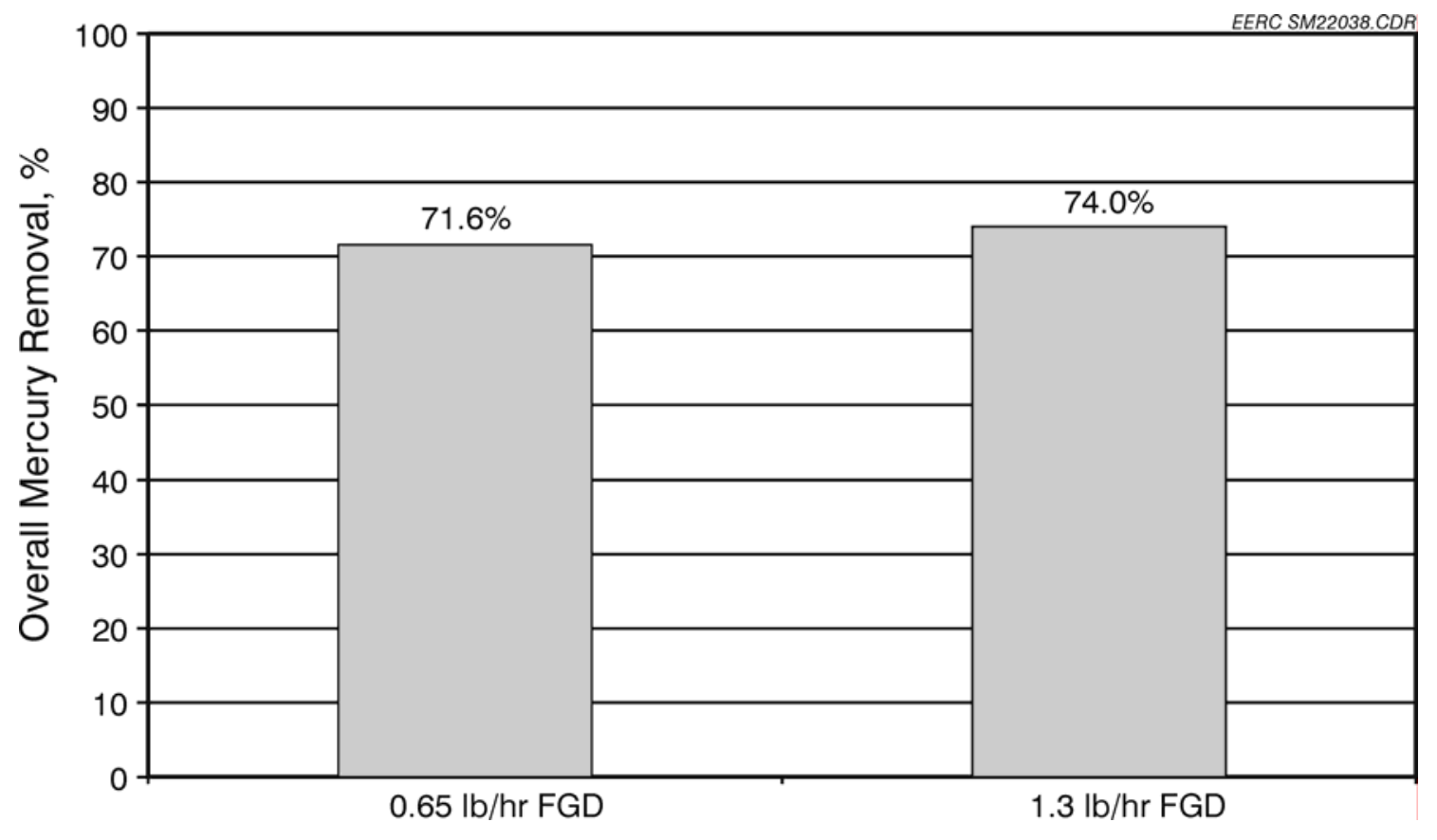

Figure 6.3.4.8. The effect of sorbent injection rate on mercury removal (May 12, 2003). 
comparison of mercury removal in the Advanced Hybrid ${ }^{\mathrm{TM}}$ filter with and without ESP power is not the same as a comparison between the Advanced Hybrid ${ }^{\mathrm{TM}}$ filter and a conventional PJBH.

A summary of mercury removal efficiencies with the ESP power on and off (Figure 6.3.4.9) shows consistently higher levels of mercury capture when the ESP was shut down, which suggests better or more uniform gas-solid contact. The pressure drop across the Advanced Hybrid $^{\mathrm{TM}}$ filter unit, however, was dramatically increased when the ESP power was off, reaching as high as $3.3 \mathrm{kPa}$ (13 in. W.C.) depending on filtration velocity.

\section{Effect of Iodine-Impregnated Carbon on Mercury Removal}

On May, 17 2003, IAC provided by Barneby \& Sutcliffe was tested in the Advanced Hybrid $^{\mathrm{TM}}$ filter unit at an injection rate of $0.2 \mathrm{~kg} / \mathrm{hr}(0.46 \mathrm{lb} / \mathrm{hr})$, corresponding to $17.6 \mathrm{mg} / \mathrm{m}^{3}$ $(1.1 \mathrm{lb} / \mathrm{Macf})$, to evaluate its effectiveness on mercury removal. The overall mercury collection efficiency, however, was only 57.3\% (shown in Figure 6.3.4.10), which is lower than expected. A possible reason is that the particle size of the IAC is -200 mesh (less than $74 \mu \mathrm{m}$ ), which is larger than the NORIT FGD carbon whose size is -325 mesh (less than $45 \mu \mathrm{m}$ ), according to supplier information. The larger-sized IAC results in a less efficient usage of the activated

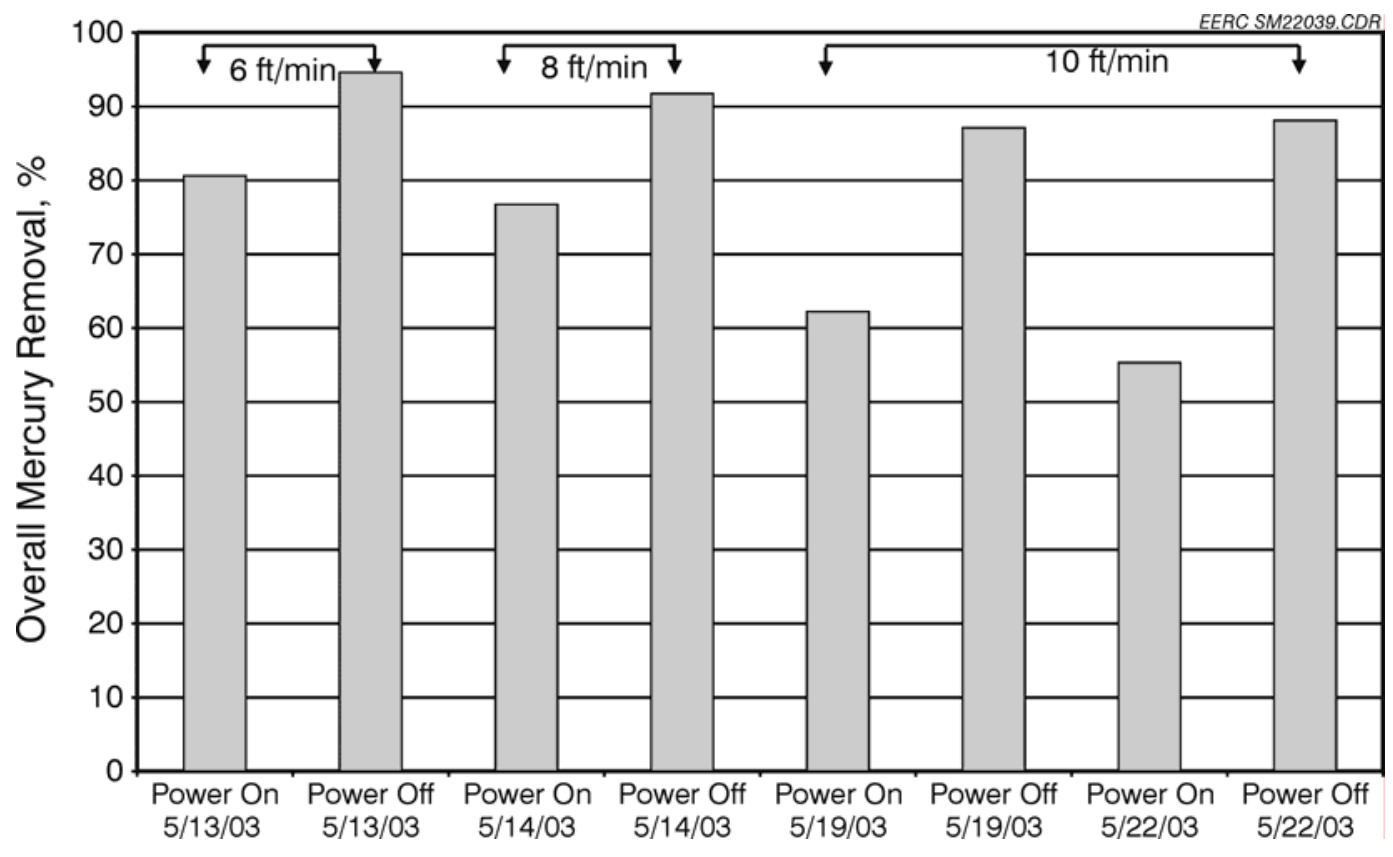

Figure 6.3.4.9. Summary of mercury removal efficiencies with the ESP power on and off. 
carbon. The ESP power was shut off for a short time to confirm the maximum mercury removal by IAC, showing only increased to $64.5 \%$, a lower mercury capture than that of the FGD carbon at the same injection rate.

\subsubsection{Results from Mercury Stability Tests}

Two Advanced Hybrid ${ }^{\mathrm{TM}}$ filter hopper ashes were collected on May 10 and 21, 2003, labeled as 03-061 and 03-060, respectively, and evaluated at the EERC for mercury stability as part of another project. More detailed discussion can be found in the DOE report $(12,13)$.

Table 6.3.4.4 lists the total mercury contents of the Advanced Hybrid ${ }^{\mathrm{TM}}$ filter ash samples, showing moderate levels of mercury concentration with both samples in the range typically seen in standard coal combustion fly ash samples produced without mercury emission controls. However, the mercury concentration for Sample 03-060 was approximately three times greater than that for 03-061, indicating improved mercury capture with the addition of a carbon-based sorbent.

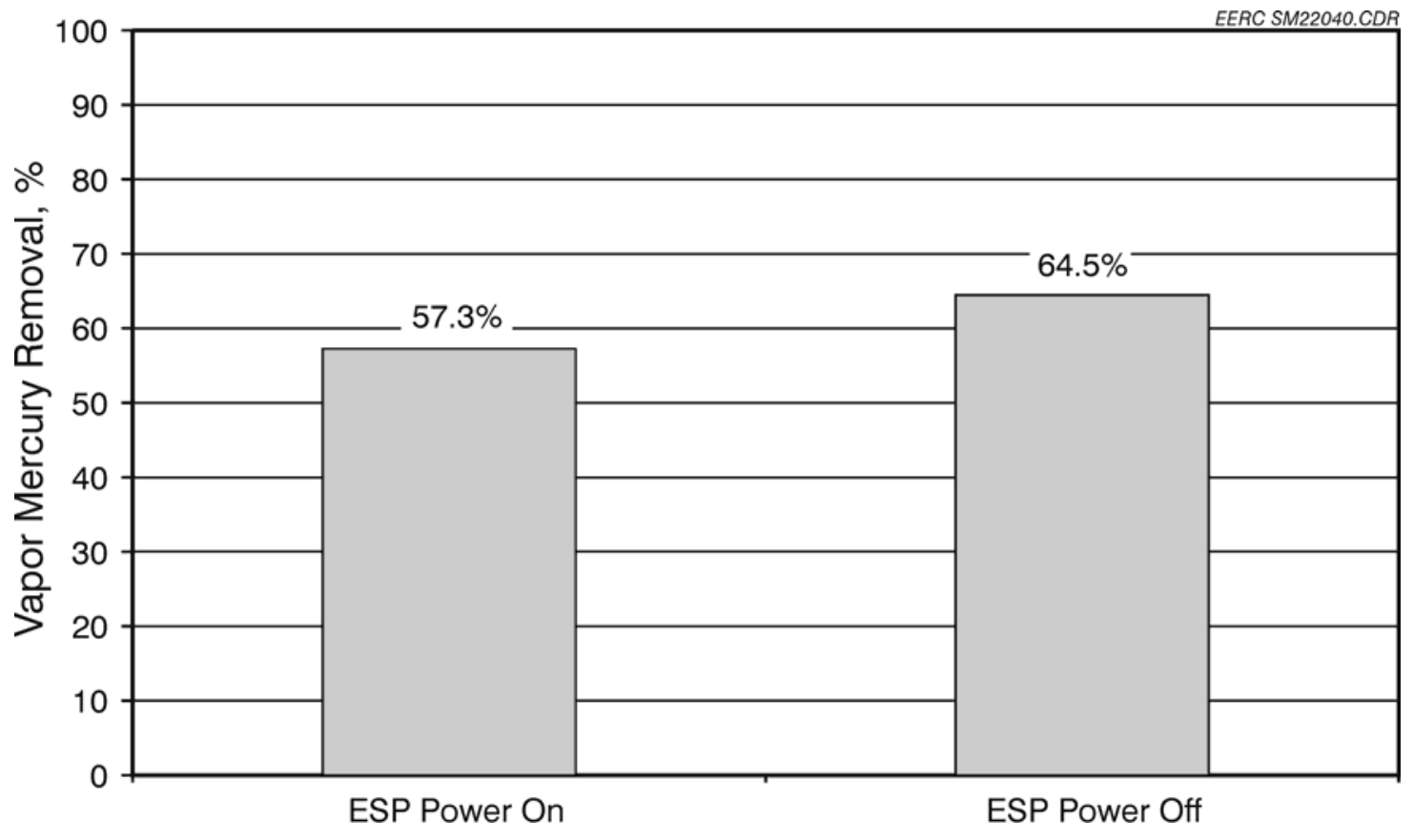

Figure 6.3.4.10. Mercury removals with the 2.5-MW (9000-acfm) Advanced Hybrid ${ }^{\mathrm{TM}}$ filter under $17.6 \mathrm{mg} / \mathrm{m}^{3}$ (1.1-lb/Macf) IAC injection. 
Total major chemical composition is reported as \% oxides for the Advanced Hybrid ${ }^{\mathrm{TM}}$ filter samples is shown in Table 6.3.4.5. Moisture and LOI are also included in Table 6.3.4.5. The dominant carbon form in Sample 03-060 was anisotropic coke, whereas it was isotropic coke in Sample 03-061. These carbon forms have been shown to be present in samples containing activated carbon and to be associated with elevated mercury concentrations in coal combustion fly ash where they are present.

\section{SGLP and LTL Leaching Results}

Leaching data, including final leachate $\mathrm{pH}$ and mercury concentrations, for the Advanced Hybrid $^{\mathrm{TM}}$ filter samples using synthetic groundwater leaching procedure (SGLP), 30-day, and 60-day long-term leaching (LTL) tests are shown in Table 6.3.4.6.

Most leaching testing data show the mercury concentrations in the leachate solutions were below detection limit except for the 60-day LTL tests where both 03-060 and 03-061 samples indicated measurable mercury concentrations of $0.034 \mu \mathrm{g} / \mathrm{L}$ and $0.33 \mu \mathrm{g} / \mathrm{L}$, respectively, in the leachate solutions.

Table 6.3.4.4. Total Mercury Content of Advanced Hybrid ${ }^{\mathrm{TM}}$ Filter Samples, $\mu \mathrm{g} / \mathrm{g}$

\begin{tabular}{lc}
\hline ID No. & $\mathrm{Hg}$ \\
\hline $03-060$ & 1.86 \\
$03-061$ & 0.578 \\
\hline
\end{tabular}

Table 6.3.4.5. Bulk Oxide Data for Advanced Hybrid ${ }^{\mathrm{TM}}$ Filter Samples (\%)

\begin{tabular}{l|c|c|c|c|c|c|c|c|c|c|c|c|c|c|c}
\hline ID No. & $\mathrm{SiO}_{2}$ & $\mathrm{Al}_{2} \mathrm{O}_{3}$ & $\mathrm{Fe}_{2} \mathrm{O}_{3}$ & $\mathrm{CaO}$ & $\mathrm{MgO}$ & $\mathrm{Na}_{2} \mathrm{O}$ & $\mathrm{K}_{2} \mathrm{O}$ & $\mathrm{TiO}_{2}$ & $\mathrm{MnO}_{2}$ & $\mathrm{P}_{2} \mathrm{O}_{5}$ & $\mathrm{SrO}$ & $\mathrm{BaO}$ & $\mathrm{SO}_{3}$ & LOI & $\begin{array}{c}\text { Moisture, as } \\
\text { received }\end{array}$ \\
\hline $03-060$ & 30.07 & 17.63 & 5.87 & 27.50 & 6.11 & 2.42 & 0.68 & 1.35 & 0.02 & 2.31 & 0.44 & 0.84 & 2.54 & 2.22 & 0.09 \\
\hline $03-061$ & 22.64 & 17.25 & 6.87 & 31.56 & 8.48 & 2.99 & 0.49 & 1.21 & 0.03 & 1.24 & 0.19 & 0.87 & 4.73 & 1.15 & 0.11 \\
\hline
\end{tabular}

Table 6.3.4.6. Leaching Data on Advanced Hybrid ${ }^{\mathrm{TM}}$ Filter Samples, $\mu \mathrm{g} / \mathrm{L}$

\begin{tabular}{lccc}
\hline ID No. & Test & $\mathrm{Hg}$ & $\mathrm{pH}$ \\
\hline $03-060$ & SGLP & $<0.01$ & 12.15 \\
$03-060$ & 30 LTL & $<0.01$ & 12.46 \\
$03-060$ & $60 \mathrm{LTL}$ & 0.034 & 12.38 \\
$03-061$ & SGLP & $<0.01$ & 12.40 \\
$03-061$ & 30 LTL & $<0.01$ & 12.63 \\
$03-061$ & 60 LTL & 0.33 & 12.58 \\
\hline
\end{tabular}




\section{Microbiological Releases}

Microbiological leaching tests were completed for Sample 03-060, and the results are shown in Table 6.3.4.7. These results show that more elemental mercury is being released from the flasks than organomercury. The mass of elemental mercury released from the flasks in the aerobic environment was much higher than in the anaerobic environment. All mercury releases and final bacterial counts were greater in the glucose-fed flasks than in the starved flasks.

\section{Long-Term Ambient Temperature Release}

Long-term ambient temperature mercury release results obtained from individual sample containers for this effort are shown in Figure 6.3.4.11, including the Advanced Hybrid ${ }^{\mathrm{TM}}$ filter samples. Over the duration of the entire 187 days of the experiment, five samples showed overall mercury release, including the Advanced Hybrid ${ }^{\mathrm{TM}}$ filter samples, and seven samples showed overall mercury sorption. The release of mercury, expressed as $\mathrm{pg} / \mathrm{g} / \mathrm{day}$, was less for most samples in the final 90-day collection period than for the previous 90-day collection period. As evident in Figure 6.3.4.11, the variability of the data is relatively high, averaging -0.0002 $\mathrm{pg} / \mathrm{g} / \mathrm{day}$. In part, the variability can be attributed to the variability inherent in the analysis of the extremely low concentrations of mercury captured by and desorbed from the gold-coated analytical traps.

\section{Thermal Desorption at Elevated Temperatures}

Thermal desorption results for the Advanced Hybrid ${ }^{\mathrm{TM}}$ filter sample are shown in Figures 6.3.4.12 and 6.3.4.13. The thermal curves generated for each of these samples show one peak of mercury release. The peak mercury release was at $395^{\circ} \mathrm{C}\left(743^{\circ} \mathrm{F}\right)$ for Sample $03-060$ and $383^{\circ} \mathrm{C}$ $\left(721^{\circ} \mathrm{F}\right)$ for Sample 03-061.

\subsubsection{Conclusions}

The gaseous mercury concentration in the flue gas during the May 2003 test ranged from $4.98-10.6 \mu \mathrm{g} / \mathrm{m}^{3}$ with $20 \%$ to $70 \% \mathrm{Hg}^{0}$. The variation in mercury speciation is likely caused by varying coal as well as cofiring TDF and waste seeds.

At low carbon feed concentrations, in the range of $17-48 \mathrm{mg} / \mathrm{m}^{3}(1-3 \mathrm{lb} / \mathrm{Macf})$, the Advanced Hybrid ${ }^{\mathrm{TM}}$ filter demonstrated overall mercury collection efficiencies, from $65 \%$ to $95 \%$. On further increasing carbon concentration in the flue gas, however, only a marginal 
Table 6.3.4.7. Microbiologically Mediated Release of Vapor-Phase Mercury and Total Bacterial Count Data for Sample 03-060

\begin{tabular}{|c|c|c|c|c|c|c|c|}
\hline Condition & $\begin{array}{c}\text { Elemental } \\
\text { Mercury, pg/g } \\
\text { (pg/g/day) }\end{array}$ & $\begin{array}{l}\text { Organomercury, } \\
\mathrm{pg} / \mathrm{g} \text { (pg/g/day) }\end{array}$ & $\begin{array}{c}\text { Bacterial } \\
\text { Count, \#/mL }\end{array}$ & Condition & $\begin{array}{c}\text { Elemental } \\
\text { Mercury, pg/g } \\
\text { (pg/g/day) }\end{array}$ & $\begin{array}{l}\text { Organomercury, } \\
\mathrm{pg} / \mathrm{g} \text { (pg/g/day) }\end{array}$ & $\begin{array}{c}\text { Bacterial } \\
\text { Count, \#/mL }\end{array}$ \\
\hline $\begin{array}{l}\text { Anaerobic- } \\
\text { Fed }\end{array}$ & $2.42(0.0691)$ & $0.28(0.0080)$ & $>24,000,000$ & Aerobic-fed & $57.9(1.65)$ & $0.36(0.0103)$ & $>24,000,000$ \\
\hline $\begin{array}{l}\text { Anaerobic- } \\
\text { Fed }\end{array}$ & $3.21(0.0917)$ & $0.26(0.0074)$ & $1,500,000$ & Aerobic-fed & $22.8(0.651)$ & $0.62(0.0177)$ & $>24,000,000$ \\
\hline $\begin{array}{l}\text { Anaerobic- } \\
\text { Fed }\end{array}$ & $1.15(0.0329)$ & $0.07(0.0020)$ & 930,000 & Aerobic-fed & $45.7(1.31)$ & $0.25(0.0071)$ & $>24,000,000$ \\
\hline $\begin{array}{l}\text { aerobic- } \\
\text { Starved }\end{array}$ & $0.87(0.0249)$ & $0.04(0.0011)$ & $<30$ & $\begin{array}{l}\text { Aerobic- } \\
\text { starved }\end{array}$ & $0.85(0.0243)$ & $0.09(0.0026)$ & 4300 \\
\hline $\begin{array}{l}\text { Anaerobic- } \\
\text { Starved }\end{array}$ & $0.75(0.0214)$ & $0.03(0.0009)$ & 40 & $\begin{array}{c}\text { Aerobic- } \\
\text { starved }\end{array}$ & $0.71(0.0203)$ & $0.07(0.0020)$ & 430 \\
\hline $\begin{array}{l}\text { Anaerobic- } \\
\text { Starved }\end{array}$ & $1.72(0.0491)$ & $0.07(0.0020)$ & 40 & $\begin{array}{c}\text { Aerobic- } \\
\text { starved }\end{array}$ & $1.34(0.0383)$ & $0.06(0.0017)$ & $<30$ \\
\hline
\end{tabular}




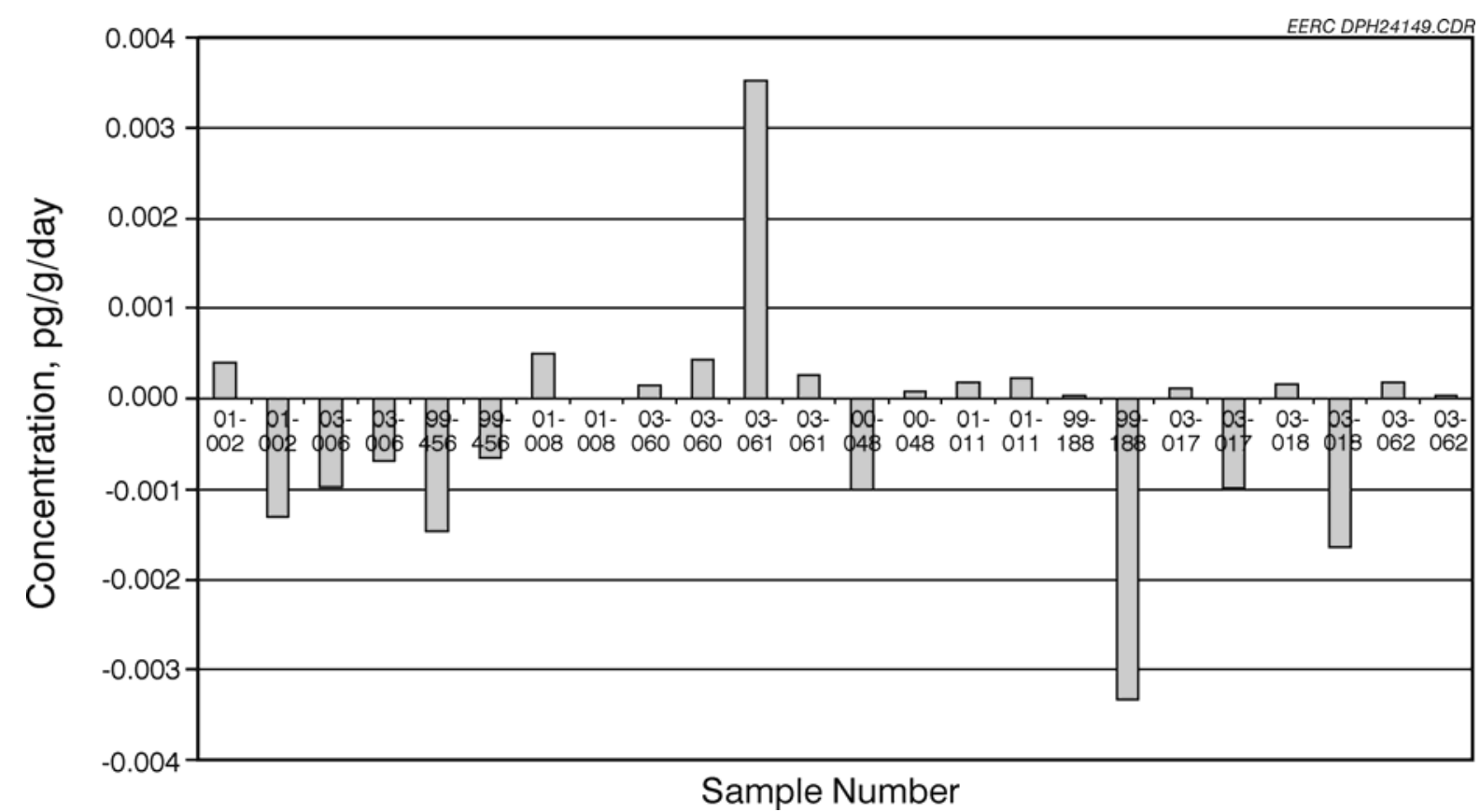

Figure 6.3.4.11. Average total long-term ambient-temperature mercury release or sorption as related to blank values, $\mathrm{pg} / \mathrm{g} / \mathrm{day}$. Positive values indicate release and negative values indicate sorption of mercury.

Run No. 1087

Start

Oct 2, $2004 \quad 01: 27: 37$

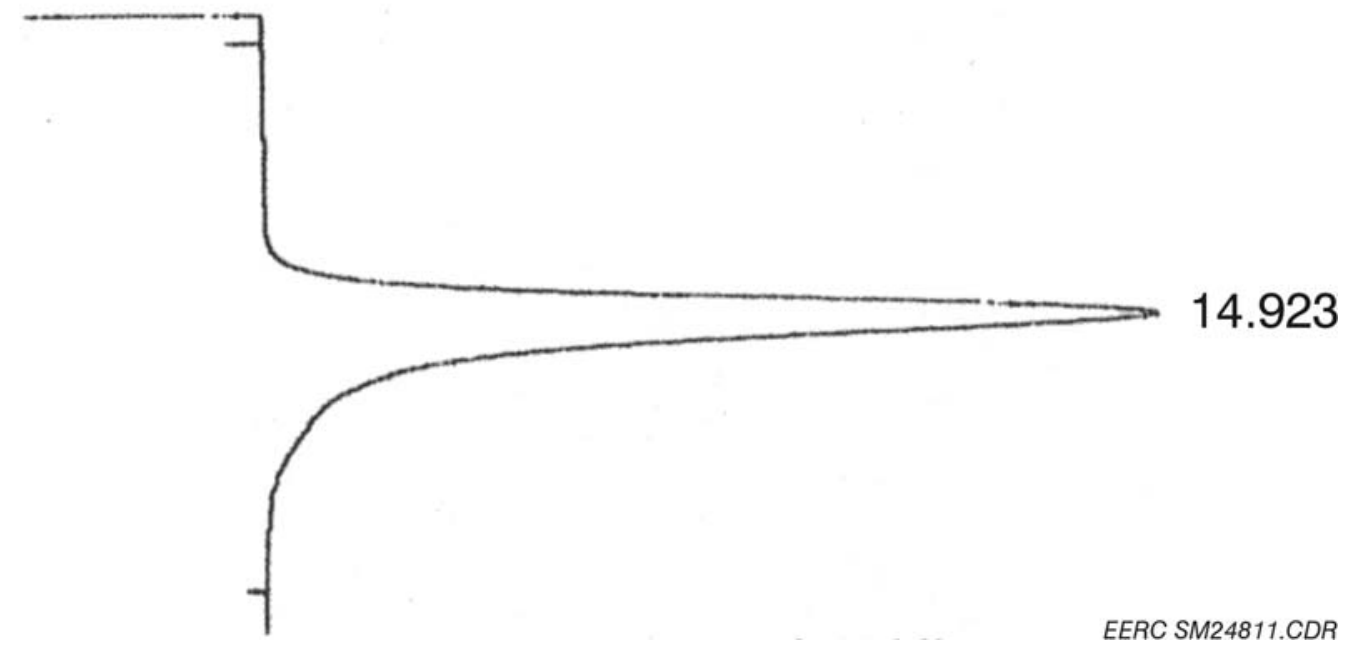

Figure 6.3.4.12. Thermal desorption curve for Sample 03-060. 
Run No. 1088

Oct. 2, $2004 \quad 23: 55: 18$

Start

EERC SM24810.CDR

Figure 6.3.4.13. Thermal desorption curve for Sample 03-061

benefit was seen on mercury removal, possibly due to the low level of $\mathrm{HCl}$ in the WSB coal flue gas.

Extending the in-flight time of sorbent did not benefit mercury capture in the Advanced Hybrid $^{\mathrm{TM}}$ filter significantly.

The leaching experiments indicated that the mercury present was not readily leached from the ash samples. There is no observable correlation between total mercury and leachable mercury.

Organomercury compounds were present in leachates from microbiological experiments, but the data reported on microbiological rerelease of mercury are too preliminary for reliable comparisons to be drawn at this time.

The Advanced Hybrid ${ }^{\mathrm{TM}}$ filter samples appeared to release a small amount of mercury in the long-term ambient temperature release experiments. Most other samples evaluated act as mercury sinks in ambient-temperature vapor-phase release experiments.

The Advanced Hybrid ${ }^{\mathrm{TM}}$ filter samples released mercury in the elevated temperature release experiments, and both samples released mercury at similar temperatures. This indicated that the mercury forms present are likely similar. Most samples evaluated exhibit a single- or 
double- peak mercury release profile, and mercury is generally released at temperatures greater than $200^{\circ} \mathrm{C}\left(392^{\circ} \mathrm{F}\right)$.

\subsection{Pilot-Scale Testing of Mercury Oxidation Upstream of Dry Scrubber 6.4.1 Test Conditions}

A brief summary of the results of this work are provided in this section. Further details of the mercury oxidation work are provided in a separate report (14).

A North Dakota lignite from Center Mine was burned in the pilot-scale combustion system to test various $\mathrm{Hg}$ control strategies. The coal combustion flue gas was cooled to approximately $149^{\circ} \mathrm{C}\left(300^{\circ} \mathrm{F}\right)$ before entering the SDA and PJBH. Seven tests were completed to evaluate the effectiveness of potential $\mathrm{Hg}$ sorbents (NORIT FGD) and $\mathrm{Hg}^{0}$ oxidation and sorbent enhancement additives $\left(\mathrm{NaCl}, \mathrm{SEA} 2\right.$, and $\left.\mathrm{CaCl}_{2}\right)$ to remove $\mathrm{Hg}$ using an SDA and PJBH. The test matrix is presented in Table 6.4.1. Potential $\mathrm{Hg}^{0}$ oxidation and sorbent enhancement additives were metered into the coal using a screw feeder prior to combustion, whereas the $\mathrm{Hg}$ sorbents were metered with a K-Tron dual-screw feeder upstream of the SDA.

Two CMMs were used to measure $\mathrm{Hg}^{0}$ and $\mathrm{Hg}(\mathrm{g})$ concentrations simultaneously at the SDA inlet and FF outlet locations to determine the $\mathrm{Hg}(\mathrm{g})$ removal efficiency of various control strategies designed to improve the mercury capture of the SDA-PJBH pollutant control system.

Table 6.4.1 Mercury Control Test Matrix

\begin{tabular}{|c|c|c|c|}
\hline $\begin{array}{l}\text { Coal } \\
\text { Additive }\end{array}$ & $\begin{array}{l}\text { Feed Rate, } \mathrm{mg} / \mathrm{m}^{3} \\
(\mathrm{lb} / \text { Macf })\end{array}$ & Sorbent & $\begin{array}{l}\text { Injection Rate, } \mathrm{mg} / \mathrm{m}^{3} \\
\text { (lb/Macf) }\end{array}$ \\
\hline None & NA & None & NA \\
\hline None & NA & NORIT FGD & $\begin{array}{l}29.44,58.72,117.6 \text {, and } 176.0 \\
(1.84,3.67,7.35, \text { and } 11.0)\end{array}$ \\
\hline $\mathrm{NaCl}$ & $\begin{array}{l}58.72,117.6 \text {, and } 176.0 \\
(3.67,7.35, \text { and } 11.0)\end{array}$ & None & NA \\
\hline $\mathrm{NaCl}$ & $\begin{array}{l}58.72,117.6 \text {, and } 176.0 \\
(3.67,7.35 \text {, and } 11.0)\end{array}$ & NORIT FGD & $\begin{array}{l}58.72 \\
(3.67)\end{array}$ \\
\hline SEA2 & $\begin{array}{l}29.44 \text { and } 58.72 \\
(1.84 \text { and } 3.67)\end{array}$ & None & NA \\
\hline SEA2 & $\begin{array}{l}29.44 \text { and } 58.72 \\
(1.84 \text { and } 3.67)\end{array}$ & NORIT FGD & $\begin{array}{l}29.44 \\
(1.84)\end{array}$ \\
\hline $\mathrm{CaCl}_{2}$ & $\begin{array}{l}58.72,117.6 \text {, and } 176.0 \\
(3.67,7.35, \text { and } 11.0)\end{array}$ & None & NA \\
\hline $\mathrm{CaCl}_{2}$ & $\begin{array}{l}58.72,117.6 \text {, and } 176.0 \\
(3.67,7.35, \text { and } 11.0)\end{array}$ & NORIT FGD & $\begin{array}{l}58.72 \\
(3.67)\end{array}$ \\
\hline
\end{tabular}


During tests involving the addition of Cl-containing compounds, infrared spectroscopy (Model $15^{\circ} \mathrm{C} \mathrm{HCl}$ analyzer) combined with a Perma Pure GASS ${ }^{\text {TM }}$ drying system was used to measure $\mathrm{HCl}$ concentrations at the SDA inlet.

\subsubsection{Coal and Flue Gas Analyses}

Proximate and ultimate analysis results for the North Dakota Center Mine lignite are presented in Tables 6.4.2 and 6.4.3, respectively. The $\mathrm{Hg}$ and $\mathrm{Cl}$ contents of the Center lignite are presented in Table 6.4.4. Based on the proximate and ultimate analysis data, theoretically, the $\mathrm{Hg}$ (total) and $\mathrm{HCl}$ concentrations of the Center lignite combustion flue gas should be $13.8 \mu \mathrm{g} / \mathrm{Nm}^{3}$ and $1.59 \mathrm{ppmv}$, respectively (on a dry flue gas at $3.0 \% \mathrm{O}_{2}$ basis).

Table 6.4.4 summarizes the representative flue gas compositions in the North Dakota lignite flue gas entering the SDA. CO concentrations ranged from $<50$ to $145 \mathrm{ppmv}$, which is

Table 6.4.2 Center Lignite Coal Proximate Analysis Results

\begin{tabular}{lc}
\hline Analysis Parameters & Concentration, as-received, $\mathrm{wt} \%$ \\
\hline Moisture & 30.5 \\
Volatile Matter & 33.4 \\
Fixed Carbon & 29 \\
Ash & 7.19 \\
Heating Value, Btu/lb & 7330 \\
\hline
\end{tabular}

Table 6.4.3 Center Lignite Coal Ultimate Analysis Results

\begin{tabular}{lc}
\hline Analysis Parameters & Concentration, as-received, \\
\hline Carbon & 43.8 \\
Hydrogen $^{1}$ & 2.82 \\
Nitrogen & 0.83 \\
Sulfur & 0.84 \\
Ash & 7.19 \\
Oxygen (by difference) $^{1}$ & 14 \\
Total Moisture $^{1}$ & 30.5 \\
\hline
\end{tabular}

${ }^{1}$ Hydrogen and oxygen do not include $\mathrm{H}$ and $\mathrm{O}$ in sample moisture.

Table 6.4.4 Major Flue Gas Compositions of Center Lignite Flue Gas

\begin{tabular}{lllll}
\hline $\mathrm{O}_{2}, \%$ & $\mathrm{CO}_{2}, \%$ & $\mathrm{CO}, \mathrm{ppm}$ & $\mathrm{NO}_{\mathrm{x}}, \mathrm{ppm}$ & $\mathrm{SO}_{2}, \mathrm{ppm}$ \\
\hline $4-6$ & $14-16$ & $<50-145$ & $560-0710$ & $438-854$ \\
\hline
\end{tabular}


indicative of efficient coal combustion and thus very low concentrations of unburned carbon in the fly ash. SDA inlet $\mathrm{SO}_{2}$ concentrations ranged from 438 to $854 \mathrm{ppm}$, which is similar to the calculated $\mathrm{SO}_{2}$ concentration, based on proximate and ultimate coal analysis. The concentration of NOx was in the range of 560-710 ppm.

\subsubsection{Discussion of Mercury Results}

\section{Baseline Test}

Compared in Figure 6.4.1 are mercury results that were obtained simultaneously using the Ontario Hydro method and CMMs during the combustion of Center coal at the SDA and PJBH inlet and outlet showing little mercury removal.

\section{NORIT FGD Carbon Injection Tests}

During this test, the NORIT FGD carbon was continuously injected into the SDA at four different rates in the range of $29.44 \mathrm{mg} / \mathrm{m}^{3}(1.84 \mathrm{lb} / \mathrm{Macf})$ to $176.0 \mathrm{mg} / \mathrm{m}^{3}$ (11 lb/Macf). Table 6.4.5 summarizes the overall mercury capture efficiency across the SDA-PJBH in the carbon injection tests. Compared to the very low $2.5 \%$ inherent mercury capture in the baseline test, with carbon injection, the $\mathrm{Hg}(\mathrm{g})$ removal efficiency of the SDA-PJBH improved immediately

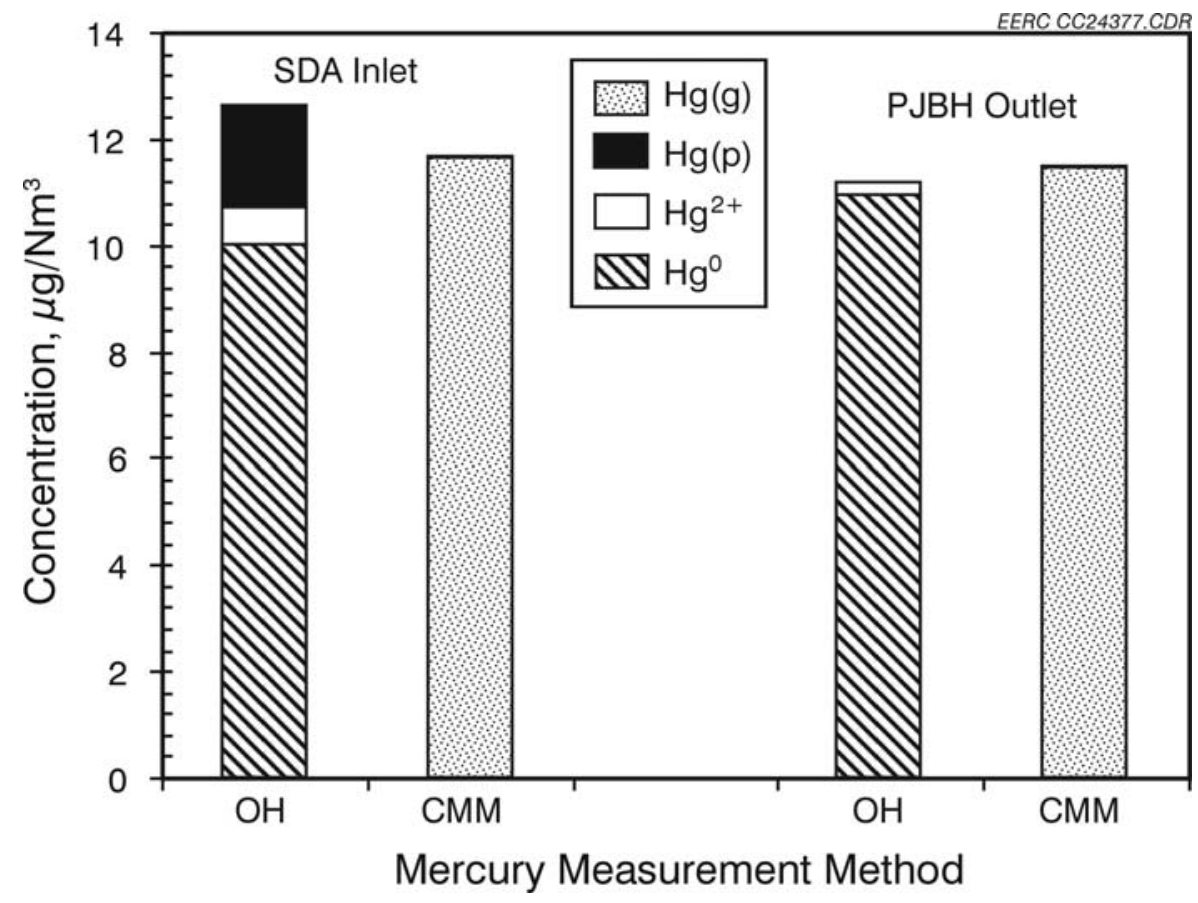

Figure 6.4.1. SDA inlet and PJBH outlet mercury results in the SDA and PJBH baseline test. 
Table 6.4.5 SDA-PJBH Hg(g) Removal Efficiencies (\%) with NORIT FGD Injection

\begin{tabular}{llllll}
\hline $\begin{array}{l}\text { Injection Rate, } \mathrm{mg} / \mathrm{m}^{3} \\
\text { (lb/Macf) }\end{array}$ & 0.0 & 29.44 & 58.72 & 117.6 & 176.0 \\
\hline Average & $(0.0)$ & $(1.84)$ & $(3.67)$ & $(7.35)$ & $(11)$ \\
& 40.0 & 584.0 & 691.2 & 888.0 & 948.8 \\
& $(2.5)$ & $(36.5)$ & $(43.2)$ & $(55.5)$ & $(59.3)$ \\
\hline 95\% Confidence Limit & \pm 13.12 & \pm 40.0 & \pm 20.8 & \pm 35.2 & \pm 54.4 \\
& $( \pm 0.82)$ & $( \pm 2.5)$ & $( \pm 1.3)$ & $( \pm 2.2)$ & $( \pm 3.4)$ \\
\hline
\end{tabular}

and continued to improve with increasing injection rates until it approached about $60 \%$ at an injection rate of $117.6 \mathrm{mg} / \mathrm{m}^{3}(7.35 \mathrm{lb} / \mathrm{Macf})$.

\section{Mercury Oxidation and Sorbent Enhancement Additive Performance}

Three mercury oxidation and sorbent enhancement additives including $\mathrm{NaCl}, \mathrm{CaCl}_{2}$, and SEA2 were tested separately for their effectiveness of mercury oxidation and capture across the SDA-PJBH in the North Dakota lignite flue gas. Additional tests were also completed to evaluate the beneficial effects of these additives on mercury sorbent injection technology.

Figure 6.4.2 and Table 6.4.6 summarize and compare the average SDA-FF $\mathrm{Hg}(\mathrm{g})$ removal efficiencies when $\mathrm{NaCl}, \mathrm{CaCl}_{2}$, and SEA2 additives were used with and without NORIT FGD injection. The combination of SEA2 addition and NORIT FGD injection provided the best SDA$\mathrm{FF} \mathrm{Hg}(\mathrm{g})$ removal efficiency, even at the lowest addition and injection rates of $1.84 \mathrm{lb} / \mathrm{Macf}$. $\mathrm{NaCl}$ and $\mathrm{CaCl}_{2}$ addition combined with NORIT FGD injection provided similar high levels of SDA-FF $\mathrm{Hg}(\mathrm{g})$ removal, $70 \%-90 \%$, although the lone addition of SEA2 at $58.72 \mathrm{mg} / \mathrm{m}^{3}$ (3.67 lb/Macf) also provided a similar level of efficient $\mathrm{Hg}(\mathrm{g})$ removal.

\subsubsection{Conclusions}

NORIT FGD and three $\mathrm{Hg}^{0}$ oxidation and sorbent enhancement additives $\mathrm{NaCl}, \mathrm{CaCl}_{2}$, SEA2 were evaluated in the PTC equipped with an SDA-PJBH. A Center lignite coal was burned in the unit while $\mathrm{Hg}(\mathrm{g})$ concentrations were measured using CMMs at the SDA inlet and PJBH outlet to evaluate $\mathrm{Hg}$ removal performance. The inlet center lignite flue gas had $12-$ $13 \mu \mathrm{g} / \mathrm{Nm}^{3}$ mercury, and there was only $2.5 \%$ inherent mercury capture across the SDA-PJBH

The $\operatorname{Hg}(g)$ removal efficiency when activated carbon was injected upstream of the SDA improved with increasing injection rates until it approached about $60 \%$ at an injection rate of $117.6 \mathrm{mg} / \mathrm{m}^{3}$ (7.35 lb/Macf). 


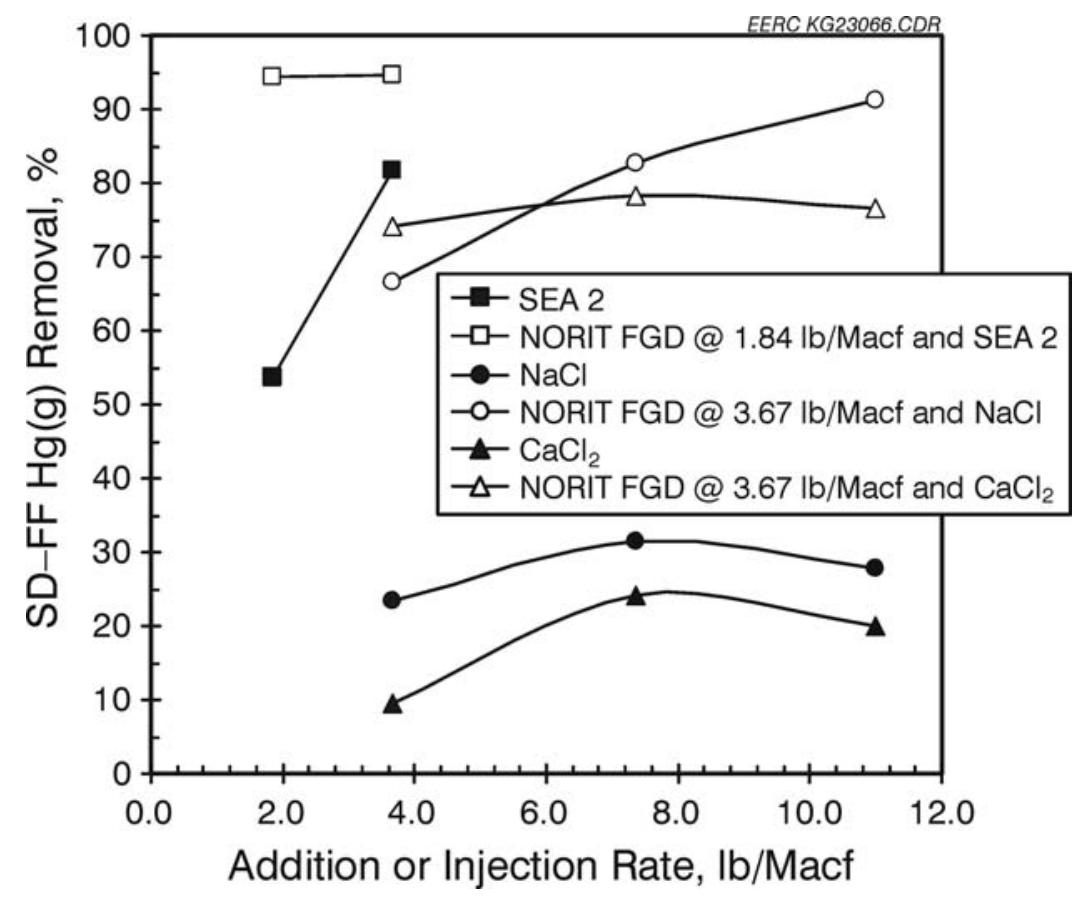

Figure 6.4.2. Comparisons of mercury removals in SDA-PJBH with additive alone and in combination with FGD injection.

Table 6.4.6 Average ( $\pm 95 \%$ confidence limit) SDA-FF Hg(g) Removal Efficiencies for Sorbents and Additives, \%

\begin{tabular}{|c|c|c|c|c|}
\hline & \multicolumn{4}{|c|}{ Injection or Addition Rate, $\mathrm{mg} / \mathrm{m}^{3}$ (lb/Macf) } \\
\hline \multirow[b]{2}{*}{ Sorbent and/or Additive } & 29.44 & 58.72 & 117.6 & 176.0 \\
\hline & $(1.84)$ & $(3.67)$ & $(7.35)$ & (11) \\
\hline \multirow{3}{*}{ NORIT FGD } & $584.0 \pm 40.0$ & $691.2 \pm 20.8$ & $888.0 \pm 35.2$ & $948.8 \pm 54.4$ \\
\hline & $(36.5 \pm 2.5)$ & $(43.2 \pm 1.3)$ & $(55.5 \pm 2.2)$ & $(59.3 \pm 3.4)$ \\
\hline & & $376.0 \pm 57.6$ & $504.0 \pm 36.8$ & $444.8 \pm 6.4$ \\
\hline \multirow[t]{2}{*}{$\mathrm{NaCl}$} & NT & $(23.5 \pm 3.6)$ & $(31.5 \pm 2.3)$ & $(27.8 \pm 0.4)$ \\
\hline & & $152.0 \pm 12.8$ & $387.2 \pm 22.4$ & $320.0 \pm 44.8$ \\
\hline \multirow[t]{2}{*}{$\mathrm{CaCl}_{2}$} & NT & $(9.5 \pm 0.8)$ & $(24.2 \pm 1.4)$ & $(20.0 \pm 2.8)$ \\
\hline & $\begin{array}{c}859.2 \pm 84.8 \\
(53.7 \pm 5.3)\end{array}$ & $\begin{array}{c}1308.8 \pm 19.0 \\
(818+12)\end{array}$ & NT & NT \\
\hline NORIT FGD@ $@ 58.72$ mg/m $\mathrm{m}^{3}$ & & $1065.6 \pm 38.4$ & $1321.6 \pm 38.4$ & $1459.2 \pm 8.0$ \\
\hline (3.67 lb/Macf) and $\mathrm{NaCl}$ & NT & $(66.6 \pm 2.4)$ & $(82.6 \pm 2.4)$ & $(91.2 \pm 0.5)$ \\
\hline NORIT FGD@ @ 58.72 mg/m³ & & $1187.2 \pm 27.2$ & $1254.4 \pm 33.6$ & $1224.0 \pm 72.0$ \\
\hline (3.67 lb/Macf) and $\mathrm{CaCl}_{2}$ & NT & $(74.2 \pm 1.7)$ & $(78.4 \pm 2.1)$ & $(76.5 \pm 4.5)$ \\
\hline NORIT FGD@29.44 mg/m³ & $1513.6 \pm 14.4$ & $1508.8 \pm 41.6$ & & \\
\hline$(1.84 \mathrm{lb} / \mathrm{Macf})$ and SEA2 & $(94.6 \pm 0.9)$ & $(94.3 \pm 2.6)$ & NT & NT \\
\hline
\end{tabular}


The addition of $\mathrm{NaCl}$ or $\mathrm{CaCl}_{2}$ to the Center lignite did not significantly increase the level of oxidized mercury, but the combination of the additive and NORIT FGD injection was very effective in capturing $\mathrm{Hg}(\mathrm{g})$ in the SDA-PJBH pollution control devices. $176.0 \mathrm{mg} / \mathrm{m}^{3}$ $(11 \mathrm{lb} / \mathrm{Macf}) \mathrm{NaCl}$ in conjuction with $58.72 \mathrm{mg} / \mathrm{m}^{3}$ (3.67 lb/Macf) NORIT FGD provided $90 \%$ overall mercury removal with the SDA-PJBH. Injection of NORIT FGD at a rate of $58.72 \mathrm{mg} / \mathrm{m}^{3}$ (3.67 lb/Macf) with $176.0 \mathrm{mg} / \mathrm{m}^{3}$ (11 lb/Macf) $\mathrm{CaCl}_{2}$ addition to the coal resulted in $80 \% \mathrm{Hg}(\mathrm{g})$ removal across the SDA-PJBH.

The addition of SEA2 alone to the coal at a rate of $58.72 \mathrm{mg} / \mathrm{m}^{3}(3.67 \mathrm{lb} /$ Macf) resulted in about $80 \%$ removal across the SDA-PJBH. The combination of NORIT FGD injection at $29.44 \mathrm{mg} / \mathrm{m}^{3}$ (1.84 lb/Macf) and SEA2 addition provided exceptional SDA-FF $\mathrm{Hg}(\mathrm{g})$ capture, $>90 \%$, even at the lower addition rate of $29.44 \mathrm{mg} / \mathrm{m}^{3}$ (1.84 lb/Macf).

These tests were not conducted with an Advanced Hybrid ${ }^{\mathrm{TM}}$ filter, but they addressed specifically a possible application for the Advanced Hybrid ${ }^{\mathrm{TM}}$ filter: the case where it would be installed downstream of a spray dryer scrubber. The testing proved that the Hg oxidant and sorbent enhancement additives, similar to cofiring TDF, formed very reactive species in the combustion zone, which effectively converted elemental mercury to oxidized and/or particlebound mercury and improved the reactivity between gaseous mercury and injected carbons. As a result, the particle-bound mercury was easily captured on the filter bags. These results apply directly to mercury control with the Advanced Hybrid ${ }^{\mathrm{TM}}$ filter and offer additional alternatives to help achieve a very high level of control while minimizing the amount of carbon required. 


\subsection{CONCLUSIONS}

\subsection{Bench-Scale Tests at the EERC}

Bench-scale results confirmed that the $\mathrm{SO}_{2}$ and $\mathrm{NO}_{2}$ concentration effects were additive and had a significant effect on sorbent performance. This finding facilitated predicting sorbent performance in real systems when the $\mathrm{SO}_{2}$ and $\mathrm{NO}_{2}$ concentrations were known.

Another key finding from the bench-scale tests was that the fixed-bed sorbent-screening tests using simulated flue gas were in good agreement with similar tests sampling real flue gas. This suggests that as long as the main flue gas components are duplicated, the bench-scale fixedbed tests can be utilized to indicate sorbent performance in larger-scale systems.

\subsection{Pilot-Scale Tests at the EERC}

Eight weeks of pilot-scale tests were completed in this project to measure Advanced Hybrid $^{\mathrm{TM}}$ filter mercury control with NORIT FGD carbon injection for both EB and WSB coal flue gases. Several operating parameters, including carbon injection rate $19 \mathrm{mg} / \mathrm{m}^{3}-38 \mathrm{mg} / \mathrm{m}^{3}$ (1.2-2.4 lb/Macf), carbon residence time ( 1 and $24 \mathrm{hr}$ ), injection mode (continuous vs. batch), and corona current (0.5-4.0 mA), were varied during the tests to understand their impacts on mercury emissions from the Advanced Hybrid ${ }^{\mathrm{TM}}$ filter. Alternative mercury control technologies including TDF cofiring by the EERC, treated carbon by the EERC, amendate silicate by ADA, iodine-treated activated carbon from Barneby and Sutcliffe, and a cartridge filter insert by W.L. Gore were tested in this project for mercury removal with the Advanced Hybrid ${ }^{\mathrm{TM}}$ filter. Additional tests were completed to determine mercury control efficiency in a PJBH compared to the Advanced Hybrid ${ }^{\mathrm{TM}}$ filter under the same conditions.

The mercury species in the WSB coal flue gas was primarily elemental mercury, $65 \%$ $75 \% ; 20 \%-30 \%$ oxidized mercury; and less than $5 \%$ particle-bound mercury. The inherent mercury removal across the Advanced Hybrid ${ }^{\mathrm{TM}}$ filter or PJBH with typical WSB flue gas was at low levels of $0 \%-20 \%$ as a result of low LOI in the fly ash and low levels of particle-bound mercury and acid gases in the flue gas.

With continuous NORIT FGD injection into a typical WSB flue gas entering the Advanced Hybrid $^{\mathrm{TM}}$ filter, the Advanced Hybrid ${ }^{\mathrm{TM}}$ filter mercury removal was $50 \%-60 \%$ at an injection rate of $19 \mathrm{mg} / \mathrm{m}^{3}$ (1.2 lb/Macf), and increased to $65 \%-87 \%$ at $38 \mathrm{mg} / \mathrm{m}^{3}$ (2.4 lb/Macf). A comparison of short and long residence time in the Advanced Hybrid ${ }^{\mathrm{TM}}$ filter indicated no significant mercury desorption from the injected carbon upon continued exposure to the low- 
sulfur flue gases up to $24 \mathrm{hr}$. Reducing corona current improved overall mercury capture in the Advanced Hybrid ${ }^{\mathrm{TM}}$ filter since more carbon deposited on the perforated plates and filter bags at the reduced corona current. An extreme case was when the unit was operated as a PJBH by completely shutting off the high-voltage power while maintaining continuous carbon injection. At $19-\mathrm{mg} / \mathrm{m}^{3}$ (1.2-lb/Macf) NORIT FGD carbon injection into the PJBH, the overall mercury removal with the PJBH was $72.7 \%$ with the WSB coal flue gas. However, the PJBH experienced frequent pulse cleaning and high particulate matter emissions under the high filtration velocity.

Power-off batch injection of the activated carbon provided somewhat better mercury removal than continuous injection in the Advanced Hybrid ${ }^{\mathrm{TM}}$ filter. A $71.2 \%$ overall mercury removal across the Advanced Hybrid ${ }^{\mathrm{TM}}$ filter was attained with WSB coal flue gas at $19 \mathrm{mg} / \mathrm{m}^{3}$ (1.2 lb/Macf) power-off NORIT FGD batch injection and $87 \%$ mercury collection efficiency at $38 \mathrm{mg} / \mathrm{m}^{3}$ (2.4 lb/Macf) power-off NORIT FGD batch injection. A power-on NORIT FGD injection, at $38 \mathrm{mg} / \mathrm{m}^{3}$ (2.4 lb/Macf), provided $75.5 \%$ overall mercury capture with the Advanced Hybrid $^{\mathrm{TM}}$ filter for the typical WSB coal flue gas.

Cofiring TDF with a WSB coal had a significant effect on mercury speciation in the flue gas. $47 \%$ of the total mercury was oxidized with $5 \%$ (mass basis) TDF cofiring, and the oxidized mercury percentage increased to $87 \%$ at $10 \%$ TDF cofiring. The inherent mercury removal across the Advanced Hybrid ${ }^{\mathrm{TM}}$ filter was approximately $30 \%$ with $10 \%$ TDF cofiring, compared to less than $10 \%$ for the baseline tests. The possible reasons could be elevated $\mathrm{HCl}$ concentration, activated unburned carbon, or other changes in combustion and flue gas components.

Cofiring TDF also enhanced mercury capture with NORIT FGD carbon for the WSB coal. Cofiring 5\%-10\% TDF combined with $24 \mathrm{mg} / \mathrm{m}^{3}$ (1.5 lb/Macf) NORIT FGD injection provided 88\%-95\% overall mercury capture across the Advanced Hybrid ${ }^{\mathrm{TM}}$ filter with the western subbituminous coal flue gas compared to $48.4 \%-71.2 \% \mathrm{Hg}$ capture efficiency with NORIT FGD carbon injection alone.

The proprietary sorbent developed by the EERC demonstrated over $90 \%$ mercury removal with the perforated plate only Advanced Hybrid ${ }^{\mathrm{TM}}$ filter at an injection rate of $32 \mathrm{mg} / \mathrm{m}^{3}$ (2 lb/Macf).

The IAC provided no better mercury removal with the Advanced Hybrid ${ }^{\mathrm{TM}}$ filter in the WSB coal flue gas than the FGD carbon. However, with the IAC, a larger fraction of mercury was oxidized across the Advanced Hybrid ${ }^{\mathrm{TM}}$ filter. 
The cartridge filters of Insert A and B showed excellent (over 98\%) mercury oxidation in the Advanced Hybrid ${ }^{\mathrm{TM}}$ filter, and Cartridge B attained 75\% overall mercury removal efficiency in the WSB coal flue gas after 20-hr operation. The mercury capture performance of the cartridge filter was highly temperature-dependent. The best operating temperature was in the range of $124^{\circ} \sim 149^{\circ} \mathrm{C}\left(255^{\circ} \sim 300^{\circ} \mathrm{F}\right)$.

In an EB coal flue gas with high levels of acid gases, most of the mercury was in oxidized form. A number of short- and longer-term tests with NORIT FGD carbon injection at both $135^{\circ}$ and $160^{\circ} \mathrm{C}\left(275^{\circ}\right.$ and $\left.320^{\circ} \mathrm{F}\right)$ with both the Advanced Hybrid ${ }^{\mathrm{TM}}$ filter and the PJBH showed that this sorbent was completely ineffective at mercury control for the EB coal flue gas. Amended silicate developed by ADA also showed ineffective mercury capture for this coal flue gas.

\subsection{Field Demonstration at the Big Stone Power Plant}

Two 1-week short-term and two 1-month long-term field tests were completed with the 2.5-MW (9000-acfm) Advanced Hybrid ${ }^{\mathrm{TM}}$ filter unit at the Big Stone Power Plant to demonstrate mercury control with the Advanced Hybrid ${ }^{\mathrm{TM}}$ filter by using carbon injection and to evaluate the corresponding impacts on Advanced Hybrid ${ }^{\mathrm{TM}}$ filter performance.

Without significant TDF cofiring, the average mercury species was 51\% elemental, 32\% oxidized, and 17\% particle-bound mercury. Inherent mercury capture with the Advanced Hybrid $^{\mathrm{TM}}$ filter for baseline tests was $0 \%-10 \%$.

Without any TDF cofiring, 24-mg/m³ $(1.5-\mathrm{lb} / \mathrm{Macf})$ continuous NORIT FGD carbon injection into the Advanced Hybrid ${ }^{\mathrm{TM}}$ filter resulted in 63\%-90\% overall mercury removal. Part of the reason for the widely varying mercury collection efficiency could be the varying flue gas temperatures. Increasing the carbon injection rates yielded only a marginal benefit on mercury removal.

Short-term tests indicated that power-off batch carbon injection and reducing corona current improved Advanced Hybrid ${ }^{\mathrm{TM}}$ filter mercury capture, while extending the in-flight time of sorbent did not benefit mercury capture significantly. High mercury removals were seen both for the $2.0-\mathrm{kPa}$ pulse trigger tests, which resulted in a 3-hr pulse interval, and for the 20-min pulse interval tests, indicating that a long pulse interval is not necessary to achieve good mercury capture in the Advanced Hybrid ${ }^{\mathrm{TM}}$ filter.

A small amount of TDF cofiring, 150-177 tons a day, significantly changed mercury species in the WSB coal flue gas: $6.4 \%$ elemental, $38.1 \%$ oxidized, and $55.4 \%$ particle-bound 
mercury. The corresponding inherent mercury capture with Advanced Hybrid ${ }^{\mathrm{TM}}$ filter was up to $49 \%$, compared to the $0 \%-10 \%$ in the baseline tests without cofiring TDF.

TDF cofiring also enhanced carbon effectiveness on mercury capture by improving the reactivity between mercury and carbon. Depending on the cofiring rate of TDF, 24-mg $/ \mathrm{m}^{3}$ (1.5-lb/Macf) NORIT FGD carbon injection attained mercury removals in the Advanced Hybrid ${ }^{\mathrm{TM}}$ filter of $68 \%$ to $97 \%$.

Based on measured pressure drop across the Advanced Hybrid ${ }^{\mathrm{TM}}$ filter, bag-cleaning interval, $\mathrm{K}_{2} \mathrm{C}_{\mathrm{i}}$, and residual drag, there was no perceptible effect of carbon addition on the performance of the Advanced Hybrid ${ }^{\mathrm{TM}}$ filter.

The leaching results from the Advanced Hybrid ${ }^{\mathrm{TM}}$ filter hopper ash, which contained spent carbon sorbent, indicated that the mercury present was not readily leachable. There was no observable correlation between the total mercury in the ash and the leachable mercury.

\subsection{Pilot-Scale Testing of Mercury Oxidation Upstream of the Dry Scrubber}

NORIT FGD and three $\mathrm{Hg}^{0}$ oxidation and sorbent enhancement additives $\left(\mathrm{NaCl}, \mathrm{CaCl}_{2}\right.$, and SEA2) were evaluated in a Center lignite flue gas under an SDA-PJBH configuration. The inlet Center lignite flue gas had $12-13 \mu \mathrm{g} / \mathrm{Nm}^{3}$ mercury, and there was only $2.5 \%$ inherent mercury capture across the SDA-PJBH.

The $\mathrm{Hg}(\mathrm{g})$ removal efficiency when activated carbon was injected upstream of the SDA improved with increasing injection rates until it approached about $60 \%$ at an injection rate of $117.6 \mathrm{mg} / \mathrm{m}^{3}$ (7.35 lb/Macf).

The addition of $\mathrm{NaCl}$ or $\mathrm{CaCl}_{2}$ to the Center lignite did not significantly increase the level of oxidized mercury, but the combination of the additive and NORIT FGD injection was very effective in capturing $\mathrm{Hg}(\mathrm{g})$ in the SDA-PJBH pollution control devices. $176.0 \mathrm{mg} / \mathrm{m}^{3}$ (11 lb/Macf) $\mathrm{NaCl}$ in conjuction with $58.7 \mathrm{mg} / \mathrm{m}^{3}$ (3.67 lb/Macf) NORIT FGD provided 90\%

overall mercury removal in the SDA-PJBH. Injection of NORIT FGD at a rate of $58.7 \mathrm{mg} / \mathrm{m}^{3}$ ( $3.67 \mathrm{lb} / \mathrm{Macf}$ ) with $176.0 \mathrm{mg} / \mathrm{m}^{3}$ (11 lb/Macf) $\mathrm{CaCl}_{2}$ addition to the coal resulted in $80 \% \mathrm{Hg}(\mathrm{g}$ ) removal across the SDA-PJBH.

The addition of SEA2 alone to the coal at a rate of $58.72 \mathrm{mg} / \mathrm{m}^{3}(3.67 \mathrm{lb} / \mathrm{Macf})$ resulted in about $80 \%$ removal across the SDA-PJBH. The combination of NORIT FGD injection at $29.4 \mathrm{mg} / \mathrm{m}^{3}$ (1.84 $\left.\mathrm{lb} / \mathrm{Macf}\right)$ and SEA2 addition provided exceptional SDA-FF $\mathrm{Hg}(\mathrm{g})$ capture, $>90 \%$, even at the lower addition rate of $29.4 \mathrm{mg} / \mathrm{m}^{3}$ (1.84 lb/Macf). 


\subsection{Significance of Conclusions}

A goal of the project was to demonstrate $90 \%$ mercury control with the Advanced Hybrid $^{\mathrm{TM}}$ filter using low addition rates of carbon. This was demonstrated for WSB coals under some conditions. With supplemental TDF cofiring, results showed that over $90 \%$ mercury control is achievable with a small addition rate $\left(24 \mathrm{mg} / \mathrm{m}^{3}[1.5 \mathrm{lb} / \mathrm{Macf}]\right)$ of carbon injected upstream of the Advanced Hybrid ${ }^{\mathrm{TM}}$ filter. Without TDF cofiring, the level of mercury control was typically in the range from 50\%-75\%. These findings are significant because they indicate that mercury removal is limited more by the flue gas and sorbent chemistry rather than a mass transfer limit of the gas-solid contact within the Advanced Hybrid ${ }^{\mathrm{TM}}$ filter. This was further proven in perforated plate tests, which showed that $90 \%$ mercury control was achieved across the perforated plates alone with a superior sorbent. To achieve high levels of mercury control, the carbon injection rate of the FGD sorbent can be increased, but results indicate that a better approach might be to alter the flue gas chemistry to make the sorbent more effective or to use an alternative advanced sorbent. The oxidation tests with an SDA scrubber also demonstrated that additives can significantly improve mercury capture with a reasonably low carbon addition rate.

Another highly significant result from the research was that the carbon injection had no effect on the pressure drop or bag-cleaning interval of the Advanced Hybrid ${ }^{\mathrm{TM}}$ filter. This finding is not surprising because the Advanced Hybrid ${ }^{\mathrm{TM}}$ filter is designed to handle a full dust loading, so a small increase in dust loading from the carbon addition would be expected to have only a minor effect on pressure drop. In addition, since over $90 \%$ of the dust is collected on the perforated plates, most of the increased loading from the carbon injection never reaches the bags. This means that the Advanced Hybrid ${ }^{\mathrm{TM}}$ filter is capable of handling much higher carbon loadings without a significant effect on pressure drop. This is a major advantage of the Advanced Hybrid $^{\mathrm{TM}}$ filter over a PJBH that is installed as a polishing device downstream of an ESP. In that case, the PJBH is designed to handle only a very low dust loading so that any additional carbon injection would likely significantly affect the pressure drop and/or bag-cleaning interval. 


\subsection{REFERENCES}

1. Miller, S.J. Advanced Hybrid Particulate Collector, A New Concept for Air Toxics and FineParticle Control. Presented at the Advanced Coal-Based Power and Environmental Systems '97 Conference, Pittsburgh, PA, July 22-24, 1997.

2. Miller, S.J.; Schelkoph, G.L.; Dunham, G.E.; Krigmont, H.; Walker, K. Advanced Hybrid Particulate Collector, A New Concept for Fine-Particle Control. Presented at the PARTEC 98 International Congress for Particle Technology 4th European Symposium, Nürnberg, Germany, March 10-12, 1998.

3. Miller, S.J. Advanced Hybrid Particulate Collector, A New Concept for Air Toxics and FineParticle Control. Presented at the Advanced Coal-Based Power and Environmental Systems '98 Conference, Pittsburgh, PA, July 21-23, 1998.

4. Miller, S.J.; Schelkoph, G.L.; Dunham, Walker, K.; Krigmont, H. Advanced Hybrid Particulate Collector, A New Concept for Air Toxics and Fine-Particle Control. Presented at the EPRI-DOE-EPA Combined Utility Air Pollutant Control Mega Symposium, Washington, DC, Aug 25-29, 1997.

5. Gebert, R.; Darrow, J.; Miller, S.J.; Feeley, T.; Swanson, W. Advanced Hybrid Particulate Collector: A New Method for Control of Fine-Particles. Presented at the Air \& Waste Management Association's 93rd Annual Conference \& Exhibition, Salt Lake City, UT, June $18-22,2000$.

6. Miller, S.J.; Jones, M.; Walker, K.; Gebert, R.; Darrow, J.; Krigmont, H.; Feeley, T. Field Testing of the Advanced Hybrid Particulate Collector, A New Concept for Fine-Particle Control. Presented at the 2000 ACS Symposium, San Francisco, CA, March 26-31, 2000.

7. Gebert, R.; Darrow, J.; Miller, S.J.; Feeley, T.; Swanson, W. Advanced Hybrid Particulate Collector: A New Method for Control of Fine Particles. Presented at the Air \& Waste Management Association's 93rd Annual Conference \& Exhibition, Salt Lake City, UT, June $18-22,2000$.

8. Oglesby, S.; Nichols, G.B. Electrostatic Precipitation; Marcel Dekker: New York, NY 1978. 
9. Dennis, R. et al. Filtration Model for Coal Fly Ash with Glass Fabrics, EPA-600/7-77-084. Aug 1977.

10. Leith, D.; Rudnick, S.N. First M.W. High-Velocity, High-Efficiency Aerosol Filtration, EPA-600/2-761-620, Jan 1976.

11. Miller, S.J.; Dunham, G.E.; Olson, E.S.; Brown, T.D. Mercury Sorbent Development for Coal-Fired Boilers. In Proceedings of the Air Quality: Mercury, Trace Elements and Particulate Matter Conference, McLean, VA, Dec 1-4, 1998.

12. Hassett, D.J.; Heebink, L.V.; Pflughoeft-Hassett, D.F. Mercury and Air Toxic Element Impacts of Coal Combustion By-Product Disposal and Utilization; Year 1 Annual Report for U.S. Department of Energy Contract No. DE-FC26-03NT41727; Energy \& Environmental Research Center: Grand Forks, ND, April 2004.

13. Pflughoeft-Hassett, D.F.; Buckley, T.D. Mercury and Air Toxic Element Impacts of Coal Combustion By-Product Disposal and Utilization: Year 3 Continuation Application. Proposal Prepared for the U.S. Department of Energy National Energy Technology Laboratory; Dec 2004.

14. Benson, S.A.; Crocker, C.R.; Galbreath, K.C.; Gunderson, J.R.; :Holmes, M.J.; Laumb, J.D.; Mackenzie, J.M.; Olderbak, M.R.; Pavlish, J.H.; Yan, L.; Zhuang, Y. Pilot- and Full-Scale Demonstration of Advanced Mercury Control Technologies for Lignite-Fired Power Plants; Final Report for U.S. Department of Energy National Energy Technology Laboratory Cooperative Agreement No. DE-FC26-03NT41897 and Multiclients; EERC Publication 2005-EERC-02-05; Energy \& Environmental Research Center: Grand Forks, ND, Feb 2005. 